Florida International University

FIU Digital Commons

$10-30-2018$

\title{
A Holistic Process Model for Evaluating Alternative Biosolids Technologies and Operational Methodologies to Improve Performance and Sustainable Decision-making at High Purity Oxygen Wastewater Treatment Plants
}

Manuel E. Moncholi

Florida International University, mmonc002@fiu.edu

Follow this and additional works at: https://digitalcommons.fiu.edu/etd

Part of the Environmental Engineering Commons

\section{Recommended Citation}

Moncholi, Manuel E., "A Holistic Process Model for Evaluating Alternative Biosolids Technologies and Operational Methodologies to Improve Performance and Sustainable Decision-making at High Purity Oxygen Wastewater Treatment Plants" (2018). FIU Electronic Theses and Dissertations. 4010.

https://digitalcommons.fiu.edu/etd/4010

This work is brought to you for free and open access by the University Graduate School at FIU Digital Commons. It has been accepted for inclusion in FIU Electronic Theses and Dissertations by an authorized administrator of FIU Digital Commons. For more information, please contact dcc@fiu.edu. 


\section{FLORIDA INTERNATIONAL UNIVERSITY}

Miami, Florida

A HOLISTIC PROCESS MODEL FOR EVALUATING ALTERNATIVE BIOSOLIDS TECHNOLOGIES AND OPERATIONAL METHODOLOGIES TO IMPROVE PERFORMANCE AND SUSTAINABLE DECISION-MAKING AT HIGH PURITY OXYGEN WASTEWATER TREATMENT PLANTS

A dissertation submitted in partial fulfillment of the requirements for the degree of DOCTOR OF PHILOSOPHY in CIVIL ENGINEERING

by

Manuel Ezequiel Moncholí 
To: Dean John L. Volakis

College of Engineering and Computing

This dissertation, written by Manuel Ezequiel Moncholí, and entitled A Holistic Process Model for Evaluating Alternative Biosolids Technologies and Operational Methodologies to Improve Performance and Sustainable Decision-Making at High Purity Oxygen Wastewater Treatment Plants, having been approved in respect to style and intellectual content, is referred to you for judgment.

We have read this dissertation and recommend that it be approved.

Yelena Katsenovich

Shonali Laha

Helena Solo-Gabriele

Michael Sukop

Date of Defense: October 30, 2018

Berrin Tansel, Major Professor

The dissertation of Manuel Ezequiel Moncholí is approved.

Dean John L. Volakis

College of Engineering and Computing

Andrés G. Gil

Vice President for Research and Economic Development

And Dean of the University Graduate School

Florida International University, 2019 


\section{DEDICATION}

I dedicate this dissertation to my parents and grandparents, who instilled in me the love of nature and science, always encouraged me to grow academically, and have given me the love, understanding and support to pursue my passions. 


\section{ACKNOWLEDGMENTS}

I would like to give thanks to my colleagues on the piloting efforts for thickening and dewatering centrifuges, which provided some of the data for this research, Dr. Mohammad Abu-Orf, Ismael Diaz, Terry Goss and Brian Stitt; the plant staff at SDWWTP, CDWWTP, and NDWWTP, especially Leo Pou, Francois Saint-Phard, Peter Basil, Mike Garcia and David Hall for the outstanding support during the pilot testing. I also thank the undergraduate and graduate interns Gabriela Aramayo (FIU), Alejandro Cepero (FIU), Andres McEwen (FIU), Yareliz Negron (FIU), and Kate Ireland (UM) who helped by monitoring pilot operations, collecting samples and running numerous laboratory tests.

I would like to thank my dissertation committee for their patience, guidance and encouragement, especially my advisors, Drs. Berrin Tansel and Shonali Laha for convincing me to seek out my $\mathrm{PhD}$ and lending me the strength to finish. To my longtime co-worker and mentor at the Miami-Dade Water and Sewer Department, Ernesto Coro, I give special thanks for guiding me on how to be a plant process engineer, always searching for the truth, sifting through the information to separate fact from fiction, and always treating me as his peer and equal.

It is with great sadness that I report that during the second data collection phase, my longtime friend and colleague, Luis Somodevilla passed away. Luis was the South District WWTP data manager. His assistance in providing data, identifying its original source, and explanation of various data collection methods was essential to this study. 


\begin{abstract}
OF THE DISSERTATION
A HOLISTIC PROCESS MODEL FOR EVALUATING ALTERNATIVE BIOSOLIDS

TECHNOLOGIES AND OPERATIONAL METHODOLOGIES TO IMPROVE

PERFORMANCE AND SUSTAINABLE DECISION-MAKING AT HIGH PURITY

OXYGEN WASTEWATER TREATMENT PLANTS
\end{abstract}

by

Manuel Ezequiel Moncholí

Florida International University, 2019

Miami, Florida

Professor Berrin Tansel, Major Professor

In the span of the last decade the regulatory, public and commercial sentiments in Florida towards wastewater biological sludges, termed biosolids, have resulted in more restrictive land application rules, public cynicism about quality and agricultural benefits, and defensive posturing and marketing to appease public opinion. To determine and recommend the most cost effective and sustainable combination of biosolids treatment technologies to achieve Class B biosolids at the MDWASD facilities, the author created a holistic process model that is novel in the realm of wastewater treatment.

The research methodology focused on the analyses of historical data, analyses of pilot-testing data, development of a biosolids process evaluation framework consisting of a holistic process model, model calibration using historical and pilot data, and technical evaluations carried out by the author. The process evaluation framework was applied to existing and alternative biosolids treatment processes to formulate a sustainable path 
forward for biosolids processing efforts at the South District and Central District Wastewater Treatment Plants in Miami-Dade (SDWWTP and CDWWTP). This research has contributed to significant advancements in the field of biosolids treatment, operations and management which are highlighted below:

- Developed a framework to evaluate biosolids treatment options for wastewater treatment facilities, comparing both existing and proposed technologies;

- Identified the most effective means of sludge thickening, anaerobic digestion and digested sludge dewatering ensuring Class B biosolids treatment while reducing biosolids production and hauling quantities at a lower capital and operational expenditure when existing equipment reaches end of useful life;

- Evaluated alternative struvite control methods to achieve higher dewatered sludge solids concentrations and improved struvite management;

- Identified the shortcomings of the traditionally used design and operating parameters provided in textbooks and provided necessary corrections and justifications.

The data analyses and holistic modeling efforts conducted during this study identified alternative biosolids treatment technologies and operational modifications for SDWWTP and CDWWTP. These recommendations were the replacement of existing gravity thickening with thickening centrifuges, retrofitting sludge stabilization from traditional primary-secondary anaerobic mesophilic digestion to single-stage anaerobic mesophilic digestion, and upgrading dewatering centrifuges to new highly-automated and more energy efficient units. 


\section{TABLE OF CONTENTS}

CHAPTER

PAGE

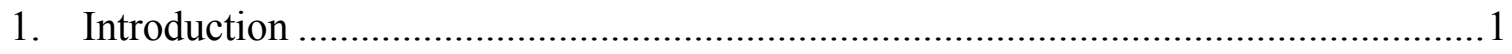

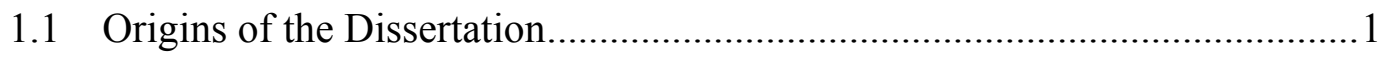

1.2 Research Hypotheses ....................................................................... 1

Hypothesis 1 - Better Sludge Thickening ...........................................2

Hypothesis 2 - Innovations In Digestion Operational Methods And Technologies...................................................................... 3

Hypothesis 3 - Cost Conscious Sludge Stabilization Improvements.........4

Hypothesis 4 - Approaches For Struvite Control And Improved

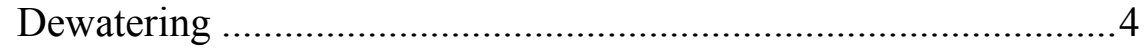

Hypothesis 5 - A Framework For Biosolids Treatment Evaluations ..........5

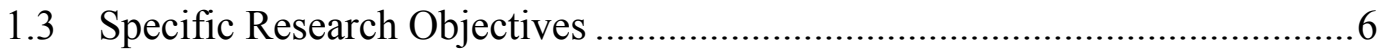

1.4 Highlighting the Innovative Aspects of this Research .............................

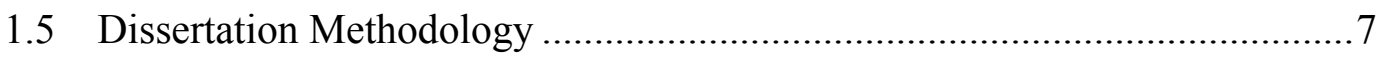

1.6 Dissertation Outline.............................................

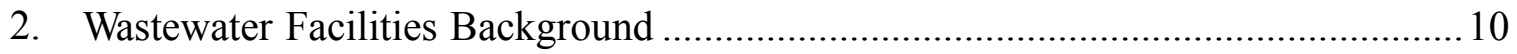

3. Process Evaluation Methodology and Historical Data Analyses ............................. 12

3.1 Whole Plant Mass Balance Model (MBM) ............................................ 12

3.2 Historical Data Collection and Analyses.............................................24

3.3 Mass Balance Model (MBM) Scenario A Run and Model Calibration .......39

3.4 Pilot Study Overview and Objectives............................ 50

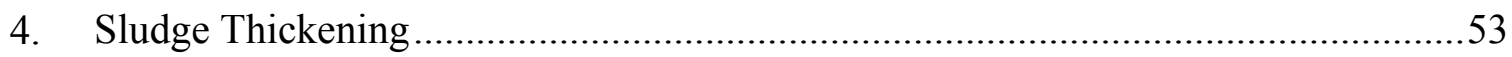

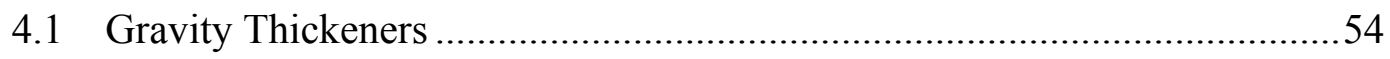




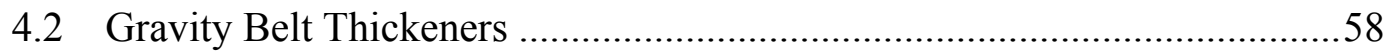

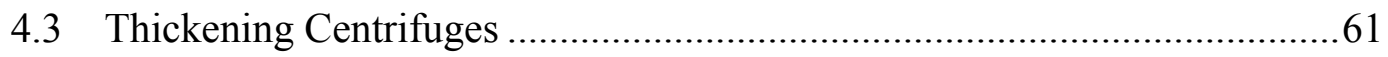

4.4 SDWWTP Pilot Phase 1 - Thickening pilot testing ....................................63

Thickening Pilot Testing - no polymer operation........................................64

Thickening Pilot Testing - Emulsion polymer setup and initial testing ...66

Thickening Pilot Testing - Dry polymer setup ……………………….....67

Thickening pilot testing - Results ........................................................... 68

Thickening pilot testing - Polymer curve results for emulsion and dry polymer .................................................................................69

Thickening Pilot Testing - Extended operation results ...............................75

4.5 CDWWTP Pilot Phase 1 - Thickening Pilot Testing ...................................77

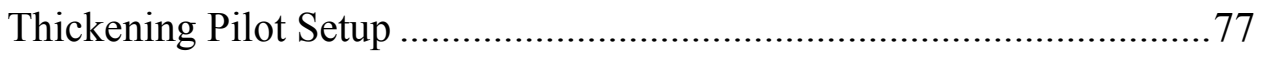

Thickening Pilot Testing - CDWWTP WAS .............................................78

Thickening Pilot Testing - NDWWTP primary sludge and WAS.............82

4.6 Chapter Summary: Discussion of results, impact of pilot tests on model inputs and other model assumptions for sludge thickening........................8

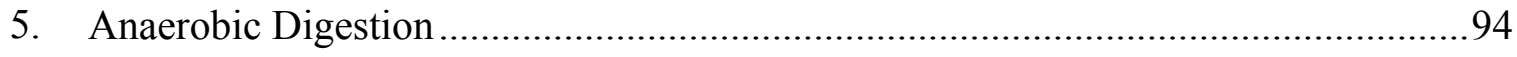

5.1 Primary-Secondary Anaerobic Mesophilic Digestion Method at SDWWTP and CDWWTP...................................................................................94

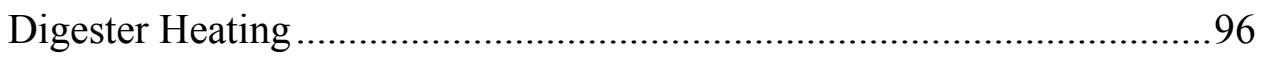

Digester Mixing .........................................................................................

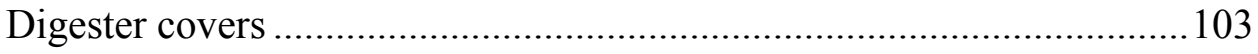

5.2 High-rate single-stage digestion conversion design considerations ............104

5.3 Model Considerations for the Anaerobic Digestion Systems.......................106

5.4 SDWWTP Pilot Phase 2 -continuous thickening pilot operation and simulated high-rate single stage mesophilic digestion .............................116 
5.5 CDWWTP Pilot Phase 2 - continuous thickening pilot operation and simulated high-rate single stage mesophilic digestion

5.6 Chapter Summary: Discussion of results, impact of pilot tests on model inputs and other model assumptions for anaerobic digestion.

6. Sludge Dewatering

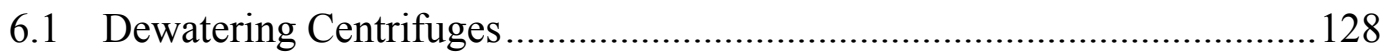

6.2 SDWWTP Pilot Phase 3 - Dewatering pilot testing ............................... 130

Dewatering pilot testing - emulsion polymer initial testing ..................131

Dewatering pilot testing - dry polymer setup ................................... 131

Dewatering pilot testing - polymer injection location optimization .......132

Dewatering pilot testing - polymer curve results ............................. 132

Dewatering pilot testing - extended operation results .........................136

6.3 The struvite complex - struvite removal to improve sludge dewaterability 138

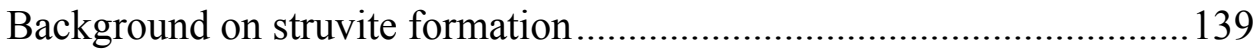

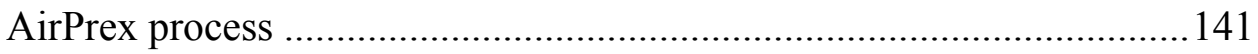

AirPrex Piloting At SDWWTP .................................................... 141

AirPrex performance data............................................................ 145

Dewatering results during Airprex trials ........................................... 149

Dry polymer curve testing ....................................................... 150

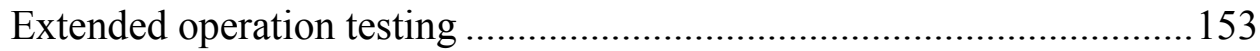

6.4 CDWWTP Pilot Phase 3 - dewatering pilot testing............................... 157

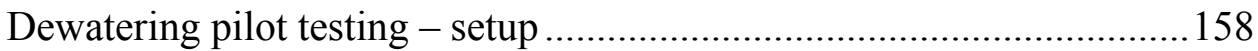

Dewatering pilot testing - polymer curve testing.............................. 159

Dewatering pilot testing - extended operation results ......................... 162 
6.5 Chapter Summary: Discussion of results, Impact of pilot tests on model inputs and other model assumptions for sludge dewatering....

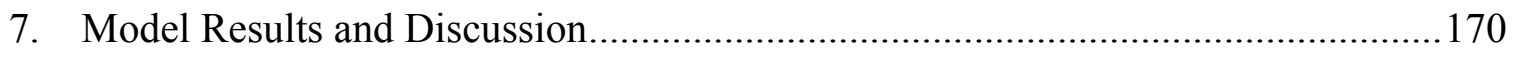

7.1 MBM Results.................................................................................. 170

Sludge Thickening MBM Results ................................................ 170

Sludge Digestion MBM Results ................................................. 173

Sludge Dewatering MBM Results ........................................................179

Recycle Streams MBM Results ...................................................... 183

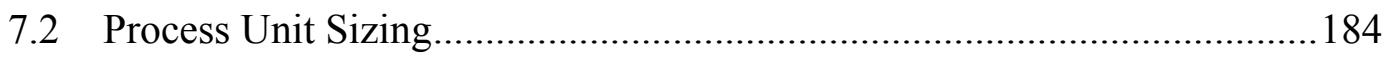

Sludge Thickening Unit Sizing ................................................ 186

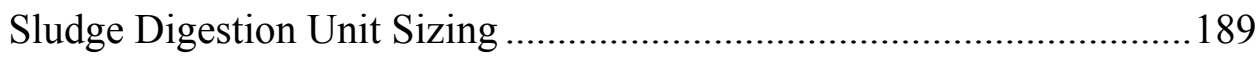

Sludge Dewatering Unit Sizing ................................................... 195

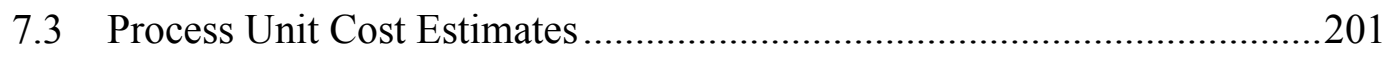

Sludge Thickening Cost Estimates ................................................202

Sludge Digestion Cost Estimates.................................................207

Sludge Dewatering Cost Estimates .................................................213

Combined Cost Estimates...............................................................2218

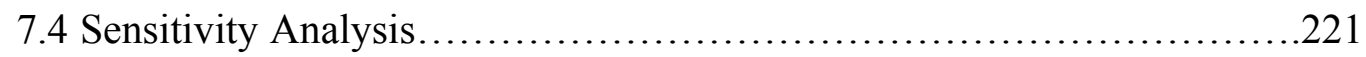

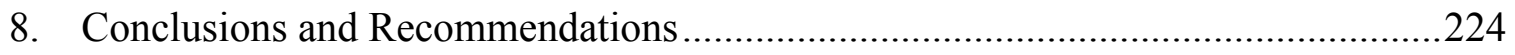

8.1 Acceptance or Rejection of Research Hypotheses ................................224

Hypothesis 1 - Better Sludge Thickening ........................................224

Hypothesis 2 - Innovations in digestion operational methods and

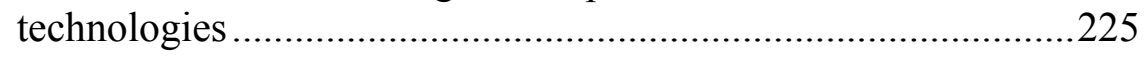

Hypothesis 3 - Cost Conscious sludge stabilization improvements .......225

Hypothesis 4 - Multiple approaches to struvite control and improved dewatering 
Hypothesis 5 - A framework for biosolids treatment evaluations

8.2 Recap of Objectives.

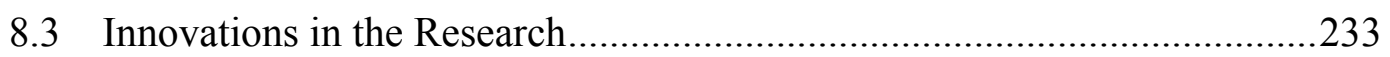

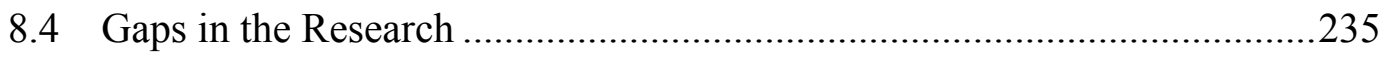

8.5 Areas for Further Study Based on the Research...................................2237

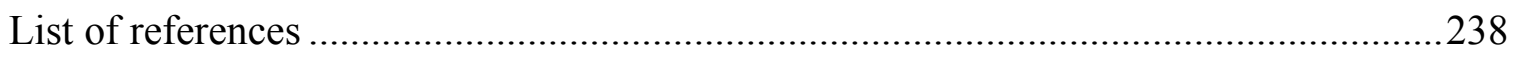

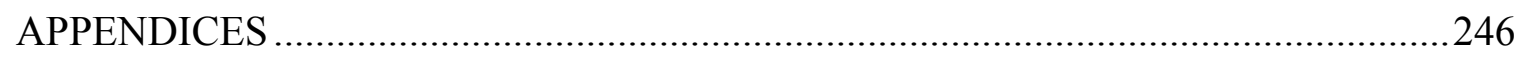

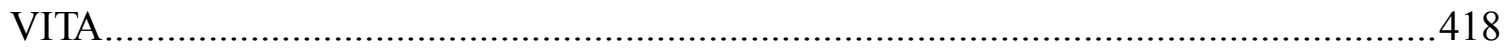


Table 1 : Range of Observed Yields for varying SRTs and Yields...................................15

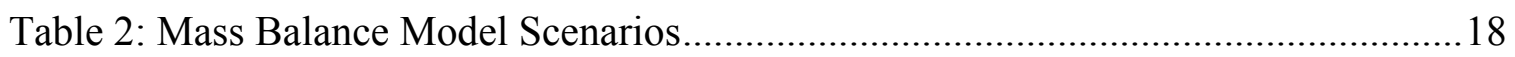

Table 3: Input Data for Mass Balance Model ...............................................................25

Table 4: Summary of Historical Plant Data and Assumptions..........................................36

Table 5: SDWWTP Scenario A model recycle flow results ..............................................41

Table 6: CDWWTP Scenario A model recycle flow results ...............................................42

Table 7: Historical data for confirmation of intermediate model results ............................43

Table 8: SDWWTP results with no model calibration........................................................4

Table 9: CDWWTP results with no model calibration ....................................................4

Table 10: SDWWTP results of first attempt at model calibration ....................................46

Table 11: CDWWTP results of first attempt at model calibration ...................................46

Table 12: SDWWTP model results and historical data comparison with modified

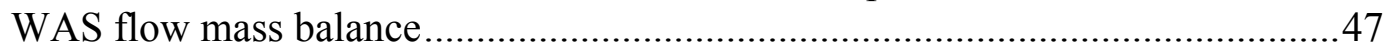

Table 13: CDWWTP model results and historical data comparison with modified

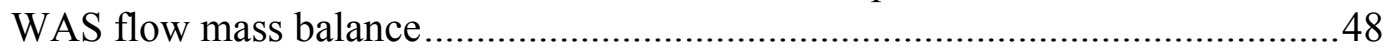

Table 14: SDWWTP Calibrated MBM with flow correction factor ..................................49

Table 15: CDWWTP Calibrated MBM with flow correction factor..................................50

Table 16 Summary of Pilot Testing Phases.....................................................................51

Table 17: Liquid stream historical data, calculated results and assumed values for SDWWTP and CDWWTP

Table 18: Sludge Thickening historical data, pilot measurement, calculated results and assumed values for SDWWTP and CDWWTP ...........................................93

Table 19: Comparison of estimated VSR for standard and high rate digesters...............111

Table 20: SDWWTP Scenario B MBM brief results summary ......................................114

Table 21: CDWWTP Scenario B MBM brief results summary ......................................114 
Table 22: Anaerobic digestion historical data, pilot measurements, calculated results and assumed values for SDWWTP and CDWWTP

Table 23: Summary of AirPrex Performance Data

Table 24: Summary of Dry Polymer Curve Tests from Digester 10

Table 25: Optimal Settings for Flow based on the Polymer Curves from Digester 10 ...151

Table 26: Sludge dewatering historical data, pilot measurements, calculated results and assumed values for SDWWTP and CDWWTP.

Table 27: Summary of MBM Results for SDWWTP Sludge Thickening Scenarios in SI and US units.

Table 28: Summary of MBM Results for CDWWTP Sludge Thickening Scenarios in SI and US units.

Table 29: Summary of MBM Results for SDWWTP Sludge Digestion Scenarios in SI and US units

Table 30: Summary of MBM Results for CDWWTP Sludge Digestion Scenarios in SI and US units

Table 31: Summary of MBM Results for SDWWTP Sludge Dewatering Scenarios in SI and US units.

Table 32: Summary of MBM Results for CDWWTP Sludge Dewatering Scenarios in SI and US units.

Table 33: Summary of MBM Results for SDWWTP and CDWWTP Scenarios' Recycle Loads in SI and US units

Table 34: SDWWTP Sludge Thickening Unit Sizing

Table 35: CDWWTP Sludge Thickening Unit Sizing

Table 36: SDWWTP Sludge Digestion Unit Sizing.

Table 37: CDWWTP Sludge Digestion Unit Sizing 194

Table 38: Hours of weekly coverage based on 8-hr./ 7 day shifts 196

Table 39: SDWWTP Sludge Dewatering Unit Sizing 198

Table 40: CDWWTP Sludge Dewatering Unit Sizing..... 
Table 41: SDWWTP and CDWWTP Sludge Thickening Comparative Capital Cost

Estimates.

Table 42: SDWWTP and CDWWTP Sludge Thickening Comparative Chemical and

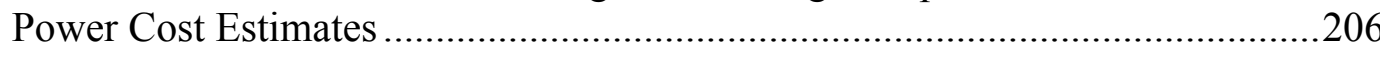

Table 43: SDWWTP and CDWWTP Sludge Digestion Comparative Capital Cost Estimates

Table 44: SDWWTP and CDWWTP Sludge Digestion Comparative Chemical and Power Cost Estimates.

Table 45: SDWWTP and CDWWTP Sludge Dewatering Comparative Capital Cost Estimates.

Table 46: SDWWTP and CDWWTP Sludge Dewatering Comparative Chemical and Power Cost Estimates

Table 47: Combined Comparative Estimated Costs for SDWWTP and CDWWTP Biosolids Treatment Scenarios

Table 48: Sensitivity analysis of comparative cost of scenarios, reduced thickening centrifuge power consumption and increased biosolids hauling cost

Table 49: Sensitivity analysis of comparative cost of scenarios, reduced gravity belt thickener polymer consumption 
FIGURE

Figure 1: Process Flow Diagram of Scenarios A and B ……………….........................20

Figure 2: Process Flow Diagram of Scenario C ………………….................................2

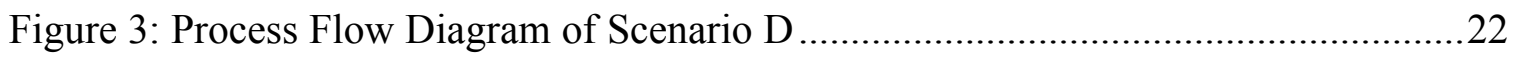

Figure 4: Process Flow Diagram of Scenario E ………………................................23

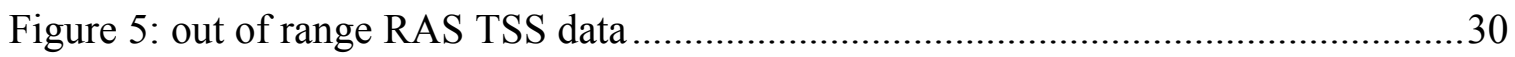

Figure 6: out of range centrate volatile fraction data..........................................................31

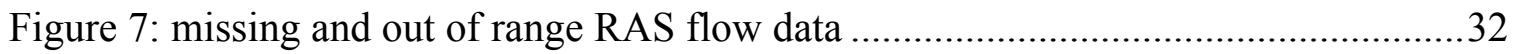

Figure 8: Plot of 90th percentile rule for filtering data ....................................................34

Figure 9: Plot of average of a data set based on 90th percentile filter ...............................35

Figure 10: CDWWTP Pilot Site Plan Showing Centrifuge Installation.............................53

Figure 11: SDWWTP Pilot Site Plan Showing Centrifuge Installation ............................53

Figure 12 Photos of Pilot Equipment, Thickening (left), Dewatering (right) ...................54

Figure 13: Existing Gravity Thickeners at SDWWTP (MDWASD, May 2005)..............55

Figure 14: gravity thickener schematic (WEF MOP No. $116^{\text {th }}$ Edition, 2008) ................56

Figure 15: Gravity belt thickener schematic (WEF MOP No. $116^{\text {th }}$ Edition, 2008) ........58

Figure 16: Gravity belt thickener chicanes and ramp (WEF MOP No. $116^{\text {th }}$ Edition,

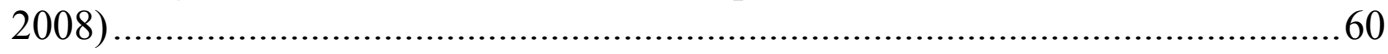

Figure 17: GBT enclosed gravity table, Tres Rios WRF, Tucson, AZ ……………….......61

Figure 18: thickening centrifuge schematic (WEF MOP No. $116^{\text {th }}$ Edition, 2008) ….....63

Figure 19 No Polymer Operation, Medium Bowl Speed (2,590 RPM) ............................65

Figure 20: Thickening Polymer Injection Point ……………………………...................67

Figure 21 Temporary Dry Polymer Set Up ................................................................68

Figure 22: Emulsion Polymer - 130 and 150 gpm WAS feed, Medium Bowl Speed.......70 
Figure 23: Dry Polymer - 130 gpm WAS Feed, Internal and External Injection, Medium Bowl Speed

Figure 24: Dry Polymer - 150 gpm, Internal and External Injection, Medium Bowl Speed

Figure 25: Extended Thickening Operation at $135 \mathrm{gpm}$ 76

Figure 26: Feed and thickened sludge concentrations of WAS-only Extended

Operation at varying polymer dosages June 14, 2016.

Figure 27: Centrate concentrations and solids recovery of WAS-only Extended Operation at varying polymer dosages June 14, 2016.

Figure 28: Feed and thickened sludge concentrations of WAS-only Extended Operation at varying polymer dosages June 22, 2016.

Figure 29: Centrate concentrations and solids recovery of WAS-only Extended

Operation at varying polymer dosages June 22, 2016. .80

Figure 30: Feed and thickened sludge concentrations of WAS-only extended operation at $160 \mathrm{gpm}, 3 \mathrm{lb} / \mathrm{DT}$ dry polymer dose target on June 7, 2016

Figure 31: Centrate and percent recovery results of WAS-only extended operation at $160 \mathrm{gpm}, 3 \mathrm{lb} / \mathrm{DT}$ dry polymer dose target on June 7, 2016

Figure 32 CDWWTP Lakeside Raptor Screens for NDWWTP sludge .83

Figure 33 CDWWTP and NDWWTP Blend Tank .85

Figure 34 CDWWTP and NDWWTP cake solids at varying differential bowl speeds and polymer dosages .85

Figure 35 CDWWTP and NDWWTP solids recovery at varying differential bowl speeds and polymer dosages

Figure 36 CDWWTP and NDWWTP polymer curve and extended Operating testing data at two differential bowl speeds from Sept. 13, 2016 .86

Figure 37: Primary-Secondary digestion system process flow diagram (WEF MOP No. $85^{\text {th }}$ Edition, 2010)

Figure 38: Existing Primary-Secondary Digester Configuration at SDWWTP and CDWWTP (MDWASD, May 2005) 95

Figure 39: Gas lance mixing system schematic (WEF MOP No. $116^{\text {th }}$ Edition, 2008) ...98 
Figure 40: Draft tube mixing schematic (WEF MOP No. $116^{\text {th }}$ Edition, 2008) .99

Figure 41: Digester pump mixing system schematic (WEF MOP No. $116^{\text {th }}$ Edition, 2008)

Figure 42: pump mixing internal digester nozzles (WEF MOP No.11 $6^{\text {th }}$ Edition, 2008)

Figure 43: gas holder digester covers with LMMs, Tres Rios WRF, Tucson, AZ

Figure 44: LMM gearbox, Salt Lake City, UT (right), LMM drive assembly diagram (Haughton et al., 2015) (left).

Figure 45: Digester floating cover schematic (WEF MOP No. 11 6th Edition, 2008) ...104

Figure 46: high-rate single-stage digestion process flow diagram (WEF MOP No. 8 $5^{\text {th }}$ Edition, 2010). 105

Figure 47: SDWWTP Pilot Phase 2 site layout.

Figure 48: Pilot Phase 2 Continuous Thickening Operation 118

Figure 49: Digester Concentration Comparison, Digester 9 vs. Plant Records 119

Figure 50: Digester 9 Turnover Progress during Pilot Phase 2 Operation. 120

Figure 51: CDWWTP Pilot Phase 2 site layout 121

Figure 52: CDWWTP Pilot Phase 2 Continuous Thickening Operation 123

Figure 53: Compiled Dry Polymer Curves from Digester 9 134

Figure 54: Compiled Emulsion Polymer Curves from Digester 9 135

Figure 55: Extended Operation using Dry Polymer

Figure 56: Extended Operation using Emulsion Polymer 137

Figure 57: Typical AirPrex Process Flow Diagram (Courtesy of CNP).

Figure 58: Picture of AirPrex Pilot and Fractionation Tank 143

Figure 59: Digester 9 Solids Concentration accidental dilution during Pilot Phase 2 ....144

Figure 60: AirPrex Orthophosphate Monitoring 147

Figure 61: AirPrex Ammonia Monitoring. 148 
Figure 62: AirPrex pH Monitoring

Figure 63: Recovered Struvite Product

Figure 64: Summary of sludge cake solids versus polymer dose for Digester 10 - Dry

Polymer with and without AirPrex

Figure 65: Summary of solids recovery versus polymer dose for Digester 10 - Dry

Polymer with and without AirPrex....

Figure 66: Centrifuge Operation with Dry Polymer@ 60 gpm (4/14/16).

Figure 67: Centrifuge Operation with Dry Polymer @80 gpm (4/15/16).....

Figure 68: CDWWTP Dewatering Polymer Curve Testing with and without ferric sulfate

Figure 69: CDWWTP centrate concentration for dewatering polymer testing with and without ferric sulfate.

Figure 70: CDWWTP Dewatering with and without ferric sulfate

Figure 71: Sludge Feed and Cake Concentrations under Extended Operation using Dry Polymer on August 19, 2016

Figure 72: Centrate Concentrations and Solids Recovery under Extended Operation using Dry Polymer on August 19, 2016

Figure 73: downward trend in SDWWTP dewatered cake \%solids 
Equation 1: Aeration Basin SRT, based on MOP 8 p. 14-38 ………………………........ 14

Equation 2: Observed Yield, MOP 8 Eq. 20.3 ............................................................... 15

Equation 3: Solids Capture Rate for Sludge Thickening.................................................57

Equation 4: Hydraulic Capacity of a Solid Bowl Centrifuge ............................................62

Equation 5: Solids Retention Time of Active Digester Volume …………………….......107

Equation 6: Estimate of VSR for standard-rate digesters..............................................109

Equation 7: Estimate of VSR for high-rate digesters ....................................................110

Equation 8: Modified high-rate VSR estimate for SDWWTP ......................................112

Equation 9: Modified high-rate VSR estimate for CDWWTP .......................................112

Equation 10: Digested Sludge Solids Concentration, from an Estimated VSR ..............113

Equation 11: Derived Equation for VSR of a known system.........................................115

Equation 12: Solids Capture Rate for Sludge Dewatering Centrifuge ............................129 


\section{A LIST OF ACRONYMS}

\begin{tabular}{|l|l|}
\hline \multicolumn{1}{|c|}{ Acronym } & \multicolumn{1}{|c|}{ Detail } \\
\hline ADF & Average Daily Flow \\
\hline BOD & Biological Oxygen Demand \\
\hline CBOD & Carbonaceous Biological Oxygen Demand \\
\hline CDWWTP & Central District Wastewater Treatment Plant \\
\hline FOG & Fats, Oils and Grease \\
\hline$k_{d}$ & endogenous decay rate \\
\hline MBM & Mass Balance Model \\
\hline MDWASD & Miami-Dade Water and Sewer Department \\
\hline MLSS & Mixed Liquor Suspended Solids \\
\hline MLVSS & Mixed Liquor Volatile Suspended Solids \\
\hline NDWWTP & North District Wastewater Treatment Plant \\
\hline PF & Wet Weather Peak Flow \\
\hline Pfactor & Peak Factor \\
\hline PS & Primary Sludge \\
\hline RAS & Return Activated Sludge \\
\hline SDWWTP & South District Wastewater Treatment Plant \\
\hline SRT & Solids Retention Time \\
\hline TS & Total Solids \\
\hline TSS & Total Suspended Solids \\
\hline TWAS & Thickened Waste Activated Sludge \\
\hline UBOD & Ultimate Biological Oxygen Demand \\
\hline VF & Volatile Fraction \\
\hline VFA & Volatile Fatty Acid \\
\hline VSR & Volatile Solids Reduction \\
\hline VSS & Volatile Suspended Solids \\
\hline WAS & Waste Activated Sludge \\
\hline Y & Yield \\
\hline Yobs & Observed yield \\
\hline
\end{tabular}


1. Introduction

\subsection{Origins of the Dissertation}

The overall goal of this research is to determine a path forward for Miami-Dade Water and Sewer Department (MDWASD) to process biosolids in an efficient and effective manner that will meet future growth demands and the dynamic regulatory landscape in the State of Florida. With the author of this work as its program manager, Miami-Dade is currently in the process of planning, designing, and constructing aspects of a biosolids program to improve biosolids treatment, reduce the quantity of biosolids production, and use the end-product (concentrated, stabilized, and dewatered Class B biosolids) for more sustainable practices. The research efforts conducted in this research focused on improving the biosolids management of the subject facilities through historical and experimental data analyses and holistic numerical modeling.

\subsection{Research Hypotheses}

In the course of developing a framework to evaluate the biosolids treatment process of the SDWWTP and CDWWTP there were several points of interest that merited consideration. The intent of the dissertation is to answer the following questions and inspire others to continue the research by exploring gaps in the existing body of research and expanding it to evaluate other technologies and other wastewater treatment facilities within the framework developed and presented here. The research hypotheses explored during this study are described below: 
Hypothesis 1 - Better Sludge Thickening

A more applicable sludge thickening technology for waste activated sludge (WAS) and mixed primary and waste activated sludges in subtropical climates such as in the large scale wastewater treatment facilities of MDWASD is capable of vastly improving thickened sludge concentrations at comparable solids recovery rates.

One of the key early observations of the research was that sludge gravity thickening in the constantly hot and humid conditions of South Florida is very prone to septic conditions. Septic conditions manifest in poor sludge thickening (lower thickened sludge concentrations), a high solids rejection rate (poor solids capture), and frequent process upsets resulting in the bulking of the sludge blanket. Gravity thickeners are primarily designed for primary, lime and combined sludges, but are poorly suited for waste activated sludge, where the process produces lower sludge underflow concentration and lower solids recovery (WEF MOP No. $85^{\text {th }}$ edition, 2008). Miami-Dade County's experience with normal operation of sludge gravity concentrators has been a constant battle to fight process failure rather than an opportunity to optimize the process for better performance. The solution proposed then and whose design considerations were the basis of a multi-plant design-build project employing mechanical thickening of sludge to $5-6 \%$ total solids (TS) from the current thickened sludge concentrations of $2-4 \%$.

As an initial plan, MDWASD was to rehabilitate the existing gravity thickening process at its South District Wastewater Treatment Plant (SDWWTP) and Central District Wastewater Treatment Plant (CDWWTP). Through the efforts of the author of this research, alternative biosolids thickening technologies including the use of rotary drum thickeners, gravity belt thickeners, and thickening centrifuges were considered in 
lieu of the gravity thickeners. These technologies were selected for consideration due to their ease of operation and maintenance, suitability for thickening WAS, and ability to produce higher thickened sludge concentrations in a stable manner. Due to their high throughput, space considerations, and the utility's familiarity with dewatering centrifuges that allow for similar operations and maintenance, centrifuges were finally selected as the technology to design around for thickening (WEF MOP No. $116^{\text {th }}$ Edition, 2008). This in turn required careful study of centrifuges based on concerns over the specific sludge conditions and downstream process impacts at both plants.

Hypothesis 2 - Innovations In Digestion Operational Methods And Technologies

Single-stage anaerobic mesophilic digestion carried out at high solids concentrations will achieve a higher volatile solids reduction (VSR) than primarysecondary anaerobic mesophilic digestion in the same digester volume with minimal digester upgrades.

In tandem with changes to the sludge thickening, the anaerobic digestion process at each plant is being changed from the existing two-stage mesophilic anaerobic digestion (with heated and mixed primary digesters and unheated, minimally mixed secondary digesters) to single-stage mesophilic anaerobic digestion at Central District WWTP and acid-gas mesophilic anaerobic digestion at South District WWTP with all rehabilitated digesters having the capacity for heating and mixing. As the thickened sludge concentration would be higher, the study incorporated mesophilic anaerobic digestion at steady-state under high feed solids conditions at a 30-day detention time, as these would be the proposed future design condition with the ultimate goal of achieving greater 
volatile solids reduction (VSR), producing more biogas and reducing overall biosolids production, a strategy mirrored in several research initiatives (Canels et al., 1994 and Liu et al., 2001).

Hypothesis 3 - Cost Conscious Sludge Stabilization Improvements

Class B biosolids stabilization is achievable with alternate technologies at SDWWTP and CDWWTP at a lower capital cost as well as lower operation and maintenance cost than in-kind rehabilitation of the existing technologies.

As a result of cyclical stresses over the life of sludge stabilization operations all sludge stabilization processes are currently scheduled for rehabilitation, refurbishment or replacement at the SDWWTP and the CDWWTP (MWH, February 2015, and CH2M, 2015). In this research the existing sludge stabilization method employed at the subject facilities consisting of primary-secondary mesophilic anaerobic digestion, and an alternative sludge stabilization process that uses single-stage mesophilic anaerobic digestion, are comparatively evaluated through the use of a holistic process model based on analysis of historical plant data, in parallel with pilot testing data (Goss et al., 2017 and Moncholi et al., 2018), and assumptions based on literary research.

Hypothesis 4 - Approaches For Struvite Control And Improved Dewatering

The addition of ferric sulfate to digested sludge will achieve similar benefits to sludge dewatering as more commonly used metal salts, i.e., ferric chloride, or more innovative struvite recovery technologies, i.e. AirPrex.

Due to the equipment age and the vast improvements in energy efficiency of newer, lighter machines, the dewatering centrifuges were slated for replacement. The 
ripple effect of the aforementioned process changes impacts the digested sludge concentrations and potentially sludge dewaterability. This dissertation compares the results of the pilot studies at the SDWWTP (Vadiveloo et al., 2012 and Stitt et al., 2017) and the CDWWTP (Mudragada et al., 2014 and Moncholi et al., 2018) that used different sludge conditioning approaches to control struvite formation and as a result positively impact sludge dewatering. The later pilot studies included the testing of the future dewatering feed sludge conditions on both the dewatering centrifuge design considerations and final dewatered sludge quality and quantity to achieve a $24 \%$ cake solids concentration with 95\% solids capture rate (Stitt et al., 2017 and Moncholi et al., 2018).

Hypothesis 5 - A Framework For Biosolids Treatment Evaluations

Evaluations of biosolids treatment alternatives can be significantly improved through the development of a generic framework that considers a whole plant biosolids mass balance to determine the appropriate unit sizing and cost estimates of existing and future technologies combinations.

Existing commercially available whole-plant simulators are designed for plants with conventional activated sludge and biological nutrient removal secondary treatment processes, e.g. BioWin and GPS-X. Through sophisticated model manipulation and extensive data collection for model calibration these whole-plant simulators are capable of determining the biosolids production of plants with high purity oxygen secondary treatment (Griborio et al., 2017). For this research, a holistic process model was developed to determine the biosolids production of the subject facilities, which operate 
with high purity oxygen secondary treatment, with less model specific sampling and analysis required for model calibration than the commercially available process models. Additional functionality was programed into the process model, through unit sizing and cost estimation modules that directly used process mass balance results to arrive at both the required number of process units and estimate capital and operational cost for base case and alternative process scenarios.

\subsection{Specific Research Objectives}

- Determine best practices for biosolids treatment at a large wastewater treatment plant

- Achieve a reduction in biosolids quantity to be disposed of to reduce hauling costs

- Identify the most effective means of sludge thickening by comparing gravity thickeners, gravity belt thickeners, and thickening centrifuges

- Develop a framework to evaluate a biosolids treatment option

- Develop a model that can evaluate different future technologies for the subject plants

- Develop a model that can be modified to evaluate biosolids treatment options for other wastewater treatment facilities

- Develop a model to evaluate a combination of different biosolids treatment technologies to identify a cost effective means of producing and disposing Class B biosolids

- Achieve Class B stabilization at a lower capital and operational expenditure when existing equipment reaches end of useful life 
- Evaluate different struvite control methods to achieve greater dewatered sludge solids concentrations

- Determine if single-stage digestion can achieve significantly greater VSR than primary-secondary digestion within the same digester volume at a higher influent solids concentration

1.4 Highlighting the Innovative Aspects of this Research

- Development of a holistic plant model including process mass balance, process unit sizing, and comparative capital and operational cost estimation modules that process seamlessly with user provided inputs

- Incorporation of linear motion mixer and AirPrex, two innovative technologies, into a process model evaluation. The open architecture model developed allows for incorporation of new technologies

- Development of a mathematical model to analyze steady-state conditions at the subject facilities, two high purity oxygen secondary treatment wastewater treatments plants

- Identification of appropriate technologies and operational parameters that result in improved biosolids concentration to downstream biosolids treatment processes, lowered biosolids production quantities and afforded cost savings for the subject facilities

1.5 Dissertation Methodology

- Problem Statement/hypotheses/objectives

- $\quad$ Preliminary Numerical Model 
- $\quad$ Research into new technologies compatible with the subject treatment plants

- Selection of potential compatible technologies

- $\quad$ Evaluation of historical data including statistical analyses

- $\quad$ Analysis of pilot testing data for site-specific characteristics

- Development of a holistic mass balance model to determine possible performance of different options at full scale

- $\quad$ Technical evaluation of selected technologies based on model

- $\quad$ Recommendations based on analysis of historical data, pilot testing data and mathematical modeling

\subsection{Dissertation Outline}

- $\quad$ Chapter 1 presents the introduction including the establishment of the hypotheses and objectives of the dissertation.

- Chapter 2 provides a description of the South District Wastewater Treatment Plant and Central District Wastewater Treatment Plant, the wastewater treatment facilities that are the subject of the dissertation.

- $\quad$ Chapter 3 describes the development of the whole plant process mass balance model, presents historical data for the subject facilities, and demonstrates the statistical analysis used to arrive at the inputs for the model. Chapter 3 additionally contains the steps taken to calibrate the model by use of the historical data and briefly describes chronologically the pilot testing conducted at SDWWTP and CDWWTP that was used to establish the data input for proposed technologies evaluated in the model. 
- Chapter 4 describes the various sludge thickening technologies evaluated in the dissertation and presents the sludge thickening pilot data used in the model

- Chapter 5 describes the various sludge digestion operational methods and technologies applicable to the subject plants, highlights the two operational methods evaluated in the model to achieve Class B biosolids stabilization, and presents pilot data for anaerobic digestion used in the model.

- Chapter 6 describes the stabilized sludge dewatering technology evaluated in this dissertation and includes dewatering pilot data used in the model. Chapter 6 additionally goes into detail in two methods of struvite control that were employed in the pilot testing that contribute to the pilot data used in the model.

- Chapter 7 presents the model results for the whole plant process mass balance including process unit sizing, and comparative capital and operational cost modules developed in this dissertation.

- Chapter 8 discusses the outcomes of this dissertation in response to the initial hypotheses and objectives, gaps in the research that can be investigated in later research, and recommendations for the subject facilities based on the model results. Chapter 8 additionally includes a sensitivity analysis of the model based on modification of the parameters most likely to change based on the subject site. Chapter 8 concludes with a discussion of suggested future uses for the model developed in the dissertation and possible expansions on the research. 


\section{Wastewater Facilities Background}

SDWWTP is located in the southeastern portion of Miami-Dade County and serves the southern and southwestern portion of the county. The SDWWTP is a highpurity oxygen activated sludge secondary treatment facility with a permitted capacity of 112.5 million gallons per day (mgd) or 17,740 cubic meters per hour $\left(\mathrm{m}^{3} / \mathrm{h}\right)$. (MDWASD, May 2005)

SDWWTP produces only waste activated sludge (WAS) and wasting is controlled using a modulating valve and flow meter that is tapped off the return activated sludge pumps. The WAS is mixed with polymer in the piping and sent to four 55 -foot (16.8 meter) diameter gravity thickeners with 13 -foot ( 4.0 meter) side-water depth. The gravity thickeners thicken the solids to $2-3 \%$ total solids (TS) before being stabilized in twelve 105-foot (32 meter) diameter anaerobic digesters each with a nominal operating volume of 1.5 million gallons (5,700 cubic meters). The digesters are arranged in three clusters of four digesters per cluster, where two digesters per cluster operate as primary digesters and two operate as secondary digesters. Digester Cluster 3 normally operates with two of the digesters acting as sludge storage tanks before dewatering. Digester 9 is located in Cluster 3 and acts as a primary digester that discharges to Digester 10 which acts as a secondary digester. The digested biosolids are further dewatered using four (4) Alfa Laval PM 75000 centrifuges which achieve $18-22 \%$ TS. The sludge fed to the centrifuges is currently conditioned using a dry polymer type system. (MDWASD, May 2005)

The CDWWTP, located on Virginia Key, is the oldest existing sewer treatment plant operated by the Miami-Dade Water and Sewer Department (WASD) and was 
originally constructed in 1956. The CDWWTP is a high-purity oxygen activated sludge secondary treatment facility with a permitted capacity of 143 million gallons per day (mgd) or 22,555 cubic meters per hour $\left(\mathrm{m}^{3} / \mathrm{h}\right)$. The plant has two separate liquid processing streams: Plant 1 rated at 60 MGD ADF $\left(9,464 \mathrm{~m}^{3} / \mathrm{h}\right)$ and Plant 2 rated at 83 $\operatorname{MGD} \operatorname{ADF}\left(13,091 \mathrm{~m}^{3} / \mathrm{h}\right)$. (MDWASD, March 2005)

The CDWWTP also produces only waste activated sludge (WAS). The WAS is mixed with polymer in the piping and sent to eight 55 -foot (16.8 meter) diameter gravity thickeners with a 13-foot (4.0 meter) side-water depth. Both Plant 1 and Plant 2 contain four gravity thickeners each. The gravity thickeners thicken the solids to $2-4 \%$ total solids (TS) before being stabilized in twenty-four 105-foot (32 meter) diameter anaerobic digesters each with a nominal operating volume of 1.5 million gallons $(5,700$ cubic meters) operated under two stage mesophilic conditions. Plant 1 consists of two digester clusters each with four digesters and Plant 2 consists of four digester clusters each with four digesters. The digested biosolids are further dewatered using Alfa Laval DS 706 centrifuges which achieve greater than $25 \%$ TS. The sludge fed to the centrifuges is currently conditioned using a dry polymer type system. Ferric sulfate is also added to the dewatering feed primarily for struvite control (MDWASD, March 2005).

CDWWTP also receives primary sludge and WAS from the North District Wastewater Treatment Plant (NDWWTP). The Sludge Transfer Building at the NDWWTP houses four sludge transfer pumps with variable speed drives. The pumps are used to pump sludge through two 16-inch force mains. The force mains are parallel for about 10 miles before they join at an interconnection. From the interconnection, sludge can be directed to the sewage collection system of the CDWWTP (Force Main \# 2) or to 
an extension of one 16-inch force main that continues another 6 miles where it discharges to the gravity sludge thickeners located at Plant 2 of the CDWWTP (Force Main \#1). The sludge from NDWWTP contains an exorbitant amount of rags, plastics, and grit, which have historically been problematic for CDWWTP sludge thickening operations. Screening of NDWWTP sludges will be implemented to remedy this operational challenge. For the majority of recent history outside of the sludge thickening pilot testing described in this study, NDWWTP's primary sludge and WAS contribution have been received via the interconnection the collection system for CDWWTP sewer collection system and not directly to CDWWTP's biosolids treatment processes. (MDWASD, March 2005)

3. Process Evaluation Methodology and Historical Data Analyses

\subsection{Whole Plant Mass Balance Model (MBM)}

In order to best compare the existing design and method of operation of MiamiDade County's South and Central District Wastewater Treatment Plant with any proposed alternate biosolids treatment technologies, an understanding of the proposed design implications is required. Current solids production quantity and quality are known through historical data. For future designs, the solids quality and quantities need to be estimated as changes in solids treatment technologies can have a significant impact on both downstream and upstream flowrates, liquid and solids quality, and process equipment selection and sizing. As SDWWTP and CDWWTP are existing facilities, many of the variables required for design improvements can be determined through the historical data. Influent wastewater characteristics are known and for purposes of this 
study will be considered to reflect future conditions. Effluent wastewater characteristics will likewise be assumed to be the same as the current condition in order to meet effluent permit limits. The intermediate solids quantities and qualities are likely to change as a result of the use of new technologies and changes in operational strategies. Therefore, solids quantities and qualities need to be estimated in order to determine the necessary design upgrades specific to the proposed technologies and operational strategies.

Generally, the primary solids loading to biosolids treatment would have to be estimated; however, the SDWWTP and the CDWWTP have pretreatment screening but no primary settling. Therefore, there is no primary sludge contribution to the biosolids. Also, all preliminary screening and grit are segregated from further treatment processes and sent to landfills for final disposal. A caveat to the lack of primary treatment does exist, as a third facility owned and operated by Miami-Dade County, the North District Wastewater Treatment Plant (NDWWTP), has both primary and secondary treatment and conveys all of its waste solids to CDWWTP. The CDWWTP has the option to convey the NDWWTP solids directly to biosolids treatment or discharge them into the sewer conveyance system that makes up part of CDWWTP's influent. Miami-Dade County for most of the past 30 years has used the second mode of operation. This contribution of NDWWTP solids entering through CDWWTP's influent is reflected in the historical plant data and therefore was considered as the mode of operation for the study. (WEF MOP No. $84^{\text {th }}$ Edition, 2003)

The secondary solids quantities were based on the reaction kinetics for activated sludges with low solids retention times (SRTs) as both subject facilities are high-purity oxygen activated sludge plants with relatively short SRTs of 1.0 to 1.5 days. The SRTs 
were calculated based on the following equation, a derivation of which can be found in Appendix 1: Derived Equations, Equation 1 (WEF MOP No. $84^{\text {th }}$ Edition, 2003).

Equation 1: Aeration Basin SRT, based on MOP 8 p. 14-38

where,

$\mathrm{SRT}=\frac{\mathrm{V}_{\mathrm{REACTOR}(\mathrm{S})} * \mathrm{MLSS}}{\mathrm{Q}_{\mathrm{WAS}} * \mathrm{X}_{\mathrm{TSS}, \mathrm{WAS}}+\mathrm{Q}_{\mathrm{EFF}} * \mathrm{X}_{\mathrm{TSS}, \mathrm{EFF}}}$

$\mathrm{V}_{\mathrm{REACTOR}(\mathrm{S})}=$ volume of biological reactor $\left(\mathrm{MG}\right.$ or $\left.\mathrm{m}^{3}\right)$

$\mathrm{Q}_{\mathrm{WAS}}=$ waste activated sludge flowrate $\left(\mathrm{MGD}\right.$, gpm or $\left.\mathrm{m}^{3} / \mathrm{d}\right)$

$\mathrm{Q}_{\mathrm{EFF}}=$ secondary clarifier effluent flowrate (MGD, gpm or $\left.\mathrm{m}^{3} / \mathrm{d}\right)$

$\mathrm{X}_{\mathrm{TSS}, \mathrm{WAS}}=$ solids concentration in waste activate sludge stream $\left(\mathrm{mg} / \mathrm{L}\right.$ or $\left.\mathrm{g} / \mathrm{m}^{3}\right)$

$\mathrm{X}_{\mathrm{TSS}, \mathrm{EFF}}=$ solids concentration in secondary clarifier effluent $\left(\mathrm{mg} / \mathrm{L}\right.$ or $\left.\mathrm{g} / \mathrm{m}^{3}\right)$

MLSS $=$ solids concentration in reactor, mixed liquor suspended solids $\left(\mathrm{mg} / \mathrm{L} \mathrm{or} \mathrm{g} / \mathrm{m}^{3}\right)$

The reaction kinetics considerations were based on the mathematical expression below Equation 2. A more complex kinetic relationship would be more suitable for a model of the low SRT high-purity oxygen to produce an accurate solids yield (Daigger et al., 1995 and Novak et al., 1995). Unfortunately, there are insufficient data to establish a more complex model and as the secondary treatment process is not the focus of this study, this expression and the range of observed biomass yields based on SRT and the true yield as shown in the adjoining table will suffice (Table 1). Although research in the realm of activated sludge kinetics is plentiful, the research is directed in great part to reaction kinetics of biological nutrient removal, fixed film systems and membrane bioreactors (Canziani et al., 2006, He et al., 2009, and Zuthi et al., 2013). No recent research on reaction kinetics for high purity oxygen activated sludge systems was found 
during the model development portion of the study. The solids contribution to biosolids treatment was considered as solely from secondary waste activated sludge. This can significantly affect the solids production quantities for biosolids treatment and the selection of appropriate technologies. (WEF MOP No. $84^{\text {th }}$ Edition, 2003)

Equation 2: Observed Yield, MOP 8 Eq. 20.3

where,

$$
\mathrm{Y}_{\mathrm{obs}} \quad=\frac{\mathrm{Y}}{1+\mathrm{k}_{\mathrm{d}}\left(\theta_{\mathrm{c}}\right)}
$$

$\mathrm{Y}_{\mathrm{obs}}=$ observed yield (lb biomass/lb substrate or $\mathrm{g}$ biomass $/ \mathrm{g}$ substrate)

$\mathrm{Y}=$ yield (lb biomass/ lb substrate or $\mathrm{g}$ biomass/ $\mathrm{g}$ substrate)

$\mathrm{k}_{\mathrm{d}}=$ endogenous decay rate ( $\mathrm{lb}$ biomass $/ \mathrm{lb}$ substrate- $\mathrm{d}^{-1}$ or $\mathrm{g}$ biomass $/ \mathrm{g}$ substrate- $\mathrm{d}^{-1}$ )

$\theta_{\mathrm{c}}=\operatorname{SRT}$ or MCRT $(\mathrm{d})$

Table 1 : Range of Observed Yields $\left(Y_{o b s}\right)$ for varying SRTs and Yields

\begin{tabular}{|l|l|l|l|l|l|l|l|l|l|}
$\mathrm{kd}$ & $=$ & 0.06 \\
\hline $\mathrm{Y}$ & 0.1 & 0.2 & 0.3 & 0.4 & 0.5 & 0.6 & 0.7 & 0.8 & 0.9 \\
\hline$\theta_{\mathrm{c}}$ & \multicolumn{7}{|c|}{$\mathrm{Y}$ obs } \\
\hline $\mathrm{d}$ & \multicolumn{10}{|c|}{$\mathrm{kg} / \mathrm{kg}(\mathrm{lb} / \mathrm{lb})$} \\
\hline 0.25 & 0.10 & 0.20 & 0.30 & 0.39 & 0.49 & 0.59 & 0.69 & 0.79 & 0.89 \\
\hline 0.5 & 0.10 & 0.19 & 0.29 & 0.39 & 0.49 & 0.58 & 0.68 & 0.78 & 0.87 \\
\hline 0.75 & 0.10 & 0.19 & 0.29 & 0.38 & 0.48 & 0.57 & 0.67 & 0.77 & 0.86 \\
\hline 1 & 0.09 & 0.19 & 0.28 & 0.38 & 0.47 & 0.57 & 0.66 & 0.75 & 0.85 \\
\hline 1.25 & 0.09 & 0.19 & 0.28 & 0.37 & 0.47 & 0.56 & 0.65 & 0.74 & 0.84 \\
\hline 1.5 & 0.09 & 0.18 & 0.28 & 0.37 & 0.46 & 0.55 & 0.64 & 0.73 & 0.83 \\
\hline 1.75 & 0.09 & 0.18 & 0.27 & 0.36 & 0.45 & 0.54 & 0.63 & 0.72 & 0.81 \\
\hline 2 & 0.09 & 0.18 & 0.27 & 0.36 & 0.45 & 0.54 & 0.63 & 0.71 & 0.80 \\
\hline
\end{tabular}


In order to estimate the theoretical solids production of both the existing plants as well as the theoretical solids production after proposed changes in technology a mass balance model with several iterations was developed to determine solids loadings, flow rates, recycle stream impacts and biosolids production quantities. The Mass Balance Models (MBM) were based on methodologies described in the American Society of Civil Engineers/Water Environment Federation's Manual of Practice No. 8, Design of Municipal Wastewater Treatment Plants and Metcalf and Eddy's Wastewater Engineering Treatment and Reuse. The example plants utilized in the reference differ in some treatment processes and operational strategies; however, the examples provided a sound basis to develop the Mass Balance Models for the SDWWTP and the CDWWTP (WEF Mop 8. $5^{\text {th }}$ Edition, 2010; Metcalf et al. $4^{\text {th }}$ Edition., 2003; Lin, 2001).

The subject plants' current performance based on historical data is used for comparison, but to directly compare historical data and plant performance against model results for alternate technologies would omit the reality that aging wastewater treatment plants will seldom perform as designed. Worn out or malfunctioning equipment; accumulation of grit, sand, and inert solids in process units; and operators' preferences about times to operate out of normal operating conditions often result in plants that operate well below their designed optimal performance.

To account for the historical data being for a plant under a certain level of deterioration and not directly analogous to either a new plant or theoretical plant design, a mass balance model of the plant as currently designed and operated was also developed during this research. Differences in flow rates and solids production between the plant data and the model results were analyzed and discussed. The table below presents all the 
model runs that were performed and the overall differences in technologies and process operation between them (Table 2). More detailed analyses on the technologies evaluated, sizing of process units, and operational and capital cost estimates were performed. 
Table 2: Mass Balance Model Scenarios

\begin{tabular}{|c|c|c|c|c|}
\hline $\begin{array}{l}\text { Scenarios } \\
\text { evaluated }\end{array}$ & Description & $\begin{array}{c}\text { Sludge } \\
\text { thickening }\end{array}$ & $\begin{array}{c}\text { Anaerobic } \\
\text { digestion }\end{array}$ & $\begin{array}{l}\text { Dewatering w/ } \\
\text { struvite control }\end{array}$ \\
\hline \multicolumn{5}{|c|}{ Miami-Dade South District Water Resource Recovery Facility } \\
\hline SD-A & existing plant (based on plant data) & $\begin{array}{c}\text { gravity } \\
\text { concentrator }\end{array}$ & $\begin{array}{l}\text { two-stage } \\
\text { mesophilic }\end{array}$ & $\begin{array}{l}\text { centrifuge } \\
\text { dewatering }\end{array}$ \\
\hline SD-B & $\begin{array}{l}\text { existing plant fully operational (design/ } \\
\text { theoretical) }\end{array}$ & $\begin{array}{c}\text { gravity } \\
\text { concentrator }\end{array}$ & $\begin{array}{l}\text { two-stage } \\
\text { mesophilic }\end{array}$ & $\begin{array}{l}\text { centrifuge } \\
\text { dewatering }\end{array}$ \\
\hline $\mathrm{SD}-\mathrm{C}$ & $\begin{array}{l}\text { existing plant (design/ theoretical) with } \\
\text { gravity belt thickeners }\end{array}$ & $\begin{array}{l}\text { gravity belt } \\
\text { thickener }\end{array}$ & $\begin{array}{l}\text { two-stage } \\
\text { mesophilic }\end{array}$ & $\begin{array}{l}\text { centrifuge } \\
\text { dewatering }\end{array}$ \\
\hline SD-D & modified plant with gravity belt thickeners & $\begin{array}{l}\text { gravity belt } \\
\text { thickener }\end{array}$ & $\begin{array}{l}\text { single stage } \\
\text { mesophilic }\end{array}$ & $\begin{array}{l}\text { centrifuge } \\
\text { dewatering }\end{array}$ \\
\hline SD-E & modified plant with centrifuge thickeners & $\begin{array}{l}\text { thickening } \\
\text { centrifuge }\end{array}$ & $\begin{array}{l}\text { single stage } \\
\text { mesophilic }\end{array}$ & $\begin{array}{c}\text { centrifuge } \\
\text { dewatering }\end{array}$ \\
\hline \multicolumn{5}{|c|}{ Miami-Dade Central District Water Resource Recovery Facility } \\
\hline CD-A & existing plant (based on plant data) & $\begin{array}{c}\text { gravity } \\
\text { concentrator }\end{array}$ & $\begin{array}{l}\text { two-stage } \\
\text { mesophilic }\end{array}$ & $\begin{array}{l}\text { centrifuge } \\
\text { dewatering }\end{array}$ \\
\hline CD-B & $\begin{array}{l}\text { existing plant fully operational (design/ } \\
\text { theoretical) }\end{array}$ & $\begin{array}{c}\text { gravity } \\
\text { concentrator }\end{array}$ & $\begin{array}{l}\text { two-stage } \\
\text { mesophilic }\end{array}$ & $\begin{array}{l}\text { centrifuge } \\
\text { dewatering }\end{array}$ \\
\hline $\mathrm{CD}-\mathrm{C}$ & $\begin{array}{l}\text { existing plant (design/ theoretical) with } \\
\text { gravity belt thickeners }\end{array}$ & $\begin{array}{l}\text { gravity belt } \\
\text { thickener }\end{array}$ & $\begin{array}{l}\text { two-stage } \\
\text { mesophilic }\end{array}$ & $\begin{array}{l}\text { centrifuge } \\
\text { dewatering }\end{array}$ \\
\hline CD-D & modified plant with gravity belt thickeners & $\begin{array}{l}\text { gravity belt } \\
\text { thickener }\end{array}$ & $\begin{array}{l}\text { single stage } \\
\text { mesophilic }\end{array}$ & $\begin{array}{l}\text { centrifuge } \\
\text { dewatering }\end{array}$ \\
\hline CD-E & modified plant with centrifuge thickeners & $\begin{array}{l}\text { thickening } \\
\text { centrifuge }\end{array}$ & $\begin{array}{l}\text { single stage } \\
\text { mesophilic }\end{array}$ & $\begin{array}{l}\text { centrifuge } \\
\text { dewatering }\end{array}$ \\
\hline
\end{tabular}


Process flow diagrams describing the different scenarios of the proposed biosolids treatment process modifications are shown in Figures $1-4$.

- $\quad$ Scenarios A and B depict the existing biosolids treatment process flow for both SDWWTP and CDWWTP (Figure 1).

- Scenario C depicts a change from gravity concentrators to gravity belt thickeners for thickening technology followed by existing primary-secondary anaerobic mesophilic digester system (Figure 2).

- Scenario D continues with the selection of gravity belt thickeners followed by a process modification to single-stage high-rate anaerobic mesophilic digestion followed by the existing dewatering centrifuge technology (Figure 3).

- Scenario E, the final scenario, includes thickening centrifuges to replace the current sludge thickening method, single-stage high-rate anaerobic mesophilic digestion, and dewatering centrifuges, the existing technology, for the dewatering process (Figure 4). 


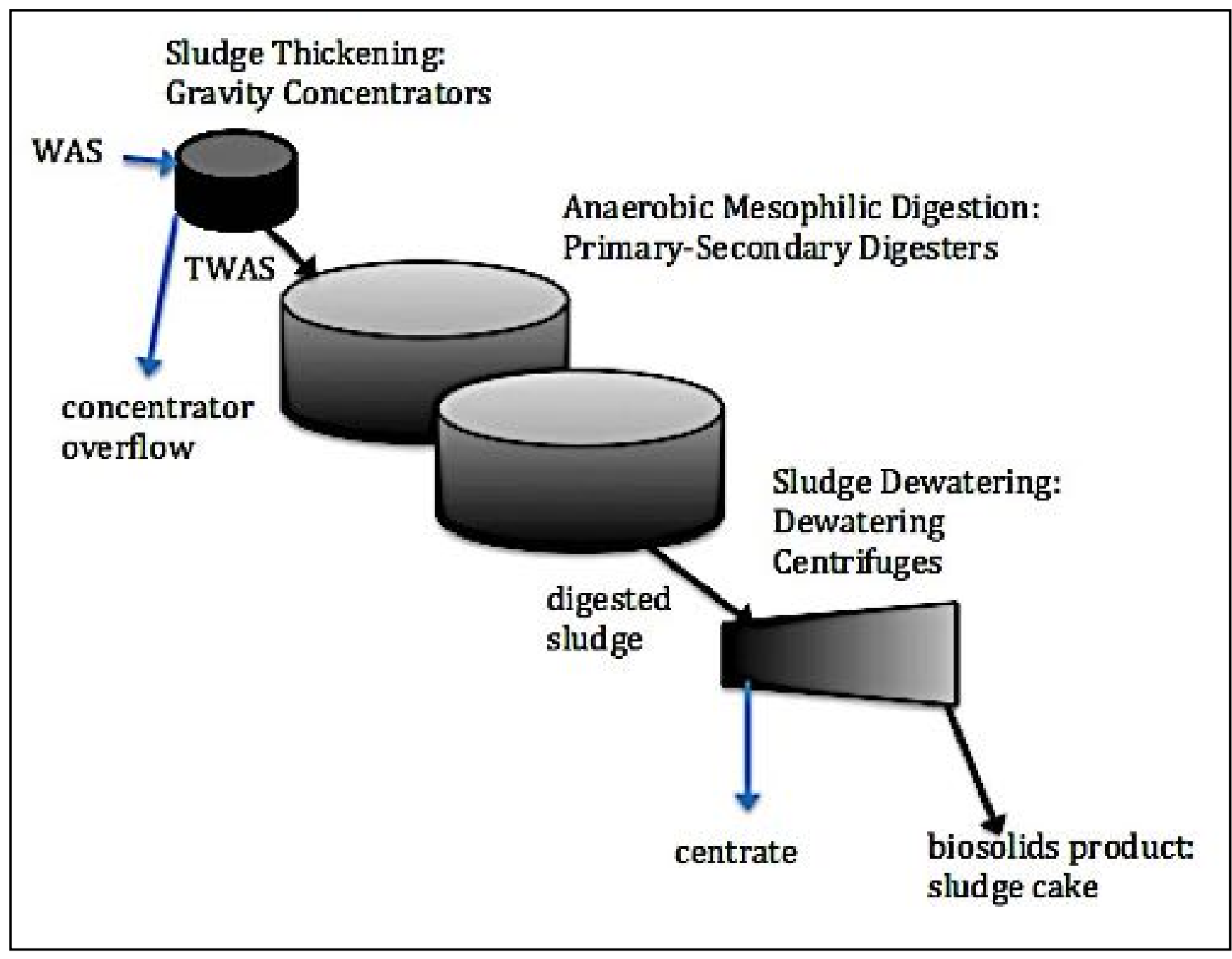

Figure 1: Process Flow Diagram of Scenarios A and B 


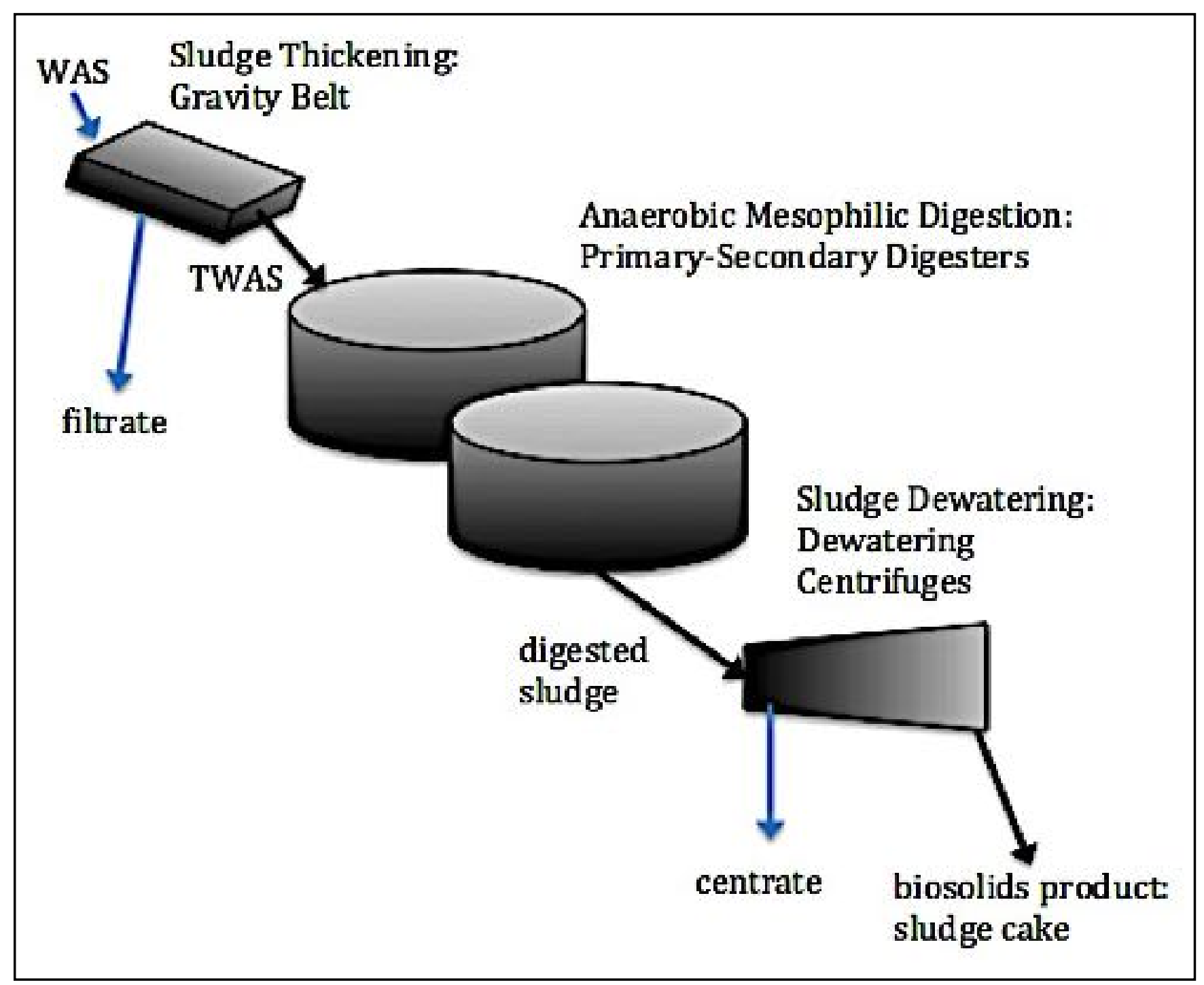

Figure 2: Process Flow Diagram of Scenario C 


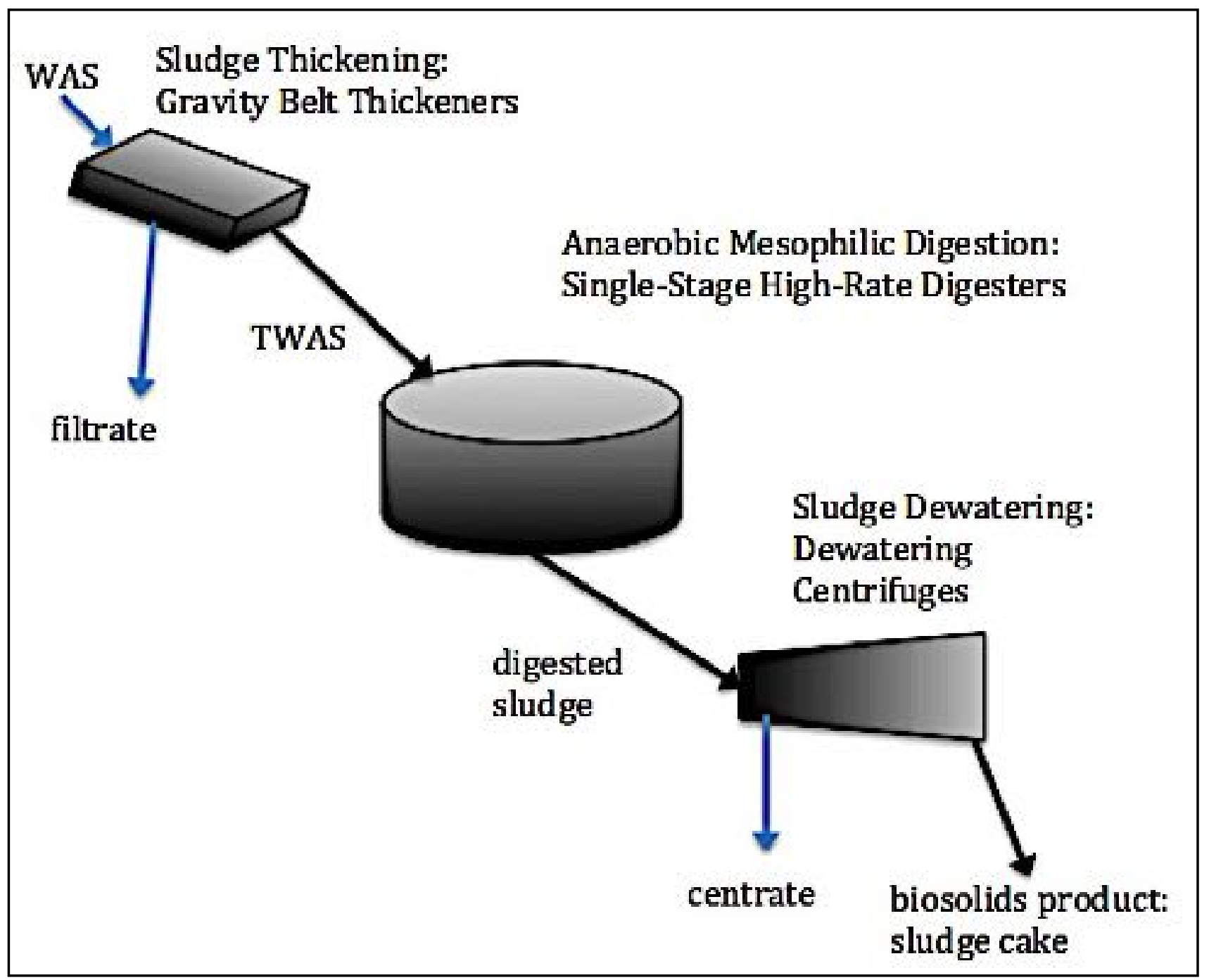

Figure 3: Process Flow Diagram of Scenario D 


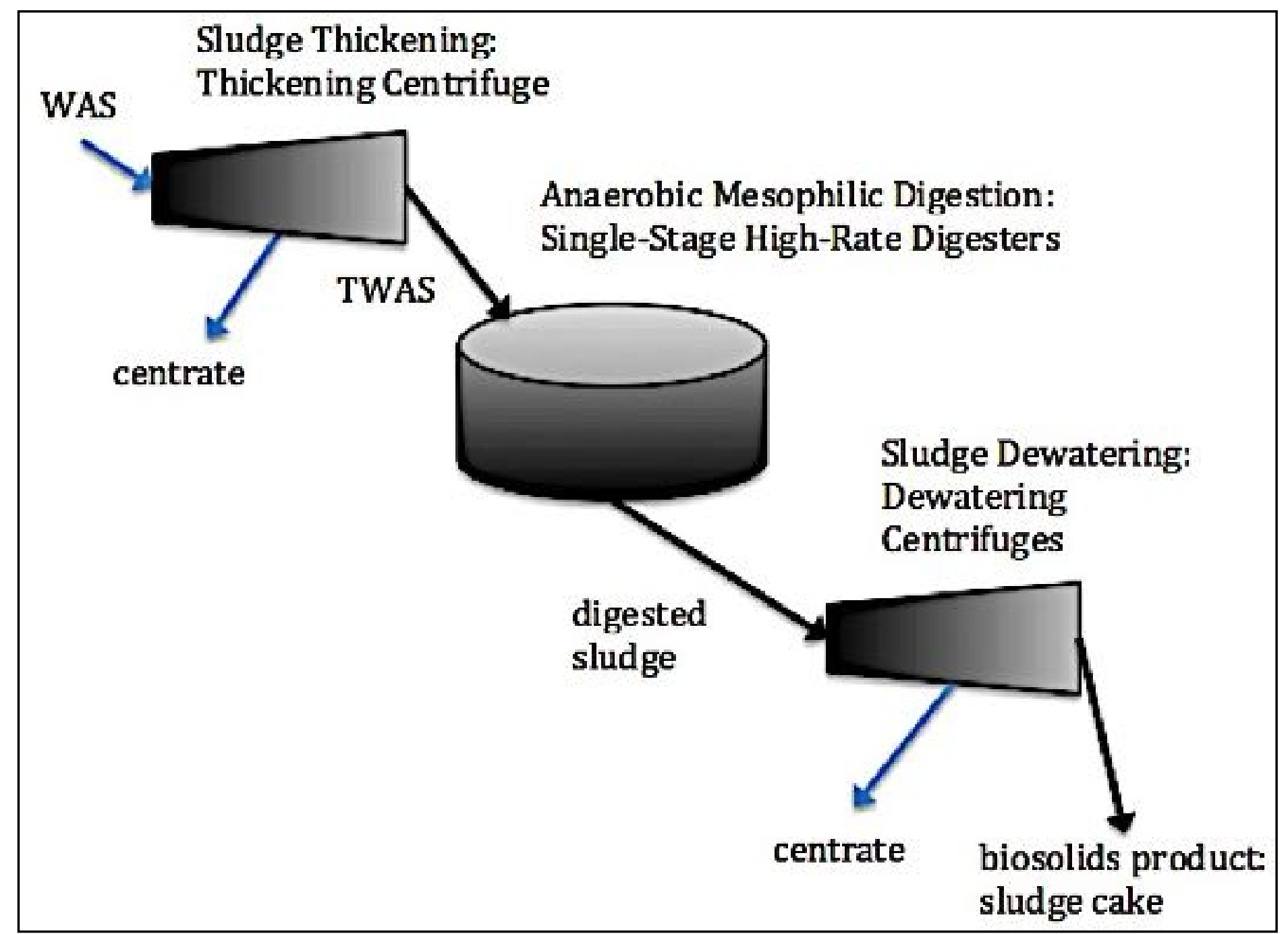

Figure 4: Process Flow Diagram of Scenario E 


\subsection{Historical Data Collection and Analyses}

In order to understand the current plant performance and as a point of comparison to proposed improvements, analyses of the plant operating data during the period between 2008 and 2017 were conducted. The analyses were conducted in two phases after the first analysis left unresolved questions as to plant performance. There were inconsistencies in the data from consecutive processes that upon inclusion in the mass balance model demonstrated that either the plant did not behave as the model plant or some of the data were erroneous or misidentified. The first data set consisted of monthly averages. As the plants were being assumed to be operating under steady-state conditions, the use of monthly averages should not have posed any problem, and in fact, the data were further averaged to one data point per variable in the mass balance model. During further investigation, several issues were discovered that ultimately required the data to be discarded and assumptions to be made in order to properly develop and analyze the mass balance models.

Firstly, several crucial model parameters were not part of the plants' sampling regimes. Influent volatile solids (VS), total suspended solids (TSS) after grit removal, and VS after grit removal are among a few analytes that although critical for a mass balance are not collected by the plants. This information, valuable for operations management at these facilities, was either never collected for all crucial process parameters or ceased to be collected at some point in the past as noted in Table 4 . Amongst the lab analysis not conducted at CDWWTP and SDWWTP on a regular basis is $\mathrm{BOD}_{5}$ or the total 5-day biochemical oxygen demand (APHA/AWWA/WEF, 1999). This is an important parameter; however, the lab instead performs $\mathrm{CBOD}_{5}$ (5-day 
carbonaceous biochemical oxygen demand) tests. CBOD is less than BOD since it excludes the oxygen demand exerted by nitrogen. Under normal circumstances this would influence the model results as bacteria utilizing nitrogen also contribute to the biomass growth in most wastewater treatment facilities (Canales et al., 1994). As the SDWWTP and CDWWTP are very high-rate, high-purity oxygen activated sludge plants they are not conducive to the growth of nitrifying and denitrifying bacteria. The amount of sampling and lab analyses for these facilities to comply with regulatory requirements is large. The majority of internal plant process data, albeit critical for proper plant operations and optimization, is not required by state and federal regulations. Due to equipment and staffing limitations, a balance is often struck with what is the most crucial non-regulatory data and what operating parameters would be good to collect but not as essential. This question surely plagues many utilities as laboratory budgets and staffing beyond that necessary to meet regulatory requirements are highly scrutinized. As a result of a lack of some data necessary for the model, certain conservative assumptions were made to account for the missing data. The following table identifies required data inputs for the MBM and the categories of data integrity (Table 3).

Table 3: Input Data for Mass Balance Model

\begin{tabular}{|l|l|l|l|}
\hline Defined variable (analyte/flow stream) & $\begin{array}{l}\text { Standard } \\
\text { units }\end{array}$ & SI units & Data source \\
\hline Plant Influent Conditions & & & \\
\hline Average Daily Flow & $\mathrm{mgd}$ & $\mathrm{m}^{3} / \mathrm{d}$ & historical plant data \\
\hline Wet Weather Peak Factor & {$[-]$} & {$[-]$} & calculated \\
\hline Wet Weather Peak Flow & $\mathrm{mgd}$ & $\mathrm{m}^{3} / \mathrm{d}$ & historical plant data \\
\hline Carbonaceous Biological Oxygen Demand & $\mathrm{mg} / \mathrm{L}$ & $\mathrm{g} / \mathrm{m}^{3}$ & historical plant data \\
\hline Total Suspended Solids & $\mathrm{mg} / \mathrm{L}$ & $\mathrm{g} / \mathrm{m}^{3}$ & historical plant data \\
\hline Total Suspended Solids after grit removal & $\mathrm{mg} / \mathrm{L}$ & $\mathrm{g} / \mathrm{m}^{3}$ & $\begin{array}{l}\text { assumed, historical } \\
\text { data not available }\end{array}$ \\
\hline Volatile fraction of influent TSS & $\%$ & $\%$ & $\begin{array}{l}\text { assumed, historical } \\
\text { data not available }\end{array}$ \\
\hline
\end{tabular}




\begin{tabular}{|c|c|c|c|}
\hline Volatile fraction of grit removed & $\%$ & $\%$ & $\begin{array}{l}\text { assumed, historical } \\
\text { data not available }\end{array}$ \\
\hline \multicolumn{4}{|l|}{ Plant Effluent Conditions } \\
\hline Total Suspended Solids & $\mathrm{mg} / \mathrm{L}$ & $\mathrm{g} / \mathrm{m}^{3}$ & historical plant data \\
\hline Carbonaceous Biological Oxygen Demand & $\mathrm{mg} / \mathrm{L}$ & $\mathrm{g} / \mathrm{m}^{3}$ & historical plant data \\
\hline UBOD factor & $\mathrm{lb} / \mathrm{lb}$ & $\mathrm{g} / \mathrm{g}$ & assumed, literature \\
\hline effluent BOD to TSS & $\%$ & $\%$ & assumed, literature \\
\hline \multicolumn{4}{|l|}{ Plant Primary Treatment Conditions } \\
\hline Concentration of Primary Solids & $\mathrm{mg} / \mathrm{L}$ & $\mathrm{g} / \mathrm{m}^{3}$ & not applicable \\
\hline primary solids specific gravity & {$[-]$} & {$[-]$} & not applicable \\
\hline \multicolumn{4}{|l|}{ Plant Secondary Treatment Conditions } \\
\hline biodegradable fraction of biological solids & $\%$ & $\%$ & assumed, literature \\
\hline $\begin{array}{l}\text { volatile fraction of TSS to secondary } \\
\text { treatment }\end{array}$ & $\%$ & $\%$ & $\begin{array}{l}\text { assumed, historical } \\
\text { data not available }\end{array}$ \\
\hline Mixed-Liquor Suspended Solids & $\mathrm{mg} / \mathrm{L}$ & $\mathrm{g} / \mathrm{m}^{3}$ & historical plant data \\
\hline Volatile fraction of MLSS & $\%$ & $\%$ & historical plant data \\
\hline Aeration tank volume & MG & $\mathrm{m}^{3}$ & design data \\
\hline Secondary treatment solids retention time & $\mathrm{d}$ & $\mathrm{d}$ & calculated \\
\hline Observed yield & $\mathrm{lb} / \mathrm{lb}$ & $\mathrm{kg} / \mathrm{kg}$ & calculated \\
\hline Yield & $\mathrm{lb} / \mathrm{lb}$ & $\mathrm{kg} / \mathrm{kg}$ & assumed, literature \\
\hline secondary treatment kinetic factor & $\mathrm{d}^{-1}$ & $\mathrm{~d}^{-1}$ & assumed, literature \\
\hline \multicolumn{4}{|l|}{ Plant Sludge Thickening Conditions } \\
\hline $\begin{array}{l}\text { Concentration of thickened waste-activated } \\
\text { sludge }\end{array}$ & $\mathrm{mg} / \mathrm{L}$ & $\mathrm{g} / \mathrm{m}^{3}$ & historical plant data \\
\hline thickened solids specific gravity & {$[-]$} & {$[-]$} & historical plant data \\
\hline Sludge thickening solids capture & $\%$ & $\%$ & calculated \\
\hline \multicolumn{4}{|l|}{ Plant Sludge Digestion Conditions } \\
\hline Total Suspended Solids of digested sludge & $\mathrm{mg} / \mathrm{L}$ & $\mathrm{g} / \mathrm{m}^{3}$ & historical plant data \\
\hline Digester tank volume & MG & $\mathrm{m}^{3}$ & design data \\
\hline Digester Solids Retention Time & $\mathrm{d}$ & $\mathrm{d}$ & calculated \\
\hline VSS destruction during digestion & $\%$ & $\%$ & historical plant data \\
\hline Gas Production & $\begin{array}{l}\mathrm{ft}^{3} / \mathrm{lb} \text { of } \\
\mathrm{VSS} \\
\text { destroyed }\end{array}$ & $\begin{array}{l}\mathrm{m}^{3} / \mathrm{kg} \text { of } \\
\mathrm{VSS} \\
\text { destroyed }\end{array}$ & assumed, literature \\
\hline Digester Supernatant TSS & $\mathrm{mg} / \mathrm{L}$ & $\mathrm{g} / \mathrm{m}^{3}$ & not applicable \\
\hline Digester Supernatant BOD & $\mathrm{mg} / \mathrm{L}$ & $\mathrm{g} / \mathrm{m}^{3}$ & not applicable \\
\hline \multicolumn{4}{|l|}{ Plant Sludge Dewatering Conditions } \\
\hline Dewatered sludge cake percent solids & $\begin{array}{l}\text { \% solids } \\
\text { by wt. }\end{array}$ & $\begin{array}{l}\text { \% solids } \\
\text { by wt. }\end{array}$ & historical plant data \\
\hline dewatered sludge cake specific gravity & {$[-]$} & {$[-]$} & historical plant data \\
\hline Sludge dewatering solids capture & $\%$ & $\%$ & calculated \\
\hline Centrate BOD & $\mathrm{mg} / \mathrm{L}$ & $\mathrm{g} / \mathrm{m}^{3}$ & $\begin{array}{l}\text { assumed, historical } \\
\text { data not available }\end{array}$ \\
\hline
\end{tabular}


A second issue with some of the data is the values of some of the parameters that are significantly out of the proper ranges for the process. A number of factors could lead to this phenomenon. Sampling is often time consuming and plant operators can often be in a rush. Many plant sample locations are not immediately next to the process stream being sampled. As a result, sampling points are generally piped under pressure of the respective vessel or pumped through a sampling pump. In either case, a length of piping must be traveled for the sample to get from the sample vessel to the sampling point. This can take from several seconds to a few minutes for some of the sampling points in these facilities. Furthermore, these long line lengths, especially for higher solids samples, require periodic or constant flushing with water to ensure the lines do not clog. As a result, samples taken without allowing the appropriate amount of volume to flow through the line before taking a sample can result in non-representative samples. This can manifest itself in a manner of ways in the data. Solids build up in the lines can cause samples of material sitting in the sampling lines to have higher than normal amounts of solids. Due to the consistently warm weather in Miami, samples of biologically active sludges can continue to digest/react in the line and if samples are not taken frequently enough, the detention time in the line can further degrade volatile solids resulting in a lower than representative volatile fraction. Flushing out of sampling lines can also cause samples to be diluted with plant process water and hence not be representative at all or may represent a mixture and hence containing lower than normal solids content. Also, in the realm of poor sampling practices, less experienced operators can erroneously sample from the wrong sampling point. Based on personal experience, this can also happen if 
the operator is rushed, very hot, or exhausted, which are all conditions under which plant operators must work in these facilities.

Over a decade of plant process data were collected and analyzed for SDWWTP and CDWWTP. The period of data that were used as input values was significantly shorter for several reasons. Much of the flow rate data used for calibration of the models were not available prior to 2015 . Instances of both flowrate and laboratory data prior to this timeframe were severely beyond the data range of stable plant operations. Return Activated Sludge (RAS) concentration data for South District were one case where concentration values were at least an order of magnitude out of scale (Figure 5.) It would not be possible to operate the existing high-purity oxygenation basins or clarifiers with RAS concentrations at this level, as it would be $4-6 \%$ solids. The ramification would be that the clarifiers' centrifugal pumps would not be able to pump so thick a sludge. Additionally, bioreactor mixers would be unable to rotate and hence there would be no oxygen transfer. Similarly, historical data on SDWWTP's centrate demonstrates very high volatile solids fractions (Figure 6). The data values are nonsensical as plant volatile are reported on a 1-100 scale, representing a 1-100\% volatile fraction of a sample. Suddenly in 2016, the data drop to acceptable value ranges. SDWWTP RAS flow data demonstrates that both signal outages and values far out of range produce data that would not be suitable for analysis (Figure 7). 
The sources of these anomalies were not further researched and none of the suspect data mentioned here were used in creation of the mass balance models. Two-year and three-year periods of relatively stable and consistent plant performance were selected for SDWWTP and CDWWTP, respectively. The SDWWTP data period used for indepth analysis was $12 / 31 / 2015$ - 12/31/2017. The CDWWTP data period used for indepth analysis was 12/31/2014-12/31/2017. 


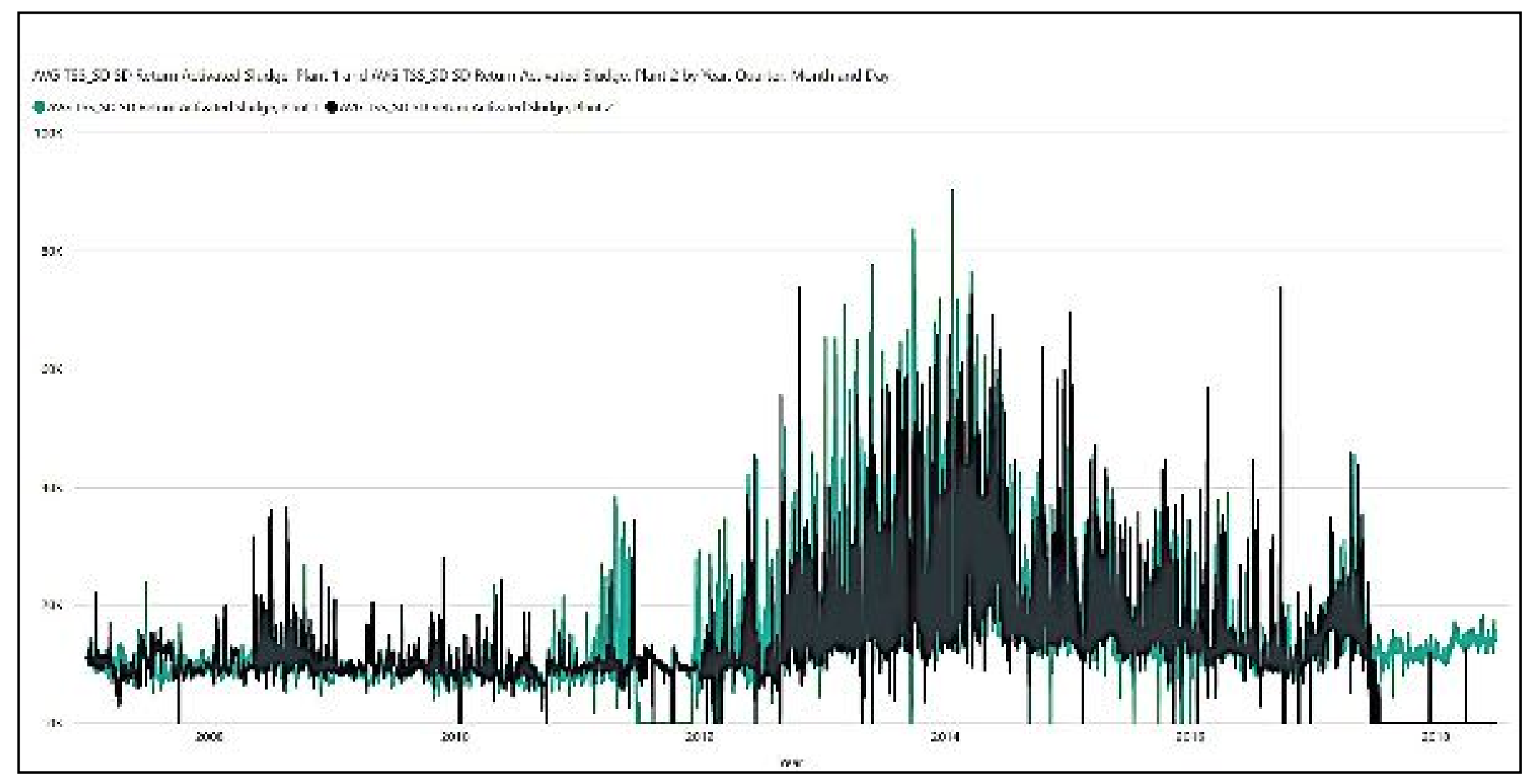

Figure 5: Out of range RAS TSS data 


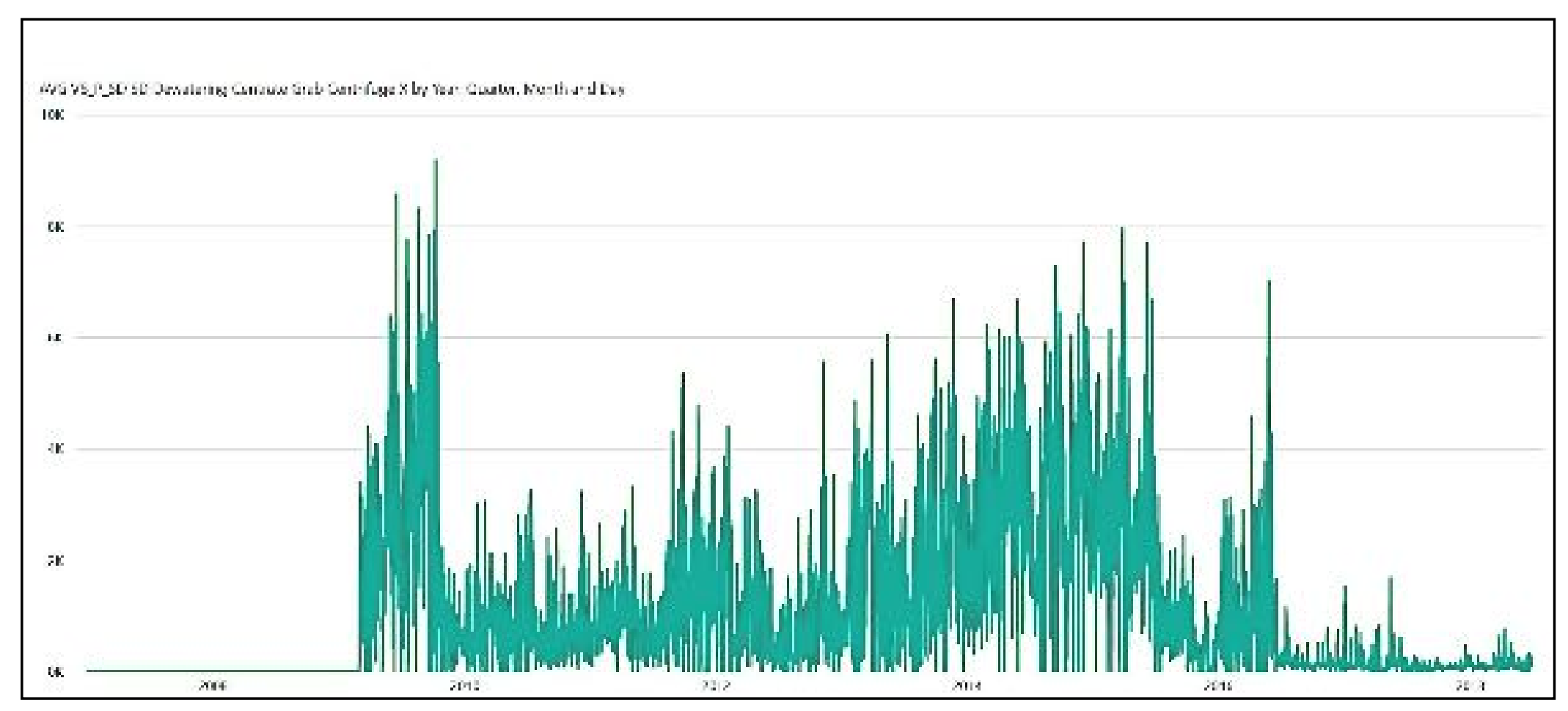

Figure 6: Out of range centrate volatile fraction data 


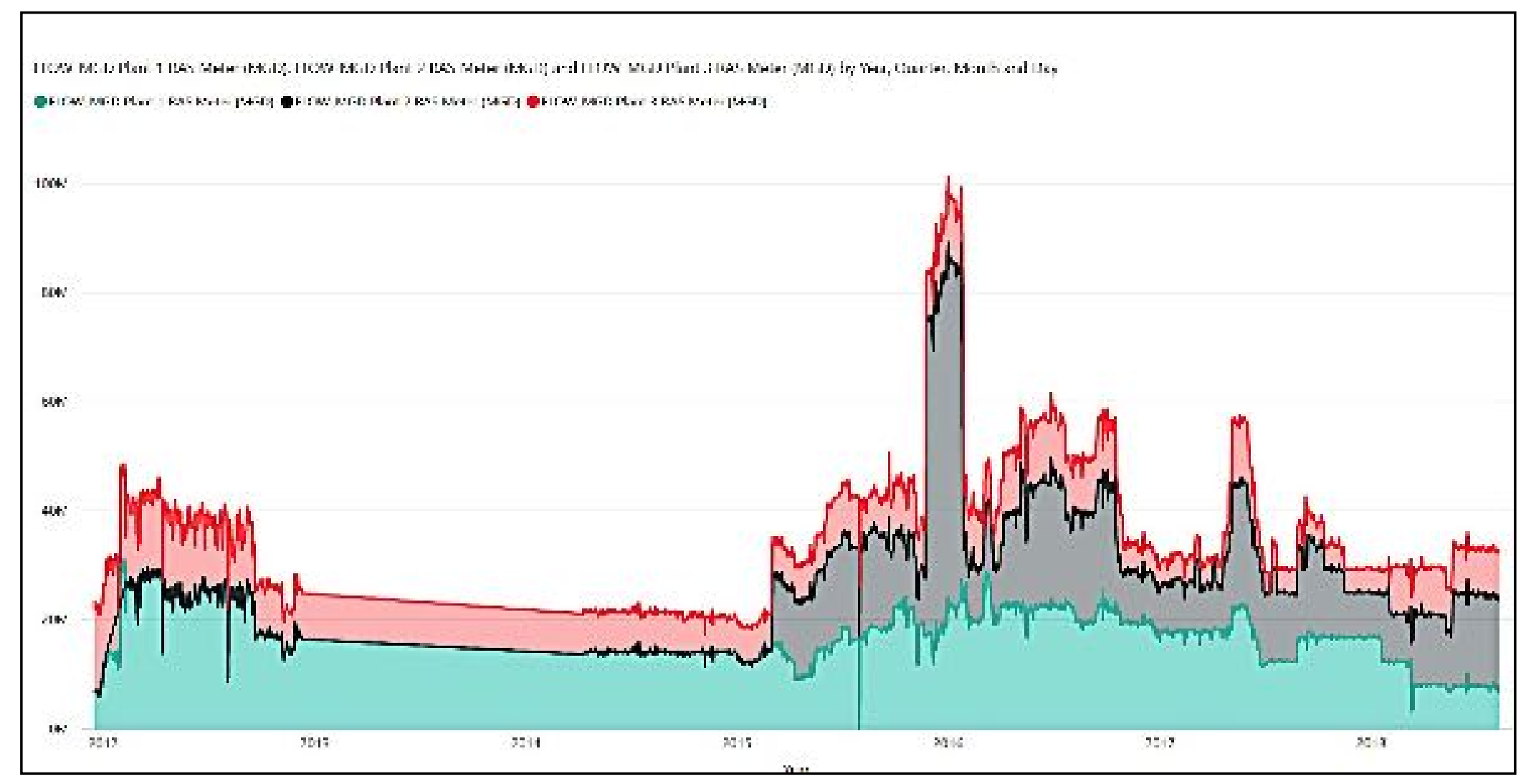

Figure 7: Missing and out of range RAS flow data 
A final issue that could greatly affect results but not strictly be a sampling or lab analysis issue is the sampling of processes that are either in upset conditions or otherwise not operating at steady-state. Although these samples are representative of the existing plant condition at the time, for the purposes of this study and the mass balance model the data taken under non-steady state conditions are not considered representative of the plants' operating conditions. Cases where this is most notable are around the dewatering centrifuge as these machines are often stopped and started in a day and require several minutes to achieve steady-state producing both acceptable sludge cake and discharging target centrate.

For these reasons, a second phase of data collection was conducted for this study to retrieve daily plant data, conduct data analysis and statistical analysis and arrive at truly representative average steady-state parameters. Not all data were available as daily samples and therefore a mixture of data frequencies was used in arriving at the parameters used. Where possible a $90^{\text {th }}$ percentile rule was used to exclude historical data that were the lowest and highest $5 \%$ of the data values, as much of these extremes were clearly out of range of normal operation of the study facilities. The following plots demonstrate the technique using visualizations in MS Power BI (Figure 8 and Figure 9). Due to the scarcity in data points for satisfactory pilot testing runs, pilot test data were not subjected to this exclusion rule. 


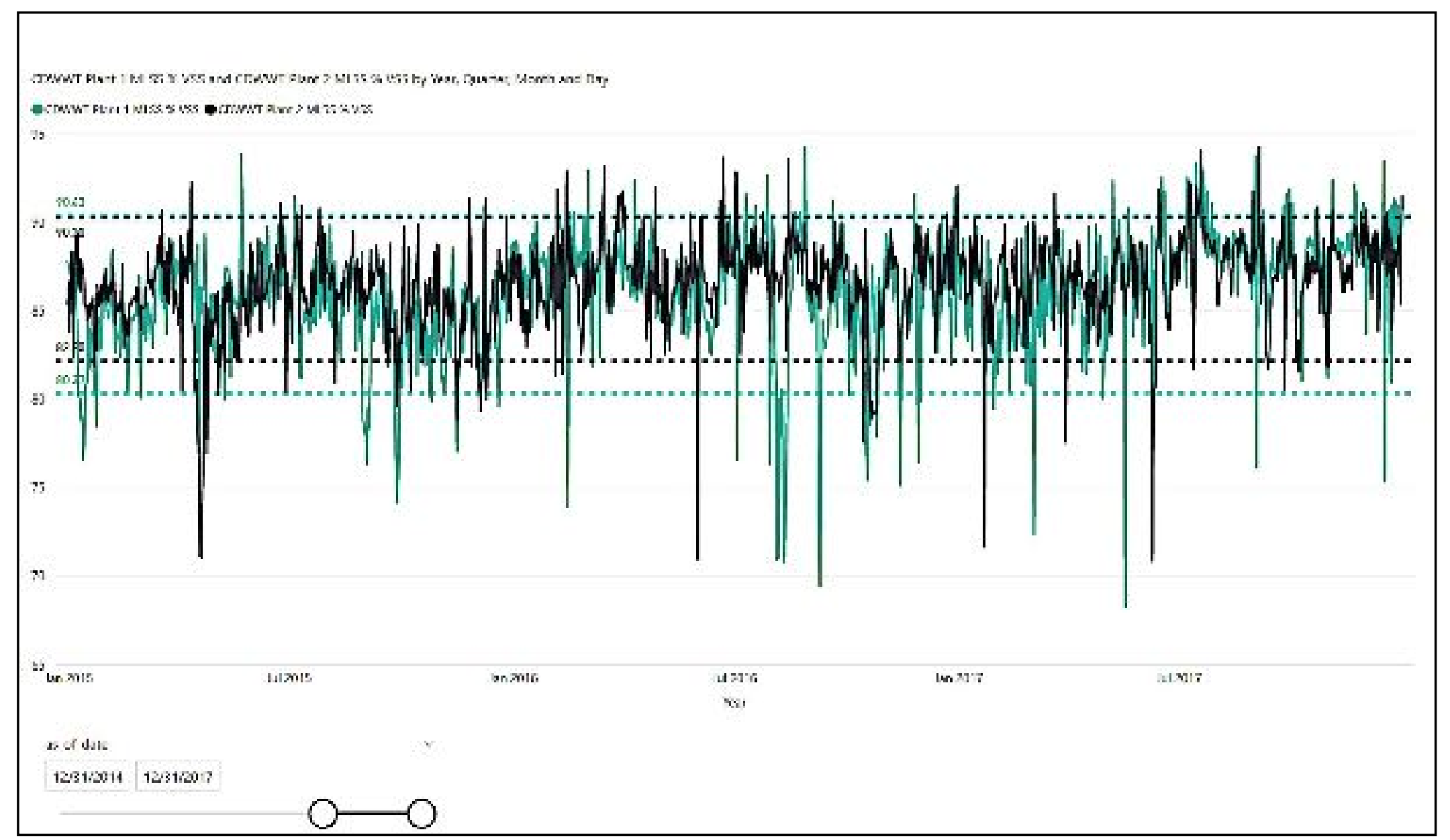

Figure 8: Plot of 90th percentile rule for filtering data 


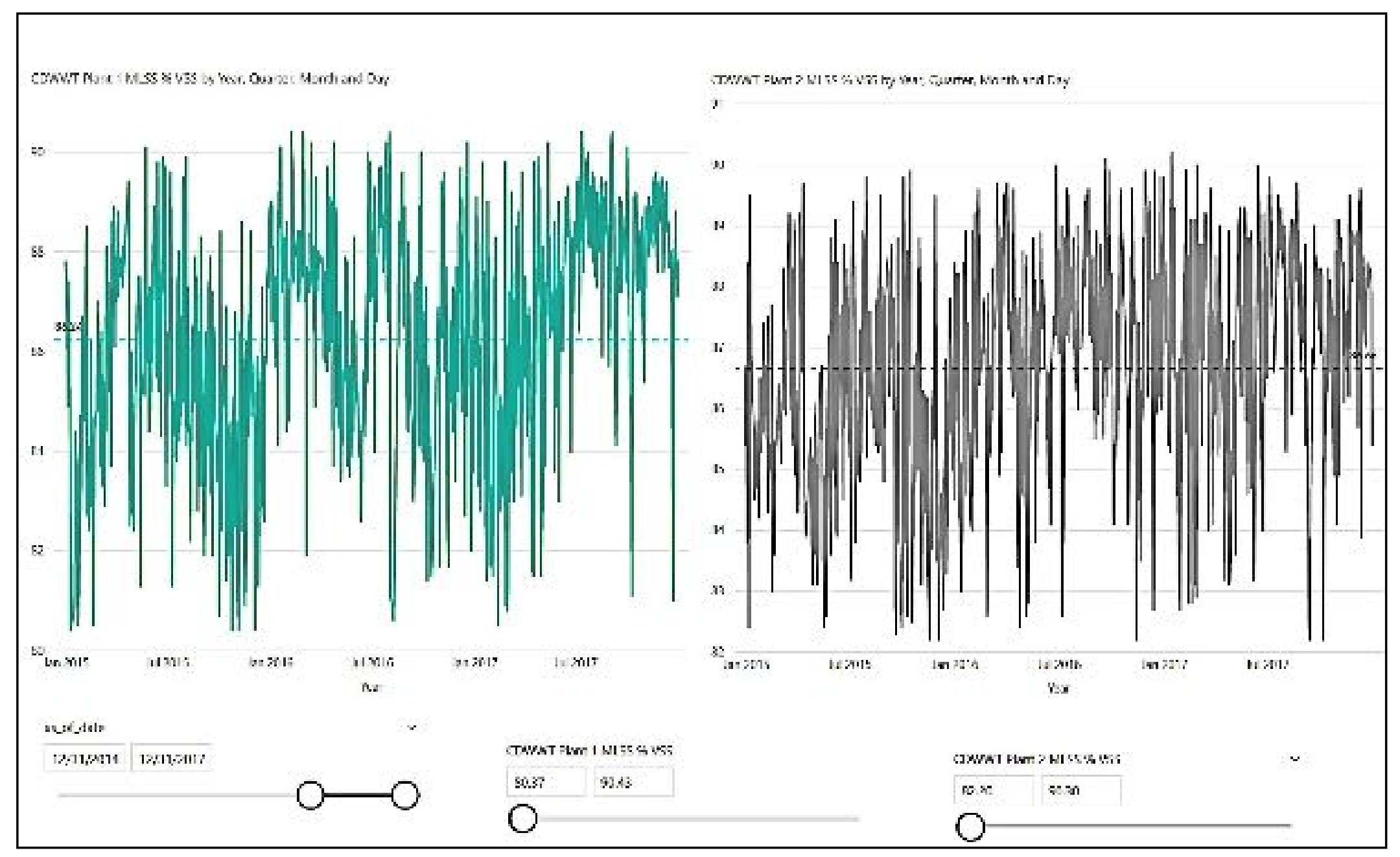

Figure 9: Plot of average of a data set based on 90th percentile filter 
Below is the summary of the averaged historical data collected, analyzed, and used in the mass balance model (MBM) for the base case scenario, and for influent and effluent wastewater characteristics for the model scenarios considered in this study (Table 4). Plots for all historical data analyzed can be found in Appendix 2: Charts of Historical Data.

Table 4: Summary of Historical Plant Data and Assumptions

\begin{tabular}{|c|c|c|c|}
\hline Data Source & $\begin{array}{l}\text { Historical } \\
\text { data }\end{array}$ & $\begin{array}{l}\text { By design, } \\
\text { calculated }\end{array}$ & $\begin{array}{l}\text { Assumed, } \\
\text { literature }\end{array}$ \\
\hline defined variables (analyte/ flowstream) & US unit & $\begin{array}{l}\text { SDWWTP } \\
\text { plant data }\end{array}$ & $\begin{array}{l}\text { CDWWTP } \\
\text { plant data }\end{array}$ \\
\hline \multicolumn{4}{|l|}{ Plant Influent Conditions } \\
\hline Average Daily Flow & $\operatorname{mgd}$ & 98.64 & 117.33 \\
\hline Wet Weather Peak Factor & {$[-]$} & 2.53 & 2.80 \\
\hline Wet Weather Peak Flow & $\operatorname{mgd}$ & 249.6 & 328.2 \\
\hline $\begin{array}{l}\text { Carbonaceous Biological Oxygen } \\
\text { Demand }\end{array}$ & $\mathrm{mg} / \mathrm{L}$ & 214.3 & 125.9 \\
\hline Total Suspended Solids & $\mathrm{mg} / \mathrm{L}$ & 223.8 & 166.3 \\
\hline Total Suspended Solids after grit removal & $\mathrm{mg} / \mathrm{L}$ & 200 & 160 \\
\hline Volatile fraction of influent TSS & $\%$ & 81.5 & 84.9 \\
\hline Volatile fraction of grit removed & $\%$ & 10 & 10 \\
\hline \multicolumn{4}{|l|}{ Plant Effluent Conditions } \\
\hline Total Suspended Solids & $\mathrm{mg} / \mathrm{L}$ & 3.59 & 12.4 \\
\hline $\begin{array}{l}\text { Carbonaceous Biological Oxygen } \\
\text { Demand }\end{array}$ & $\mathrm{mg} / \mathrm{L}$ & 5.18 & 8.66 \\
\hline UBOD factor & $\mathrm{lb} / \mathrm{lb}$ & 1.42 & 1.42 \\
\hline
\end{tabular}




\begin{tabular}{|c|c|c|c|}
\hline effluent BOD to TSS & $\%$ & 68 & 68 \\
\hline \multicolumn{4}{|l|}{ Plant Primary Treatment Conditions } \\
\hline Concentration of Primary Solids & $\mathrm{mg} / \mathrm{L}$ & 0 & 0 \\
\hline primary solids specific gravity & {$[-]$} & 1 & 1 \\
\hline \multicolumn{4}{|l|}{ Plant Secondary Treatment Conditions } \\
\hline biodegradable fraction of biological solids & $\%$ & 65 & 65 \\
\hline $\begin{array}{l}\text { volatile fraction of TSS to secondary } \\
\text { treatment }\end{array}$ & $\%$ & 90 & 87.9 \\
\hline Mixed-Liquor Suspended Solids & $\mathrm{mg} / \mathrm{L}$ & 2552 & 2563 \\
\hline Volatile fraction of MLSS & $\%$ & 87.03 & 86.50 \\
\hline Aeration tank volume/ tank & MG & 1.38 & 1.38 \\
\hline Aeration tanks in operation & $\begin{array}{l}\text { no. of } \\
\text { units }\end{array}$ & 6 & 5 \\
\hline Aeration tank volume total & MG & 8.28 & 6.90 \\
\hline Observed yield & $\mathrm{lb} / \mathrm{lb}$ & 0.3125 & 0.3125 \\
\hline Yield & $\mathrm{lb} / \mathrm{lb}$ & 0.50 & 0.50 \\
\hline secondary treatment kinetic factor & $\mathrm{d}-1$ & 0.06 & 0.06 \\
\hline \multicolumn{4}{|l|}{ Plant Sludge Thickening Conditions } \\
\hline concentration of WAS & $\mathrm{mg} / \mathrm{L}$ & 13237 & 10401 \\
\hline $\begin{array}{l}\text { Concentration of thickened waste- } \\
\text { activated sludge }\end{array}$ & $\%$ & 2.31 & 3.90 \\
\hline Volatile fraction of TWAS & $\%$ & 87 & 82.4 \\
\hline thickened solids specific gravity & {$[-]$} & 1 & 1 \\
\hline $\begin{array}{l}\text { sludge thickening solids recycle } \\
\text { concentration }\end{array}$ & $\mathrm{mg} / \mathrm{L}$ & 254 & 536 \\
\hline
\end{tabular}




\begin{tabular}{|c|c|c|c|}
\hline polymer dose & $\mathrm{lb} / \mathrm{DT}$ & & \\
\hline ferric dose & $\mathrm{mg} / \mathrm{L}$ & & \\
\hline \multicolumn{4}{|l|}{ Plant Sludge Digestion Conditions } \\
\hline digester tank volume/ tank & MG & 1.64 & 1.64 \\
\hline tanks in operation (primaries only) & $\begin{array}{l}\text { no. of } \\
\text { units }\end{array}$ & 5 & 6 \\
\hline digesters total active volume & MG & 8.19 & 9.83 \\
\hline Total Solids of digested sludge & $\begin{array}{l}\% \text { solids } \\
\text { by wt. }\end{array}$ & 1.29 & 2.32 \\
\hline VSS destruction during digestion & $\%$ & 48.8 & 52.5 \\
\hline Gas Production & $\begin{array}{l}\text { cu.ft./lb of } \\
\text { VSS } \\
\text { destroyed }\end{array}$ & 18 & 18 \\
\hline Digester Supernatant TSS & $\mathrm{mg} / \mathrm{L}$ & 0 & 0 \\
\hline Digester Supernatant BOD & $\mathrm{mg} / \mathrm{L}$ & 0 & 0 \\
\hline \multicolumn{4}{|l|}{ Plant Sludge Dewatering Conditions } \\
\hline Dewatered sludge cake percent solids & $\begin{array}{l}\% \text { solids } \\
\text { by wt. }\end{array}$ & 16.1 & 24.5 \\
\hline dewatered sludge cake specific gravity & {$[-]$} & 1.06 & 1.06 \\
\hline Centrate TSS & $\begin{array}{l}\% \text { solids } \\
\text { by wt. }\end{array}$ & 0.250 & 0.026 \\
\hline Centrate BOD & $\mathrm{mg} / \mathrm{L}$ & 2000 & 2000 \\
\hline polymer dose & lb/DT & & \\
\hline ferric dose & $\mathrm{mg} / \mathrm{L}$ & & \\
\hline
\end{tabular}


Much of the data collected and analyzed at the plants were not at the appropriate level of precision or representative of the processes currently used at the plants. As an example, what is measured as percent volatile is the difference between the weights of batch samples measure after being subjected to $150^{\circ} \mathrm{C}$ vs. $104^{\circ} \mathrm{C}$. Both temperatures are out of the range of biological activity experienced within the plant process and not directly related to the energetic pathways that bacteria and a multitude of unidentified species interact to consume and convert volatile solids. Similarly, CBOD is based on a 5day test whereas the hydraulic retention time within these facilities is in hours and the solids retention time between 1 and 2 days for secondary treatment. Therefore, in this study, the data are used as a method of comparison between different alternatives and not to be taken as absolute operational conditions.

\subsection{Mass Balance Model (MBM) Scenario A Run and Model Calibration}

Based on the historical data analyzed and assumptions used in view of existing literature and field experience, the mass balance model was run under the conditions of Scenario A for SDWWTP and CDWWTP. The model achieved convergence within 3 iterations as measured against the recycle stream properties between the last and prior iteration as advised in the texts (WEF MOP No. $85^{\text {th }}$ Edition, 2010 and Metcalf and Eddy $4^{\text {th }}$ Edition, 2003). As seen in the tables below, there are not significant differences, above $5 \%$, between the $2^{\text {nd }}$ and $3^{\text {rd }}$ iterations (Table 5 and Table 6 ) This confirms that based on the input data, the mass balance model runs agree internally with themselves. For confirmation that the model is truly representative of the plants it is modeling, 
process flow meter readings for WAS, TWAS to digestion, digested sludge to dewatering operations, and final biosolids production, a data set external to the input data used within the model, must be used. Based on the inputs to the model the only flow parameter entered was influent flow and no data on the final biosolids production was inputted as that was the ultimate model result. Therefore in order to confirm the accuracy of the model historical data for internal flows and the final biosolids production were collected, analyzed and converted to SI units, as the model used runs in metric units, and are presented in Table 7 below. Plots of the historical data used for comparison are located in Appendix 2:Charts of Historical Data. 
Table 5: SDWWTP Scenario A model recycle flow results

\begin{tabular}{|c|c|c|c|c|c|c|}
\hline & & & & \multicolumn{3}{|c|}{$\begin{array}{l}\text { Incremental change from previous } \\
\text { iteration }\end{array}$} \\
\hline \multirow[t]{2}{*}{ Operation } & Flow & BODm & TSSm & Flow & BODm & TSSm \\
\hline & $\mathrm{m} 3 / \mathrm{d}$ & $\mathrm{kg} / \mathrm{d}$ & $\mathrm{kg} / \mathrm{d}$ & $\mathrm{m} \cdot 3 / \mathrm{d}$ & $\mathrm{kg}^{\prime} \mathrm{d}$ & $\mathrm{kg} / \mathrm{d}$ \\
\hline gravity thickener recycle & $1,902.0$ & 367.5 & 585.6 & -243.0 & 25.6 & 40.8 \\
\hline Digester supematant & - & - & - & 0.0 & 0.0 & 0.0 \\
\hline Centrate & $2,935.1$ & $5,870.2$ & $7,309.0$ & 204.4 & 408.8 & 509.2 \\
\hline \multirow{2}{*}{ Total } & $4,837.1$ & $6,237.7$ & $7,894.6$ & -38.6 & 434.4 & 550.0 \\
\hline & \multicolumn{3}{|c|}{ Percent of incremental change from } & & & \\
\hline \multirow[t]{2}{*}{ Operation } & \multirow[b]{2}{*}{ Flow/ change } & \multirow{2}{*}{$\begin{array}{c}\begin{array}{c}\text { BODm/ } \\
\text { change }\end{array} \\
\end{array}$} & \multirow{3}{*}{\begin{tabular}{|c|}
$\begin{array}{c}\text { TSSm/ } \\
\text { change }\end{array}$ \\
\end{tabular}} & \multirow{6}{*}{\multicolumn{3}{|c|}{$\begin{array}{l}\text { As calculated result ended in more } \\
\text { than a } 5 \% \text { difference a third iteration } \\
\text { is warranted }\end{array}$}} \\
\hline & & & & & & \\
\hline gravity thickener recycle & $-13 \%$ & $7 \%$ & & & & \\
\hline Digester supernatant & NiA & N/A & N/A & & & \\
\hline Centrate & $7 \%$ & $7 \%$ & $7 \%$ & & & \\
\hline Total & $-1 \%$ & $7 \%$ & $7 \%$ & & & \\
\hline
\end{tabular}


Table 6: CDWWTP Scenario A model recycle flow results

\begin{tabular}{|c|c|c|c|c|c|c|}
\hline & & & & \multicolumn{3}{|c|}{$\begin{array}{l}\text { Incremental change from previous } \\
\text { itcration }\end{array}$} \\
\hline \multirow[t]{2}{*}{ Opcration } & Flow & BODm & TSSm & Flow & BODm & TSSm \\
\hline & $\mathrm{m} 3 / \mathrm{d}$ & $\mathrm{kg} / \mathrm{d}$ & $\mathrm{kg} / \mathrm{d}$ & $\mathrm{m} 3 / \mathrm{d}$ & $\mathrm{kg} / \mathrm{d}$ & $\mathrm{kg} / \mathrm{d}$ \\
\hline gravity thickener rocycle & $3,343.0$ & $1,205.4$ & $1,920.6$ & -27.0 & 71.9 & 114.5 \\
\hline Digester supernatant & - & - & - & 0.0 & 0.0 & 0.0 \\
\hline Centrate & $1,033.2$ & $2,066.4$ & 265.0 & 22.9 & 45.9 & 6.0 \\
\hline \multirow[t]{2}{*}{ Total } & $4,376.2$ & $3,271.8$ & $2,185.6$ & -4.1 & 117.7 & 120.5 \\
\hline & \multicolumn{3}{|c|}{ Percent of incremental change from } & & & \\
\hline Operation & \multirow{2}{*}{$\begin{array}{l}\text { Flow/ } \\
\text { change }\end{array}$} & \multirow{2}{*}{$\begin{array}{l}\begin{array}{l}\text { BODm/ } \\
\text { change }\end{array} \\
\end{array}$} & \multirow{2}{*}{$\begin{array}{l}\text { TSSm/ } \\
\text { change }\end{array}$} & \multirow{6}{*}{\multicolumn{3}{|c|}{$\begin{array}{l}\text { As calculated result ended in more } \\
\text { than a } 5 \% \text { difrerence a third iteration } \\
\text { is warranted }\end{array}$}} \\
\hline & & & & & & \\
\hline gravity thickener recycle & $-1 \%$ & $6 \%$ & $6 \%$ & & & \\
\hline Digester supernatant & N/A & N/A & $\mathrm{N} / \mathrm{A}$ & & & \\
\hline Centrate & $2 \%$ & $2 \%$ & $2 \%$ & & & \\
\hline Total & $0 \%$ & $4 \%$ & $6 \%$ & & & \\
\hline
\end{tabular}


Table 7: Historical data for confirmation of intermediate model results

\begin{tabular}{|l|l|l|l|l|}
\hline SDWWTP & $\begin{array}{l}\text { Standard } \\
\text { value }\end{array}$ & $\begin{array}{l}\text { Standard } \\
\text { units }\end{array}$ & SI value & $\begin{array}{l}\text { SI } \\
\text { units }\end{array}$ \\
\hline WAS flow & 1.516 & MGD & 5,746 & $\mathrm{~m} 3 / \mathrm{d}$ \\
\hline TWAS (Digester feed) flow & 0.603 & MGD & 2,285 & $\mathrm{~m} 3 / \mathrm{d}$ \\
\hline $\begin{array}{l}\text { Digester sludge (dewatering feed) } \\
\text { flow* }\end{array}$ & & MGD & - & $\mathrm{m} / \mathrm{d}$ \\
\hline Dewatered Biosolids (dry wt.)** & - & tons/yr. & - & $\mathrm{MT} / \mathrm{yr}$ \\
\hline Dewatered Biosolids (wet wt.) & 83,640 & tons/yr. & 75,862 & $\mathrm{MT} / \mathrm{yr}$ \\
\hline & & & & \\
\hline CDWWTP & & & & \\
\hline WAS flow & 2.87 & MGD & 10,877 & $\mathrm{~m} / \mathrm{d}$ \\
\hline TWAS (Digester feed) flow & 0.618 & MGD & 2,342 & $\mathrm{~m} / \mathrm{d}$ \\
\hline Digester sludge (dewatering feed) flow & 0.663 & MGD & 2,513 & $\mathrm{~m} / \mathrm{d}$ \\
\hline Dewatered Biosolids (dry wt.) & 10,427 & tons/yr & 9,457 & $\mathrm{MT} / \mathrm{yr}$ \\
\hline Dewatered Biosolids (wet wt.) & 42,647 & tons/yr & 38,681 & $\mathrm{MT} / \mathrm{yr}$ \\
\hline
\end{tabular}

* digester sludge flow to dewatering was not available

**based on calculation from wet wt. and avg. cake solids for the study period

When results from the model and the historical data were compared for waste activated sludge flow, thickened sludge flow, digested sludge flow, and biosolids production; there were significant differences, as presented in Table 8 and Table 9 below. The most notable disparities were Table 9 in the CDWWTP comparison where historical data for biosolids production was 2.5 times the estimated from the model and thickened sludge feed to the digester was more than 5 times the model predictions. 
Table 8: SDWWTP results with no model calibration

\begin{tabular}{|l|l|l|l|l|l|}
\hline Flow stream & Units & $\begin{array}{l}\text { Model } \\
\text { result }\end{array}$ & $\begin{array}{l}\text { Historical } \\
\text { data }\end{array}$ & diff. & $\%$ diff. \\
\hline WAS flow & $\mathrm{m}^{3} / \mathrm{d}$ & 34,328 & 5,746 & 28,583 & $83.3 \%$ \\
\hline $\begin{array}{l}\text { TWAS (Digester feed) } \\
\text { flow }\end{array}$ & $\mathrm{m}^{3} / \mathrm{d}$ & 1,184 & 2,285 & $(1,101)$ & $-93.0 \%$ \\
\hline $\begin{array}{l}\text { Digester sludge } \\
\text { (dewatering feed) flow* }\end{array}$ & $\mathrm{m}^{3} / \mathrm{d}$ & 1,231 & - & $\mathrm{n} / \mathrm{a}$ & $\mathrm{n} / \mathrm{a}$ \\
\hline $\begin{array}{l}\text { Dewatered Biosolids (dry } \\
\text { wt.)** }\end{array}$ & $\mathrm{MT} / \mathrm{yr}$ & 4,748 & - & $\mathrm{n} / \mathrm{a}$ & $\mathrm{n} / \mathrm{a}$ \\
\hline $\begin{array}{l}\text { Dewatered Biosolids (wet } \\
\text { wt.) }\end{array}$ & $\mathrm{MT} / \mathrm{yr}$ & 29,455 & 75,862 & $(46,406)$ & $-157.5 \%$ \\
\hline
\end{tabular}

* historical data for digester sludge flow to dewatering were not available

**historical data for dewatered biosolids (wet weight basis) were not available, comparison will be based on calculation from wet wt. and avg. cake solids for the study period

Table 9: CDWWTP results with no model calibration

\begin{tabular}{|l|l|l|l|l|l|}
\hline & Units & $\begin{array}{l}\text { Model } \\
\text { result }\end{array}$ & $\begin{array}{l}\text { Historical } \\
\text { data }\end{array}$ & diff. & $\%$ diff. \\
\hline WAS flow & $\mathrm{m}^{3} / \mathrm{d}$ & 11,759 & 10,877 & 882 & $7.5 \%$ \\
\hline $\begin{array}{l}\text { TWAS (Digester feed) } \\
\text { flow }\end{array}$ & $\mathrm{m}^{3} / \mathrm{d}$ & 367 & 2,342 & $(1,975)$ & $-538.5 \%$ \\
\hline $\begin{array}{l}\text { Digester sludge } \\
\text { (dewatering feed) flow }\end{array}$ & $\mathrm{m}^{3} / \mathrm{d}$ & 337 & 2,513 & $(2,176)$ & $-645.8 \%$ \\
\hline $\begin{array}{l}\text { Dewatered Biosolids (dry } \\
\text { wt.) }\end{array}$ & $\mathrm{MT} / \mathrm{yr}$ & 2,824 & 9,457 & $(6,633)$ & $-234.9 \%$ \\
\hline $\begin{array}{l}\text { Dewatered Biosolids (wet } \\
\text { wt.) }\end{array}$ & $\mathrm{MT} / \mathrm{yr}$ & 11,508 & 38,681 & $(27,173)$ & $-236.1 \%$ \\
\hline
\end{tabular}


In an attempt to calibrate the model, $\mathrm{Y}_{\mathrm{obs}}, \mathrm{Y}$ and $\mathrm{k}_{\mathrm{d}}$ were adjusted independently for both facilities, until biosolids production between the model predictions and the historical data were within 5\%. At the time of the first calibration effort, the interrelationship between $\mathrm{Y}_{\mathrm{obs}}, \mathrm{Y}$, and $\mathrm{k}_{\mathrm{d}}$ described in Equation 2 was not fully understood. The outcome of this first calibration attempt was perplexing as can be seen in Table 10 and Table 11 below. When biosolids production results between the model and historical data reconciled, the flowrate results from the model and the historical data were no better and conspicuously, the waste activated sludge flows estimated by the model were nearly 29 times and 15 times higher than the historical data had shown. This triggered a more detailed analysis of the mass balance model mechanics. During model development, initially, I overlooked that the model presented in both Metcalf and Eddy $4^{\text {th }}$ Edition and WEF MOP No. $85^{\text {th }}$ Edition took the MLSS concentration to be applied to the sludge thickening operation where it is then multiplied by the WAS flowrate, an internally calculated value, which only occurs in very unique cases where secondary clarifiers are not needed such as membrane biological reactors, moving bed biofilm reactors and fixed film reactors (Boe et al., 2009 and Kim et al., 2011). In the case of the example plant the process flow diagram depicts the waste activated sludge stream originating from the flow stream between the reactor and the clarifier. A secondary wastewater treatment process where the waste stream by-passes the compaction that occurs in the secondary clarifier, instead opting to directly waste MLSS is not typically encountered. However, this highly unconventional operational scenario explained why the mass balance model for the example scenario links the MLSS concentration directly 
with the WAS flow. As a result, in order to balance the solids production, a very high flow occurred for the sludge thickening process (Metcalf et al. $4^{\text {th }}$ Edition, 2003).

Table 10: SDWWTP results of first attempt at model calibration

\begin{tabular}{|l|l|l|l|l|l|}
\hline Flow stream & Units & $\begin{array}{l}\text { Model } \\
\text { result }\end{array}$ & $\begin{array}{l}\text { Historical } \\
\text { data }\end{array}$ & diff. & \% diff. \\
\hline WAS flow & $\mathrm{m}^{3} / \mathrm{d}$ & 165,951 & 5,746 & 160,205 & $96.5 \%$ \\
\hline $\begin{array}{l}\text { TWAS (Digester feed) } \\
\text { flow }\end{array}$ & $\mathrm{m} / \mathrm{d}$ & 3,050 & 2,285 & 765 & $25.1 \%$ \\
\hline $\begin{array}{l}\text { Digester sludge } \\
\text { (dewatering feed) } \\
\text { flow* }\end{array}$ & $\mathrm{m}^{3} / \mathrm{d}$ & 3,172 & - & $\mathrm{n} / \mathrm{a}$ & $\mathrm{n} / \mathrm{a}$ \\
\hline $\begin{array}{l}\text { Dewatered Biosolids } \\
\text { (dry wt.)** }\end{array}$ & $\mathrm{MT} / \mathrm{yr}$ & 12,231 & - & $\mathrm{n} / \mathrm{a}$ & $\mathrm{n} / \mathrm{a}$ \\
\hline $\begin{array}{l}\text { Dewatered Biosolids } \\
\text { (wet wt.) }\end{array}$ & $\mathrm{MT} / \mathrm{yr}$ & 75,874 & 75,862 & 12 & $0.0 \%$ \\
\hline
\end{tabular}

* historical data for digester sludge flow to dewatering was not available

** historical data for dewatered biosolids (wet weight basis) was not available, comparison will be based on calculation from wet wt. and avg. cake solids for the study period.

Table 11: CDWWTP results of first attempt at model calibration

\begin{tabular}{|l|l|l|l|l|l|}
\hline Flow stream & Units & $\begin{array}{l}\text { Model } \\
\text { result }\end{array}$ & $\begin{array}{l}\text { Historical } \\
\text { data }\end{array}$ & diff. & \% diff. \\
\hline WAS flow & $\mathrm{m}^{3} / \mathrm{d}$ & 166,229 & 10,877 & 155,351 & $93.5 \%$ \\
\hline $\begin{array}{l}\text { TWAS } \\
\text { (Digester feed) } \\
\text { flow }\end{array}$ & $\mathrm{m}^{3} / \mathrm{d}$ & 1,287 & 2,342 & $(1,055)$ & $-82.0 \%$ \\
\hline $\begin{array}{l}\text { Digester sludge } \\
\text { (dewatering } \\
\text { feed) flow }\end{array}$ & $\mathrm{m}^{3} / \mathrm{d}$ & 1,182 & 2,513 & $(1,331)$ & $-112.6 \%$ \\
\hline $\begin{array}{l}\text { Dewatered } \\
\begin{array}{l}\text { Biosolids (dry } \\
\text { wt.) }\end{array}\end{array}$ & $\mathrm{MT} / \mathrm{yr}$ & 9,907 & 9,457 & 450 & $4.5 \%$ \\
\hline $\begin{array}{l}\text { Dewatered } \\
\text { Biosolids (wet } \\
\text { wt.) }\end{array}$ & $\mathrm{MT} / \mathrm{yr}$ & 40,371 & 38,681 & 1,690 & $4.2 \%$ \\
\hline
\end{tabular}


The mass balance model was modified to be representative of the flow scheme of the the SDWWTP and CDWWTP where WAS is taken from the bottom of the secondary clarifier along with the RAS. The impact of this change to the model produced results that more closely resembled the historical plant flow while maintaining biosolids

production values in keeping with the historical data. These results are summarized in Table 12 and 
Table 13.

Table 12: SDWWTP model results and historical data comparison with modified WAS flow mass balance

\begin{tabular}{|l|l|l|l|l|l|}
\hline $\begin{array}{l}\text { Model } \\
\text { Calibration }\end{array}$ & Units & $\begin{array}{l}\text { Model } \\
\text { result }\end{array}$ & $\begin{array}{l}\text { Historical } \\
\text { data }\end{array}$ & diff. & \% diff. \\
\hline WAS flow & $\mathrm{m}^{3} / \mathrm{d}$ & 6,940 & 5,746 & 1,194 & $17.2 \%$ \\
\hline $\begin{array}{l}\text { TWAS } \\
\text { (Digester feed) } \\
\text { flow }\end{array}$ & $\mathrm{m}^{3} / \mathrm{d}$ & 3,068 & 2,285 & 782 & $25.5 \%$ \\
\hline $\begin{array}{l}\text { Digester sludge } \\
\text { (dewatering } \\
\text { feed) flow* }\end{array}$ & $\mathrm{m}^{3} / \mathrm{d}$ & 3,190 & - & & \\
\hline $\begin{array}{l}\text { Dewatered } \\
\begin{array}{l}\text { Biosolids (dry } \\
\text { wt.)** }\end{array}\end{array}$ & & & & & $\mathrm{n} / \mathrm{a}$ \\
\hline $\begin{array}{l}\text { Dewatered } \\
\text { Biosolids (wet } \\
\text { wt.) }\end{array}$ & $\mathrm{MT} / \mathrm{yr}$ & 12,300 & 12,229 & 71 & $0.6 \%$ \\
\hline
\end{tabular}

* historical data for digester sludge flow to dewatering were not available

** historical data for dewatered biosolids (wet weight basis) were not available, comparison based on calculation from wet wt. and avg. cake solids for the study period 
Table 13: CDWWTP model results and historical data comparison with modified WAS flow mass balance

\begin{tabular}{|l|l|l|l|l|l|}
\hline Model Calibration & Units & $\begin{array}{l}\text { Model } \\
\text { result }\end{array}$ & $\begin{array}{l}\text { Historical } \\
\text { data }\end{array}$ & diff. & \% diff. \\
\hline WAS flow & $\mathrm{m}^{3} / \mathrm{d}$ & 11,428 & 10,877 & 551 & $4.8 \%$ \\
\hline $\begin{array}{l}\text { TWAS (Digester feed) } \\
\text { flow }\end{array}$ & $\mathrm{m}^{3} / \mathrm{d}$ & 1,290 & 2,342 & $(1,052)$ & $-81.6 \%$ \\
\hline $\begin{array}{l}\text { Digester sludge } \\
\text { (dewatering feed) flow }\end{array}$ & $\mathrm{m}^{3} / \mathrm{d}$ & 1,185 & 2,513 & $(1,328)$ & $112.1 \%$ \\
\hline $\begin{array}{l}\text { Dewatered Biosolids (dry } \\
\text { wt.) }\end{array}$ & $\mathrm{MT} / \mathrm{yr}$ & 9,932 & 9,457 & 475 & $4.8 \%$ \\
\hline $\begin{array}{l}\text { Dewatered Biosolids (wet } \\
\text { wt.) }\end{array}$ & $\mathrm{MT} / \mathrm{yr}$ & 40,475 & 38,681 & 1,794 & $4.4 \%$ \\
\hline
\end{tabular}

Up to this stage of mathematical modeling effort, in calibrating the model, the biological treatment process reaction kinetics $\mathrm{Y}_{\mathrm{obs}}$ and $\mathrm{Y}$ were treated as independent variables. The simplified reaction kinetics relationship (Equation 2) was applied to the model to determine $\mathrm{Y}_{\mathrm{obs}}$. Based on the process characteristics of SDWWTP and CDWWTP extremely short detention times, it was determined that fixing the value of $\mathrm{k}_{\mathrm{d}}$ to $0.06 \mathrm{~d}^{-1}$ and only directly varying $\mathrm{Y}$ within physically possible values, albeit values seldom found in the literature, would be the most reasonable way to calibrate the model (Menniti et al., 2012). The combination of $\mathrm{Y}_{\mathrm{obs}}$ and $\mathrm{Y}$ for SDWWTP and CDWWTP to produce a biosolids production calibrated model was $\mathrm{Y}_{\mathrm{obs}}=0.74 \mathrm{~g}$ biomass $/ \mathrm{g}$ substrate, $\mathrm{Y}=0.8 \mathrm{~g}$ biomass $/ \mathrm{g}$ substrate for SDWWTP and $\mathrm{Y}_{\mathrm{obs}}=0.82 \mathrm{~g}$ biomass $/ \mathrm{g}$ substrate, $\mathrm{Y}=$ $0.88 \mathrm{~g}$ biomass/ $\mathrm{g}$ substrate for CDWWTP. These are extraordinarily high yields of substrate to biomass conversion but may be a consequence of the extremely low reactor SRTs reducing environmental factors that normally reduced the apparent yield of the resident bacterial population, such as eukaryotic predation that may not occur at 
SDWWTP and CDWWTP because the majority of protozoa have lifecycles that necessitate SRTs higher than those in the study plants (Grady et al., 1999).

Even with the modified calibration based on adjusting the biological reactor yield, the results for waste activated sludge flow, thickened sludge flow, and digested sludge flow were not a match. Correction factors for each of these streams were applied to bring the model and historical data flow rate to within 5\% with the now calibrated model the results of which are presented in Table 14 and Table 15 below.

Table 14: SDWWTP Calibrated MBM with flow correction factor

\begin{tabular}{|c|c|c|c|c|c|c|}
\hline Model Calibration & units & model result & $\begin{array}{l}\text { historical } \\
\text { data }\end{array}$ & diff. & $\%$ diff. & $\begin{array}{c}\text { flow } \\
\text { correction } \\
\text { factor }{ }^{*}\end{array}$ \\
\hline WAS flow & $\mathrm{m}^{3} / \mathrm{d}$ & 4,937 & 5,746 & (809) & $-16.4 \%$ & 1.16 \\
\hline $\begin{array}{l}\text { TWAS (Digester } \\
\text { feed) flow }\end{array}$ & $\mathrm{m}^{3} / \mathrm{d}$ & 3,050 & 2,285 & 765 & $25.1 \%$ & 0.75 \\
\hline $\begin{array}{l}\text { Digester sludge } \\
\text { (dewatering feed) } \\
\text { flow** }\end{array}$ & $\mathrm{m}^{3} / \mathrm{d}$ & 3,145 & $=$ & 859 & $27.3 \%$ & 0.73 \\
\hline $\begin{array}{l}\text { Dewatered Biosolids } \\
\text { (dry wt.) }\end{array}$ & MT/yr & 12,126 & 12,229 & (103) & $-0.8 \%$ & \\
\hline $\begin{array}{l}\text { Dewatered Biosolids } \\
\text { (wet wt.) }\end{array}$ & MT/yr & 75,223 & 75,862 & (639) & $-0.8 \%$ & \\
\hline
\end{tabular}


Table 15: CDWWTP Calibrated MBM with flow correction factor

\begin{tabular}{|c|c|c|c|c|c|c|}
\hline Model Calibration & units & model result & $\begin{array}{l}\text { historical } \\
\text { data }\end{array}$ & diff. & $\%$ diff. & $\begin{array}{c}\text { flow } \\
\text { correction } \\
\text { factor* }\end{array}$ \\
\hline WAS flow & $\mathrm{m}^{3} / \mathrm{d}$ & 4,578 & 10,877 & $(6,299)$ & $-137.6 \%$ & 2.38 \\
\hline $\begin{array}{l}\text { TWAS (Digester } \\
\text { feed) flow }\end{array}$ & $\mathrm{m}^{3} / \mathrm{d}$ & 1,237 & 2,342 & $(1,106)$ & $-89.4 \%$ & 1.89 \\
\hline $\begin{array}{l}\text { Digester sludge } \\
\text { (dewatering feed) } \\
\text { flow }\end{array}$ & $\mathrm{m}^{3} / \mathrm{d}$ & 1,136 & 2,513 & $(1,377)$ & $-121.2 \%$ & 2.06 \\
\hline $\begin{array}{l}\text { Dewatered } \\
\text { Biosolids (dry wt.) }\end{array}$ & MT/yr & 9,521 & 9,457 & 63 & $0.7 \%$ & \\
\hline $\begin{array}{l}\text { Dewatered } \\
\text { Biosolids (wet wt.) }\end{array}$ & MT/yr & 38,797 & 38,681 & 116 & $0.3 \%$ & \\
\hline
\end{tabular}

In addition to the calibrated mass balance model (MBM), input data from the pilot studies were required in order to run models for Scenarios B, C, D, and E.

\subsection{Pilot Study Overview and Objectives}

To better establish performance criteria for proposed thickening centrifuges, highrate single-stage anaerobic mesophilic digestion and dewatering centrifuges, a nearly year-long centrifuge thickening, digestion and centrifuge dewatering pilot study was conducted at SDWWTP and CDWWTP. The pilot study was set up to simulate future thickening, digestion, and dewatering operating conditions to establish thickening, digestion and dewatering performance criteria. The pilot operation was conducted in three distinct phases at each plant as outlined in Table 16. Samples were collected throughout each phase pertinent to understanding of equipment performance and identifying the design criteria. The results of the pilot testing effort were utilized to support the necessary input parameters for MBM Scenario E along with some inputs in the analyses of the other scenarios evaluated. 
Table 16: Summary of Pilot Testing Phases

\begin{tabular}{|c|c|c|c|c|}
\hline Pilot Phase & Objective & $\begin{array}{l}\text { Duration } \\
\text { SDWWTP } \\
\text { 10/ 2015- } \\
04 / 2016\end{array}$ & $\begin{array}{l}\text { Duration } \\
\text { CDWWTP } \\
05 / 2016- \\
09 / 2016\end{array}$ & $\begin{array}{l}\text { Sample } \\
\text { measurements }\end{array}$ \\
\hline $\begin{array}{l}\text { Pilot Phase 1: } \\
\text { Thickening pilot } \\
\text { operating with } \\
\text { unthickened waste } \\
\text { activated sludge } \\
\text { (WAS) and Primary } \\
\text { Sludge (CDWWTP } \\
\text { only) }\end{array}$ & $\begin{array}{l}\text { Determine centrifuge } \\
\text { WAS thickening } \\
\text { performance criteria }\end{array}$ & 4 weeks & $\begin{array}{l}5 \text { weeks } \\
\text { (WAS } \\
\text { only) } \\
10 \text { weeks } \\
\text { (Primary } \\
\text { sludge } \\
\text { +WAS) }\end{array}$ & $\begin{array}{l}\text { TS - all } \\
\text { TSS - centrate }\end{array}$ \\
\hline $\begin{array}{l}\text { Pilot Phase 2: High } \\
\text { Rate Steady State } \\
\text { Digestion. } \\
\text { Thickening pilot } \\
\text { operating with } \\
\text { gravity thickened } \\
\text { WAS }\end{array}$ & $\begin{array}{l}\text { Simulate high rate } \\
\text { anaerobic digestion to } \\
\text { monitor performance } \\
\text { and prepare sludge for } \\
\text { Pilot Phase } 3\end{array}$ & 18 weeks & 10 weeks & $\begin{array}{l}\text { TS }- \text { all } \\
\text { VS }- \text { digester } \\
\text { feed and } \\
\text { digested } \\
\text { biosolids } \\
\text { pH - digested } \\
\text { biosolids } \\
\end{array}$ \\
\hline $\begin{array}{l}\text { Pilot Phase 3: } \\
\text { Dewatering pilot } \\
\text { operating with } \\
\text { anaerobically } \\
\text { digested biosolids } \\
\text { following Pilot Phase } \\
2 \text { Thickening } \\
\end{array}$ & $\begin{array}{l}\text { Determine centrifuge } \\
\text { dewatering } \\
\text { performance criteria } \\
\text { with centrifuge } \\
\text { thickened anaerobically } \\
\text { digested sludge }\end{array}$ & 7 weeks & 3 weeks & $\begin{array}{l}\mathrm{TS} \text { - all } \\
\mathrm{TSS} \text { - centrate }\end{array}$ \\
\hline
\end{tabular}

Figure 10 and Figure 11 present plan view layouts of the facilities and identify the locations for the centrifuge thickening and dewatering pilot trailers. Figure 12 provides photos of the pilot testing trailers provided by Centrisys, Kenosha, Wisconsin. 


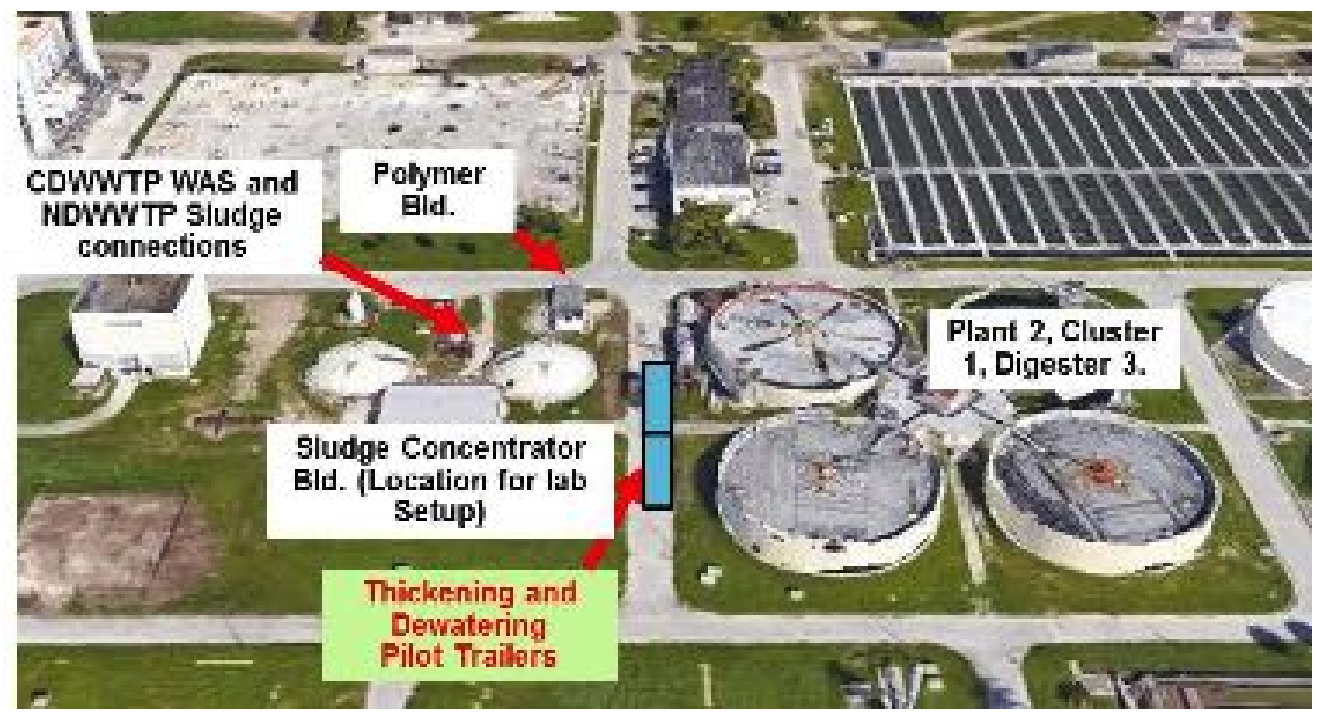

Figure 10: CDWWTP Pilot Site Plan Showing Centrifuge Installation

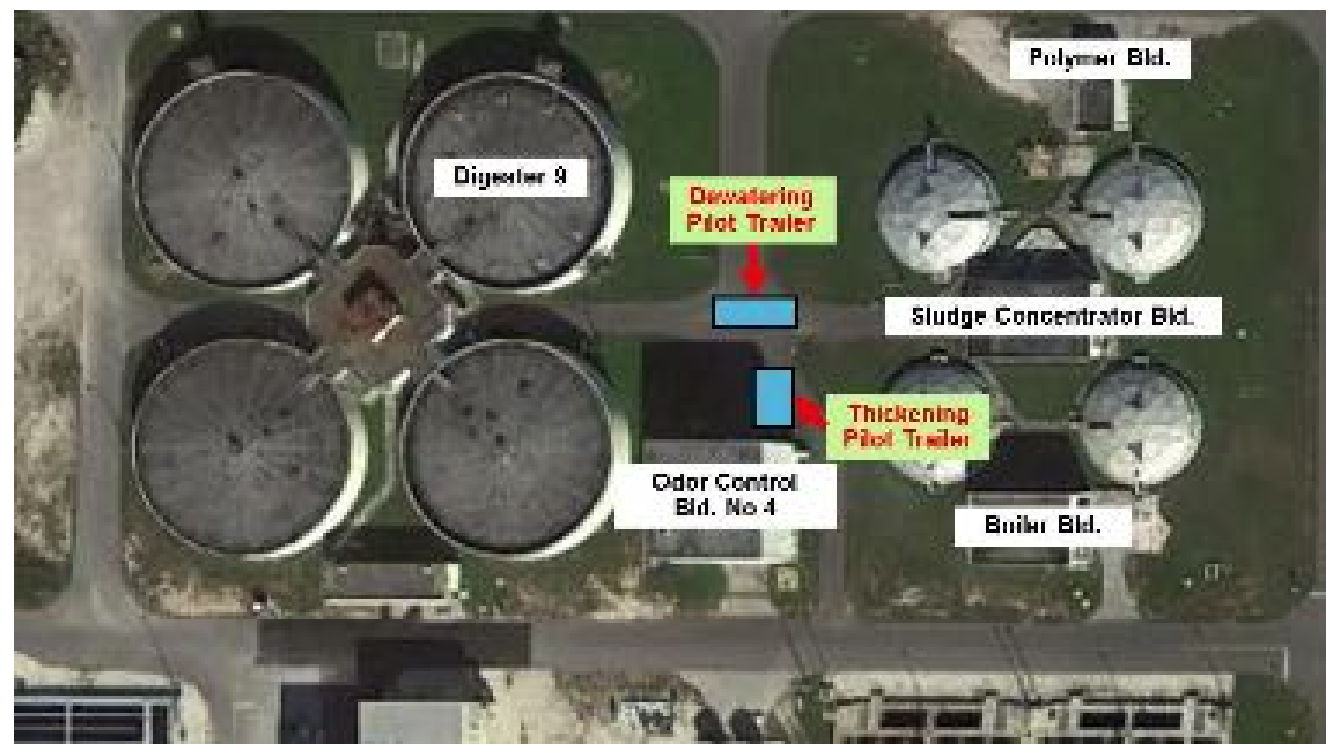

Figure 11: SDWWTP Pilot Site Plan Showing Centrifuge Installation 

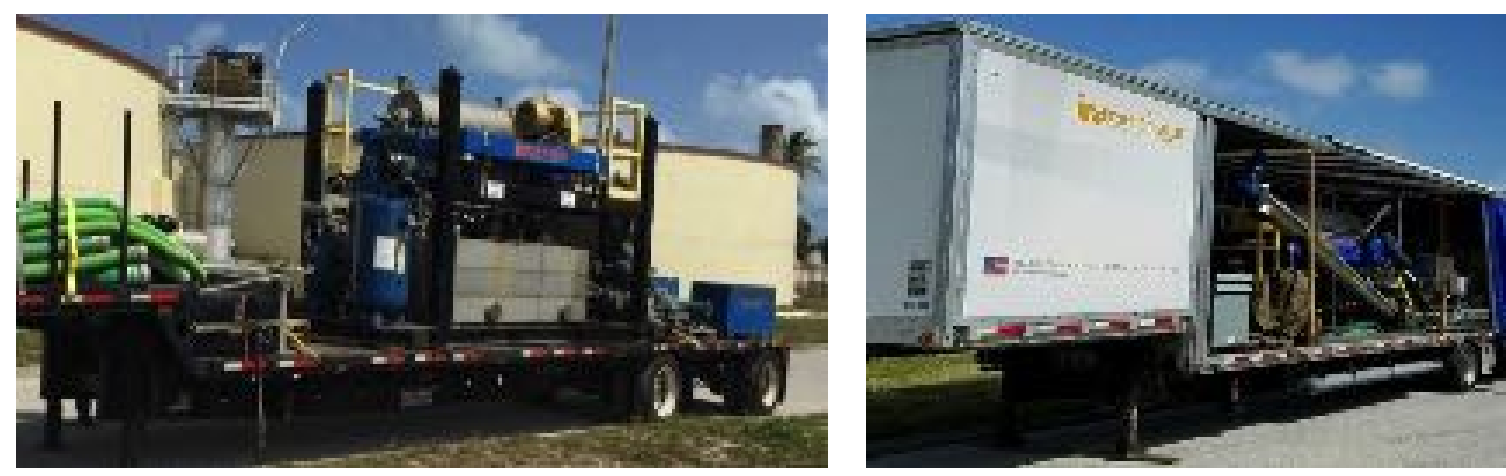

Figure 12: Pilot Equipment, thickening (left), dewatering (right)

Periodic samples collected throughout the pilot operation were all analyzed for total solids (TS). During Pilot Phase 2 and Pilot Phase 3, volatile solids (VS) content of the thickened sludge fed to the digester and digested biosolids samples were regularly monitored. Digested biosolids $\mathrm{pH}$ was also measured. The centrate samples were also analyzed for total suspended solids (TSS).

\section{4. $\quad$ Sludge Thickening}

Sludge thickening is a wastewater treatment process at the beginning of what is considered the biosolids treatment portion of a wastewater treatment facility. The purpose of sludge thickening is to increase the concentration of biological solids in waste activated sludge, in order to decrease the volume of WAS flow conveyed for sludge stabilization via digestion. The reason this is essential is due to the very long solids retention times required for sludge stabilization through standard anaerobic mesophilic digestion (15 days minimum and generally greater than a month), so that digestion capacity is at a premium. Other considerations are a reduction in heating and mixing requirements which translates to lower equipment capacity needs, less expensive 
equipment, and significantly less energy input for the same amount of solids reduction potential.

Between the existing sludge thickening method at SDWWTP and CDWWTP and the proposed options for higher sludge thickening, there are major differences that require understanding prior to making a process selection. The sludge thickening technologies evaluated are described below.

\subsection{Gravity Thickeners}

The existing sludge thickening operations at SDWWTP and CDWWTP are gravity thickeners, also known as gravity concentrators or picket thickeners, as shown in Figure 13. The machines work much like secondary clarifiers as they rely on natural gravitational force for solids separation and compaction of the sludge. They require polymer to promote flocculation and capture of colloidal particles. Due to the close proximity of discrete particles in the tank there is much more interaction between particles in a gravity thickener than in a secondary clarifier and two to three distinct settling regimes occur within a properly performing gravity thickener. The first regime, discrete settling, occurs if the influent stream is relatively dilute, $<1.5 \%$ solids, as in the case of both SDWWTP and CDWWTP typical WAS total suspended solids concentrations. In discrete settling, particles maintain their normal settling characteristic as in the clarifier. The second regime is zone settling, where particle-to-particle interaction is more prevalent, and particles settle as a blanket or porous matrix. The final settling regime is compression settling where clusters of particles, referred to as floc, settle upon each other with little discernable interspace. The sludge compaction in this 
settling regime occurs under the weight of the floc themselves as well as resistance to further compaction due to the structural integrity of the floc. The gravity thickeners at both facilities have a unique design feature that differs from the circular secondary clarifier that aid in compression settling. The tanks have angle irons, sometimes referred to as pickets, pointed vertically from the radial arms of the thickener sludge collection mechanisms, as can be seen in Figure 14. The pickets aid in shearing through the floc blanket, allowing entrapped water to escape upwards, much like the separation of curds from whey in the cheese making process, and allow the sludge to further compact (WEF MOP No. $116^{\text {th }}$ Edition, 2008)

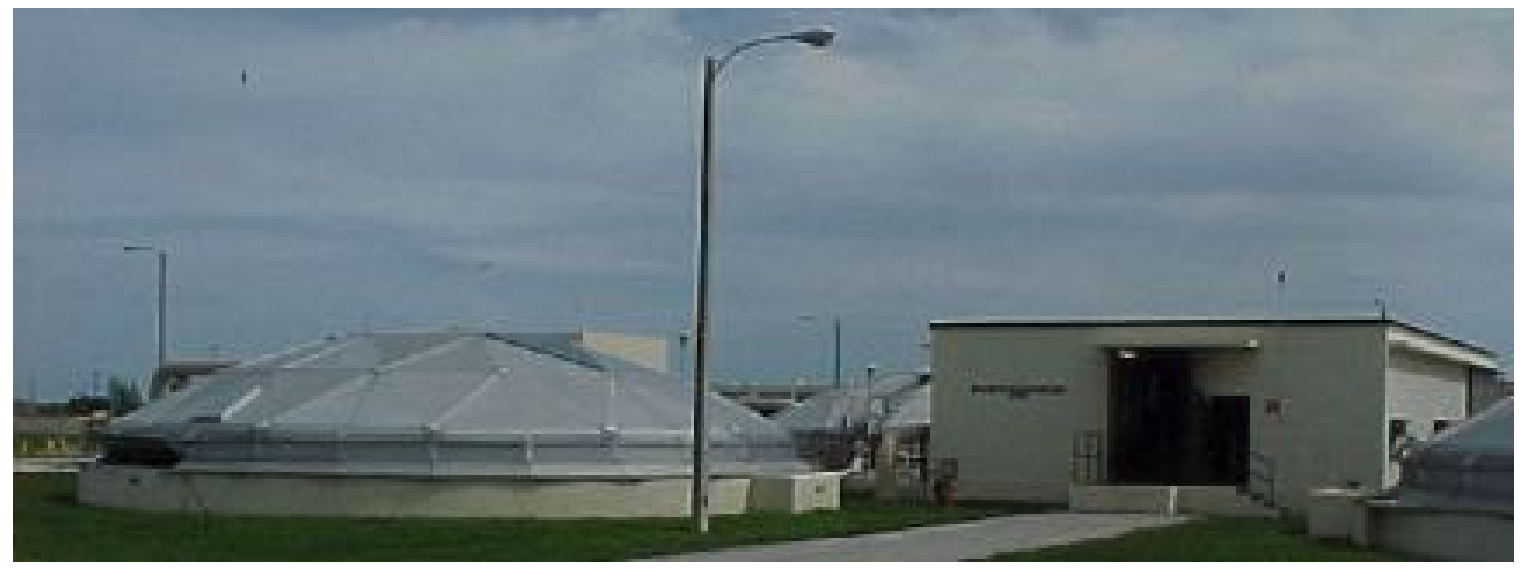

Figure 13: Existing Gravity Thickeners at SDWWTP (MDWASD, May 2005) 


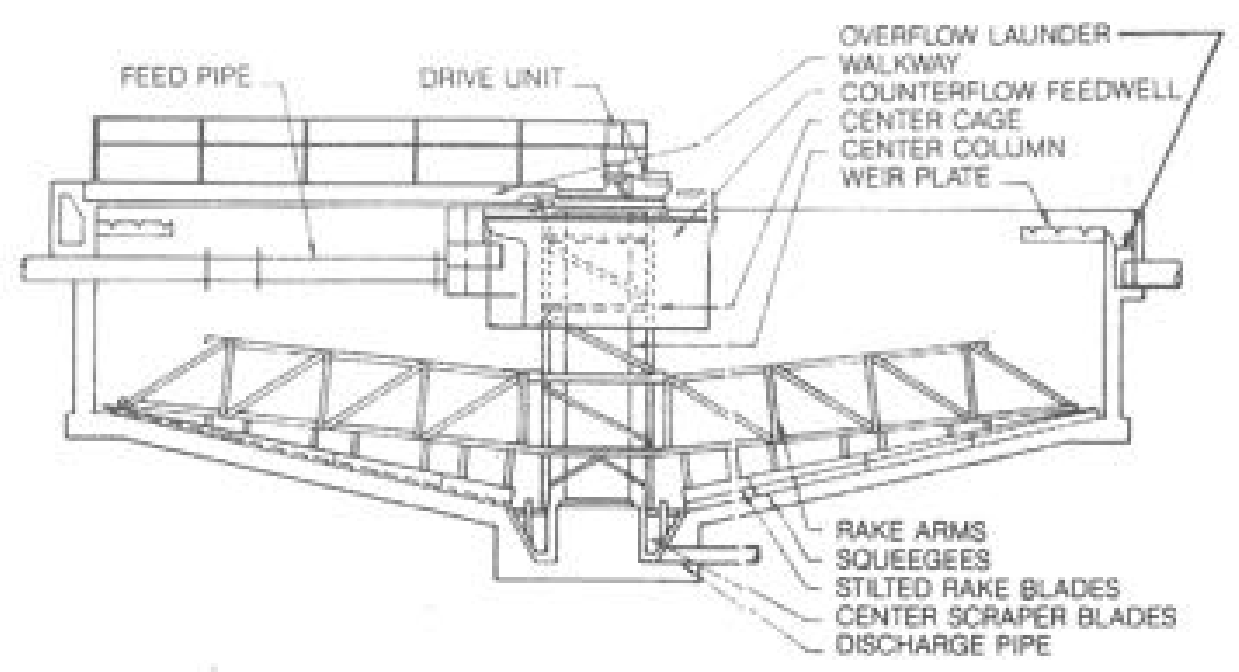

Figure 14: Gravity Thickener Schematic (WEF MOP No. $116^{\text {th }}$ Edition, 2008)

SDWWTP is currently testing the introduction of ferric salts to the influent of the gravity concentrators to enhance the colloidal capture properties of polymer addition to prevent septic conditions in the tank, and to sequester sulfur during the process to avoid hydrogen sulfide release both in the concentrator off-gas and in downstream processes (Apples et al., 2008). Laboratory-scale tests several years ago did prove ferric salt addition improved capture of colloidal material but did not significantly improve the overall solids capture or level of sludge compaction. The current full-scale testing is still in its early stages.

To fully understand the performance of the existing gravity thickeners and to compare them with proposed thickening technologies, calculations were carried out based on the historical data, typical ranges for other thickening technologies and the pilot testing conducted on sludge-thickening centrifuges. Based on Total Solids and Total Suspended Solids concentrations of waste activated sludge (WAS), thickened waste 
activated sludge (TWAS), and gravity thickener overflow, the percent solids capture was calculated based on the equation below (Equation 3). A full derivation of the solids capture rate equation is presented in Appendix 1: Derived Equations. The solids capture equation also works for the other sludge thickening and sludge dewatering mechanisms in this study and is used as an important point of comparison. The gravity thickeners for SDWWTP and CDWWTP achieved average solids captures of $99.2 \%$ and $96.2 \%$, respectively. These results are better than the target capture rate set for proposed technologies and a surprise, as anecdotally these gravity concentrators at these facilities tended to have severe bulking issues.

\section{Equation 3: Solids Capture Rate for Sludge Thickening}

$$
\% \text { Solids Capture }=\frac{\mathrm{X}_{\mathrm{TSS}, \mathrm{TWAS}} *\left(\mathrm{X}_{\mathrm{TSS}, \mathrm{WAS}}-\mathrm{X}_{\mathrm{FILTRATE}}\right)}{\mathrm{X}_{\mathrm{TSS}, \mathrm{WAS}} *\left(\mathrm{X}_{\mathrm{TSS}, \mathrm{TWAS}}-\mathrm{X}_{\mathrm{TSS}, \mathrm{FiLTRATE}}\right)}
$$

where,

$$
\begin{aligned}
& \mathrm{X}_{\text {TSS,WAS }}=\quad \text { solids concentration in waste activate sludge }\left(\mathrm{mg} / \mathrm{L} \text { or } \mathrm{g} / \mathrm{m}^{3}\right) \\
& \mathrm{X}_{\text {TSS,TWAS }}=\quad \text { solids concentration in thickened waste activate sludge }(\mathrm{mg} / \mathrm{L} \text { or } \\
& \left.\mathrm{g} / \mathrm{m}^{3}\right) \\
& \mathrm{X}_{\text {TSS,FILTRATE }}=\quad \text { solids concentration in filtrate stream }\left(\mathrm{mg} / \mathrm{L} \mathrm{or} \mathrm{g} / \mathrm{m}^{3}\right)
\end{aligned}
$$

Although the solids capture rate of the existing gravity thickeners is relatively good with the thickened sludge percent solids of $2.3 \%$ and $3.9 \%$ for SDWWTP and CDWWTP, respectively; these values are lower than desirable levels to improve digester performance and reduce biosolids production quantities significantly. The low solids thickening performance was reflected in the performance ability of Scenarios A and B in 
the results of the mass balance model. As the equipment has aged to the point of requiring complete mechanical rehabilitation and possibly structural rehabilitation as well, alternate technologies were considered as possible process upgrade options to increase biosolids concentration as described below.

\subsection{Gravity Belt Thickeners}

Gravity belt thickening is a well-established and popular sludge thickening method in the wastewater industry. Gravity belt thickeners (GBTs) consist of several stages and are more of a horizontal fine filtering process than the strictly gravity-driven liquid-solids separation process of clarifiers and gravity thickeners. The typical configuration of a gravity belt thickener is presented below in Figure 15 .

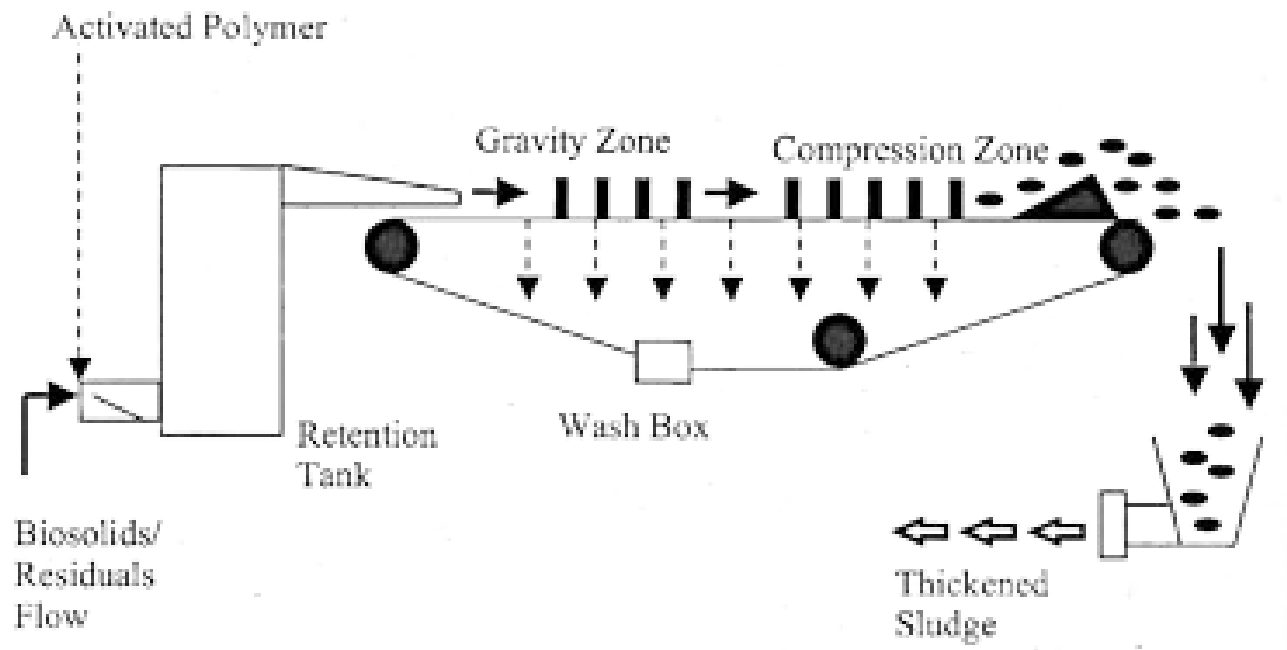
2008)

Figure 15: Gravity Belt Thickener Schematic (WEF MOP No. $116^{\text {th }}$ Edition,

Initially, the incoming sludge is conditioned chemically to initiate floc formation. Polymer is the most common coagulant aid used in municipal wastewater treatment plants, but additions of ferric salts or alum in concert with polymer or on their own are 
also used. After chemical injection the feed sludge is allowed to maturate in a retention tank in order to flocculate before entering the next stage, the gravity table. The gravity table is a moving belt, moving in the same direction as the as the conditioned sludge. The material of the belt is a woven plastic or metal typically 1 to 3 meters wide. As the belts move with the flocculated sludge riding on them, free water in the sludge filters through the belt fabric to be collected beneath the belt. Along the path are a series of staggered plows, called chicanes (reminiscent of foos men on a foosball table), shearing through the oncoming sludge leaving furrows in their wake further allowing free water to drain away from the sludge, as can be seen in Figure 16. As the sludge nears the end of the gravity table, a ramp or dam results in a compression zone that produces a temporary accumulation of solids prior to discharge to further thicken the sludge. The thickened sludge travels down a chute and onto pumping to digestion. The belt flips direction past the rear sprocket, returning beneath the gravity table where washwater sprays the belt fabric clean. The dirty washwater and filtrate dripping through from the surface of the gravity table comingle and return to liquid treatment as a recycle stream (WEF MOP No. $85^{\text {th }}$ Edition, 2010 and WEF MOP No. $116^{\text {th }}$ Edition, 2008) 


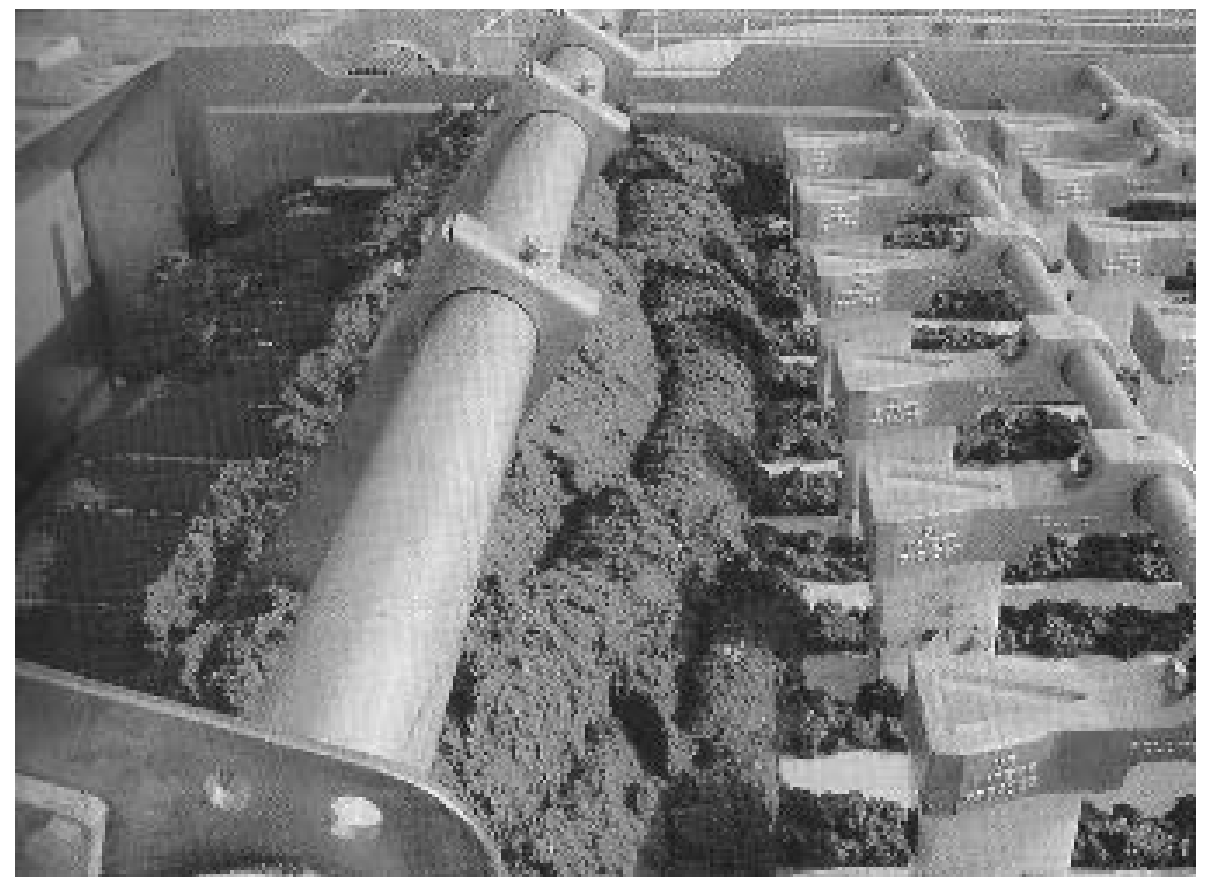

Figure 16: Gravity Belt Thickener Chicanes and Ramp (WEF MOP No. $116^{\text {th }}$ Edition, 2008)

GBTs were not piloted during this research effort, but their common use for thickening of WAS results in an abundance of data from other facilities and their behavior with sludge of similar characteristic and conditioning is consistent, including the Tres Rios Water Reused Facility in Pima County, Arizona I visited in. One of the GBTs at the Tres Rios facility is depicted in the photograph below (Figure 17). Generally accepted performance criteria for the capabilities of GBTs will be use in the holistic process model. The GBTs will be modeled as replacement of the existing sludge thickening technology at the subject facilities, i.e., gravity thickeners, in proposed plant modifications under Scenarios $C$ and D. The GBTs are expected to produce a 5.5\% thickened sludge from the same WAS solids concentration currently received by the gravity thickeners at a solids capture rate of $95 \%$ or greater (WEF MOP No. $85^{\text {th }}$ Edition, 
2010). This level of performance is possible with the proper hydraulic and solids loading, and significantly higher polymer usage than the amounts used at SDWWTP and CDWWTP currently for gravity thickeners.

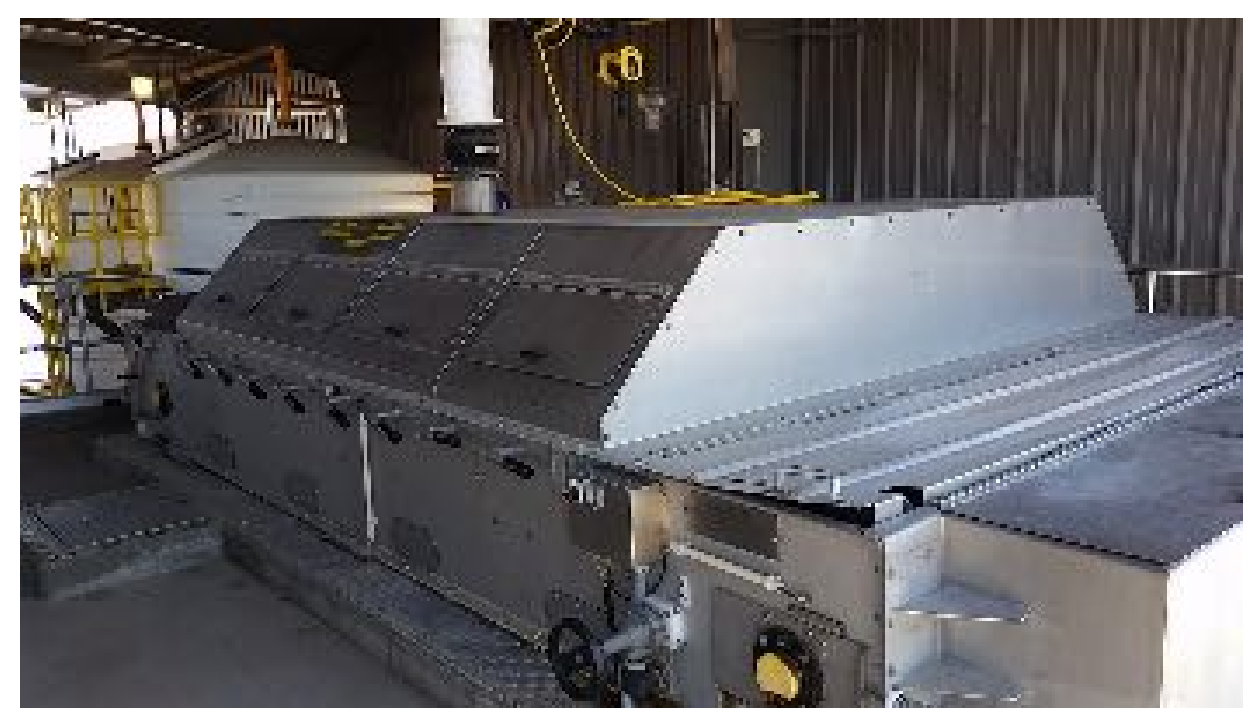

Figure 17: GBT Enclosed Gravity Table, Tres Rios WRF, Tucson, AZ

\subsection{Thickening Centrifuges}

Thickening, or decanter, centrifuges are horizontal cylindrical vessels with an interior cylinder, or bowl, and tapered screw, or scroll, that both spin about a central axis at slightly different rotational speeds, as shown in Figure 18. In general principle, a centrifuge behaves similarly to clarifiers and gravity thickeners in that physical separation of solid from liquid is a result of gravity and can be aided by metal coagulants and organic polymers which increase particle density and promote flocculation. The liquid sludge enters in through the scroll with chemical coagulants added prior to entry or within the scroll itself. The advantages of centrifuges to enhance the rate or settling, 
sludge concentration and solids recovery is a result of centripetal forces being thousands of times greater than the gravitational force experienced in a clarifier. Due to the speed differential between the bowl and the scroll, the thickened sludge pressed against the bowl is conveyed by the scroll screw toward the tapered end of the scroll and then ejected from the machine. The free water that is separated from the sludge ponds within the machine, filling a portion of the void between the thickened sludge and the scroll. An adjustable circular weir plate (referred to as the pond or pool) within the bowl and adjustable weir plates in the flat end of the bowl control the free water liquid level retained within the centrifuge, the pond/pool depth, with the free water exiting over the weir plate. The hydraulic capacity of a centrifuge can be expressed as a function of the centrifuges dimensions and the acceleration force experienced within the centrifuge due to the speed of rotation of the centrifuge, Equation 4 (WEF MOP No. $85^{\text {th }}$ edition, 2008).

\section{Equation 4: Hydraulic Capacity of a Solid Bowl Centrifuge}

$$
\Sigma=2 \Pi l \frac{\omega^{2}}{100 g}\left(0.75 r_{2}^{2}+0.25 r_{1}^{2}\right)
$$

where:

$\Sigma=$ theoretical hydraulic capacity $\left(\mathrm{cm}^{2}\right)$;

$l=$ centrifuge bowl's effective clarifying length $(\mathrm{cm})$;

$\omega=$ centrifuge bowl's angular velocity $(\mathrm{rad} / \mathrm{s})$;

$g=$ acceleration from gravity $\left(\mathrm{m} / \mathrm{s}^{2}\right) ;$

$r_{1}=$ radius from centrifuge centerline to the liquid surface in the centrifuge bowl $(\mathrm{cm})$;

$r_{2}=$ radius from centrifuge centerline to the inside wall of the centrifuge bowl $(\mathrm{cm})$. 


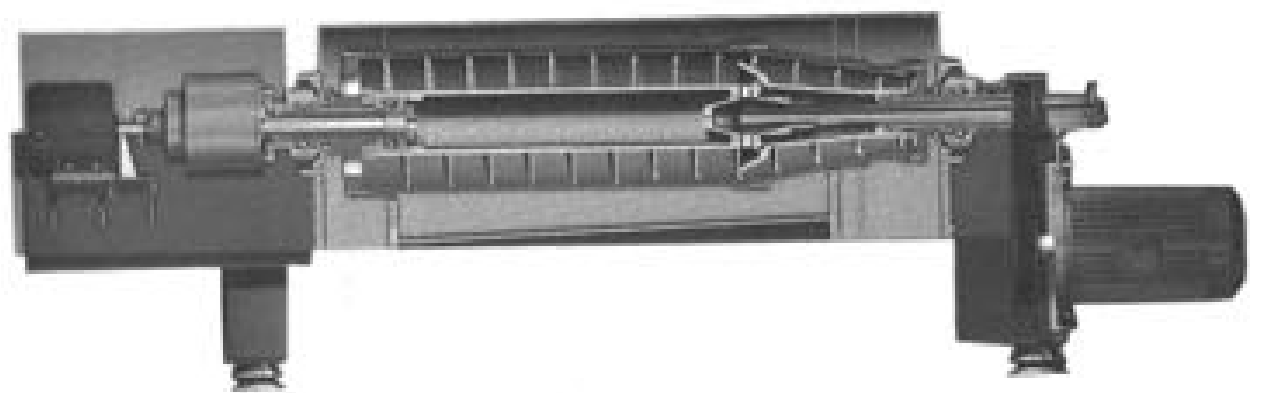

Figure 18: Thickening Centrifuge Schematic (WEF MOP No. $116^{\text {th }}$ Edition, 2008)

The above equation helps in determining the maximum hydraulic capacity for a size of machine and operational settings. When sizing a facility, this assists in calculating a minimum number of units to achieve a hydraulic throughput. Unfortunately for design and operations, centrifuge performance is additionally dependent on the input sludge conditions, polymer dose, metal salt dosing, pumping considerations, and other factors. Due the variability of sludges between treatment plants, even those with similar treatment processes and influent wastewater characteristics, to determine the real-world number of centrifuges to successfully process a plant's sludge to both a certain sludge concentration and solids recovery while managing chemical and power costs, pilot testing is essential (WEF MOP No. $85^{\text {th }}$ edition, 2008; CH2M Hill, 2015).

\subsection{SDWWTP Pilot Phase 1 - Thickening pilot testing}

Pilot Phase 1 operation was based on feeding unthickened WAS to the pilot thickening centrifuge. The purpose of Pilot Phase 1 operation was to determine the optimum polymer design conditions and performance of the centrifuge thickening. The overall target for the centrifuge thickening performance was to thicken the WAS to 5.5\% 
TS while maintaining greater than $95 \%$ solids recovery. Determining the necessary polymer dose to achieve this performance is also important. Parameters that were adjusted for the centrifuge thickening included the pool depth, bowl speed and differential scroll speed (Goss et al., 2017).

Thickening Pilot Testing - no polymer operation

The system initially started up on lower sludge flows with no polymer injection. Figure 19 summarizes the operation without polymer for a medium bowl speed equal to 2,590 revolutions per minute (RPM) and differential speed of 12 RPM with flow rates ranging from 40 to 100 gallons per minute (gpm) or 151 to 379 liters per minute (L/min).

This operation showed that it was possible to thicken the sludge up to $6 \% \mathrm{TS}$ without the use of polymer, but at higher throughputs (above $60 \mathrm{gpm}$ or $227 \mathrm{~L} / \mathrm{min}$ ), the solids recovery was sacrificed. The tests were conducted at a deep pool depth, a medium pool depth and a shallow pool depth. The trend shows that at the shallowest pool depth solids recovery improved but total thickened solids was sacrificed. The thickened solids concentration at the deepest and medium pool depths were nearly the same but it should be noted that the feed solid content was lower when testing the deepest pool depth $(0.9 \%$ TS) while the feed solids were closer to $1.4 \%$ solids when testing the medium pool depth. If testing was done on the same feed solids concentration, it would be expected that the solids would be thicker at the deepest pool depth. 
Results of the testing without polymer indicated that it is possible to maintain the desired thickened TS concentrations without the use of polymer. Although the operation without polymer may sacrifice solids recovery, future operation at this condition may be desired when sludge production is below design capacity as it could reduce operation and maintenance costs associated with polymer consumption (Goss et al., 2017).

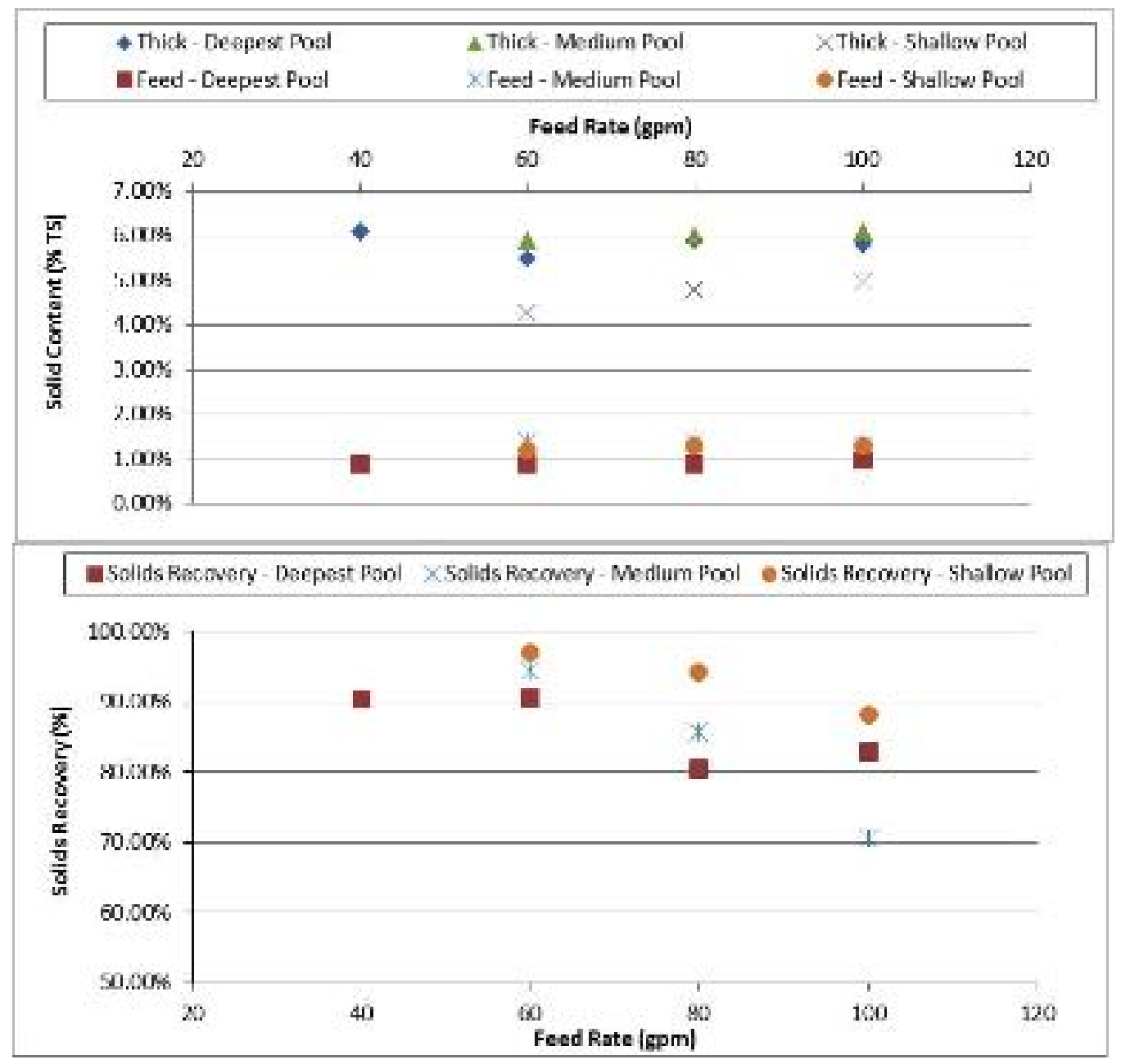

Figure 19: No Polymer Operation, Medium Bowl Speed (2,590 RPM) 
Thickening Pilot Testing - Emulsion polymer setup and initial testing

The pilot unit was set up to allow injection of polymer at two locations as illustrated in Figure 20, either directly into the bowl of the unit, internal injection, or in the sludge feed line upstream of the centrifuge inlet, external injection. Polymer flow was measured during each sampling event using a calibration column located on the pilot trailer. Both emulsion, i.e. oil immersed, and dry granular polymer, conditioned with water and matured, were tested to determine the dosing rates and performance with different polymer types.

The initial polymer used was PRAESTOL ${ }^{\circledR}$ K144-L which is a cationic, i.e. positively charged, high molecular weight emulsion polymer. Polymer dosage, using internal injection, was slowly increased at a constant throughput of $100 \mathrm{gpm}(379 \mathrm{~L} / \mathrm{min})$ while visually monitoring the clarity of the centrate. The testing was conducted at the shallowest pool depth and a differential speed of 12 RPM. Once polymer was added, the bowl speeds were reduced from 2,590 RPM to between 1,900 to 2,100 RPM to keep the thickened solids from being too thick. The results showed that with the increased polymer dosages and reduction in bowl speed, the thickened solid content remained steady, but the solids recovery improved.

Once relatively clear centrate was achieved, the flowrate to the machine was increased to maximize throughput while optimizing solids recovery (based on visual observations of centrate quality). In addition to PRAESTOL K144-L, the other cationic, high molecular weight emulsion polymers tested in the machine were PRAESTOL K148L, K275-FLX and K290-FLX. Optimization testing showed that the PRAESTOL K144L polymer worked the best (Goss et al., 2017). 


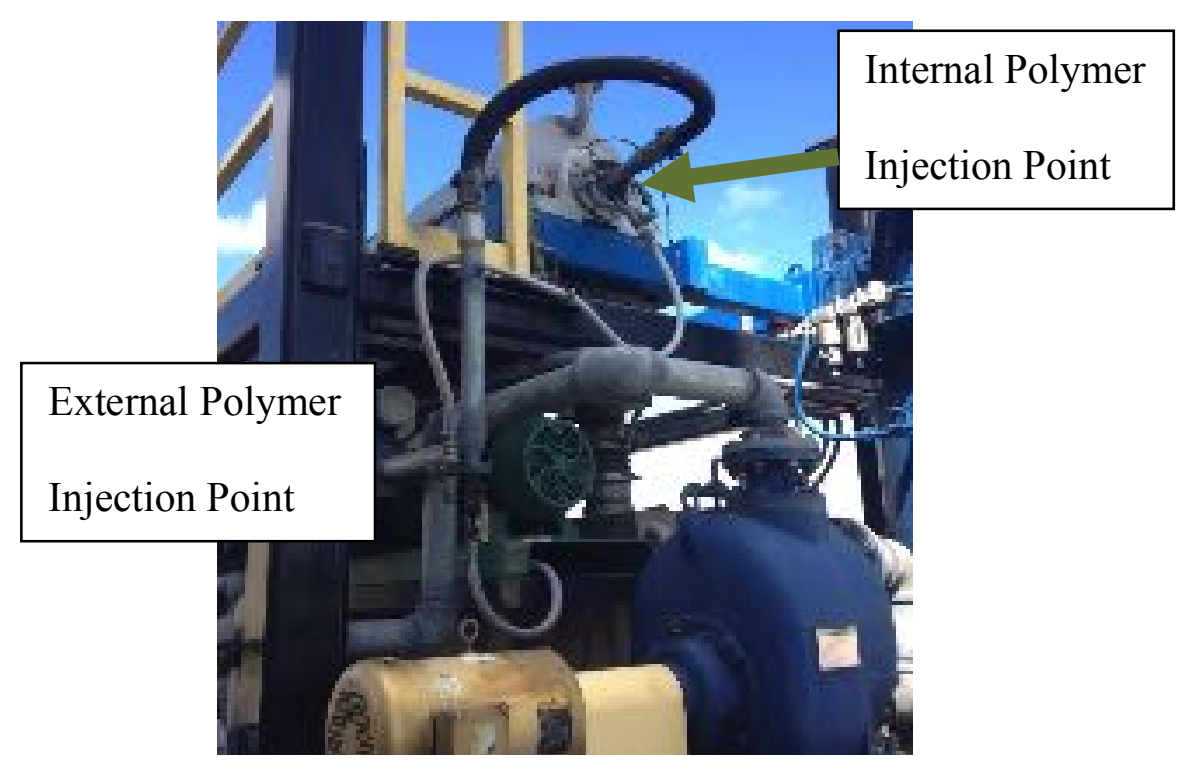

Figure 20: Thickening Polymer Injection Point

Thickening Pilot Testing - Dry polymer setup

The thickening unit contains an emulsion polymer system and was not set up with the provisions to operate on dry polymer so a creative solution was required to facilitate testing dry polymer in the pilot centrifuge. In order to allow the testing, one of SDWWTP polymer make up systems, which was not in use at the time, was used to make up a solution of water and $0.4-0.8 \%$ by weight of dry polymer, " $0.4 \%-0.8 \%$ polymer", which was then pumped to a chemical storage tote that was connected to a dedicated portable pump to meter the dry polymer solution into the centrifuge. Photos of set up are provided in Figure 21. 


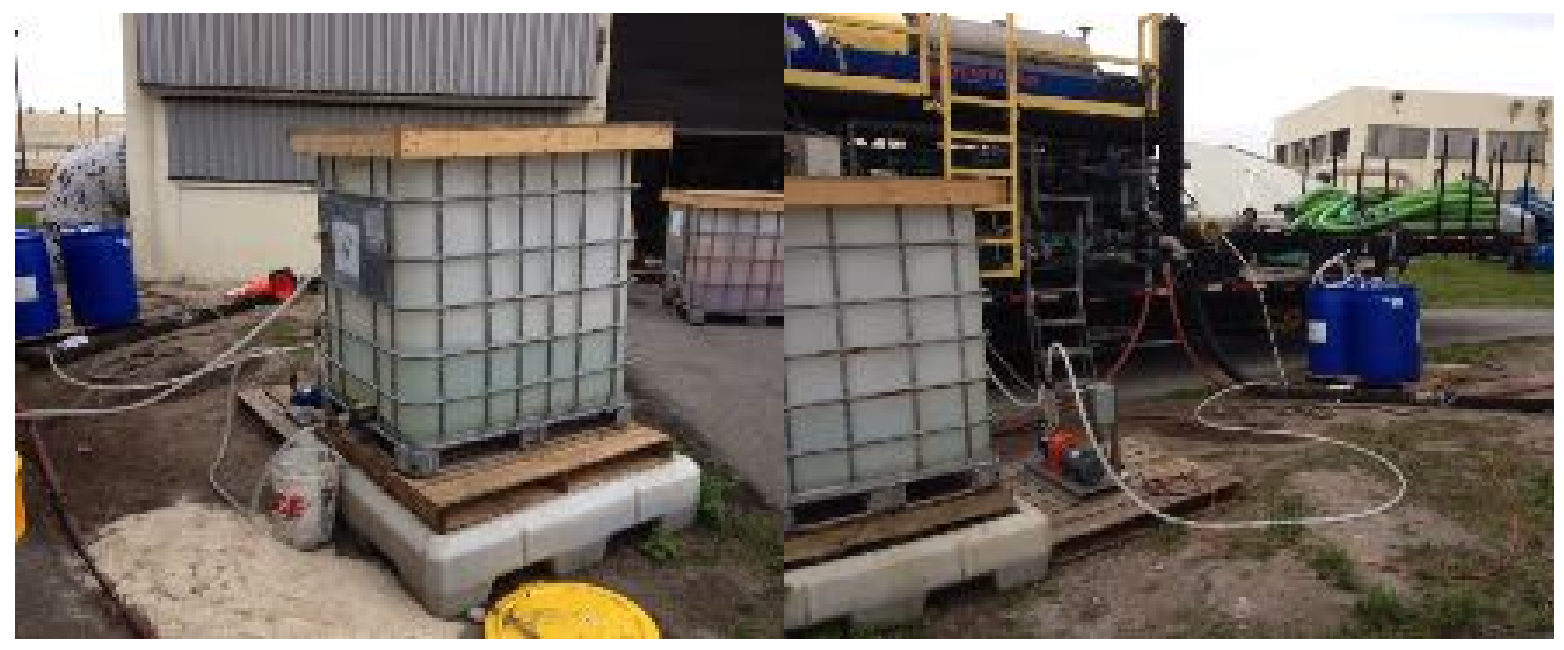

Figure 21: Temporary Dry Polymer Set Up

To account for the polymer viscosity, a pump flowrate to pump variable frequency drive control calibration curve was developed for the polymer pump by a series of bucket tests conducted at different pump speeds and the curve was compared to the theoretical pump curve showing good convergence. The dry polymer used for testing was Polydyne C-3283 which is the cationic, high molecular weight polymer the plant currently uses in their dewatering centrifuges.

Thickening pilot testing - Results

Pilot tests were run to further determine results for the centrifuge thickening operation. The results from the optimization trials showed that good performance could be achieved with medium bowl speeds of 2,400 to 2,600 RPM. At a lower flowrate of $100 \mathrm{gpm}(379 \mathrm{~L} / \mathrm{min})$, an emulsion polymer dose of 1 pound per dry ton (lb/DT) or 0.5 grams per dry kilogram $(\mathrm{g} / \mathrm{kg})$ showed good results but as the sludge feed flow to the thickening centrifuge was increased to $150 \mathrm{gpm}(568 \mathrm{~L} / \mathrm{min})$, at least $2 \mathrm{lb} / \mathrm{DT}(1 \mathrm{~g} / \mathrm{kg})$ was needed. In addition to higher polymer dose requirements occurring at higher flows; 
polymer dosing at the internal polymer injection, depicted in Figure 20, required a higher polymer dose to achieve the same solids thickness as the point external polymer injection, allowing a brief polymer to sludge contact time. The polymer curves and flow curves, plotting processed sludge thickness and centrifuge solids capture rate to polymer dose and sludge feed flowrate, respectively, were conducted during the performance testing period to further test the limits of machine performance for the operational parameters. Additional performance testing was conducted in March of 2016 using SDWWTP's dry polymer, Polydyne C-3283. The purpose was to repeat the November testing but with the dry polymer that more closely represents future operation (Goss et al., 2017).

Thickening pilot testing - Polymer curve results for emulsion and dry polymer

Polymer curve tests were conducted by maintaining a constant volumetric throughput of sludge feed to the centrifuge but changing the polymer dose to measure the impact. With the exception of changing polymer dose, all other parameters on the centrifuge remained the same for each polymer curve test. In November 2015, three different polymer curves were generated for the 144-L emulsion polymer at $100 \mathrm{gpm}$ (379 L/min), $150 \mathrm{gpm}(568 \mathrm{~L} / \mathrm{min})$, and $170 \mathrm{gpm}(644 \mathrm{~L} / \mathrm{min})$ WAS flow rates through the pilot centrifuge. In March 2016, an additional 144-L emulsion polymer curve was conducted at $130 \mathrm{gpm}(492 \mathrm{~L} / \mathrm{min})$ and several dry polymer curves were conducted at 130, 150, and $170 \mathrm{gpm}(492,568$, and $644 \mathrm{~L} / \mathrm{min})$.

Figure 22 also shows the data for emulsion polymer curves at the $130 \mathrm{gpm}$ (492 $\mathrm{L} / \mathrm{min})$ and $150 \mathrm{gpm}(568 \mathrm{~L} / \mathrm{min}) \mathrm{WAS}$ feed, conducted at medium bowl speed $(2,400-$ 2,600 RPM). At $130 \mathrm{gpm}(492 \mathrm{~L} / \mathrm{min})$ WAS feed, the curve was conducted with internal 
polymer injection and at $150 \mathrm{gpm}(568 \mathrm{~L} / \mathrm{min})$ WAS feed, the curve was conducted with external polymer injection. The concentration of the WAS during this testing ranged from $1.1 \%$ to $1.5 \%$ TS.

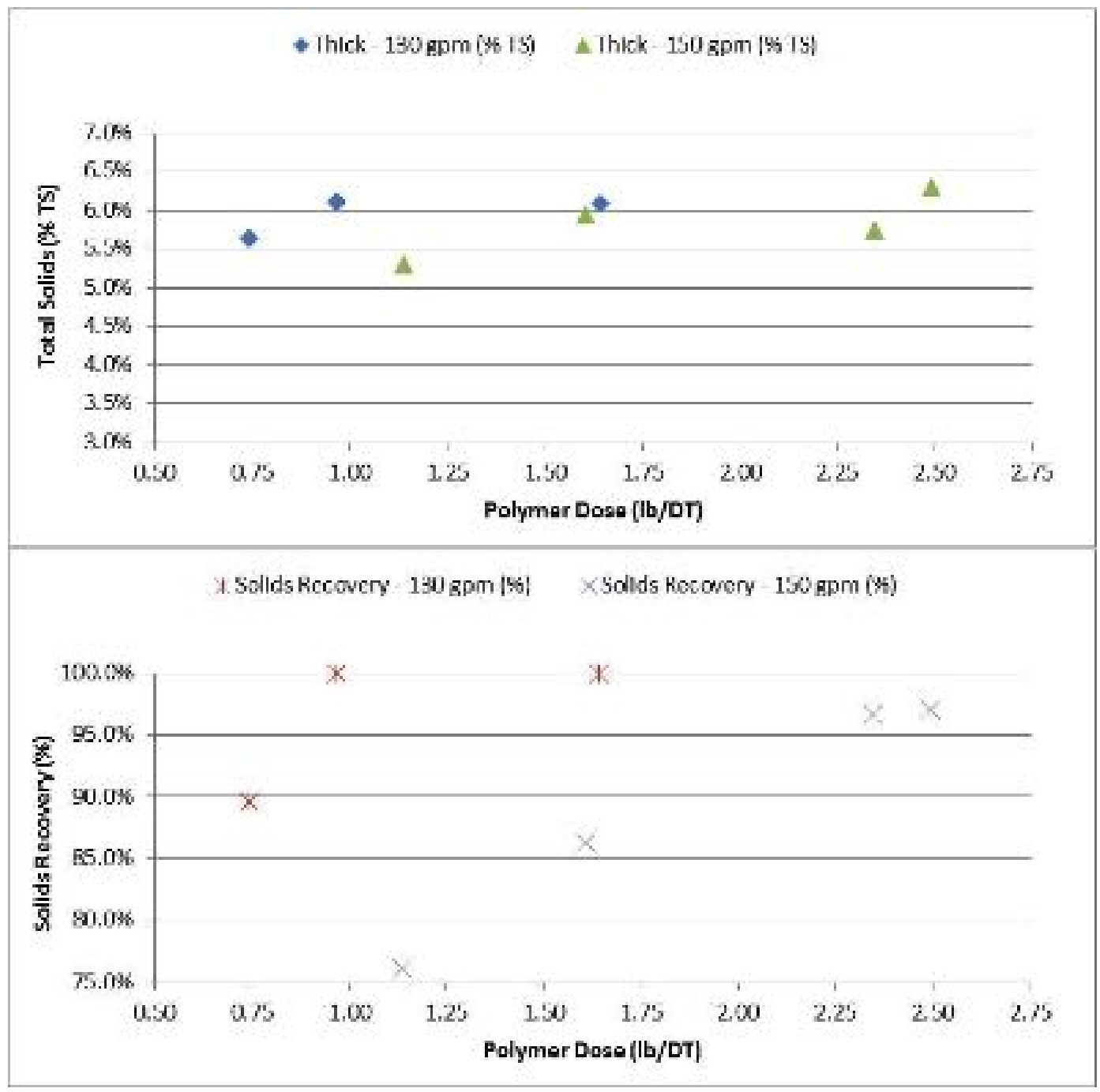

Figure 22: Emulsion Polymer - 130 and 150 gpm WAS feed, Medium Bowl Speed 
As shown in Figure 22, at 130 gpm (492 L/min) WAS feed with internal emulsion polymer injection and a deep pool depth, good performance is obtained for polymer doses greater than $1 \mathrm{lb} / \mathrm{DT}(0.5 \mathrm{~g} / \mathrm{kg})$ active, achieving close to $6 \%$ TS and $100 \%$ solids recovery. Surpassing $1.0 \mathrm{lb} / \mathrm{DT}(0.5 \mathrm{~g} / \mathrm{kg})$ as a polymer dose to $1.6 \mathrm{lb} / \mathrm{DT}(0.8 \mathrm{~g} / \mathrm{kg})$ active did not have much of an impact on the solids concentration or the solids recovery.

At $150 \mathrm{gpm}(568 \mathrm{~L} / \mathrm{min})$ WAS feed with external emulsion polymer injection and a shallow pool depth, greater than 5\% TS was achieved for all polymer doses tested. The solids recovery exceeded $95 \%$ for the two highest dosing points when active dosing was greater than $2.3 \mathrm{lb} / \mathrm{DT}(1.2 \mathrm{~g} / \mathrm{kg})$. The dry polymer curve for the WAS flow rate of 130 gpm (492 L/min) with both internal and external dry polymer injection is shown in Figure 23 for a medium bowl speed of 2,586 RPM and deep pool depth. The prepared polymer concentration in solution during these tests was approximately $0.8 \%$ mass basis. An additional 130 gpm (492 L/min) WAS polymer curve, also shown in Figure 23, used a 0.4\% Polymer solution (with internal dry polymer injection) at a bowl speed of 2,408 RPM and deep pool depth. For all tests, the feed averaged 1.2 to $1.4 \%$ TS. 


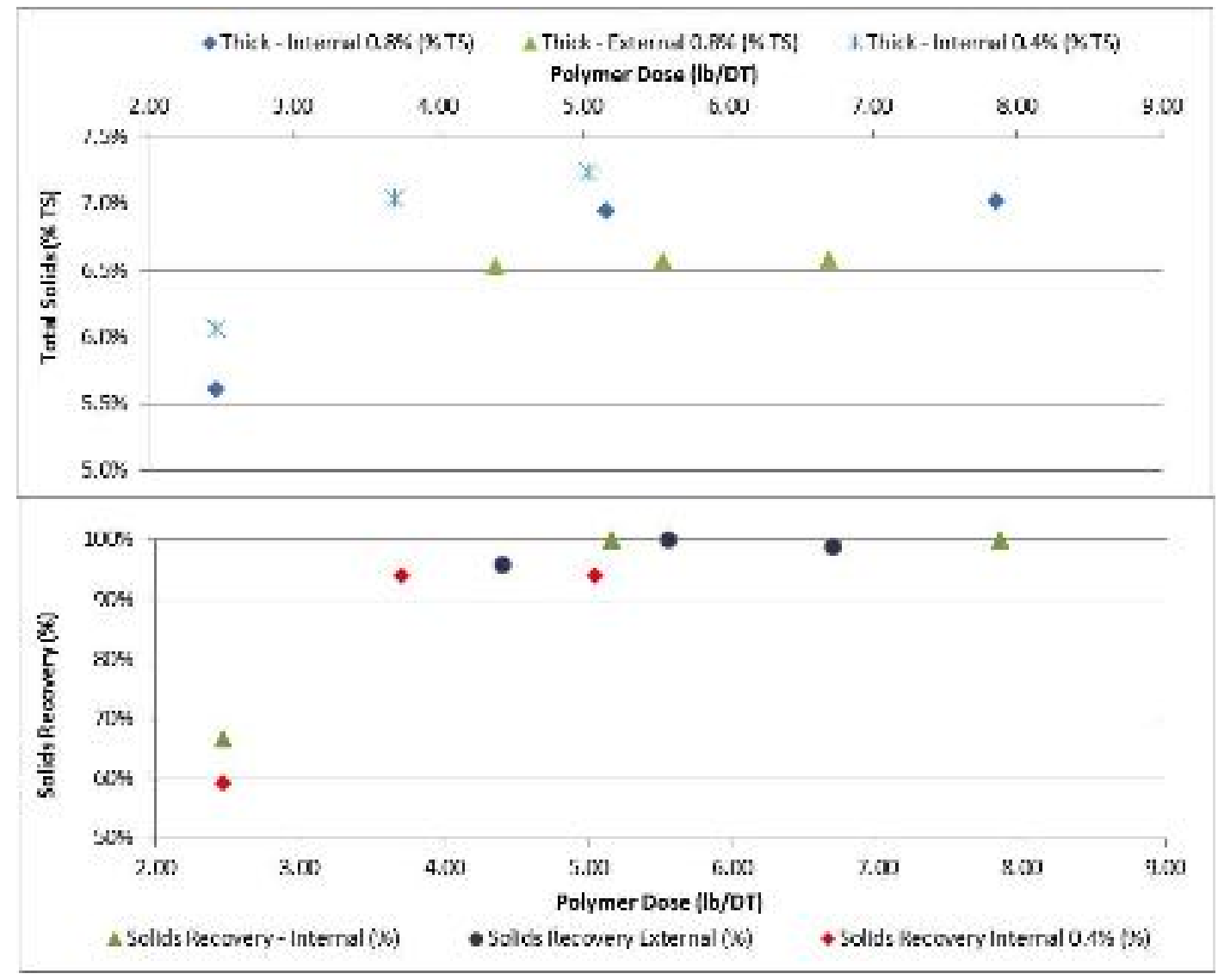

\section{Figure 23: Dry Polymer - 130 gpm WAS Feed, Internal and External Injection, Medium Bowl Speed}

For internal dry polymer injection with a $0.8 \%$ polymer solution, greater than 5.5 $\%$ TS was achieved for all polymer doses tested, however, greater than $95 \%$ recovery was achieved only at polymer doses greater than $5 \mathrm{lb} / \mathrm{DT}(2.5 \mathrm{~g} / \mathrm{kg})$. For external dry polymer injection with a $0.8 \%$ polymer solution, the active polymer dose ranging from 4.3 to 6.7 lb/DT (2.2 to $3.4 \mathrm{~g} / \mathrm{kg}$ ) did not show significant differences in centrifuge performance in terms of solids content. The thickened solids content ranged from 6.5 to $6.6 \%$ TS and the solids recoveries were greater than $95 \%$ for all samples. The TSS sample analyzed for $4.3 \mathrm{lb} / \mathrm{DT}(2.4 \mathrm{~g} / \mathrm{kg})$ may also have had an error and it was noted that the centrate was 
visually dirtier than the samples with high polymer dosages. For internal dry polymer injection with a $0.4 \%$ polymer solution, greater than $5.5 \%$ TS was achieved for all polymer doses tested and at polymer doses greater than $3.8 \mathrm{lb} / \mathrm{DT}(1.9 \mathrm{~g} / \mathrm{kg})$, the solids recovery was near the $95 \%$ target. The thickening pilot results show that at $130 \mathrm{gpm}$ (492 L/min) WAS feed, approximately $5 \mathrm{lb} / \mathrm{DT}(2.5 \mathrm{~g} / \mathrm{kg})$ of the dry polymer is required to maintain greater than $95 \%$ recovery but at the settings tested, the thickened sludge exceeds the needed solids content and approaches $7 \%$ TS. Further optimization would be required to maintain the target of $5.5 \%$ TS such as lowering the pool depth.

The dry polymer curves for the WAS flow rate of $150 \mathrm{gpm}(568 \mathrm{~L} / \mathrm{min})$ with both internal and external dry polymer injection is shown in Figure 24 for a medium bowl speed of approximately 2,585 RPM and deep pool depth. The polymer concentration during these tests ranged between 0.7 to $0.8 \%$ TS. For all tests, the feed sludge averaged 1.2 to $1.3 \%$ TS. 


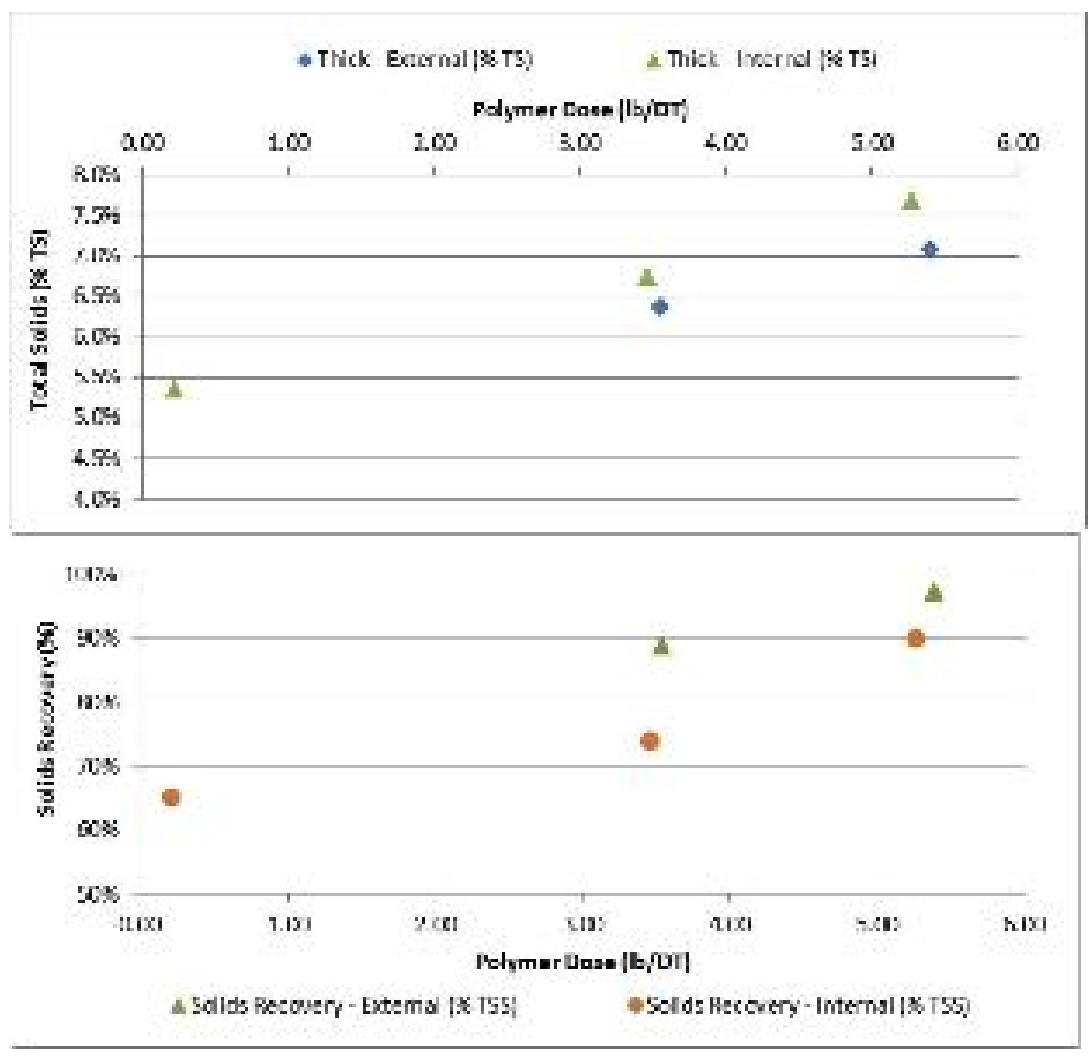

\section{Figure 24: Dry Polymer - 150 gpm, Internal and External Injection, Medium Bowl Speed}

For internal dry polymer injection, greater than $5 \%$ TS was achieved for all polymer doses tested, however, none of the points achieved greater than $95 \%$ recovery. Flocs were observed in the centrate for the external polymer injection testing so it was evident that this sludge feed flow was too high for the internal polymer injection to work efficiently. For external injection, greater than $6 \%$ TS was achieved for all polymer doses tested. The solids recovery, however, was only greater than $95 \%$ for the highest active polymer dose which was $5.3 \mathrm{lb} / \mathrm{DT}(2.7 \mathrm{~g} / \mathrm{kg})$. It may have been possible to get better performance (closer to $5.5 \%$ TS with greater than 95\% solids recovery) with a shallower pool depth (Goss et al., 2017). 
Thickening Pilot Testing - Extended operation results

After generating the polymer, flow and bowl speed curves, the unit was operated several days at a constant flowrate with optimized settings to test the stability of operation throughout the course of a day. During November 2015, these tests were conducted using the 144-L emulsion polymer at a WAS flow rate of 135 gpm (511 $\mathrm{L} / \mathrm{min}), 165 \mathrm{gpm}(625 \mathrm{~L} / \mathrm{min})$ and $200 \mathrm{gpm}$ (757). In March 2016, the extended operation testing with dry polymer was repeated twice at $135 \mathrm{gpm}(511 \mathrm{~L} / \mathrm{min})$. Samples were collected during these trials approximately once every hour. The results with emulsion polymer were stable throughout the course of a run but the results with the dry polymer showed more fluctuation with solid recovery degradation over time (Figure 25). It was planned to again repeat the $135 \mathrm{gpm}(511 \mathrm{~L} / \mathrm{min})$ extended operation testing using the dry polymer, however, the gearbox on the progressive cavity pump to convey thickened sludge failed before this testing was completed. Due to the lead-time to repair, it was not possible to conduct the additional testing within the Pilot testing schedule. It is believed that limitations in the set-up and lack of mixing on the polymer chemical storage tote contributed to the poor performance for the extended operation testing with dry polymer. The concentration of polymer samples collected throughout the extended run varied between 20 to $40 \%$ from the target of $0.8 \%$ polymer on both days tested. 
A comparison of the extended operation at $135 \mathrm{gpm}(511 \mathrm{~L} / \mathrm{min})$ with emulsion and dry polymer is depicted in Figure 25 . The runs with dry polymer at 4-7 lb/DT (2-3.5 $\mathrm{g} / \mathrm{kg}$ ) active polymer dosages were conducted with a deeper pool depth than the run with emulsion polymer conducted at 2-3 lb/DT (1-1.5 g/kg) active polymer dosages. The deeper pool depth is likely the reason the solid content was higher with the dry polymer testing than the emulsion polymer testing. The feed WAS concentration during all three runs ranged from 1.1 to $1.5 \% \mathrm{TS}$.

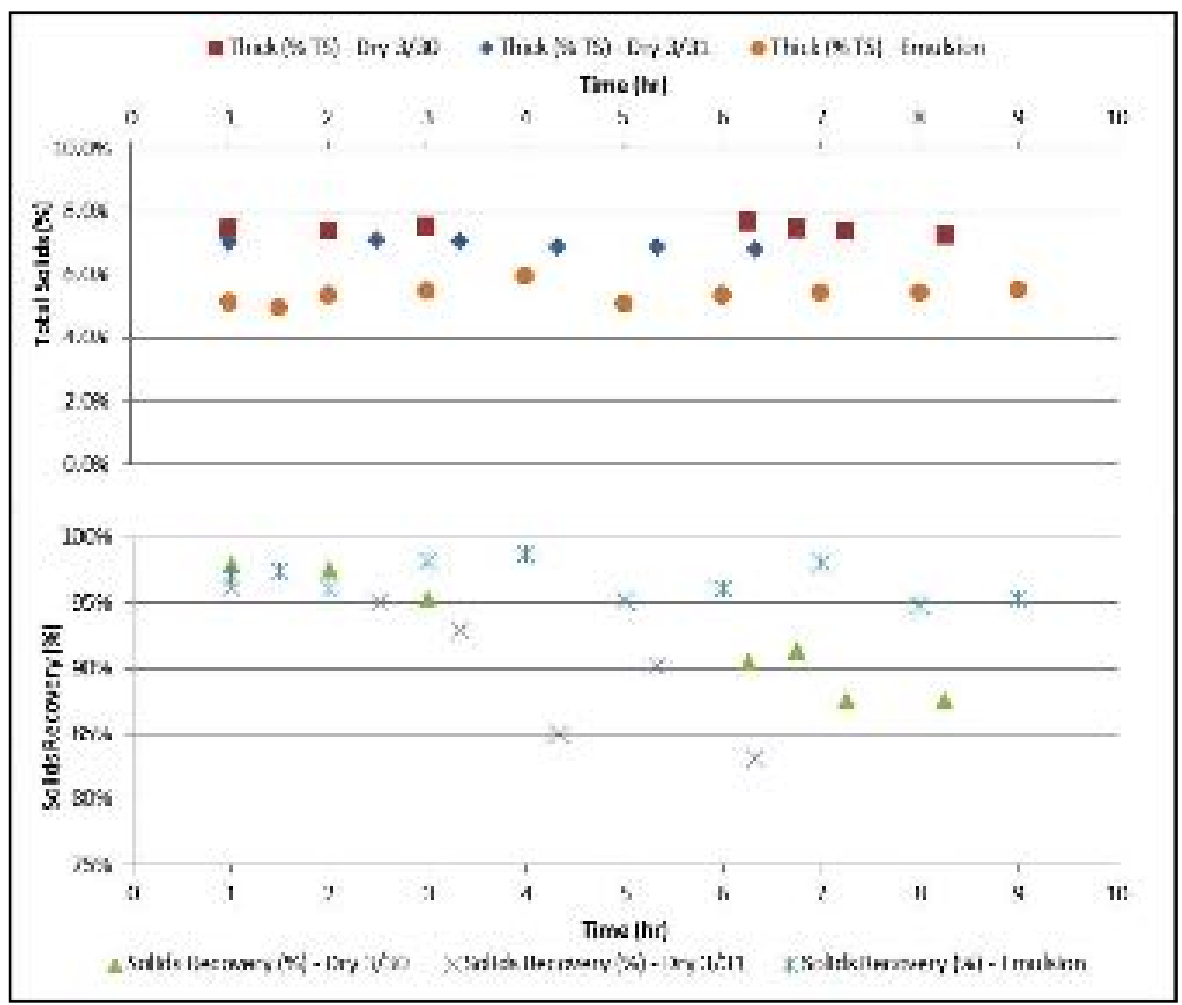

Figure 25: Extended Thickening Operation at $135 \mathrm{gpm}$ 
The thickening pilot testing showed that the centrifuge could produce solids at 5$6 \%$ TS and achieve greater than $95 \%$ solids recovery, other than the solids capture rate deterioration during longer test runs on March 31, 2016 that may be the effect of poor mixing in the polymer day tank as previously mentioned. Testing was conducted using both dry and emulsion polymers. The dry polymer required 5-7 lb/DT $(2.5-3.5 \mathrm{~g} / \mathrm{kg})$ active dosing compared to $1-3 \mathrm{lb} / \mathrm{DT}(0.5-1.5 \mathrm{~g} / \mathrm{kg})$ active based on the emulsion. It was also possible to thicken the sludge to $5-6 \%$ TS without the use of polymer but this required reducing the hydraulic throughput of feed sludge by about 50\%, 60-80 gpm (327-436 $\left.\mathrm{m}^{3} / \mathrm{d}\right)$, to allow solids recoveries to remain above $90 \%$ (Goss et al., 2017).

\subsection{CDWWTP Pilot Phase 1 - Thickening Pilot Testing}

\section{Thickening Pilot Setup}

Similar to the pilot testing at SDWWTP, thickening in the pilot unit was tested without polymer, with emulsion polymer and with dry polymer. The pilot unit was set up to allow injection of polymer at two locations as illustrated in Figure 20 either directly into the bowl of the unit, internal injection, or in the sludge feed line upstream of the centrifuge inlet, external injection. Polymer flow was measured during each sampling event using a calibration column located on the pilot trailer. 
The emulsion polymer used for testing was again the previously used cationic, high molecular weight emulsion polymer PRAESTOL® K144-L. In addition, two different dry polymers were also tested including the dry polymer currently used in CDWWTP's gravity concentrators (SNF Polydyne Clarifloc SE-1138) and a dry polymer currently used in CDWWTP's dewatering centrifuges (SNF Polydyne Clarifloc SE1141).

\section{Thickening Pilot Testing - CDWWTP WAS}

For the CDWWTP WAS only thickening pilot testing operation, the system was set up and operated with emulsion polymer, dry polymer and without polymer. Polymer curve tests were conducted by maintaining a constant volumetric throughput of sludge feed to the centrifuge while changing the polymer dose. After generating the polymer curves, the unit was operated several days at a constant flowrate with optimized settings to test the stability of operation throughout the course of a day.

The testing showed that the centrifuge, operating on CDWWTP WAS-only, could reliably thicken the WAS from $0.9-1.3 \%$ TS to $5-6 \%$ TS and achieve greater than $95 \%$ solids recovery, as can be seen in Figure 27 and Figure 29 below. Testing was conducted using both dry and emulsion polymers. As show in Figure 26 and Figure 28, the dry polymer required 3 to 4 pounds per dry ton (lb/DT) or 1.5 to 2 grams per dry kilogram $(\mathrm{g} / \mathrm{kg})$ active dosing compared to 0.6 to $3 \mathrm{lb} / \mathrm{DT}(0.3$ to $1.5 \mathrm{~g} / \mathrm{kg}$ ) based on the emulsion. It was also possible to thicken the sludge to 5-6\% TS without the use of polymer but this required the WAS flowrate to the pilot unit to be reduced by $25 \%$, to $120 \mathrm{gpm}\left(654 \mathrm{~m}^{3} / \mathrm{d}\right)$ to allow solids recoveries to remain above 95\% (Moncholi et al., 2018). 


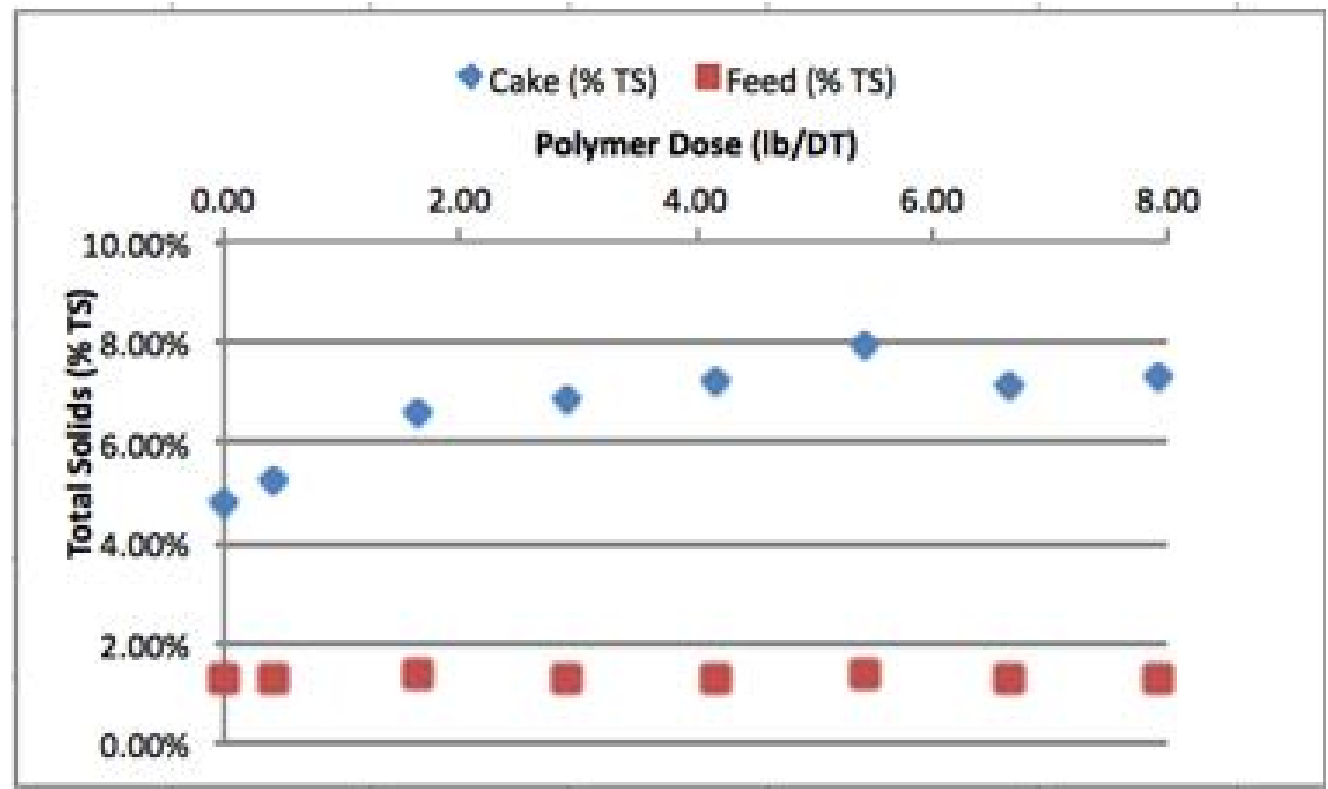

Figure 26: Feed and thickened sludge concentrations of WAS-only Extended Operation at varying polymer dosages June 14, 2016

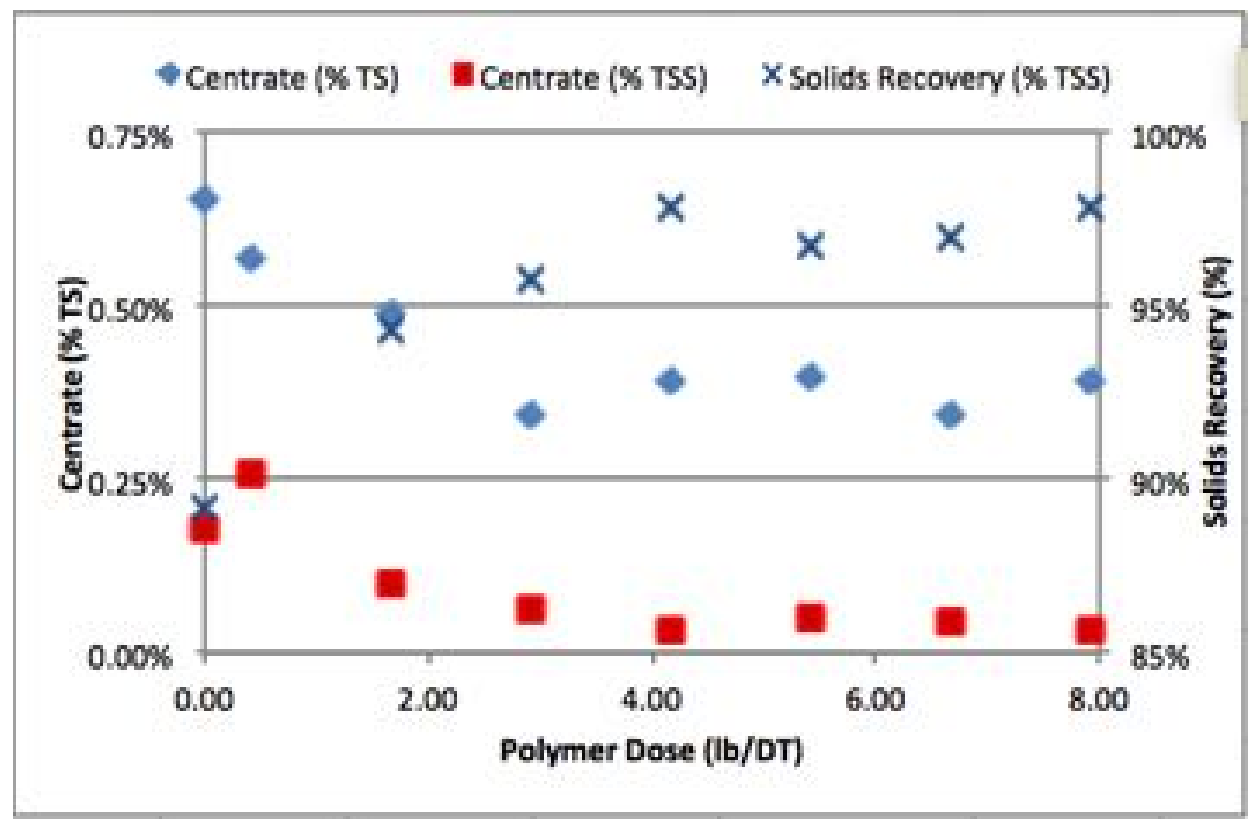

Figure 27: Centrate concentrations and solids recovery of WAS-only Extended Operation at varying polymer dosages June 14, 2016 


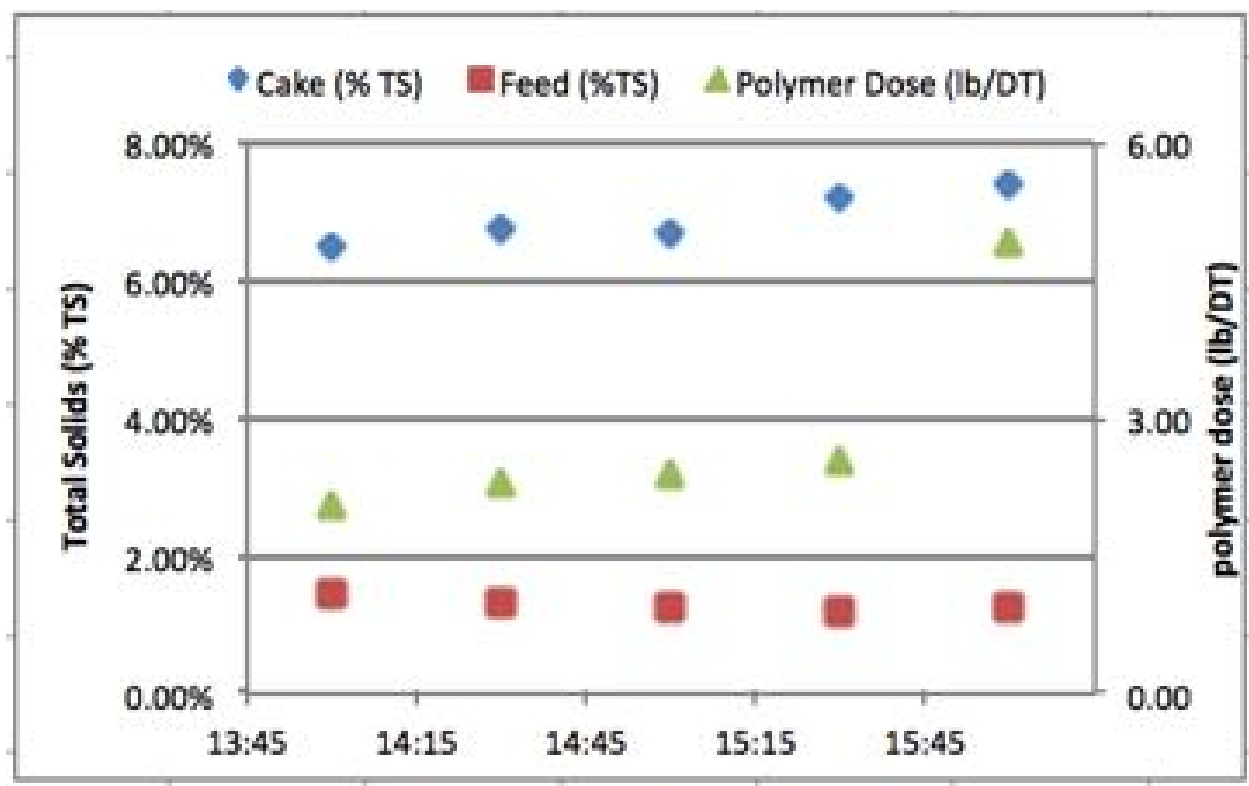

Figure 28: Feed and thickened sludge concentrations of WAS-only Extended Operation at varying polymer dosages June 22, 2016

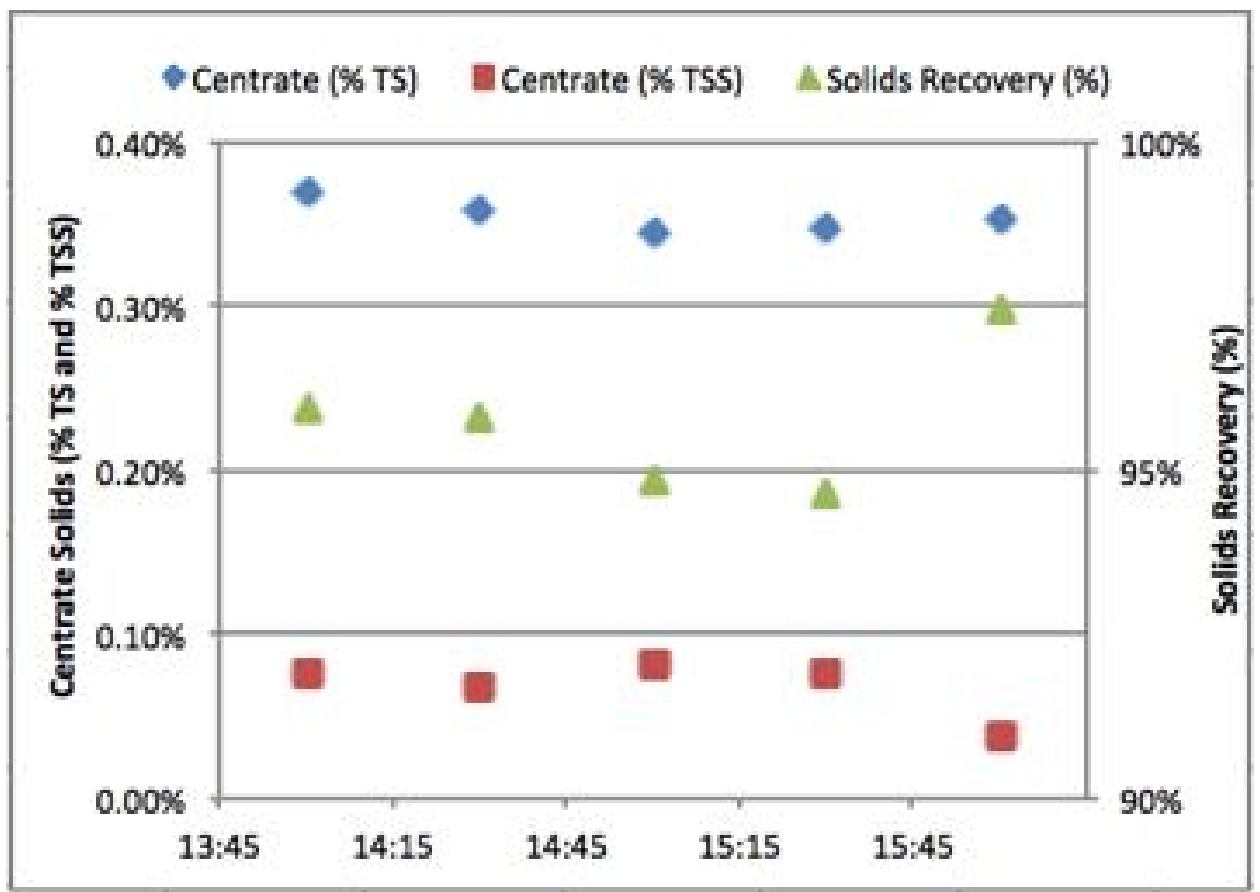

Figure 29: Centrate concentrations and solids recovery of WAS-only Extended Operation at varying polymer dosages June 22, 2016 
For modeling proposes thickening centrifuge pilot test runs between $6-6.5 \%$ thickened solids concentrations were used. In fact much of the thicken sludge extended run data show that the thickening centrifuges were more stable at higher thickened sludge outputs between $6-7 \% \mathrm{TS}$ and even beyond $8 \% \mathrm{TS}$, as demonstrated in Figure 30 and Figure 31 below.

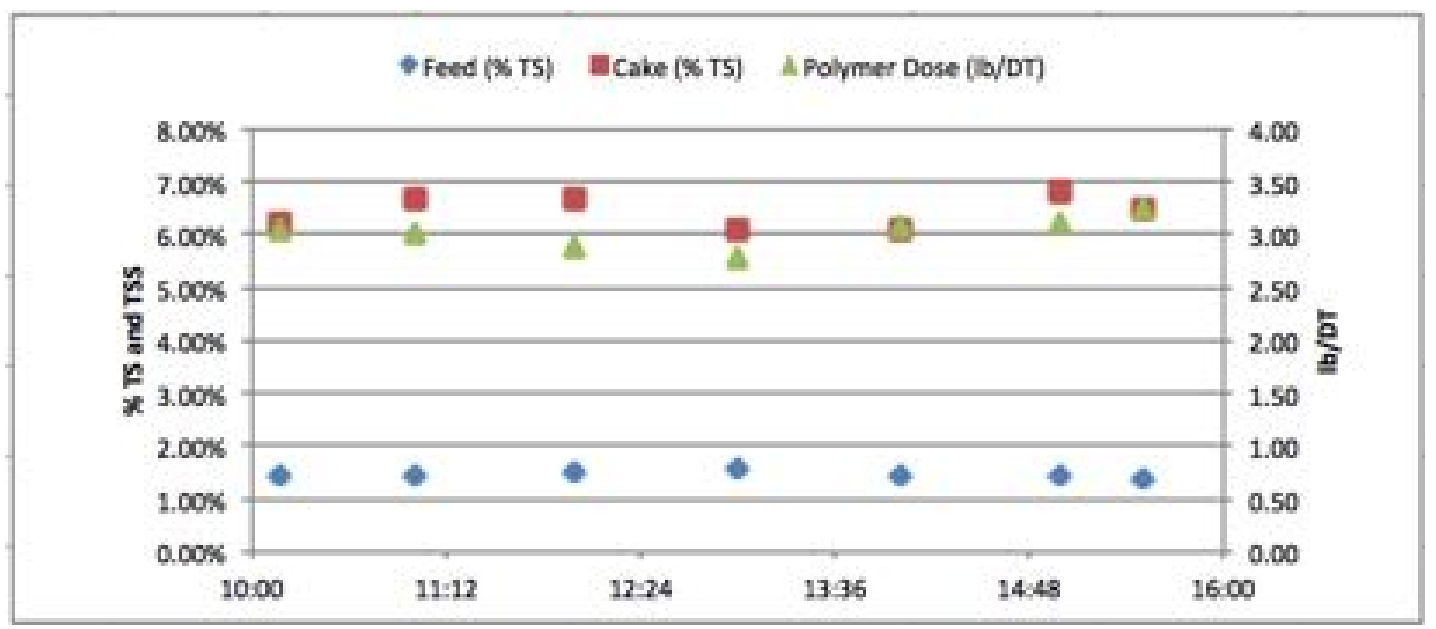

Figure 30: Feed and thickened sludge concentrations of WAS-only extended operation at $160 \mathrm{gpm}, 3 \mathrm{lb} / \mathrm{DT}$ dry polymer dose target on June 7, 2016

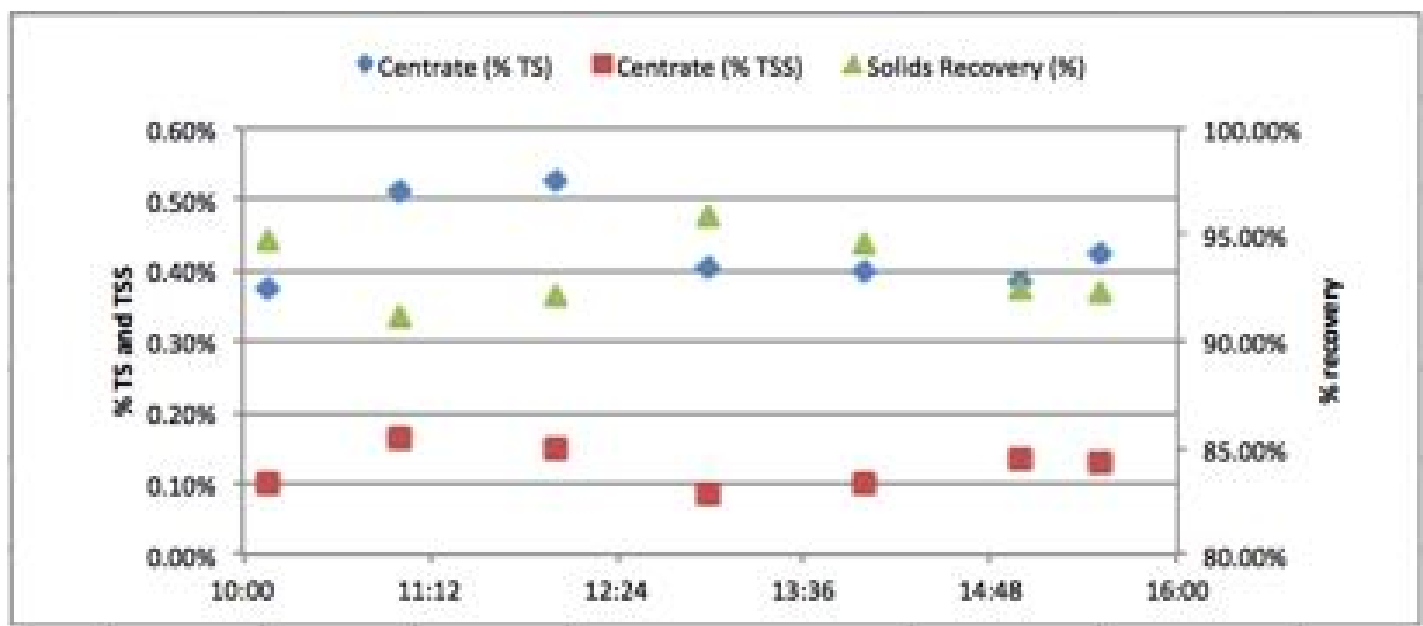

Figure 31: Centrate and percent recovery results of WAS-only extended operation at $160 \mathrm{gpm}, 3 \mathrm{lb} / \mathrm{DT}$ dry polymer dose target on June 7, 2016 
Thickening Pilot Testing - NDWWTP primary sludge and WAS

When pilot operation initially began in May of 2016, the 6-mile, 16-inch line from the interceptor that allowed NDWWTP sludge to be fed to the CDWWTP gravity thickeners was out of service so pilot testing of the NDWWTP sludge could not begin until this was brought back in service. In addition, the amount of debris and grit in the sludge from NDWWTP, which have historically been problematic for CDWWTP operations, was exacerbated during the piloting period since the primary sludge degritters at NDWWTP were out of service for replacement.

In order to minimize the impact of rags and grit, two Raptor Screens manufactured by Lakeside Equipment Corporation of Bartlett, Illinois shown in Figure 32 were installed on the receiving pipe for NDWWTP's sludge. These units contain a screening system and an aerated grit chamber that provide removal of both rags and grit to a dumpster. The NDWWTP sludge from the raptor screens was directed to one of CDWWTP's gravity concentrators in order to homogenize the North District Sludge and serve for normal plant operations sludge thickening between thickening centrifuge pilot runs. 

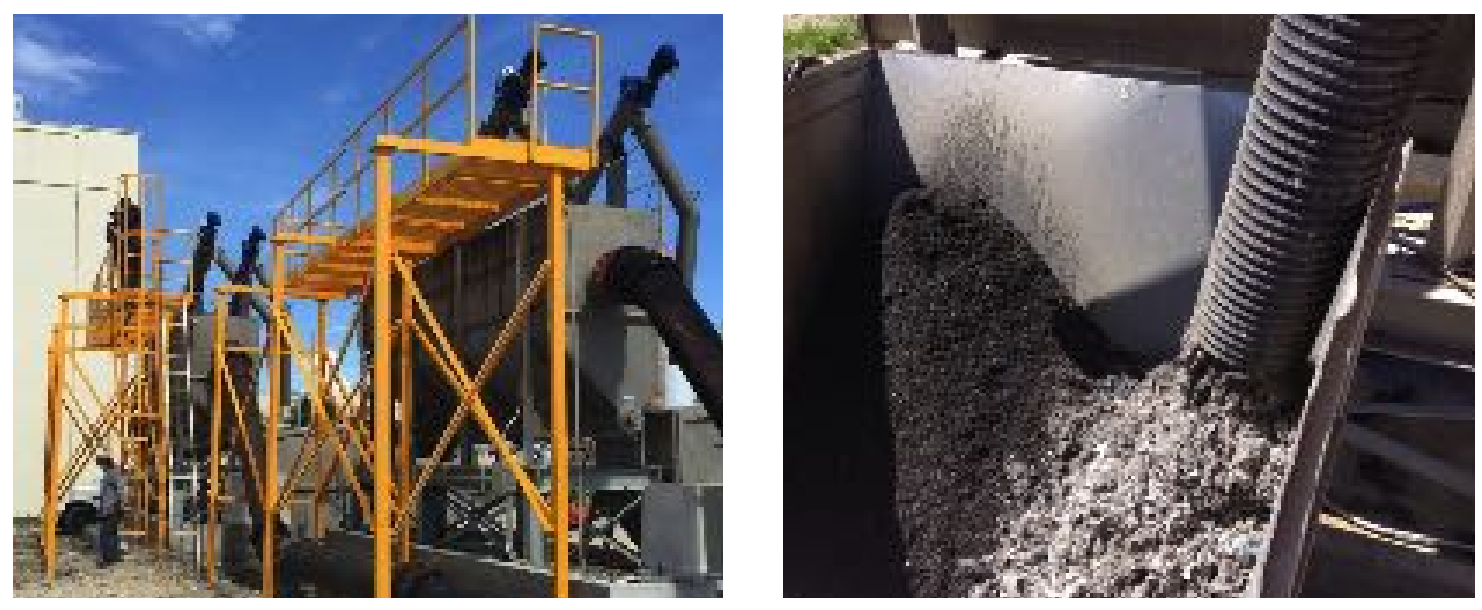

Figure 32: CDWWTP Lakeside Raptor Screens for NDWWTP sludge

Testing of NDWWTP's sludge started at the end of June 2016 and testing ultimately continued through mid-September 2016. The preliminary design assumption for the NDWWTP sludge concentration was $0.75 \%$ TS average with a range from 0.5 to $1 \%$ TS but data collected showed that the NDWWTP concentration was typically less than $0.5 \%$ TS. Initial testing was conducted mostly on NDWWTP primary sludge since a large proportion of the WAS was directed to Sludge Force Main \#2 to the influent of CDWWTP due to limitation in the piping. The combination of thin sludge and the high proportion of primary sludge made thickening in the pilot centrifuge very difficult.

When the NDWWTP sludge was blended with CDWWTP sludge in the blend tank, shown in Figure 33, stable operation could be maintained in the centrifuge and greater than $5.5 \%$ TS thickened sludge with greater than $95 \%$ solids recovery could be achieved. The dry polymer required 1.5 to $3 \mathrm{lb} / \mathrm{DT}(0.75$ to $1.5 \mathrm{~g} / \mathrm{kg})$ active dosing compared to 2 to $3 \mathrm{lb} / \mathrm{DT}$ ( 1 to $1.5 \mathrm{~g} / \mathrm{kg}$ ) based on the emulsion. The testing showed that including a blend tank to mix the CDWWTP and NDWWTP sludge would be important 
for future operation to be successful. Example data collected for thickening the CDWWTP and NDWWTP sludge blend to determine the performance range for thickened sludge solids (cake \% solids) and percent solids capture, at varying differential bowl speeds and feed \% solids are provided in Figure 34, Figure 35, and Figure 36 (Moncholi et al., 2018). 

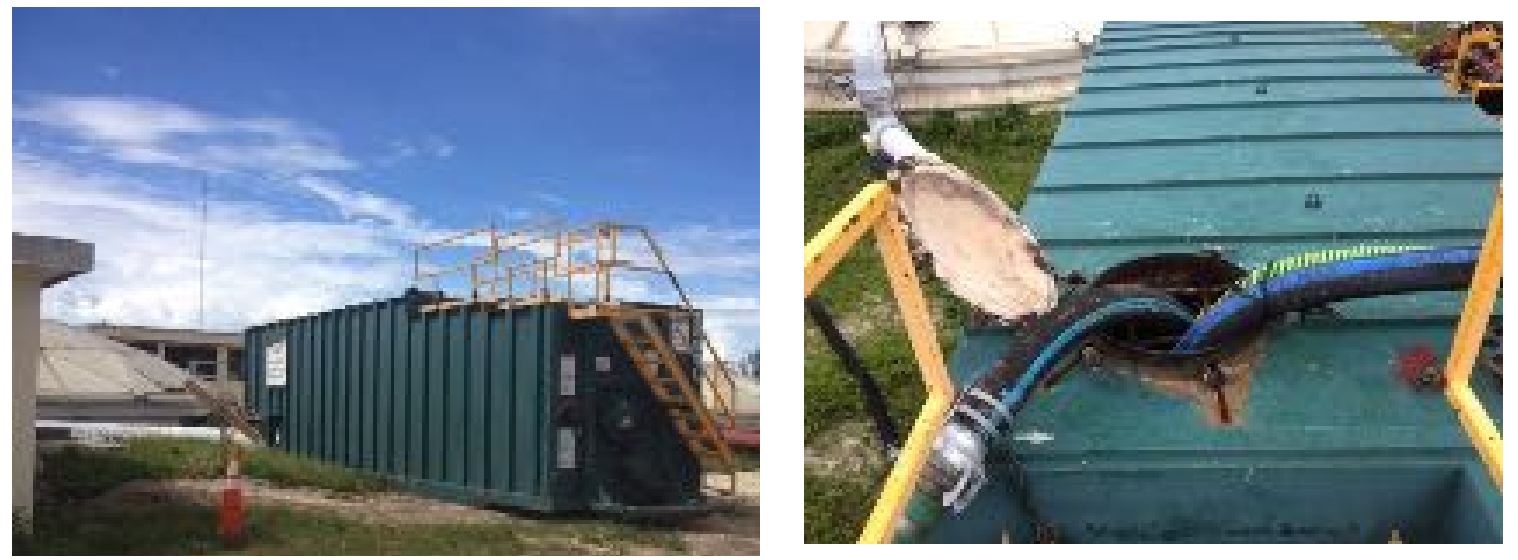

Figure 33: CDWWTP and NDWWTP Blend Tank

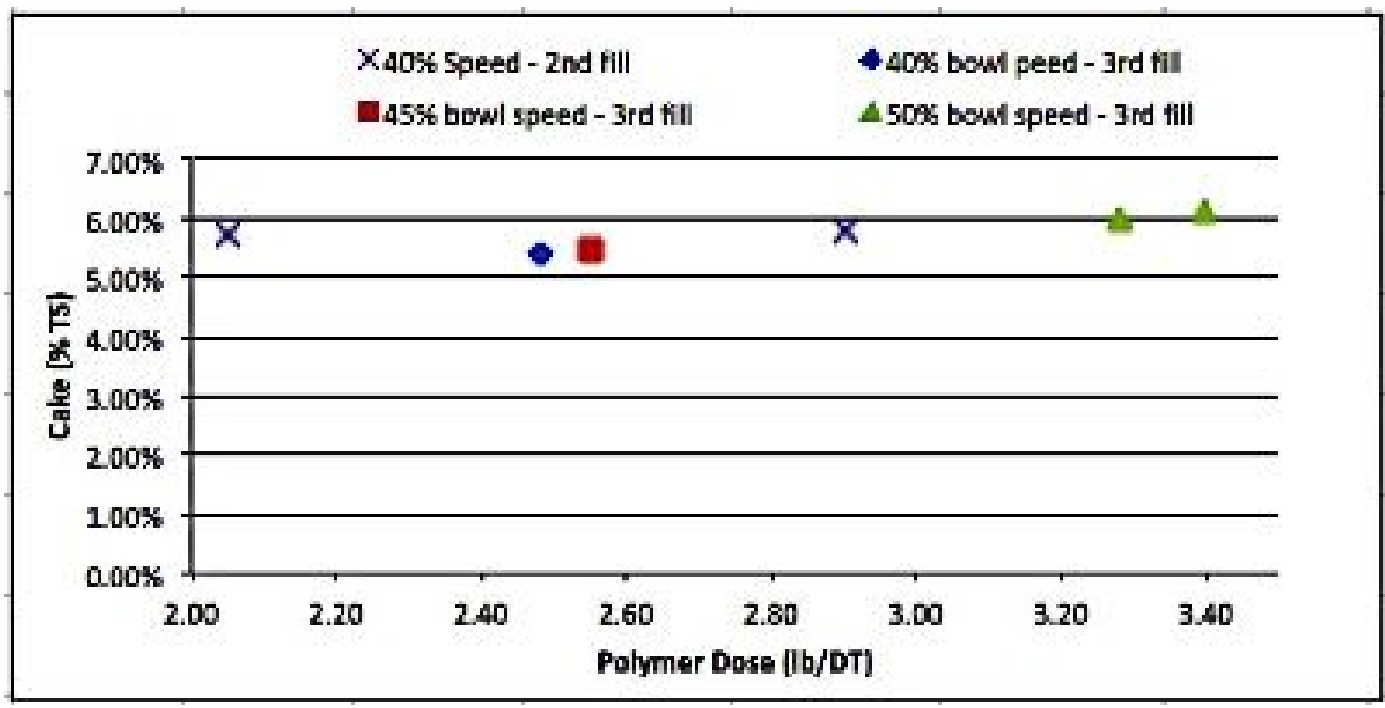

Figure 34 CDWWTP and NDWWTP cake solids at varying differential bowl speeds and polymer dosages 


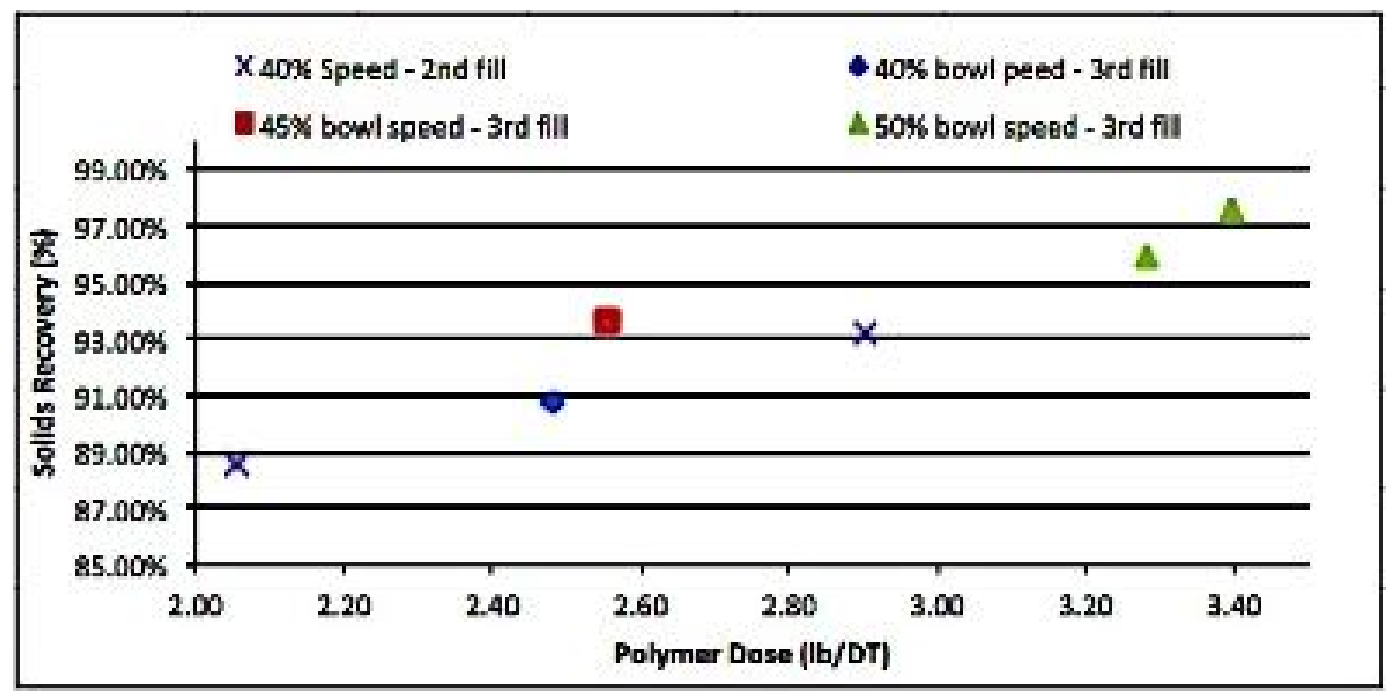

Figure 35: CDWWTP and NDWWTP solids recovery at varying differential bowl speeds and polymer dosages

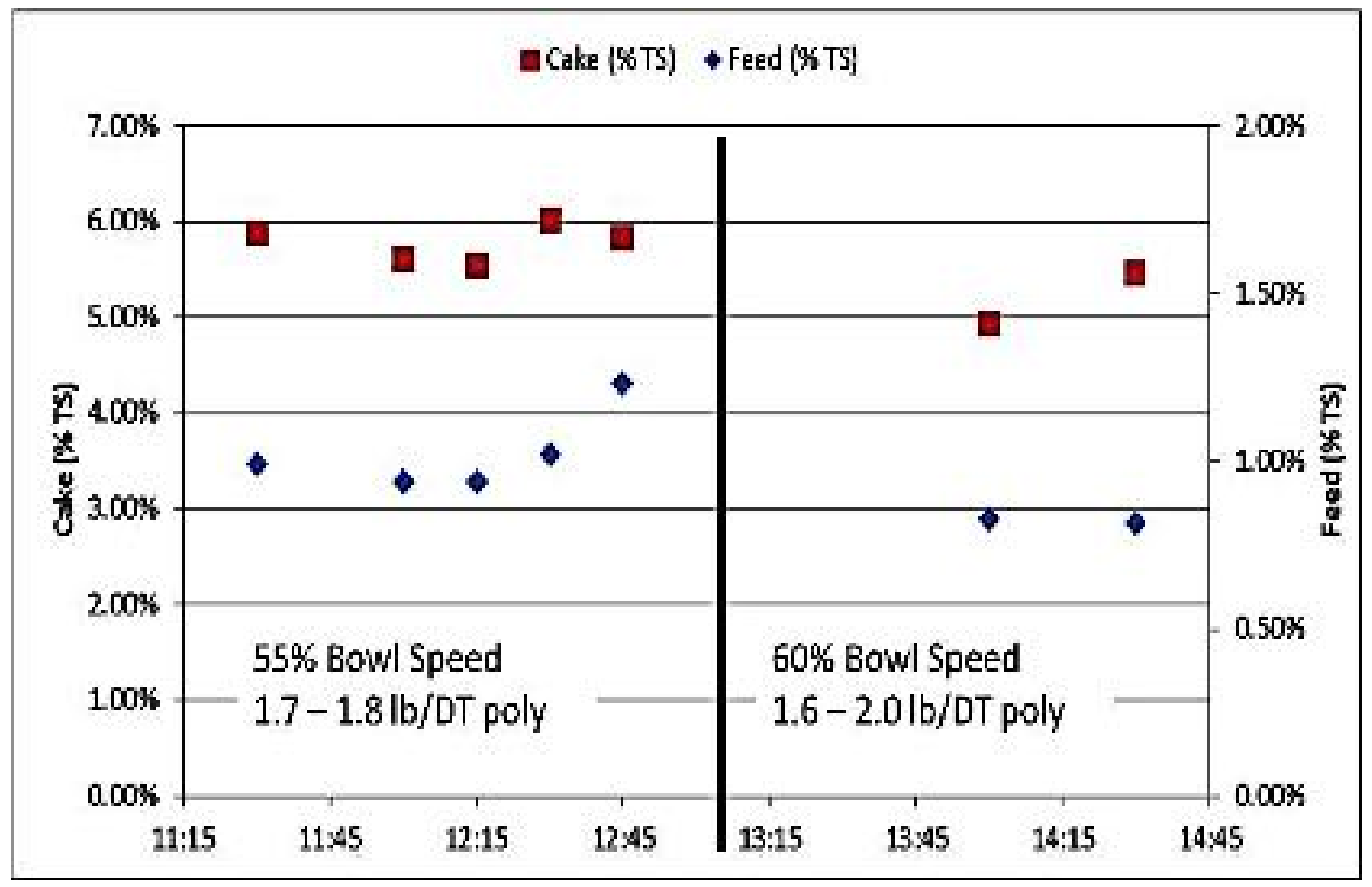

Figure 36: CDWWTP and NDWWTP polymer curve and extended Operating testing data at two differential bowl speeds from Sept. 13, 2016 
The setup used during the pilot, however, had several limitations with regard to capacity, tank mixing, and flow metering that should not be issues in a full-scale system. Because of the limitations, there were some variations noted for day-to-day operation. In addition, during the time of testing, the feed pump on the pilot centrifuge was wearing out and close to failure due to excessive wear on the stator from grit. Because of these issues, it was not possible to run an extended operation run for more than 2 to 3 hours at a time. As this was not a problem encountered either during the SDWWTP pilot testing, which only processed WAS or the CDWWTP WAS-only continuous operation during

4.6 Chapter Summary: Discussion of results, impact of pilot tests on model inputs and other model assumptions for sludge thickening

From analysis of the historical plant data of both SDWWTP and CDWWTP the process performance of the gravity thickeners, the existing sludge thickening process, have excellent solids capture rates of $99.2 \%$ and $96.2 \%$, respectively. They are limited in their sludge thickening performance with solids outputs of $2.3 \%$ solids and $3.9 \%$ solids, for SDWWTP and CDWWTP respectively. The sludge thickening performance is especially poor at SDWWTP as the WAS entering the gravity thickeners averaged $1.3 \%$ solids during the study period. This further showcases the need for an improved sludge thickening operation or process to improve digestion capacity and reduce heating, pumping, and mixing energy. 
The review of gravity belt thickening technology both in the literature and utility site visits showed promise as a reliable technology with the potential to achieve sustained sludge thickening operations in the target goals for the utility. The probability of meeting or exceeding the $5.5 \%$ thickened sludge goal for solids concentration from the current and even thinner WAS concentrations is sufficient to accept as a model and design parameter. The percent capture target of $95 \%$ or greater is also achievable, but will be a function of polymer consumption at higher dosages than required for either the existing gravity thickeners or thickening centrifuges (MWH, September 2015).

Throughout the pilot studies at SDWWTP and CDWWTP, two plants with identical treatment processes, the results clearly show how site-specific wastewater influent characteristics, wastewater effluent characteristics, and sludge conditions drive the thickening, anaerobic digestion and dewatering process performance. Pilot testing for the design of sludge thickening, anaerobic digestion and sludge dewatering is a crucial step in properly designing and setting plant expectations. The SDWWTP Pilot Phase 1 thickening testing showed that the centrifuge could reliably produce solids at 5-6\% TS and achieve greater than $95 \%$ solids recovery. Testing was conducted using both dry and emulsion polymers. The dry polymer required 5 to $7 \mathrm{lb} / \mathrm{DT}(2.5$ to $3.5 \mathrm{~g} / \mathrm{kg})$ active dosing compared to 1 to $3 \mathrm{lb} / \mathrm{DT}(0.5$ to $1.5 \mathrm{~g} / \mathrm{kg}$ ) based on the emulsion. It was also possible to thicken the sludge to 5 to $6 \%$ TS without the use of polymer, but this required reducing the hydraulic load on the pilot centrifuge by about 50\%, $60-80 \mathrm{gpm}(327-436$ $\mathrm{m}^{3} / \mathrm{d}$ ), to allow solids recovery to remain above $90 \%$. 
The CDWWTP Pilot Phase 1 WAS-only thickening testing showed that the centrifuge, operating on CDWWTP WAS-only, could reliably produce solids at 5-6\% TS and achieve greater than $95 \%$ solids recovery, even without polymer albeit at a reduced hydraulic loading. Testing was conducted using both dry and emulsion polymers. The dry polymer required 3 to $4 \mathrm{lb} / \mathrm{DT}$ ( 1.5 to $2 \mathrm{~g} / \mathrm{kg}$ ) active dosing compared to 0.6 to 3 lb/DT ( 0.3 to $1.5 \mathrm{~g} / \mathrm{kg}$ ) based on the emulsion.

Although the CDWWTP WAS-only sludge was easily able to thicken in the pilot centrifuge, the NDWWTP Primary Sludge and WAS, which was more dilute and exhibited other operationally undersireable characterisitcs, was difficult to handle. After testing the NDWWTP Primary Sludge and WAS alone, stable operation could not be maintained. Initial attempts to blend NDWWTP Primary and WAS with CDWWTP WAS using an in-pipe blending system were also unsuccessful. Because of the difficulties with the NDWWTP Primary and WAS operation, a separate tank was used to allow a buffer for the NDWWTP Primary and WAS and for better control of blending the CDWWTP WAS and NDWWTP Primary and WAS. When the NDWWTP sludge was effectively blended with CDWWTP sludge in the blend tank, stable operation could be maintained in the centrifuge and greater than 5.5\% TS thickened sludge with greater than $95 \%$ solids recovery could be achieved. The dry polymer required 1.5 to $3 \mathrm{lb} / \mathrm{DT}$ ( 0.75 to $1.5 \mathrm{~g} / \mathrm{kg}$ ) active dosing compared to 2 to $3 \mathrm{lb} / \mathrm{DT}$ ( 1 to $1.5 \mathrm{~g} / \mathrm{kg}$ ) based on the emulsion. It is uncertain why the combination of primary sludge and WAS would favor a dry polymer solution versus an emulsion when most other trails showed a better dose response to emulsion polymer. This should be a topic of future study, but does not figure into proposed plans as the plants made the operational decision to select a dry polymer 
based full scale system due to the logistics and cost of shipping and storage of emulsion polymer chemical storage totes. The testing showed that including a blend tank to mix the CDWWTP and NDWWTP sludge along with proper screening and grit removal of primary sludge are important for future operation to be successful. For the purpose of the MBM, the CDWWTP WAS only option was considered with all NDWWTP being a contribution to the CDWWTP plant influent, the condition that is represented in the historical data collected.

A summary of the liquid stream and sludge thickening data collected and analyzed in order to gather input parameters for the MBM is presented below in Table 17 and Table 18. 
Table 17: Liquid stream historical data, calculated results and assumed values for SDWWTP and CDWWTP

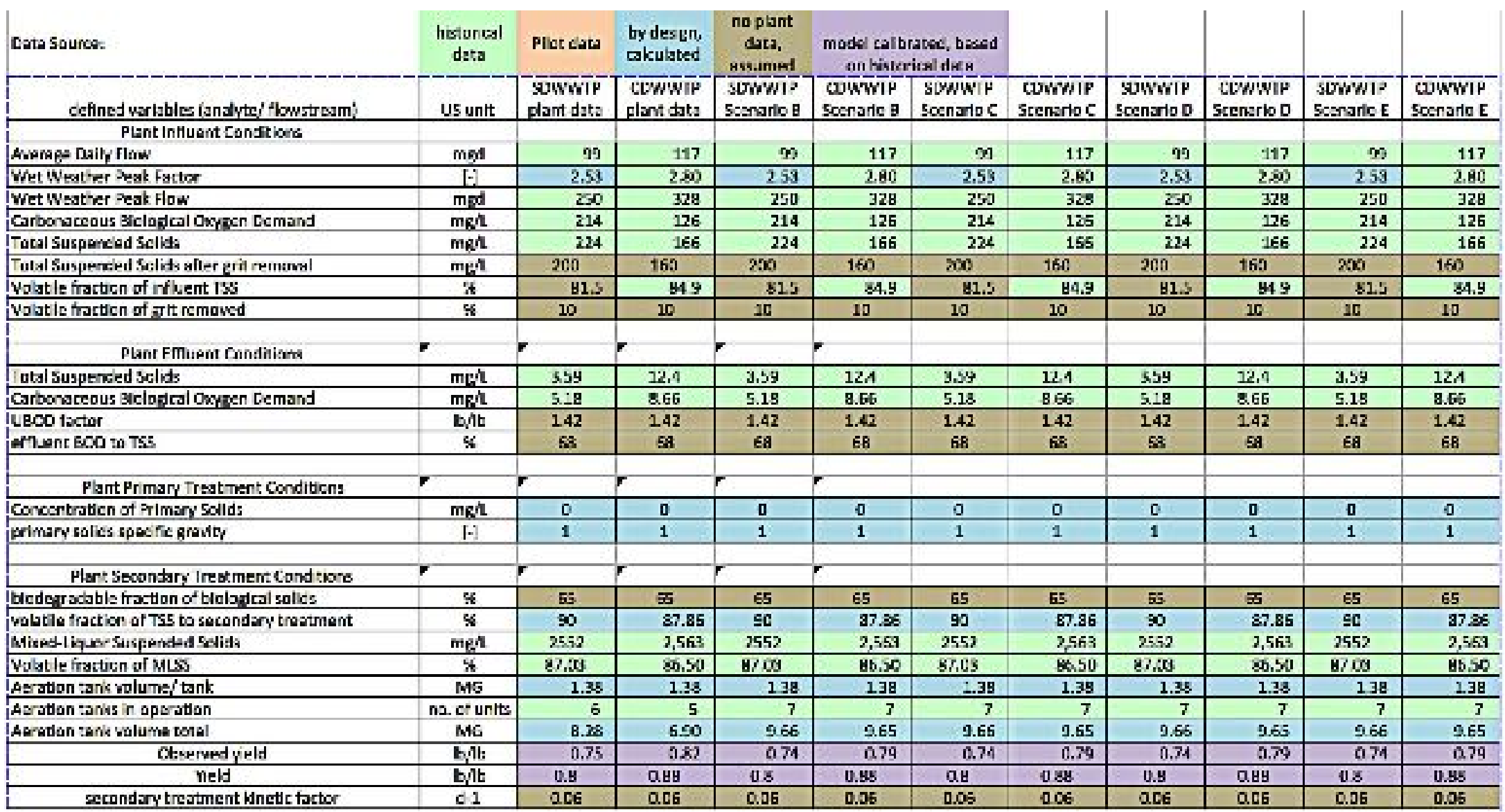


Table 18: Sludge Thickening historical data, pilot measurement, calculated results and assumed values for SDWWTP and CDWWTP

\begin{tabular}{|c|c|c|c|c|c|c|c|c|c|c|c|}
\hline Dan Sourcex & $\begin{array}{l}\text { Mesurikel } \\
\text { Itis }\end{array}$ & Pilot cas & $\begin{array}{l}\text { by desiges } \\
\text { calım iukel }\end{array}$ & 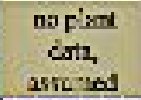 & $\begin{array}{l}\text { model calib } \\
\text { an histn }\end{array}$ & $\begin{array}{l}\text { ratied, bused } \\
\text { real dite }\end{array}$ & & & & & \\
\hline 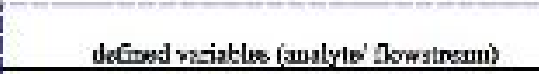 & CS init & $\begin{array}{l}\text { 5DWWTr } \\
\text { plar: diss }\end{array}$ & $\begin{array}{l}\text { CDWWTP } \\
\text { plant data }\end{array}$ & $\begin{array}{l}\text { SnWwTt } \\
\text { Sरxсsriv B }\end{array}$ & $\begin{array}{l}\text { CTWWTT } \\
\text { Scensrio B }\end{array}$ & $\begin{array}{l}\text { SDWWTT } \\
\text { scourio C }\end{array}$ & $\begin{array}{l}\text { CDWWTP } \\
\text { Strensive C }\end{array}$ & $\begin{array}{l}\text { SnWwTP } \\
\text { Sixorriv D }\end{array}$ & $\mid \begin{array}{l}\text { CDWwTP } \\
\text { Scensrio D }\end{array}$ & $\begin{array}{l}\text { 5DWWTR } \\
\text { Swewsio } \mathrm{E}\end{array}$ & $\begin{array}{l}\text { CDWWTP } \\
\text { Stemsrive }\end{array}$ \\
\hline \multicolumn{12}{|l|}{ Plant Sludze I liveksaing Contrisas } \\
\hline ecetoentrotion ar'W:As & megi. & 13,237 & 10,4111 & 13,253 & 30,451 & 13,235 & 211,201 & 13,237 & 10.4111 & 13,1100 & $4,3,00$ \\
\hline 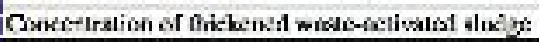 & $\%$ & 2.3 & 3,90 & 231 & 590 & 5.5 & 5,80 & 5.5 & $5.5 n$ & 6.13 & 6,30 \\
\hline Whatile frastion of TQMS & $\%$ & 67.03 & 82.37 & $\mathrm{Bn} .0 \mathrm{C}$ & 82.37 & 57.03 & $\$ 2.37$ & 87.03 & 62.37 & 57.00 & 85.30 \\
\hline 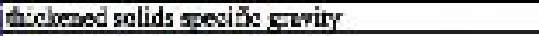 & 日 & 1 & 1 & 1 & 1 & 1 & 1 & 1 & 1 & 1 & $\mathrm{~L}$ \\
\hline 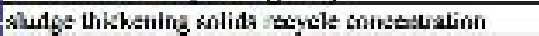 & megl. & 254 & 536 & 254 & 536 & $\mathrm{RSII}$ & GDO & 450 & 100 & son & $\sin 0$ \\
\hline palymer dose & b.DT & 3.40 & 254 & 3.43 & 2.54 & 12 & 12 & 12 & .2 & 2.94 & 3,00 \\
\hline fecrododess_- & palihoog pal & 0.43 & 0 & 11.43 & 0 & 0. & e & 0 & 0 & 0 & 0 \\
\hline
\end{tabular}




\section{Anaerobic Digestion}

5.1 Primary-Secondary Anaerobic Mesophilic Digestion Method at SDWWTP and CDWWTP

The existing biosolids stabilization process used at the subject facilities is anaerobic primary-secondary digestion operated at mesophilic temperatures. This configuration typically involves the primary digester (first tank in series) to be heated and well mixed. The secondary digester (second tank in series) is generally neither heated nor well mixed, as shown in Figure 37 below. The purpose of the secondary digester is for solids separation where the liquid fraction, referred to as supernatant because it is found above the solids fraction and is decanted, is recycled to the activated sludge system and the solids portion continues on, typically to a sludge dewatering process. (WEF MOP No. $85^{\text {th }}$ Edition, 2010; Aranaiz et al., 2006; Appels et al., 2008; MWH Global, 2015)

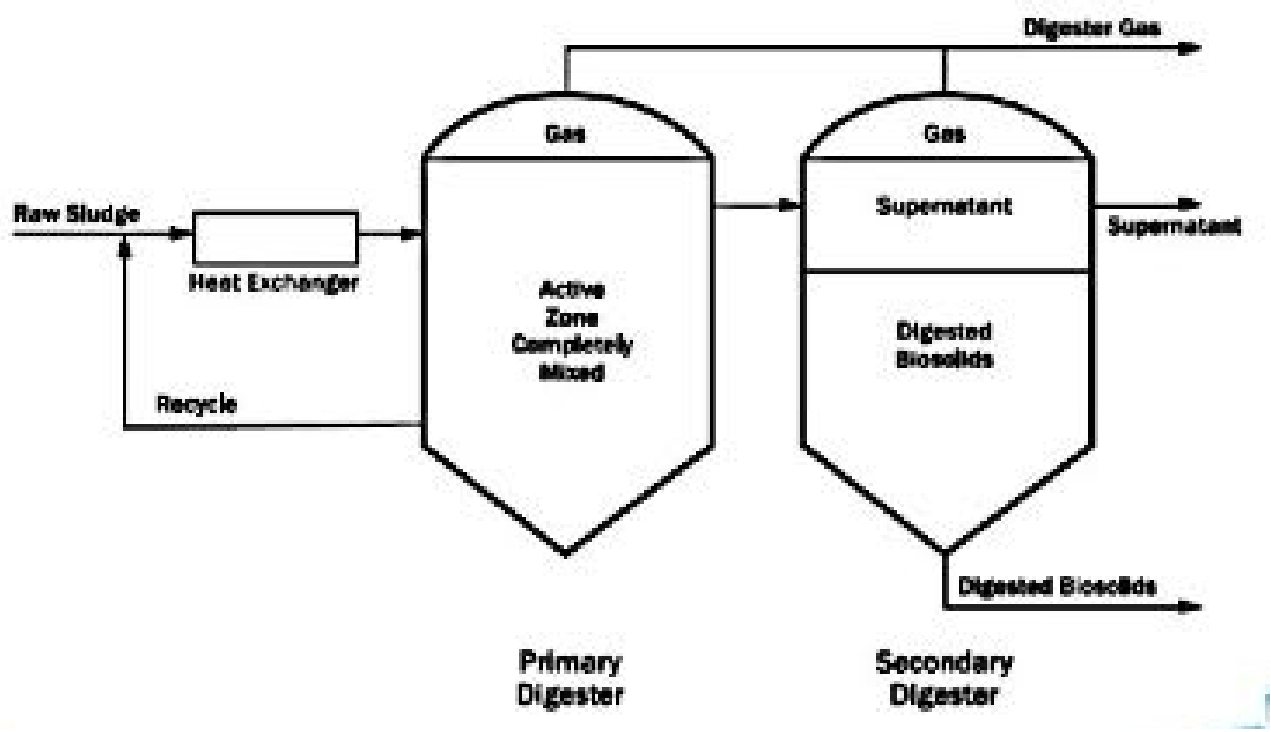

Figure 37: Primary-Secondary digestion system process flow diagram (WEF MOP No. $85^{\text {th }}$ Edition, 2010) 
Both subject plants were designed based on the general primary-secondary anaerobic digestion configuration, seen in Figure 38 below. Other than mixing system failures and minor retrofits, they continue to be operated in this mode with one significant difference. The secondary digesters at SDWWTP and CDWWTP are not used for solidliquid separation, i.e., decanting of supernatant. Removal of supernatant can dramatically increase a digestion system's sludge retention time. Recent research into the processing of the supernatant for nutrient recovery has been promising (Huang et al., 2015, Rodriguez-Garcia et al., 2014, and Yoshino et al., 2003).

However, the practice of decanting supernatant comes with its challenges. Historically removal of supernatant was practiced at SDWWTP and CDWWTP, but over the years this practice has gone out of favor in the utility due to the difficulties in locating the interphase between liquid and solid within the tanks and the frequent occurrence of "flipped" stratification, where the majority of solids are located above the liquid layer, or no discernable phase separation could be found. This is not atypical for anaerobic digesters processing biological solids, i.e., those derived from the secondary treatment process. In fact, the primary-secondary digester configuration is best suited for digestion of primary solids. Under this case the separation between a solids layer and a liquid is very distinct. Conversely the general experience in the industry is that biological solids, as those of the subject plants waste activated sludge, do not separate well and the decanted supernatant contains high solids loading that can be detrimental when retuned directly to secondary treatment. 
Multiple bench scale experiments conducted early on in my career with the utility, circa 2005, on primary and secondary digester sludges at SDWWTP experienced this phenomena of poor stratification and sludge blanket inversion and hence confirmed that discontinuing the practice of extraction of supernatant was prudent (WEF MOP. $85^{\text {th }}$ Edition, 2010).

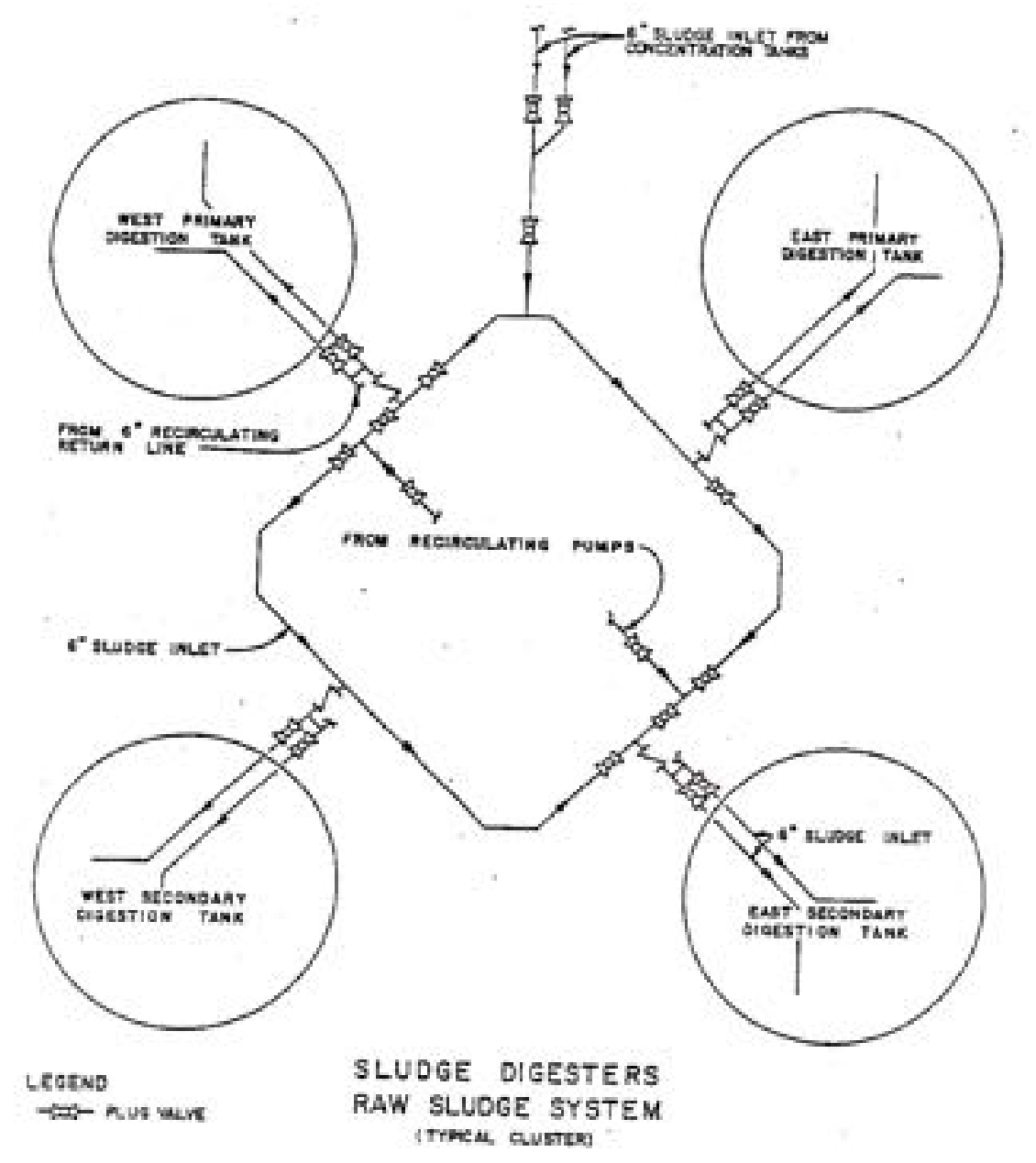

Figure 38: Existing Primary-Secondary Digester Configuration at SDWWTP and CDWWTP (MDWASD, May 2005) 
The State of Florida Department of Environmental Protection (FDEP) does not recognize the SRT within secondary digesters as part of the required SRT to meet Class $\mathrm{B}$ requirement as a process to significantly reduce pathogens (PSRP) as they are not heated and mixed. Therefore, only the SRT within the existing primary digesters can be counted towards achieving the minimum 15-day SRT, a requirement for Class B biosolids, the current target classification for the utility's biosolids (Iranpour et al., 2004).

\section{Digester Heating}

The existing method of sludge heating is based on external tube-in-shell countercurrent heat exchangers with heat conveyed from the co-generation engine cooling system waste heat and only provided for primary digesters. This system is a practical use of the low-grade waste heat from the co-generation engines. Proposed improvements to heating the thickened sludge include a change to tube-in-tube counter current heat exchangers, similar to a 2010 patent-pending design for a sludge heat exchanger, for easier access for cleaning and the use of automated temperature regulation with digital thermocouples and actuated valves to provide for more consistent temperature control (Carlson, 2010). As the proposed digester mode of operation is for single-stage digestion, all digesters will be equipped with heat exchangers. Although, the digesters are designed to be operated at mesophilic temperature ranges, the proposed heat exchangers are sized and selected to provide sufficient heat transfer for the digesters to be capable of achieving thermophilic temperature ranges. 


\section{Digester Mixing}

The existing mixing system differs based on the age of construction of the digesters clusters. Primary digesters constructed before the mid-1990's were equipped with gas lance mixing systems that utilized a ring of 12 lances roughly $2 / 3$ of the distance from the digester center to the rim and a $13^{\text {th }}$ lance in the central dome, as depicted in Figure 39 below. This mixing method was based on the recirculation of digester gas within the digester much like blowing bubbles through a straw in a thick milkshake (Craig et al., 2013). Due to the finite quantity of digester gas held within the digester's headspace, there is only a sufficient quantity of gas to 2 or 3 gas lances at any one time at the design flowrate of $200 \mathrm{cfm}\left(5.7 \mathrm{~m}^{3} / \mathrm{min}\right)$ for the system present at SDWWTP and CDWWTP. This mixing method had several maintenance issues resulting from the rotator mechanism, or actuated valves, to the lances sticking in the open or closed position. The result for gas recirculation at fewer discharge points than designed could lead to uneven digester mixing and tilting of digester covers (MDWASD, March 2005). 


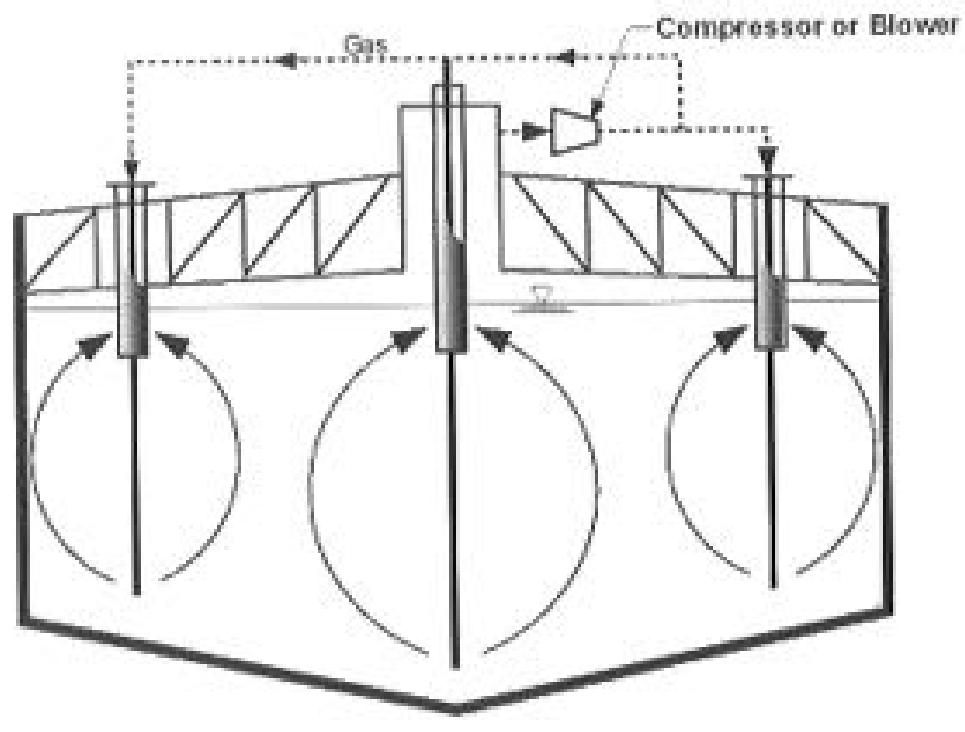

Figure 39: Gas lance mixing system schematic (WEF MOP No. $116^{\text {th }}$ Edition, 2008)

Gas recirculation as a mixing technology was not wholly embraced as an effective mixing method by the utility. In the mid-1990's both new digester clusters and some existing digester cluster were fitted with external draft tube mixers to the primary digesters. The draft tubes extend from just under the base of the floating digester cover to a few feet above the base of the digester at its outer edge. Figure 40 below demonstrates an external draft tube configuration on the right side of the of the example digester. At the SDWWTP and CDWWTP there are 3 draft tubes per digester. The draft tube mixers can be operated in either a top to bottom or bottom to top circulation pattern (Meroney et al., 2009). 


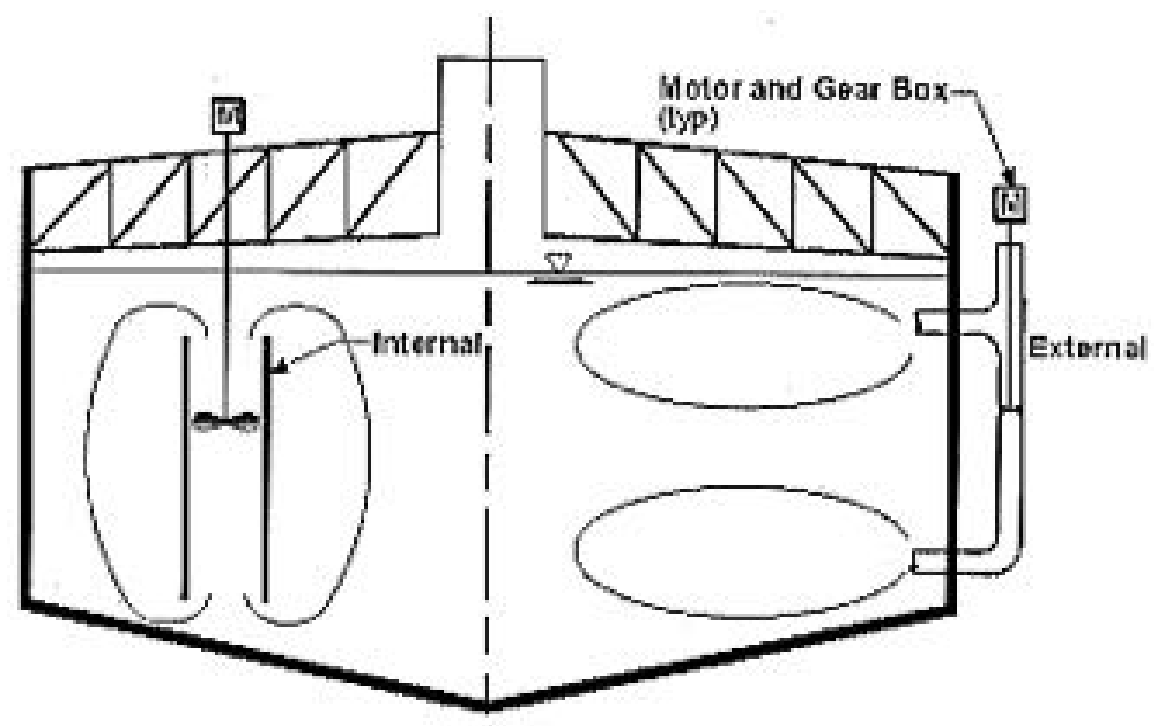

Figure 40: Draft tube mixing schematic (WEF MOP No. $116^{\text {th }}$ Edition, 2008)

Two mixing system were initially proposed as the third generation of digester mixing technologies for the utility. The prime candidate was pump mixing which consisted of a network of pipes and nozzles installed at the bottom of the digester and a recirculating sludge pump located outside the digester at grade, depicted in Figure 41 and Figure 42 below. As envisioned this would be a high energy mixing system with a duty and lag pumps (CH2M, 2015). The system could be operated with both pumps working simultaneously for even higher mixing energy with the intent of resuspending inert solids accumulation on the digester bottom. 


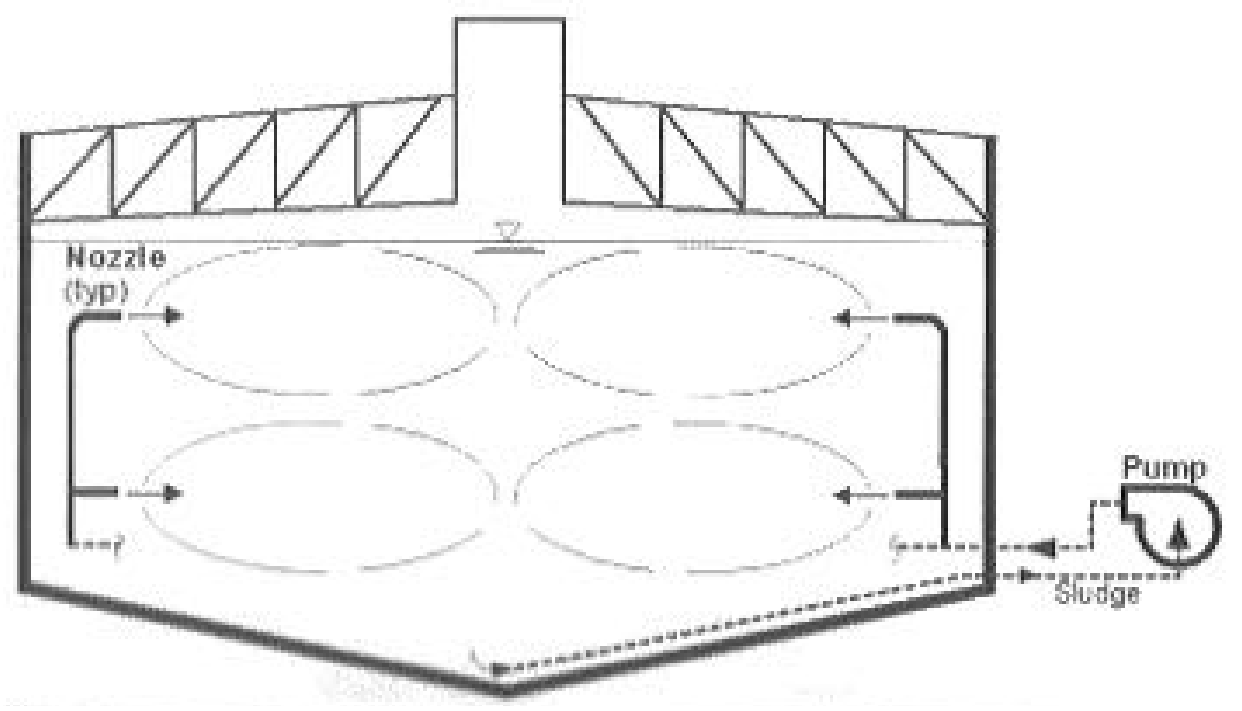

Figure 41: Digester pump mixing system schematic (WEF MOP No. $116^{\text {th }}$ Edition, 2008)

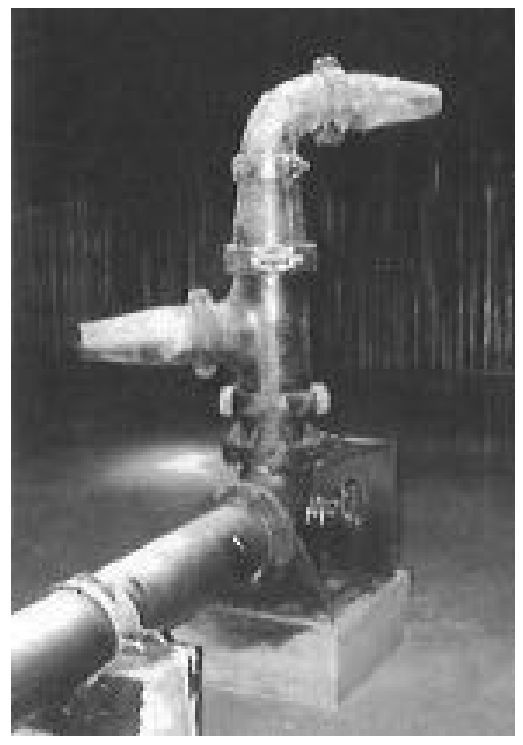

Figure 42: Pump mixing internal digester nozzles (WEF MOP No.11 $6^{\text {th }}$ Edition, 2008) 
The alternate technology, a linear motion mixer (LMM), was a lower energy mixing system that consisted of a central oscillating disc. Figure 43 shows LMMs installed on gas-holder floating-cover digesters not unlike the new floating-cover digesters that will be installed at SDWWTP and CDWWTP. The unique and energy saving feature of this technology revolves around the railroad track style gear assembly shown in Figure 44 (Haughton et al., 2015).

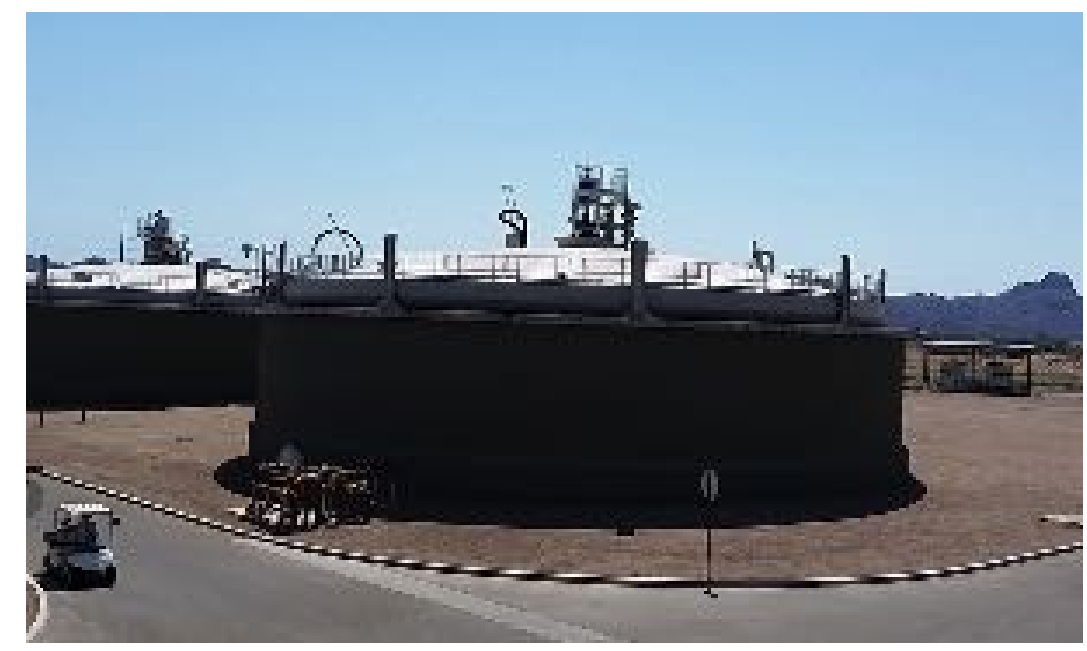

Figure 43: Gas holder digester covers with LMMs, Tres Rios WRF, Tucson, AZ 

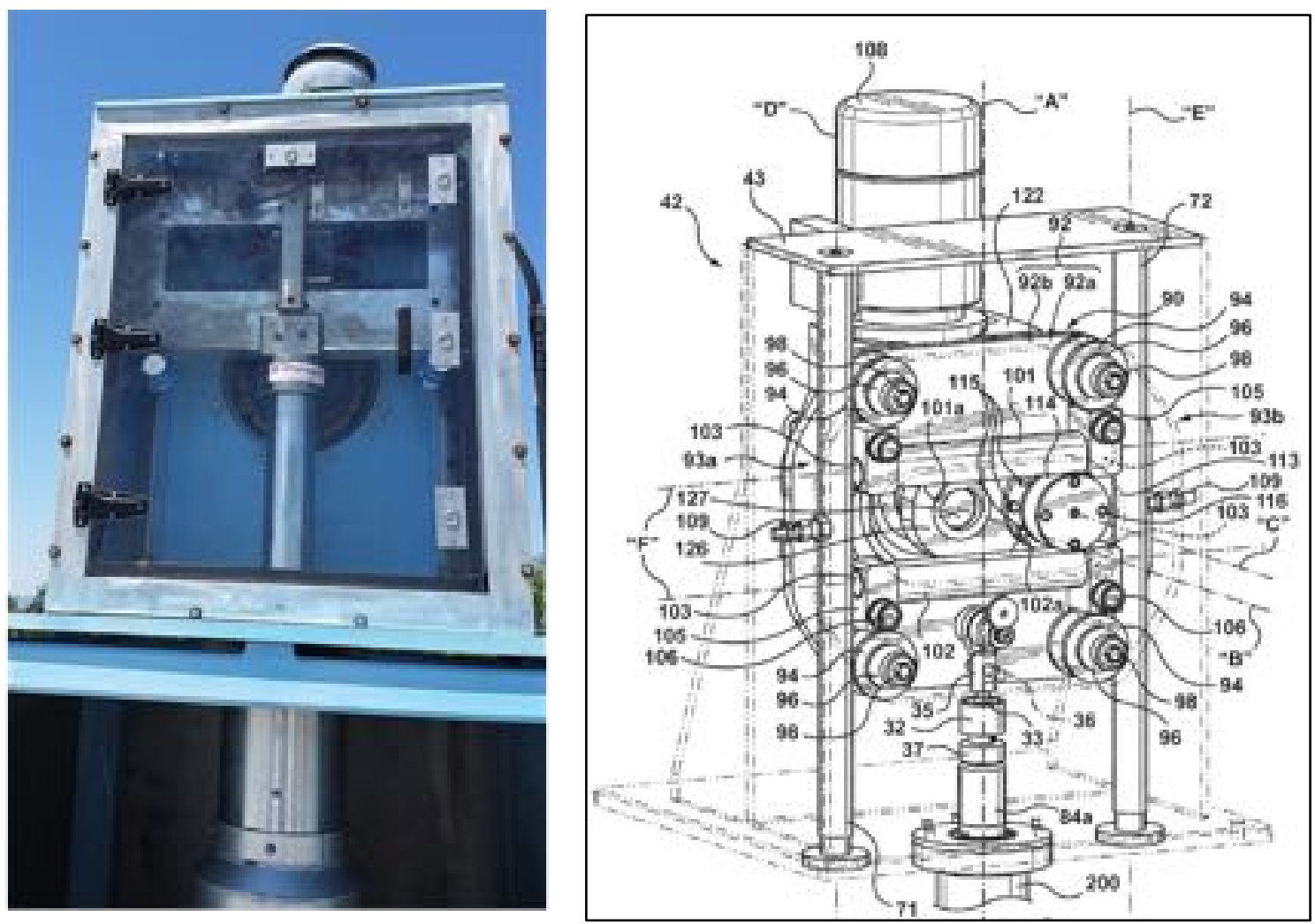

Figure 44: LMM gearbox, Salt Lake City, UT (right), LMM drive assembly diagram (Haughton et al., 2015) (left)

Additionally, I conducted phone surveys of utilities operating both proposed mixing technologies and visiting plants with both system to determine the efficacy of the mixing designs and the level of maintenance required. It was determined through anecdotal evidence that both mixing systems could adequately mix digesters in the solids concentrations being considered in this study, with significantly lower rates of failure than both gas lance and external draft tube mixing, and with satisfactory levels of maintenance requirements. Neither the pump mixing or linear motion mixer were piloted for this study, but capital cost and energy requirements were collected and used to evaluate these technologies versus the existing external draft tube mixing systems. 


\section{Digester covers}

The existing plant digesters are designed with floating digester covers, similar in style to the digester depicted in Figure 45 below. The selection of floating covers is common in the industry and preferred by the utility even though by design they have a lower active volume than fixed cover digester of the same dimensions. The utility did convert one cluster of four digesters to three fixed cover primary digesters and one floating cover secondary digester at the CDWWTP in the mid-1990s. The operation of the fixed cover digester cluster was plagued with problems due to operational challenges tied to external draft-tube mixer failures, excessive foaming of sludge within the fixed cover digesters resulting in poor gravity transfer to the secondary digester, and a few documented fixed cover ruptures of the fixed covers resulting from over pressurization.

Floating covers are not without their own challenges such as rapid-rise upon overfeeding, cover collapse if overdrawn, cover tilting and unintended rotation of covers. All these issues can and have caused floating cover failure at the utility in both acute cases and premature failures due to material compatibility and repetitive stress.

With proper operational oversight, process controls, improved floating cover designs and material selection these potentials for failure can be significantly reduced or eliminated. Scenarios D and E contemplate radial beam single skin carbon steel or stainless steel floating covers (MWH, Feb 2015 and CH2M, 2015). 


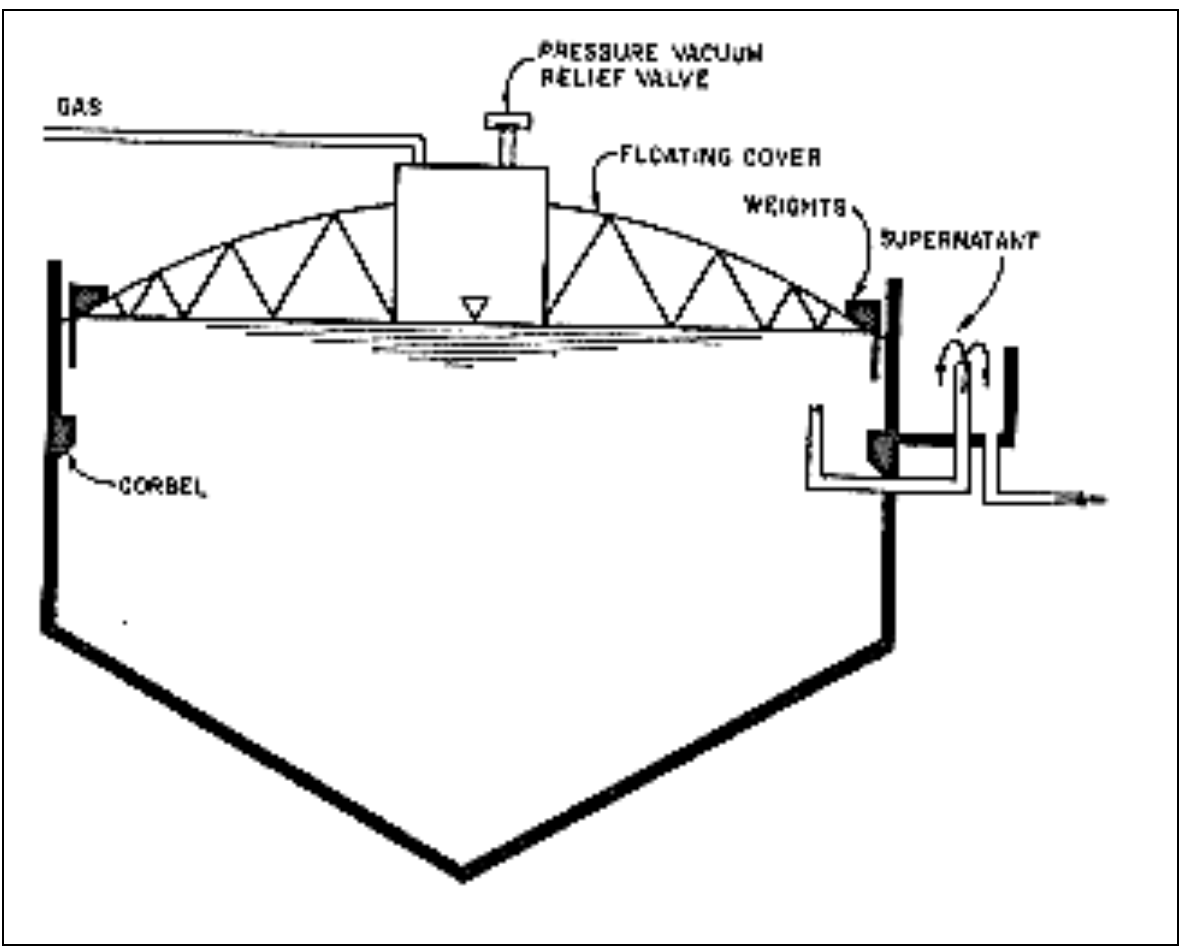
2008)

Figure 45: Digester floating cover schematic (WEF MOP No. 11 6th Edition,

5.2 High-rate single-stage digestion conversion design considerations

The proposed digestion method for scenarios $\mathrm{D}$ and $\mathrm{E}$ is high-rate single-stage anaerobic mesophilic digestion, a digestion system commonly employed in modern plant design, shown in the schematic below (Figure 46). Under the proposed modifications to single-stage, high-rate anaerobic digestion operated at mesophilic temperatures, all digesters would be heated and mixed. This would have a significant impact on digestion capacity, as the SRT of all digesters would be recognized in evaluating the minimum 15day SRT requirement for mesophilic digestion to meet state and federal regulations for Class B biosolids. A minimum of $38 \%$ volatile solids reduction (VSR) is also required to achieve Class B biosolids status. The piloting efforts will demonstrate whether or not this minimum VSR is achievable at higher solids loading with the same mesophilic range (Jenicek et al., 2012). 


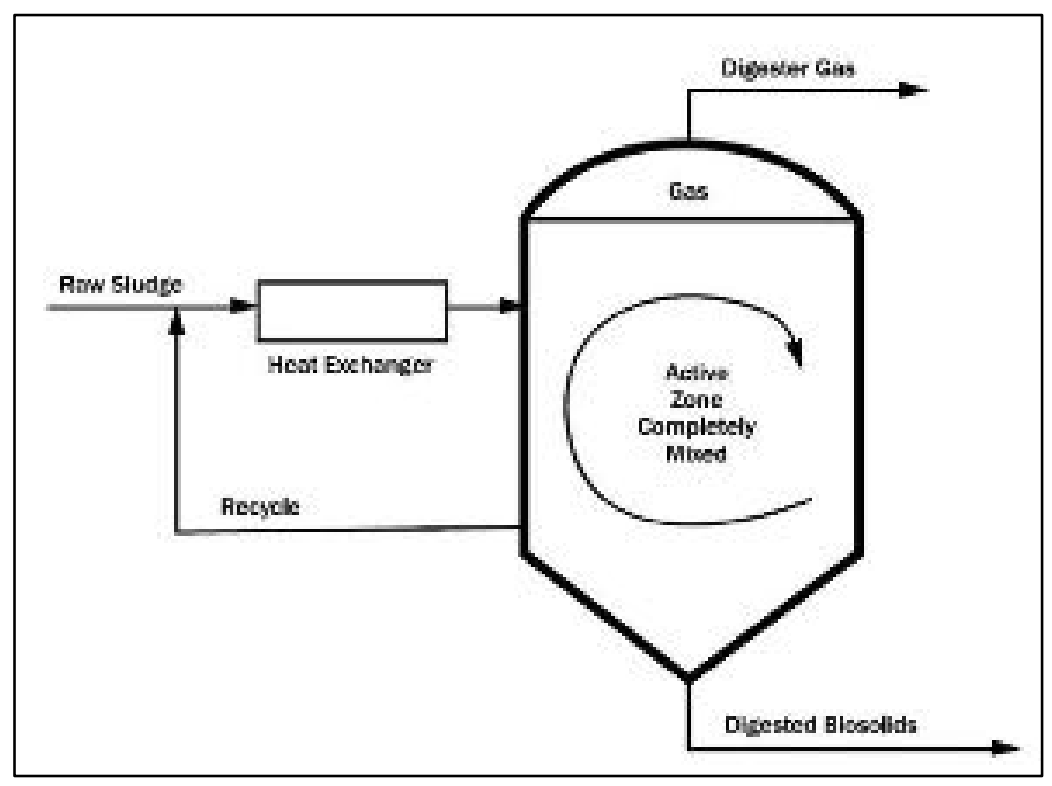

Figure 46: High-rate single-stage digestion process flow diagram (WEF MOP No. $85^{\text {th }}$ Edition, 2010)

Coincidentally, the conversion of all digesters to being heated and mixed highrate digesters allows the utility to operate the digesters as high-rate single-stage anaerobic mesophilic digestion; single-stage anaerobic thermophilic digestion by increasing heat exchanger heat rate of heat transfer; two-stage mesophilic digestion by putting two highrate digesters in series, if the capacity allows; or two-stage temperature phased anaerobic mesophilic-thermophilic digestion by putting to digesters in series and increasing the rate of heat transfer to the second digester in series. As potential benefits, two-stage digestion avoids short-circuiting ensuring pathogen reduction, greater volatile solids destruction, greater gas production, and improved product stability (Schafer et al., 2000). Thermophilic digestion either in single-stage or as part of a two-stage process would further increase the volatile solids reduction, allow for higher solids loading, increase gas production, and reduce the required SRT due to the significantly higher reaction kinetics, 
and produce better sludge dewaterability downstream, but come at a higher heating requirement (Schafer et al., 2002 and Song et al., 2004). The intent of this study and the piloting efforts concentrated on single-stage mesophilic anaerobic digestion as depicted in Figure 46 above, but the flexibility to transition to these other modes of high-rate digestion allows for further study and potentially greater digester performance and biosolids treatment capacity.

\subsection{Model Considerations for the Anaerobic Digestion Systems}

Scenarios B, C, and D have not been pilot tested and no historical data sets exist upon which to provide anaerobic digestion system model inputs for their respective model runs at SDWWTP and CDWWTP. Scenario E does not have this issue as all the proposed modifications for this scenario have been pilot tested at full-scale in one digester at each subject facility under steady-state conditions in order to simulate both SDWWTP and CDWWTP biosolids stabilization under Scenario E conditions. The required model parameters for Scenario E have been sampled and measured during the pilot tests. In order to create realistic model inputs for the hypothetical digestion systems in Scenarios B, C and D a couple of parameters have to be calculated or estimated. 
The fist parameter that will need calculation is the digester solids retention time and the calculation can be found below in Equation 5. This parameter requires calculation for all scenarios as there is uncertainty in historical data and pilot data taking into account the digester flowrate and active digester volume as defined in this study for both SDWWTP and CDWWTP.

\section{Equation 5: Solids Retention Time of Active Digester Volume}

SRT

where, $\mathrm{V}_{\text {ACTIVE DIGESTER(S) }}=$ active digestion volume $\left(\mathrm{MG}\right.$ or $\left.\mathrm{m}^{3}\right)$ $\mathrm{Q}_{\mathrm{DS}}=$ flowrate of digester sludge to dewatering $\left(\mathrm{MGD}\right.$ or $\left.\mathrm{m}^{3} / \mathrm{d}\right)$

The relationship for SRT as described in Equation 5 appears extremely simple, but the derivation for the general case is much more complex and can be seen in Appendix 1: Derived Equations. The streamlined equation above is due to the particular mode of operation currently employed at SDWWTP and CDWWTP. Since the study plants have a primary-secondary digestion system arrangement, but do not decant supernatant from their secondary digesters the denominator of Equation 5 is reduced to being simply the flowrate out of the digester system to the dewatering process. As the proposed process modification to the digestion system is single-phase high-rate anaerobic digestion operating continuously, the simplification of Equation 5 would still hold true.

A further consideration is the active digester volume. Active digester volume within the terms of this study is defined as the volume of SDWWTP and CDWWTP digesters that are mixed and heated. For the purposes of this study this will not include 
secondary digesters in the primary-secondary digestion system that are currently in operation at both SDWWTP and CDWWTP. This will also not include detention time in digesters used as holding tanks prior to dewatering. The lower cone section will be disregarded in the volume calculation due to the consistent buildup of inert solids and struvite precipitation that occurs in all digesters at SDWWTP and CDWWTP between cleaning cycles; a typical issue for anaerobic digestion systems with high magnesium loads and ammonia and phosphorous release (Vadiveloo et al., 2012, Sharp et al., 2013, Abel-Denne et al., 2018, and Johnson et al., 2018). The subtractions of the inactive or simply less active zone in the digester volume is a conservative approach to ensure that the plants are meeting both federal EPA and state FDEP requirements for sludge stabilization. Further studies could be conducted to determine what the rate of digestion is specific to these zones, because this could account for SDWWTP's apparently high VSR as correlated to SRT as estimated by Equation 6 as the plant currently has more "nonactive" secondary-digesters in operation than "active" primary digesters. CDWWTP's SRT estimates would not be as affected in this study due to the fact that the plant currently has significantly more secondary digesters out of service and very low plant influent loading rates, i.e. comparatively low digester solids loading and flowrates.

Once SRT is calculated the Volatile Solids Reduction (VSR) can be estimated for Scenarios B, C, and D; and calculated for Scenario E. Scenario A's VSR was determined by a rolling average mass balance and the Van Kleek method in the plant historical records (Switzenbaum et al., 2003). The data sets were collected, analyzed and observed to have varying levels of accuracy as described in Chapter 2, Historical Data Section. 
VSR is one of the most critical parameters to achieve lower biosolids production in relation to the biological solids generated in the plant. Since VSR is a measure of volatile solids removed from the system, a better way of expressing this is that the factors leading to increasing VSR are critical in reducing biosolids production. Consistent heating, adequate mixing, consistent digester feeding and withdrawal cycles, maintaining target digester feed sludge thickness and digester cleaning to ensure low levels of inert solids accumulation are all good practices to yield the best VSR within the existing digestion system of a plant and should be addressed before considering upgrading or expanding a plant's biosolids treatment processes (Auerbach et al., 2018, and Pfeffer et al., 2018). The estimate for VSR was arrived at for Scenarios B, C and D using Equation 6 and Equation 7. The decision to treat the existing plant digestion system as either standard-rate or highrate for Scenarios B and C was based on the relative VSR to calculated SRTs of Scenario A. The historical plant data for VSR were compared to the calculated SRT values for SDWWTP (48.75\% VSR and 14.7-day SRT) and CDWWTPs (52.52\% VSR and 16.9day SRT). These values were then compared to estimated values for VSR at varying SRTs for both standard-rate and high-rate digesters in Table 19.

\section{Equation 6: Estimate of VSR for standard-rate digesters}

$$
\mathrm{VSR}=30+\frac{\mathrm{SRT}}{2}
$$

where,

VSR $=\quad$ Volatile Solids Reduction (\%)

$\mathrm{SRT}=$ time of digestion $(\mathrm{d})$

(WEF MOP No. $85^{\text {th }}$ Edition, 2010 Eq. 25.5) 


\section{Equation 7: Estimate of VSR for high-rate digesters}

$$
\mathrm{VSR}=13.7 * \ln (\mathrm{SRT})+18.94
$$

where,

$\mathrm{VSR}=\quad$ Volatile Solids Reduction (\%)

SRT $=$ design SRT $(d)$

(WEF MOP No. $85^{\text {th }}$ Edition, 2010 Eq. 25.6)

Table 19: Comparison of estimated VSR for standard and high rate digesters

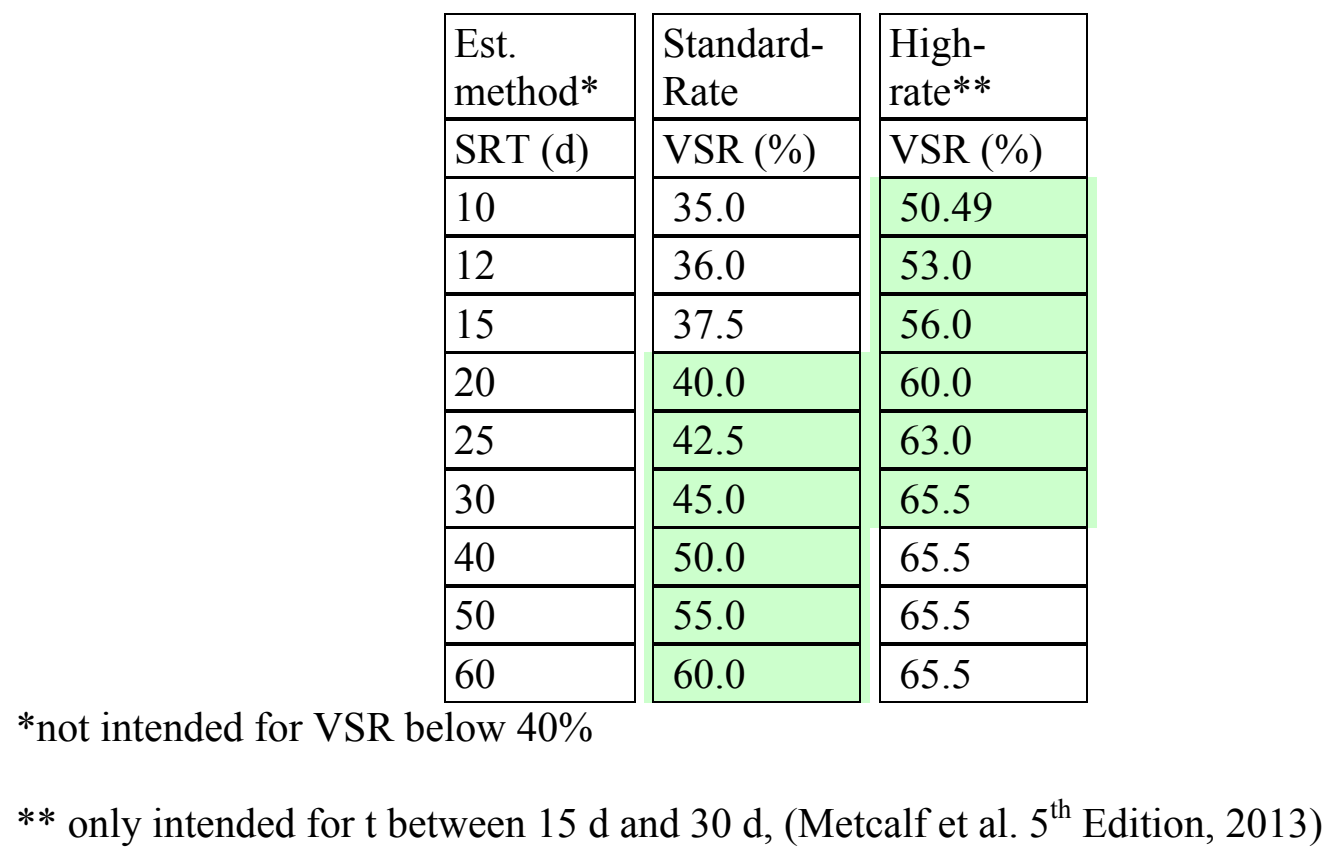

As can be noted in Table 22 at the end of the chapter, the values of the existing plant performance more closely approximate the high-rate anaerobic digestion system VSR estimate. This could be a result of either the primary digester being sufficiently mixed and heated to behave as high-rate digesters or the secondary digesters having a significant enough contribution to VSR that the assumption to neglect the volume was 
not a wholly sound assumption. Although the historical data values are higher than the corresponding standard-rate VSRs, the historical values are not above the VSR corresponding to the VSR estimate for a high-rate system. It would stand to reason that the primary digesters being heated and mixed, even if not to optimal levels, would in theory behave as high-rate digesters. For this reason, the high-rate digester system equation will be used. To account for a less that optimal VSR to SRT relationship in the actual digester performance for SDWWTP and CDWWTP compared to Equation 7 an adjustment to the equations slope ' $a$ ' and intercept ' $b$ ' will be employed to better simulate the VSR to SRT relationship for SDWWTP and CDWWTP individually. As two separate historical data sets were not analyzed for each plant the first order derivative of Equation 7 is needed to determine the slope ' $a$ ' and then the intercept ' $b$ ' for the modified plant specific incarnation of Equation 7: Estimate of VSR for high-rate digesters.

$$
\mathrm{VSR}=\mathrm{a}^{*} \ln (\mathrm{SRT})+\mathrm{b}
$$

VSR and SRT were previously defined and ' $a$ ' and ' $b$ ' are the coefficients of the pseudo-high-rate digestion curve that need to be determined. To find the slope of the equation the first derivate must be calculated.

$\operatorname{VSR}^{\prime}=a / x$ is the slope of the curve and is unknown as it is still in terms of ' $a$ ' 
Therefore, $\mathrm{VSR}=(\mathrm{a} / \mathrm{x}) * \ln (\mathrm{SRT})+\mathrm{b}$, but the equation is still no closer to being solved. Through substitution ' $b$ ' can be defined in term of 'a', $\mathrm{SRT}_{0}$ and $\mathrm{VSR}_{0}$. As SRT is a function of natural $\log$, a $y$-intercept is not possible because $\ln (0)$ cannot mathematically exist. The equation remains unsolved. The most reasonable assumption is to accept the assumption that the historical data match the high-rate digester curve (Widder $2^{\text {nd }}$ Edition, 1961).

An inability to find the slope through and intercept by the above method meant another means of approximating a site-specific version of Equation 7 was required. Although not the most elegant of solutions, the intercept ' $b$ ' was varied while keeping the slope of the original Equation 7, a =13.7, to maintain the shape of the curve utilizing the VSR and SRT coordinates for SDWWTP and CDWWTP, presented in Table 22. This yielded the following equations for SDWWTP, Equation 8, and CDWWTP, Equation 9.

\section{Equation 8: Modified high-rate VSR estimate for SDWWTP}

$$
\mathrm{VSR}=13.7 \ln (\mathrm{SRT})+11.93
$$

The highest estimated VSR for the SDWWTP will be capped at 50\%, due to the fact that the plant only currently only processes WAS and that pilot testing of the highrate condition at noted later in Table 22 did not exceed $50 \%$ VSR. The co-digestion of Fats, Oils, and Grease (FOG) could substantially increase the total VSR potential (CH2M, 2017).

\section{Equation 9: Modified high-rate VSR estimate for CDWWTP}

$$
\mathrm{VSR}=13.7 \ln (\mathrm{SRT})+13.80
$$

Once the VSR has been estimated, the digested sludge solid concentration can be calculated via Equation 10, the derivation of which is presented in Appendix 1: Derived 
Equations. This is the final model input required for the anaerobic digestion component of the mass balance model in order to run Scenarios B, C, and D.

\section{Equation 10: Digested Sludge Solids Concentration, from an Estimated VSR}

$$
\mathrm{X}_{\mathrm{TSS}, \mathrm{DS}}=\mathrm{X}_{\mathrm{TSS}, \mathrm{TWAS}}\left(1-\mathrm{VSR} * \% \mathrm{~V}_{\mathrm{TWAS}}\right)
$$

where,

$$
\begin{aligned}
& \mathrm{X}_{\mathrm{TSS}, \mathrm{DS}}=\quad \text { solids concentration of digested sludge }\left(\mathrm{mg} / \mathrm{L} \mathrm{or} \mathrm{g} / \mathrm{m}^{3}\right) \\
& \text { VSR }=\quad \text { volatile solids reduction (\%) [previously estimated] } \\
& \% \mathrm{~V}_{\text {TWAS }} \quad=\quad \text { volatile fraction of thickened sludge }(\%) \\
& \mathrm{X}_{\text {TSS,TWAS }}=\quad \text { solids concentration of thickened sludge }\left(\mathrm{mg} / \mathrm{L} \text { or } \mathrm{g} / \mathrm{m}^{3}\right)
\end{aligned}
$$

Based on equations for a VSR estimate and digested sludge solids concentration, the models for Scenario B can be run. The results of Scenario B are presented in Table 20 and Table 21 for the SDWWTP and CDWWTP, respectively, and not surprisingly were very similar to the results for Scenario A. As the only real improvement in Scenario B was the increase in digester detention time based on all digesters being functional, the only factor present to reduce biosolids production would be an increase in volatile solids reduction (VSR) based on fully functional digesters. 
Table 20: SDWWTP Scenario B MBM brief results summary

\begin{tabular}{|l|l|l|l|l|l|}
\hline & SI unit & $\begin{array}{l}\text { model } \\
\text { result }\end{array}$ & $\begin{array}{l}\text { design } \\
\text { design } \\
\text { value* }\end{array}$ & $\begin{array}{l}\text { value } \\
\text { (US) }\end{array}$ & US unit \\
\hline WAS flow & $\mathrm{m}^{3} / \mathrm{d}$ & $5,087.6$ & 5,818 & 1,067 & $\mathrm{gpm}$ \\
\hline TWAS (Digester feed) flow & $\mathrm{m}^{3} / \mathrm{d}$ & $3,125.4$ & 2,317 & 425 & $\mathrm{gpm}$ \\
\hline $\begin{array}{l}\text { Digester sludge (dewatering } \\
\text { feed) flow }\end{array}$ & $\mathrm{m}^{3} / \mathrm{d}$ & $3,125.4$ & 2,247 & 412 & $\mathrm{gpm}$ \\
\hline $\begin{array}{l}\text { Dewatered Biosolids (dry wt.) } \\
\text { Dewatered Biosolids (wet }\end{array}$ & $\mathrm{MT} / \mathrm{yr}$ & 12,222 & 12,222 & $13,469.07$ & tons/yr. \\
\hline $\begin{array}{l}\text { wt.) } \\
\text { MT }\end{array}$ & $\mathrm{MT} / \mathrm{yr}$ & 75,821 & 75,821 & $83,555.02$ & tons/yr. \\
\hline
\end{tabular}

* flow correction factor determined in Scenario A applied

Table 21: CDWWTP Scenario B MBM brief results summary

\begin{tabular}{|l|l|l|l|l|l|}
\hline & SI unit & $\begin{array}{l}\text { model } \\
\text { result }\end{array}$ & $\begin{array}{l}\text { design } \\
\text { value } \\
\text { (SI) }\end{array}$ & $\begin{array}{l}\text { design } \\
\text { value } \\
\text { (US) }\end{array}$ & US unit \\
\hline WAS flow & $\mathrm{m}^{3} / \mathrm{d}$ & 4,265 & 10,245 & 1,879 & $\mathrm{gpm}$ \\
\hline TWAS (Digester feed) flow & $\mathrm{m}^{3} / \mathrm{d}$ & 1,154 & 2,195 & 403 & $\mathrm{gpm}$ \\
\hline $\begin{array}{l}\text { Digester sludge (dewatering } \\
\text { feed) flow }\end{array}$ & $\mathrm{m}^{3} / \mathrm{d}$ & 1,116 & 2,312 & 424 & $\mathrm{gpm}$ \\
\hline \begin{tabular}{l} 
Dewatered Biosolids (dry wt.) \\
\hline $\begin{array}{l}\text { Dewatered Biosolids (wet } \\
\text { wt.) }\end{array}$
\end{tabular} & $\mathrm{MT} / \mathrm{yr}$ & 9,519 & 9,519 & 10,490 & tons/yr. \\
\hline
\end{tabular}

* flow correction factor determined in Scenario A applied

The unusually high VSRs when correlated to the low SRTs of the current SDWWTP digesters, present a design challenge. With a theoretical 50\% VSR cap as a reasonable assumption under conventional digestion methods for WAS only sludge feed and little additional detention time that can be gained based on the number of existing digesters and current digestion method for the SDWWTP, there is simply not much room for biosolids treatment performance improvement while maintain the existing process 
technologies and operational methodologies (CH2M, 2017). An in depth investigation into the existing systems digestion kinetics, such as the extensive effort of the IWA Anaerobic Digestion Modeling Task Group, could reveal if certain properties of the feed sludge, anaerobic microbial population or simply less than perfect sampling technique are factors in the seeming stellar VSR performance of SDWWTP's existing low SRT digestion system (Batstone et al., 2002, Blumensaat et al., 2005 and Fezzani et al., 2008). For the purposes of this study, which has a wide scope, analysis of historical data, piloting of a complete high-rate single stage system and an estimate of all points in between will suffice at this stage.

As the pilot testing for high-rate digestion at steady-state provides a more accurate set of digester performance parameters, Scenario E will forego estimation of the VSR, for a calculated value determined using Equation 11, the derivation of which is located in Appendix 1: Derived Equations.

Equation 11: Derived Equation for VSR of a known system

Where,

$$
\mathrm{VSR}=1-\frac{\% \mathrm{~V}_{\mathrm{DS}} * \mathrm{X}_{\mathrm{TSS}, \mathrm{DS}}}{\% \mathrm{~V}_{\mathrm{TWAS}} * \mathrm{X}_{\mathrm{TSS}, \mathrm{TWAS}}}
$$

$$
\begin{aligned}
& \% \mathrm{~V}_{\mathrm{DS}}=\quad \text { volatile fraction of digested sludge }(\%) \\
& \mathrm{X}_{\mathrm{TSS}, \mathrm{DS}}=\quad \text { solids concentration of digested sludge }\left(\mathrm{mg} / \mathrm{L} \text { or } \mathrm{g} / \mathrm{m}^{3}\right) \\
& \% \mathrm{~V}_{\mathrm{TWAS}} \quad=\quad \text { volatile fraction of thickened sludge }(\%) \\
& \mathrm{X}_{\text {TSS,TWAS }}=\quad \text { solids concentration of thickened sludge }\left(\mathrm{mg} / \mathrm{L} \text { or } \mathrm{g} / \mathrm{m}^{3}\right)
\end{aligned}
$$


All independent variables in Equation 11 have been measured as part of the pilot test during steady-state operations. It is key to run any digestion pilot test for a period of time longer than the digester SRT, preferably 3 times longer that the digester SRT to ensure steady-state. As the target SRT was 30 days, a 3 SRT period of three months for continually feeding and testing was the target for thickening pilot and digester pilot operation at consistent flows and loads. Unfortunately, due to challenges within the pilot test due to feed sludge conditions, equipment malfunctions, and operational challenges in both plants, a true 3 times target SRT steady-state period was not sustained. Instead pilot tests ran for durations of 2 and 1.5 digester target SRTs, i.e. two and 1.5 months, at SDWWTP and CDWWTP, respectively, during the digestion portion of the pilot tests, and the data reflect those limitations. Due to the operational effort and expense of a fullscale pilot at the magnitude of SDWWTP and CDWWTP, a second piloting effort would not be feasible at this time. The pilot effort, challenges, achievements, and lessons learned are presented below.

5.4 SDWWTP Pilot Phase 2-continuous thickening pilot operation and simulated high-rate single stage mesophilic digestion

During Pilot Phase 2 operation, mechanically thickened sludge was fed to Digester 9 to simulate future high-rate digestion conditions and to increase the solids content of the digested biosolids for the Pilot Phase 3 dewatering pilot operations (Figure 47). The feed to the thickening pilot was switched to gravity thickened sludge to increase solids loading through the thickener to increase Digester 9's turnover rate transitioning from an internal sludge concentration of $1.3 \%$ total solids to $3.5 \%$ total solids. This 
mode of operation started in December 2015, continued through March 2016, and remained running in parallel with the dewatering piloting conducted in Pilot Phase 3. During Pilot Phase 2 operation, the thickening centrifuge was fed approximately 100 to $150 \mathrm{gpm}(379$ to $568 \mathrm{~L} / \mathrm{min}$ ) of sludge from the gravity concentrator and operated continuously. Figure 48 summarizes the centrifuge performance during the Pilot Phase 2 operation. On March 21, 2016 the feed was switched back to the unthickened WAS when the additional thickening testing using dry polymer was conducted.

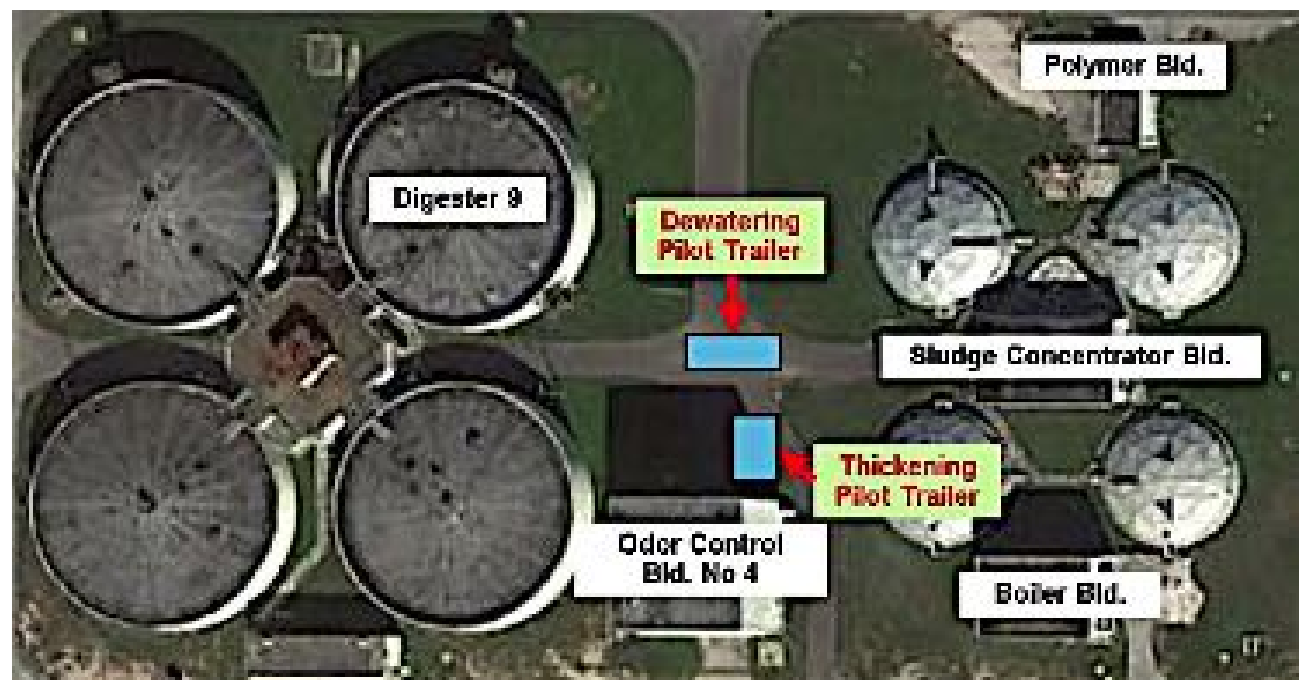

Figure 47: SDWWTP Pilot Phase 2 site layout

During Pilot Phase 2 operation, the feed from the gravity concentrators averaged $2.2 \% \mathrm{TS}$, and ranged between 1 to $3 \%$ TS. The thickened solids content averaged $6.2 \%$ TS, but fluctuated between 5 to 7\% TS. During the Pilot Phase 1 operation, the hydraulic pressures inside the thickening centrifuge increased overtime, likely due to grit building up in the thickening centrifuge. In order to mitigate this, the thickening centrifuge was operated at a lower speed with higher polymer doses for most of the Pilot Phase 2 operation which allowed for the unit to operate continuously. 


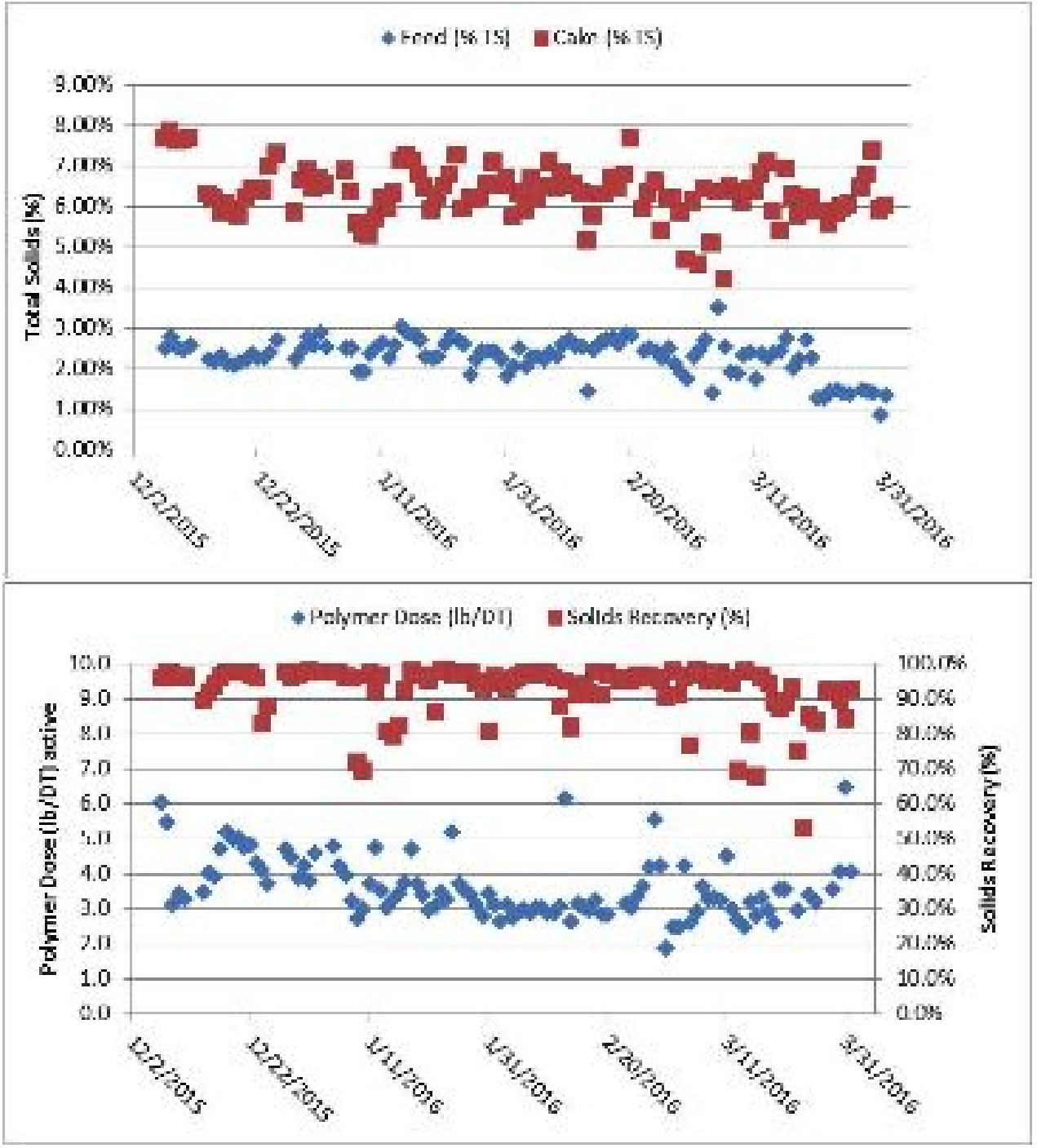

Figure 48: Pilot Phase 2 Continuous Thickening Operation 
Throughout Pilot Phase 2 operation, the solids content in Digester 9 was increased to approximately $3.5 \%$ TS by use of the thickening centrifuge to control the sludge feed concentration and flow rate. In comparison during this period, the other operational digesters operated at 1 to $2 \%$ TS as shown in Figure 49.

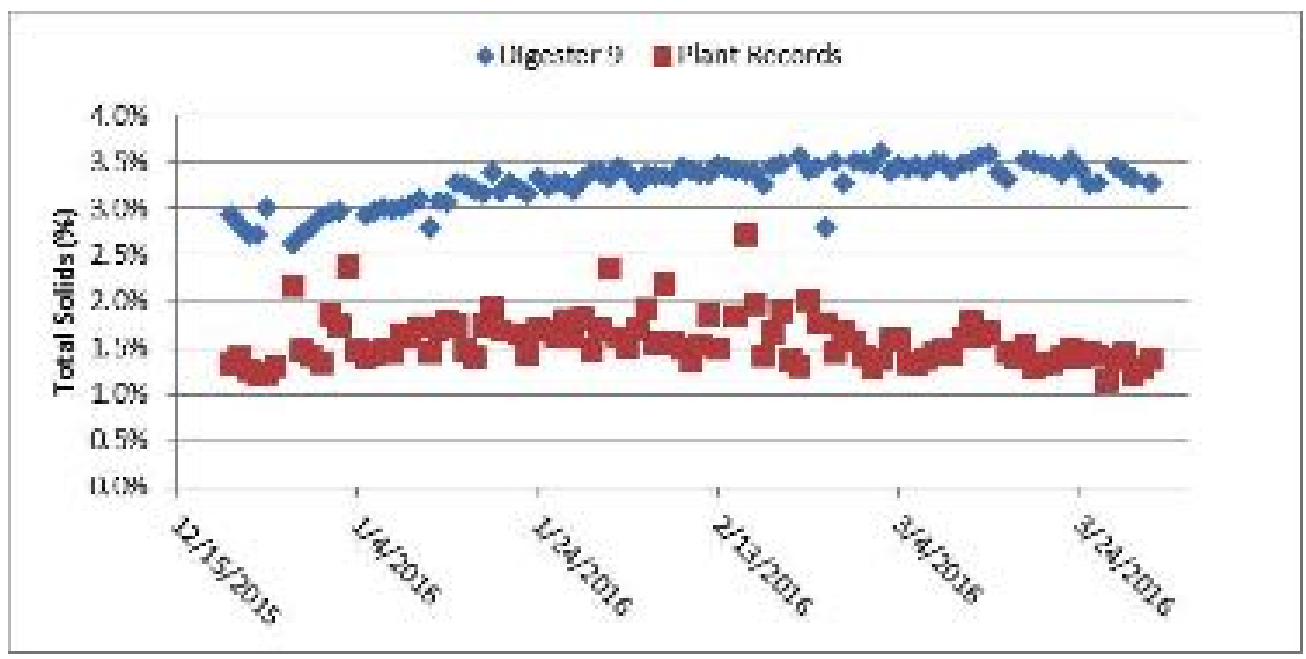

Figure 49: Digester Concentration Comparison, Digester 9 vs. Plant Records

During the Pilot Phase 2 operation period, Digester 9 achieved approximately 49\% VSR, as calculated using Equation 11, with raw undigested sludge averaging $87 \%$ VS and digested biosolids averaging 77\% VS. Gas production averaged $16 \mathrm{ft}^{3} / \mathrm{lb}$ VSR (1 $\mathrm{m}^{3} / \mathrm{kg}$ VSR) throughout the four months of operation. The Solids Retention Time (SRT) in the digesters averaged a little more than 30 days and solids loading rate (SLR) averaged $0.11 \mathrm{lb} \mathrm{VS} / \mathrm{ft}^{3}-\mathrm{d}\left(1.8 \mathrm{~kg} \mathrm{VS} / \mathrm{m}^{3}\right)$. When comparing the pilot data to the plant's other digesters, the volatile solids feed matched the plant records, but the average digester SRT in plant records for the Pilot Phase 2 period were closer to 20 days and a $42 \%$ VSR. 
Thus, it appears that operating digestion with longer SRT and higher thickened sludge increased the VSR, reducing the biosolids for downstream dewatering and beneficial use.

It was desired to have Digester 9 at a new steady-state before starting the dewatering pilot test, so dewatering was targeted to start after the subject digester had been operating for approximately 3 digester SRT's, i.e., three months, had been achieved. Figure 50 confirms that the dewatering performance testing was conducted after three digester turnovers were achieved in Digester 9. The data in Figure 50 showed that the concentration in Digester 9 reached a consistent value of approximately 3.5\% TS by March 2016 (Goss et al., 2017).

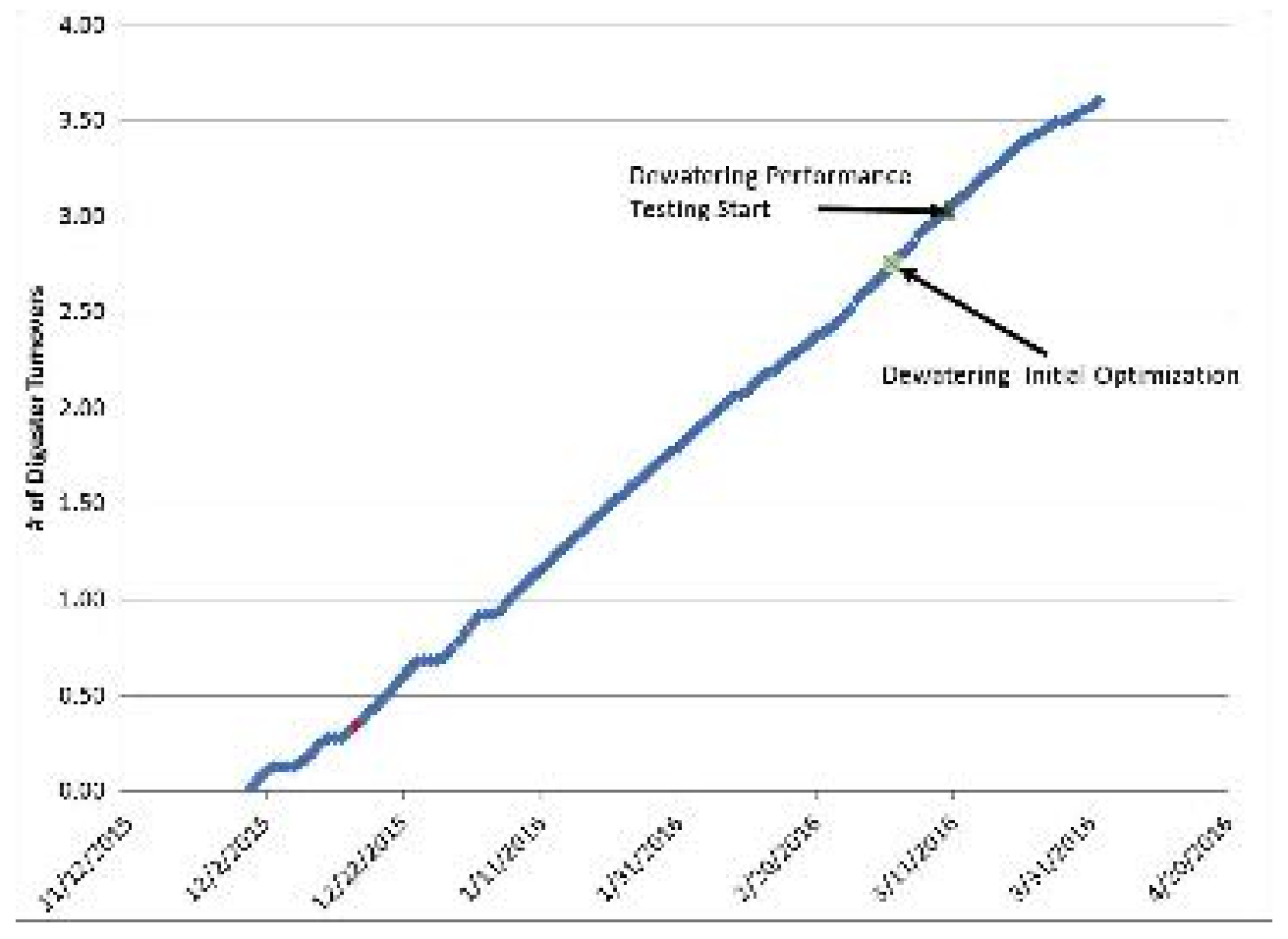

Figure 50: Digester 9 Turnover Progress during Pilot Phase 2 Operation 


\subsection{CDWWTP Pilot Phase 2 - continuous thickening pilot operation and simulated}

high-rate single stage mesophilic digestion

Centrifuge thickened sludge was fed to Plant 2, Cluster 1, Digester 3 (the test digester) to simulate future high rate single stage mesophilic anaerobic digestion conditions and to increase the solids content of the digested biosolids for the dewatering pilot operations (Figure 51). Near continuous operation began in mid-June 2016 and was maintained through mid-August 2016. Performance testing on CDWWTP sludge, NDWWTP sludge, or a combination of both continued to be conducted during normal workday hours. The operation switched to CDWWTP WAS-only for overnight and weekend operations. A manifold was set up to allow switching between the NDWWTP and CDWWTP sludges and was also used initially to blend the sludges. Mechanical problems with the unit, specifically the thickened cake pump, limited the throughput and the operation time.

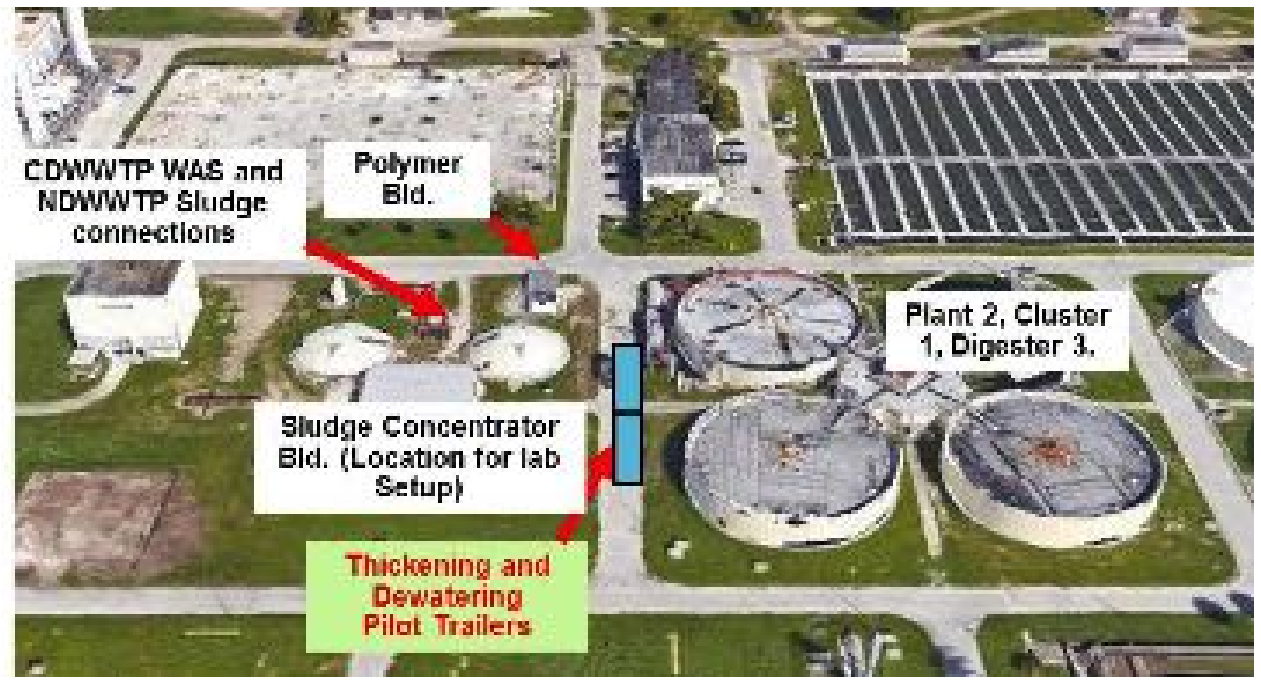

Figure 51: CDWWTP Pilot Phase 2 site layout 
For the stable period shown in Figure 52, the thickened solids content to the digester averaged $6.3 \%$ TS with a $2.3 \mathrm{lb} / \mathrm{DT}(1.15 \mathrm{~g} / \mathrm{kg})$ active polymer dose and the volatile solids content of the raw sludge being fed to the digester averaged $86 \%$ VS. The solids content in the test digester was increased to approximately 2.8 to $3.0 \% \mathrm{TS}$ and a volatile solids content in the digested sludge of $71 \%$. For comparison, the rest of the digesters operating at CDWWTP were being fed gravity thickened sludge at approximately $3.8 \%$ TS with a volatile solids content of $83 \%$ VS and the other operational digesters operated at an internal solids content averaged 2.2\% TS. The Plant 2, Digester 3, the test digester, VSR estimations during this period ranged from $50 \%$ to greater than $70 \%$ while the digester was approaching a steady state (Moncholi et al., 2018).

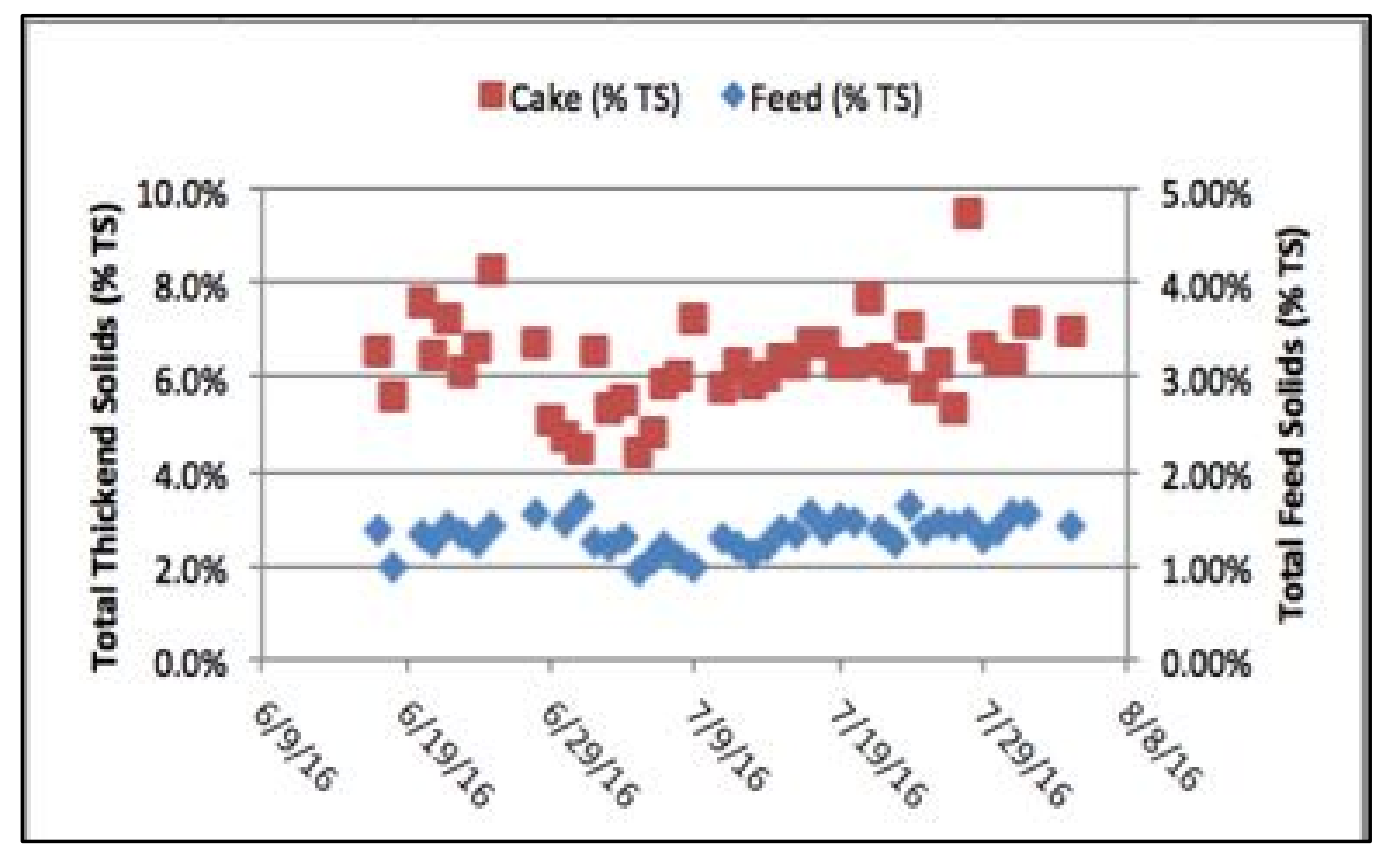




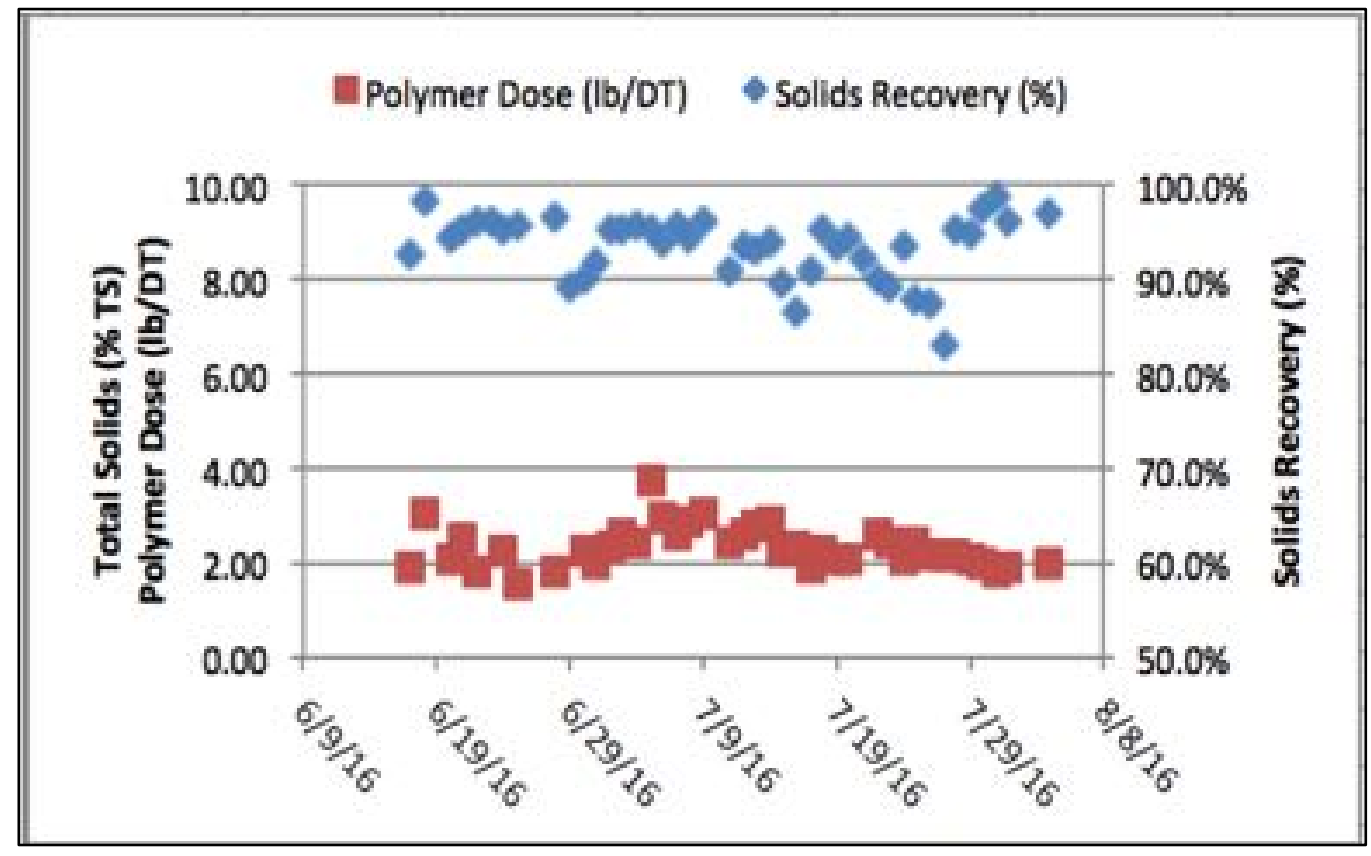

Figure 52: CDWWTP Pilot Phase 2 Continuous Thickening Operation

5.6 Chapter Summary: Discussion of results, impact of pilot tests on model inputs and other model assumptions for anaerobic digestion

Based on the historical plant data, the SDWWTP and CDWWTP have good VSRs in relation to their active digester volume and SRTs during the study period, even though operating at such low SRTs for extended periods of time is not recommended for primary-secondary anaerobic digestion systems (WEF MOP No. $116^{\text {th }}$ Edition, 2008). It should be noted that as the study facilities currently operate as primary-secondary digestion systems, the active volume does not include either the secondary digesters or post-digestion holding tanks in SRT calculations. Therefore, the total number of digesters in operation, being monitored, and maintained is at least double that of a highrate single-stage digestion system for the same credited SRT. That is a factor to consider when weighing the options of how many digesters to rehabilitate or construct new to meet existing and future solids loadings. 
During SDWWTP Pilot Phase 2, the solids content in Digester 9 was increased from approximately $2 \%$ to approximately 3.4 to $3.5 \%$ TS and Digester 9 , the test digester, achieved a 49\% VSR with a digester SRT of approximately 30 days. During the same period of time, the other digesters at the plant received gravity concentrated sludge at $1.5 \%$ to $3 \%$ TS and averaged approximately $42 \%$ VSR with a digester SRT of approximately 20 days. The increase in VSR was likely due to the longer SRT and higher solids concentration.

The near continuous operation of CDWWTP Pilot Phase 2 began in mid-June 2016 and the team maintained continuous operation through mid-August 2016, but mechanical problems with the unit, specifically the thickened WAS cake pump, limited the throughput and the operation time. For the stable period, the thickened solids content to the digester averaged $6.3 \%$ TS with a $2.3 \mathrm{lb} / \mathrm{DT}(1.15 \mathrm{~g} / \mathrm{kg})$ active polymer dose and the volatile solids content of the raw sludge being fed to the digester averaged $86 \%$ VS. The solids content in the test digester was increased to approximately $2.8-3.0 \%$ TS. For comparison, the rest of the digesters operating at CDWWTP were being fed gravity thickened sludge at about $3.8 \%$ TS with a volatile solids content of $83 \% \mathrm{VS}$ and the other operational digesters operated at an average of $2.2 \%$ TS. The VSR estimates for the CDWWTP test digester during this period ranged from $50 \%$ to over $70 \%$ while the digester was approaching a steady state.

One positive takeaway from analysis of both the historical data and pilot testing is that although the design target for high-rate digestion has been set for a 30 day SRT, this is highly conservative based on the remarkably high VSRs being achieved at a 30-day SRT in the pilot test at the facilities and the VSR at the much lower SRTs in the historical 
record of these plants still exceeds $38 \%$, the state and federal requirement for Class B biosolids. The VSR estimates for high-rate digestion systems, Equation 7, although based on a highly simplified expression concur with this conclusion. Essentially, either as a design consideration or future operational strategy both plants could run at 15-20 day SRTs without sacrificing reasonable VSRs and biogas production. Table 22 summarizes the data collected, estimated, and calculated through a combination of literature review of research, site-specific engineering reports, analysis of SDWWTP and CDWWTP historical plant process and flow data, and extensive piloting efforts. All of this information has contributed toward development and operation of the site-specific mass balance models, MBMs. 
Table 22: Anaerobic digestion historical data, pilot measurements, calculated results and assumed values for SDWWTP and CDWWTP

\begin{tabular}{|c|c|c|c|c|c|c|c|c|c|c|c|}
\hline Dota Sourte: & $\begin{array}{c}\text { histarical } \\
\text { tats }\end{array}$ & Pibt ఉat: & $\begin{array}{l}\text { by design } \\
\text { cribilated }\end{array}$ & $\begin{array}{l}\text { nu plant } \\
\text { data, } \\
\text { azusmed }\end{array}$ & $\begin{array}{l}\text { medel calb } \\
\text { on hisıo }\end{array}$ & $\begin{array}{l}\text { ated, based } \\
\text { sal teaca }\end{array}$ & & & & & \\
\hline dechec warbables iandlyte/ flawstreami & us unit & $\begin{array}{l}\text { sywivip } \\
\text { plant data }\end{array}$ & $\begin{array}{l}\text { cuWwip } \\
\text { olant data }\end{array}$ & $\begin{array}{l}50 \text { sowip } \\
\text { socrario } \mathrm{E}\end{array}$ & {$\left[\begin{array}{l}\text { cowwip } \\
\text { scovolo B }\end{array}\right.$} & $\begin{array}{l}\text { suwwip } \\
\text { Stcearb c }\end{array}$ & $\begin{array}{c}\bar{w} \text { wisp } \\
\text { scensrlac }\end{array}$ & $\begin{array}{l}5 . \bar{W} / \mathrm{P} \\
\text { socrartc D }\end{array}$ & $\begin{array}{l}\text { CUWWTP } \\
\text { scorvio D }\end{array}$ & $\begin{array}{l}s \bar{w} w \mid P \\
\text { socrario }\end{array}$ & $\begin{array}{l}c 0 w W \\
\text { scovilo }\end{array}$ \\
\hline \multicolumn{12}{|l|}{ Fât Sludgs Dpaizlan Comeitiars } \\
\hline dizester tark volume/'tank & $\mathrm{MKG}$ & 1,64 & 2.64 & 194 & 1,04 & 169 & 1.64 & 1.64 & 1.64 & 2.64 & 194 \\
\hline tanls In cperstlon (orimseres only) & na af units & 5 & 5 & $E$ & 12 & 4 & 7 & 4 & 7 & 4 & 3 \\
\hline digestera retal acrhop val. me & MK & ค.19 & 2.8 .3 & 983 & 19.66 & 6.55 & 11.47 & 6.55 & 11.47 & 655 & 1147 \\
\hline Total Solds of of geted sludse & $\begin{array}{l}\text { At soids by } \\
\text { w. }\end{array}$ & 129 & 2.32 & 130 & 1.89 & 3.105575 & 27330959 & 3.106675 & 2.7830959 & 3.5 & 27 \\
\hline Divester Solids Resention lime & $c$ & 14.7 & $26, y$ & 17.8 & 351 & 29s & 29.1 & 24.5 & 29.1 & 32.7 & 332 \\
\hline vss destructlon duting diacstior & H & 4875 & 52.52 & 50.03 & 62.54 & 50.03 & 59.97 & 50.00 & 모.57 & 49.47 & 6403 \\
\hline Gas Produc:Ion & $\begin{array}{l}\text { auft./th of } \\
\text { WSs } \\
\text { destrayed }\end{array}$ & 16 & 16 & 18 & 16 & 16 & 16 & LE & 16 & 16 & 16 \\
\hline Dogestar Spernataent TSS & $\mathrm{mgh}$ & 0 & $a$ & n & n & n & 0 & $D$ & 0 & a & n \\
\hline Qupestersperna:ant 000 & $\mathrm{mP}$ & 므. & 0 & 0 & $\underline{\underline{0}}$ & 0 & 0. & D. & 0 & -0. & 0 \\
\hline
\end{tabular}




\section{Sludge Dewatering}

Prior to the advent on organic coagulant polymers, the vacuum and pressure filter presses were the only viable options for mechanical dewatering of biosolids. The machines were very large relative to their hydraulic and solids loading when compared to mechanical dewatering technologies of today. Vacuum and pressure filter presses consumed large quantities of chemical coagulants (iron salts, alum, lime, etc.) and used far more power to do so than the dewatering technologies of today (WEF MOP No. $116^{\text {th }}$ Edition, 2008). In 1954, when CDWWTP was built, the vacuum filter press was the dewatering technology available, selected, constructed and operated for many years with moderate success. As early as the 1960's research was ongoing to improve sludge dewatering with centrifuge technology with patents being granted in the late 1960's (Baumann et al., 1967). In the mid-1970's design and construction began to replace this technology at CDWWTP with dewatering centrifuges, PM-75000 of the former Sharples Corporation, Philadelphia, Pennsylvania. The machines installed then are some of the same machines still in use now, relocated to the SDWWTP.

The South and Central District Wastewater Treatment Plants currently operate centrifuges for dewatering operations. The exiting dewatering buildings, including some of their piping, wiring, equipment and controls, are over 30 and 40 years old for SDWWTP and CDWWTP, respectively. Due to their building age, useful lifecycle of equipment, and level of deterioration, new dewatering centrifuges are proposed for the subject facilities. Dewatering centrifuges continue to be the most common technology for dewatering of municipal wastewater treatment sludge at the scale of the subject facilities 
due to the dewatering centrifuge's capability of continuous, remotely monitored operation, and high solids and hydraulic loading to footprint ratios when compared to other popular technologies, e.g. belt, screen, and bucher presses. Dewatering centrifuges are the preferred choice in my and the utility's opinion, a common trend in the industry (Gillette et al., 2000). Therefore, the focus of this aspect of the study, is the capabilities of new dewatering centrifuges, chemical dosing and process control automation and their potential performance in line with the previously discussed proposed technology and biosolids processing method changes to SDWWTP and CDWWTP.

\subsection{Dewatering Centrifuges}

Dewatering centrifuges are cylindrical drums that exert centrifugal forces upon the contents within via rotating at high speeds, forces that increase by the bowl speed squared. (WEF MOP $116^{\text {th }}$ Edition, 2008). They are internally compartmentalized with an internal cylinder, or bowl, and within the bowl a tapered screw, or scroll, that both spin about a central axis at slightly different rotational speeds.

In general principle a centrifuge behaves similarly to clarifiers and gravity thickeners in that physical separation of solid from liquid as a result of gravitational forces and can be aided by metal coagulants and organic polymers which increase particle density and promote flocculation. The liquid sludge enters in through the scroll with chemical coagulants added prior to entry or within the scroll itself. The advantages of centrifuges to enhance the rate or settling, sludge concentration and solids recovery is a result of centripetal forces being thousands of times greater than the gravitational force

experienced in a clarifier (WEF MOP No. $85^{\text {th }}$ Edition, 2010). If the sounds similar to 
the fundamental workings of a thickening centrifuge, that is no surprise. Thickening and dewatering centrifuges function on exactly the same principles. The ability to convert a decanting, thickening centrifuge into a dewatering centrifuge is a patented technology (Hensley et al., 2006). At least one major centrifuge manufacturer even produces machines that perform both functions by on-the-fly mechanical modifications and process control parameters adjustments based on patents emerging in the 1980's and 1990's (Høhne, 1981 and Schlip et al., 1992). Research continues on the understanding of how centrifuge technology interplays with both feed sludge characteristics and machine settings (Peeter et al., 2004, Bicudo et al., 2018, and Beightol et. al, 2018).

In order to determine the performance of both existing plant performance and pilot results the solids capture had to be determined. A small modification of the solids capture equation presented for sludge thickening, Equation 3, is applied to sludge dewatering, Equation 12, for the existing sludge dewatering process efficiency and the pilots at SDWWTP and CDWWTP. The full derivation of Equation 3 and Equation 12 can be found in Appendix 1: Derived Equations.

\section{Equation 12: Solids Capture Rate for Sludge Dewatering Centrifuge}

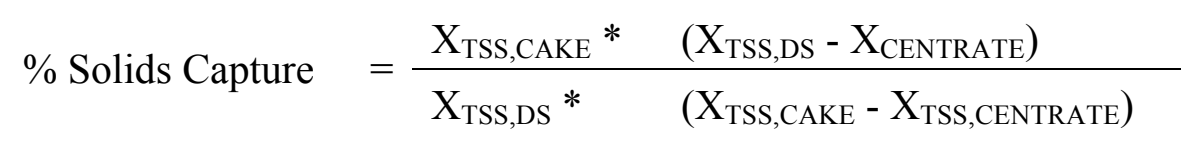

where,

$$
\begin{aligned}
& \mathrm{X}_{\mathrm{TSS}, \mathrm{DS}}=\quad \text { solids concentration in digested sludge }(\mathrm{mg} / \mathrm{L} \text { or } \mathrm{g} / \mathrm{m} 3) \\
& \mathrm{X}_{\mathrm{TSS}, \mathrm{CAKE}}=\quad \text { solids concentration in dewatered sludge cake }(\mathrm{mg} / \mathrm{L} \text { or g/m3) } \\
& \mathrm{X}_{\mathrm{TSS}, \mathrm{CENTRATE}} * \quad=\quad \text { solids concentration in centrate stream }(\mathrm{mg} / \mathrm{L} \text { or g/m3) }
\end{aligned}
$$


* Meant here as the sludge dewatering process reject stream. Both facilities in the study currently operate dewatering centrifuges and plan to continue in the future. The term would be conventionally called filtrate in the case of belt filter presses, bucher presses, screw presses, etc.

Because of the complexities of the of the solids characteristics to centrifuge performance, piloting of site-specific conditions is often the only way to determine centrifuge performance and limitations accurately for design purposes. Data from existing plant operation would not be sufficient as dewatering centrifuge design and performance have changed with time and the digested sludge characteristics would be changing due to proposed changes to anaerobic digestion as often is the case when modifying upstream processes for Scenarios C, D and E (Jo et al., 2018). Chemical dosing of coagulants aid, such as iron salts, also effect the dewatering performance of centrifuges and the over solids production (Schafer et al., 2018; Boráň et al., 2010). Hence the dynamics of sludge solids characteristics both present and future merited piloting at SDWWTP and CDWWTP.

\subsection{SDWWTP Pilot Phase 3 - Dewatering pilot testing}

The purpose of Pilot Phase 3 operation was to determine the optimal design conditions and performance of the dewatering centrifuge using the thickened biosolids fed from Digester 9. The overall target for the centrifuge dewatering performance as stated in the basis of design and specifications was to dewater the thickened digested biosolids to $20 \%$ TS while maintaining greater than $95 \%$ solids recovery. The necessary polymer dose to achieve this performance is also important to determine. The draft 
specifications indicate that active polymer dose should be less than $25 \mathrm{lb} / \mathrm{DT}$. Textbook values for anaerobically digested WAS only biosolids are not readily available as most anaerobic digesters in the industry digest WAS blended with primary sludge. Metcalf and Eddy $5^{\text {th }}$ edition lists 16 to $25 \%$ TS expected for untreated WAS and lists 22 to $25 \%$ TS expected for anaerobically digested combined WAS and primary. For both untreated WAS and anaerobically digested WAS and primary, the polymer consumption is expected to be 15 to $30 \mathrm{lb} / \mathrm{DT}$ ( 7.5 to $15 \mathrm{~g} / \mathrm{kg}$ ) active and solids recoveries are expected to be $95 \%$ or greater (Metcalf et al. $5^{\text {th }}$ edition, 2013).

Dewatering pilot testing - emulsion polymer initial testing

The initial testing started with emulsion polymers on March 2, 2016. Five cationic, high molecular weight emulsion polymers were tested in order to select the most effective two polymer types for further testing. The emulsion polymers were able to achieve 22 to $25 \%$ TS (PRAESTOL 274 FLX and 290 FLX emulsion polymers).

Dewatering pilot testing - dry polymer setup

The centrifuge pilot trailer had a dry polymer feeding system that was rarely used and required some effort to make it functional. The polymer blending system did not provide adequate mixing of the dry polymer and left unmixed and residual portions of polymer in the tank. The dry polymer feed pump, however, provided suitable control to deliver a dry polymer solution to the centrifuge. SDWWTP also had a dry polymer make up system that was no longer used, however, was functional. Initially, dry polymer solution was metered from the plant's make-up system directly to the dewatering centrifuge, however, the plant's polymer pumps could not adequately control the polymer 
feed for testing. In order to conduct the testing, a hybrid of both dry polymer systems was used. Polymer solution made up using the plant's system was pumped into the dry polymer solution hopper on the pilot dewatering centrifuge. The polymer pump was then used to meter the polymer to the centrifuge. The dry polymer used for the dewatering testing was Polydyne C-3283 which is currently used for the SDWWTP dewatering centrifuges.

Dewatering pilot testing - polymer injection location optimization

Polymer injection location in the biosolids is important in getting proper biosolids flocculation for the desired dewatering. Several injection locations were tested using the plant's dry polymer. A mixed injection system, which included dosing a portion of the polymer in a static mixer in the interconnecting hose and the rest of the polymer injected at the grinder on the pilot trailer, was initially found to be the best method for polymer injection based on visual observations of the centrate clarity. However, later testing found that injecting polymer directly into the feed tube of the centrifuge provided better centrate quality. The first few weeks of testing were based primarily on the mixed polymer injection and the later testing was conducted using primarily the feed tube injection point.

Dewatering pilot testing - polymer curve results

Polymer curve tests were conducted by maintaining a constant volumetric throughput of digested biosolids feed to the centrifuge while changing the polymer dose to measure the impact. With the exception of changing polymer dose, most of the other parameters on the centrifuge remained the same for each polymer curve test. During some of the tests, however, the differential speed was adjusted to increase cake solids 
while still trying to maintain good quality centrate based on visual observations. Testing showed that reducing the differential speed would increase cake solids but could sacrifice centrate quality and solids recovery.

Polymer curve tests were conducted using both emulsion and dry polymer with both mixed and feed tube polymer injection. All of the dry polymer curves conducted on thickened biosolids from Digester 9 are presented in Figure 53 and the data depict the injection point and polymer concentration.

For most of the dry polymer testing, the targeted polymer concentration was $0.8 \%$, however, actual concentrations were measured daily throughout testing and solution concentration appeared to vary from day to day. In addition, the team conducted testing with a more dilute dry polymer concentration. The red circle on Figure 53 denotes the area targeted for optimization with dry polymer. All of the emulsion polymer curves conducted on thickened biosolids from Digester 9 is presented in Figure 54. 


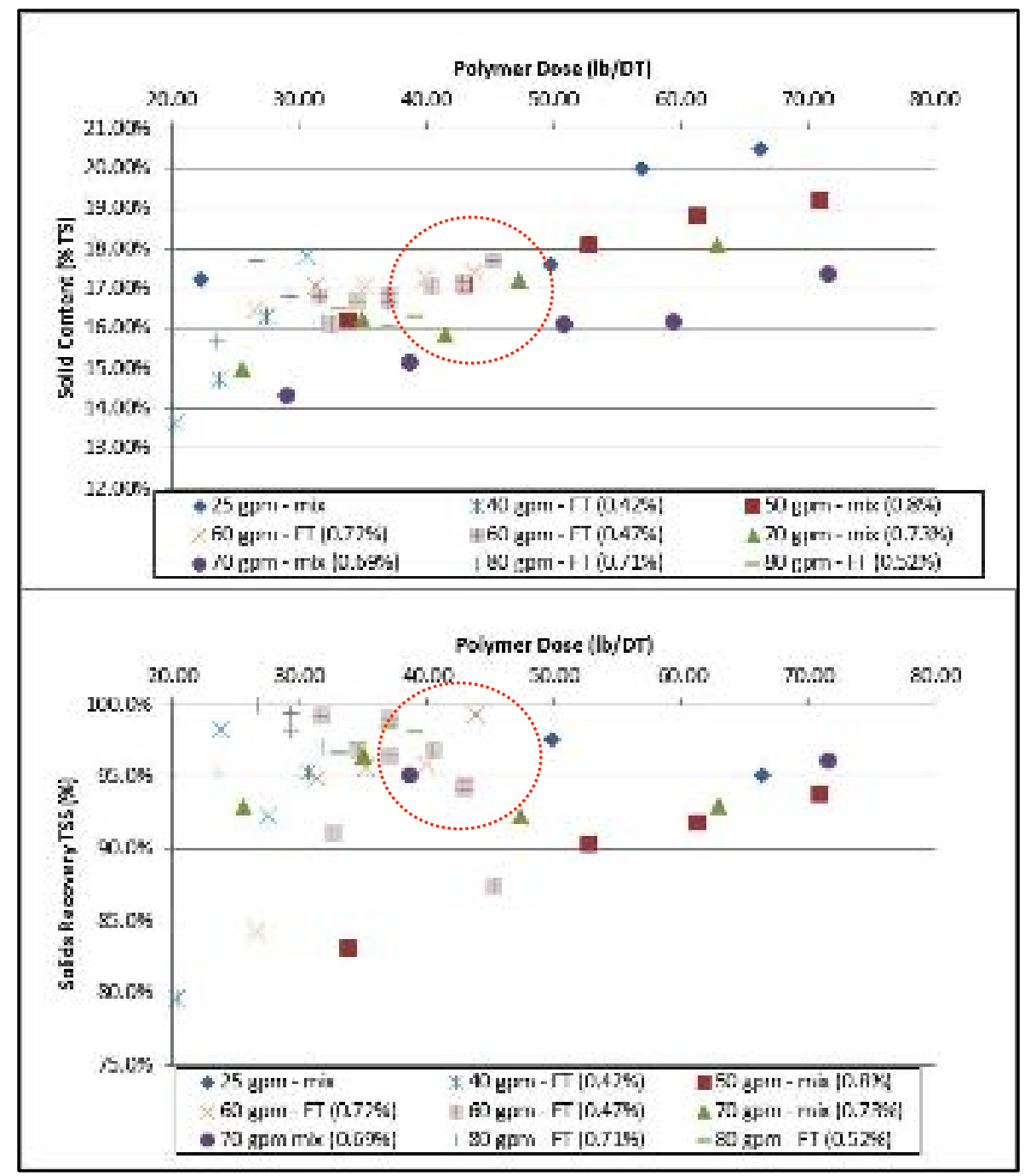

Figure 53: Compiled Dry Polymer Curves from Digester 9 ("mix" represents "mixed polymer injection and "FT" represent "feed tube polymer injection") 


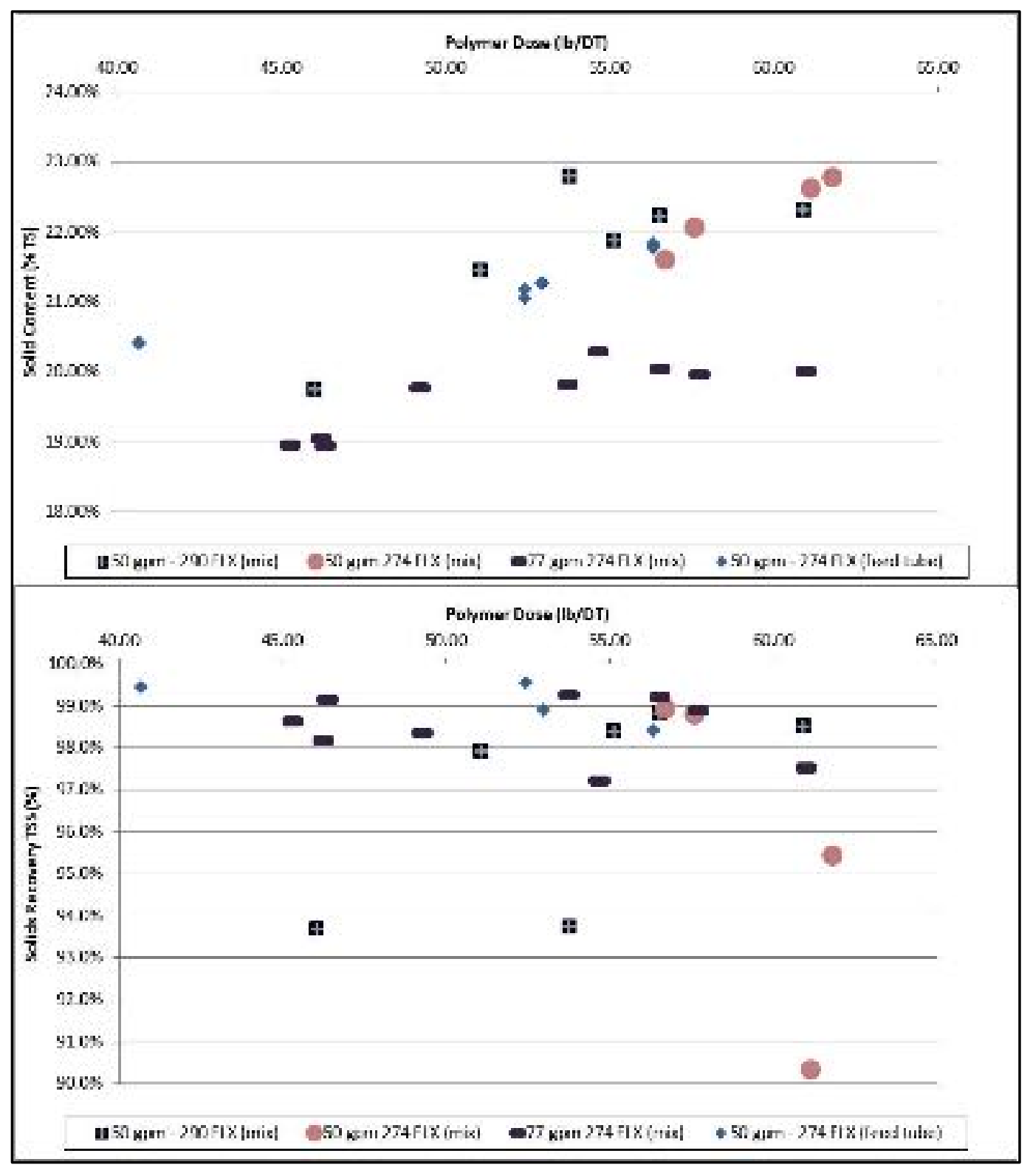

Figure 54: Compiled Emulsion Polymer Curves from Digester 9

The polymer testing curves showed that SDWWTP's digested biosolids did not dewater to the level anticipated in the preliminary design ( $\geq 20 \%$ TS $)$ at active polymer doses of $25 \mathrm{lb} / \mathrm{DT}(12.5 \mathrm{~g} / \mathrm{kg})$. Using the plant's dry polymer (Polydyne C-3283), it was difficult to dewater to greater than $18 \%$ TS unless the active polymer dose was above 50 
lb/DT (25 g/kg), a polymer dose that would be exceedingly expensive and requires a larger capacity dry polymer system that proposed. Dryer cake could be produced using emulsion polymer but high polymer doses were also required. For the dry polymer, using feed tube injection versus the external or mixed injection allowed for lower polymer doses while still maintaining recoveries above $95 \%$.

Dewatering pilot testing - extended operation results

In addition to polymer curve tests, the dewatering centrifuge was operated several days at a constant flowrate to test the stability of operation throughout the course of a day. Three tests were conducted at $50 \mathrm{gpm}(189 \mathrm{~L} / \mathrm{min})$, two with dry polymer and one with 274-FLX emulsion polymer. Two tests were also conducted at $75 \mathrm{gpm}(284 \mathrm{~L} / \mathrm{min})$, one with dry polymer and one with 274-FLX emulsion polymer.

The extended runs using dry polymer are shown in Figure 55. The data show stable performance with high recoveries (>98\%) for lower active polymer doses of 19 to $23 \mathrm{lb} / \mathrm{DT}(9.5$ to $11.5 \mathrm{~g} / \mathrm{kg}$ ) as compared to results from the polymer curve testing. The dewatered cake solids during the extended operation tests averaged 17 to $17.5 \%$ TS at 50 gpm (189 L/min) feed flow with 19 to $22 \mathrm{lb} / \mathrm{DT}(9.5$ to $11 \mathrm{~g} / \mathrm{kg}$ ) active polymer dose. At $75 \mathrm{gpm}(284 \mathrm{~L} / \mathrm{min})$ with an active polymer dose of $23 \mathrm{lb} / \mathrm{DT}(11.5 \mathrm{~g} / \mathrm{kg})$, the dewatered cake solids averaged 16 to $16.5 \%$ TS. 


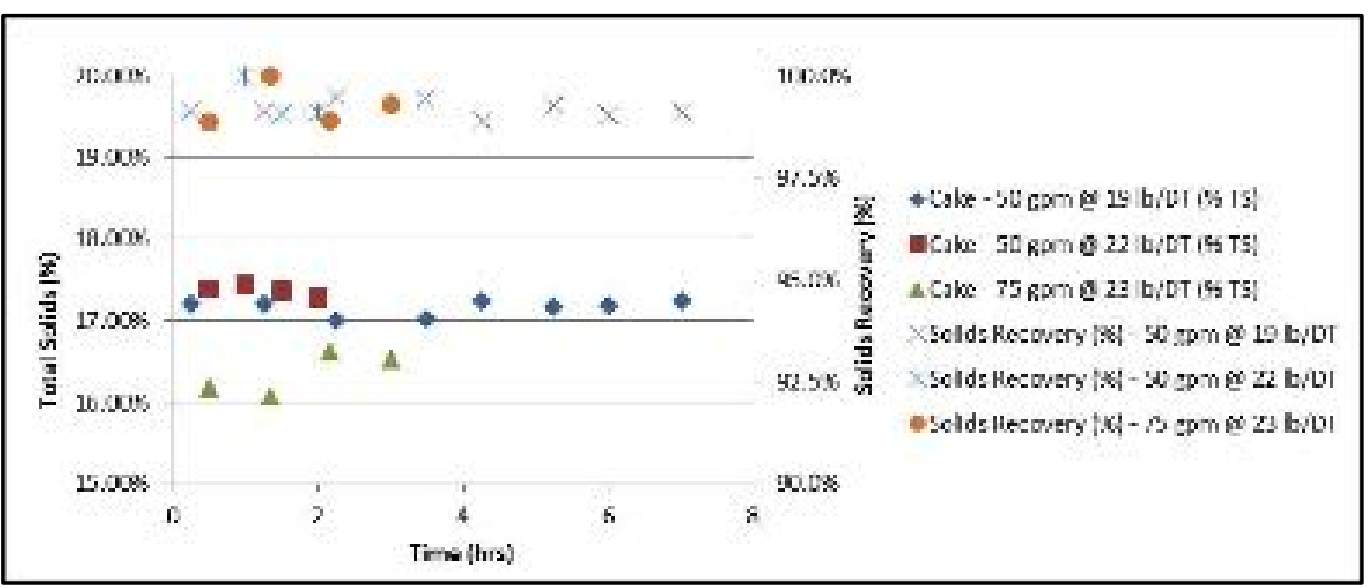

Figure 55: Extended Operation using Dry Polymer

The extended runs using emulsion 274 FLX polymer are shown in Figure 56. The data show stable performance with high recoveries $(>96 \%)$ for active polymer doses of 37 to $44 \mathrm{lb} / \mathrm{DT}$ (18.5 to $22 \mathrm{~g} / \mathrm{kg}$ ). The dewatered cake solids during this tests averages 20.5 to $21 \%$ TS at $50 \mathrm{gpm}(189 \mathrm{~L} / \mathrm{min})$ feed flow with $44 \mathrm{lb} / \mathrm{DT}(22 \mathrm{~g} / \mathrm{kg})$ active polymer dose. At $75 \mathrm{gpm}(284 \mathrm{~L} / \mathrm{min})$ with an active polymer dose of $37 \mathrm{lb} / \mathrm{DT}(18.5 \mathrm{~g} / \mathrm{kg})$, the dewatered cake solids averaged 19.3 to $19.6 \%$ TS.

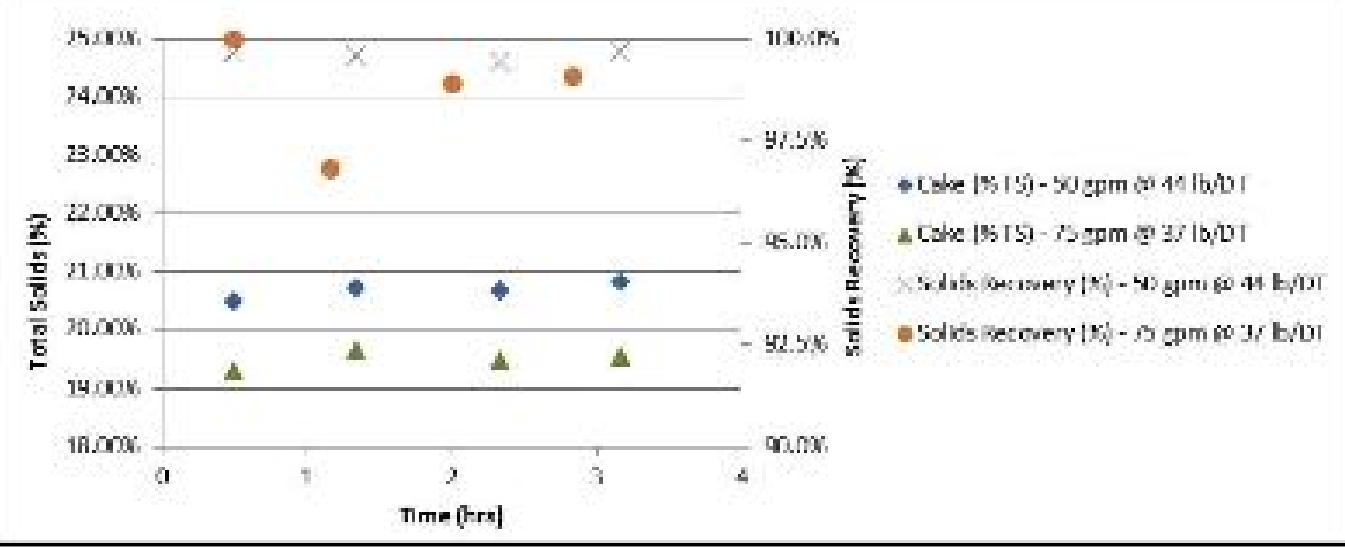

Figure 56: Extended Operation using Emulsion Polymer 
The Pilot Phase 3 dewatering testing showed that 16 to $18 \%$ TS cake could be achieved with 20 to $30 \mathrm{lb} / \mathrm{DT}$ ( 10 to $15 \mathrm{~g} / \mathrm{kg}$ ) active dosing of dry polymer. The pilot testing showed that the dewatered cake solids were lower than the preliminary design value of $20 \%$ TS with a presumed $25 \mathrm{lb} / \mathrm{DT}(12.5 \mathrm{~g} / \mathrm{kg})$ active polymer when using dry polymer. Dryer cake at 20 to $22 \%$ TS could be produced using emulsion polymer but required higher dosages above $40 \mathrm{lb} / \mathrm{DT}$ active $(20 \mathrm{~g} / \mathrm{kg})$.

6.3 The struvite complex - struvite removal to improve sludge dewaterability

Struvite accumulation and fouling has historically been one of the major maintenance issues for the SDWWTP operations, consuming resources for continuous pipe cleaning to maintain steady, uninterrupted operation of the existing digestion and dewatering process. Struvite is magnesium ammonium phosphate $\left(\mathrm{MgNH}_{4} \mathrm{PO}_{4(\mathrm{~s})}\right)$ and results from high soluble orthophosphate $\left(\mathrm{PO}_{4}-\mathrm{P}\right)$ concentrations in the digested biosolids when adequate ammonia and magnesium are present. The potential for struvite formation is expected to increase in the future with improved thickening prior to anaerobic digestion resulting in greater solids concentrations in digestion hence greater ammonium and orthophosphate release. Moreover, increasing the $\mathrm{PO}_{4}-\mathrm{P}$ concentration in the biosolids has been reported to reduce dewatering performance in terms of lower cake solids and higher polymer dosing requirements (Kopp et al., 2016).

Goss et al. (2017) presented the results from centrifuge thickening piloting, digestion high rate piloting and centrifuge dewatering piloting at the SDWWTP. SDWWTP Digester 9 was isolated to receive mechanically thickened sludge from a pilot thickening centrifuge to simulate future high rate anaerobic digestion. The digester was 
operated in this manner to allow the digester to reach a steady state with mechanically thickened sludge. The solids content in Digester 9 was increased from 2 to $2.5 \%$ total solids (TS) to approximately 3.4 to $3.5 \%$ TS. Once three digester SRT turnovers were achieved in Digester 9, pilot centrifuge dewatering testing was conducted, but the results showed that only $18 \%$ TS could be achieved with active dry polymer dosages of 20 to 30 pounds per dry ton $(\mathrm{lb} / \mathrm{DT})$ or 10 to 15 grams per dry kilogram $(\mathrm{g} / \mathrm{kg})$. The initial goal was to achieve greater than $20 \%$ TS with greater than $95 \%$ solids recovery using an active dry polymer dose of less than $25 \mathrm{lb} / \mathrm{DT}(12.5 \mathrm{~g} / \mathrm{kg})$.

Since it was desired to improve dewatering and mitigate the maintenance issues associated with struvite fouling, methods for struvite control which could also enhance dewatering were evaluated. In the AirPrex ${ }^{\circledR}$ process struvite is crystallized directly from the biosolids stream from an anaerobic digester prior to dewatering. The precipitation of struvite prior to dewatering is one potential method to achieve both improved dewatering and reduced maintenance costs. The objective of the pilot study presented herein was to demonstrate the technology at SDWWTP and document the struvite precipitation and centrifuge dewatering performance results. The AirPrex ${ }^{\circledR}$ pilot testing was conducted after a series of thickening, digestion, and dewatering pilot testing were completed at SDWWTP (Stitt et al., 2017).

Background on struvite formation

Struvite, magnesium ammonium phosphate precipitation, is a common problem in wastewater treatment plants where it often can foul piping and equipment. Struvite typically forms in plants that contain anaerobic digesters with upstream biological 
phosphorous removal. Struvite precipitation occurs when the release of orthophosphate and ammonia from cell hydrolysis during anaerobic digestion reacts with magnesium ions at $\mathrm{pH}$ conditions conducive for struvite formation, $\mathrm{pH}$ of 7.5 to 10 . Struvite accumulation tends to occur at locations where pressure is low and $\mathrm{CO}_{2}$ is released from solution thus increasing the $\mathrm{pH}$. Manual cleaning, dilution, dosing an iron salt to precipitate the phosphorous, or using an anti-scaling agent to lower the $\mathrm{pH}$ has traditionally solved unwanted struvite fouling (Abel-Denee and Eskicioglu, 2018).

The following chemical equation describes the chemical reaction for struvite formation (Snoeyink, et al, 1980).

$$
\mathrm{MgNH}_{4} \mathrm{PO}_{4} \cdot 6 \mathrm{H}_{2} \mathrm{O} \leftrightarrow \mathrm{Mg}_{2}{ }^{+}+\mathrm{NH}_{4}{ }^{+}+\mathrm{PO}_{4}{ }^{3-}+6 \mathrm{H}_{2} \mathrm{O} \quad \quad \mathrm{pK}_{\mathrm{SO}}=12.6
$$

Under these conditions, the activities $\left\{\mathrm{Mg}^{2+}\right\}\left\{\mathrm{NH}_{4}{ }^{+}\right\}\left\{\mathrm{PO}_{4}{ }^{3-}\right\}$ can increase above the solubility product or solubility equilibrium, defined at $\mathrm{K}_{\mathrm{SO}}$, causing struvite precipitation. The common places for struvite accumulation are locations where pressure is low and $\mathrm{CO}_{2}$ is released from the solution thus increasing the $\mathrm{pH}$ (Snoeyink et al., 1980).

For every kilogram of phosphorus recovered, 7.9 kilograms of dry struvite is produced. Typically, magnesium concentration in the wastewater or in the anaerobic digester is at a lower molar ratio than the phosphorous so magnesium is generally the limiting reagent for unintended struvite formation. Therefore, the addition of a magnesium salt is required and a common feature of most controlled struvite precipitation and removal processes. 


\section{AirPrex process}

The AirPrex process, was developed and patented by Berliner Wasserbetriebe of Germany in collaboration with the Berlin Institute of Technology and is marketed in North America by CNP Corporation of Kenosha, Wisconsin. In this process, struvite is crystallized directly from the biosolids stream out of an anaerobic digester, rather than from centrate, as is the case with more developed struvite crystallization processes such as the Ostara Pearl process. A general process flow diagram for the AirPrex process is provided in Figure 57.

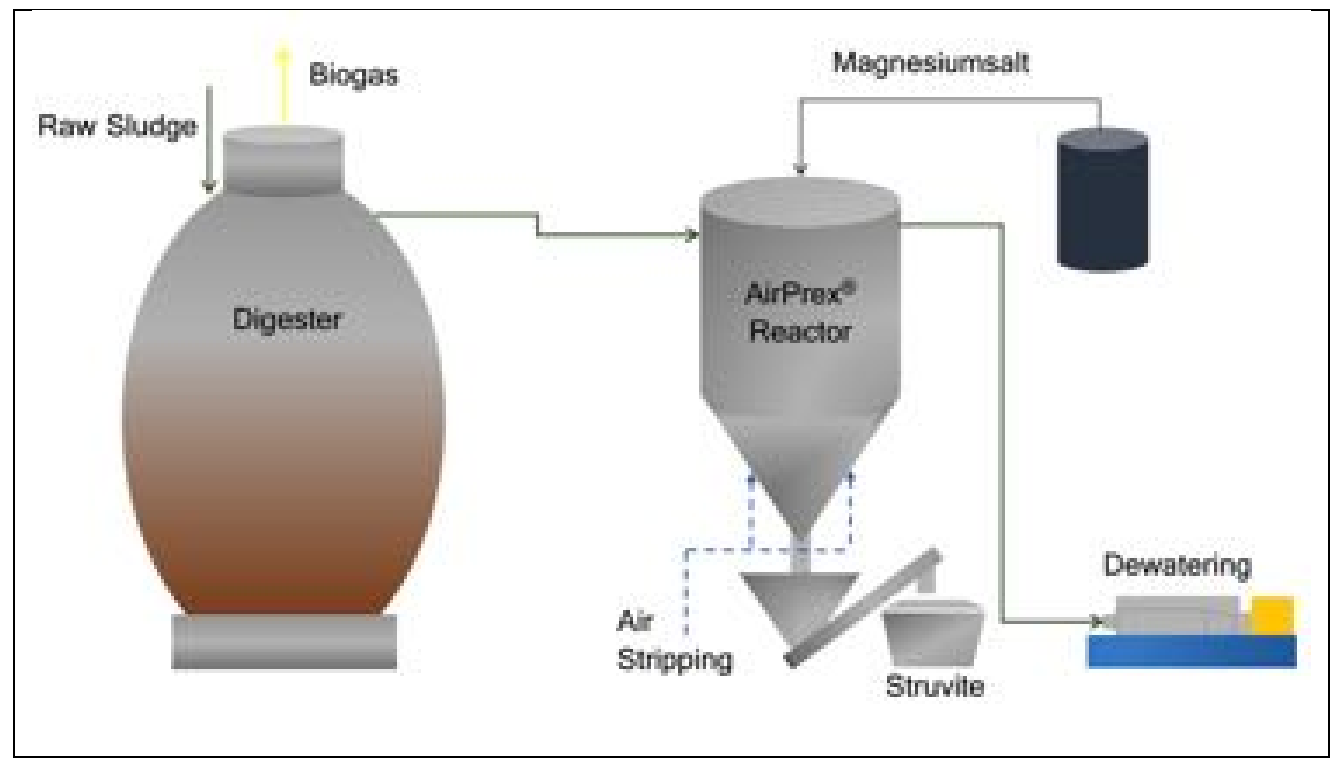

Figure 57: Typical AirPrex Process Flow Diagram (Courtesy of CNP)

\section{AirPrex Piloting At SDWWTP}

The AirPrex piloting was conducted in April 2016 and the AirPrex treated biosolids was dewatered using the same pilot dewatering centrifuge used throughout SDWWTP's Pilot Phase 3. The AirPrex reactor was equipped with aerators that strip out carbon dioxide to increase the $\mathrm{pH}$ to between 7.9 and 8.2. The aeration also provides 
circulation of the struvite crystals inside the reactor, which grow until they reach a sedimentation point and settle to the bottom of the cone shaped reactor. Magnesium chloride was also dosed to the reactor as a $30 \%$ liquid solution and the dosing was set to be proportional to the orthophosphate concentrations and biosolids flow. For the pilot operation, the magnesium chloride dosing rate was set at 1.8 liters per cubic meter of digested biosolids (1.8 gallons per 1,000 gallons of digested biosolids) (Stitt, et al 2017; CH2M Hill, 2017).

During the pilot period, the AirPrex unit operated continuously with a digested biosolids flow that ranged from 30 to 45 liters per $\min (\mathrm{L} / \mathrm{min})$ or 8 to 12 gallons per minute (gpm) and the treated sludge was stored in a mobile fractionation tank equipped with mechanical mixers that provided a buffer and storage between the AirPrex system and pilot centrifuge. The fractionation tank was filled continuously during operation but since the dewatering pilot throughput was up to four to ten times the flowrate of the AirPrex pilot, the pilot dewatering unit needed about 2 to 4 hours of operation time to empty the fractionation tank. Photos of the pilot unit reactor and fractionation tank are provided in Figure 58.

The feed to the dewatering pilot was set up to allow testing of both the AirPrex and non-AirPrex treated digested biosolids in the same day. This allowed for consecutive testing to be conducted to determine impact of the technology on the dewaterability of the digested biosolids. The objective of the demonstration was to verify the performance of the technology in terms of:

- Percent of orthophosphate $\left(\mathrm{PO}_{4}-\mathrm{P}\right)$ removal from the digested biosolids,

- Change in dry cake solids against the baseline, 
- Change in polymer consumption compared to the baseline, and

- Ability to generate MAP (Struvite) that can be recovered.

Specified dewatering requirements were to achieve greater than $20 \%$ TS with greater than $95 \%$ solids recovery at an active polymer dose of $25 \mathrm{lb} / \mathrm{DT}(12.5 \mathrm{~g} / \mathrm{kg})$ or less (MWH, January 2016).

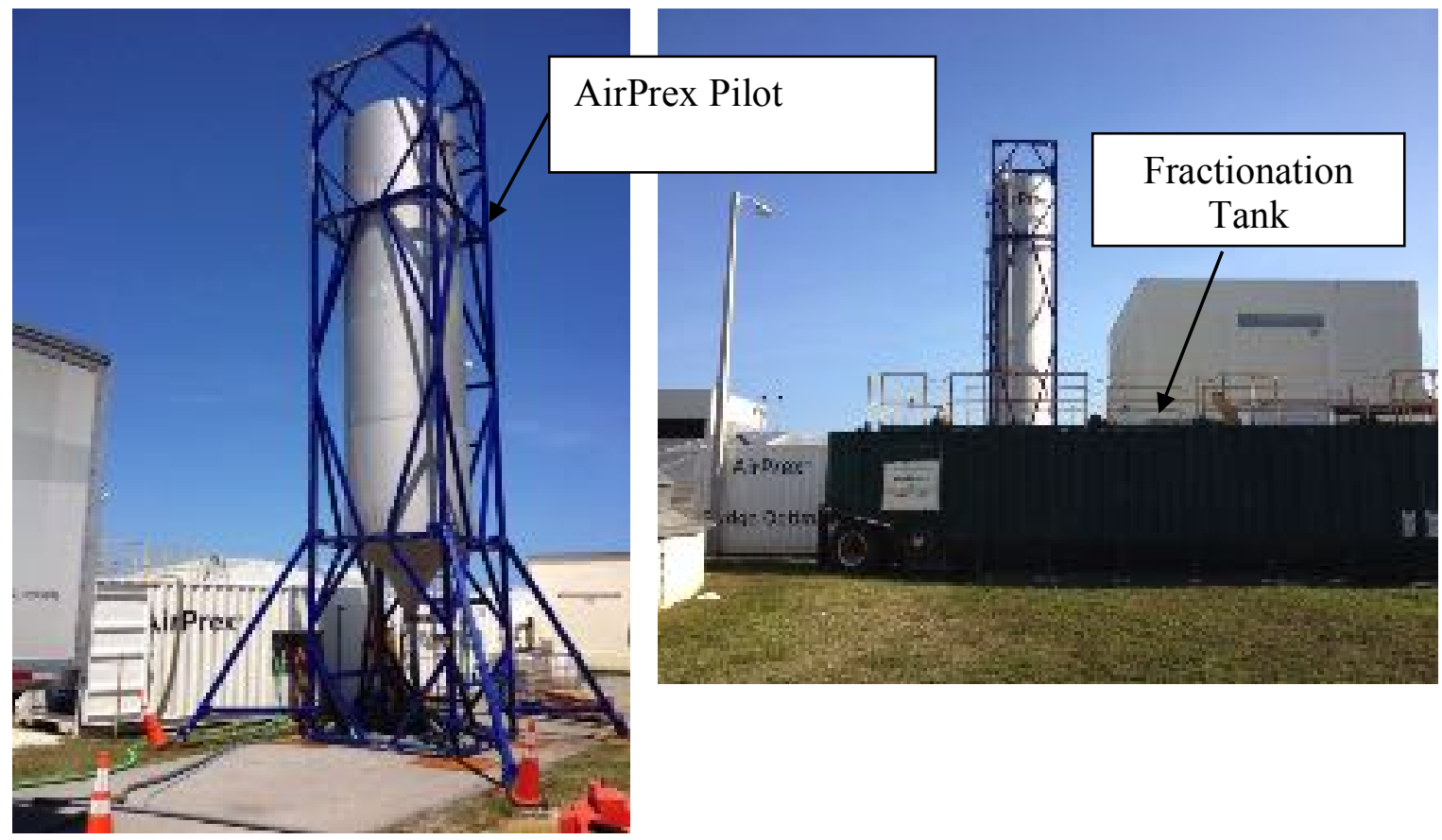

Figure 58: Picture of AirPrex Pilot and Fractionation Tank

The AirPrex reactor was first fed digested biosolids from Digester 9 on April 4, 2016 and the dewatering centrifuge first started processing AirPrex treated biosolids on April 5, 2016. Digester 9 was chosen since it was being operated as a pilot digester that was receiving mechanically thickened sludge for four months prior to the start of this stage of testing. The first week of dewatering operation was performed to optimize the dewatering centrifuge for the AirPrex treated biosolids. After a few days of operation, 
however, it was noted that the feed solids to the centrifuge from Digester 9 were decreasing rapidly. It was found that a flushing water valve was left open for several days that allowed water to fill Digester 9, diluting the digester. Based on the trend shown in Figure 59, it appears that dilution started at the end of March 2016, reducing the concentration in Digester 9 from 3.3 to $3.5 \%$ TS down to $2 \%$ TS. Because of the accidental dilution, the feed to the AirPrex reactor was switched from Digester 9 to Digester 10 on April 12, 2016. Digester 10 was acting as a secondary digester that was receiving only mechanically thickened digested sludge from Digester 9 and the concentration in the digester was steady at approximately $2.5 \%$ TS (Stitt et al., 2017).

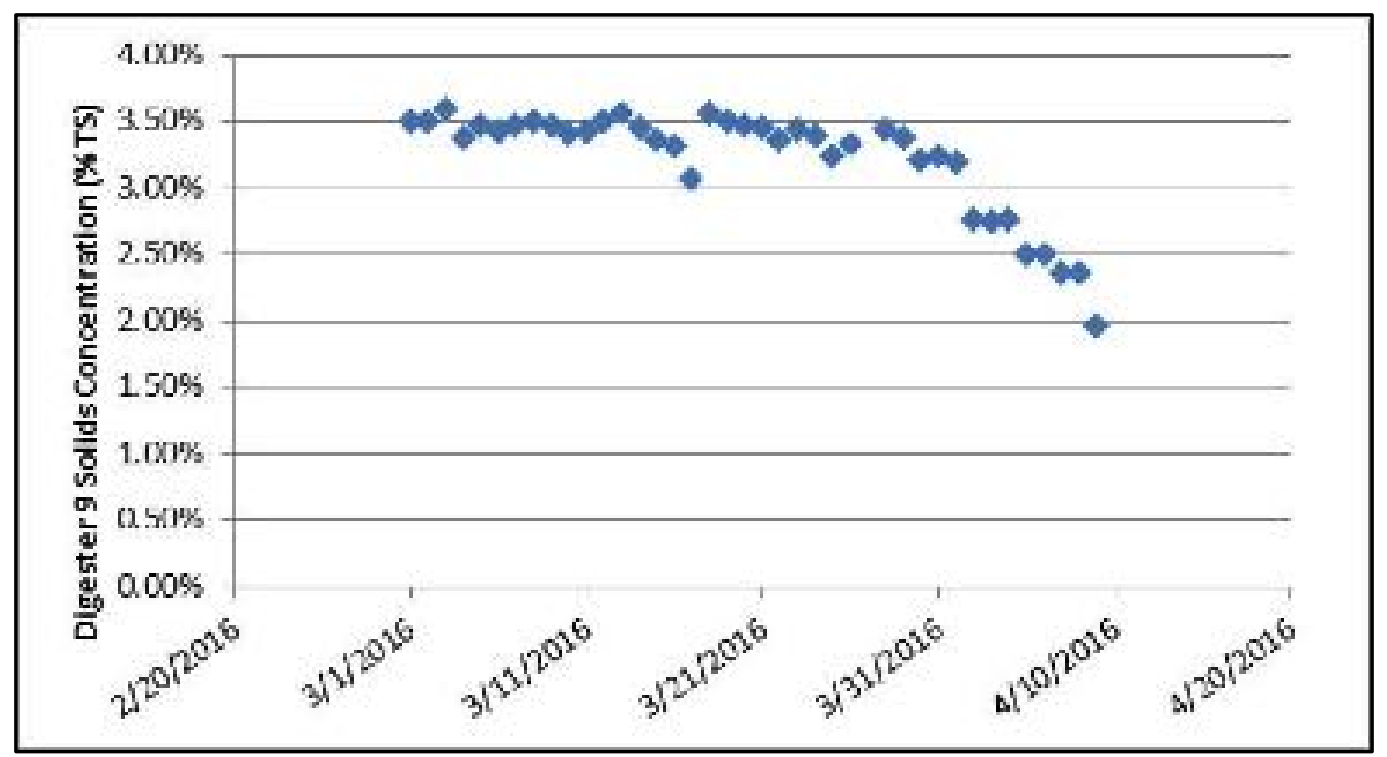

Phase 2

Figure 59: Digester 9 Solids Concentration accidental dilution during Pilot 
AirPrex performance data

Daily sampling was conducted from the AirPrex reactors to monitor the orthophosphate and ammonia concentrations, as well as the $\mathrm{pH}$ of the inflow feeding the AirPrex unit and the outflow, which fed the fractionation tank and was the feed for AirPrex treated biosolids dewatering testing. Centrate samples from the dewatering unit were also collected for a period to monitor ammonia and orthophosphate concentrations, as well as $\mathrm{pH}$. Figure 60, Figure 61, and Figure 62 summarizes the data monitored during the AirPrex testing and a vertical red line was added to the figures to depict the point where the feed to the AirPrex unit was switched from Digester 9 to Digester 10 . The data did not show a large difference in the orthophosphate concentrations when switched from Digester 9 to Digester 10. However, the ammonia concentration in Digester 9 decreased over time as the digester was diluted. When switching to Digester 10 , both the ammonia concentration and the $\mathrm{pH}$ of the inflow biosolids increased. When operating with feed biosolids from Digester 9, the $\mathrm{pH}$ averaged 7.6 but when switched to Digester 10, the $\mathrm{pH}$ averaged 7.8. 
After the first day of AirPrex operation, the process was optimized and approximately $91 \%$ orthophosphate reduction was maintained throughout the pilot reactor, ranging from 89 to $93 \%$, reducing the concentration from approximately 200 milligrams per liter $(\mathrm{mg} / \mathrm{L})$ down to less than $20 \mathrm{mg} / \mathrm{L}$. In addition, the AirPrex process also provided a 14 to $16 \%$ reduction in ammonia concentration. Although the SDWWTP plant does not currently have ammonia or total nitrogen limits, this could prove useful for plants where nutrient removal is a requirement. Table 23 provides the average orthophosphate and ammonia concentrations in and out of the AirPrex pilot reactor throughout the test. The data for Digester 9 and Digester 10 presented in Table 23 cover the period of Pilot Phase 2 (Stitt et al., 2017). 
Table 23: Summary of AirPrex Performance Data

\begin{tabular}{|l|l|l|l|}
\hline \multicolumn{2}{|l|}{ Inflow (mg/L) } & Outflow (mg/L) & Reduction \\
\hline Orthophosphate & 18.7 & $90.7 \%$ \\
\hline Average for entire test & 202.3 & 18.2 & $90.8 \%$ \\
\hline Digester 9 & 197.9 & 19.0 & $90.8 \%$ \\
\hline Digester 10 & 206.1 & 1,597 & $14.2 \%$ \\
\hline Ammonia & 1,408 & $14.6 \%$ \\
\hline Average for entire test & 1,862 & 1,716 & $16.3 \%$ \\
\hline Digester 9 & 1,648 & & \\
\hline Digester 10 & 2,049 &
\end{tabular}

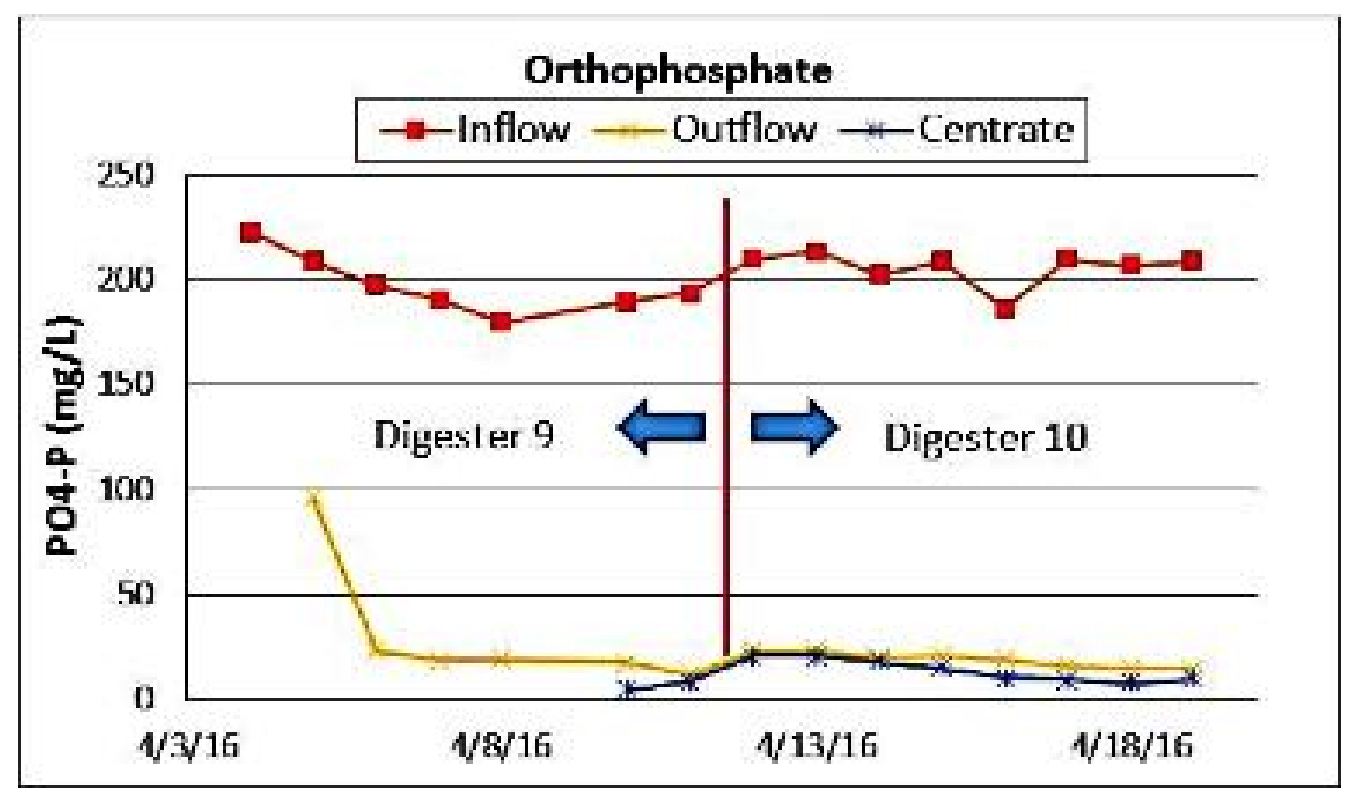

Figure 60: AirPrex Orthophosphate Monitoring 


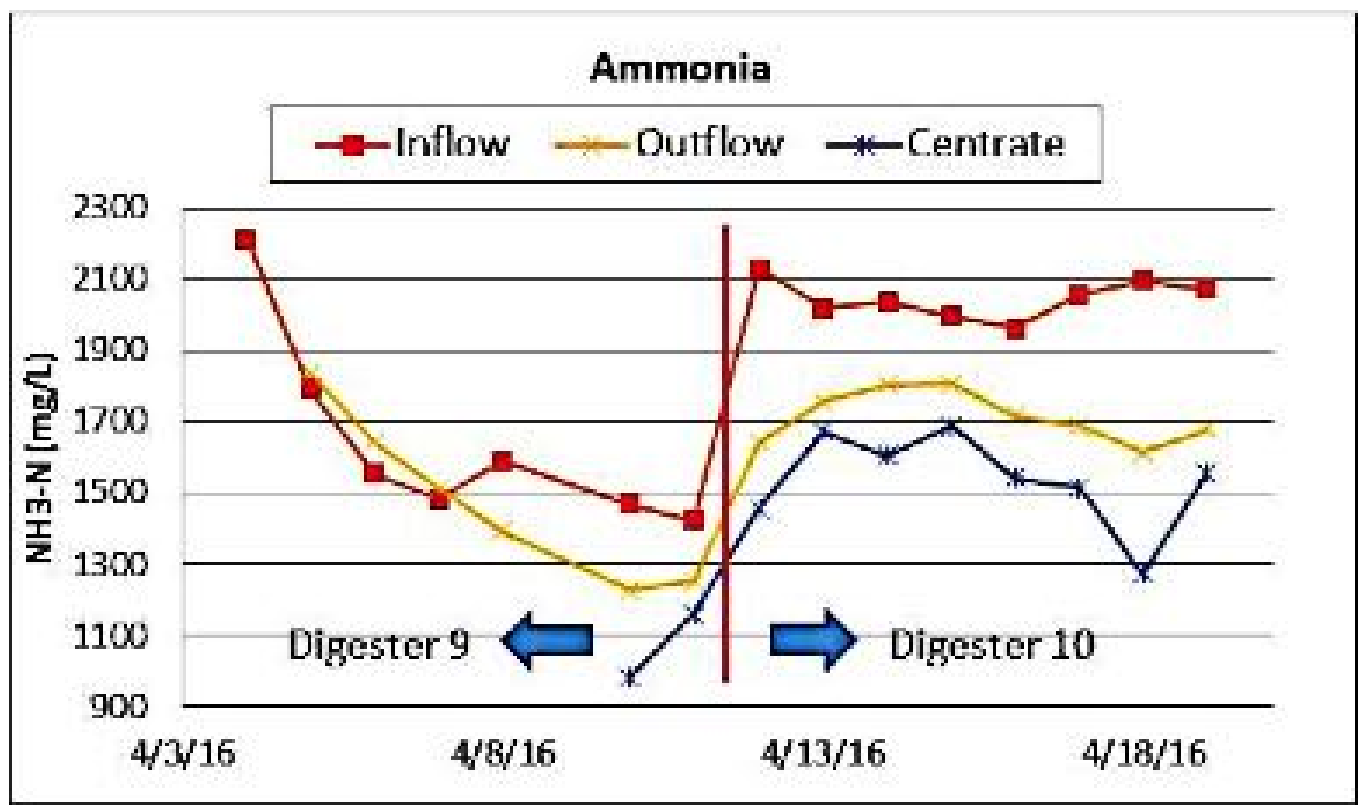

Figure 61: AirPrex Ammonia Monitoring

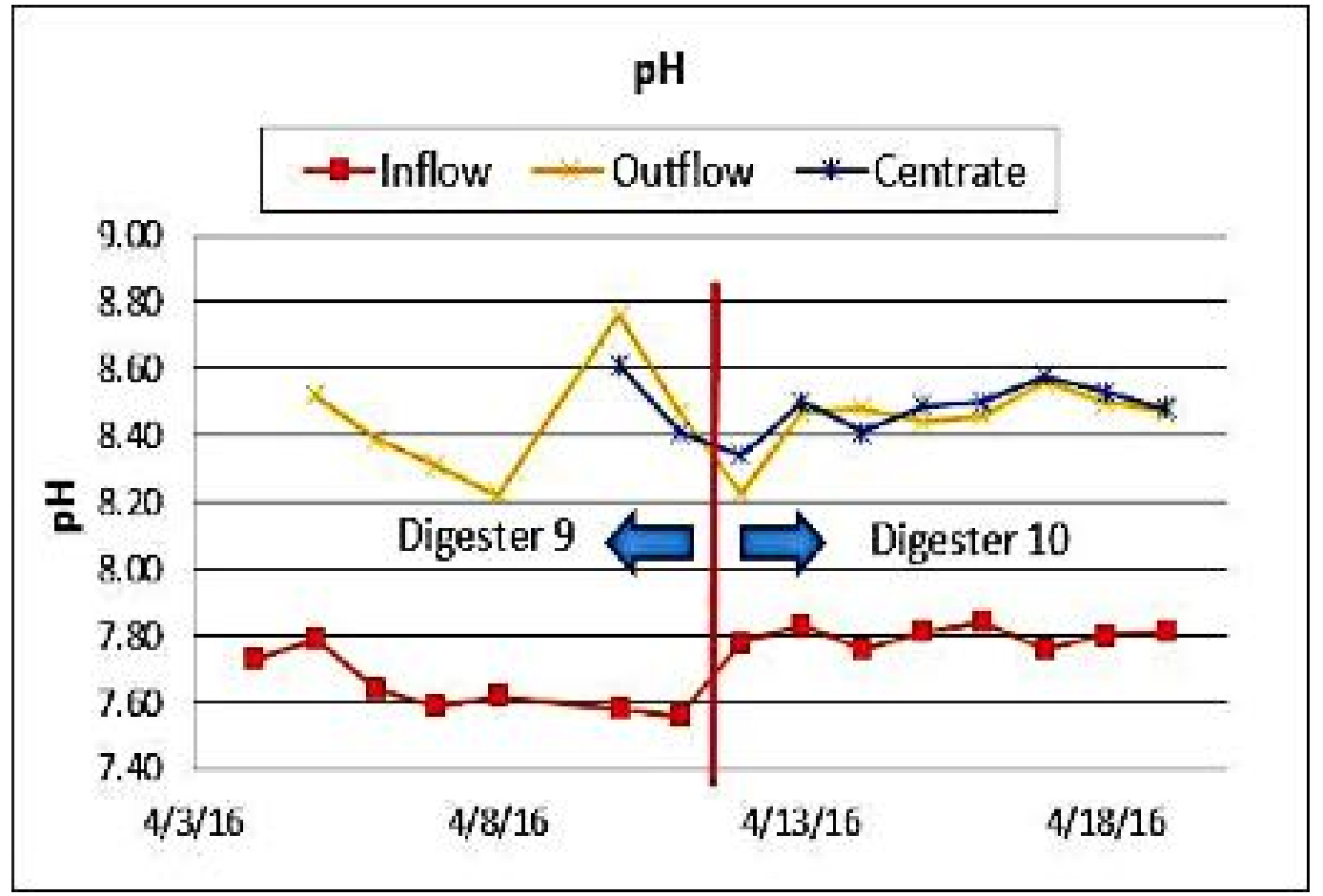

Figure 62: AirPrex pH Monitoring 
From the reactor, the struvite collected in the cone was sent to a grit washer but limitations in the pilot set up showed that the struvite recovered was in a crude form and contained sludge and other debris. Pictures of the struvite product are provided in Figure 63.
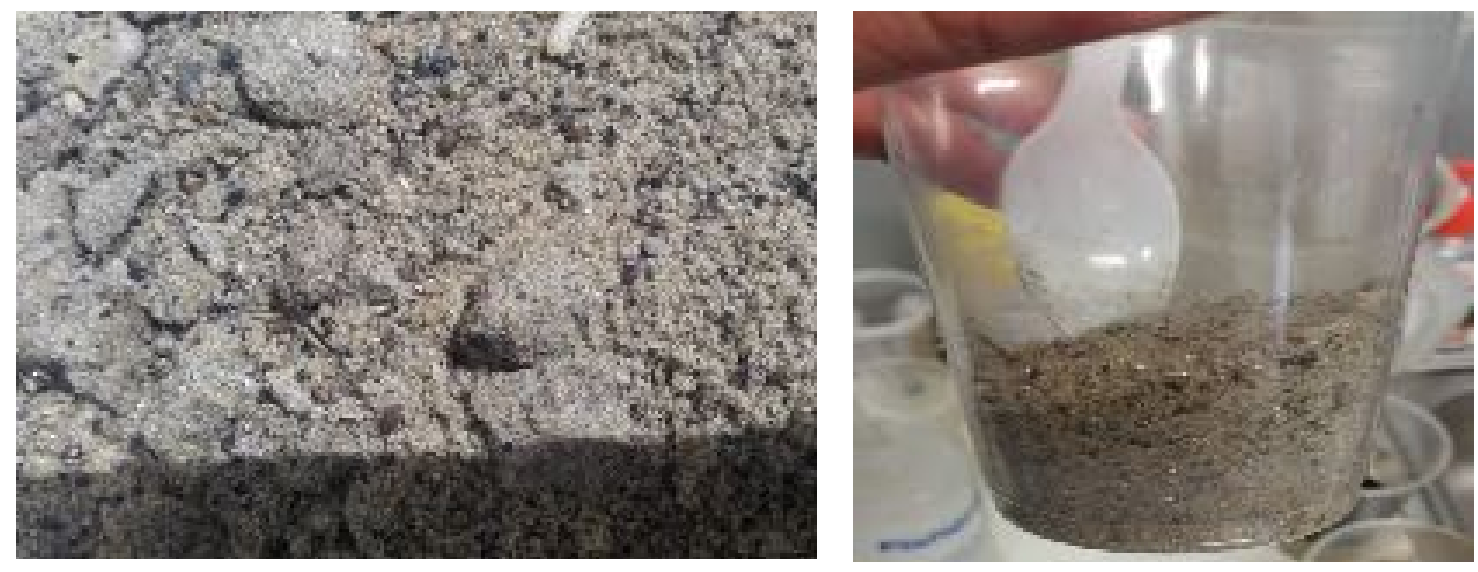

Figure 63: Recovered Struvite Product

Dewatering results during Airprex trials

The majority of the dewatering testing with Airprex was conducted with the same dry polymer used in the plants existing dewatering centrifuges and previously used in the dewatering tests (Polydyne C-3283) at a targeted concentration of $0.4 \%$ TS. However, some additional testing was also conducted with emulsion polymer, based on results from onsite jar testing. 
The first week of dewatering operation, using sludge from Digester 9, was performed to optimize the machine for the AirPrex treated biosolids but because of the dilution issue, the results could not be directly compared to the previous pilot dewatering testing conducted without AirPrex pretreatment. Optimization included adjusting pool depths, bowl speeds, differential speed, and polymer dosing. The initial dewatering results were, however, promising and results of greater than $21 \%$ TS were being achieved compared to $18 \%$ TS prior to starting the AirPrex struvite control system.

Because of the dilution in Digester 9, it was decided to conduct sequential testing with and without AirPrex treated digested biosolids to gauge the impact of the technology on dewaterability of SDWWTP's digested biosolids. Since the concentration in Digester 9 was diluted, the feed to the AirPrex unit and to the pilot centrifuge was switched from Digester 9 to Digester 10 on April 12, 2016 and the remainder of the Pilot Phase 3 dewatering tests were conducted using the digested biosolids from Digester 10 (Stitt et al., 2017).

Dry polymer curve testing

In order to better gauge the impact that the AirPrex treatment had on the dewaterability of the digested biosolids from Digester 10, several dry polymer curve tests were conducted at 45, 60 and $80 \mathrm{gpm}(170,227$, and $303 \mathrm{~L} / \mathrm{min})$ with and without AirPrex pretreatment. The flowrate, feed concentrations, dry polymer concentration and dates for these tests is summarized in Table 24. For all of the tests the bowl speed was maintained at $93 \%$, which is equal to 3,100 revolutions per minute (RPM). 
Table 24: Summary of Dry Polymer Curve Tests from Digester 10

\begin{tabular}{|l|l|l|l|l|l|l|}
\hline \multirow{2}{*}{$\begin{array}{l}\text { Flow } \\
(\mathrm{gpm})\end{array}$} & \multicolumn{3}{|l|}{ Test with AirPrex } & \multicolumn{3}{l|}{ Test without AirPrex } \\
\cline { 2 - 7 } \\
$\begin{array}{l}\text { Feed } \\
(\% \mathrm{TS})\end{array}$ & $\begin{array}{l}\text { Polymer }(\% \\
\text { TS) }\end{array}$ & Date & $\begin{array}{l}\text { Feed } \\
(\% \mathrm{TS})\end{array}$ & $\begin{array}{l}\text { Polymer }(\% \\
\text { TS) }\end{array}$ & Date \\
\hline 45 & $2.40 \% \mathrm{TS}$ & $0.44 \% \mathrm{TS}$ & $4 / 16 / 16$ & $2.45 \% \mathrm{TS}$ & $0.46 \% \mathrm{TS}$ & $4 / 15 / 16$ \\
\hline 60 & $2.48 \% \mathrm{TS}$ & $0.43 \% \mathrm{TS}$ & $4 / 13 / 16$ & $2.40 \% \mathrm{TS}$ & $0.43 \% \mathrm{TS}$ & $4 / 13 / 16$ \\
\hline 80 & $2.54 \% \mathrm{TS}$ & $0.43 \% \mathrm{TS}$ & $4 / 13 / 16$ & $2.42 \% \mathrm{TS}$ & $0.42 \% \mathrm{TS}$ & $4 / 14 / 16$ \\
\hline
\end{tabular}

All of the dry polymer curves conducted with and without AirPrex on the digested biosolids from Digester 10 are summarized in Figure 64 and Figure 65. The data for all three polymer curves show that with AirPrex pretreatment, the sludge dewatering was improved, allowing close to a 3\%-point increase in the dry solids content at the same polymer dosing rate. The data also show that the driest cake achievable without AirPrex pretreatment can be achieved with AirPrex pretreatment at a lower polymer dose. When comparing the trends with and without AirPrex, however, it can be seen that without AirPrex, the optimal polymer dose, meaning the point where additional polymer dose does not improve cake solids, is lower without AirPrex than with AirPrex. Table 25 summarizes the optimal point based on the polymer curves with and without AirPrex treatment.

Table 25: Optimal Settings for Flow based on the Polymer Curves from

\section{Digester 10}

\begin{tabular}{|l|l|l|l|l|l|l|l|l|}
\hline & \multicolumn{9}{|l|}{ AirPrex } & \multicolumn{2}{l|}{ No AirPrex } \\
\cline { 2 - 9 } $\begin{array}{l}\text { Flow } \\
(\mathrm{gpm})\end{array}$ & $\begin{array}{l}\text { Cake } \\
(\% \mathrm{TS})\end{array}$ & $\begin{array}{l}\text { Solids } \\
\text { Recovery } \\
(\%)\end{array}$ & $\begin{array}{l}\text { Polymer } \\
(\mathrm{lb} / \mathrm{DT})\end{array}$ & $\begin{array}{l}\text { Differential } \\
\text { Speed } \\
(\mathrm{RPM})\end{array}$ & $\begin{array}{l}\text { Cake } \\
(\% \mathrm{TS})\end{array}$ & $\begin{array}{l}\text { Solids } \\
\text { Recovery } \\
(\%)\end{array}$ & $\begin{array}{l}\text { Polymer } \\
(\mathrm{lb} / \mathrm{DT})\end{array}$ & $\begin{array}{l}\text { Differential } \\
\text { Speed } \\
(\mathrm{RPM})\end{array}$ \\
\hline 45 & $23.0 \%$ & $93.9 \%$ & 31.1 & 1.4 & $20.4 \%$ & $95.0 \%$ & 29.8 & 2 \\
\hline 60 & $21.5 \%$ & $93.8 \%$ & 32.0 & 2.2 & $18.7 \%$ & $96.9 \%$ & 29.7 & 3.3 \\
\hline 80 & $20.8 \%$ & $95.6 \%$ & 30.9 & 3.1 & $18.4 \%$ & $96.5 \%$ & 28.7 & 4.1 \\
\hline
\end{tabular}




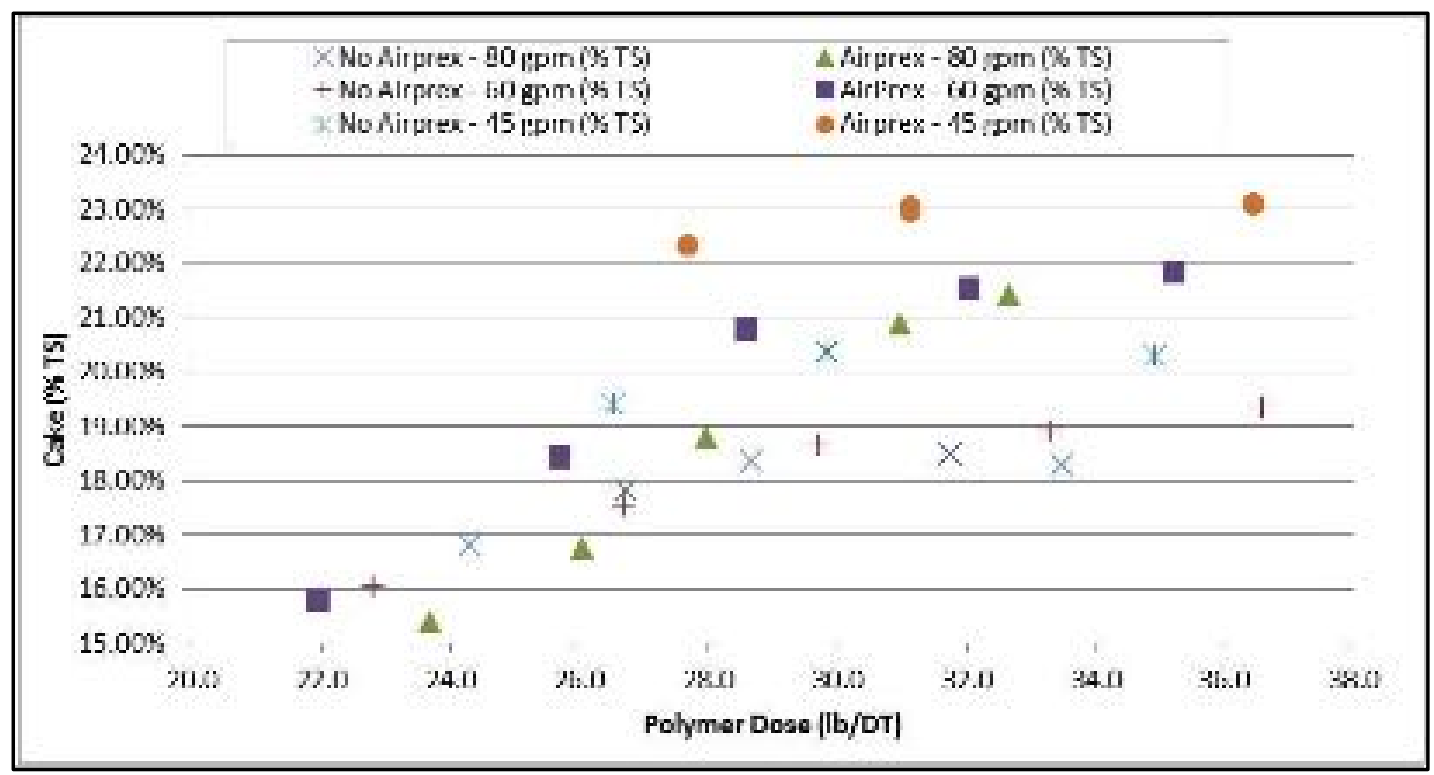

Figure 64: Summary of sludge cake solids versus polymer dose for Digester 10 - Dry Polymer with and without AirPrex

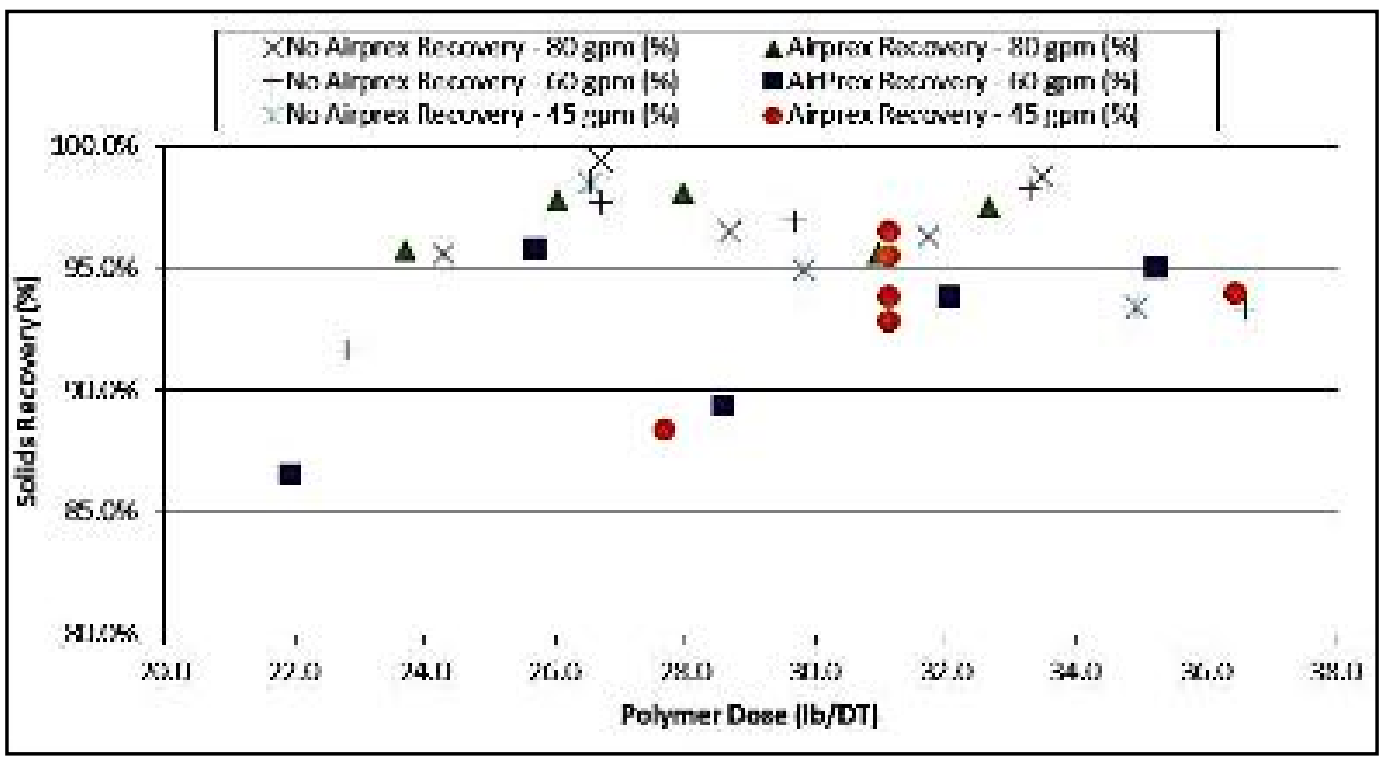

Figure 65: Summary of solids recovery versus polymer dose for Digester 10 Dry Polymer with and without AirPrex 
The data show that with lower throughputs, lower differential speeds can be maintained, and dryer cake can be produced with AirPrex treatment compared to operation without AirPrex treatment. The results also indicated that with AirPrex treatment, up to 21 to $23 \%$ TS cake could be achieved with recoveries at or above $93 \%$ when a 30 to $32 \mathrm{lb} / \mathrm{DT}$ ( 15 to $16 \mathrm{~g} / \mathrm{kg}$ ) active polymer dosage rate was used. This is compared to operation without AirPrex that shows 18 to $20 \%$ TS cake can be achieved with recoveries at or above $95 \%$ when a 29 to $30 \mathrm{lb} / \mathrm{DT}$ ( 14.5 to $15 \mathrm{~g} / \mathrm{kg}$ ) active polymer dosage rate was used (Stitt et al., 2017).

Extended operation testing

In order to test the stability of dewatering operation for the AirPrex treated digested biosolids, several extended operation tests were conducted at 45, 60 and 80 gpm (170, 227, and $303 \mathrm{~L} / \mathrm{min})$ using digested biosolids from Digester 10. For all of the tests, the bowl speed was maintained at 93\% (3,100 RPM) and polymer concentrations were approximately $0.4 \%$ TS. With the tests conducted at 60 and 80 gpm (227 and 303 $\mathrm{L} / \mathrm{min}$ ), the testing started with an extended run on non-AirPrex treated biosolids based on the optimal settings and then switched to AirPrex treated biosolids to see the impact over the course of the run.

On April 14, 2016, an extended operation test was conducted at $60 \mathrm{gpm} \mathrm{(227}$ $\mathrm{L} / \mathrm{min}$ ), targeting the optimal setting from Table 25 , and the results are summarized in Figure 64 and Figure 65. When running on the non-AirPrex treated biosolids with a differential speed of $3.3 \mathrm{RPM}$ and a polymer dose of $27.6 \mathrm{lb} / \mathrm{DT}(13.8 \mathrm{~g} / \mathrm{kg})$ active, the centrifuge dewatered the biosolids from approximately $2.4 \%$ TS to $18.9 \%$ TS with a 
solids recovery of $97.7 \%$. When the centrifuge feed was switched to AirPrex treated biosolids at the same polymer dose $(27.6 \mathrm{lb} / \mathrm{DT}$ or $13.8 \mathrm{~g} / \mathrm{kg}$ active) but with a lower differential speed of 2.5 RPM, the dewatered cake solids increased to 20.1\% TS (starting with a $2.5 \%$ TS feed) and recoveries were maintained at $98.2 \%$. Further increasing the polymer dose to $31 \mathrm{lb} / \mathrm{DT}(15.5 \mathrm{~g} / \mathrm{kg})$ active improved the dewatered cake solids to $21.3 \%$ TS and recoveries were near $100 \%$. Because of the high recovery, the differential was further reduced to $2.3 \mathrm{RPM}$ but this did not show improvement in dewatering and recoveries were still at 98.5\%. During the run on April 14, 2016, the non-AirPrex treated feed averaged $2.4 \%$ TS and the AirPrex treated feed averaged $2.5 \%$ TS. The polymer concentration averaged $0.42 \% \mathrm{TS}$. The results, based on the optimal setting, matched the results indicated by the previously conducted polymer curve shown in Figure 64 and Figure 65.

On April 15, 2016, an extended operation test was conducted at $80 \mathrm{gpm}$ (303 $\mathrm{L} / \mathrm{min}$ ) and the results are summarized in Figure 67. The test targeted the optimized setting outlined in Table 25 but the testing was further expanded to gauge the impacts on the differential speed and polymer dose on dewaterability. The test started with nonAirPrex treated biosolids using the optimized differential speed settings (3.1 RPM) and polymer dose settings $(31.4 \mathrm{lb} / \mathrm{DT}$ or $15.7 \mathrm{~g} / \mathrm{kg}$ ) for the AirPrex treated biosolids. At these settings, up to $19.3 \%$ TS cake was produced but recovery was only $83.6 \%$. When the differential was increased to 4.2 RPM and the polymer dose was reduced to 28.4 lb/DT (14.2 g/kg), the dewatering was reduced to $18.3 \%$ TS but recoveries improved to 93\%. When switching to the AirPrex treated biosolids without adjusting any of the centrifuge parameters, the dewatered cake solids improved to $19.9 \%$ TS and recoveries 
improved to $98.1 \%$. Lowering the differential to 3.2 RPM with the same polymer dose increased the dewatered cake solids to $20.7 \%$ TS and recoveries were still high at $97.1 \%$ (Stitt et al., 2017).

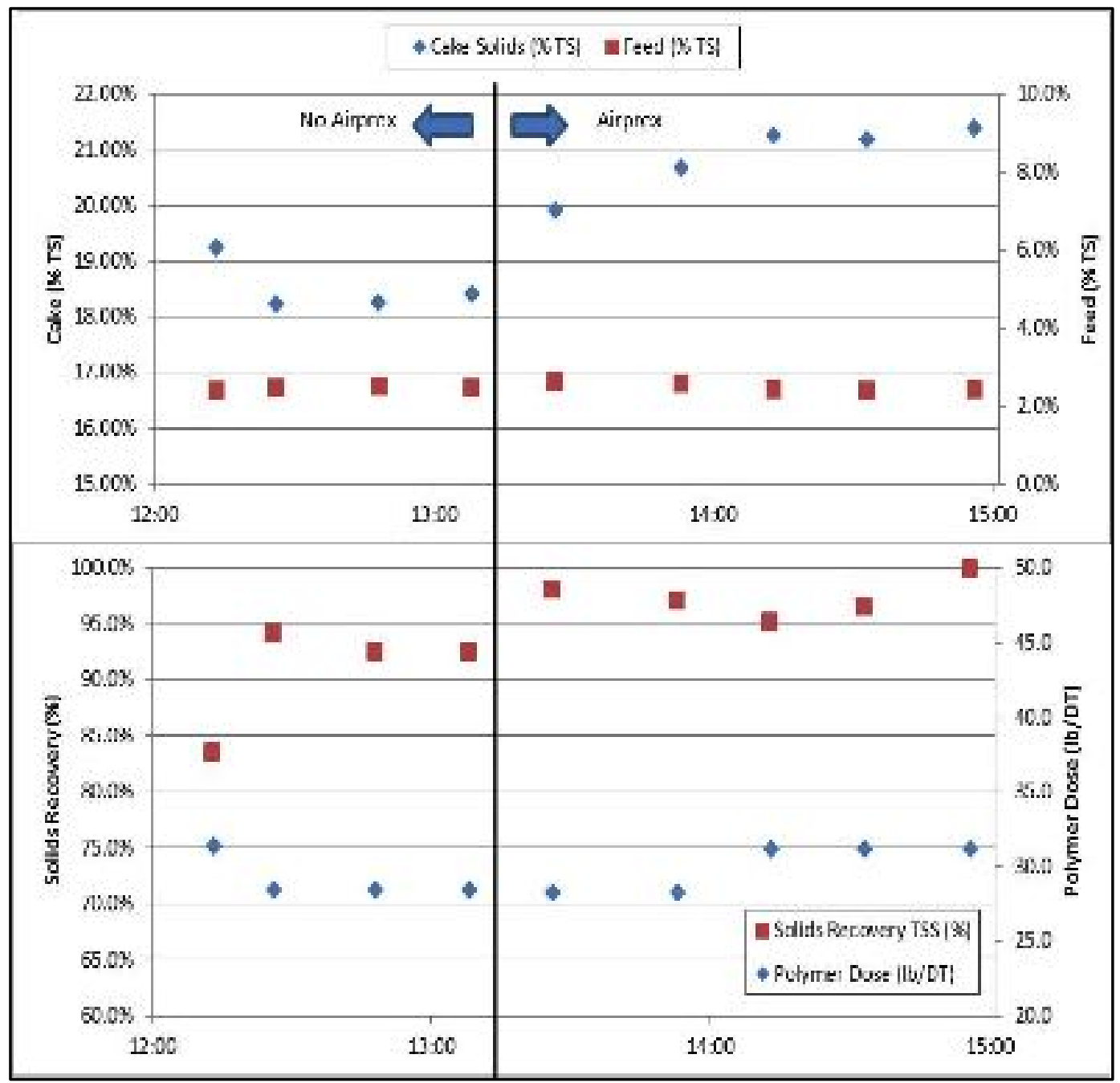

Figure 66: Centrifuge Operation with Dry Polymer @ 60 gpm (4/14/16) 


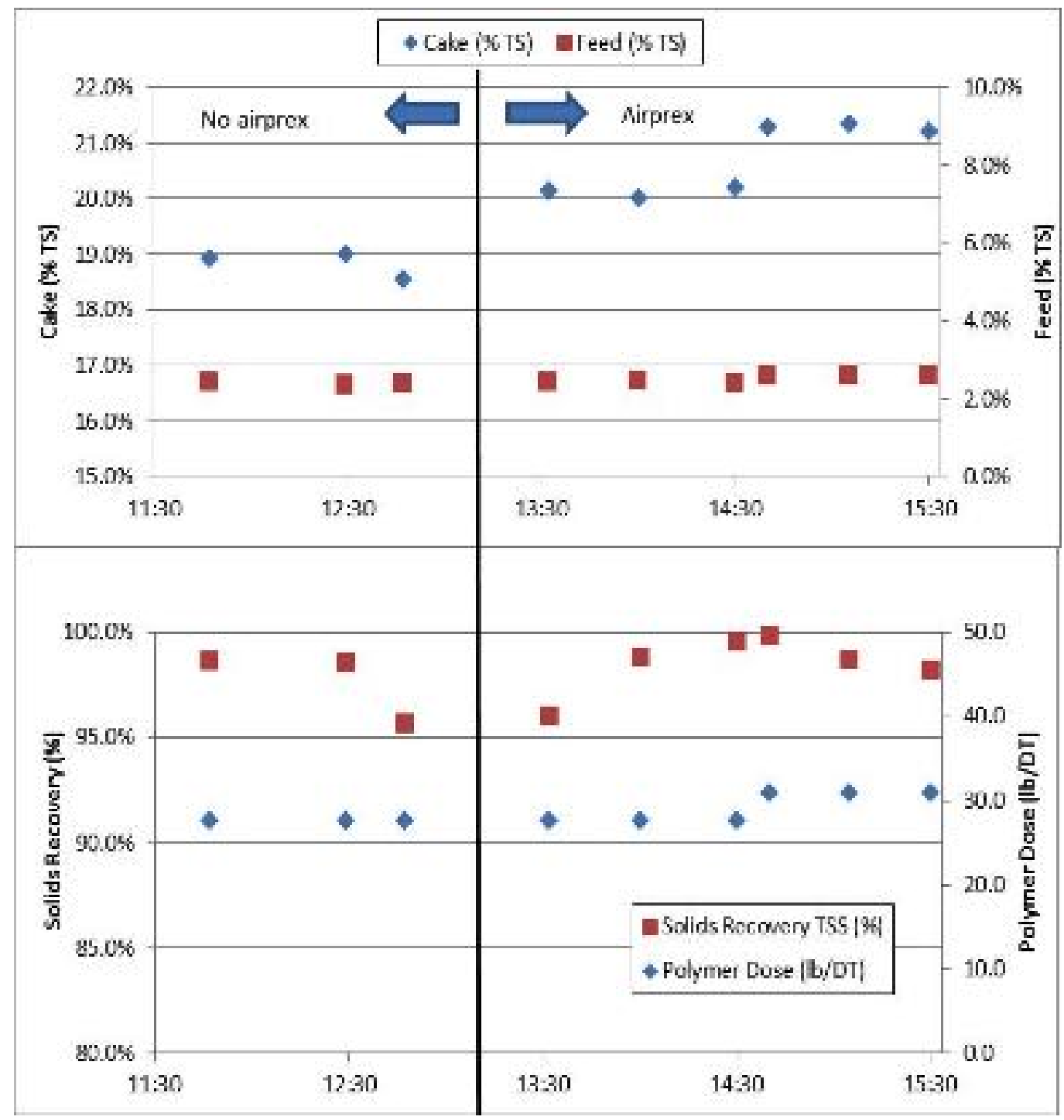

Figure 67: Centrifuge Operation with Dry Polymer@80 gpm (4/15/16)

Finally, when adjusting the differential speed and polymer to the optimized AirPrex setting outlined in Table 25 at $3.1 \mathrm{RPM}$ and $31.2 \mathrm{lb} / \mathrm{DT}$ [15.6 g/kg] active polymer does, the dewatered cake solids improved to $21.3 \%$ TS with recoveries of $97.3 \%$ showing slightly better results than indicated by the previously conducted polymer curve (Figure 66 and Figure 67). Throughout the testing, the feed biosolids concentration, both with and without AirPrex treatment, averaged 2.5\% TS and the polymer concentration averaged $0.43 \% \mathrm{TS}$. 
On April 16, 2016 an extended operation test was conducted at 45 gpm (170 $\mathrm{L} / \mathrm{min})$ right after conducting the $45 \mathrm{gpm}(170 \mathrm{~L} / \mathrm{min})$ polymer dose test with AirPrex treated sludge. The testing showed that when operating at a 1.5 RPM differential speed and an active polymer dose of $31.1 \mathrm{lb} / \mathrm{DT}(15.6 \mathrm{~g} / \mathrm{kg})$ that dewatering up to $23.0 \% \mathrm{TS}$ with recoveries at $95 \%$ were possible. The marginal increase in differential speed allowed the solids recoveries to improve to $95 \%$. The feed solids concentration during this run averaged $2.4 \%$ TS and the polymer concentration averaged $0.44 \%$ TS (Stitt et al., 2017).

\subsection{CDWWTP Pilot Phase 3 - dewatering pilot testing}

The purpose of the dewatering pilot operation was to determine the optimal design conditions and performance of the dewatering centrifuge using the thickened biosolids fed from the test digester. The overall target for the centrifuge dewatering performance as stated in the basis of design and specifications was to dewater the thickened digested biosolids to greater than $24 \%$ TS while maintaining greater than $95 \%$ solids recovery. The necessary polymer dose to achieve this performance is also important to determine. The target active polymer dose should be less than $25 \mathrm{lb} / \mathrm{DT}$ based on previously historical polymer consumption ranges and those of other facilities. Metcalf and Eddy $5^{\text {th }}$ edition lists 22 to $25 \%$ TS expected for anaerobically digested WAS and primary sludge. For anaerobically digested WAS and primary sludge, the polymer consumption is expected to be 15 to $30 \mathrm{lb} / \mathrm{DT}$ active polymer dose and solids recoveries are expected to be $95 \%$ or greater (Metcalf et al. $5^{\text {th }}$ edition, 2013). CDWWTP currently doses ferric sulfate at a rate of 1.9 gallons per 1000 gallons of 
sludge ahead of their centrifuges for struvite control, a struvite control method first implemented in 2010 (Mudragada et al., 2014). This practice is planned to continue in the future operation, so a temporary ferric dosing system was also included with the pilot.

Dewatering pilot testing - setup

For the dewatering pilot, the system was set up and tested with emulsion and dry polymer. Additionally, the digested sludge was conditioned with ferric sulfate prior to dewatering, similar to the current CDWWTP dewatering operation. The majority of the testing was conducted using the plant's dry polymer, which is more representative of the future design, however, some limited testing was also conducted using emulsion polymer to provide a comparison.

Initial dewatering operation was dedicated to optimizing the machine for the sitespecific operation. Adjustable parameters included the pool depth, bowl speed and differential scroll speed. The pool depth was adjusted manually through adjustment of the outlet weir plate and throughout all of the dewatering operation, the system was operated with the B weir plate which corresponds to the second deepest pool depth. For most of the dewatering operation the centrifuge also operated at the highest bowl speed of $3,350 \mathrm{rpm}$. It was also found that injecting polymer directly into the feed tube was the best injection point compared to other polymer injection locations tested.

Initial testing started with emulsion polymers on August 11, 2016. Three cationic, high molecular weight emulsion polymers were tested in order to determine the top polymer type for further testing. The emulsion polymers were able to achieve 21 to 
$26 \%$ TS with greater than $95 \%$ solids recovery, but required higher polymer doses than the target dose at more than $30 \mathrm{lb} / \mathrm{DT}(15 \mathrm{~g} / \mathrm{kg})$. Since the emulsion polymer dosing requirements were high compared to the target dose for a dry polymer, only limited further testing was conducted using emulsion polymer (Moncholi et al., 2018).

Dewatering pilot testing - polymer curve testing

The dry polymer used for all of the dewatering testing was Polydyne Clarifloc CSE-1141 that is currently used for the CDWWTP dewatering centrifuges. The dewatering centrifuge dry polymer testing and dosing was optimized to start performance testing on August 17, 2016.

Polymer curve tests were conducted by maintaining a constant volumetric throughput of digested biosolids feed to the centrifuge while changing the polymer dose to measure the impact. With the exception of changing polymer dose, most of the other parameters on the centrifuge remained the same for each polymer curve test.

Polymer curve tests were conducted primarily on dry polymer with feed tube polymer injection. Testing was mostly done with ferric sulfate dosing but testing without dosing ferric sulfate was also done as a comparison as visually noticeable in Figure 70. The data for this comparison are shown in Figure 68 and Figure 69. The cake solids ranged from $23.5 \%$ to $26.3 \%$ TS with addition of ferric sulfate. Without the addition of ferric sulfate the cake solids were 3 to $4 \%$ points lower ranging from $21 \%$ to $24 \%$ TS. The difference in solid content was visibly noticeable as can be seen in Figure 70 . 
Without the addition of ferric sulfate, the solids recovery was also noticeably worse than operation with ferric sulfate.

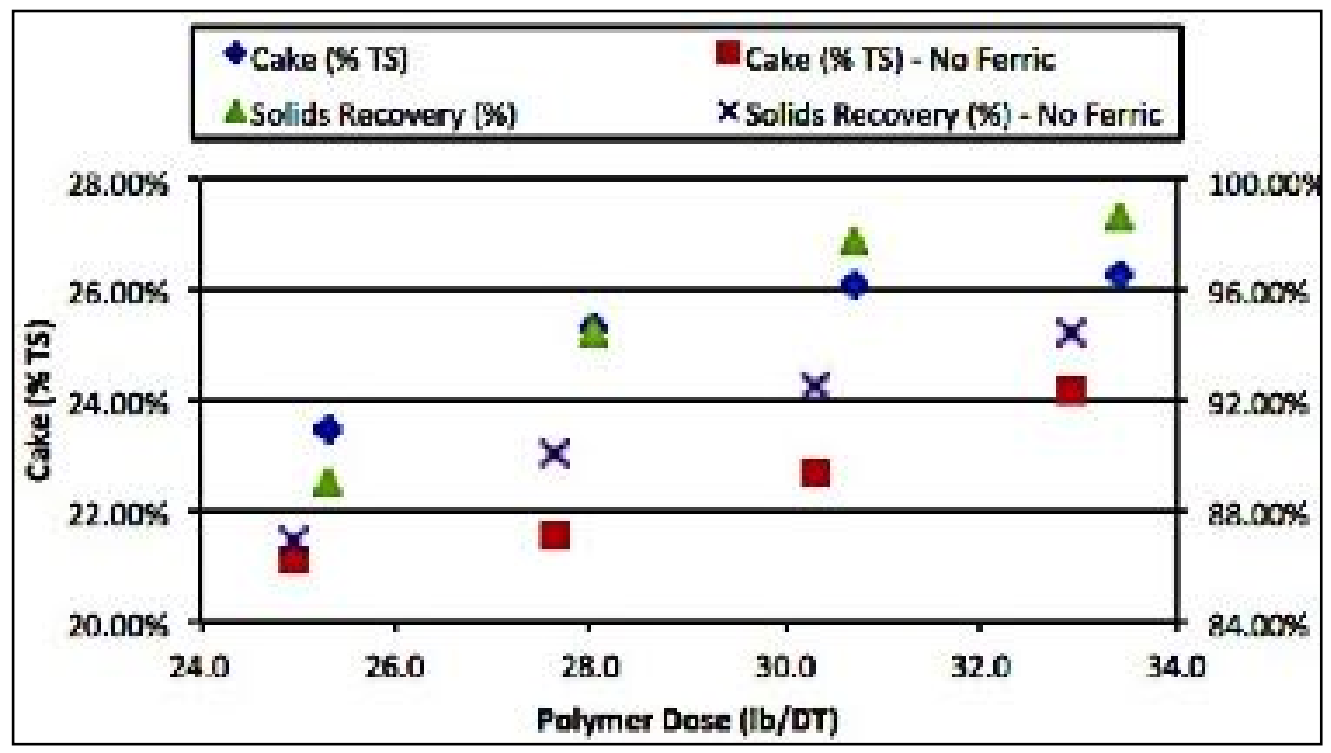

Figure 68: CDWWTP Dewatering Polymer Curve Testing with and without ferric sulfate 


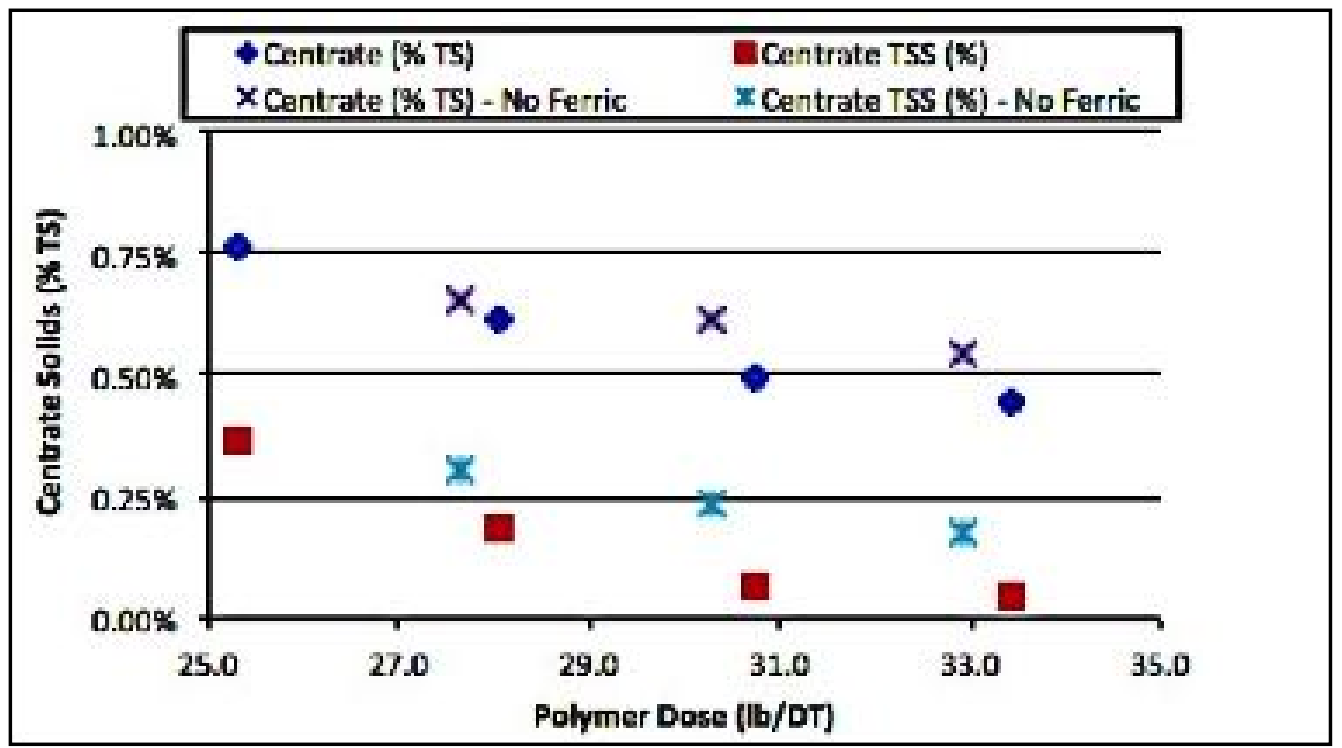

Figure 69: CDWWTP centrate concentration for dewatering polymer testing with and without ferric sulfate

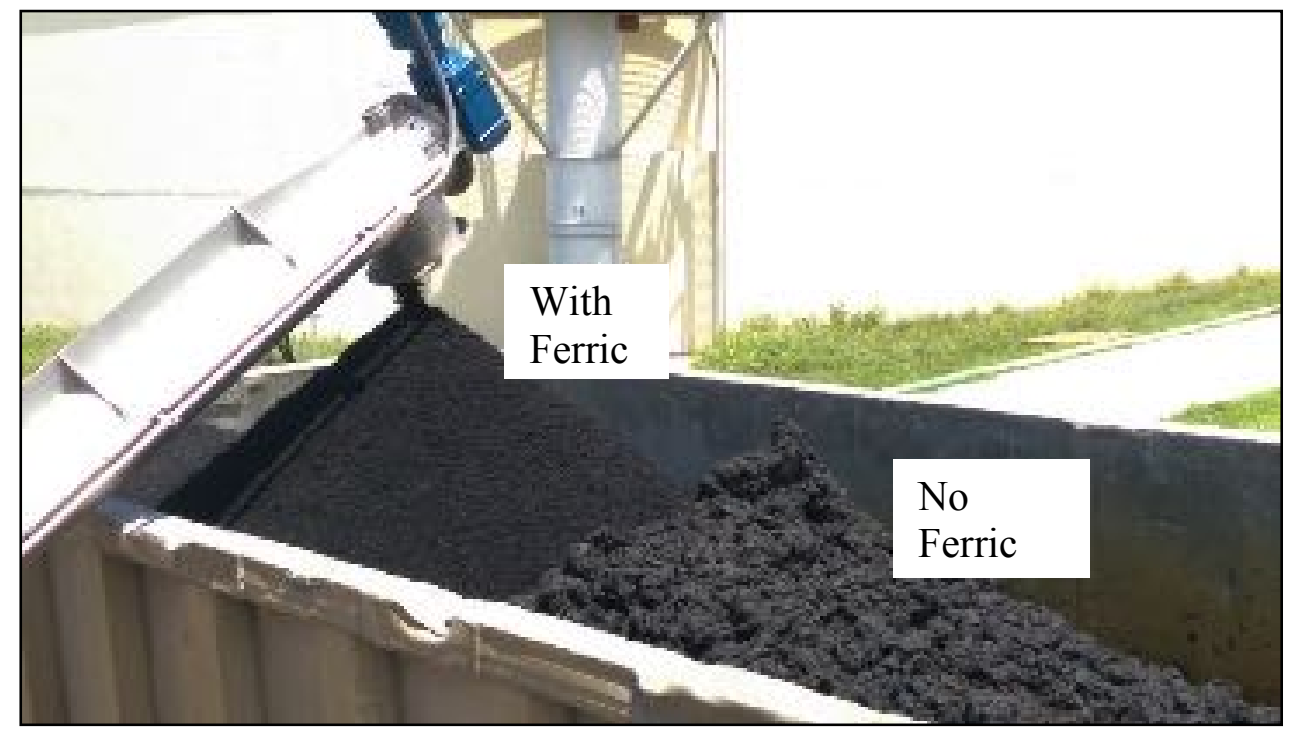

Figure 70: CDWWTP Dewatering with and without ferric sulfate 
Dewatering pilot testing - extended operation results

In addition to polymer curve tests, the dewatering centrifuge was operated two days at a constant flowrate to test the stability of operation throughout the course of a day. Two tests were conducted at $80 \mathrm{gpm}\left(18.2 \mathrm{~m}^{3} / \mathrm{h}\right)$ using dry polymer. Throughout the course of the test, it was desired to maintain constant settings. However, periodic adjustments were made based on visual observations of both the dewatered solids concentration and the centrate quality. Samples were collected during these trials approximately once every $30 \mathrm{~min}$ to 1 hour depending on the total duration of the particular test.

One extended run using dry polymer is shown in Figure 71 and Figure 72. Performance during this run was stable with dewatered cake solids averaging $25 \%$ TS and solids recoveries averaging over $98 \%$ for all samples collected. The feed during this run was consistent, averaging $3 \%$ TS. The differential speed was held at 3 RPM during 5 hours of operation. The power consumption averaged about $0.19 \mathrm{~kW} / \mathrm{gpm}(0.83$ $\mathrm{kW} /(\mathrm{m} 3 / \mathrm{hr}))$. The polymer concentration during this run averaged $0.8 \%$ and the active polymer dose averaged $25.8 \mathrm{lb} / \mathrm{DT}(12.9 \mathrm{~g} / \mathrm{kg})$. 


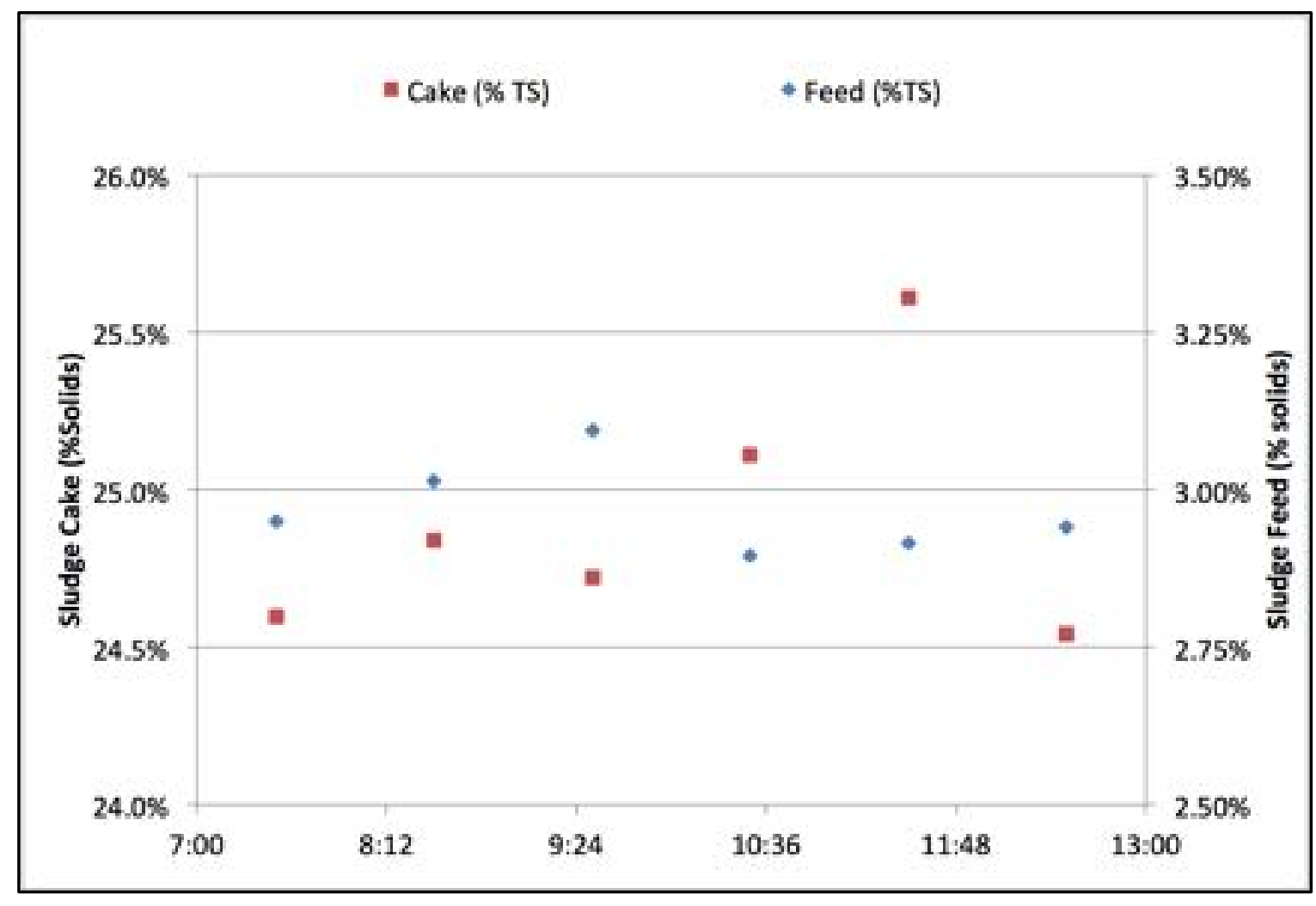

Figure 71: Sludge Feed and Cake Concentrations under Extended Operation using Dry Polymer on August 19, 2016 


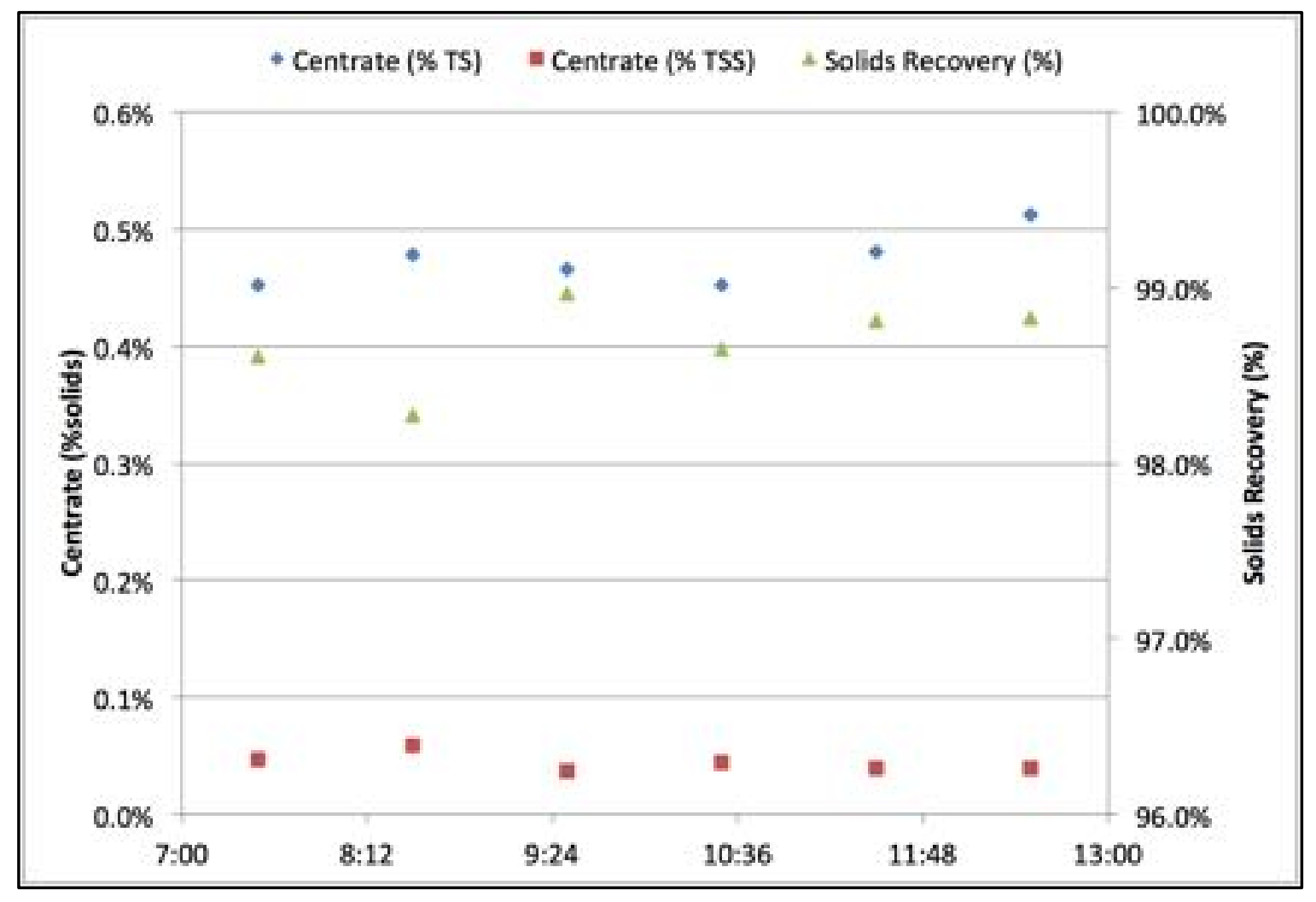

Figure 72: Centrate Concentrations and Solids Recovery under Extended Operation using Dry Polymer on August 19, 2016

The results of the dewatering piloting indicate that the centrifuge dewatering unit will be able to achieve a total cake solids of $\geq 24 \%$ TS and solids recovery requirements of $\geq 95 \%$. The testing showed that $>24 \%$ TS cake could be achieved with $25 \mathrm{lb} / \mathrm{DT}(12.5$ $\mathrm{g} / \mathrm{kg}$ ) active dosing of dry polymer and a ferric sulfate dose equal to 1.9 gal ferric sulfate per 1,000 gal of sludge. Testing conducted without the use of ferric sulfate conditioning showed that dewatering performance was reduced by 2 to $4 \%$ TS in cake solids and that solids recovery percentages were lower. The centrifuge could achieve 26 to $28 \%$ TS with emulsion polymer, but the polymer dosages are higher and almost double than the desired maximum of $25 \mathrm{lb} / \mathrm{DT}(12.5 \mathrm{~g} / \mathrm{kg}$ ) active polymer (Moncholi et al., 2018). 
6.5 Chapter Summary: Discussion of results, Impact of pilot tests on model inputs and other model assumptions for sludge dewatering

The SDWWTP Pilot Phase 3 dewatering testing showed that 16 to $18 \%$ TS cake could be achieved with 20 to $30 \mathrm{lb} / \mathrm{DT}$ (10 to $15 \mathrm{~g} / \mathrm{kg}$ ) active dosing of dry polymer. The pilot testing showed that the dewatered cake solids were lower than the preliminary design value of $20 \%$ TS with a presumed $25 \mathrm{lb} / \mathrm{DT}(12.5 \mathrm{~g} / \mathrm{kg})$ active polymer when using dry polymer without sludge pretreatment. Dryer cake at 20 to $22 \%$ TS could be produced using emulsion polymer but required higher dosages, above $40 \mathrm{lb} / \mathrm{DT}(20 \mathrm{~g} / \mathrm{kg})$ active polymer. It was found that with removal of orthophosphate through struvite recovery within the digestion process resulted a 2 to $4 \%$ increase in the cake solids in the downstream dewatering process compared to operation without struvite recovery at similar active polymer dosages. The conclusion of the pilot determined that to achieve a greater than $20 \%$ cake solids, and to up to $22 \%$ cake solids, was achieved with AirPrex pretreatment as a means of orthophosphate removal, compared to $19 \%$ without digested sludge conditioning using 25 to $35 \mathrm{lb} / \mathrm{DT}$ (12.5 to $17.5 \mathrm{~g} / \mathrm{kg}$ ) active polymer dosages.

The results of the CDWWTP Pilot Phase 3 dewatering piloting indicate that the centrifuge dewatering unit will be able to achieve a total cake solids of $\geq 24 \%$ TS and solids recovery requirements of $\geq 95 \%$. The testing showed that $>24 \%$ TS cake could be achieved with $25 \mathrm{lb} / \mathrm{DT}(12.5 \mathrm{~g} / \mathrm{kg})$ active dosing of dry polymer and a ferric sulfate dose equal to 1.9 gal ferric sulfate per 1,000 gal of sludge. Testing conducted without the use of ferric sulfate conditioning showed that dewatering performance was reduced by 2 to $4 \% \mathrm{TS}$ in cake solids and that solids recovery percentages were lower. The centrifuge 
could achieve 26 to $28 \%$ TS with emulsion polymer, but the polymer dosages were almost double the desired maximum of $25 \mathrm{lb} / \mathrm{DT}(12.5 \mathrm{~g} / \mathrm{kg})$ active polymer dose.

The dewatering portion of this pilot at SDWWTP accentuated the importance of properly identifying possible dewatering challenges, namely the impact of high struvite potential and that to achieve performance goals extra considerations may need to be added. The pilot results as a whole highlight the importance of piloting to determine operational difficulties and to refine design performance criteria.

Initial review of the historical plant data for the SDWWTP brought into question the reason for such low present day dewatered sludge, cake, \% solids as seen Figure 73, below. Add in that even with such a low cake solids concentration, the lowest average solids capture for sludge thickening or dewatering equipment came from the SDWWTP dewatering facility during the study period, averaging just under $82 \%$ solids capture. Through my discussions with plant operations the factors that contribute to these performance issues became apparent. Currently post dewatering open-air processes at the SDWWTP struggle to windrow sludge to $30 \%$ dryness or better and then stockpile the biosolids in hopes that contracted sludge haulers come to collect the Class B biosolids before constant summer rains soak in and saturate, turning a month's worth of work tilling and turning into naught. Emphasized by recent downpours such as Tropical Storm Gordon, the SDWWTP dewatering and post dewatering operations has been fighting a losing battle during the wet weather months. 


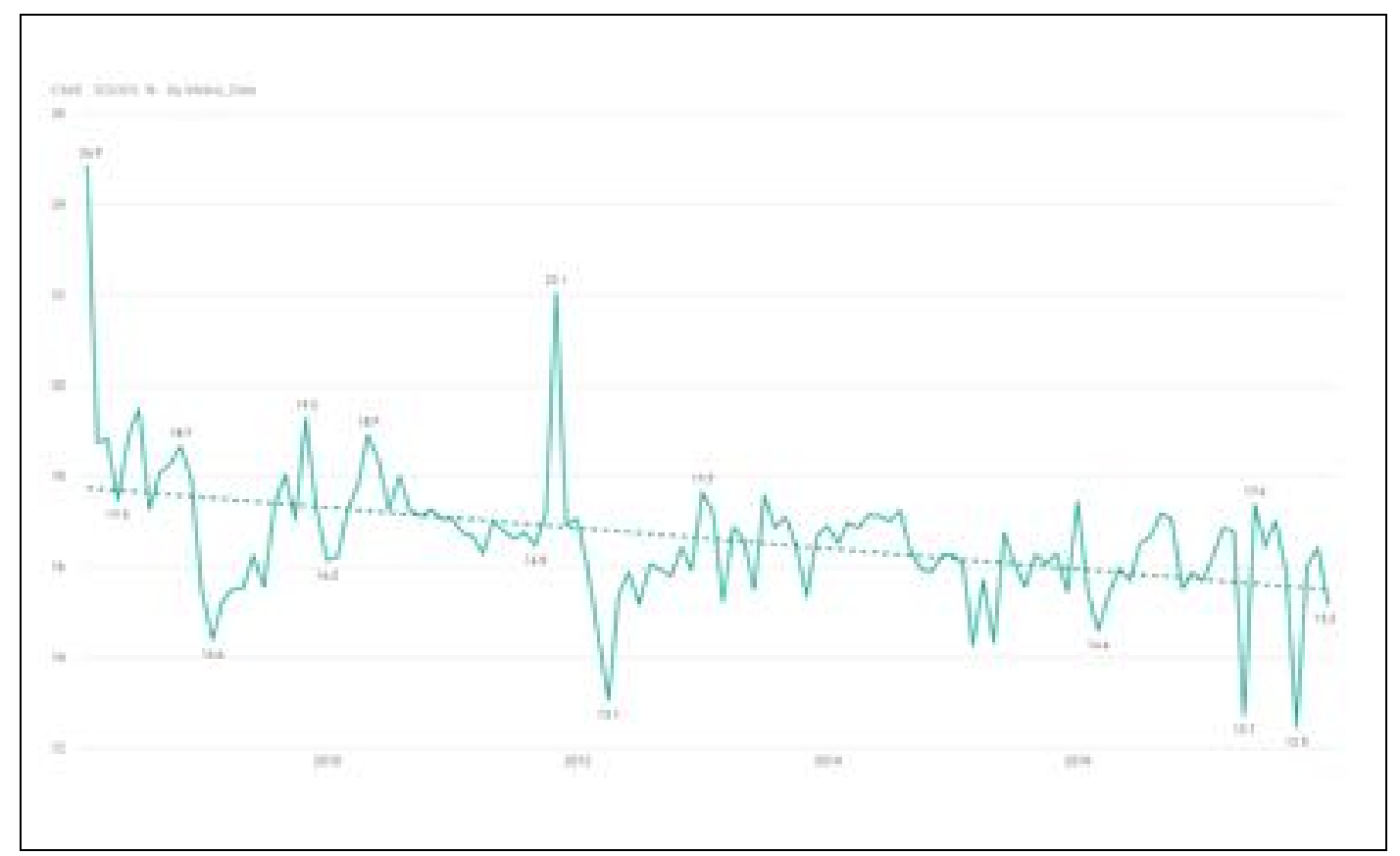

Figure 73: downward trend in SDWWTP dewatered cake \%solids

Therefore, the impetus in more effective sludge dewatering operations at SDWWTP is lost as the post dewatering process currently larger challenges that render upstream achieved gains as wasted effort. This viewpoint within operations is changing with the proposed construction of a new sludge dewatering facility as described in Scenarios SD-C, SD-D, and SD-E and a different biosolids management philosophy.

CDWWTP, on the other hand, boasts high percent solids and solids capture both in the historical and pilot data, 99\% solids capture with $24.5 \%$ cake solids as a historical average for the study period, and just under $98 \%$ solids capture and $26.5 \%$ cake solids during some of the better piloting runs at acceptable polymer consumption levels. The takeaway from historical data and piloting efforts for dewatering at SDWWTP and CDWWTP is that information can be deceiving if the story behind it is not known or understood. Some well placed effort in procuring pre-dewatering sludge conditioning, 
modern, smartly automated and energy-efficient dewatering centrifuges, and post dewatering, weather-tight cake storage capacity at SDWWTP and CDWWTP are capable of producing dewatered sludge cake that can be much more economic than using larger quantities of polymer, paying to dispose of cake made up of $80-85 \%$ water, and struggling to do so. The final input data for the MBM, dewatering operations are presented below in Table 26. 
Table 26: Sludge dewatering historical data, pilot measurements, calculated results and assumed values for SDWWTP and CDWWTP

\begin{tabular}{|c|c|c|c|c|c|c|c|c|c|c|c|}
\hline Dans Sourcex & $\begin{array}{l}\text { Besturied } \\
\text { Iteis }\end{array}$ & 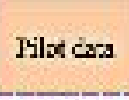 & $\begin{array}{l}\text { by desigh } \\
\text { eslarivicil }\end{array}$ & $\begin{array}{l}\text { na pind } \\
\text { doth, } \\
\text { asterod }\end{array}$ & $\begin{array}{l}\text { model calib } \\
\text { an histror }\end{array}$ & $\begin{array}{l}\text { crited, bused } \\
\text { ned, dite }\end{array}$ & & & & & \\
\hline 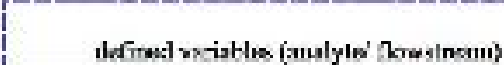 & [S unil & $\begin{array}{l}\text { SDWWTF } \\
\text { dist dies }\end{array}$ & $\begin{array}{l}\text { CDWWTP } \\
\text { plant tals }\end{array}$ & $\begin{array}{l}\text { SDWWTP } \\
\text { 3.2esriu B }\end{array}$ & $\begin{array}{l}\text { CDWWTT } \\
\text { Scensria B }\end{array}$ & $\begin{array}{l}\text { SDWWTP } \\
\text { Seasario } C\end{array}$ & $\begin{array}{l}\text { CDWWTP } \\
\text { Stmariv C }\end{array}$ & $\begin{array}{l}\text { SDWWTP } \\
\text { S.Rrmiu D }\end{array}$ & $\begin{array}{l}\text { CDWWTP } \\
\text { Scensria D }\end{array}$ & $\begin{array}{l}\text { SDWWTP } \\
\text { Seasario } 8\end{array}$ & $\begin{array}{l}\text { CDWWTP } \\
\text { Sเmative }\end{array}$ \\
\hline \multicolumn{12}{|l|}{ Plant Sludse Dewaboring Conditions } \\
\hline Devalited aludpe wike percen. sollida & $\begin{array}{c}\text { \% so ids hy } \\
\text { ut. }\end{array}$ & 16,12 & 24.54 & 1fi: 2 & 24.54 & 2,00 & 25,00 & 2200 & 25.00 & 23,00 & 26.53 \\
\hline 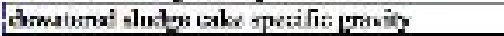 & $\mathrm{H}$ & 1.25 & 106 & 106 & .05 & 1.06 & 106 & 106 & 05 & 1.06 & 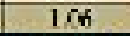 \\
\hline Shodges dewalerins solids capture & & $815 \%$ & $99.0 \%$ & $52.1 \%$ & $96.7 \%$ & $967 \%$ & $97.9 \%$ & $96 \%$ & 97.97 & $97.1 \%$ & $97.8 \%$ \\
\hline Centute TSS & $\begin{array}{c}S e \text { sonds thy } \\
\mathrm{uL}\end{array}$ & 0.25 & an:26i & a.25 & 0.026 & a.18 & O.nST & ก.118 & nowi7 & Q.118 & O.nST \\
\hline Ganente ROB & $m e^{7}$ & 2000 & 2000 & $x 00$ & $2 \times 00$ & 2000 & 2000 & $x 00$ & $2 \times 00$ & 2800 & 300 \\
\hline palymer dose & thWI & $21.1 \mathrm{~B}$ & 17.38 & 21.18 & 13.78 & $31.3 \mathrm{~J}$ & 24.00 & 31गt & 24.03 & 31.31 & 24.00 \\
\hline ferr.o dess & palifocer bal & $\therefore .83$ & 2.18 & 183 & 218 & 0 & 1.9 & It & 1.9 & 0 & 1.9 \\
\hline
\end{tabular}

As a follow-up to the data presented here, in the most recent plant data, after the study period, SDWWTP's solids capture has risen to $99 \%$, cake solids are still low. The change is a mixture of replacement of malfunctioning solids sensing and flow metering instrumentation and a greater focus on solids capture. 
7. Model Results and Discussion

In order to aid in the presentation and discussion of scenario results from the MBM, the results are presented and discussed by biosolids unit process. As the MBM is created for metric units those results will be presented first followed by US standard units as they are the common vernacular of the subject plants and the wastewater industry on a national level.

\subsection{MBM Results}

\section{Sludge Thickening MBM Results}

The most notable differences in sludge thickening results between the SDWWTP Scenarios, as presented in Table 27, is the low percent solids value of the thickened sludge of Scenarios A and B compared to the values of the gravity belt thickeners and the thickening centrifuges, albeit with much higher capture rates than both of the competing technologies. The excellent capture rates are also reflected in the significantly lower TSS

loading in the recycle stream as compared to Scenarios C, D, and E. The CDWWTP sludge thickening results do mirror this trend of poorer thickened solids concentration and better solids capture rates for the gravity concentrator, although not as pronounced, as visible below in Table 28. 
Table 27: Summary of MBM Results for SDWWTP Sludge Thickening Scenarios in SI and US units

\begin{tabular}{|l|r|r|r|r|r|r|r|r|r|r|}
\hline South District WWTP & \multicolumn{2}{|c|}{ Machine Loading } & \multicolumn{2}{c|}{ Chemical Dosing } & \multicolumn{2}{c|}{ Biosolids Production } & \multicolumn{2}{c|}{ Filtrate/Centrate Loading } \\
\hline $\begin{array}{c}\text { Scenario } \\
\text { correction } \\
\text { factor }\end{array}$ & $\begin{array}{c}\text { Hydraulic } \\
\text { Load }\end{array}$ & Solids load & $\begin{array}{c}\text { Polymer } \\
\text { Dose }\end{array}$ & $\begin{array}{c}\text { Ferric iron } \\
\text { dose }\end{array}$ & $\begin{array}{c}\text { Thickened } \\
\text { Sludge } \% \\
\text { Solids }\end{array}$ & Capture rate & Flow & BODm & TSSm \\
\hline SD-A & 1.16 & $\mathrm{~m} 3 / \mathrm{d}$ & $\mathrm{kg} / \mathrm{d}$ & $\mathrm{g} / \mathrm{kg}$ & $\mathrm{m} 3 / 1000 \mathrm{~m} 3$ & $\%$ & $\%$ & $\mathrm{~m} 3 / \mathrm{d}$ & $\mathrm{kg} / \mathrm{d}$ & $\mathrm{kg} / \mathrm{d}$ \\
\hline SD-B & 1.16 & 5,648 & 69,839 & 1.72 & 0.43 & $2.3 \%$ & $99.2 \%$ & 1,855 & 363 & 579 \\
\hline SD-C & 1.16 & 5,646 & 68,343 & 6 & 0 & $5.5 \%$ & $95.0 \%$ & 3,670 & 2,124 & 3,385 \\
\hline SD-D & 1.16 & 5,646 & 68,343 & 6 & 0 & $5.5 \%$ & $95.0 \%$ & 3,670 & 2,124 & 3,385 \\
\hline SD-E & 1.16 & 5,747 & 67,898 & 1.47 & 0 & $6.1 \%$ & $95.7 \%$ & 3,878 & 1,829 & 2,914 \\
\hline
\end{tabular}

\begin{tabular}{|c|c|c|c|c|c|c|c|c|c|}
\hline South District WWTP & \multicolumn{2}{|c|}{ Machinc Loading } & \multicolumn{2}{|c|}{ Chemical Dosing } & \multicolumn{2}{|c|}{ Biosolids Production } & \multicolumn{3}{|c|}{ Filtrate/Centrate Loading } \\
\hline Scenario & $\begin{array}{c}\text { Hydraulic } \\
\text { Load }\end{array}$ & $\begin{array}{c}\text { Solids } \\
\text { load }\end{array}$ & $\begin{array}{c}\text { Polymer } \\
\text { Dose }\end{array}$ & $\begin{array}{c}\text { Ferric iron } \\
\text { dose }\end{array}$ & $\begin{array}{l}\text { Cake } \% \\
\text { Solids }\end{array}$ & $\begin{array}{c}\text { Capture } \\
\text { rate }\end{array}$ & Flow & BODm & TSSm \\
\hline US units & gpm & $\mathrm{lb} / \mathrm{h}$ & $\mathrm{lb} / \mathrm{DT}$ & $\mathrm{gal} / 1000 \mathrm{gal}$ & $\%$ & $\%$ & MGD & $\mathrm{lb} / \mathrm{d}$ & $\mathrm{lb} / \mathrm{d}$ \\
\hline SD-A & 1,054 & 6,527 & 3.43 & 0.43 & $2.3 \%$ & $99.2 \%$ & 0.50 & 815 & 1,298 \\
\hline SD-B & 1,036 & 6,415 & 3.43 & 0.43 & $2.3 \%$ & $99.2 \%$ & 0.49 & 801 & 1,276 \\
\hline SD-C & 1,036 & 6,278 & 12 & 0 & $5.5 \%$ & $95.0 \%$ & 0.97 & 4,684 & 7,462 \\
\hline SD-D & 1,036 & 6,278 & 12 & 0 & $5.5 \%$ & $95.0 \%$ & 0.97 & 4,684 & 7,462 \\
\hline SD-E & 1,055 & 6,237 & 2.94 & 0 & $6.1 \%$ & $95.7 \%$ & 1.02 & 4,032 & 6,424 \\
\hline
\end{tabular}


Table 28: Summary of MBM Results for CDWWTP Sludge Thickening Scenarios in SI and US units

\begin{tabular}{|c|c|c|c|c|c|c|c|c|c|c|}
\hline \multicolumn{2}{|c|}{ Central District WWTP } & \multicolumn{2}{|c|}{ Machine Loading } & \multicolumn{2}{|c|}{ Chemical Dosing } & \multicolumn{2}{|c|}{ Biosolids Production } & \multicolumn{3}{|c|}{ Filtrate/Centrate Loading } \\
\hline \begin{tabular}{|l|} 
\\
Scenario \\
\end{tabular} & \begin{tabular}{|c|} 
flow \\
correction \\
factor \\
\end{tabular} & $\begin{array}{c}\text { Hydraulic } \\
\text { Load }\end{array}$ & Solids load & $\begin{array}{c}\text { Polymer } \\
\text { Dose }\end{array}$ & $\begin{array}{c}\text { Ferric iron } \\
\text { dose }\end{array}$ & $\begin{array}{c}\text { Thickened } \\
\text { Sludge \% } \\
\text { Solids } \\
\end{array}$ & Capture rate & Flow & BODm & TSSm \\
\hline SI units & & $\mathrm{m} 3 / \mathrm{d}$ & $\mathrm{kg} / \mathrm{d}$ & $\mathrm{g} / \mathrm{kg}$ & $\mathrm{m} 3 / 1000 \mathrm{~m} 3$ & $\%$ & $\%$ & $\mathrm{~m} 3 / \mathrm{d}$ & $\mathrm{kg} / \mathrm{d}$ & $\mathrm{kg} / \mathrm{d}$ \\
\hline \begin{tabular}{|l|}
$\mathrm{CD}-\mathrm{A}$ \\
\end{tabular} & 2.38 & 10,877 & 50,212 & 1.27 & \begin{tabular}{r|}
0 \\
\end{tabular} & $3.9 \%$ & $96.2 \%$ & 3,342 & 1,208 & 1,925 \\
\hline CD-B & 2.38 & 10,913 & 49,590 & 1.27 & 0 & $3.9 \%$ & $96.2 \%$ & 3,372 & 1,193 & 1,901 \\
\hline CD-C & 2.38 & 10,595 & 48,479 & 6 & 0 & $5.5 \%$ & $95.3 \%$ & 3,620 & 1,439 & 2,293 \\
\hline CD-D & 2.38 & 10,595 & 48,479 & 6 & 0 & $5.5 \%$ & $95.3 \%$ & 3,620 & 1,439 & 2,293 \\
\hline CD-E & 2.38 & 7,704 & 48,331 & 1.54 & 0 & $6.3 \%$ & $95.6 \%$ & 2,509 & 1,329 & 2,117 \\
\hline
\end{tabular}

\begin{tabular}{|c|c|c|c|c|c|c|c|c|c|}
\hline Central District WWTP & \multicolumn{2}{|c|}{ Machine Loading } & \multicolumn{2}{|c|}{ Chemical Dosing } & \multicolumn{2}{|c|}{ Biosolids Production } & \multicolumn{3}{|c|}{ Filtrate/Centrate Loading } \\
\hline Scenario & $\begin{array}{c}\text { Hydraulic } \\
\text { Load }\end{array}$ & $\begin{array}{c}\text { Solids } \\
\text { load }\end{array}$ & $\begin{array}{c}\text { Polymer } \\
\text { Dose }\end{array}$ & $\begin{array}{c}\text { Ferric iron } \\
\text { dose }\end{array}$ & $\begin{array}{c}\text { Cake \% } \\
\text { Solids }\end{array}$ & $\begin{array}{c}\text { Capture } \\
\text { rate }\end{array}$ & Flow & BODm & TSSm \\
\hline US units & gpm & $\mathrm{lb} / \mathrm{h}$ & $\mathrm{lb} / \mathrm{DT}$ & $\mathrm{gal} / 1000 \mathrm{gal}$ & $\%$ & $\%$ & MGD & $\mathrm{lb} / \mathrm{d}$ & $\mathrm{lb} / \mathrm{d}$ \\
\hline CD-A & 1,996 & 4,612 & 2.54 & \begin{tabular}{r|}
0 \\
\end{tabular} & $3.9 \%$ & $96.2 \%$ & 0.88 & 2,663 & 4,244 \\
\hline CD-B & 2,002 & 4,555 & 2.54 & 0 & $3.9 \%$ & $96.2 \%$ & 0.89 & 2,630 & 4,191 \\
\hline $\mathrm{CD}-\mathrm{C}$ & 1,944 & 4,453 & 12 & 0 & $5.5 \%$ & $95.3 \%$ & 0.96 & 3,173 & 5,055 \\
\hline CD-D & 1,944 & 4,453 & 12 & 0 & $5.5 \%$ & $95.3 \%$ & 0.96 & 3,173 & 5,055 \\
\hline CD-E & 1,413 & 4,440 & 3.08 & 0 & $6.3 \%$ & $95.6 \%$ & 0.66 & 2,929 & 4,667 \\
\hline
\end{tabular}


A curious difference between the results for SDWWTP and CDWWTP can be observed when comparing Table 27 and Table 28. Although the hydraulic loads to the sludge thickening process of CDWWTP is nearly double that of the hydraulic loads for SDWWTP, 1900+ gpm compared to $1,000+$ gpm respectively, SDWWTP has significantly higher solids loading than CDWWTP. This will later show itself to be a factor in the design criteria for hydraulically vs. solids limited process loadings.

\section{Sludge Digestion MBM Results}

The trend of higher solids loading in SDWWTP than CDWWTP continues through into the sludge digestion process as can be compared between Table 29 and Table 30. The trend for higher hydraulic loading at the CDWWTP also continues. This ultimately does not play a role in different design criteria for sizing as both plants are hydraulically limited rather than being solids limited as it relates to mesophilic digestion. Even at the highest solids loading encountered in the study, SD-A at 70,465 $\mathrm{kg} / \mathrm{d}(4,436$ $\mathrm{lb} / \mathrm{h}$ ) the organic loading rate was estimated at $0.16 \mathrm{lb} / \mathrm{cu} . \mathrm{ft}-\mathrm{d}$ of organic loading, well below the recommended the maximum organic loading limit of $0.2 \mathrm{lb} / \mathrm{cu} . \mathrm{ft}-\mathrm{d}$ for highrate mesophilic digestion. (WEF MOP $116^{\text {th }}$ Edition, 2008).

The highest organic loading to the digesters for CDWWTP was estimated at 0.07 lb/cuft-d; hence significantly lower than the recommended solids limit. This facet of the organic solids loading makes the possibility of further sludge thickening to increase digestion capacity or the addition of high organic solids streams such as restaurant grease trap waste or homogenized food scraps a possible feed stock without requiring more digestion capacity. This combination of feedstocks into the anaerobic digestion process, 
referred to as co-digestion, and the potential of greater biogas and power production and synergistic effects of co-digestion merits further study (Allen and Hanson, 2018).

Another noteworthy outcome of the study was the estimated volatile solids reduction at both facilities through all the scenarios investigated. Even with relatively low primary digester detention times of around 15 days, a nearly $49 \%$ VSR was achievable at SDWWTP and 52.5\% VSR was maintained at CDWWTP. With proposed improvements, the pilot study and the model results both confirm that at greater detention times around 30 days, VSRs of more than $60 \%$ can be expected under high-rate mesophilic anaerobic digestions conditions at CDWWTP, Table 30. As the SDWWTP pilot results did not demonstrate a significant increase in VSR at detention times just above 30 days, a theoretical cap on maximum VSR was placed on equations for SDWWTP. Therefore, no model results with VSR above $50 \%$ are shown, in keeping with design consultant engineering reports for SDWWTP (CH2M, 2015). 
Table 29: Summary of MBM Results for SDWWTP Sludge Digestion Scenarios in SI and US units

\begin{tabular}{|c|c|c|c|c|c|c|c|c|c|c|c|}
\hline \multicolumn{2}{|c|}{ South District WWTP } & \multicolumn{2}{|c|}{ Digester loading } & \multicolumn{2}{|c|}{ Chemical dosing } & \multicolumn{2}{|c|}{ Biosolids Production } & & \multicolumn{3}{|c|}{ Supernatant Loading } \\
\hline Scenario & \begin{tabular}{|c|} 
flow \\
correction \\
factor \\
\end{tabular} & $\begin{array}{c}\text { Hydraulic } \\
\text { Load }\end{array}$ & Solids load & $\begin{array}{c}\text { Polymer } \\
\text { Dose }\end{array}$ & $\begin{array}{c}\text { Ferric iron } \\
\text { dose }\end{array}$ & $\begin{array}{c}\text { Digested } \\
\text { Sludge } \% \\
\text { solids }\end{array}$ & $\begin{array}{c}\text { Detention } \\
\text { time }\end{array}$ & VSR & Flow & BODm & TSSm \\
\hline SI units & & $\mathrm{m} 3 / \mathrm{d}$ & $\mathrm{kg} / \mathrm{d}$ & $\mathrm{g} / \mathrm{kg}$ & $\mathrm{m} 3 / 1000 \mathrm{~m} 3$ & $\%$ & d & $\%$ & $\mathrm{~m} 3 / \mathrm{d}$ & $\mathrm{kg} / \mathrm{d}$ & $\mathrm{kg} / \mathrm{d}$ \\
\hline SD-A & 0.75 & 2,285 & 70,465 & 0 & \begin{tabular}{r|}
0 \\
\end{tabular} & $1.29 \%$ & 14.7 & $48.8 \%$ & - & - & - \\
\hline SD-B & 0.75 & 2,246 & 69,260 & 0 & 0 & $1.30 \%$ & 17.9 & $50.0 \%$ & 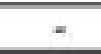 & - & $=$ \\
\hline SD-C & 0.75 & 885 & 64,958 & 0 & 0 & $3.11 \%$ & 29.6 & $50.0 \%$ & - & - & - \\
\hline SD-D & 0.75 & 885 & 64,958 & 0 & 0 & $3.11 \%$ & 29.6 & $50.0 \%$ & $=$ & $=$ & $=$ \\
\hline SD-E & 0.75 & 794 & 64,984 & 0 & 0 & $3.50 \%$ & 32.7 & $49.5 \%$ & - & - & - \\
\hline
\end{tabular}

\begin{tabular}{|c|c|c|c|c|c|c|c|c|c|c|}
\hline South District WWTP & Digester & ading & Chemic & al dosing & Biosolids P & roduction & & Sup & natant Lo & ding \\
\hline Scenario & $\begin{array}{l}\text { Hydraulic } \\
\text { Load }\end{array}$ & $\begin{array}{c}\text { Solids } \\
\text { load }\end{array}$ & $\begin{array}{l}\text { Polymer } \\
\text { Dose }\end{array}$ & $\begin{array}{c}\text { Ferric iron } \\
\text { dose }\end{array}$ & $\begin{array}{c}\text { Digested } \\
\text { Sludge \% } \\
\text { solids }\end{array}$ & $\begin{array}{c}\text { Detention } \\
\text { time }\end{array}$ & VSR & Flow & BODm & TSSm \\
\hline US units & gpm & $\mathrm{lb} / \mathrm{h}$ & $\mathrm{lb} / \mathrm{DT}$ & $\mathrm{gal} / 1000 \mathrm{gal}$ & $\%$ & d & $\%$ & MGD & $\mathrm{lb} / \mathrm{d}$ & $\mathrm{lb} / \mathrm{d}$ \\
\hline SD-A & 419 & 6,473 & 0 & 0 & $1.29 \%$ & 14.67 & $48.8 \%$ & - & - & - \\
\hline SD-B & 412 & 6,362 & 0 & 0 & $1.3 \%$ & 17.85 & $50.0 \%$ & $=$ & $=$ & - \\
\hline SD-C & 162 & 5,967 & 0 & 0 & $3.1 \%$ & 29.57 & $50.0 \%$ & $=$ & $=$ & - \\
\hline SD-D & 162 & 5,967 & 0 & 0 & $3.1 \%$ & 29.57 & $50.0 \%$ & - & - & - \\
\hline SD-E & 146 & 5,969 & 0 & 0 & $3.5 \%$ & 32.73 & $49.5 \%$ & - & - & - \\
\hline
\end{tabular}


A mishap during the digestion piloting phase at SDWWTP may have negatively influenced the VSR results of this study, Table 29. It was discovered near completion of the digestion phase of the SDWWTP pilot testing that a process water valve to the study digester was inadvertently opened at some point during the pilot test. This accidental flow stream into the digester both diluted the contents of the digester in addition to adding a chlorinated stream into the digester. The full scope of the error can only be hypothesized, as there were no flow meters on the process water line or on the digested sludge line leaving the study digester. To salvage the last phase of sludge dewatering pilot testing the secondary digester was employed as the feed source for the conclusion of the dewatering pilot testing. The digested solids concentration of the secondary digester was not as greatly impacted compared the diluted primary digester. Even so, the known impacts would be a lowering of the digested sludge concentration leaving the digester, which would impact VSR calculations. A cooling of the digester contents as the process water is roughly $10 \quad$ F below the target digester temperature of $95 \quad$ F. This would have affected the digestion kinetics, and therefore the VSR. The chlorinated process water, albeit containing chloramines and not free chlorine, could also have had a negative impact on microbial activity in the digester and similarly lowered digestion reaction kinetics leading to a lower VSR to detention time rate. All of these probable impacts point toward a depressed VSR result in the SDWWTP digestion phase pilot test.

Unfortunately, due to the expense, operational commitment, and time requirements to conduct such full scale pilots at such large wastewater treatment facilities, a second testing phase to determine SDWWTP true potential VSR at 30 day detention times and beyond was impractical within the confines of this study. As the 
SDWWTP will soon begin construction of retrofits to digesters similar to those presented in Scenarios D and E a monitoring at full scale for longer detention times will be possible in a few years to confirm the hypothesis that SDWWTP's WAS only digestion process is capable of exceeding VSR of 50\% with sufficiently long digester detention times and will confirm that the results of the pilot study were negatively impacted by the inadvertent introduction of flushing water to the study digester. 
Table 30: Summary of MBM Results for CDWWTP Sludge Digestion Scenarios in SI and US units

\begin{tabular}{|c|c|c|c|c|c|c|c|c|c|c|c|}
\hline \multicolumn{2}{|c|}{ Central District WWTP } & \multicolumn{2}{|c|}{ Digester loading } & \multicolumn{2}{|c|}{ Chemical dosing } & \multicolumn{2}{|c|}{ Biosolids Production } & & \multicolumn{3}{|c|}{ Supermatant Loading } \\
\hline Scenario & \begin{tabular}{|c|} 
flow \\
correction \\
factor
\end{tabular} & $\begin{array}{c}\text { Hydraulic } \\
\text { Load }\end{array}$ & Solids load & $\begin{array}{c}\text { Polymer } \\
\text { Dose }\end{array}$ & $\begin{array}{c}\text { Ferric iron } \\
\text { dose }\end{array}$ & $\begin{array}{c}\text { Digested } \\
\text { Sludge \% } \\
\text { solids }\end{array}$ & $\begin{array}{c}\text { Detention } \\
\text { time }\end{array}$ & VSR & Flow & BODm & TSSm \\
\hline SI units & & $\mathrm{m} 3 / \mathrm{d}$ & $\mathrm{kg} / \mathrm{d}$ & $\mathrm{g} / \mathrm{kg}$ & $\mathrm{m} 3 / 1000 \mathrm{~m} 3$ & $\%$ & d & $\%$ & $\mathrm{~m} 3 / \mathrm{d}$ & $\mathrm{kg} / \mathrm{d}$ & $\mathrm{kg} / \mathrm{d}$ \\
\hline CD-A & 1.89 & 2,342 & 48,287 & 0 & 0 & $2.32 \%$ & 16.9 & $52.5 \%$ & - & - & - \\
\hline CD-B & 1.89 & 2,313 & 47,689 & 0 & 0 & $1.90 \%$ & 34.4 & $62.3 \%$ & - & $=$ & $=$ \\
\hline CD-C & 1.89 & 1,591 & 46,186 & 0 & 0 & $2.79 \%$ & 28.9 & $59.9 \%$ & - & - & - \\
\hline CD-D & 1.89 & 1,591 & 46,186 & 0 & 0 & $2.79 \%$ & 28.9 & $59.9 \%$ & $=$ & $=$ & $=$ \\
\hline CD-E & 1.89 & 1,389 & 46,214 & 0 & 0 & $2.70 \%$ & 33.0 & $64.0 \%$ & - & - & - \\
\hline
\end{tabular}

\begin{tabular}{|c|c|c|c|c|c|c|c|c|c|c|}
\hline \multirow[t]{2}{*}{ Central District WWTP } & \multicolumn{2}{|c|}{ Digester loading } & \multicolumn{2}{|c|}{ Chemical dosing } & \multicolumn{2}{|c|}{ Biosolids Production } & & \multicolumn{3}{|c|}{ Supematant Loading } \\
\hline & $\begin{array}{c}\text { Hydraulic } \\
\text { Load }\end{array}$ & $\begin{array}{c}\text { Solids } \\
\text { load }\end{array}$ & $\begin{array}{c}\text { Polymer } \\
\text { Dose }\end{array}$ & $\begin{array}{c}\text { Ferric iron } \\
\text { dose }\end{array}$ & $\begin{array}{c}\text { Digested } \\
\text { Sludge \% } \\
\text { solids }\end{array}$ & $\begin{array}{c}\text { Detention } \\
\text { time }\end{array}$ & VSR & Flow & BODm & TSSm \\
\hline US units & gpm & $\mathrm{lb} / \mathrm{h}$ & $\mathrm{Ib} / \mathrm{DT}$ & $\mathrm{gal} / 1000 \mathrm{gal}$ & $\%$ & $\mathrm{~d}$ & $\%$ & MGD & $\mathrm{lb} / \mathrm{d}$ & $\mathrm{lb} / \mathrm{d}$ \\
\hline CD-A & 430 & 4,436 & 0 & 0 & $2.3 \%$ & 16.9 & $52.5 \%$ & - & - & - \\
\hline CD-B & 424 & 4,381 & 0 & 0 & $1.9 \%$ & 34.4 & $62.3 \%$ & $\cdot$ & - & $=$ \\
\hline CD-C & 292 & 4,243 & 0 & 0 & $2.8 \%$ & 28.9 & $59.9 \%$ & 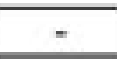 & - & $=$ \\
\hline CD-D & 292 & 4,243 & 0 & 0 & $2.8 \%$ & 28.9 & $59.9 \%$ & - & - & - \\
\hline CD-E & 255 & 4,245 & 0 & 0 & $2.7 \%$ & 33.0 & $64.0 \%$ & $=$ & - & $=$ \\
\hline
\end{tabular}




\section{Sludge Dewatering MBM Results}

The most notable feature regarding the MBM results for sludge dewatering across the scenarios is the reduction in hydraulic loading for the process between the scenarios under the existing plant configuration, Scenarios A and B, and the scenarios of the proposed modified configurations, Scenarios C, D and E. The later having hydraulic loading rates less than half of those of A and B for SDWWTP specifically, and less pronounced at CDWWTP where Scenarios C, D, and E have hydraulic loading rates 30\% lower than Scenarios A and B, Table 31 and Table 32. This proves to be an important factor in sizing of units for the proposed dewatering process as discuss later in this chapter.

The low cake solids and capture rates in Scenarios SD-A and SD-B demonstrate two important impacts. As shown in Table 31, the cake solids concentration of $16 \%$ solids result in a total sludge cake mass of $450,000 \mathrm{lb} / \mathrm{d}$ wet weight. The improved dewatering results of Scenarios SD-C, SD-D, and SD-E yield a $20 \%$ to $25 \%$ lower amount of sludge cake to be disposed by wet weight. As shown later in this chapter that provides a significant cost saving and reduce the logistics of sludge disposal as it would require less sludge hauling trucks on a daily basis. 
Similar results occur when comparing Scenarios CD-A to CD-C, CD-D, and C-E where the reduction in sludge cake biosolids production for disposal is $18 \%$ to $28 \%$ relative to the existing condition, as can be seen in Table 32. These reductions in biosolids production result from improved sludge thickening and dewatering performance, especially in the case of SDWWTP, in combination with the increased volatile solids reduction of the digestion process mentioned previously in this chapter. 
Table 31: Summary of MBM Results for SDWWTP Sludge Dewatering Scenarios in SI and US units

\begin{tabular}{|c|c|c|c|c|c|c|c|c|c|c|c|c|c|}
\hline \multicolumn{2}{|c|}{ South District WWTP } & \multicolumn{2}{|c|}{ Machine Loading } & \multicolumn{2}{|c|}{ Chemical Dosing } & \multicolumn{5}{|c|}{ Biosolids Production } & \multicolumn{3}{|c|}{ Centrate Loading } \\
\hline Scenario & $\begin{array}{c}\text { flow } \\
\text { correction } \\
\text { factor }\end{array}$ & $\begin{array}{c}\text { Hydraulic } \\
\text { Load }\end{array}$ & $\begin{array}{c}\text { Solids } \\
\text { load }\end{array}$ & $\begin{array}{c}\text { Polymer } \\
\text { Dose }\end{array}$ & $\begin{array}{c}\text { Ferrie iron } \\
\text { dose }\end{array}$ & $\begin{array}{l}\text { Cake \% } \\
\text { Solids }\end{array}$ & $\begin{array}{c}\text { Capture } \\
\text { rate }\end{array}$ & $\begin{array}{l}\text { Cake mass } \\
\text { load, Tssm }\end{array}$ & $\begin{array}{c}\text { Cake mass } \\
\text { load (wet wt.) }\end{array}$ & $\begin{array}{c}\text { Cake } \\
\text { Volume }\end{array}$ & Flow & $\mathrm{BODm}$ & TSSm \\
\hline \begin{tabular}{|l} 
SI units \\
\end{tabular} & & $\mathrm{m} 3 / \mathrm{d}$ & $\mathrm{kg} / \mathrm{d}$ & $\mathrm{g} / \mathrm{kg}$ & $\mathrm{m} 3 / 1000 \mathrm{~m} 3$ & $\%$ & $\%$ & $\mathrm{~kg} / \mathrm{d}$ & $\mathrm{kg} / \mathrm{d}$ & $\mathrm{m} 3 / \mathrm{d}$ & $\mathrm{m} 3 / \mathrm{d}$ & $\mathrm{kg} / \mathrm{d}$ & $\mathrm{kg} / \mathrm{d}$ \\
\hline SD-A & 0.73 & 2,285 & 40,569 & 10.6 & 1.83 & $16.1 \%$ & $81.9 \%$ & 33,222 & 206,091 & 194 & 2,950 & 5,901 & 7,347 \\
\hline SD-B & 0.73 & 2,179 & 39,122 & 10.6 & 1.83 & $16.1 \%$ & $82.1 \%$ & 32,124 & 199,281 & 188 & 2,810 & 5,621 & 6,997 \\
\hline SD-C & 0.73 & 858 & 36,692 & 15.7 & 0 & $22.0 \%$ & $96.7 \%$ & 35,486 & 161,301 & 152 & 1,029 & 2,058 & 1,205 \\
\hline SD-D & 0.73 & 858 & 36,692 & 15.7 & 0 & $22.0 \%$ & $96.7 \%$ & 35,485 & 161,296 & 152 & 1,029 & 2,058 & 1,206 \\
\hline SD-E & 0.73 & 768 & 37,008 & 15.7 & 0 & $23.0 \%$ & $97.1 \%$ & 35,942 & 156,269 & 147 & 910 & 1,820 & 1,066 \\
\hline
\end{tabular}

\begin{tabular}{|c|c|c|c|c|c|c|c|c|c|c|c|c|}
\hline \multirow[t]{2}{*}{ South District WWTP } & \multicolumn{2}{|c|}{ Machine Loading } & \multicolumn{2}{|c|}{ Chemical Dosing } & \multicolumn{5}{|c|}{ Biosolids Production } & \multicolumn{3}{|c|}{ Centrate Loading } \\
\hline & $\begin{array}{c}\text { Hydraulic } \\
\text { Load }\end{array}$ & $\begin{array}{c}\text { Solids } \\
\text { load }\end{array}$ & $\begin{array}{c}\text { Polymer } \\
\text { Dose }\end{array}$ & $\begin{array}{c}\text { Ferric iron } \\
\text { dose }\end{array}$ & $\begin{array}{l}\text { Cake \% } \\
\text { Solids }\end{array}$ & $\begin{array}{c}\text { Capture } \\
\text { rate }\end{array}$ & $\begin{array}{l}\text { Cake } \\
\text { mass } \\
\text { load, } \\
\text { Tssm }\end{array}$ & $\begin{array}{c}\text { Cake mass } \\
\text { load (wet } \\
\text { wt.) }\end{array}$ & $\begin{array}{c}\text { Cake } \\
\text { Volume }\end{array}$ & Flow & BODm & TSSm \\
\hline US units & gpm & $\mathrm{lb} / \mathrm{h}$ & $\mathrm{Ib} / \mathrm{DT}$ & $\mathrm{gal} / 1000 \mathrm{gal}$ & $\%$ & $\%$ & $\mathrm{lb} / \mathrm{d}$ & $\mathrm{lb} / \mathrm{d}$ & $y d 3 / d$ & MGD & $\mathrm{lb} / \mathrm{d}$ & $\mathrm{lb} / \mathrm{d}$ \\
\hline SD-A & 419 & 3,727 & 21.18 & 1.83 & $16.1 \%$ & $81.9 \%$ & 73,240 & 454,344 & 254 & 0.78 & 13,009 & 16,197 \\
\hline SD-B & 400 & 3,594 & 21.18 & 1.83 & $16.1 \%$ & $82.1 \%$ & 70,820 & 439,332 & 246 & 0.74 & 12,391 & 15,427 \\
\hline SD-C & 157 & 3,370 & 31.31 & 0 & $22.0 \%$ & $96.7 \%$ & 78,232 & 355,601 & 199 & 0.27 & 4,537 & 2,657 \\
\hline SD-D & 157 & 3,370 & 31.31 & 0 & $22.0 \%$ & $96.7 \%$ & 78,230 & 355,591 & 199 & 0.27 & 4,537 & 2,660 \\
\hline SD-E & 141 & 3,399 & 31.31 & 0 & $23.0 \%$ & $97.1 \%$ & 79,237 & 344,509 & 193 & 0.24 & 4,012 & 2,350 \\
\hline
\end{tabular}


Table 32: Summary of MBM Results for CDWWTP Sludge Dewatering Scenarios in SI and US units

\begin{tabular}{|c|c|c|c|c|c|c|c|c|c|c|c|c|c|}
\hline \multicolumn{2}{|c|}{ Central District WWTP } & \multicolumn{2}{|c|}{ Machine Loading } & \multicolumn{2}{|c|}{ Chemical Dosing } & \multicolumn{5}{|c|}{ Biosolids Production } & \multicolumn{3}{|c|}{ Centrate Losding } \\
\hline Scenario & $\begin{array}{c}\text { flow } \\
\text { correction } \\
\text { factor }\end{array}$ & $\begin{array}{c}\text { Hydraulic } \\
\text { Load }\end{array}$ & $\begin{array}{c}\text { Solids } \\
\text { load }\end{array}$ & $\begin{array}{c}\text { Polymer } \\
\text { Dose }\end{array}$ & $\begin{array}{c}\text { Ferric iron } \\
\text { dose }\end{array}$ & $\begin{array}{l}\text { Cake \% } \\
\text { Solids }\end{array}$ & $\begin{array}{c}\text { Capture } \\
\text { rate }\end{array}$ & $\begin{array}{l}\text { Cake mass } \\
\text { load, Tssm }\end{array}$ & $\begin{array}{c}\text { Cake mass } \\
\text { load (wet wt.) }\end{array}$ & $\begin{array}{c}\text { Cake } \\
\text { Volume }\end{array}$ & Flow & BODm & TSSm \\
\hline SI units & & $\mathrm{m} 3 / \mathrm{d}$ & $\mathrm{kg} / \mathrm{d}$ & $\mathrm{g} / \mathrm{kg}$ & $\mathrm{m}^{3} / 1000 \mathrm{~m} 3$ & $\%$ & $\%$ & $\mathrm{~kg} / \mathrm{d}$ & $\mathrm{kg} / \mathrm{d}$ & $\mathrm{m} 3 / \mathrm{d}$ & $\mathrm{m} 3 / \mathrm{d}$ & $\mathrm{kg} / \mathrm{d}$ & $\mathrm{kg} / \mathrm{d}$ \\
\hline $\mathrm{CD}-\mathrm{A}$ & 2,06 & 2,342 & 26,350 & 8.9 & 2.18 & $24.5 \%$ & $99.0 \%$ & 26,084 & 106,293 & 100 & 1,035 & 2,071 & 265 \\
\hline CD-B & 2.06 & 2,386 & 22,008 & 8.9 & 2.18 & $24.5 \%$ & $98.7 \%$ & 21,732 & 88,558 & 84 & 1,073 & 2,147 & 275 \\
\hline CD-C & 2.06 & 1,647 & 22,262 & 12.0 & 1.9 & $25.0 \%$ & $97.9 \%$ & 21,787 & 87,149 & 82 & 717 & 1,433 & 475 \\
\hline CD-D & 2.06 & 1,647 & 22,262 & 12.0 & 1.9 & $25.0 \%$ & $97.9 \%$ & 21,787 & 87,149 & 82 & 717 & 1,433 & 475 \\
\hline CD-E & 2.06 & 1,575 & 20,619 & 12.0 & 1.9 & $26.5 \%$ & $97.8 \%$ & 20,160 & 75,991 & 72 & 692 & 1,384 & 459 \\
\hline
\end{tabular}

\begin{tabular}{|c|c|c|c|c|c|c|c|c|c|c|c|c|}
\hline \multirow[t]{2}{*}{ Central District WWTP } & \multicolumn{2}{|c|}{ Machine Loading } & \multicolumn{2}{|c|}{ Chemical Dosing } & \multicolumn{5}{|c|}{ Biosolids Production } & \multicolumn{3}{|c|}{ Centrate Loading } \\
\hline & $\begin{array}{c}\text { Hydraulic } \\
\text { Load }\end{array}$ & $\begin{array}{c}\text { Solids } \\
\text { load }\end{array}$ & $\begin{array}{c}\text { Polymer } \\
\text { Dose }\end{array}$ & $\begin{array}{c}\text { Ferric iron } \\
\text { dose }\end{array}$ & $\begin{array}{c}\text { Cake \% } \\
\text { Solids }\end{array}$ & $\begin{array}{l}\text { Capture } \\
\text { rate }\end{array}$ & $\begin{array}{l}\text { Cake } \\
\text { mass } \\
\text { load, } \\
\text { Tssm }\end{array}$ & $\begin{array}{c}\text { Cake mass } \\
\text { load (wet } \\
\text { wt.) }\end{array}$ & $\begin{array}{c}\text { Cake } \\
\text { Volume }\end{array}$ & Flow & BODm & TSSm \\
\hline US units & gpm & $\mathrm{Ib} / \mathrm{h}$ & $\mathrm{Ib} / \mathrm{DT}$ & $\mathrm{gal} / 1000 \mathrm{gal}$ & $\%$ & $\%$ & $\mathrm{lb} / \mathrm{d}$ & lb/d & $\mathrm{yd} 3 / \mathrm{d}$ & MGD & $\mathrm{lb} / \mathrm{d}$ & $\mathrm{lb} / \mathrm{d}$ \\
\hline CD-A & 430 & 2,420 & 17.78 & 2.18 & $24.5 \%$ & $99.0 \%$ & 57,505 & 234,333 & 131 & 0.27 & 4,566 & 585 \\
\hline CD-B & 438 & 2,022 & 17.78 & 2.18 & $24.5 \%$ & $98.7 \%$ & 47,910 & 195,234 & 109 & 0.28 & 4,732 & 607 \\
\hline CD-C & 302 & 2,045 & 24.03 & 1.9 & $25.0 \%$ & $97.9 \%$ & 48,032 & 192,127 & 108 & 0.19 & 3,159 & 1,046 \\
\hline CD-D & 302 & 2,045 & 24.03 & 1.9 & $25.0 \%$ & $97.9 \%$ & 48,032 & 192,127 & 108 & 0.19 & 3,159 & 1,046 \\
\hline CD-E & 289 & 1,894 & 24.03 & 1.9 & $26.5 \%$ & $97.8 \%$ & 44,445 & 167,529 & 94 & 0.18 & 3,051 & 1,011 \\
\hline
\end{tabular}


Recycle Streams MBM Results

Table 33: Summary of MBM Results for SDWWTP and CDWWTP Scenarios' Recycle Loads in SI and US units

\begin{tabular}{|c|c|c|c|}
\hline South District WWTP & \multicolumn{3}{|c|}{ total recycle return loading } \\
\hline Scenario & Flow & BODm & TSSm \\
\hline SI units & $\mathrm{m} 3 / \mathrm{d}$ & $\mathrm{kg} / \mathrm{d}$ & $\mathrm{kg} / \mathrm{d}$ \\
\hline SD-A & 4,836 & 6,270 & 7,936 \\
\hline SD-B & 4,665 & 5,984 & 7,576 \\
\hline SD-C & 4,699 & 4,182 & 4,590 \\
\hline SD-D & 4,699 & 4,182 & 4,591 \\
\hline SD-E & 4,788 & 3,649 & 3,980 \\
\hline
\end{tabular}

\begin{tabular}{|c|c|c|c|}
\hline Central District WWTP & \multicolumn{3}{|c|}{ recycle return loading } \\
\hline Scenario & Flow & BODm & TSSm \\
\hline SI units & $\mathrm{m} 3 / \mathrm{d}$ & $\mathrm{kg} / \mathrm{d}$ & $\mathrm{kg} / \mathrm{d}$ \\
\hline CD-A & 4,377 & 3,279 & 2,190 \\
\hline CD-B & 4,445 & 3,340 & 2,177 \\
\hline CD-C & 4,337 & 2,872 & 2,767 \\
\hline CD-D & 4,337 & 2,872 & 2,767 \\
\hline CD-E & 3,201 & 2,713 & 2,576 \\
\hline
\end{tabular}

\begin{tabular}{|l|r|r|c|}
\hline South District WWTP & \multicolumn{3}{|c|}{ total recycle retum loading } \\
\hline Scenario & Flow & \multicolumn{1}{|c|}{ BODm } & \multicolumn{1}{c|}{ TSSm } \\
\hline US units & MGD & \multicolumn{1}{|c|}{ lb/d } & \multicolumn{1}{l|}{ lb/d } \\
\hline SD-A & 1.28 & 13,824 & 17,495 \\
\hline SD-B & 1.23 & 13,192 & 16,702 \\
\hline SD-C & 1.24 & 9,220 & 10,119 \\
\hline SD-D & 1.24 & 9,220 & 10,122 \\
\hline SD-E & 1.26 & 8,044 & 8,774 \\
\hline
\end{tabular}

\begin{tabular}{|l|c|c|c|}
\hline Central District WWTP & \multicolumn{3}{|c|}{ recycle retum loading } \\
\hline Sccnario & Flow & BODm & TSSm \\
\hline SI units & MGD & lb/d & lb/d \\
\hline CD-A & 1.16 & 7,229 & 4,829 \\
\hline CD-B & 1.17 & 7,363 & 4,798 \\
\hline CD-C & 1.15 & 6,332 & 6,101 \\
\hline CD-D & 1.15 & 6,332 & 6,101 \\
\hline CD-E & 0.85 & 5,980 & 5,678 \\
\hline
\end{tabular}


An important feature of the MBM is its ability to predict the load returned to the liquid stream portion of the study plants from each biosolids unit process. As can be seen in Table 33, both the SDWWTP and CDWWTP results, reflect the previous unit specific results in that the combined recycle loads appear to differ greatly from Scenarios A and B to Scenarios C, D, and E. Not surprisingly, SDWWTP Scenarios A and B are greatly affected by the poor dewatering solids capture rate of $82 \%$ during the study period. This is in spite of the excellent capture rate of the existing gravity thickeners having a $99 \%+$ capture rate. The lowest over all recycle loads are found in CDWWTP's Scenario E. It may be possible that the assumed capture rate for the gravity belt thickeners, conservatively set at $95 \%$ based on capture rate quotes in the literature, could be improved upon, achieving better capture rates at much lower polymer doses. This is not improbable as actual plant data had more positive outcomes than the ranges in the literature for the exiting gravity thickeners and the pilot-tested thickening centrifuges. Future pilot testing of gravity belt thickeners under a scientific framework may demonstrate that the technology would also produce better than $95 \%$ solids capture at both study facilities and with lower polymer requirements than stated in the literature (MWH, Sept. 2015).

\subsection{Process Unit Sizing}

The MBM was instrumental in comparing technologies and the combinations of technologies. This tool provided more than just a framework for determining the estimated biosolids production of each scenario. With both hydraulic and solids loading outputs for each biosolids process (sludge thickening, anaerobic digestion, and sludge 
dewatering), the MBM makes it possible to estimate the number of units for each unit process that would be required to meet average day sludge loading conditions. The typical design standard is maximum week loading for sludge thickening and dewatering, and maximum month for sludge digestion (WEF MOP No. $85^{\text {th }}$ Edition, 2010).

Determining the number of units required for maximum week and maximum month conditions can be accomplished when utilizing known flows and loads from historical data to trend these above average conditions. This design procedure was not used for this study as this would have only been valid for the existing condition, scenario A, and not scenarios B, C, D, and E. As idealized cases based on average conditions these proposed scenarios have no fluctuations, the definition of a steady-state model. An effort could be made to simulate maximum week and maximum month variations, but such effort was not done as a part of this study. Instead, as a point of comparison the ' $n$ ' number of required units was estimated based on the hydraulic and solids loads of each process divided by the hydraulic and solids loading capacity for the existing and proposed process equipment for each scenario. To ensure sufficient units would be available for both maximum conditions and maintenance activities ' $n+1$ ' and ' $n+2$ ' number of units were selected over the minimum required number of units, 'n'. Sizing of sludge thickening, sludge digestion and sludge dewatering is described in detail in the following sections. 


\section{Sludge Thickening Unit Sizing}

Sizing of sludge thickening units for scenarios A and B was based on gravity concentrator, i.e. gravity thickener, design and operation specification in the Operation and Maintenance Manuals for SDWWTP and CDWWTP (MDWASD, March 2005 and MDWASD, May 2005). Sizing of sludge thickening units for scenarios C, D, and E was based on the alternative technology evaluations section of the basis of design reports for SDWWTP and CDWWTP sludge thickening and sludge dewatering capital projects, a part of Miami-Dade County's 2013 federal consent decree (MWH, September 2015, and CH2M, 2015).

As can be noted in Table 34 below, the solids loading capacity of the existing gravity thickeners of scenarios A and B is significantly lower than the solids loading capacity per unit of the proposed gravity belt thickeners and thickening centrifuges of

scenarios $\mathrm{C}, \mathrm{D}$, and $\mathrm{E}$. Whereas, the hydraulic loading capacity of the existing gravity thickeners per unit is on par with the proposed gravity belt thickeners and higher than the hydraulic loading capacity of the proposed thickening centrifuges by $50 \%$ per unit. Due to the high solids loading of SDWWTP as previously noted, the lower solids loading capacity of the gravity thickeners dictate a theoretical number of these units that would be required to meet the WAS demand, much higher than the existing number. As there are only 4 existing gravity thickening tanks at SDWWTP, an additional 5 units would be required just to meet the minimum demand and an additional 2 units would be required to meet ' $n+2$ '. This may very well explain the poor sludge thickening capacity of the existing units as there may simply not be enough time for the proper settling of WAS in the existing units. 
Table 34: SDWWTP Sludge Thickening Unit Sizing

\begin{tabular}{|c|c|c|c|r|r|r|r|}
\hline Sccnario & $\begin{array}{c}\text { Thickening } \\
\text { Technology }\end{array}$ & manufacturer & model & $\begin{array}{c}\text { Unit Hydraulic } \\
\text { loading }\end{array}$ & $\begin{array}{c}\text { \% fecd } \\
\text { solids }\end{array}$ & $\begin{array}{c}\text { unit solids } \\
\text { load }\end{array}$ & $\begin{array}{c}\text { \% thickcned } \\
\text { solids }\end{array}$ \\
\hline & & & & gpm & & \multicolumn{1}{l}{ lbs./hr. } & \\
\hline A & Gravity thickener & existing & bespoke & 751 & 1.2 & 791.94 & 3.9 \\
\hline B & Gravity thickener & existing & bespoke & 751 & 1.2 & 791.94 & 3.9 \\
\hline C & $\begin{array}{c}\text { Gravity Belt } \\
\text { Thickener }\end{array}$ & Alfa Laval & AS-H 300 & 750 & 1.2 & 3,646 & 3.9 \\
\hline D & $\begin{array}{c}\text { Gravity Belt } \\
\text { Thickener }\end{array}$ & Alfa Laval & AS-H 300 & 750 & 1.2 & 3,646 & 3.9 \\
\hline E & $\begin{array}{c}\text { Thickcning } \\
\text { Centrifuge }\end{array}$ & Alfa Laval & G3 125 & 500 & 1.2 & 2,917 & 3.9 \\
\hline
\end{tabular}

\begin{tabular}{|c|c|c|c|c|c|}
\hline Scenario & $\begin{array}{l}\text { Thickening } \\
\text { Technology }\end{array}$ & $\begin{array}{l}\text { daily operational } \\
\text { equivelent }\end{array}$ & units required & $\begin{array}{l}\text { minimum } \\
\text { design } \\
\text { standard }\end{array}$ & $\begin{array}{l}\text { Plant staff } \\
\text { preference }\end{array}$ \\
\hline & & $\mathrm{n}^{\prime}$ & $\mathrm{n}$ & $n+1$ & $\mathrm{n}+2$ \\
\hline A & Gravity thickener & 8.24 & 9 & 10 & 11 \\
\hline B & Gravity thickener & 8.10 & 9 & 10 & 11 \\
\hline C & $\begin{array}{l}\text { Gravity Belt } \\
\text { Thickener }\end{array}$ & 1.72 & 2 & 3 & 4 \\
\hline $\mathrm{D}$ & $\begin{array}{l}\text { Gravity Belt } \\
\text { Thickener }\end{array}$ & 1.72 & 2 & 3 & 4 \\
\hline E & $\begin{array}{l}\text { Thickening } \\
\text { Centrifuge }^{2}\end{array}$ & 2.14 & 3 & 4 & 5 \\
\hline
\end{tabular}

${ }^{1}$ MDWASD May 2005

${ }^{2}$ MWH 2016 
Table 35: CDWWTP Sludge Thickening Unit Sizing

\begin{tabular}{|c|c|c|c|c|c|c|c|}
\hline Scenario & $\begin{array}{l}\text { Thickening } \\
\text { Tochnology }\end{array}$ & manufacturer & model & $\begin{array}{c}\text { Unit IIydraulic } \\
\text { loading }\end{array}$ & $\begin{array}{l}\% \text { feed } \\
\text { solids }\end{array}$ & $\begin{array}{l}\text { unit solids } \\
\text { load }\end{array}$ & $\begin{array}{l}\% \text { thickened } \\
\text { solids }\end{array}$ \\
\hline & & & & gpm & & Ibs./hr. & \\
\hline A & Gravity thickencr ${ }^{2}$ & existing & bespoke & 751 & 1.2 & 791.94 & 3.9 \\
\hline B & Gravity thickener & existing & bespoke & 751 & 1.2 & 791.94 & 3.9 \\
\hline C & $\begin{array}{c}\text { Gravity Belt } \\
\text { Thickener }^{2}\end{array}$ & Andrizt & $3 \mathrm{~m}$ bclt & 750 & 1.2 & 3,646 & 3.9 \\
\hline $\mathrm{D}$ & $\begin{array}{l}\text { Gravity Belt } \\
\text { Thickencr }^{2}\end{array}$ & Andrizt & 3m belt & 750 & 1.2 & 3,646 & 3.9 \\
\hline E & $\begin{array}{l}\text { Thickening } \\
\text { Ccntrifuge }{ }^{2}\end{array}$ & Alfa Laval & G3 125 & 500 & 1.2 & 2,917 & 3.9 \\
\hline
\end{tabular}

\begin{tabular}{|c|c|c|c|c|c|}
\hline Sccnario & $\begin{array}{l}\text { Thickening } \\
\text { Tcchnology }\end{array}$ & $\begin{array}{c}\text { daily operational } \\
\text { cquivalcnt }\end{array}$ & units required & $\begin{array}{l}\text { minimum } \\
\text { design } \\
\text { standard }\end{array}$ & $\begin{array}{l}\text { Plant staff } \\
\text { prefercence }\end{array}$ \\
\hline & & $\mathrm{n}^{\prime}$ & n & $n+1$ & $n+2$ \\
\hline A & Gravity thickener' & 5.82 & 6 & 7 & 8 \\
\hline $\mathbf{B}$ & Gravity thickener $^{1}$ & 5.75 & 6 & 7 & 8 \\
\hline $\mathrm{C}$ & $\begin{array}{c}\text { Grevity Belt } \\
\text { Thickener }^{2}\end{array}$ & 2.59 & 3 & 4 & 5 \\
\hline D & $\begin{array}{l}\text { Gravity Bclt } \\
\text { Thickener }^{2}\end{array}$ & 2.59 & 3 & 4 & 5 \\
\hline $\mathbf{E}$ & $\begin{array}{l}\text { Thickening } \\
\text { Centrifuge }^{2}\end{array}$ & 2.83 & 3 & 4 & 5 \\
\hline
\end{tabular}

${ }^{1}$ MDWASD March 2005

${ }^{2}$ MWH September 2015 
The sludge thickening unit sizing of CDWWTP shows a similar solids loading capacity limitation for the existing gravity thickening tanks (Table 35). As the CDWWTP condition of minimum required gravity concentrators for scenario A, 6, does not exceed the existing number of units, 8 , this may explain why the sludge thickening performance of CD-A is exceedingly better than that of SD-A. The higher hydraulic loading condition of CDWWTP when compared to SDWWTP triggers a hydraulic rather than a solids limiting condition for the minimum number of units required for the sludge gravity belt thickeners and sludge-thickening centrifuges of CDWWTP scenarios C, D, and $\mathrm{E}$.

Sludge Digestion Unit Sizing

Sludge digester sizing was estimated based on the target detention time against both the hydraulic loading and solids loading capacity of both existing and proposed digester systems. Hydraulic loading rates were determined based on the model output of TWAS flowrates to the digesters for each scenario. Maximum recommended volatile, or organic, solids loading capacities in the literature ranged from 0.2 to $0.3 \mathrm{lb} / \mathrm{cuft}-\mathrm{d}$ (Metcalf and Eddy $4^{\text {th }}$ Edition, 2003 and WEF MOP No. $85^{\text {th }}$ Edition, 2010). The maximum solids loading capacity presented in the subject plants' existing operation and maintenance manual was chosen as it was had already been set as a design parameter for the existing digesters. The solids loading calculations were based on a $0.25 \mathrm{lb} / \mathrm{cuft}-\mathrm{d}$ organic solids loading capacity against active digester volume (MDWASD, May 2005). 
Upon calculating the hydraulic and organic loadings for the scenarios, it was discovered that based on the TWAS flows and volatile solids concentrations, the hydraulic loading was the deciding factor in the number of digesters required in all scenarios for both subject plants.

For digester unit sizing considerations, the number of digesters required was determined to the nearest integer and then the detention time was recalculated for both active volume and total digester volume by including secondary digesters and holding tanks. In all scenarios this led to estimated detention times somewhat lower than the target detention times for each scenario. As the design target for this study is 30 days, values approaching, but not meeting the targeted 30 days still go beyond the design standards for high-rate digestion of 15 days and would meet all federal regulation, as both a process to significantly reduce pathogens, PSRP, through time and temperature, and meet vector attraction reduction requirement by exceeding a 38\% VSR (WEF MOP No. 8 $5^{\text {th }}$ Edition, 2010).

There was one exception to the pervious statement. In scenario SD-A the final active volume hydraulic detention was estimated to be 13.6 days, as noted in Table 36 . This value is below the required 15 day detention time to meet federal regulations for Class B biosolids based on time and temperature for a process to significantly reduce pathogens, PSRP, and therefore would not meet recommended design standards for anaerobic mesophilic digestion in the United States. As Scenario SD-A is the existing condition and no additional digesters are current available at the SDWWTP the conclusion is that the existing site conditions may not meet federal regulations for a Class B biosolids if mesophilic anaerobic digestion is the method being utilized. As these 
calculations are based solely on model outputs and not directly based on plant data, scenario SD-A may not reflect the true digester detention time currently experienced at SDWWTP. Fortunately, even if the detention time were to fall below 15 days, the SDWWTP currently has both sludge drying beds and hauling contracts in place to further process or properly dispose of biosolids that do not meet Class B biosolids standards. These measures of additional solids processing or alternate biosolids disposal are not considered in proposed scenarios as the SDWWTP intends to discontinue use of the existing sludge drying beds in order to facilitate a planned plant expansion.

None of the other SDWWTP or CDWWTP scenarios encountered active volume detention times below 15 days based on the MBM input parameters. Scenario SD-B did not have enough digester to meet the $\mathrm{n}+2$ condition. This does not affect the active volume detention time under normal conditions but would mean that during required maintenance activities there would be no holding tank if a greater than 15 day active volume detention time is to be maintained. In both the SDWWTP and CDWWTP model runs enhanced sludge thickening was needed to meet the target 30 day active volume detention time as noted in Table 36 and Table 37 by virtue that only scenarios C, D, and E are close to the 30 day active volume detention time. 
Scenarios D and E, where all digesters were converted to single-stage high rate digester by adding adequate mixing and heating, showed a significantly lower number of digesters required for rehabilitation compared to Scenarios B and C, as can be observed in Table 36 and Table 37. As mentioned in Chapter 2, almost all existing digesters require significant rehabilitation due to their age and existing condition. As such, all digesters except for SDWWTP digester 9-12, were slated for refurbishment or replacement as per a federal consent decree. A reduction in the number of digesters required to process the study facilities' biosolids loading would therefore be both a cost savings and more sustainable by requiring less replacement materials, construction and power consumption both during reconstruction and later in operation. 
Table 36: SDWWTP Sludge Digestion Unit Sizing

\begin{tabular}{|c|c|c|c|c|c|c|c|c|c|}
\hline Scenario & digestion system & manufacturer & $\begin{array}{c}\text { tank } \\
\text { volume }\end{array}$ & $\begin{array}{l}\text { possible } \\
\text { active } \\
\text { digesters }\end{array}$ & $\begin{array}{c}\text { possible } \\
\text { digesters } \\
\text { w/o mixing } \\
\text { heating }\end{array}$ & $\begin{array}{c}\text { holding } \\
\text { tanks }\end{array}$ & $\begin{array}{l}\text { target } \\
\text { hydraulic } \\
\text { retention } \\
\text { time }\end{array}$ & $\begin{array}{l}\text { target } \\
\text { hydraulic } \\
\text { loading } \\
\text { digester }\end{array}$ & $\begin{array}{c}\text { target solids } \\
\text { loading/ } \\
\text { digester }(Q) \\
0.25 \text { Ibicuft-d }\end{array}$ \\
\hline & & & MG & no. & no. & no. & d & gpm & Ib/d \\
\hline A & Primary-Secondary $^{l}$ & existing & 1.64 & 5 & 5 & 2 & 14.7 & 77.6 & 54,768 \\
\hline B & Primary-Secondary ${ }^{1}$ & existing & 1.64 & 6 & 5 & 1 & 17.9 & 63.7 & 54,768 \\
\hline D & Single-stage ${ }^{2}$ & proposed & 1.64 & 10 & 0 & 2 & 29.6 & 38.5 & 54,768 \\
\hline E & Single-stage ${ }^{2}$ & proposed & 1.64 & 10 & 0 & 2 & 32.7 & 34.8 & 54,768 \\
\hline
\end{tabular}

\begin{tabular}{|c|c|c|c|c|c|c|c|c|}
\hline Scenario & digestion system & $\begin{array}{l}\text { active } \\
\text { units } \\
\text { required }\end{array}$ & $\begin{array}{l}\text { secondary } \\
\text { units } \\
\text { required }\end{array}$ & $\begin{array}{l}\text { digester } \\
\text { units } \\
\text { required }\end{array}$ & $\begin{array}{c}\text { minimum } \\
\text { design standard } \\
(1 \text { holding tank) }\end{array}$ & $\begin{array}{c}\text { Plant staff } \\
\text { prefercnce (2 } \\
\text { holding tanks) }\end{array}$ & $\begin{array}{c}\text { Total } \\
\text { active } \\
\text { hydraulic } \\
\text { retention } \\
\text { time }\end{array}$ & $\begin{array}{c}\text { Total } \\
\text { hydraulic } \\
\text { retention } \\
\text { time }\end{array}$ \\
\hline & & $\mathrm{n}$ & $\mathrm{n}$ & $\mathrm{n}$ & $\mathrm{n}+1$ & $\mathrm{n}+2$ & d & d \\
\hline A & Primary-Sccondary $^{1}$ & 5 & 5 & 10 & 11 & 12 & 13.6 & 32.6 \\
\hline B & Primary-Secondary $^{1}$ & 6 & 5 & 11 & 12 & 12 & 16.6 & 33.1 \\
\hline $\mathrm{C}$ & Primary-Secondary & 4 & 4 & 8 & 9 & 10 & 28.0 & 70.1 \\
\hline $\mathrm{D}$ & Single-stage ${ }^{2}$ & 4 & - & 4 & 5 & 6 & 28.0 & 42.1 \\
\hline $\mathrm{E}$ & Singlc-stag $\mathrm{c}^{2}$ & 4 & $=$ & 4 & 5 & 6 & 31.2 & 46.9 \\
\hline
\end{tabular}

${ }^{1}$ MDWASD May 2005

${ }^{2}$ CH2M 2015 
Table 37: CDWWTP Sludge Digestion Unit Sizing

\begin{tabular}{|c|c|c|c|c|c|c|c|c|c|}
\hline Scenario & digestion system & manufacturer & $\begin{array}{c}\text { tank } \\
\text { volume }\end{array}$ & $\begin{array}{l}\text { possible } \\
\text { active } \\
\text { digesters }\end{array}$ & $\begin{array}{c}\text { possible } \\
\text { digcstcrs } \\
\text { wio mixing } \\
\text { heating }\end{array}$ & $\begin{array}{l}\text { holding } \\
\text { tanks }\end{array}$ & $\begin{array}{l}\text { Target } \\
\text { hydraulic } \\
\text { retcntion } \\
\text { time }\end{array}$ & $\begin{array}{l}\text { target } \\
\text { bydraulic } \\
\text { loading/ } \\
\text { digester }\end{array}$ & $\begin{array}{c}\text { target solids } \\
\text { loading' } \\
\text { digester } Q \text { ) } \\
0.25 \text { Ibicuft-d }\end{array}$ \\
\hline & & & $\mathrm{MG}$ & no. & no. & no. & d & gpm & lb/d \\
\hline A & Primary-Sccondary $^{l}$ & cxisting & 1.64 & 6 & 7 & 2 & 16.95 & 67.15 & 54,768 \\
\hline B & Primary-Secondary $^{1}$ & existing & 1.64 & 12 & 10 & 2 & 34.36 & 33.12 & 54,768 \\
\hline $\mathrm{C}$ & Primary-Secondary ${ }^{1}$ & existing & 1.64 & 12 & 10 & 2 & 28.90 & 39.38 & 54,768 \\
\hline D & Single-stage ${ }^{2}$ & proposed & 1.64 & 22 & 0 & 2 & 28.90 & 39.38 & 54,768 \\
\hline E & Single-stage ${ }^{2}$ & proposed & 1.64 & 22 & 0 & 2 & 32.98 & 34.51 & 54,768 \\
\hline
\end{tabular}

\begin{tabular}{|c|c|c|c|c|c|c|c|c|}
\hline Scenario & digcstion systcm & $\begin{array}{l}\text { active } \\
\text { units } \\
\text { required }\end{array}$ & $\begin{array}{l}\text { secondary } \\
\text { units } \\
\text { required }\end{array}$ & $\begin{array}{l}\text { digester } \\
\text { units } \\
\text { required }\end{array}$ & $\begin{array}{c}\text { minimum } \\
\text { design standard } \\
\text { (1 holding tank) }\end{array}$ & $\begin{array}{c}\text { Plant staff } \\
\text { preference (2 } \\
\text { holding tanks) }\end{array}$ & $\begin{array}{c}\text { Total } \\
\text { active } \\
\text { hydraulic } \\
\text { retention } \\
\text { time }\end{array}$ & $\begin{array}{l}\text { Total } \\
\text { hydraulic } \\
\text { retention } \\
\text { time }\end{array}$ \\
\hline & & $\mathrm{n}$ & $\mathrm{n}$ & $\mathrm{n}$ & $\mathrm{n}+1$ & $\mathrm{n}+2$ & d & d \\
\hline A & Primary-Sccondary $^{l}$ & 6 & 6 & 12 & 13 & 14 & 15.9 & 37.1 \\
\hline B & Primary-Secondary ${ }^{1}$ & 12 & 10 & 22 & 23 & 24 & 32.2 & 64.4 \\
\hline $\mathrm{C}$ & Primary-Secondary & 7 & 7 & 14 & 15 & 16 & 27.3 & 62.4 \\
\hline $\mathrm{D}$ & Single-stage ${ }^{2}$ & 7 & - & 7 & 8 & 9 & 27.3 & 35.1 \\
\hline $\mathbf{E}$ & Singlo-stagc ${ }^{2}$ & 7 & - & 7 & 8 & 9 & 31.2 & 40.2 \\
\hline
\end{tabular}

${ }^{1}$ MDWASD March 2005

${ }^{2}$ MWH February 2015 
Sludge Dewatering Unit Sizing

As mentioned in Chapter 6, the existing dewatering centrifuges at both SDWWTP and CDWWTP, Scharples DS 706's were an industry standard for decades. These machines with the proper operational care, timely maintenance and consistent overhauls, can be maintained for far longer than the standard 30-year life cycle. Therefore, unlike the existing gravity concentrators and primary-secondary digesters, a full rehabilitation and replacement would not be necessary for the existing dewatering centrifuges. Centrifuge overhauls have been maintained throughout the life of the machines and could continue. Although, SDWWTP only currently has 2 DS 706's, based on the requirement for both SDWWTP and CDWWTP as noted in Table 39 and Table 40, sufficient spare DS 706's are currently at CDWWTP, albeit in disrepair to compliment the 2 DS 706's currently at SDWWTP.

Based on the manufacturer information in the operations manual the existing DS 706's have a hydraulic load capacity of 250 gpm with a $4 \%$ solids sludge feed. The proposed units for scenarios C, D and E, Alfa Laval's G3 125's, have a higher hydraulic capacity of $400 \mathrm{gpm}$ at a lower feed solids concentration of $2.9 \%$ solids sludge feed. The existing and proposed scenario conditions have dewatering sludge feeds ranging from 1.3 to $3.5 \%$ solids based on MBM model runs, as previously shown in Table 29 and Table 30. These factors are taken into account when determining the solids load capacity of both existing and proposed unit as noted in Table 39. Based on the hydraulic and solids loading generated by the MBM for each scenario, previously presented in Table 31 and Table 32, the DS 706's are hydraulically limited for both subject facilities under 
scenarios A and B. The G3 125's turn out to be solids limited under the SDWWTP scenarios C, D, and E and hydraulically limited in the CDWWTP scenarios C, D, and E. This demonstrates how site specific and even scenario specific conditions can influence unit selection and sizing. In the case of centrifuges, the unit can be run intermittent if desired. The number of unit required for operation are presented below both in fractional, n', and whole number, n, of units in Table 39 and Table 40.

The subject facilities are operated on a 24 hour per day -7 days per week basis, normal operations are distributed amongst $3,8 \mathrm{hr}-7$ day shifts to cover the 168 hours of continuous operation throughout the week, as described in Table 38 below. Therefore, the initial assumption would be the run the dewatering facility also as a 24 hour per day, 7 days per week operation.

Table 38: Hours of weekly coverage based on 8-hr./ 7 day shifts

\begin{tabular}{|c|c|c|c|}
\hline No. of shifts & 1 & 2 & 3 \\
\hline Hrs. of weekly coverage & 56 & 112 & 168 \\
\hline
\end{tabular}

Facilities of significantly smaller sizes and operations staffing I have visited often design dewatering operations to be run either only during weekdays, only during one or 2, 8-hr. shift per day or both. The ability to run dewatering centrifuges intermittently is made possible by the flexibility in storage volume of the sludge holding tanks that are a part of the anaerobic digestion system presented above in Table 36 and Table 37. Based on the required number of units, $n$, and the number of spares units, $n+1$ and $n+2$, presented in Table 39 and Table 40 below, there is the ability to run more units than required to lower the overall time required to run dewatering operations. In this 
comparison of using spare capacity to reduce the overall hours of operation and hence save on personnel and auxiliary power requirements is where the proposed centrifuges, G3 125's demonstrate an additional benefit in their increased hydraulic and solids loading capacity. 
Table 39: SDWWTP Sludge Dewatering Unit Sizing

\begin{tabular}{|c|c|c|r|r|r|r|r|}
\hline Scenario & $\begin{array}{c}\text { dewatering } \\
\text { technology }\end{array}$ & manufacturer & model & $\begin{array}{c}\text { Unit } \\
\text { Hydraulic } \\
\text { loading }\end{array}$ & $\begin{array}{c}\% \text { feed } \\
\text { solids }\end{array}$ & $\begin{array}{c}\text { unit } \\
\text { solids } \\
\text { load } \\
\text { thickened } \\
\text { solids }\end{array}$ \\
\hline A & & & & gpm & & $1 \mathrm{~b} / \mathrm{hr}$ & \\
\hline B & dewatering centrifuge $^{2}$ & existing & DS706 & 250 & 4 & 5,004 & 25 \\
\hline C & dewatering centrifuge $^{2}$ & existing & DS706 & 250 & 4 & 5,004 & 25 \\
\hline D & dewatering centrifuge $^{2}$ & Alfa Laval & 125 & 400 & 2.9 & 5,805 & 22 \\
\hline E & dewatering centrifuge $^{2}$ & Alfa Laval & 125 & 400 & 2.9 & 5,805 & 22 \\
\hline
\end{tabular}

\begin{tabular}{|c|c|c|c|c|c|}
\hline Scenario & $\begin{array}{l}\text { dewatering } \\
\text { technology }\end{array}$ & $\begin{array}{l}\text { daily operational } \\
\text { equivalent }\end{array}$ & units required & $\begin{array}{l}\text { minimum } \\
\text { design } \\
\text { standard }\end{array}$ & $\begin{array}{l}\text { Plant staff } \\
\text { preference }\end{array}$ \\
\hline & & $\mathrm{n}^{\prime}$ & $\mathrm{n}$ & $\mathrm{n}+1$ & $\mathrm{n}+2$ \\
\hline A & dewatering centrifuge ${ }^{1}$ & 1.68 & 2 & 3 & 4 \\
\hline B & dewatering centrifuge ${ }^{1}$ & 1.60 & 2 & 3 & 4 \\
\hline $\mathrm{C}$ & dewatering centrifuge $^{2}$ & 0.58 & 1 & 2 & 3 \\
\hline D & dewatering centrifuge $^{2}$ & 0.58 & 1 & 2 & 3 \\
\hline $\mathbf{E}$ & dewatering centrifuge $^{2}$ & 0.59 & 1 & 2 & 3 \\
\hline
\end{tabular}

${ }^{1}$ MDWASD May 2005

${ }^{2}$ MWH 2016 
Table 40: CDWWTP Sludge Dewatering Unit Sizing

\begin{tabular}{|c|c|c|c|c|c|c|r|}
\hline Scenario & $\begin{array}{c}\text { dewatering } \\
\text { technology }\end{array}$ & manufacturer & model & $\begin{array}{c}\text { Unit } \\
\text { Hydraulic } \\
\text { loading }\end{array}$ & $\begin{array}{c}\% \text { feed } \\
\text { solids }\end{array}$ & $\begin{array}{c}\text { unit } \\
\text { solids } \\
\text { load }\end{array}$ & $\begin{array}{c}\% \\
\text { thickened } \\
\text { solids }\end{array}$ \\
\hline & & & gpm & & lb/hr & \\
\hline A & dewatering centrifuge $^{1}$ & existing & DS706 & 250 & 4 & 5,004 & 25 \\
\hline B & dewatering centrifuge $^{j}$ & existing & DS706 & 250 & 4 & 5,004 & 25 \\
\hline C & dewatering centrifuge $^{2}$ & Alfa Laval & 125 & 400 & 2.9 & 5,805 & 22 \\
\hline D & dewatering centrifuge $^{2}$ & Alfa Laval & 125 & 400 & 2.9 & 5,805 & 22 \\
\hline E & dewatering centrifuge $^{2}$ & Alfa Laval & 125 & 400 & 2.9 & 5,805 & 22 \\
\hline
\end{tabular}

\begin{tabular}{|c|c|c|c|c|c|}
\hline Scenario & $\begin{array}{l}\text { dewatcring } \\
\text { tcchnology }\end{array}$ & $\begin{array}{l}\text { daily opcrational } \\
\text { cquivalent }\end{array}$ & units required & $\begin{array}{l}\text { minimum } \\
\text { design } \\
\text { standard }\end{array}$ & $\begin{array}{l}\text { Plant staff } \\
\text { preference }\end{array}$ \\
\hline & & $\mathrm{n}^{\prime}$ & $\mathrm{n}$ & $\mathrm{n}+1$ & $\mathrm{n}+2$ \\
\hline $\mathrm{A}$ & dewatering centrifuge & 1.72 & 2 & 3 & 4 \\
\hline B & dewatering centrifuge & 1.75 & 2 & 3 & 4 \\
\hline $\mathrm{C}$ & dewatering centrifuge $^{2}$ & 0.76 & 1 & 2 & 3 \\
\hline D & dewatering centrifuge $^{2}$ & 0.76 & 1 & 2 & 3 \\
\hline E & dewatering centrifuge $^{2}$ & 0.72 & 1 & 2 & 3 \\
\hline
\end{tabular}

\footnotetext{
${ }^{1}$ MDWASD March 2005
}

${ }^{2}$ MWH September 2015 
Scenario SD-B, under minimum unit requirements of 2 units running, would require 3 shifts to process all the feed sludge estimated by the MBM. If this were increased to 3 machines running consistently by utilizing one of the spare units, the number of shifts required to process the same amount of feed sludge could be reduced to 2 shifts. Scenarios SD-C, D, and E under their minimum unit requirements of 1 unit running, would require 2 shifts to process all the feed sludge estimated by the MBM. If the number of units in operation were increased to 2 machines running consistently by utilizing one of the spare units for scenarios C, D and E as presented in Table 39, the number of shifts required to process the same amount of feed sludge could be reduced to 1 shift. This results in a wide spectrum on the number of people required to run dewatering operations based on the scenario selected and strategic use of spare units.

A similar comparison for potential dewatering operation arrangements at the CDWWTP does not have as dramatic a benefit in the proposed versus the existing dewatering centrifuges once the minimum number of required units is met. Scenario CD$\mathrm{B}$, under minimum unit requirements of 2 units running, would require 3 shifts to process all the feed sludge estimated by the MBM. If this were increased to 3 machines running consistently by utilizing one of the spare units, the number of shifts required to process the same amount of feed sludge could be reduced to 2 shifts. Scenarios CD-C, D, and E under their minimum unit requirements of 1 unit running, would require 3 shifts to process all the feed sludge estimated by the MBM. If number of units in operation were increased to 2 machines running consistently by utilizing one of the spare units for scenarios $\mathrm{C}, \mathrm{D}$, and $\mathrm{E}$ as presented in Table 40 , the number of shifts required to process the same amount of feed sludge could be reduced to 2 shifts. Therefore, although the 
CDWWTP would require more of the existing DS 706's, machines the plant already possess, the same strategy of running a spare unit would reduce the number of shifts required for dewatering operations from 3 to shifts for all CDWWTP scenarios.

In the following section of cost estimation of comparative capital and operational cost for all scenarios run through the MBM, this strategy of running spare units in order to reduce the number of dewatering shifts required is not presented as a operational cost consideration. In my experience the operational strategy employed by a specific facility is based on a number of factors, such as routine maintenance levels, housekeeping efforts, and labor union contracts that are beyond the scope of this study. This observation is included in this study as a possible operational strategy for readers of this study involved in the operation and maintenance of facilities.

\subsection{Process Unit Cost Estimates}

In addition to providing the internal process hydraulic loading, solids loading, and final biosolids production for each scenario, the MBM provides a framework for determining the minimum number of process units required to meet the hydraulic and solids loading a comparison of proposed as described in the previous section of this chapter and a starting point for establishing a cost comparison of the biosolids treatment processes describe in the MBM scenarios. The following section compares the alternatives relative to each other. Due to limited cost information for scenarios that deviate from projects under design or projects currently under construction, various costing sources were utilized to varying degrees of accuracy. The sources for capital costs were based on a hierarchy of preferred data resources starting from construction bid 
amount for projects that were selected, design and constructed or in construction; to cost importation provided in basis of design reports; to preliminary cost estimates used to establish capital budgets for the Miami-Dade Water and Sewer Department. The source for operational costs were current chemicals cost rates based on chemical contracts for the polymer coagulants and ferric sulfate used at the subject facilities, the current power rate structure for the subject facilities, and the site-specific hauling costs for Class B biosolids for land application under the currently sludge hauling contracts for MiamiDade Water and Sewer Department. As the proposed technologies' chemical interactions, future sludge conditions and the chemical, service and power contracts are dynamic in nature and subject to change the estimated operational cost are to likewise be taken as a point of comparison and not absolute values.

\section{Sludge Thickening Cost Estimates}

Below in Table 41 are the comparative capital costs for the various sludge thickening scenarios run in the MBM. Comparison between scenarios $\mathrm{A}$ and $\mathrm{B}$ and scenarios $\mathrm{C}, \mathrm{D}$, and $\mathrm{E}$ place scenarios $\mathrm{A}$ and $\mathrm{B}$ at a disadvantage due in part to the cost comparison method and not the true nature of the cost of rehabilitating the existing sludge thickening process versus implementing either of the proposed technologies. For the existing systems the cost of rehabilitation on the unit cost is representative of the expected rehabilitation cost of existing gravity concentrators if full rehabilitation were pursued. The MBM for the SDWWTP scenarios resulted in higher solids loadings than could be handled by the existing units. Therefore, applying the unit cost for refurbishment is a severe underestimate for the required gravity thickening units that do 
not currently exist. Further effort in costing out new gravity thickening units for scenarios $\mathrm{A}$ and $\mathrm{B}$ was not taken as this technology has proven to not meet the target TWAS solids concentration desired to gain hydraulic digester capacity. Sufficient gravity thickeners exist at the CDWWTP to meet $n+2$ gravity thickening units.

As permanent gravity belt thickening or thickening centrifuge facilities have yet to be built at the subject facilities units cost from basis of design reports were selected as the point of comparison. This excludes the cost of a building or appurtenances so a factor of 3 was used to account for installing units into a future sludge thickening facility. As the number of units presented in Table 34 and Table 35 differ from any current designs for the subject facilities, an estimated cost for a sludge thickening building was not estimated for this study and it is assumed that the building required to house either gravity belt thickeners or thickening centrifuges would be roughly the same and based on the number of units selected for units of similar capacity.

MBM scenarios for the SDWWTP show a comparative capital cost advantage of gravity belt thickeners, scenarios SD-C and SD-D, over thickening centrifuges, scenario SD-E, due to both the lower number of units required and the lower unit cost, Table 41. The CDWWTP comparative capital cost also shows a cost advantage to gravity belt thickeners, scenarios CD-C and CD-D, over thickening centrifuges, scenario CD-E, due to solely to the lower respective unit cost. 
Table 41: SDWWTP and CDWWTP Sludge Thickening Comparative Capital Cost Estimates

\begin{tabular}{|c|c|c|c|c|}
\hline \multicolumn{2}{|c|}{ South District } & \multirow[b]{2}{*}{ unit cost* } & \multirow[b]{2}{*}{$\begin{array}{l}\text { installed } \\
\text { equipment } \\
\text { cost* }^{*}\end{array}$} & \multirow[b]{2}{*}{$\begin{array}{l}\text { installed } \\
\text { equipment } \\
\text { cost* }\end{array}$} \\
\hline Scenario & $\begin{array}{l}\text { Thickening } \\
\text { Technology }\end{array}$ & & & \\
\hline & & (2015\$) & $(2015 \$) n+1$ & $(2015 \$) n+2$ \\
\hline A & Gravity thickener ${ }^{1}$ & 1250000 & $12,500,000$ & $13,750,000$ \\
\hline B & 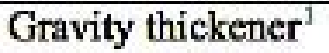 & 1250000 & $12,500,000$ & $13,750,000$ \\
\hline C & $\begin{array}{l}\text { Gravity Belt } \\
\text { Thickener }^{2}\end{array}$ & 230000 & $2,070,000$ & $2,760,000$ \\
\hline D & $\begin{array}{l}\text { Gravity Belt } \\
\text { Thickener }^{2}\end{array}$ & 230000 & $2,070,000$ & $2,760,000$ \\
\hline E & $\begin{array}{l}\text { Thickening } \\
\text { Centrifuge }^{2}\end{array}$ & 625000 & $7,500,000$ & $9,375,000$ \\
\hline
\end{tabular}

${ }^{1}$ MDWASD May 2005

${ }^{2}$ MWH 2016

* Unit cost for existing units is the cost of refurbishment. Unit cost for new units is solely the cost for the unit. Installed cost for new units includes a factor of 3 for installation costs.

\begin{tabular}{|c|c|c|c|c|}
\hline \multicolumn{2}{|c|}{ Central District } & \multirow[b]{2}{*}{ unit cost* } & \multirow{2}{*}{$\begin{array}{c}\text { installed } \\
\text { equipment } \\
\text { cost* }\end{array}$} & \multirow{2}{*}{$\begin{array}{c}\text { installed } \\
\text { equipment } \\
\text { cost* }\end{array}$} \\
\hline Scenario & $\begin{array}{l}\text { Thickening } \\
\text { Technology }\end{array}$ & & & \\
\hline & & $(2015 \$)$ & $(2015 \$) n+1$ & $(2015 \$) n+2$ \\
\hline A & Gravity thickener ${ }^{1}$ & 1250000 & $8,750,000$ & $10,000,000$ \\
\hline B & Gravity thickener $^{1}$ & 1250000 & $8,750,000$ & $10,000,000$ \\
\hline C & $\begin{array}{l}\text { Gravity Belt } \\
\text { Thickener }^{2}\end{array}$ & 290000 & $3,480,000$ & $4,350,000$ \\
\hline D & $\begin{array}{l}\text { Gravity Belt } \\
\text { Thickener }^{2}\end{array}$ & 290000 & $3,480,000$ & $4,350,000$ \\
\hline E & $\begin{array}{l}\text { Thickening } \\
\text { Centrifuge }^{2}\end{array}$ & 615000 & $7,380,000$ & $9,225,000$ \\
\hline
\end{tabular}

${ }^{1}$ MDWASD March 2005

${ }^{2}$ MWH September 2015

* Unit cost for existing units is the cost of refurbishment. Unit cost for new units is solely the cost for the unit. Installed cost for new units includes a factor of 3 for installation costs. 
A comparison of chemical and power consumption costs for the different scenarios does favor the existing gravity concentrators as they have the lowest relative combined chemical and power consumption costs, as seen below in Table 42. The gravity belt thickeners have the second lowest power consumption costs even though they potentially consume 5 times more polymer than the existing gravity thickeners or the piloted thickening centrifuges. The thickening centrifuges have the highest power consumption costs. Due to the current price of polymer and the lower polymer consumption, thickening centrifuges come out to have a more favorable combined chemical and power consumption cost than gravity belt thickeners for SDWWTP where the process is solids loading driven. As CDWWTP's sludge thickening process is hydraulically limited the gravity belt thickeners have the lower combined chemical and power consumption costs. To note the sludge gravity belt thickeners for SDWWTP and CDWWTP differ as per their respective basis of design reports. Likewise, the thickening centrifuges quoted in the respective basis of design reports differ from the thickening centrifuges used in the pilot study both in manufacturer and scale of the units. Therefore, although polymer consumption was based on the thickening pilot, power consumption was based on the rated horsepower provided for the full-scale units presented in the basis of design reports. (MWH, September 2015 and CH2M, 2015). 
Table 42: SDWWTP and CDWWTP Sludge Thickening Comparative Chemical and Power Cost Estimates

\begin{tabular}{|c|c|c|c|c|c|c|c|c|}
\hline \multicolumn{9}{|c|}{ South District } \\
\hline Scenario & Thickening Technology & $\begin{array}{l}\text { polymer } \\
\text { fecd }\end{array}$ & $\begin{array}{l}\text { ferric sulfate } \\
\text { fecd }\end{array}$ & $\begin{array}{c}\text { power } \\
\text { consumption } \\
\text { per unit }\end{array}$ & $\begin{array}{c}\text { polymer } \\
\text { cost } @ \\
\text { \$2/b. }\end{array}$ & $\begin{array}{c}\text { ferric cost } \\
@ \\
\$ 0.766 / \mathrm{lb} .\end{array}$ & $\begin{array}{c}\text { power cost } \\
@ \\
\$ 0.085 / \mathrm{kwh}\end{array}$ & $\begin{array}{l}\text { chemical and } \\
\text { power costs }\end{array}$ \\
\hline & & lbiton & $\mathrm{gal} / 1000 \mathrm{gal}$ & (hp) & $(2018 S) / y t$ & $(2018 \$) / y r$. & $(2018 \$)^{\prime} y x_{.}$ & $(2018 \$) / y r$. \\
\hline A & 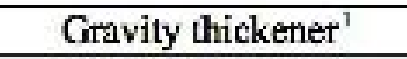 & 3.43 & \begin{tabular}{|r|}
0.43 \\
\end{tabular} & 2 & 196,110 & 275,487 & 9,205 & 480,802 \\
\hline B & 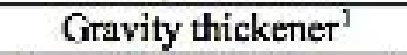 & 2.54 & 0.43 & 2 & 142,741 & 270,798 & 9,048 & 422,587 \\
\hline $\mathrm{C}$ & Gravity Belt Thickener $^{2}$ & 12 & 0 & 4 & 659,924 & - & 3,846 & 663,770 \\
\hline $\mathrm{D}$ & Gravity Belt Thickencr $^{2}$ & 12 & 0 & 4 & 659,924 & - & 3,846 & 663,771 \\
\hline $\mathbf{E}$ & Thickening Centrifuge $^{2}$ & 2.94 & 0 & 260 & 160,629 & - & 310,487 & 471,116 \\
\hline
\end{tabular}

${ }^{1}$ MDWASD May 2005

${ }^{2}$ MWH 2016

\begin{tabular}{|c|c|c|c|c|c|c|c|c|}
\hline \multicolumn{9}{|c|}{ Central District } \\
\hline Scenario & Thickening Technology & $\begin{array}{l}\text { polymer } \\
\text { foed }\end{array}$ & $\begin{array}{c}\text { ferric sulfate } \\
\text { feed }\end{array}$ & $\begin{array}{c}\text { power } \\
\text { consumption } \\
\text { per unit }\end{array}$ & $\begin{array}{c}\text { polymer } \\
\text { cost } @ \\
\$ 2 / \mathrm{lb} \text {. }\end{array}$ & $\begin{array}{c}\text { ferric cost } \\
\text { (a) } \\
50.766 / \mathrm{lb} .\end{array}$ & $\begin{array}{c}\text { power cost } \\
(a \\
\$ 0.085 / \mathrm{kwh}\end{array}$ & $\begin{array}{l}\text { chemical and } \\
\text { power costs }\end{array}$ \\
\hline & & lb/ton & $\mathrm{gal} / 1000 \mathrm{gal}$ & (hp) & $(2018 \$) / \mathrm{yt}$. & $(2018 \$) / y \mathbf{y t}$ & $(2018 \$) / \mathrm{yr}$. & $(2018 \$)$ yr. \\
\hline A & Gravity thickener & 2.54 & 0 & 2 & 102,626 & - & 6,505 & 109,131 \\
\hline B & Gravity thickener $^{1}$ & 2.54 & 0 & 2 & 101,356 & - & 6,424 & 107,781 \\
\hline $\mathrm{C}$ & Gravity Belt Thickener ${ }^{2}$ & 12 & 0 & 5 & 468,117 & - & 7,237 & 475,354 \\
\hline $\mathrm{D}$ & Gravity Bclt Thickencr $^{2}$ & 12 & 0 & 5 & 468,117 & - & 7,237 & 475,354 \\
\hline $\mathrm{E}$ & Thickening Centrifuge $^{2}$ & 3.08 & 0 & 250 & 119,784 & - & 394,655 & 514,439 \\
\hline
\end{tabular}

${ }^{1}$ MDWASD March 2005

${ }^{2}$ MWH September 2015 


\section{Sludge Digestion Cost Estimates}

Construction projects at the SDWWTP and CDWWTP currently underway provided the source of the sludge digestion comparative capital cost information for the MBM scenarios in this study (S-897, 2018 and S-909, 2018). As all digesters to be kept in service were to be refurbished or replaced as per federal consent decree the cost provided in the current construction contracts for SDWWTP and CDWWTP digesters were used to estimate the cost of both rehabilitating primary, secondary and holding tank digester and retrofitting existing digesters to single-stage digesters. The construction contracts reflect the cost of retrofitting existing digesters to high-rate single-stage digester. The retrofit consists of replacement of all piping and valves, floating digester covers to a new, lower maintenance design, new recirculation and sludge transfer pumps, new mixer designs and new heat exchanger designs along with structural repairs as necessary and other appurtenances. The same equipment and overall work would be required to refurbish existing primary digesters compared to the single-stage high-rate digesters bid in the construction contracts. Refurbishment of the existing secondary digesters and holding tanks would require the same equipment replacement except for the mixers and heat exchangers. Unit costs for single-stage digesters and primary digesters reflect a calculated unit cost based on the SDWWTP and CDWWTP construction contracts. Unit cost for secondary digesters and holding tank digesters reflect a calculated unit cost based on the SDWWTP and CDWWTP construction contracts sans the supply and installation of mixing and heat exchanger elements. 
Table 43 Presents the comparative capital costs for the sludge digestion systems of the MBM scenarios. As can be observed the need for almost double the amount of digesters for the primary-secondary digester system configuration is a large cost disadvantage even when improved thickening technologies are utilized to reduce the hydraulic load to the digestion system as done in scenarios C. To note scenarios SD-A, CD-A or SD-B do not meet the 30-day design target for active volume digester detention time which, in theory, would negatively impact VSR and the intent to reduce biosolids sludge production. Pilot testing in this study did not show a negative VSR impact from shorter digester detention times for SDWWTP, but as discussed previously this may be an artifact of mishaps during the piloting effort and the true 30-day detention time VSR could be significantly higher than demonstrated during the pilot. Alternately, if 15 days of detention time accomplishes nearly the same level of VSR as a 30-day detention time for the SDWWTP sludge conditions, then retrofitting fewer digesters to meet a target 15day detention time would have a significant cost advantage over all proposed scenarios. This would mean that a modified scenario SD-E for example could be accomplished with 2 active-single stage digesters and 2 holding tanks all other conditions being equal and achieve a 15.6-day detention time. The estimated comparative capital cost for this retrofit would be just under $\$ 28 \mathrm{M}, \$ 15 \mathrm{M}$ less than scenario SD-E. This study would not recommend such cost cutting measures, as they would not allow for flexibility in case of maintenance of either single-stage digester. Additionally, this would preclude the ability to test the possibility of greater VSRs at higher SRTs on a full-scale implementation, a conclusion that was shown to be true during the CDWWTP pilot test even though this was not demonstrated during the SDWWTP pilot test. 


\section{Table 43: SDWWTP and CDWWTP Sludge Digestion Comparative Capital Cost Estimates}

\begin{tabular}{|c|c|c|c|c|c|}
\hline SDWWTP & & & & & \\
\hline Scenario & digestion systcm & $\begin{array}{l}\text { Single-Stagef } \\
\text { Primary unit } \\
\text { cost* }\end{array}$ & $\begin{array}{c}\text { Seoncdafy' } \\
\text { holding tank unit } \\
\operatorname{cost}^{*}\end{array}$ & $\begin{array}{l}\text { irstalled } \\
\text { ecpuipment cost* }\end{array}$ & $\begin{array}{l}\text { installod } \\
\text { equipment cost }\end{array}$ \\
\hline & & (201RS) & (201RS) & $(201 \mathrm{RS}) n+1$ & $(2018 S) n+2$ \\
\hline A & Primary-Scondary ${ }^{b}$ & $7,578,750$ & $6,403,750$ & $76,316,250$ & $82,720,000$ \\
\hline B & Prinury-Secondary' & $7,578,750$ & $6,403,750$ & $83,895,000$ & $83,895,000$ \\
\hline C & Primary-Scoondary ${ }^{1}$ & $7,578,750$ & $6,409,750$ & $62,333,750$ & $68,737,500$ \\
\hline D & Single-stage ${ }^{2}$ & $7,578,750$ & $6,403,750$ & $36,718,750$ & $43,122,500$ \\
\hline $\mathbf{E}$ & Single-stape ${ }^{2}$ & $7,578,750$ & $6,403,750$ & $36,718,750$ & $43,122,500$ \\
\hline
\end{tabular}

${ }^{1} \mathrm{~S}-8972018$

${ }^{2}$ S-897 2018

* Unit cost for single-stage digesters, primary digesters, secondary digesters, and holding tanks derived from bid documents. Secondary digesters and holding tanks priced w/o mixers or heat exchangers.

\begin{tabular}{|c|c|c|c|c|c|}
\hline CDWWTP & & & & & \\
\hline Scenario & digcstion systcm & $\begin{array}{c}\text { Single-Stagef } \\
\text { Primary unit } \\
\text { cost* }\end{array}$ & $\begin{array}{c}\text { Seoncdafy' } \\
\text { holding tank unit } \\
\operatorname{cost}^{*}\end{array}$ & $\begin{array}{l}\text { installed } \\
\text { exuipment cost }\end{array}$ & $\begin{array}{l}\text { installed } \\
\text { equipment cost }\end{array}$ \\
\hline & & $(2018 . \$)$ & $(2018 \$)$ & $(201 \mathrm{RS}) n+1$ & $(20185) n+2$ \\
\hline $\mathrm{A}$ & Primary-Scomolary & $6,272,000$ & $5,187,000$ & $73,941,000$ & $79,128,000$ \\
\hline $\bar{B}$ & Primery-Secondary & $6,272,000$ & $5,187,000$ & $132,321,000$ & $137,508,000$ \\
\hline C & Primary-Scoondary ${ }^{1}$ & $6,272,000$ & $5,187,000$ & $85,400,000$ & $90,587,000$ \\
\hline $\mathrm{D}$ & Single-stage ${ }^{2}$ & $6,272,000$ & $5,187,000$ & $49,091,000$ & $54,278,000$ \\
\hline $\mathbf{E}$ & Single-stape ${ }^{2}$ & $6,272,000$ & $5,187,000$ & $49,091,000$ & $54,278,000$ \\
\hline
\end{tabular}

${ }^{1}$ S-909 2018

2 S-909 2018

* Unit cost for single-stage digesters, primary digesters, secondary digesters, and holding tanks derived from bid documents. Secondary digesters and holding tanks priced w/o mixers or heat exchangers. 
The comparative chemical and power consumption cost for the sludge digestion scenarios is reduced to power consumption costs as there are no chemical uses within digestion in either the existing or proposed scenarios. The power consumption used is based on the existing mixing and pumping systems for scenarios $\mathrm{A}, \mathrm{B}$, and $\mathrm{C}$ and proposed mixing and pumping systems for scenarios D and E, as shown in Table 44 below. Although, for capital costs consideration all new pumping and mixing systems were considered, there was significant resistance to changing mixing and pumping systems to lower energy consuming equipment, as the salvage right to the existing mixing and pumping systems belongs to the utility and may in fact choose to place those systems back in service this comparative power consumption cost analysis considers the existing sludge digestion primary-secondary digestion system with its existing mixing and pumping equipment.

As noted in Table 44 scenarios A, B, and C show higher comparative power costs than scenarios D and E. CDWWTP this is more pronounced as there are sufficient digesters to achieve a 30-day active volume digester detention time. SDWWTP's power consumption is kept lower for the existing system, scenarios SD-A, SD-B, and SD-C because there are insufficient digesters to reach 30-day active volume digestion time with the existing primary-secondary digester configuration and consequently less equipment to power relative to what would be necessary to run a digestion system at a 30-day active volume sludge detention time. 
The impact of operating less digesters and doing so more efficiently is clear when comparing $\mathrm{CD}-\mathrm{B}$ and $\mathrm{CD}-\mathrm{E}$ which have similar active volume sludge detention times and VSR, but the comparative power consumption of CD-E is less than $1 / 5^{\text {th }}$ that of CD-B. Small changes such as these, to utilize new, low maintenance, energy efficient technologies to achieve the same or better levels of treatment are all part of refocusing municipal utilities to embrace greater sustainability while doing so in a practical manner. 
Table 44: SDWWTP and CDWWTP Sludge Digestion Comparative Chemical and Power Cost Estimates

\begin{tabular}{|c|c|c|c|c|c|c|c|c|c|c|}
\hline SDWWTT & & & & & & & & & & \\
\hline \multirow[t]{2}{*}{ 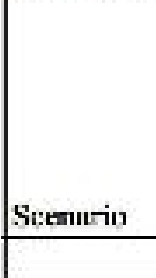 } & digestixn systemn & $\begin{array}{l}\text { polymer } \\
\text { feed }\end{array}$ & $\begin{array}{c}\text { ferric sulfate } \\
\text { feed }\end{array}$ & $\begin{array}{c}\text { power } \\
\text { comsumption } \\
\text { ol mixers per } \\
\text { digester } \\
\text { (activc) }\end{array}$ & $\begin{array}{l}\text { power bea: } \\
\text { system } \\
\text { purmps per } \\
\text { digester } \\
\text { (activc) }\end{array}$ & $\begin{array}{l}\text { power recire- } \\
\text { ulation pumps } \\
\text { per digester (oll } \\
\text { digesters) }\end{array}$ & $\begin{array}{l}\text { polymer } \\
\text { cost (g) } \\
82 / \mathrm{lh} .\end{array}$ & $\begin{array}{l}\text { ferric cost } \\
\text { (ब) } \\
\text { \$il. } 766^{\prime} \mathrm{lh} \text {, }\end{array}$ & $\begin{array}{l}\text { power cost } \\
6, \\
\$ 0,018.5, \mathrm{kwh}\end{array}$ & $\begin{array}{l}\text { checricel mod } \\
\text { powerr vosis }\end{array}$ \\
\hline & & Ibs.thon & galí1000 gal & (hp) & $(\mathrm{kp})$ & (hip) & $(201 \mathrm{gS}) \mathrm{yt}$ & (2018\$)yr. & $(2018 \$)$ yr. & (2018\$)/yt. \\
\hline A & Pritnary-Sccotidafy' & 0 & . & 60 & 20 & 10 & $\cdot$ & $=$ & 290,394 & 290,394 \\
\hline B & Primary-Sccondary & 0 & - & 60 & 20 & 10 & $\cdot$ & - & 335,070 & 335,070 \\
\hline $\mathrm{C}$ & Primary-Sccondary & 0 & - & 60 & 20 & 10 & - & - & 234,549 & 234,549 \\
\hline D & Single-gtage ${ }^{2}$ & 0 & - & 20 & 20 & 10 & - & - & 122.859 & 122,859 \\
\hline $\mathrm{E}$ & Single-stage ${ }^{2}$ & 0 & - & 20 & 20 & 10 & - & - & 122,859 & 122,859 \\
\hline
\end{tabular}

${ }^{1}$ MDWASD May 2005

${ }^{2}$ CH2M 2015

\begin{tabular}{|c|c|c|c|c|c|c|c|c|c|c|}
\hline CDWWTP & & & & & & & & & & \\
\hline \multirow[t]{2}{*}{ Scenatio } & digcstion system & $\begin{array}{l}\text { polymer } \\
\text { feed }\end{array}$ & $\begin{array}{l}\text { ferric sulfute } \\
\text { feed }\end{array}$ & $\begin{array}{c}\text { power } \\
\text { cotsumption } \\
\text { of mixers pes } \\
\text { digcster } \\
\text { (activc) }\end{array}$ & $\begin{array}{l}\text { powern hen: } \\
\text { system } \\
\text { pumps nex } \\
\text { digcstex } \\
\text { (active) }\end{array}$ & $\begin{array}{c}\text { power recirc- } \\
\text { ulation pumps } \\
\text { par digester (nil } \\
\text { digesterr) }\end{array}$ & $\begin{array}{l}\text { polymert } \\
\text { cxist (o) } \\
82 i l b .\end{array}$ & $\begin{array}{l}\text { ferric cost } \\
w^{3} \\
\text { \$0.766'll. }\end{array}$ & $\begin{array}{l}\text { power cost } \\
(4, \\
\$ 0.185, \mathrm{kwh}\end{array}$ & $\begin{array}{l}\text { chernical amd } \\
\text { powwer costs }\end{array}$ \\
\hline & & Ibs.rton & galí7000 gal & $(h p)$ & $(\mathrm{kp})$ & $(h p)$ & $(2018 S)$ yt. & (2018\$)yr. & (2018\$) $y$ yr. & (2018\$)/yt. \\
\hline$A$ & Pritnary-Sccondary' & 0 & 0 & 60 & 30 & 40 & $\cdot$ & - & 614,295 & 614,295 \\
\hline $\bar{B}$ & Primary-Sccondary' & 0 & 0 & 60 & 30 & 40 & - & - & $1,139,238$ & $1,139,238$ \\
\hline $\mathrm{C}$ & Primary-Sccondary ${ }^{1}$ & 0 & 0 & 60 & 30 & 40 & - & - & 709232 & 709,232 \\
\hline D & Single-gtnge ${ }^{2}$ & 0 & 0 & 20 & 20 & 10 & - & - & 206,627 & 206,627 \\
\hline $\mathrm{E}$ & Single-stage $e^{2}$ & 0 & 0 & 20 & 20 & 10 & - & - & 206,627 & 206,627 \\
\hline
\end{tabular}

${ }^{1}$ MDWASD March 2005

${ }^{2}$ MWH February 2015 
Sludge Dewatering Cost Estimates

The capital cost comparison of the sludge dewatering process takes a different approach to that of the existing sludge thickening and digestion systems. The existing dewatering centrifuges, DS 706's, in spite of their age are still viable machines. The cost that would be incurred for a complete overhaul has been applied to scenarios A and B unit costs in this capital cost comparison. Units costs for scenarios C, D, and E are for new G3 125's as quoted in the respective basis of design reports for SDWWTP and CDWWTP (MWH, September 2015 and MWH, 2016). As the division line on the number of machines required for the scenarios broke between the use of DS 706's and G3 $125^{\prime}$ 's the comparative capital costs for sludge dewatering broke along the same lines with the same costs for scenarios A and B and the same costs for scenarios C, D, and E for their respective plants, as seen in Table 45 below.

Table 45: SDWWTP and CDWWTP Sludge Dewatering Comparative Capital Cost Estimates

\begin{tabular}{|c|l|r|r|r|}
\hline SDWWTP & & & & \\
\hline Sccnario & $\begin{array}{c}\text { dewatcring } \\
\text { technology }\end{array}$ & unit cost* & $\begin{array}{c}\text { installed } \\
\text { cquipment } \\
\text { cost* }\end{array}$ & $\begin{array}{c}\text { installcd } \\
\text { cquipment } \\
\text { cost* }\end{array}$ \\
\hline & & $(2015 \$)$ & $(2015 \$) \mathrm{n}+1$ & $(2015 \$) \mathrm{n}+2$ \\
\hline A & dewatering centrifuge $^{*}$ & 150,000 & 450,000 & 600,000 \\
\hline B & dewatering centrifuge $^{*}$ & 150,000 & 450,000 & 600,000 \\
\hline C & dewatering centrifuge $^{2}$ & 615,000 & $3,690,000$ & $5,535,000$ \\
\hline D & dewatering centrifuge $^{2}$ & 615,000 & $3,690,000$ & $5,535,000$ \\
\hline E & dewatering centrifuge $^{2}$ & 615,000 & $3,690,000$ & $5,535,000$ \\
\hline
\end{tabular}

\footnotetext{
${ }^{1}$ MDWASD May 2005

${ }^{2}$ MWH 2016

* Unit cost for existing units is the cost of refurbishment. Unit cost for new units is solely the cost for the unit. Installed cost for new units includes a factor of 3 for installation costs.
} 


\begin{tabular}{|c|c|c|c|c|}
\hline CDWWTP & & & & \\
\hline \multirow[t]{2}{*}{ Scenario } & $\begin{array}{l}\text { dcwatcring } \\
\text { tcchnology }\end{array}$ & unit cost* & $\begin{array}{l}\text { installed } \\
\text { cquipment } \\
\text { cost* }\end{array}$ & $\begin{array}{l}\text { installed } \\
\text { equipment } \\
\text { cost* }^{*}\end{array}$ \\
\hline & & $(2015 \$)$ & $(2015 \$) n+1$ & $(2015 \$) n+2$ \\
\hline A & dewatering centrifuge & 150,000 & 450,000 & 600,000 \\
\hline B & dewatering centrifuge & 150,000 & 450,000 & 600,000 \\
\hline C & dewatering centrifuge $e^{2}$ & 625,000 & $3,750,000$ & $5,625,000$ \\
\hline D & dewatering centrifuge $e^{2}$ & 625,000 & $3,750,000$ & $5,625,000$ \\
\hline E & dewatering centrifuge $e^{2}$ & 625,000 & $3,750,000$ & $5,625,000$ \\
\hline
\end{tabular}

${ }^{1}$ MDWASD March 2005

${ }^{2}$ MWH September 2015

* Unit cost for existing units is the cost of refurbishment. Unit cost for new units is solely the cost for the unit. Installed cost for new units includes a factor of 3 for installation costs.

On the subject of comparative operational costs amongst the various scenarios another component is taken into account for sludge dewatering operations, in addition to chemical and power consumption. Outdoor sludge drying, currently practiced at SDWWTP, is planned to cease as previously discussed. Future post-dewatering options may replace the current sludge drying operations, but to date no permanent postdewatering process has been selected. As such, for purposes of this study it is assumed that sludge dewatering is the last biosolids process for the subject facilities and the cost of sludge hauling for land application as a beneficial use product is being applied here.

Upon analysis of comparative operational cost data for sludge dewatering across the scenarios the interplay between polymer and ferric sulfate cost are apparent. These data are solely based on two data points for polymer and ferric dosage and it is very possible that the analysis would be quite different if a greater array of data were analyzed for polymer and ferric dosages. Based on existing operations polymer dosages and cost 
applied to scenarios $\mathrm{A}$ and $\mathrm{B}$ were lower than those during pilot testing, applied to scenarios $\mathrm{C}, \mathrm{D}$ and $\mathrm{E}$. This does not necessarily mean that new dewatering centrifuges would require more polymer than the existing centrifuges. It must be noted that the cake solids during pilot testing for SDWWTP was $23 \%$ solids for the stated polymer dosage of $31 \mathrm{lb}$ of polymer/ dry ton of sludge processed in Table 46 . The cake solids concentration for SDWWTP's existing operations that reflects a polymer dosage of $21 \mathrm{lb}$ of polymer/ dry ton of sludge processed was $16 \%$ cake solids. So, polymer consumption and cost are not factors that can be analyzed independently.

The use of ferric sulfate also plays a significant part in the sludge cake dryness through the binding of orthophosphate and the amount of polymer required as previously explained in Chapter 6. As can be seen in Table 46, as the ferric sulfate was tied to hydraulic loading the consumption the cost of ferric sulfate was significantly lower for scenarios $\mathrm{C}, \mathrm{D}$, and $\mathrm{E}$ as these scenarios witnessed significant drops in hydraulic loading to dewatering operations when compared to scenarios A and B. Likewise the hauling costs for scenarios SD- C through SD-E were reduced by nearly $25 \%$ compared to SD-A, the existing condition. Hauling costs for scenarios CD- B through CD-D were reduced by more than $15 \%$ compared to CD-A, the existing condition. Hauling costs for scenario CD-E was reduced by nearly $30 \%$ compared to CD-A, the existing condition. These reductions were a result of reduction in biosolids production and increase dewatering cake solids, reducing the volume of material requiring offsite hauling.

The interplay and optimization between polymer dose, ferric sulfate dose, cake dryness and dewatering solids capture can be an in-depth research topic unto itself and often is. For the sake of this study the interaction of dewatering technology with the line- 
up of upstream technologies to deliver the lowest biosolids output within practical technical and cost parameters was the goal as the perspective was to deliver an overall sustainable set of alternatives. Along those lines a factor that has only previously been mentioned in this study is the improved energy efficiency of the proposed G3 125's when compared to the DS 706's. The G3 125 has a much higher hydraulic capacity at 400 gpm than the DS 706 at $250 \mathrm{gpm}$. The G3 125 additionally has a lower rated power consumption of 175 to $250 \mathrm{hp}$ per unit compared to the $300 \mathrm{hp}$ per unit of the DS 706; producing and overall much lower hp/gpm ratio. If compared on a solids loading basis the hp/lb-d $\mathrm{d}^{-1}$ ratio for the G3 125 is also lower than that of the DS 706, with 0.03 to 0.04 $\mathrm{hp} / \mathrm{lb}-\mathrm{d}^{-1}$ and $0.06 \mathrm{hp} / \mathrm{lb}-\mathrm{d}^{-1}$, respectively. As the dewatering equipment capacity limitations during this study were hydraulic and not solids loading the influence of a new machine with a lower power to flowrate ratio resulted in lower power consumption as can been seen in Table 46. Under the study conditions the proposed dewatering centrifuge of scenarios $\mathrm{C}, \mathrm{D}$, and $\mathrm{E}$ was a more energy efficient option than the existing dewatering centrifuge of scenarios A and B. The SDWWTP and CDWWTP scenario E has the lowest respective comparative operational cost amongst all related alternatives for dewatering operations. Scenarios SD-C and SD-D closely followed the comparative operational cost of scenario SD-E. This was not the case for the CDWWTP sludge dewatering scenarios where CD-C and CD-D were $9 \%$ higher in comparative operational costs than CD-E primarily due to biosolids hauling costs. 
Table 46: SDWWTP and CDWWTP Sludge Dewatering Comparative Chemical and Power Cost Estimates

\begin{tabular}{|c|c|c|c|c|c|c|c|c|c|}
\hline SDWWTP & & & & & & & & & \\
\hline \multirow[t]{2}{*}{ Scenario } & dewatering technology & $\begin{array}{l}\text { polymer } \\
\text { feed }\end{array}$ & $\begin{array}{c}\text { ferric sulfate } \\
\text { feed }{ }^{* *}\end{array}$ & $\begin{array}{c}\text { power } \\
\text { consumption } \\
\text { per unit }\end{array}$ & $\begin{array}{c}\text { polymer } \\
\text { cost @ } \\
\$ 2 / \mathrm{lb} .\end{array}$ & $\begin{array}{c}\text { ferric cost } \\
Q \\
\$ 0.766 / \mathrm{lb} .\end{array}$ & $\begin{array}{c}\text { power cost } \\
\text { (A) } \\
\$ 0.085 / \mathrm{kwh}\end{array}$ & $\begin{array}{l}\text { hauling cost } \\
\text { (a) } \$ 40 / \mathrm{DT}\end{array}$ & $\begin{array}{c}\text { sludge } \\
\text { hauling, } \\
\text { chemical and } \\
\text { power costs }\end{array}$ \\
\hline & & $\mathrm{lb} /$ ton & $\mathrm{gal} / 1000 \mathrm{gal}$ & hp & (2018S)/yr. & (20185)/yr. & (2018\$)/yr. & $(2018 \$) / y r$ & $(20185)$ yr \\
\hline A & dewatering centrifuge $^{\top}$ & 21.18 & 1.83 & 300 & 691,413 & 469,776 & 280,992 & $3,316,714$ & $4,758,895$ \\
\hline B & dewatering centrifuge & 21.18 & 1.83 & 300 & 666,748 & 447,879 & 267,894 & $3,207,122$ & $4,589,643$ \\
\hline D & dewatering centrifuge? & 31.31 & 1.9 & 175 & 924,419 & 182,840 & 56,745 & $2,595,815$ & $3,759,819$ \\
\hline $\mathrm{E}$ & dewatering centrifuge $^{2}$ & 31.31 & 1.9 & 175 & 932,390 & 163,692 & 57,234 & $2,514,916$ & $3,668,233$ \\
\hline
\end{tabular}

${ }^{1}$ MDWASD May 2005

${ }^{2}$ MWH 2016

**As there was no estimated price for AirPrex, the dosage for ferric sulfate at the CDWWTP pilot has been substituted for costs as both accomplished the same level of struvite control and dewatering improvement

\begin{tabular}{|c|c|c|c|c|c|c|c|c|c|}
\hline CDWWTP & & & & & & & & & \\
\hline \multirow[t]{2}{*}{ Scenario } & dewatering technology & $\begin{array}{l}\text { polymer } \\
\text { feed }\end{array}$ & $\begin{array}{c}\text { ferric sulfate } \\
\text { feed }\end{array}$ & $\begin{array}{c}\text { power } \\
\text { consumption } \\
\text { per unit }\end{array}$ & $\begin{array}{c}\text { polymer } \\
\text { cost @ } \\
\$ 2 / \mathrm{lb} .\end{array}$ & $\begin{array}{l}\text { ferric cost } \\
\text { (a) } \\
\$ 0.766 / \mathrm{lb} \text {. }\end{array}$ & $\begin{array}{c}\text { power cost } \\
\text { (a) } \\
50.085 / \mathrm{kwh}\end{array}$ & $\begin{array}{l}\text { bauling cost } \\
\text { (a) } \$ 52 / \mathrm{DT}\end{array}$ & $\begin{array}{c}\text { sludge } \\
\text { hauling, } \\
\text { chemical and } \\
\text { power costs }\end{array}$ \\
\hline & & lb/ton & $\mathrm{gal} / 1000 \mathrm{gal}$ & hp & $(20185) / y r$ & $(20185) / y r$ & $(2018 \$) / y r$ & $(20185) / y r$. & $(2018 S) / y r$ \\
\hline A & dewatering centrifuge $^{\prime}$ & 17.78 & 2.18 & 300 & 376,990 & 572,980 & 287,982 & $2,223,816$ & $3,461,767$ \\
\hline B & dewatering centrifuge & 17.78 & 2.18 & 300 & 314,866 & 583,589 & 293,314 & $1,852,771$ & $3,044,539$ \\
\hline D & dewatering centrifuge ${ }^{2}$ & 24.03 & 1.9 & 250 & 430,462 & 350,900 & 105,481 & $1,823,288$ & $2,710,131$ \\
\hline $\mathrm{E}$ & dewatering centrifuge ${ }^{2}$ & 24.03 & 1.9 & 250 & 398,697 & 335,498 & 100,851 & $1,589,846$ & $2,424,892$ \\
\hline
\end{tabular}

${ }^{1}$ MDWASD March 2005

${ }^{2}$ MWH September 2015 
Combined Cost Estimates

A comparative estimated cost analysis of the existing and proposed biosolids treatment process paths show similar results for the two study facilities, as presented in Table 47, below. In addition to presenting the comparative yearly operational costs and installed cost of proposed equipment, a 30-year comparative operational cost was calculated on a $2018 \$$ basis with no escalation factor in order to understand the cost impact of the operational component of technologies over their projected 30-year life cycle. Scenarios D and E have the most favorable comparative estimated costs for both capital and operational costs.

In capital costs, this is clear as SD-D and CD-D implement use of the lowest comparative cost sludge thickening and sludge digestion systems of the study Additionally, the existing equipment and structures although being significantly replaced, refurbished or rehabilitated in Scenarios A and B are not entirely new hence deterioration and risk of failure of remaining original components, such as structural elements, will result in increased maintenance costs relative to Scenarios C, D and E.

SD-E and CD-E resulted in the lowest respective comparative operational costs beating out scenarios $\mathrm{A}, \mathrm{B}$, and $\mathrm{C}$ primarily due to the lower biosolids production resulting in lower biosolids hauling costs. SD-E and CD-E also had lower biosolids production and hauling costs than SD-D and CD-D respectively, but by a slimmer margin. Due to the higher power consumption of the proposed thickening centrifuges of scenarios CD-E to the gravity belt thickeners of scenarios CD-D, the lower hauling cost were somewhat offset. Whereas, SD-E clearly stood out as the least expensive 
comparative operational cost option of the SDWWTP scenarios due to the cost implications of attaining the lowest solids production values of all the SDWWTP alternate scenarios evaluated.

As no one scenario has both the lowest comparative 30 -year operational cost and capital cost respective to each study facility, the judgment of the better option is relative. From a financial aspect a lower current capital cost and higher long term operational costs that roughly equal the current avoided cost would be preferable. This is the outcome of both scenario SD-D and CD-D. Operationally, SD-D and CD-D could be considered more challenging than alternatives SD-E and CD-E as they would incorporate a new technology, gravity belt thickeners. As SD-E and CD-E would utilize centrifuges for both thickening and dewatering, even though the machines would not be interchangeable the operation and maintenance would be similar enough to not require additional skill sets of the existing plant staff. In the larger overview of alternatives, it is clear that improvement of sludge thickening technologies, be it gravity belt thickeners or thickening centrifuges; reducing the number of digesters to be operated through a change in operational methodologies and selecting lower power consuming equipment; and similarly utilizing significantly more energy efficient centrifuges all contribute to not only a greater overall plant performance, but also significantly lower the comparative capital costs in the short term and lower the comparative operational costs in the long term. 
Table 47: Combined Comparative Estimated Costs for SDWWTP and CDWWTP Biosolids Treatment Scenarios

\begin{tabular}{|c|c|c|c|c|c|c|c|c|c|}
\hline \multirow[b]{2}{*}{ Scenutio } & \multicolumn{2}{|c|}{ Sludge Thickening } & \multicolumn{2}{|c|}{ Digestion } & \multicolumn{2}{|c|}{ Dewateding } & \multicolumn{3}{|c|}{ Seenarto } \\
\hline & $\begin{array}{c}\text { Chcmical } \\
\text { and power } \\
\text { Cost }\end{array}$ & $\begin{array}{l}\text { Installed } \\
\text { Cosis }\end{array}$ & $\begin{array}{c}\text { Chcmical } \\
\text { and power } \\
\text { Cost }\end{array}$ & $\begin{array}{l}\text { Installed } \\
\text { Cosls }\end{array}$ & $\begin{array}{l}\text { Hauling, } \\
\text { Chemical and } \\
\text { power Cost }\end{array}$ & $\begin{array}{c}\text { Installed } \\
\text { Costs }\end{array}$ & $\begin{array}{c}\text { Total } \\
\text { Comparative } \\
\text { Operutional } \\
\text { Cosl }\end{array}$ & $\begin{array}{c}\text { Total } \\
\text { Comparative } \\
\text { Operational } \\
\text { Costs over } 30 \\
\text { yeurs }\end{array}$ & $\begin{array}{c}\text { Total } \\
\text { Comparative } \\
\text { Insialled Cosis }\end{array}$ \\
\hline SDWWTP & (20183) & $(2015 \$)$ & (2018\$) & (20185) & (2018S) & $(2015 \$)$ & (2018S) & (2018S) & (2015\$) \\
\hline SD-A & 480,802 & $13,750,000$ & 290,394 & $82,720,000$ & $4,758,895$ & 600,000 & $5,530,091$ & $165,902,730$ & $97,070,000$ \\
\hline SD-B & 422,587 & $13,750,000$ & 335,070 & $83,895,000$ & $4,589,643$ & 600,000 & $5,347,300$ & $160,418,998$ & $98,245,000$ \\
\hline SD-C & 663,770 & $2,760,000$ & 234,549 & $68,737,500$ & $3,759,894$ & $5,535,000$ & $4,658,213$ & $139,746,394$ & $77,032,50 \mathrm{O})$ \\
\hline SD-D & 663,771 & $2,760,000$ & 122,859 & $43,122,500$ & $3,759,819$ & $5,535,000$ & $4,546,449$ & $136,393,459$ & $51,417,500$ \\
\hline SD-E & 471,116 & $9,375,000$ & 122,859 & $43,122,500$ & $3,668,233$ & $5,535,000$ & $4,262,208$ & $127,866,239$ & $58,032,500$ \\
\hline \multicolumn{10}{|l|}{ CDWWTP } \\
\hline CD-A & 109,131 & $10,000,000$ & 614,295 & $79,128,000$ & $3,461,767$ & 600,000 & $4,185,194$ & $125,555,805$ & $89,72 \mathrm{R}, 000$ \\
\hline $\mathrm{CD}-\mathrm{B}$ & 107,781 & $10,00 \mathrm{n}, 00 \mathrm{~N})$ & $1,139,238$ & $137,508,000$ & $3,044,539$ & 600,000 & $4,291,558$ & $128,746,744$ & $148,108,000$ \\
\hline $\mathrm{CD}-\mathrm{C}$ & 475,354 & $4,350,000$ & 709,232 & $90,587,000$ & $2,710,131$ & $5,625,000$ & $3,894,716$ & $116,841,478$ & $100,562,000$ \\
\hline CD-D & 475,354 & $4,350,000$ & 206,627 & $54,278,000$ & $2,710,131$ & $5,625,000$ & $3,392,111$ & $101,763,328$ & $64,253,000$ \\
\hline CD-E & 514,439 & $9,225,000$ & 206,627 & $54,278,000$ & $2,424,892$ & $5,625,000$ & $3,145,958$ & $94,378,737$ & $69,128,000$ \\
\hline
\end{tabular}




\subsection{Sensitivity Analysis}

The sensitivity of this analysis to the myriad of factors in this study is most evident in the comparison of scenarios D and E. From the onset of the study scenario SDE appeared to me to be the best option due to the ease with which thickening centrifuges so easily produced sludge thicknesses in excess of the $5.5 \%$ solids target as witnessed during the SDWWTP pilot phase. The MBM similarly demonstrated that scenarios SD-E and CD-E had the lowest hydraulic loads to the sludge digestion system highest VSRs and most favorably accomplished the goal of reducing biosolids production both in volume and mass. When incorporating comparative equipment costs and the compared operational components, this initial hypothesis was shown to be overly reliant on a technology whose equipment and power cost resulted in only a marginally favorable conclusion.

If hauling cost were to significantly increase to $\$ 100 /$ ton and power consumption of the proposed thickening centrifuges be reduced by $50 \%$ of the quoted values, the overall operational cost comparison for scenarios SD-E and CD-E would be much more favorable than SD-D and CD-D, even with the latter's lower comparative capital costs, as shown in Table 48 below. As this would require a large change in hauling cost, equipment cost and improved equipment energy efficiencies. Conversely, if simply the polymer consumption of gravity belt thickeners, currently an assumed value, were reduce by half to 6 pounds of dry polymer per dry ton of solids treated $(3 \mathrm{~g} / \mathrm{kg}), \mathrm{SD}-\mathrm{D}$ and CD-E would arguably be the most energy efficient and cost effective scenarios respective to their study facilities, as can be seen in Table 49. 
Table 48: Sensitivity analysis of comparative cost of scenarios, reduced thickening centrifuge power consumption and increased biosolids hauling cost

\begin{tabular}{|c|c|c|c|c|c|c|c|c|c|}
\hline \multirow[b]{2}{*}{ S̈впагіџ } & \multicolumn{2}{|c|}{ Sluslyge Thitketning } & \multicolumn{2}{|c|}{ Digatstitm } & \multicolumn{2}{|c|}{ 1) Yuralleting } & \multicolumn{3}{|c|}{ Scenarica } \\
\hline & $\begin{array}{c}\text { Chernicul and puket } \\
\text { Chyl }\end{array}$ & $\begin{array}{l}\text { Insiallent } \\
\text { Csests }\end{array}$ & $\begin{array}{l}\text { Chemical } \\
\text { amel powser } \\
\text { Csesi }\end{array}$ & $\begin{array}{l}\text { Insiulleal } \\
\text { C.usls }\end{array}$ & $\begin{array}{l}\text { Hauling, } \\
\text { Chemical and } \\
\text { puwer C.axl }\end{array}$ & $\begin{array}{c}\text { Insiallad } \\
\text { C.uosis }\end{array}$ & $\begin{array}{c}\text { Tabal } \\
\text { Corrparalive } \\
\text { Operalismal } \\
\text { C.onsl }\end{array}$ & 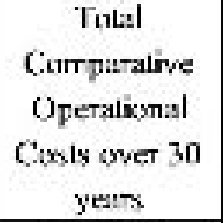 & $\begin{array}{c}\text { Toulal } \\
\text { C.impouralive } \\
\text { Inslulled C.usts }\end{array}$ \\
\hline SDWWTP & (24185) & $(2015 \$)$ & $(2,4185)$ & (2.418S) & $(2018 \%)$ & $(20153)$ & (2018\%) & (2.1)18S) & (2.0153) \\
\hline SD- $\lambda$ & 480,802 & $13,750,04 \times$ & 290,394 & $82,720,600$ & $9,733,965$ & 600,400 & $10,505,762$ & $315,154,850$ & $97,070,000$ \\
\hline $\mathrm{SD}-\mathrm{B}$ & 422,587 & $13,750.0 \times 4)$ & 335,070 & $83,895,6000$ & $9,200,326$ & 600,600 & $10,157,983$ & $314,739,496$ & is, 245,000 \\
\hline SD-C & 663,770 & $2,760.00 \times$ & 234,549 & $68,737,500$ & $7,653,729$ & $5,535,400$ & $8,532,048$ & $256,561,444$ & $77,032,300$ \\
\hline SD-D & $663,73]$ & $2,760,00 \times 0$ & 122,859 & $43,122,500$ & $7,653,542$ & $5,535,600$ & $8,440,172$ & $253,205,247$ & $51,417,500$ \\
\hline SD-E & 315,873 & 9.375 .000 & 122,859 & $43,122,500$ & $7,240,606$ & $5,535,000$ & $7,879,338$ & $236,380,134$ & $58,032,500$ \\
\hline \multicolumn{10}{|l|}{ CDWWTP } \\
\hline CD-A & $109,13]$ & $10,000,000$ & $6.4,295$ & $79,128,000$ & $5,5] 4,520$ & 600,000 & $6,237,947$ & $187,138,398$ & $89,728,000$ \\
\hline $\mathrm{CD}-\mathrm{B}$ & 107,731 & $10,000,000$ & $1,139,238$ & $137,508,000$ & $4,754,790$ & 600,000 & $6,001,809$ & $180,054,258$ & $148,108,000$ \\
\hline CD-D & 435,354 & $4,350,000$ & 206,627 & $54,278,000$ & $4,393,166$ & $5,625,000$ & $5,075,146$ & $152,254,378$ & $64,253,000$ \\
\hline CD-E & 317,112 & $9,225,000$ & 206,627 & $54,278,000$ & $3,892,443$ & $5,625,000$ & $4,4 \mathrm{~L}, 18 \mathrm{~L}$ & $132,485,423$ & $69,128,000$ \\
\hline
\end{tabular}


Table 49: Sensitivity analysis of comparative cost of scenarios, reduced gravity belt thickener polymer consumption

\begin{tabular}{|c|c|c|c|c|c|c|c|c|c|}
\hline \multirow[b]{2}{*}{ Stenaria } & \multicolumn{2}{|c|}{ Sludge Thickening } & \multicolumn{2}{|c|}{ Dipestion } & \multicolumn{2}{|c|}{ Dewatering } & \multicolumn{3}{|c|}{ Sernurio } \\
\hline & $\begin{array}{l}\text { Chemital and } \\
\text { puwer Cost }\end{array}$ & $\begin{array}{l}\text { Instullexl } \\
\text { Custs }\end{array}$ & $\begin{array}{c}\text { Chemical } \\
\text { and power } \\
\text { Cust }\end{array}$ & $\begin{array}{c}\text { Insiulled } \\
\text { Custs }\end{array}$ & $\begin{array}{l}\text { Hauling, } \\
\text { Chenicul and } \\
\text { рожкет C.st }\end{array}$ & $\begin{array}{l}\text { lnstalled } \\
\text { Costs }\end{array}$ & $\begin{array}{c}\text { Total } \\
\text { Comparative } \\
\text { Operalional } \\
\text { Coss }\end{array}$ & $\begin{array}{c}\text { Tulal } \\
\text { Comparative } \\
\text { Operational } \\
\text { Cosls ove } 30 \\
\text { years }\end{array}$ & $\begin{array}{c}\text { Total } \\
\text { Compurative } \\
\text { Iristilled Cosis }\end{array}$ \\
\hline SDWWTP & (20185) & $(2015 S)$ & $(20185)$ & $(20185)$ & (2018S) & $(20155)$ & $(2018 \$)$ & $(2018 \$)$ & $(20155)$ \\
\hline SD-B & 422,587 & $13,750,000$ & 335,070 & $83.895,000$ & $4,589,643$ & 600,000 & $5,347,300$ & $160,418,998$ & $98,245,0(0)$ \\
\hline SD.C. & 333,808 & $2,760,000$ & 234,549 & $68,737,500$ & $3,759,894$ & $5,535,000$ & $4,728,251$ & $129,847,533$ & $77,0,32,5(x)$ \\
\hline SD-D & 333,808 & $2,760,000$ & $122,8.59$ & $43,122,500$ & $3,759,819$ & $5,535,000$ & $4,216,487$ & $126,494,597$ & $51,417,500$ \\
\hline SD-E & 471,116 & $9,375,000$ & 122,859 & $43,122,500$ & $3,668,233$ & $5,535,000$ & $4,262,208$ & $127,866,239$ & $58,032,500$ \\
\hline \multicolumn{10}{|l|}{ CUWWTP } \\
\hline $\mathrm{CT}-\mathrm{A}$ & 109,131 & $10,000,000$ & $614,29,5$ & $79,128,000$ & $3,461,767$ & 600,000 & $4,185,194$ & $125,555,805$ & $89,728,000$ \\
\hline CD-B & 107,781 & $10,000,000$ & $1,139,238$ & $137,508,000$ & $3,044,539$ & 600,000 & $4,291,558$ & $123,746,744$ & $148,108,000$ \\
\hline C. [J-I] & 241,295 & $4,350,000$ & 206,627 & $54,278,000$ & $2,310,131$ & $5,625,000$ & $3,158,053$ & $94,741,577$ & $64,253,0(0)$ \\
\hline CD-F & 514,439 & $9,225,000$ & 206,627 & $54,278,000$ & $2,424,892$ & $5,625,000$ & $3,145,958$ & $94,378,737$ & $69,128,000$ \\
\hline
\end{tabular}


Based on this hypothetical example the scenarios modeled in the MBM and then comparatively evaluated for operational and capital costs are somewhat impervious to small changes in the parameters that are most likely to change overtime, barring significant swings in biosolids product marketability or the emergence of revolutionary technologies.

\section{Conclusions and Recommendations}

\subsection{Acceptance or Rejection of Research Hypotheses}

Hypothesis 1 - Better Sludge Thickening

A more applicable sludge thickening technology for waste activated sludge and mixed primary and waste activated sludges in subtropical climates such as in the largescale wastewater treatment facilities of MDWASD is capable of vastly improving thickened sludge concentrations at comparable solids recovery rates.

Through use of a holistic process model it was confirmed that gravity belt thickeners and thickening centrifuges would be an improvement in performance (Table 27 and Table 28) and total comparative costs (Table 41 and Table 42) over gravity thickeners for the sludge conditions present at the SDWWTP and CDWWTP during the study period. The sludge thickening results were obtained during the Pilot Phase 1 testing for each wastewater treatment plant as described and presented in Chapter 4). This hypothesis was confirmed. 
Hypothesis 2 - Innovations in digestion operational methods and technologies

Single-stage anaerobic mesophilic digestion carried out at high solids concentrations will achieve a higher VSR than primary-secondary anaerobic mesophilic digestion in the same digester volume with minimal digester upgrades.

The research yielded mixed results on the increase in VSR following changes in the operational methodology of sludge stabilization when analyzing results from the two subject facilities. This was investigated during Pilot Phase 2 as described in Chapter 5 . Pilot testing at the SDWWTP did not achieve significant VSR improvement by processing WAS at a higher solids loading with single-stage anaerobic mesophilic digestion compared to a lower solids loading in primary-secondary anaerobic mesophilic digestion (Table 29). The CDWWTP did achieve significant improvement in VSR by processing WAS at a higher solids loading with single-stage anaerobic mesophilic digestion compared to a lower solids loading in primary-secondary anaerobic mesophilic digestion (Table 30). As noted in Chapter 6, it was suspected that the inadvertent dilution of the digested used for the pilot test of single-stage digestion at SDWWTP caused interference in properly determining the VSR potential of single-stage digestion. Due to this mishap during pilot testing, this hypothesis is inconclusive.

Hypothesis 3 - Cost Conscious sludge stabilization improvements

Class B biosolids stabilization is achievable at SDWWTP and CDWWTP at a lower capital cost and operation and maintenance cost than in-kind rehabilitation of the existing technologies. 
Using the holistic process model the number active digestion units required for primary-secondary digestion and single-stage digestion were determined (Table 36 and Table 37). Based on the lower number of digestion units required for single-stage digestion, retrofitting the digestion process at the subject facilities is significantly less in capital (Table 43) and operational (Table 44) expenditure than direct rehabilitation of primary-secondary digestion, the existing operational method for sludge stabilization. This hypothesis is confirmed.

Hypothesis 4 - Multiple approaches to struvite control and improved dewatering

The addition of ferric sulfate to digested sludge will achieve similar benefits to sludge dewatering as more commonly used metal salts, i.e. ferric chloride, or more innovative struvite recovery technologies, i.e. AirPrex.

Through comparison of pilot test result of dewatering for both subject facilities this hypothesis was evaluated (Pilot Phase 3 presented in Chapter 6). The SDWWTP pilot tested AirPrex, a digested sludge precondition process for the removal of struvite. Dewatering pilot testing was carried out on digested sludge treated and not treated with AirPrex. The CDWWTP has been using ferric salts for the control of struvite formation since 2010, early testing was conducted with ferric chloride. Pilot testing of CDWWTP digested sludge in 2016 was conducted with and without the addition of ferric sulfate for struvite control. All testing showed improvements of sludge dewatering in both solid recovery and percent solids of dewatered sludge cake for the same amount of polymer consumption or less if struvite was controlled or removed (Figure 66, Figure 67, Figure 68, and Figure 69). The improvement of dewatered sludge cake percent solids rose by 3 
percentage points via the use of AirPrex at SDWWTP and by 2 to 4 percentage points via the use of ferric sulfate addition at CDWWTP when compared to no struvite control and during pilot testing at the respective plants. Previous use of ferric chloride on digested sludge at CDWWTP achieved the same range of dewatered sludge cake percent solids as the addition of ferric sulfate in the 2016 pilot test. Based on these comparisons the hypothesis is considered confirmed.

Hypothesis 5 - A framework for biosolids treatment evaluations

Evaluations of biosolids treatment alternatives can be improved upon through the development of a framework that considers a whole plant mass balance to determine the appropriate unit sizing and cost estimation of existing and future technologies combinations.

Prior to the use of an evaluation tool, the SDWWTP and CDWWTP facilities were intent on refurbishment of several existing biosolids treatment processes. The evaluation of different biosolids processing alternatives through the use of a holistic process model that incorporated a process mass balance, unit sizing for sludge thickening (Table 34 and Table 35), sludge stabilization (Table 36 and Table 37), and sludge dewatering (Table 39 and Table 40) and cost estimating (Table 47) of treatment alternatives identified more sustainable and pragmatic biosolids treatment alternatives specific to the conditions found at the subject facilities. This hypothesis is confirmed. 


\subsection{Recap of Objectives}

The initial goal of this study was to determine the most sustainable combination of technologies to meet the site-specific conditions, digested the greatest about of volatile solids and produced the least amount of biosolids for off-site transport and land application. In the process of carefully evaluating the scenario results of the MBM and applying unit sizing and cost factors it was concluded that due to the high energy requirements to achieve the initial goals the added dimension of comparative capital and operational costs was extremely important in understanding a broader scope for a sustainable biosolids program. The following summarizes how the objectives described in the dissertation were met:

- Determine best practices for biosolids treatment in a large wastewater treatment plant.

Through the analyses of 10 scenarios for SDWWTP and CDWWTP by use of the model developed in this dissertation the author was able to arrive at multiple scenarios that would arguably be the best practices for the subject facilities. SD-D, SD-E, CD-D, and CD-E all required overall less equipment, less rehabilitation of existing structures, and produced the most favorable economic outcomes relative to their subject facilities. 
- Achieve a reduction in biosolids to be disposed of for the reduction of hauling costs.

It was demonstrated that through multiple changes in equipment and operational methods that a lower amount of biosolids hauling and subsequently less truck traffic could be achieved. When comparing Scenario SD-E to SD-A a 55 wet ton/day reduction in biosolids hauled is achieved, at an approximate savings of $\$ 802,000$ per year in hauling costs. When comparing Scenario CD-E to CD-A a 33 wet ton/day reduction in biosolids hauled is achieved, at an approximate savings of $\$ 634,000$ per year in hauling costs.

- Investigate the most effective means of sludge thickening comparing gravity thickeners, gravity belt thickeners, and thickening centrifuges.

The existing gravity thickeners, gravity belt thickeners, and thickening centrifuges were compared in performance, unit costs and operational cost in this dissertation. Through use of the model it was determined how many units of each would be required to treat all incoming WAS at each subject facility and the cost to do so. Based on this evaluation it was determined that gravity belt thickeners would be the most appropriate technology to reduce the number of units required (Table 34) and capital cost (Table 41) at SDWWTP, but thickening centrifuges would have the lowest operational costs (Table 42). The evaluation for CDWWTP showed a an equal number of gravity belt thickener and thickening centrifuges would be required (Table 35) with gravity belt thickeners resulting in the lowest capital and operational expenditure (Table 41 and Table 42). 
The existing technology at the subject facilities, gravity thickeners, proved the least favorable technology selection on performance, number of units required, and refurbishment costs. The gravity thickeners did have the lowest operational cost, but this is outweighed by all the other factors and the down-stream impacts of their poor sludge thickening performance.

- Develop a framework to evaluate a biosolids treatment option.

Through the dissertation methodology of creating a preliminary model of the existing plant processes and proposed technologies; analysis of historical plant data, pilot testing data, and reasonable assumptions based on literature research; and using a process mass balance, unit sizing and cost estimation model that was developed for this dissertation; a framework was established that produced a pragmatic way of determining the most favorable biosolids treatment options for the subject facilities.

- Develop a model that can evaluate different future technologies for the subject plants.

Through modification of the process mass balance, unit sizing and cost estimation modules, the model developed for this dissertation can be used to evaluate other biosolids treatment technologies based on user input of operating data, performance criteria, and unit costs for the additional technologies.

- Develop a model that can be modified to evaluate biosolids treatment options for other wastewater treatment facilities

The holistic process model developed in this dissertation required historical plant data and/or reasonable assumption as user input to calibrate and run the model. Additionally, the model is specifically customized for the treatment processes and 
process flow being evaluated, as seen in Appendix 3. The holistic process model can be customized for any treatment plant or treatment process alternatives as long as the process flow is well understood, including consideration of recycle streams, plant process data of sufficient quantity and quality to determine steady-state conditions is available, and valid assumptions are made or pilot testing are conducted for any missing data.

- Develop a model to evaluate a combination of various biosolids treatment technologies to arrive at a cost-effective means of producing and disposing Class B biosolids

The holistic process model was developed to calculate unit sizing and estimate capital and operational costs based on the results of the model's own numerical mass balance. Therefore, this model contains functionality beyond other commercially available whole plant process models known to the author in this feature. As various scenarios combining biosolids treatment technologies can be run based on the full functionality of the holistic process model, comparison of those scenarios is an intrinsic feature of the model developed. 
- Achieve Class B stabilization at a lower capital and operational expenditure when existing equipment reaches end of useful life

The holistic process model determined that alternatives with single-stage digestion could achieve the same or greater VSR than alternatives with primarysecondary digestion at the same solids loading rates (Table 29 and Table 30). These results meet or exceed the VSR requirement for Process to Reduce Vector Attraction at SRTs above those required to meet the time and temperature requirements for Processes to Reduce Pathogens (Table 36 and Table 37). The cost-estimating module of the MBM calculated an economic advantage for the comparable single-stage digestion scenarios for the SDWWTP and the CDWWTP when evaluated against the respective primarysecondary digestion scenario. Hence, lower capital and operational cost biosolids Class B stabilization alternatives were identified for the SDWWTP and the CDWWTP (Table 36 and Table 37).

- Evaluate various struvite control methods to achieve greater dewatered sludge solids concentrations

Through evaluation of pilot testing data for the addition of ferric sulfate at CDWWTP and the incorporation of AirPrex in the dewatering pilot for the SDWWTP it was determined that both struvite control methods also improve sludge dewatering and achieve greater dewatered solids concentrations for the sludge conditions encountered at the subject facilities (Figure 66, Figure 67, and Figure 68). 
- Determine if single-stage digestion can achieve significantly greater VSR than primary-secondary digestion within the same digester volume at a higher influent solids concentration

Single-Stage digestion was shown to produce significantly greater VSRs during pilot testing at CDWWTP when compared to historical plant performance data for CDWWTP (Table 30) and plant data for primary-secondary digesters run in parallel to the single-stage digestion pilot test.

\subsection{Innovations in the Research}

The holistic process model, developed in this dissertation, contains a process mass balance model module (coined MBM) suitable for the estimation of biosolids production, biosolids treatment process hydraulic loading and solids loading, and recycle streams under steady-state conditions. Furthermore, the model used the results of the MBM to simultaneously size unit processes and estimate comparative capital and operational costs estimation modules with user provided inputs. This is an advantage to other commercially available whole plant simulators that do not currently have this feature to the author's knowledge. While attempting to model the results of pilot testing at the wastewater treatment plants, several shortcomings of traditionally used design and operating parameters provided in textbooks and manual were identified. The model developed attempts to provide necessary corrections and justifications so that system performance can be more accurately predicted. 
In the development of the holistic process model and the research the ability to incorporate new and innovative technologies into a biosolids treatment process evaluation was a driving force. The model demonstrates this functionality with the assessment of the linear motion mixer compared to more traditional digester mixing equipment. The model accounts for the unit costs and the power requirements of three distinct mixing systems, including the linear motion mixer, in order to provide cost comparisons with relatively few user-provided inputs. The model also has the capability of evaluating new processes based on piloting data or manufacturer provided information, as in the case of AirPrex, an innovative digester sludge conditioning struvite removal process. The open architecture of this spreadsheet-based model allows for incorporation of new technologies and processes based on users' needs and research interests.

The development of a mathematical model to analyze the steady-state conditions at the subject facilities, two high purity oxygen secondary treatment based wastewater treatments plants was the first case of a process model used at these subject facilities, and was based on a combination of historical plant data and biosolids treatment process piloting data. The combination of historical and pilot data in a numerical model to evaluate competing biosolids treatment alternatives is a powerful decision-making tool. This holistic process model undoubtedly has applications for other utilities and future evaluations at the subject facilities.

The process optimization implications of the holistic process model are substantial. Identification of technologies and operational parameters that provide improved biosolids concentration to downstream biosolids treatment processes, have a ripple effect in operational cost savings. For the subject facilities, evaluation of alternate 
technologies lowered biosolids production quantities and afforded cost savings for the subject facilities in avoidance of capital construction along with savings in operations costs.

\subsection{Gaps in the Research}

- Historical plant performance sampling and data collection

As described in Chapter 3, there were several vital components of historical plant data that were missing or erroneous. Some assumptions were made to conduct both the model calibration and the model runs of the process mass balance module of the holistic process model developed in this dissertation. Integrity of the data, sampling, and collection of key parameters is vital to producing an accurate numerical mass balance model. Development of a preliminary mass balance model and identifying parameters that are either not collected at the subject facility or demonstrate a lack of valid data integrity should be a first step, prior to establishing the full data set used in both model calibration and running the model. As a steady-state condition for the biosolids treatment process at subject wastewater treatment plants can be achieved in 45 days, the time period of data collection need not be as long as the 2 and 3 years of data used for the model runs for the SDWWTP and the CDWWTP, respectively. In retrospect, another data sampling period with all key parameters could have improved model precision and accuracy and reduced the need for flow correction factors.

- Modeling of secondary treatment reaction kinetics 
The model calibration relied on adjustments of secondary treatment reaction kinetic parameters that were initially assumed based on standard values found in the literature. The reaction kinetic parameters considered for adjustment are yield, endogenous decay rate and observed yield of the secondary treatment process. The subject facilities are high purity oxygen secondary treatment plants and operate at SRTs and MLSS concentrations well below the standard range found in the literature. The model calibration consisted of a process of trial-and-error, within physically possible values, to match model results and plant calibration data. A study of specifically the secondary treatment process at the subject facilities would ensure that the model calibration is based on site specific data or data ranges.

- Modeling of true recycle stream BOD loading As noted in the numerical mass balance model system of equations presented in Appendix 4, the BOD load for the combination of recycle streams is an assumed value due to the lack of data for the individual recycle stream. Considering the sensitivity of the model to the recycle load this information is vital to an accurate model.

- Modeling of anaerobic digestion reaction kinetics

The mass balance model currently determines VSR based on TS concentrations into and out of the digestion system. The model does not currently account for reaction kinetics of digestion systems. As percent solids at lower concentrations could be influenced by total dissolved solids, but total suspended solids would be difficult to analyze at the solids concentrations into and out of the digester a competing data source or estimating tool for digester performance would be valuable. More study into this aspect for inclusion into a holistic process model is merited based on a number of 
parameters that influence digester reaction kinetics, including digester temperature, contribution of FOG (fats, oil and grease), VFAs (volatile fatty acids), and alkalinity.

\subsection{Areas for Further Study Based on the Research}

Although this study analyzed existing plant operational performance, technology evaluations, pilot tests, and design and construction efforts that spanned a decade of work on my part, the investigations in developing site-specific answers toward a sustainable biosolids program are an ongoing effort. The landscape for uses of quality biosolids, biosolids advocacy in agriculture and resistance to their land application makes the field of biosolids marketing a dynamic area of study. In the same vein, new applications of existing technologies, is a related and relevant area of research (Crockett, 2018). The introduction of chemical processes to simultaneously improve biosolids treatment and recover nutrients such as those discussed in this dissertation are segments of the wastewater industry ripe for focus as the end result can be new marketable products. The incorporation of technologies that further enhance digestion and dewatering are also areas of interest that show merit for future research and application of the holistic process model developed in this research. 


\section{List of references}

Abel-Denee, M., Eskicioglu, C. (2018) “Using Struvite Precipitation to Remove Colloidal Material from Acid-Phase Digestion and the Effect on Downstream Gas-Phase Digestion" Proceedings of the WEF Residuals and Biosolids Management Conference 2018, Water Environment Federation, Alexandria, VA

Allen, S., Hanson, R. (2018) "Understanding Design Standards and Codes for Biogas Systems" Proceedings of the WEF Residuals and Biosolids Management Conference 2018, Water Environment Federation, Alexandria, VA

American Public Health Association, American Water Works Association, Water Environment Federation (APHA/AWWA/WEF), "Standard Methods for the Examination of Water and Wastewater" 20th ed., 1999

Appels, L., Baeyens, J., Degrève, J., Dewil, R. (2008) "Principles and potential of anaerobic digestion of waste-activated sludge" Progress in Energy and Combustion Science, Vol. 34, Iss. 6, December 2008, Elsevier Science Direct

Arnaiz, C., Gutierrez, J., Lebrato, J. (2006) "Biomass stabilization in the anaerobic digestion of wastewater sludges" Bioresource Technology Vol. 97, Iss. 10, July 2006 Elsevier Science Direct

Auerbach, E., Orpianesi, M., Deur, A., Katehis, D. (2018) "Wards Island WWTP Advanced Biosolids Handling and Sidestream Treatment Enhancements" Proceedings of the WEF Residuals and Biosolids Management Conference 2018, Water Environment Federation, Alexandria, VA

Batstone, D., Keller, J. Angelidaki, I. Kalyuzhnyi, S., Pavlostathis, G., Rozzi, A., Sanders, W., Siegrist, H., Vavilin, V. (2002) "The IWA Anaerobic Digestion Model No 1 (ADM1)" Water Scince and Technology Vol. 45 Iss. 10, 2002 The International Water Association, London, UK

Baumann, G., Thomas, G. (1967) "Method for dewatering sludge” US 3,342,731, United State Patent Sept. 19, 1967

Beightol, S., Higgins, M., Nicholson, J., Wilson, C. (2018) “A Survey of WRRF Biosolids Identifying the Parameters Affecting Dewatering and the Effect of THP" Proceedings of the WEF Residuals and Biosolids Management Conference 2018, Water Environment Federation, Alexandria, VA

Bicudo, J., Morris, S., Gerber, J., Crowley, B., Parker, W., Higgins, M., Celmer-Repin, D. (2018) "Sludge Characteristics that Impact Dewatering of Anaerobically Digested Biosolids at Multiple Facilities" Proceedings of the WEF Residuals and 
Biosolids Management Conference 2018, Water Environment Federation, Alexandria, VA

Blumensaat, F., J. Keller, J. (2005) "Modelling of two-stage anaerobic digestion using the IWA Anaerobic Digestion Model No. 1 (ADM1)” Water Research Vol. 39, Iss. 1, January 2005 The International Water Association, London, UK

Boe, R., Boltz, J., Liggins, M., Greer, G.(2009) “Comparing Membrane Bioreactors (MBRs) and Moving Bed Biofilm Reactors (MBBRs) for Compact Water Reclamation in Florida: Process Selection by Bonita Springs and Pasco County Utilities" Proceedings of WEFTEC 2009, Water Environment Federation, Alexandria, VA

Boráň, J., Houdková, L., Elsäßer, T. (2010) “Processing of sewage sludge: Dependence of sludge dewatering efficiency on amount of flocculant" Resources, Conservation and Recycling Vol. 54, Iss. 5, March 2010, Elsevier Science Direct

Canales, A., Pareilleux, A., Rols, J., Goma, G., Huyard, A. (1994) “Decreased sludge production strategy for domestic wastewater treatment" Water Science and Technology, Vol. 30 Iss. 8, October 1994, The International Waster Association, London, UK

Canziani, R., Emondi, V., Garavaglia, M., Malpei, F., Pasinetti, E., Buttiglieri, G. (2006) "Effect of oxygen concentration on biological nitrification and microbial kinetics in a cross-flow membrane bioreactor (MBR) and moving-bed biofilm reactor (MBBR) treating old landfill leachate" Journal of Membrane Science Vol. 286, Iss. 1-2, December 2006, Elsevier Science Direct

Carlson, Richard (2010) "Sludge heat exchanger" United State Patent Publication No. US 2010/0212872 A1, Aug. 26, 2010

CH2M Hill, Inc. (2015) "South District Wastewater Treatment Plant Detailed Analysis of Two Selected Thickening and FOG Codigestion Process Alternatives Consent Decree Capital Project No. 1.7" Engineering report prepared for Miami-Dade Water and Sewer Department, July 2015

CH2M Hill, Inc. (2017) "Basis of Design Update for Biosolids Processing Facilities Evaluation of 11 Biosolids Management Alternatives" Engineering report prepared for Miami-Dade Water and Sewer Department, November 2017

Consent Decree Program (2014) Technical Memorandum 2 Task Order 1 Rev 03 Subtask 2.3 Project Validation December 23, 2014 prepared for Miami-Dade Water and Sewer Department 
Craig, K., Nieuwoudt, M., Niemand, L. (2013) "CFD simulation of anaerobic digester with variable sewage rheology" Water Research Vol. 47, Iss. 13, September 2013, The International Water Association, London, UK

Crockett, R. (2018) “The Anatomy of an 'objective' legislative research study on biosolids" Proceedings of the WEF Residuals and Biosolids Management Conference 2018, Water Environment Federation, Alexandria, VA

Daigger, G., Nolasco, D. (1995) “Evaluation and design of full-scale wastewater treatment plants using biological process models" Water Science and Technology Vol. 31, Is. 2, 1995, The International Water Association, London, UK

Fezzani, B., Cheikh, R. (2008) "Implementation of IWA anaerobic digestion model No. 1 (ADM1) for simulating the thermophilic anaerobic co-digestion of olive mill wastewater with olive mill solid waste in a semi-continuous tubular digester" Chemical Engineering Journal Vol. 141, Iss. 1-3, 15 July 2008 Elsevier Science Direct

Gillette, R., Joslyn, D. (2000) "Optimization of thickening and dewatering through automation" Proceedings of the WEF WEFTEC 2000, October 2000, Water Environment Federation, Alexandria, VA

Goss, C., Stitt, B., Moncholi, M., Abu-Orf, M., Diaz, I. (2017) "Piloting to Establish Performance Conditions at Miami's South District WWTP" Proceedings of the WEF Residuals and Biosolids Management Conference 2017, Water Environment Federation, Alexandria, VA

Grady, C., Daigger, G., Lim, H. (1999) Biological Wastewater Treatment, 2nd Edition, 1999, Marcel Dekker, New York, NY

Griborio, A., Vadiveloo, E., Wang, T.J., Moncholi, M., Ferguson, J. (2017) "Comprehensive Modeling Approach Builds the Foundation for a \$6 Billion Program" Proceedings of the Florida Water Resources Conference 2017, West Palm Beach, FL

Haughton, G., Rosada, A. (2015) US 9,162,195 B2 United State Patent Publication No. WO2014/170871, October 20, 2015

He, S., Xue, G., Wang, B., (2009) "Factors affecting simultaneous nitrification and denitrification (SND) and its kinetics model in membrane bioreactor" Journal of Hazardous Materials Vol. 168, Iss. 2-3, September 2009, Elsevier Science Direct

Hensley, G., Hilpert, L. (2006) "Method of retrofitting a decanting centrifuge" US 7,001,324 B2 United State Patent Publication No. US 2004/0167005 A1 Feb. 21, 2006 
Huang, H. Liu, J., Ding, L. (2015) "Recovery of phosphate and ammonia nitrogen from the anaerobic digestion supernatant of activated sludge by chemical precipitation" Journal of Cleaner Production, Vol. 102, September 2015, Elsevier Science Direct

Iranpour, R., Cox, H., Kearney, R., Clark, J., Pincince, A., Daigger, G. (2004)"Regulations for biosolids land application in U.S. and European Union" Journal of Residuals Science and Technology, Vol. 1, No. 4-October 2004, DEStech Publications, Lancaster, PA

Jenicek, P., Bartacek, J., Kutil, J., Zabranska, J.;,Dohanyos, M. (2012) “Potentials and limits of anaerobic digestion of sewage sludge: Energy self-sufficient municipal wastewater treatment plant?" Water Science and Technology Vol. 66 Iss. 6, 2012 The International Water Association, London, UK

Jo, H., Parker, W., Kianmehr, P. (2018) "Model Development to Compare the Impacts of Thermal Pretreatment on Waste Activated Sludge" Proceedings of the WEF Residuals and Biosolids Management Conference 2018, Water Environment Federation, Alexandria, VA

Johnson, T., Downing, L., Fitzgerald, C., Leaf, W., Romero, R. (2018) "Lost CrystalsInvestigating when Nutrient Recovery isn't meeting low-P expectations" Proceedings of the WEF Residuals and Biosolids Management Conference 2018, Water Environment Federation, Alexandria, VA

Kim, H., Schuler, A., Gunsch, C., Pei, R., Gellner, J., Boltz, J., Freudenberg, R., Dodson, R. (2011) "Comparison of Conventional and Integrated Fixed-Film Activated Sludge Systems: Attached- and Suspended-Growth Functions and Quantitative Polymerase Chain Reaction Measurements" Water Environment Research Vol. 83, No. 7, July 2011, Water Environment Federation, Alexandria, VA

Kopp, J., Yoshida, H., Forstner, G. (2016) "Impact of Hydrolysis and Bio-P Removal Processes on Biosolids Dewaterability and Polymer Consumption in the Dewatering Process" Proceedings of the WEF Technical Exhibition and Conference 2016, Water Environment Federation, Alexandria, VA

Lin, S. (2001) Water and Wastewater Calculations Manual, 2001 McGraw-Hill, New York, NY

Liu, Y., Tay, J. (2001) "Strategy for minimization of excess sludge production from the activated sludge process" Biotechnology Advances Vol. 19, Iss. 2, April 2001, Elsevier Science Direct

Menniti, A., Rieger, L., Boltz, J., Johnson, B., Daigger, G., Habermacher, J., Derlon, N., Morgenroth, E. (2012) "Critical review on modeling of endogenous processes and 
the degradability of endogenous decay products" Proceedings of the Wastewater Treatment Modeling Seminar, February 2012, a joint WEF/IWA Conference

Meroney, R. (2009) "CFD simulation of mechanical draft tube mixing in anaerobic digester tanks" Water Research Vol. 43, Iss. 4, March 2009, The International Water Association, London, UK

Metcalf and Eddy, Tchobanoglous, G., Burton, F., Stensel, H. (2003). Wastewater Engineering Treatment and Reuse 4th Edition, 2003 McGraw-Hill, New York, NY

Metcalf and Eddy, Tchobanoglous, G., Stensel, H., Tsuchuhashi, R., Burton, F. (2013). Wastewater Engineering: Treatment and Resource Recovery 5th Edition, 2013 McGraw-Hill, New York, NY

Miami-Dade Water and Sewer Department (March 2005) Central District Wastewater Treatment Plant Operation and Maintenance Manual updated March 2005

Miami-Dade Water and Sewer Department (May 2005) South District Wastewater Treatment Plant Operation and Maintenance Manual updated May 2005

Moncholi, M., Goss, T., Stitt, B., Diaz, I. (2018) “Overcoming Obstacles with a Difficult to Handle Sludge - Centrifuge Piloting at Miami's Central District WWTP" Proceedings of the WEF Residuals and Biosolids Management Conference 2018, Water Environment Federation, Alexandria, VA

Mudragada, R., Kundral, S., Coro, E., Moncholi, M., Laha, S., Tansel, B. (2014) "Phosphorous removal during sludge dewatering to prevent struvite formation in sludge digesters by full scale evaluation" Journal of Water Process Engineering, Vol. 2, June 2014, Elsevier Science Direct

MWH Global (Feb. 2015) "Consent Decree Project No. 2.15 Central District Wastewater Treatment Plant Digesters Plant 2 Upgrades System-Wide Digestion Alternatives" Engineering report prepared for Miami-Dade Water and Sewer Department, February 2015

MWH Global (Sept. 2015) “Consent Decree Project 2.12, 2.13 and 2.16 Central District Wastewater Treatment Plant Dewatering - BODR and RDBS Technical Memorandum No. 2.2 Thickening/Dewatering Process Technology Alternatives Development and Evaluation" Engineering report prepared for Miami-Dade Water and Sewer Department, September 2015

MWH Global (2016) "Consent Decree Project 1.06 and1.08 South District Wastewater Treatment Plant Sludge Thickening and Dewatering Building Basis of Design 
Report” Engineering report prepared for Miami-Dade Water and Sewer Department, January 2016

Novak, L., Larrea, L., Wanner, J. (1995) "Mathematical model for soluble carbonaceous substrate biosorption" Water Science and Technology Vol. 3, Iss. 2, 1995, The International Water Association, London, UK

Peeters, B., Weis, S. (2004) "Relationship between pool depth and internal washing on the beach of a solid bowl decanter centrifuge" Filtration and Separation Vol. 41, Iss. 6, July-August 2004, Elsevier Science Direct

Per Høhne (1981) “Decanter centrifuge” US 4,298,162 United State Patent Nov. 3, 1981

Pfeffer, K., Porter, J., Lisk, B., Bullard, M., Guzman, K., Chiavaroli, M. (2018) "Selecting an Advanced Anaerobic Digestion Configuration and Biogas Management Strategy for the City of Tampa" Proceedings of the WEF Residuals and Biosolids Management Conference 2018, Water Environment Federation, Alexandria, VA

Pima County Tres Rios WRF (2018) “Optimized Sludge Thickening Process Control Using Real Time Controller Sludge Thickening Polymer Optimization Gravity Belt Thickeners" Proceedings of the WEF Residuals and Biosolids Management Conference 2018, Water Environment Federation, Alexandria, VA

Romero, A., Ramirez, M., Torrents, A. (2018) "Impact of biosolids treatment and storage conditions on odor production: Thermal Hydrolysis-Anaerobic Digestion vs. Alkaline Stabilization" Proceedings of the WEF Residuals and Biosolids Management Conference 2018, Water Environment Federation, Alexandria, VA

Rodriguez-Garcia, G., Frison, N., Vásquez-Padín, J., Hospido, A., Garrido, J., Fatone, F., Bolzonella, D., Moreira, M., Feijo, G. (2014) "Life cycle assessment of nutrient removal technologies for the treatment of anaerobic digestion supernatant and its integration in a wastewater treatment plant" Science of the Total Environment, Vol. 490, August 2014, Elsevier Science Direct

S-884 - SDWWTP SLUDGE THICKENING and DEWATERING BLDG CD 1.06, 1.08, Specification Section 467136 - CENTRIFUGES, MWH, January 20, 2016.

S-888 - CDWWTP SLUDGE THICKENING and DEWATERING BLDG Consent Decree Projects 2.12, 2.13, 2.16 (2016) Specification Section 467136 CENTRIFUGES, MWH, January 20, 2016.

S-897 - SDWWTP Digester and Control Building Upgrades, Acid Phase and Substation 7 \& 8 Consent Decree Project 1.07 (2018) Proposal Form. March 20, 2018 Miami-Dade Water and Sewer Department 
S-909 - CDWWTP PLANT 2 CLUSTER 2 DIGESTER UPGRADES Consent Decree Project 2.15(2) (2018) Bid Tabulation, bid date: February 23, 2018 Miami-Dade Water and Sewer Department

Schafer, P., Farrell, J. (2000) "Performance comparison for staged and high-temperature anaerobic digestion systems" Proceedings of the WEF, WEFTEC 2000, Water Environment Federation, Alexandria, VA

Schafer, P., Farrell, J., Newman, G., Vandenburgh, S. (2002) "Advanced anaerobic digestion performance comparisons" Proceedings of the WEF, WEFTEC 2002, Water Environment Federation, Alexandria, VA

Schafer, P., Melcer, H. (2018) "Impact of Iron Salt Addition on Solids Production and Operations" Proceedings of the WEF Residuals and Biosolids Management Conference 2018, Water Environment Federation, Alexandria, VA

Schlip, R., Epper, W. (1992) "Centrifuge for the continuous separation of substances that differ in density” US 5,169,377 Dec. 8, 1992

Schroedel, R. (2018) “Should I Use My Digester Gas? Should I Co-Digest?” Proceedings of the WEF Residuals and Biosolids Management Conference 2018, Water Environment Federation, Alexandria, VA

Sharp, R., Vadiveloo, E., Fergen, R., Moncholi, M., Pitt, P., Wankmuller, D., Latimer, R. (2013) "A Theoretical and Practical Evaluation of Struvite Control and Recovery" Water Environment Research, Vol. 85, No. 8, August 2013, Water Environment Federation

Snoeyink, V. and Jenkins, D. (1980) Water Chemistry. John Wiley and Sons, Inc., New York, NY.

Song, Y., Kwon, S., Woo, J. (2004) "Mesophilic and thermophilic temperature co-phase anaerobic digestion compared with single-stage mesophilic- and thermophilic digestion of sewage sludge" Water Research Vol. 38, Iss. 7, April 2004, The International Water Association, London, UK

Stitt, B., Goss, T., Moncholi, M., Abu-Orf M., Diaz, I. (2018) "Enhanced Dewatering with Struvite Recovery: Pilot Testing of AirPrex ${ }^{\circledR}$ Technology at Miami's South District WWTP" Proceedings of the WEF Residuals and Biosolids Management Conference 2017, Water Environment Federation, Alexandria, VA

Sunderland, J. (1987) "Electrokinetic dewatering and thickening. I. Introduction and historical review of electrokinetic applications" Journal of Applied 
Electrochemistry Vol. 17, Iss. 5 September 1987, Springer Nature, Berlin, Germany

Switzenbaum, M., Farrell, J., Pincince, A. (2003) "Relationship Between the Van Kleeck and Mass-Balance Calculation of Volatile Solids Loss" Water Environment Research, Vol. 75, No. 4, July/August 2003, Water Environment Federation, Alexandria, VA

Tasser, C., Ferrin, A. (2018) "Biogas Yields from Anaerobic Digestion of Pre-consumer and Industrial Food Waste and Solids Management at Inland BioEnergy" Proceedings of the WEF Residuals and Biosolids Management Conference 2018, Water Environment Federation, Alexandria, VA

Vadiveloo, E., Fergen, R., Moncholi, M., Pitt, P., Sharp, R., Wankmuller, D., Latimer, R. (2012) "A Theoretical and Practical Evaluation of Struvite Control and Recovery: Two Case Studies" Proceedings of the Water Environment Federation, Residuals and Biosolids 2012 Water Environment Federation

Water Environment Federation Press. (2008). Manual of Practice No. 11: Operation of Municipal Wastewater Treatment Plants. 6th Edition.

Water Environment Federation Press. (2010). Manual of Practice No. 8: Design of Municipal Wastewater Treatment Plants. 5th Edition.

Widder, D. (1961) Advanced Calculus $2^{\text {nd }}$ Edition, Prentince-Hall, Englewood, NJ

Yoshino, M., Yao, M. Tsuno, H., Somiya, I. (2003) "Removal and recovery of phosphate and ammonium as struvite from supernatant in anaerobic digestion" Water Science and Technology, Vol. 48, Iss. 1, July, 2003, The International Water Association, London, UK

Zuthi, M., Ngo, H., Guo, W., Zhang, J., Liang, S. (2013) “A review towards finding a simplified approach for modelling the kinetics of the soluble microbial products (SMP) in an integrated mathematical model of membrane bioreactor (MBR)" International Biodeterioration and Biodegradation, Vol. 85, November 2013, Elsevier Science Direct 
APPENDICES 
APPENDIX 1: DERIVED EQUATIONS 
Eq. 1 Solids Retention time

for secondary treatment biological reactor

WEF MOP $85^{\text {th }}$ Edition, 2010 p. 14-38

Solids retention time (or mean cell residence time)

$$
\text { SRT }=\frac{\text { volume of biological reactor * mixed liquor suspended solids concentration }}{\text { mass of waste solids }}
$$

Solids Retention Time (SRT) for Secondary Treatment process at SDWWTP and CDWWTP

Mass of waste solids has two contributions in the case; waste activated sludge and the solids load of the secondary clarifier effluent. Return activated sludge is an internal recycle and hence not a part of the denominator.

$$
\mathrm{SRT}=\frac{\mathrm{V}_{\mathrm{REACTOR(S)}} * \mathrm{MLSS}}{\mathrm{Q}_{\mathrm{WAS}} * \mathrm{X}_{\mathrm{TSS}, \mathrm{WAS}}+\mathrm{Q}_{\mathrm{EFF}} * \mathrm{X}_{\mathrm{TSS}, \mathrm{EFF}}}
$$

definition of variables

$\mathrm{V}_{\text {REACTOR(S) }}=\quad$ volume of biological reactor $(\mathrm{MG}$ or $\mathrm{m} 3)$

$\mathrm{Q}_{\mathrm{WAS}}=\quad$ waste activated sludge flowrate $\left(\mathrm{MGD}\right.$, gpm or $\left.\mathrm{m}^{3} / \mathrm{d}\right)$

$\mathrm{Q}_{\mathrm{EFF}}=$ secondary clarifier effluent flowrate (MGD, gpm or $\mathrm{m}^{3} / \mathrm{d}$ )

$\mathrm{X}_{\mathrm{TSS} \text {,WAS }}=$ solids concentration in waste activate sludge stream $(\mathrm{mg} / \mathrm{L}$ or

$\left.\mathrm{g} / \mathrm{m}^{3}\right)$

$\mathrm{X}_{\mathrm{TSS}, \mathrm{EFF}}=\quad$ solids concentration in secondary clarifier effluent $\left(\mathrm{mg} / \mathrm{L}\right.$ or $\left.\mathrm{g} / \mathrm{m}^{3}\right)$ 
MLSS $=\quad$ solids concentration in reactor, mixed liquor suspended solids $(\mathrm{mg} / \mathrm{L}$ or $\left.\mathrm{g} / \mathrm{m}^{3}\right)$

Eq. 2 Observed Yield, Yobs

Mop 8 Eq. 20.3

$$
\mathrm{Y}_{\mathrm{obs}}=\frac{\mathrm{Y}}{1+\mathrm{k}_{\mathrm{d}}\left(\theta_{\mathrm{c}}\right)}
$$

where,

$\mathrm{Y}_{\mathrm{obs}}=\quad$ observed yield ( $\mathrm{lb}$ biomass/ $\mathrm{lb}$ substrate or $\mathrm{g}$ biomass/ $\mathrm{g}$ substrate)

$\mathrm{Y}=\quad$ yield ( $\mathrm{lb}$ biomass/ $\mathrm{lb}$ substrate or $\mathrm{g}$ biomass/ $\mathrm{g}$ substrate)

$\mathrm{k}_{\mathrm{d}}=\quad$ endogenous decay rate $\left(\mathrm{lb}\right.$ biomass $/ \mathrm{lb}$ substrate $-\mathrm{d}^{-1}$ or $\mathrm{g}$ biomass $/ \mathrm{g}$ substrate- $\left.\mathrm{d}^{-1}\right)$

$\theta_{\mathrm{c}} \quad=\quad \mathrm{SRT}$ or MCRT $(\mathrm{d})$ 


\begin{tabular}{|c|c|c|c|c|c|c|c|c|c|}
\hline $\mathrm{k}_{\mathrm{u}}$ & $=$ & 0.06 & & & & & & & \\
\hline $\bar{Y}$ & 0.1 & 0.2 & 0.3 & 0.4 & 0.5 & 0.6 & 0.7 & 0.8 & 0.9 \\
\hline$\theta_{c}$ & \multicolumn{9}{|c|}{$\mathbf{Y}_{\mathrm{obs}}$} \\
\hline d & \multicolumn{9}{|c|}{$\mathrm{kg} / \mathrm{kg}(\mathrm{lb} / \mathrm{lb})$} \\
\hline 0.25 & 0.10 & 0.20 & 0.30 & 0.39 & 0,49 & 0.59 & 0.69 & 0.79 & 0.89 \\
\hline 0.5 & 0.10 & 0.19 & 0.29 & 0.39 & 0.49 & 0.58 & 0.68 & 0.78 & 0.87 \\
\hline 0.75 & 0.10 & 19 & 0.29 & 0.38 & 0.48 & 0.57 & 0.67 & 0.77 & 0.86 \\
\hline 1 & 0.09 & 0.19 & 0.28 & 0.38 & 0.47 & 0.57 & 0.66 & 0.75 & 0.85 \\
\hline 1.25 & 0.09 & 0.19 & 0.28 & 0.37 & 0.47 & 0.56 & 0.65 & 0.74 & 0.84 \\
\hline 1.5 & 0.09 & 0.18 & 0.28 & 0.37 & 0.46 & 0.55 & 0.64 & 0.73 & 0.83 \\
\hline 1.75 & 0.09 & 0.18 & 0.27 & 0.36 & 0.45 & 0.54 & 0.63 & 0.72 & 0.81 \\
\hline 2 & 0.09 & 0.18 & 0.27 & 0.36 & 0.45 & 0.54 & 0.63 & 0.71 & 0.80 \\
\hline 2.25 & 0.09 & 0.18 & 0.26 & 0.35 & 0.44 & 0.53 & 0.62 & 0.70 & 0.79 \\
\hline 2.5 & 0.09 & 0.17 & 0.26 & 0.35 & 0.43 & 0.52 & 0.61 & 0.70 & 0.78 \\
\hline 2.75 & 0.09 & 0.17 & 0.26 & 0.34 & 0.43 & 0.52 & 0.60 & 0.69 & 0.77 \\
\hline 3 & 0.08 & 0.17 & 0.25 & 0.34 & 0.42 & 0.51 & 0.59 & 0.68 & 0.76 \\
\hline 3.25 & 0.08 & 0.17 & 0.25 & 0.33 & 0.42 & 0.50 & 0.59 & 0.67 & 0.75 \\
\hline 3.5 & 0.08 & 0.17 & 0.25 & 0.33 & 0.41 & 0.50 & 0.58 & 0.66 & 0.74 \\
\hline 3.75 & 0.08 & 0.16 & 0.24 & 0.33 & 0.41 & 0.49 & 0.57 & 0.65 & 0.73 \\
\hline 4 & 0.08 & 0.16 & 0.24 & 0.32 & 0.40 & 0.48 & 0.56 & 0.65 & 0.73 \\
\hline 4.25 & 0.08 & 0.16 & 0.24 & 0.32 & 0.40 & 0.48 & 0.56 & 0.64 & 0.72 \\
\hline 4.5 & 0.08 & 0.16 & 0.24 & 0.31 & 0.39 & 0.47 & 0.55 & 0.63 & 0.71 \\
\hline 4.75 & 0.08 & 0.16 & 0.23 & 0.31 & 0.39 & 0.47 & 0.54 & 0.62 & 0.70 \\
\hline 5 & 0.08 & 0.15 & 0.23 & 0.31 & 0.38 & 0.46 & 0.54 & 0.62 & 0.69 \\
\hline
\end{tabular}

Eq. 3 Percent Solids Capture

for sludge thickening

Derived Equation

Solids in thickened (or dewatered) sludge

$\%$ Solids Capture $=$

Solids in sludge stream to thickening (or dewatering) process

Mass Balance for sludge thickening and dewatering processes 
Mass to thickening (dewatering) unit $=$ Mass of thickened (dewatered) sludge + Mass of recycled solids stream

$$
\mathrm{M}=\mathrm{Q} * \mathrm{X}
$$

For the derivation thickening process terms are used, but the terms for a dewatering process are interchangeable.

$$
\begin{aligned}
& \text { definition of variables } \\
& \text { QwAS } \quad=\quad \text { waste activated sludge flowrate }\left(\mathrm{MGD}, \text { gpm or } \mathrm{m}^{3} / \mathrm{d}\right) \\
& \text { Q }=\text { thickened waste activated sludge flowrate (MGD, gpm or } \mathrm{m}^{3} / \mathrm{d} \text { ) } \\
& \text { Q }_{\text {filtrate }}{ }^{*}=\quad \text { filtrate flowrate }\left(\mathrm{MGD}, \text { gpm or } \mathrm{m}^{3} / \mathrm{d}\right) \\
& \mathrm{X}_{\mathrm{TSS}, \mathrm{WAS}}=\quad \text { solids concentration in waste activate sludge }\left(\mathrm{mg} / \mathrm{L} \text { or } \mathrm{g} / \mathrm{m}^{3}\right) \\
& \mathrm{X}_{\mathrm{TSS}, \mathrm{TWAS}}=\quad \text { solids concentration in thickened waste activate sludge }(\mathrm{mg} / \mathrm{L} \text { or } \\
& \left.\mathrm{g} / \mathrm{m}^{3}\right) \\
& \mathrm{X}_{\mathrm{TSS}, \text { FILTRATE }}=\quad \text { solids concentration in filtrate stream }\left(\mathrm{mg} / \mathrm{L} \text { or } \mathrm{g} / \mathrm{m}^{3}\right) \\
& \mathrm{M}_{\text {TWAS }}=\text { mass of thickened waste activated sludge }(\mathrm{kg} / \mathrm{d}) \\
& \mathrm{M}_{\mathrm{WAS}} \quad=\quad \text { mass of waste activated sludge }(\mathrm{kg} / \mathrm{d}) \\
& \mathrm{X}_{\mathrm{TSS}, \mathrm{DS}}=\quad \text { solids concentration in digested sludge }\left(\mathrm{mg} / \mathrm{L} \text { or } \mathrm{g} / \mathrm{m}^{3}\right) \\
& \mathrm{X}_{\mathrm{TSS}, \mathrm{CAKE}}=\text { solids concentration in dewatered sludge cake }\left(\mathrm{mg} / \mathrm{L} \text { or } \mathrm{g} / \mathrm{m}^{3}\right) \\
& \mathrm{X}_{\mathrm{TSS}, \mathrm{CENTRATE}} * *=\quad \text { solids concentration in centrate stream }\left(\mathrm{mg} / \mathrm{L} \text { or } \mathrm{g} / \mathrm{m}^{3}\right)
\end{aligned}
$$


* Meant here as the sludge thickening process reject stream. Often referred to as concentrator overflow for the existing gravity concentrators, filtrate for gravity belt thickeners, and centrate for thickening centrifuges

** Meant here as the sludge dewatering process reject stream. Both facilities in the study currently operate dewatering centrifuges and plan to continue in the future. The term would be conventionally called filtrate In the case of belt filter presses, bucher presses, screw presses, etc.

flow balance

$$
\mathrm{Q}_{\mathrm{WAS}}=\mathrm{Q}_{\mathrm{TWAS}}+\mathrm{Q}_{\mathrm{FILTRATE}}
$$

mass balance

$$
\mathrm{Q}_{\mathrm{WAS}} * \mathrm{X}_{\mathrm{TSS}, \mathrm{WAS}}=\mathrm{Q}_{\mathrm{TWAS}} * \mathrm{X}_{\mathrm{TSS}, \mathrm{TWAS}}+\mathrm{Q}_{\mathrm{filtR} A T E} * \mathrm{X}_{\mathrm{TSS} \text {,FILTRATE }}
$$

solve for QfiLtRate, an unknown

$$
\mathrm{Q}_{\text {filtrate }}=\mathrm{Q}_{\mathrm{WAS}}-\mathrm{Q}_{\mathrm{TWAS}}
$$

use substitution for QFILTRATE in mass balance,

$$
\begin{aligned}
& \mathrm{Q}_{\mathrm{WAS}} * \mathrm{X}_{\mathrm{TSS}, \mathrm{WAS}}=\mathrm{Q}_{\mathrm{TWAS}} * \mathrm{X}_{\mathrm{TSS}, \mathrm{TW} A \mathrm{~S}}+\left(\mathrm{Q}_{\mathrm{WAS}}-\mathrm{Q}_{\mathrm{TWAS}}\right) * \mathrm{X}_{\mathrm{TSS}, \mathrm{FilTRATE}} \\
& \mathrm{Q}_{\mathrm{WAS}} * \mathrm{X}_{\mathrm{TSS}, \mathrm{WAS}}=\mathrm{Q}_{\mathrm{WAS}} * \mathrm{X}_{\mathrm{TSS}, \mathrm{Filtrate}}-\mathrm{Q}_{\mathrm{TWAS}} *\left(\mathrm{X}_{\mathrm{TSS}, \mathrm{TWAS}}-\mathrm{X}_{\mathrm{TSS}, \mathrm{Filt}} \text { tate }\right)
\end{aligned}
$$

solve for QTWAS 


$$
\mathrm{Q}_{\mathrm{TWAS}}=\frac{\mathrm{Q}_{\mathrm{WAS}} * \mathrm{X}_{\mathrm{TSS}, \mathrm{WAS}}-\mathrm{Q}_{\mathrm{WAS}} * \mathrm{X}_{\mathrm{FILTRATE}}}{\left(\mathrm{X}_{\mathrm{TSS}, \mathrm{TWAS}}-\mathrm{X}_{\mathrm{TSS}, \mathrm{FILTRATE}}\right)}
$$

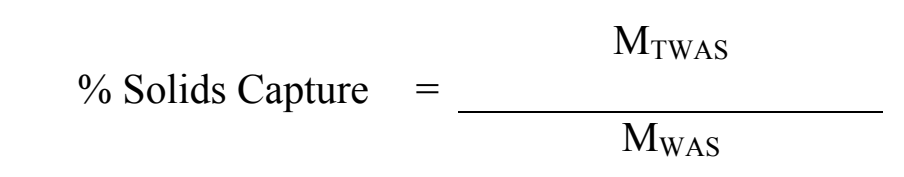

$$
\% \text { Solids Capture }=\frac{\mathrm{Q}_{\mathrm{TWAS}} * \mathrm{X}_{\mathrm{TSS}, \mathrm{TWAS}}}{\mathrm{Q}_{\mathrm{WAS}} * \mathrm{X}_{\mathrm{TSS}, \mathrm{WAS}}}
$$

substitute for $\mathrm{Q}_{\mathrm{TWAS}}$,

$$
\% \text { Solids Capture }=\frac{\mathrm{Q}_{\mathrm{WAS}} * \frac{\left(\mathrm{X}_{\mathrm{TSS}, \mathrm{WAS}}-\mathrm{X}_{\mathrm{FILTRATE}}\right)}{\left(\mathrm{X}_{\mathrm{TSS}, \mathrm{TWAS}}-\mathrm{X}_{\mathrm{TSS}, \mathrm{FILTRATE}}\right)} * \mathrm{X}_{\mathrm{TSS}, \mathrm{TWAS}}}{\mathrm{Q}_{\mathrm{WAS}} * \mathrm{X}_{\mathrm{TSS}, \mathrm{WAS}}}
$$

simplify like terms,

$$
\% \text { Solids Capture }=\frac{\mathrm{X}_{\mathrm{TSS}, \mathrm{TWAS}} *\left(\mathrm{X}_{\mathrm{TSS}, \mathrm{WAS}}-\mathrm{X}_{\mathrm{FILTRATE}}\right)}{\mathrm{X}_{\mathrm{TSS}, \mathrm{WAS}} *\left(\mathrm{X}_{\mathrm{TSS}, \mathrm{TWAS}}-\mathrm{X}_{\mathrm{TSS}, \mathrm{FILTRATE}}\right)}
$$

Eq. 5 Digester Solids Residence Time

For this study the solids retention time will only be considered for active digester volume. Active digester volume will be the volume of SDWWTP and CDWWTP digesters that are mixed and heated. For the purposes of this study this will not include secondary 
digester in a standard rate primary-secondary digestion system as is currently in operation at both SDWWTP and CDWWTP. This will also not include detention time in digesters use as holding tanks prior to dewatering. The lower cone section will be disregarded in the volume calculation due to the consistent build up of solids in all digesters between cleaning cycles. This is to ensure that the plants are meeting both federal EPA and state FDEP requirements for sludge stabilization.

$$
\mathrm{SRT}=\frac{\text { active digester volume } * \text { digester solids concentration }}{\text { mass of solids leaving digester }}
$$

generally,

$$
\mathrm{SRT}=\frac{\mathrm{V}_{\text {Active Digester }(\mathrm{S})} * \mathrm{X}_{\mathrm{TSS}, \mathrm{DS}}}{\mathrm{Q}_{\mathrm{DS}} * \mathrm{X}_{\mathrm{TSS}, \mathrm{DS}}+\mathrm{Q}_{\text {SUPeRnAtant }} * \mathrm{X}_{\mathrm{TSS}, \text { SUPERnATANT }}}
$$

definition of variables

$\mathrm{V}_{\mathrm{ACTIVE} \mathrm{DIGESTER}(\mathrm{S})}=\quad$ active digestion volume $\left(\mathrm{MG}\right.$ or $\left.\mathrm{m}^{3}\right)$

$\mathrm{Q}_{\mathrm{DS}}=\quad$ flowrate of digester sludge to dewatering (MGD, gpm or $\mathrm{m}^{3} / \mathrm{d}$ )

$\mathrm{Q}_{\text {SUPERnATANT }}=\quad$ supernatant flowrate $\left(\mathrm{MGD}\right.$, gpm or $\left.\mathrm{m}^{3} / \mathrm{d}\right)$

$\mathrm{X}_{\mathrm{TSS}, \mathrm{DS}} * \quad=\quad$ solids concentration of digested sludge $\left(\mathrm{mg} / \mathrm{L}\right.$ or $\left.\mathrm{g} / \mathrm{m}^{3}\right)$

$\mathrm{X}_{\mathrm{TSS}, \text { SUPERNATANT }}=\quad$ solids concentration in supernatant stream $\left(\mathrm{mg} / \mathrm{L}\right.$ or $\left.\mathrm{g} / \mathrm{m}^{3}\right)$

* $\mathrm{X}_{\mathrm{TSS}, \mathrm{DS}}$ here refers to both the solids concentration in the digester sludge stream and the solids concentration in the digester itself. As the active digesters in this study are continuously stirred tanks it can be assumed to be at the same concentration as the digested sludge leaving the digester. 
Mass of solids leaving the digestion system for many primary-secondary digestion systems would have two contributions; digested sludge to dewatering or further stabilization and supernatant. As previously detailed SDWWTP and CDWWTP do not practice decanting supernatant from secondary digesters. The proposed digester modification to a high-rate single stage digestion system would also not have a supernatant stream. Therefore, the solid streams leaving the digestion system for this study is just digested sludge to the dewatering process.

SRT for active digesters for SDWWTP and CDWWTP can be simplified to:

$$
\mathrm{SRT}=\frac{\mathrm{V}_{\mathrm{ACTIVE} \mathrm{DIGESTER(S)}} * \mathrm{X}_{\mathrm{TSS}, \mathrm{DS}}}{\mathrm{Q}_{\mathrm{DS}} * \mathrm{X}_{\mathrm{TSS}, \mathrm{DS}}}
$$

simplify like terms,

$$
\mathrm{SRT}=\frac{\mathrm{V}_{\text {ACTIVE DIGESTER(S) }}}{\mathrm{Q}_{\mathrm{DS}}}
$$

This is also the hydraulic retention time for the digesters. The flowrate of TWAS can be substituted for the digested sludge flowrate as they can be assumed to be equal for this case.

Eqs. 6 and 7 VSR for standard and high-rate digester systems 
Eq. 6 Estimate of VSR for standard-rate digesters

MOP 8. Eq.25.5

$$
\mathrm{VSR}=30+\frac{\mathrm{t}}{2}
$$

where,

VSR $=\quad$ Volatile Solids Reduction (\%)

$\mathrm{t}=\quad$ time of digestion $(\mathrm{d})$

Eq. 7 Estimate of VSR for high-rate digesters

MOP 8. Eq.25.6

$$
\text { VSR }=13.7 * \ln \left(\theta^{\mathrm{m}}{ }_{\mathrm{d}}\right)+18.94
$$

where,

VSR $=\quad$ Volatile Solids Reduction (\%)

$\theta^{m_{d}} \quad=\quad$ design SRT (d)

\begin{tabular}{|r|r|r|}
\hline $\begin{array}{c}\text { cst. } \\
\text { method* }\end{array}$ & $\begin{array}{c}\text { Standard- } \\
\text { Rate }\end{array}$ & High-rate** \\
\hline \multicolumn{1}{|c|}{ (d) } & VSR (\%) & VSR (\%) \\
\hline 10 & 35.0 & 50.49 \\
\hline 12 & 36.0 & 53.0 \\
\hline 15 & 37.5 & 56.0 \\
\hline 20 & 40.0 & 60.0 \\
\hline 25 & 42.5 & 63.0 \\
\hline 30 & 45.0 & 65.5 \\
\hline 40 & 50.0 & 65.5 \\
\hline 50 & 55.0 & 65.5 \\
\hline 60 & 60.0 & 65.5 \\
\hline \multicolumn{2}{|r}{} \\
\hline \multicolumn{2}{|c}{}
\end{tabular}

*not intended for VSR below $40 \%$ 
** only intended for $\mathrm{t}$ between $15 \mathrm{~d}$ and $30 \mathrm{~d}$, Metcalf \& Eddy

From these models is does seem that even primaries at SDWWTP currently behave more as high-rate digesters than standard rate. This may be a sign that they already have adequate heating and mixing. CDWWTP seems to be running more as standard-rate digesters based on these model, which will change with the switch the well mixed and heated digesters proposed in the scenarios D \& E. Designs for high-rate digesters are typically for primary or mixed sludges, and hence their VSR potential is based on that fact. As SDWWTP does not process any primary clarifier solids for VSR estimating purposes, its VSR will be capped at 55\% under its current solids loading and characteristics.

Eq. $10 \mathrm{X}_{\mathrm{TSS}, \mathrm{DS}}$, digested sludge solids concentration, from an estimated VSR For cases where a digestion system does not have supernatant and flowrate from the digester feed is equal to digester sludge draw over time.

derivation based on VSR equation:

$$
\mathrm{VSR}=1-\frac{\% \mathrm{~V}_{\mathrm{DS}} * \mathrm{X}_{\mathrm{TSS}, \mathrm{DS}}}{\% \mathrm{~V}_{\mathrm{TWAS}} * \mathrm{X}_{\mathrm{TSS}, \mathrm{TWAS}}}
$$

where,

$$
\begin{array}{lll}
\% \mathrm{~V}_{\mathrm{DS}} & = & \text { volatile fraction of digested sludge }(\%) \\
\mathrm{X}_{\text {TSS,DS }} & = & \text { solids concentration of digested sludge }(\mathrm{mg} / \mathrm{L} \text { or g/m } \\
\left.\% \mathrm{~V}_{\text {TWAS }}\right) & \text { volatile fraction of thickened sludge }(\%) \\
\mathrm{X}_{\text {TSS,TWAS }}= & \text { solids concentration of thickened sludge }\left(\mathrm{mg} / \mathrm{L} \text { or g } / \mathrm{m}^{3}\right)
\end{array}
$$


isolate $\% \mathrm{~V}_{\mathrm{DS}} * \mathrm{X}_{\mathrm{TSS}, \mathrm{DS}}$, both unknowns

$$
\begin{gathered}
1-\mathrm{VSR}=\frac{\% \mathrm{~V}_{\mathrm{DS}} * \mathrm{X}_{\mathrm{TSS}, \mathrm{DS}}}{\% \mathrm{~V}_{\mathrm{TWAS}} * \mathrm{X}_{\mathrm{TSS}, \mathrm{TWAS}}} \\
\mathrm{X}_{\mathrm{VSS}, \mathrm{DS}}=\quad \% \mathrm{~V}_{\mathrm{DS}} * \mathrm{X}_{\mathrm{TSS}, \mathrm{DS}} \\
\mathrm{X}_{\mathrm{VSS}, \mathrm{DS}}=\quad(1-\mathrm{VSR}) * \% \mathrm{~V}_{\mathrm{TWAS}} * \mathrm{X}_{\mathrm{TSS}, \mathrm{TWAS}}
\end{gathered}
$$

where,

$\mathrm{X}_{\mathrm{VSS}, \mathrm{DS}} \quad=\quad$ volatile solids concentration of digested sludge $\left(\mathrm{mg} / \mathrm{L}\right.$ or $\left.\mathrm{g} / \mathrm{m}^{3}\right)$

for any solid constituent in a flow stream the fixed solids can be defined as:

$$
\text { fixed solids }=(1-\% \mathrm{~V}) * \mathrm{X}_{\mathrm{TSS}} * \mathrm{Q}
$$

In this the case of digestion, fixed solids by definition are neither created nor degraded. In the case of SDWWTP and CDWWTP, for purposes of this study, are considered to pass from the digester feed to the digested sludge unaffected or deposited.

TWAS fixed solids $=$ digested sludge fixed solids

$$
\mathrm{Q}_{\mathrm{TWAS}} *\left(1-\% \mathrm{~V}_{\mathrm{TWAS}}\right) * \mathrm{X}_{\mathrm{TSS}, \mathrm{TWAS}}=\mathrm{Q}_{\mathrm{DS}} *\left(1-\% \mathrm{~V}_{\mathrm{DS}}\right) * \mathrm{X}_{\mathrm{TSS}, \mathrm{DS}}
$$

where,

Q $\quad=\quad$ flowas $\quad=$ of thickened sludge to digester (MGD, gpm or $\left.\mathrm{m}^{3} / \mathrm{d}\right)$

Q $\quad=\quad$ flowrate of digester sludge to dewatering (MGD, gpm or $\mathrm{m}^{3} / \mathrm{d}$ )

isolate $\% \mathrm{~V}_{\mathrm{DS}} * \mathrm{X}_{\mathrm{TSS}, \mathrm{DS}}$ 
$\mathrm{Q}_{\mathrm{TWAS}} *\left(1-\% \mathrm{~V}_{\mathrm{TWAS}}\right) * \mathrm{X}_{\mathrm{TSS}, \mathrm{TWAS}}=\mathrm{Q}_{\mathrm{DS}} * \mathrm{X}_{\mathrm{TSS}, \mathrm{DS}}-\mathrm{Q}_{\mathrm{DS}} * \% \mathrm{~V}_{\mathrm{DS}} * \mathrm{X}_{\mathrm{TSS}, \mathrm{DS}}$

Substitute $\quad \mathrm{X}_{\mathrm{VSS}, \mathrm{DS}}=\% \mathrm{~V}_{\mathrm{DS}} * \mathrm{X}_{\mathrm{TSS}, \mathrm{DS}}=(1-\mathrm{VSR}) * \% \mathrm{~V}_{\mathrm{TWAS}} * \mathrm{X}_{\mathrm{TSS}, \mathrm{TWAS}}$

$$
\mathrm{Q}_{\mathrm{TWAS}} *\left(1-\% \mathrm{~V}_{\mathrm{TWAS}}\right) * \mathrm{X}_{\mathrm{TSS}, \mathrm{TWAS}}=\mathrm{Q}_{\mathrm{DS}} * \mathrm{X}_{\mathrm{TSS}, \mathrm{DS}}-\mathrm{Q}_{\mathrm{DS}} *(1-\mathrm{VSR}) * \% \mathrm{~V}_{\mathrm{TWAS}} * \mathrm{X}_{\mathrm{TSS}, \mathrm{TWAS}}
$$

solve for $\mathrm{X}_{\mathrm{TSS}, \mathrm{DS}}$

$$
\mathrm{X}_{\mathrm{TSS}, \mathrm{DS}}=\frac{\mathrm{Q}_{\mathrm{TWAS}} *\left(1-\% \mathrm{~V}_{\mathrm{TWAS}}\right) * \mathrm{X}_{\mathrm{TSS}, \mathrm{TWAS}}+\mathrm{Q}_{\mathrm{DS}} *(1-\mathrm{VSR}) * \% \mathrm{~V}_{\mathrm{TWAS}} * \mathrm{X}_{\mathrm{TSS}, \mathrm{TWAS}}}{\mathrm{Q}_{\mathrm{DS}}}
$$

where,

$$
\begin{gathered}
\mathrm{Q}_{\mathrm{TWAS}}=\mathrm{Q}_{\mathrm{DS}} \\
\mathrm{X}_{\mathrm{TSS}, \mathrm{DS}}=\frac{\mathrm{Q}_{\mathrm{TWAS}} *\left(1-\% \mathrm{~V}_{\mathrm{TWAS}}\right) * \mathrm{X}_{\mathrm{TSS}, \mathrm{TWAS}}+\mathrm{Q}_{\mathrm{TWAS}} *(1-\mathrm{VSR}) * \% \mathrm{~V}_{\mathrm{TWAS}} * \mathrm{X}_{\mathrm{TSS}, \mathrm{TWAS}}}{\mathrm{Q}_{\mathrm{TWAS}}}
\end{gathered}
$$

gather like terms,

$$
\mathrm{X}_{\mathrm{TSS}, \mathrm{DS}}=\frac{\mathrm{Q}_{\mathrm{TWAS}} *\left[\left(1-\% \mathrm{~V}_{\mathrm{TWAS}}\right) * \mathrm{X}_{\mathrm{TSS}, \mathrm{TWAS}}+(1-\mathrm{VSR}) * \% \mathrm{~V}_{\mathrm{TWAS}} * \mathrm{X}_{\mathrm{TSS}, \mathrm{TWAS}]}\right.}{\mathrm{Q}_{\mathrm{TWAS}}}
$$

simplify like terms,

$$
\mathrm{X}_{\mathrm{TSS}, \mathrm{DS}}=\left(1-\% \mathrm{~V}_{\mathrm{TWAS}}\right) * \mathrm{X}_{\mathrm{TSS}, \mathrm{TWAS}}+(1-\mathrm{VSR}) * \% \mathrm{~V}_{\mathrm{TWAS}} * \mathrm{X}_{\mathrm{TSS}, \mathrm{TWAS}}
$$

expand terms,

$$
\mathrm{X}_{\mathrm{TSS}, \mathrm{DS}}=\mathrm{X}_{\mathrm{TSS}, \mathrm{TWAS}}-\% \mathrm{~V}_{\mathrm{TWAS}} * \mathrm{X}_{\mathrm{TSS}, \mathrm{TWAS}}+\% \mathrm{~V}_{\mathrm{TWAS}} * \mathrm{X}_{\mathrm{TSS}, \mathrm{TWAS}}-\mathrm{VSR} * \% \mathrm{~V}_{\mathrm{TWAS}} * \mathrm{X}_{\mathrm{TSS}, \mathrm{TWAS}}
$$


remove terms that cancel out,

$$
\begin{gathered}
\% \mathrm{~V}_{\mathrm{TWAS}} * \mathrm{X}_{\mathrm{TSS}, \mathrm{TWAS}}-\% \mathrm{~V}_{\mathrm{TWAS}} * \mathrm{X}_{\mathrm{TSS}, \mathrm{TWAS}}=0 \\
\mathrm{X}_{\mathrm{TSS}, \mathrm{DS}}=\mathrm{X}_{\mathrm{TSS}, \mathrm{TWAS}}-\mathrm{VSR} * \% \mathrm{~V}_{\mathrm{TWAS}} * \mathrm{X}_{\mathrm{TSS}, \mathrm{TWAS}} \\
\mathrm{X}_{\mathrm{TSS}, \mathrm{DS}}=\mathrm{X}_{\mathrm{TSS}, \mathrm{TWAS}}\left(1-\mathrm{VSR} * \% \mathrm{~V}_{\mathrm{TWAS}}\right)
\end{gathered}
$$

Eq. 11 Derived Equation for VSR of a known system

MOP 11. Eq. 30.1

$$
\operatorname{VSR}(\%)=\frac{\text { volatile solids in - volatile solids out }}{\text { volatile solids in }} * 100
$$

Mass Balance of an anaerobic digester

$\mathrm{Q}_{\text {in }} \quad=\quad \mathrm{Q}_{\text {out }}$

$\mathrm{M}_{\mathrm{in}}=\mathrm{M}_{\text {produced }}-\mathrm{M}_{\text {destroyed }}+\mathrm{M}_{\text {out }}$

where,

$\begin{array}{lll}\mathrm{Q}_{\text {in }} & = & \mathrm{Q}_{\text {TWAS }} \\ \mathrm{Q}_{\text {out }} & = & \mathrm{Q}_{\mathrm{DS}}+\mathrm{Q}_{\text {supernatant }} \\ \mathrm{Q}_{\text {supernatant }} & = & 0, \text { study plants do not practice decanting supernatant } \\ \mathrm{M} & = & \text { volatile solids }+ \text { fixed solids } \\ \mathrm{M} & = & \mathrm{Q} * \mathrm{VS}+\mathrm{Q} * \mathrm{FS}\end{array}$




$$
\begin{aligned}
\mathrm{VS}_{\text {in }} & =\mathrm{Q}_{\text {in }} * \% \mathrm{~V}_{\text {in }} * \mathrm{X}_{\mathrm{TSS}, \text { in }} \\
\mathrm{VS}_{\text {out }} & =\mathrm{Q}_{\text {out }} * \% \mathrm{~V}_{\text {out }} * \mathrm{X}_{\mathrm{TSS}, \text { out }} \\
\mathrm{VSR} & =\frac{\mathrm{Q}_{\mathrm{TWAS}} * \% \mathrm{~V}_{\mathrm{TWAS}} * \mathrm{X}_{\mathrm{TSS}, \mathrm{TWAS}}-\mathrm{Q}_{\mathrm{DS}} * \% \mathrm{~V}_{\mathrm{DS}} * \mathrm{X}_{\mathrm{TSS}, \mathrm{DS}}}{\mathrm{Q}_{\mathrm{TWAS}} * \% \mathrm{~V}_{\mathrm{TWAS}} * \mathrm{X}_{\mathrm{TSS}, \mathrm{TWAS}}}
\end{aligned}
$$

simplify like terms,

$$
\mathrm{VSR}=1-\frac{\mathrm{QDS}_{\mathrm{DS}} * \mathrm{~V}_{\mathrm{DS}} * \mathrm{X}_{\mathrm{TSS}, \mathrm{DS}}}{\mathrm{Q}_{\mathrm{TWAS}} * \% \mathrm{~V}_{\mathrm{TWAS}} * \mathrm{X}_{\mathrm{TSS}, \mathrm{TWAS}}}
$$

where,

QDS $\quad=\quad$ flowrate of digested sludge $\left(\mathrm{MGD}\right.$, gpm or $\left.\mathrm{m}^{3} / \mathrm{d}\right)$

$\% \mathrm{~V}_{\mathrm{DS}} \quad=\quad$ volatile fraction of digested sludge $(\%)$

$\mathrm{X}_{\mathrm{TSS}, \mathrm{DS}}=\quad$ solids concentration of digested sludge $\left(\mathrm{mg} / \mathrm{L}\right.$ or $\left.\mathrm{g} / \mathrm{m}^{3}\right)$

Q $=$ TWAS $=\quad$ flowrate of thickened sludge $(\mathrm{MGD}$, gpm or $\mathrm{m} 3 / \mathrm{d})$

$\% \mathrm{~V}_{\text {TWAS }} \quad=\quad$ volatile fraction of thickened sludge $(\%)$

$\mathrm{X}_{\text {TSS,TWAS }}=$ solids concentration of thickened sludge $\left(\mathrm{mg} / \mathrm{L}\right.$ or $\left.\mathrm{g} / \mathrm{m}^{3}\right)$

fixed solids $=$ non degradable solids present in the same quantity in both the thickened sludge and digested sludge ( $\mathrm{lb} / \mathrm{d}$ or $\mathrm{kg} / \mathrm{d})$ as there is no supernatant flow for this case,

$$
\mathrm{Q}_{\mathrm{TWAS}}=\mathrm{Q}_{\mathrm{DS}}
$$

simplify like terms, 


$$
\mathrm{VSR}=1-\frac{\% \mathrm{~V}_{\mathrm{DS}} * \mathrm{X}_{\mathrm{TSS}, \mathrm{DS}}}{\% \mathrm{~V}_{\mathrm{TWAS}} * \mathrm{X}_{\mathrm{TSS}, \mathrm{TWAS}}}
$$

Eq. 12 Percent Solids Capture

for sludge dewatering equipment

$$
\% \text { Solids Capture }=\frac{\mathrm{X}_{\mathrm{TSS}, \mathrm{CAKE}} * \quad\left(\mathrm{X}_{\mathrm{TSS}, \mathrm{DS}}-\mathrm{X}_{\mathrm{CENTRATE}}\right)}{\mathrm{X}_{\mathrm{TSS}, \mathrm{DS}} * \quad\left(\mathrm{X}_{\mathrm{TSS}, \mathrm{CAKE}}-\mathrm{X}_{\mathrm{TSS}, \mathrm{CENTRATE}}\right)}
$$

Note:

In MOP 8 the solids capture equation includes a term " $r$ " for a $\%$ recycle There equation reads,

$$
\begin{aligned}
& \mathrm{E}=\frac{\mathrm{Cc}(\mathrm{Ci}-\mathrm{rCf})}{\mathrm{Ci}(\mathrm{Cc}-\mathrm{Cf})} \\
& r=\frac{\mathrm{Qi}+\mathrm{Qw}}{\mathrm{Qi}}
\end{aligned}
$$

where,

$$
\begin{array}{lll}
\mathrm{E} & = & \text { solids capture }(\%) \\
\mathrm{r} & = & \text { recycle }(\%) \\
\mathrm{C}_{\mathrm{c}} & = & \text { cake solids content }(\mathrm{mg} / \mathrm{L}) \\
\mathrm{C}_{\mathrm{i}} & = & \text { feed solids content }(\mathrm{mg} / \mathrm{L}) \\
\mathrm{C}_{\mathrm{f}} & = & \text { filtrate solids content }(\mathrm{mg} / \mathrm{L})
\end{array}
$$


$\mathrm{Q}_{\mathrm{i}} \quad=\quad$ feed flow $(\mathrm{L} / \mathrm{m})$

$\mathrm{Q}_{\mathrm{f}} \quad=\quad$ filtrate flowrate $(\mathrm{L} / \mathrm{m})$

$\mathrm{Q}_{\mathrm{w}} \quad=\quad$ wash water flowrate

$\mathrm{Q}_{\mathrm{c}} \quad=\quad$ cake flowrate $(\mathrm{L} / \mathrm{m})$, not used

The addition of the \% recycle, although relevant to facilities that utilize wash water in their filter presses and centrifuges, is not relevant for SDWWTP and CDWWTP during the study period. The practice of using wash water to prevent the build up of struvite precipitation was discontinued in 2010 at CDWWTP with the introduction of ferric salts for struvite control. SDWWTP has not practiced the use of wash water for struvite accumulation. The current day practices of utilizing ferric salt additions prior to dewatering and flushing machines out with wash water only as part of the centrifuge shutdown process has proven sufficient to control struvite and prevent accumulation of deposits in the centrifuges. Therefore, the derived $\%$ solids capture equation is proper for the treatment plants in this study. 
APPENDIX 2: CHARTS OF HISTORICAL DATA 
South District WWTP Historical Data Analysis for MBM inputs

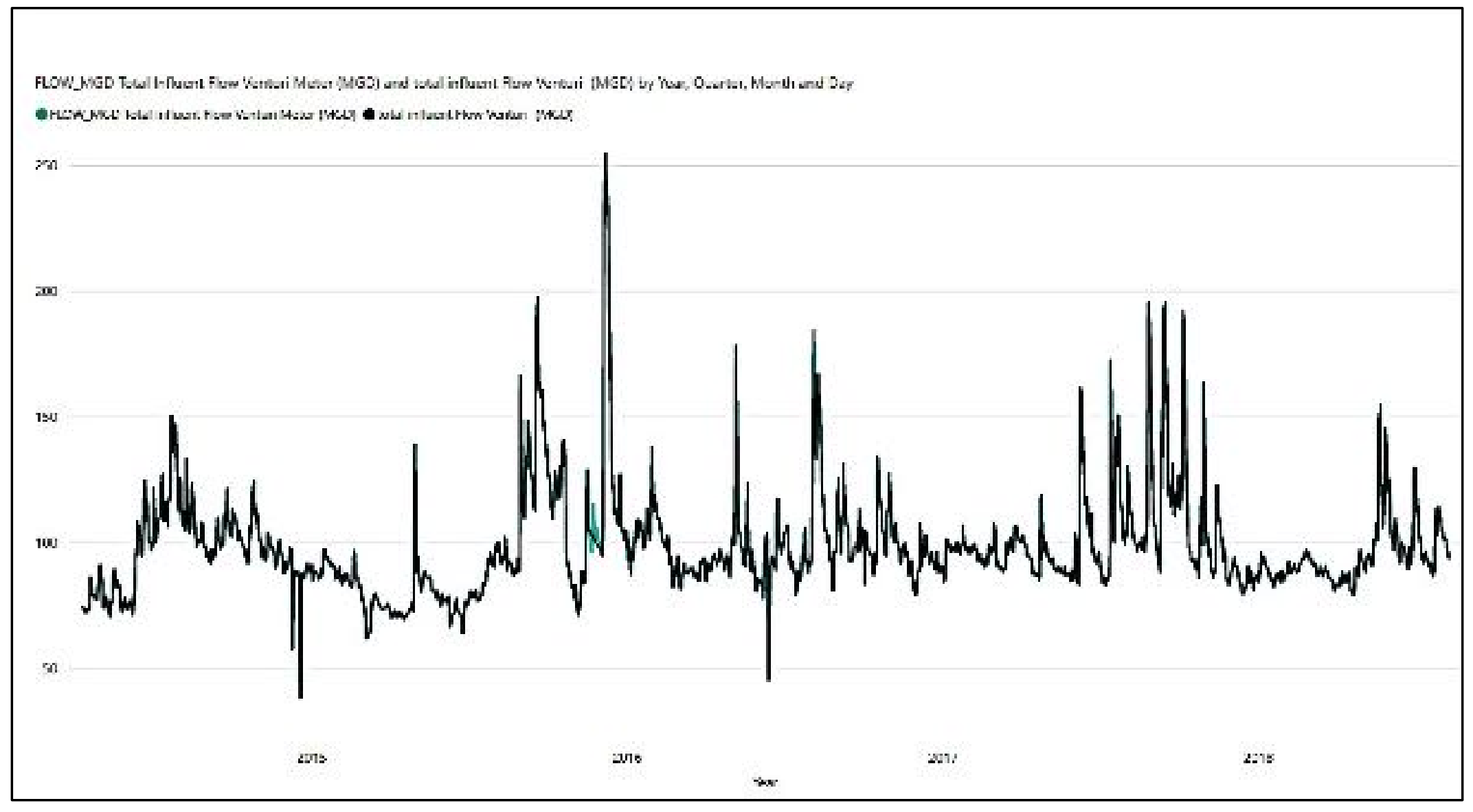




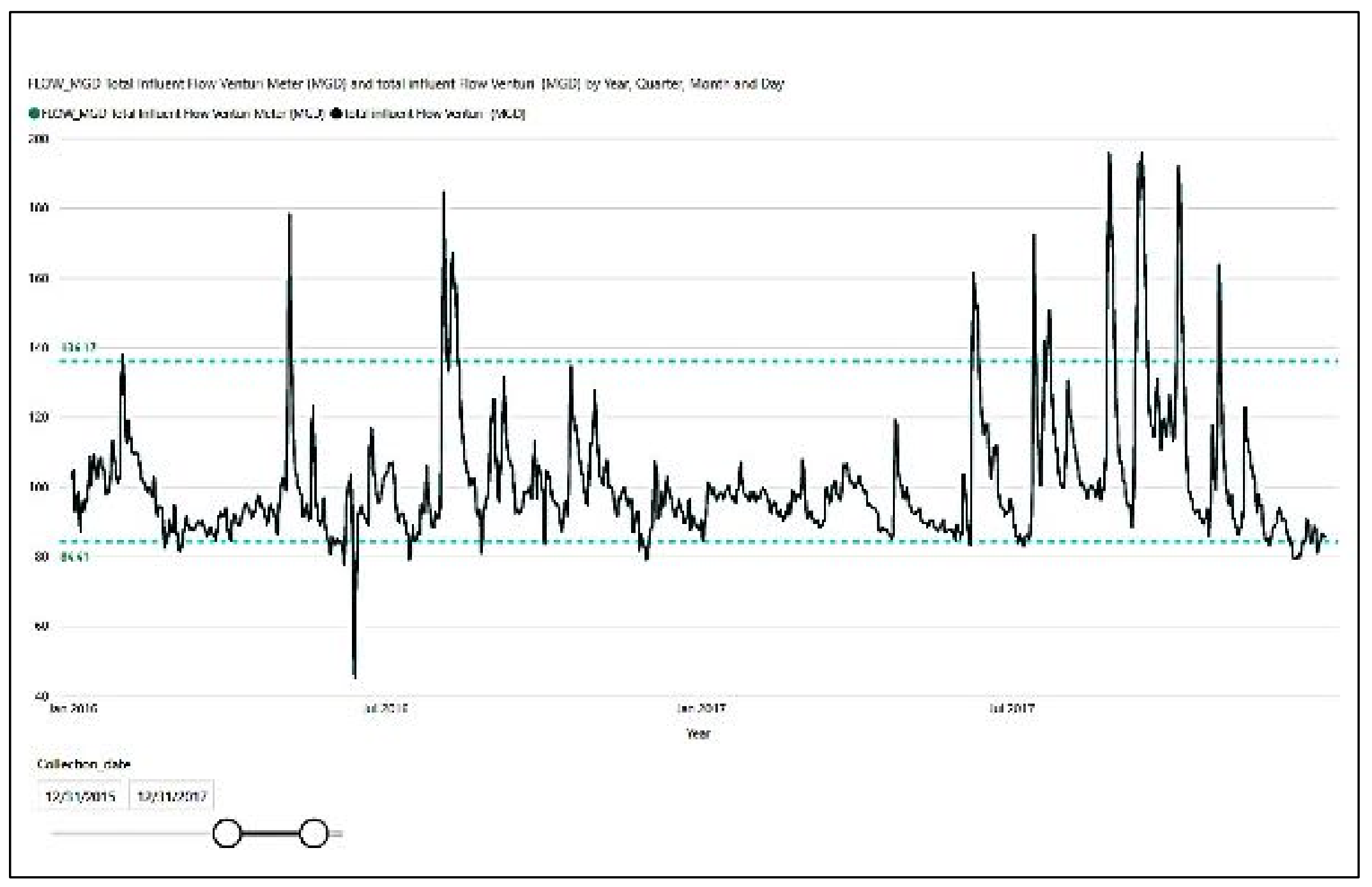

267 


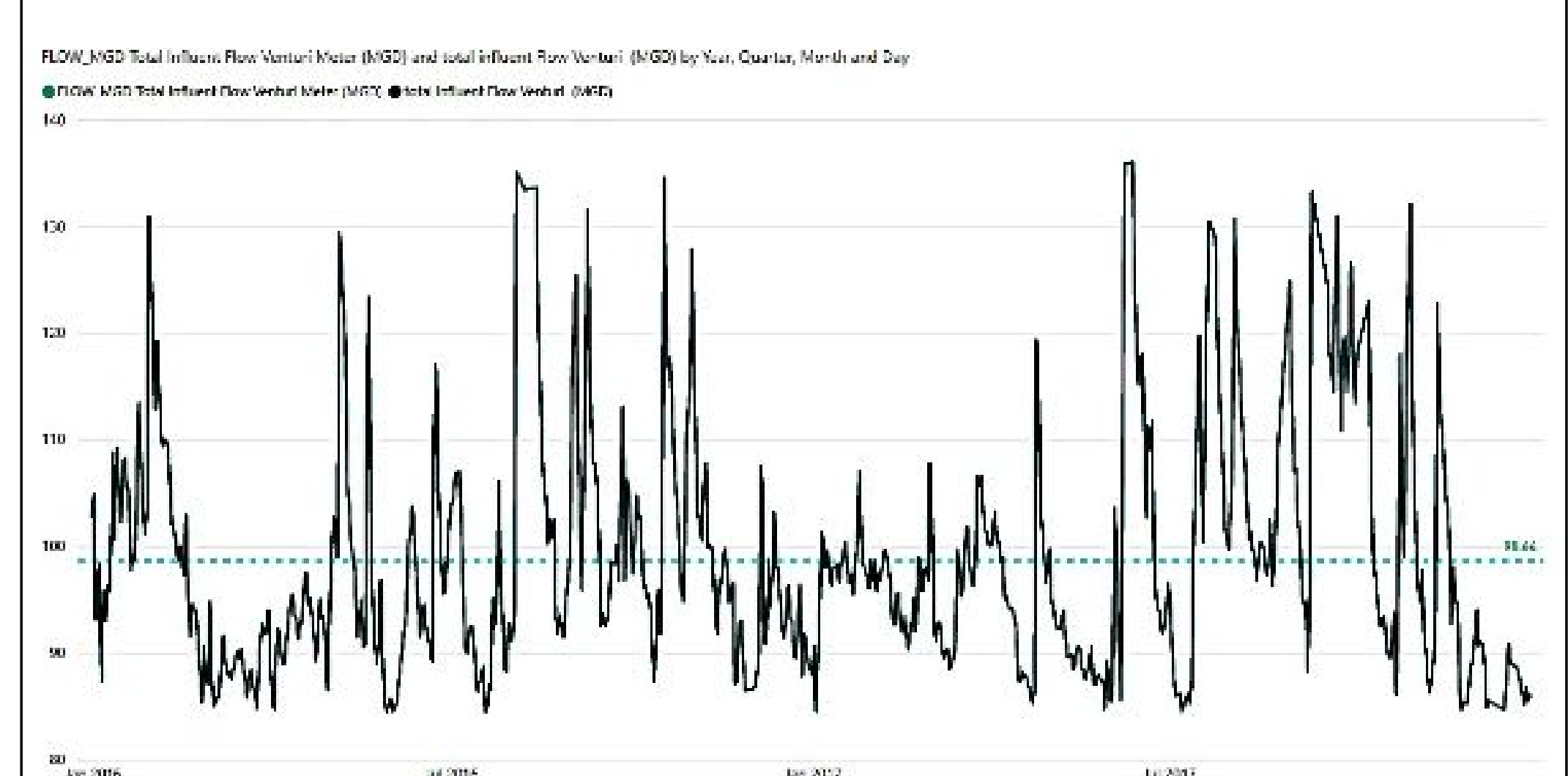




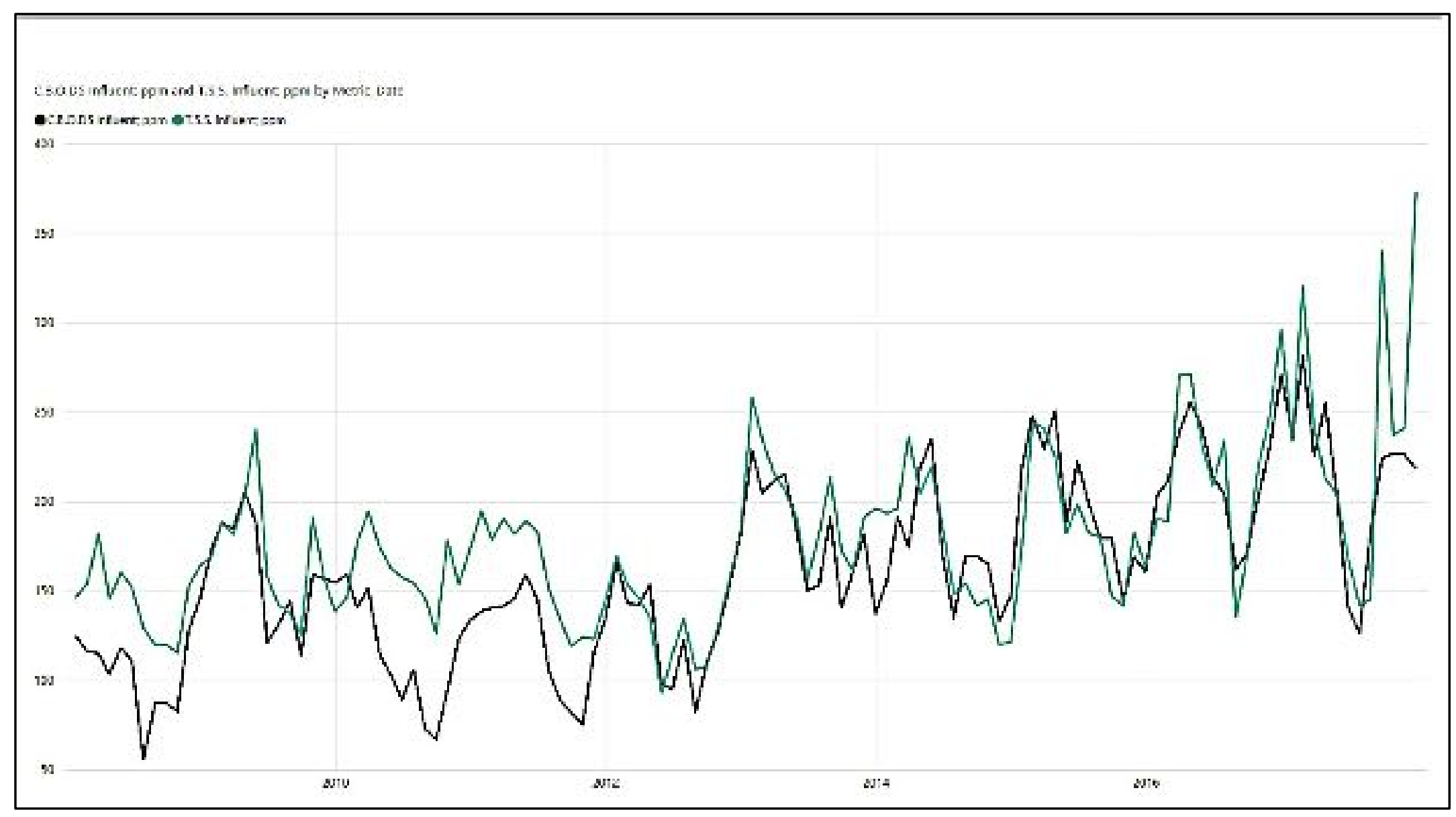

269 


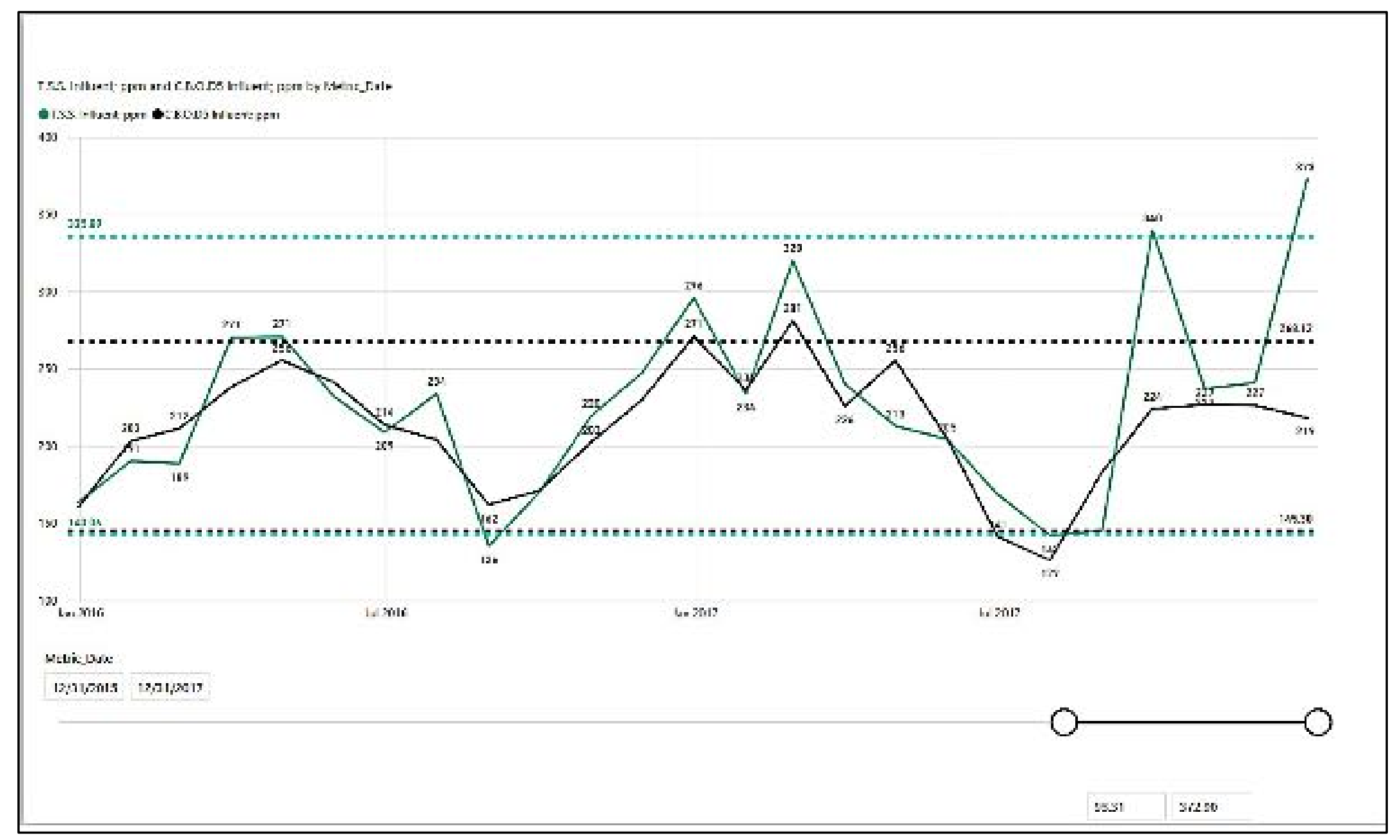




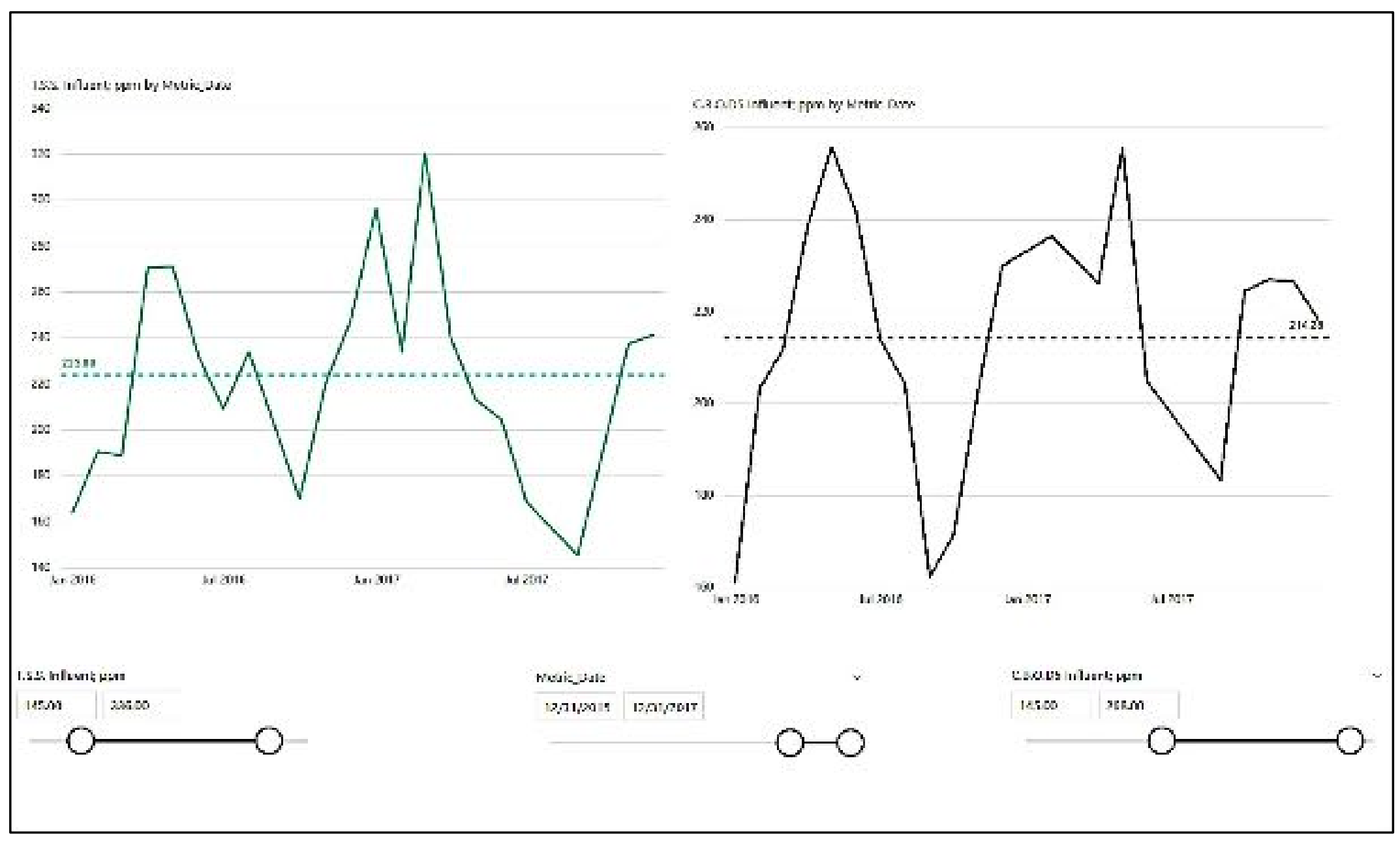




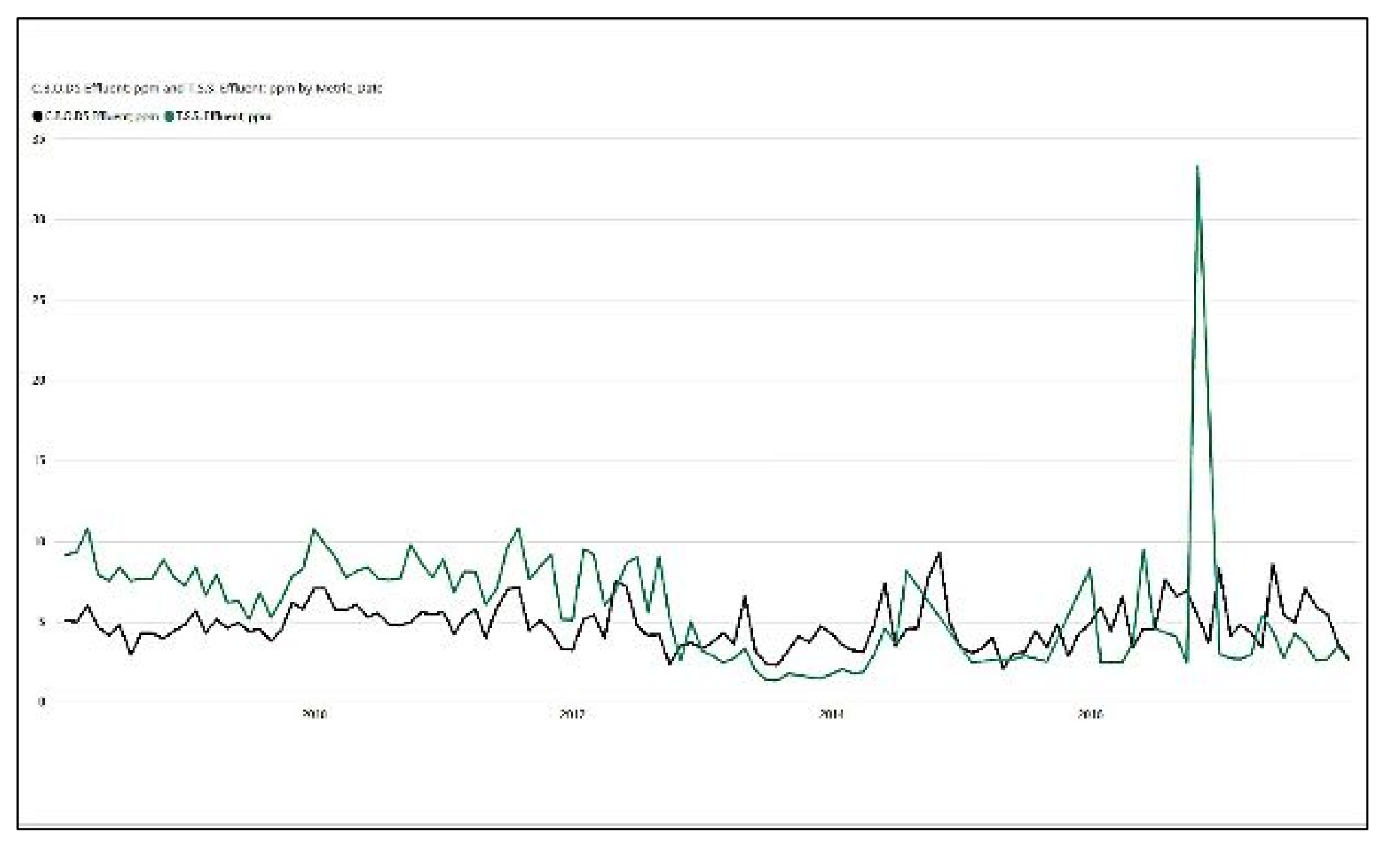




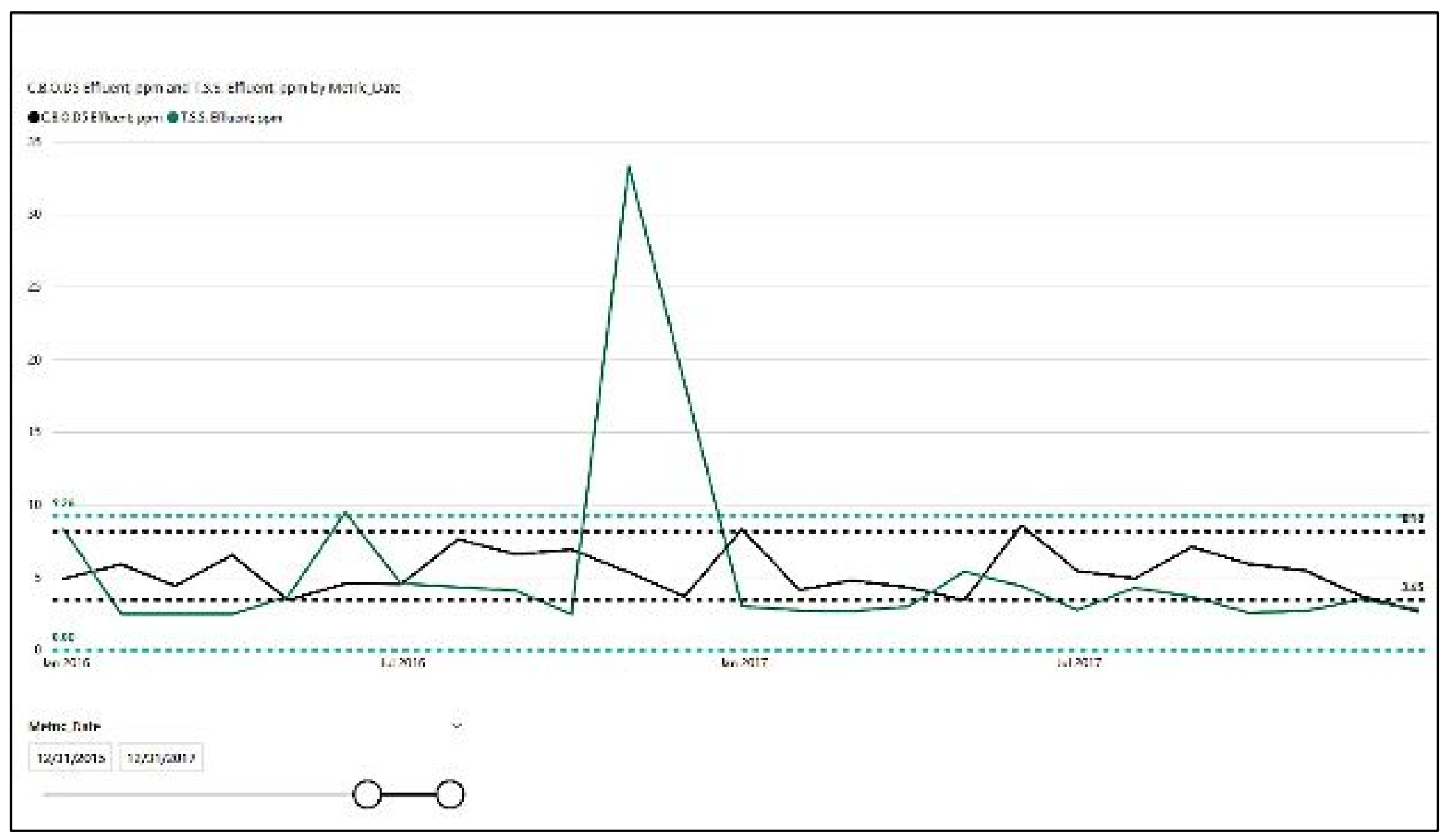




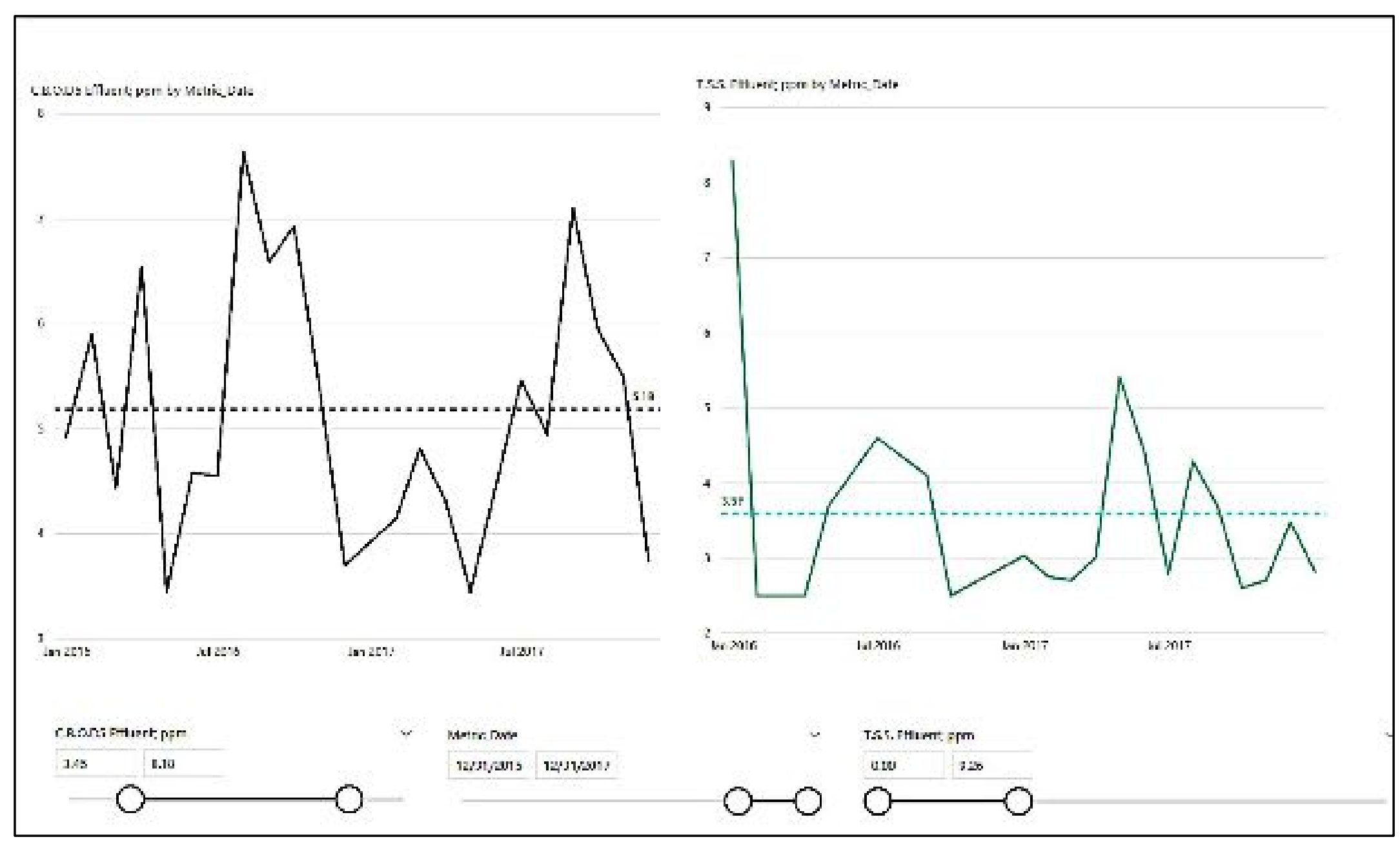

274 


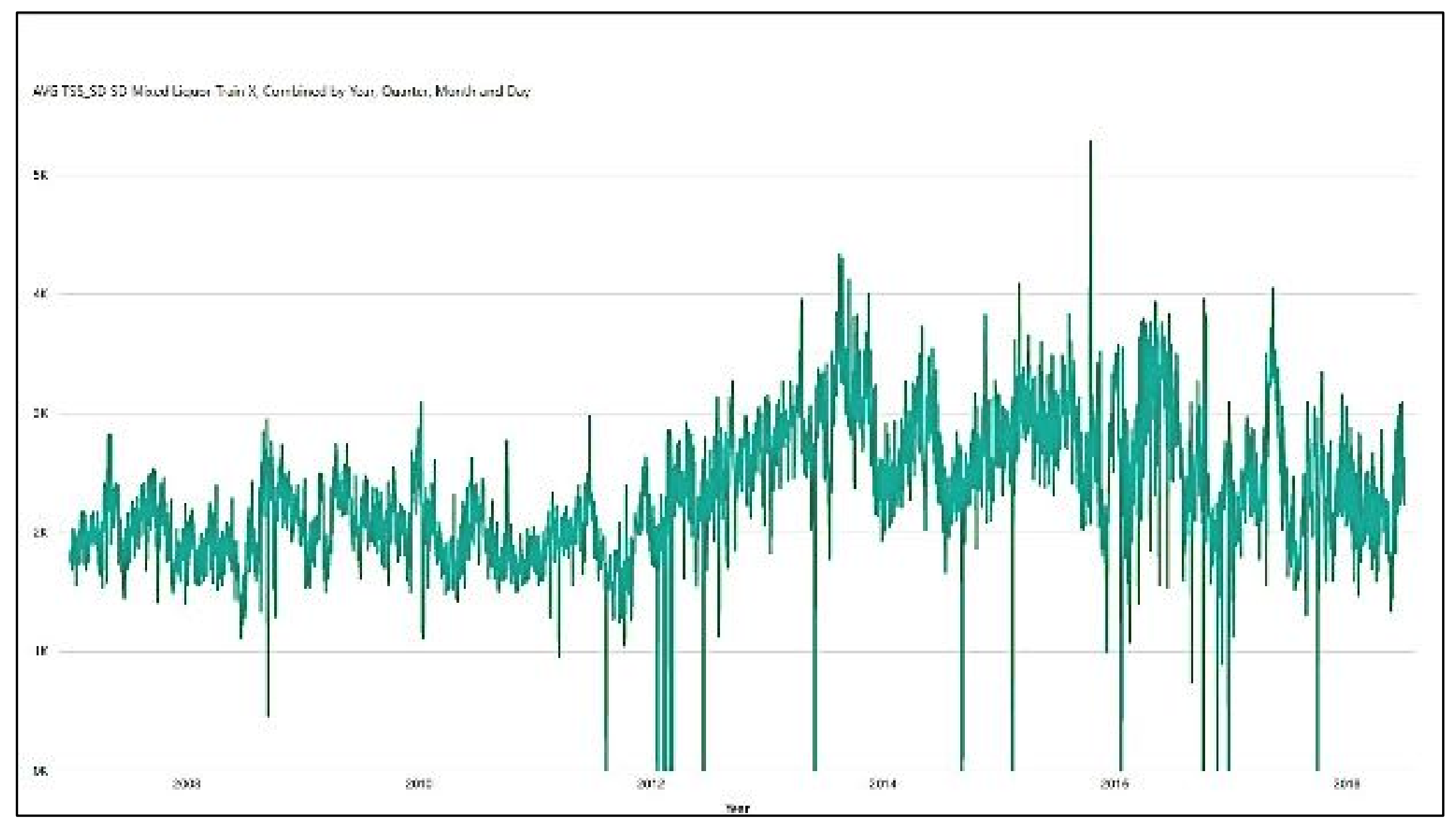




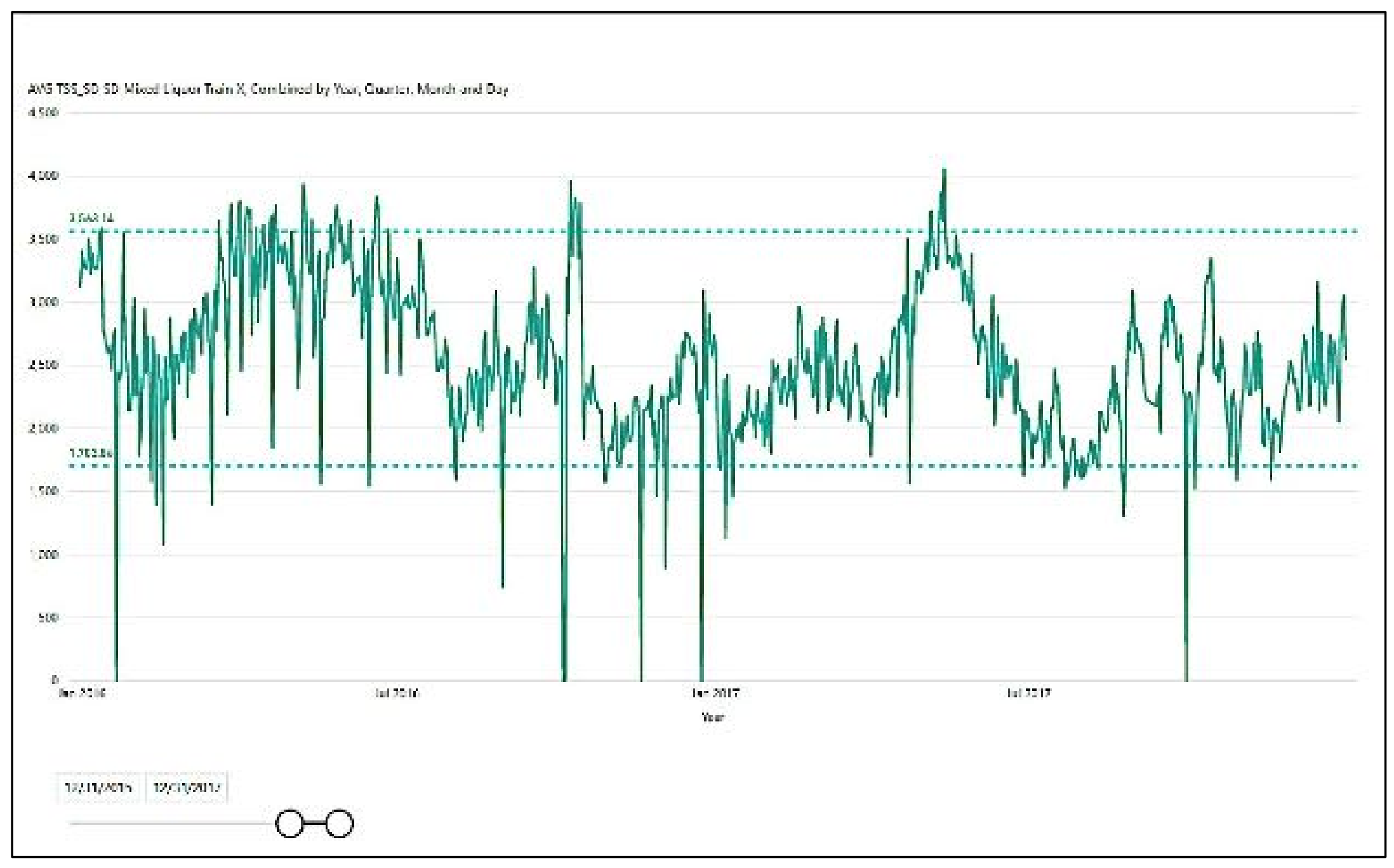




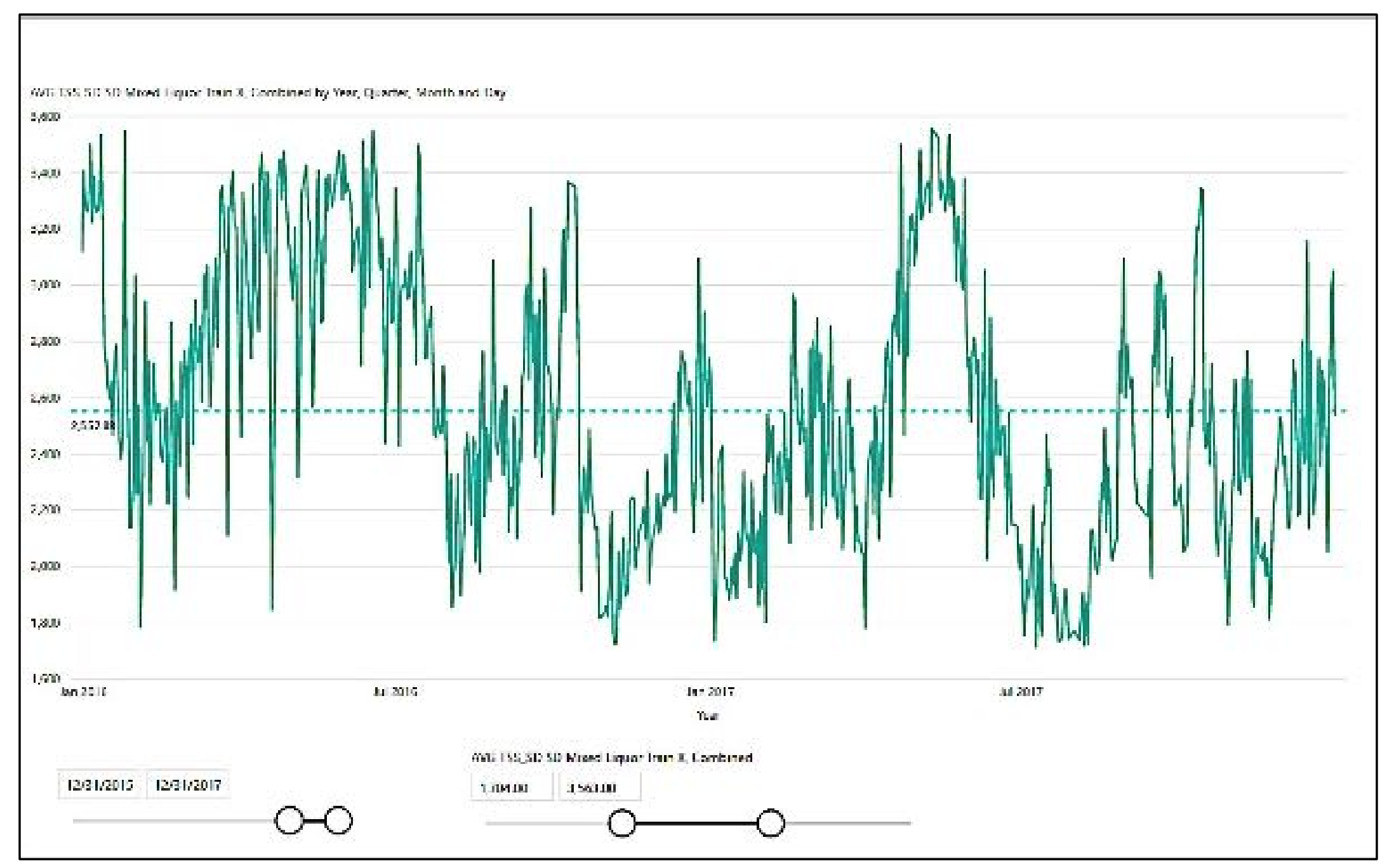




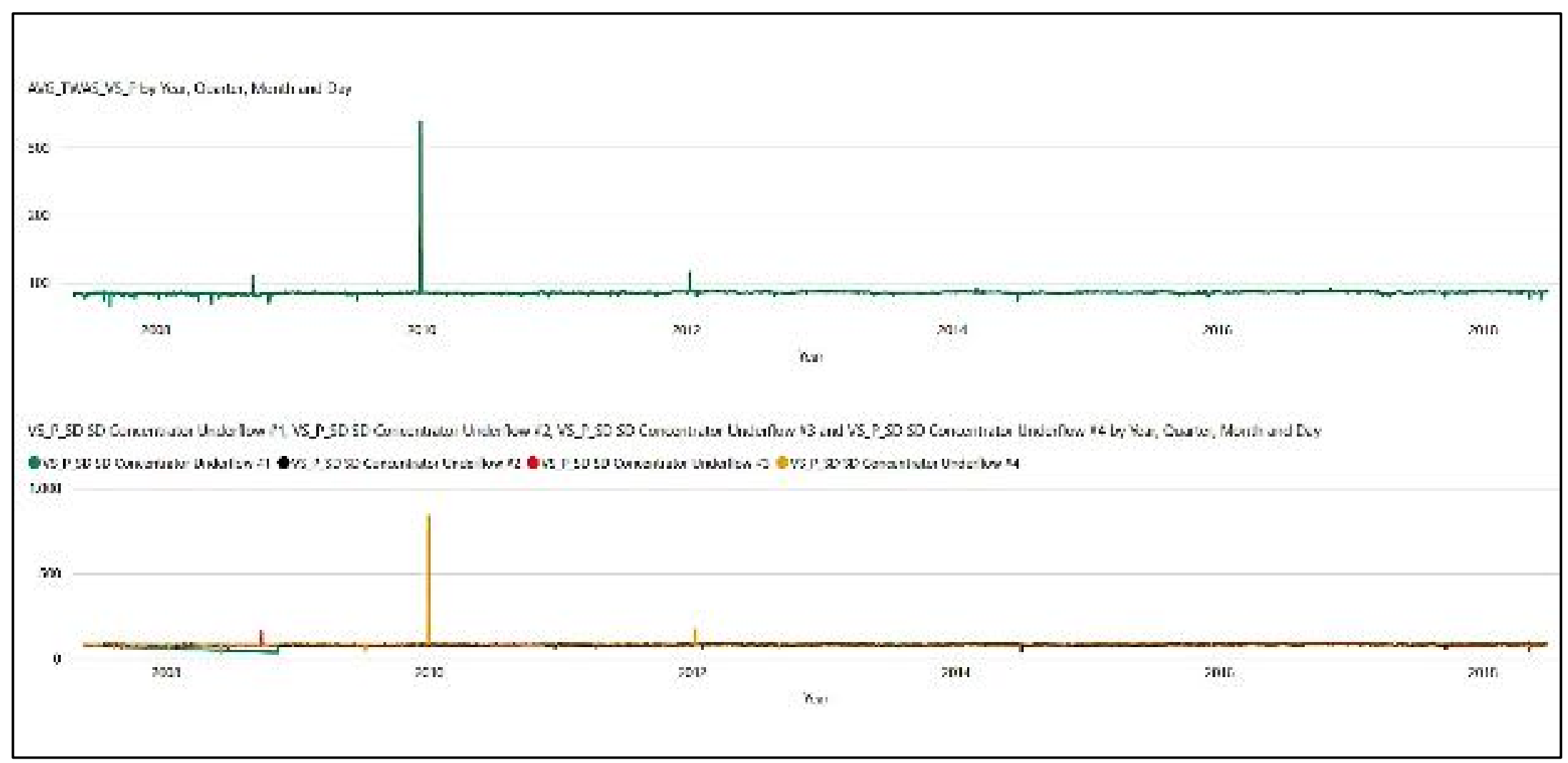




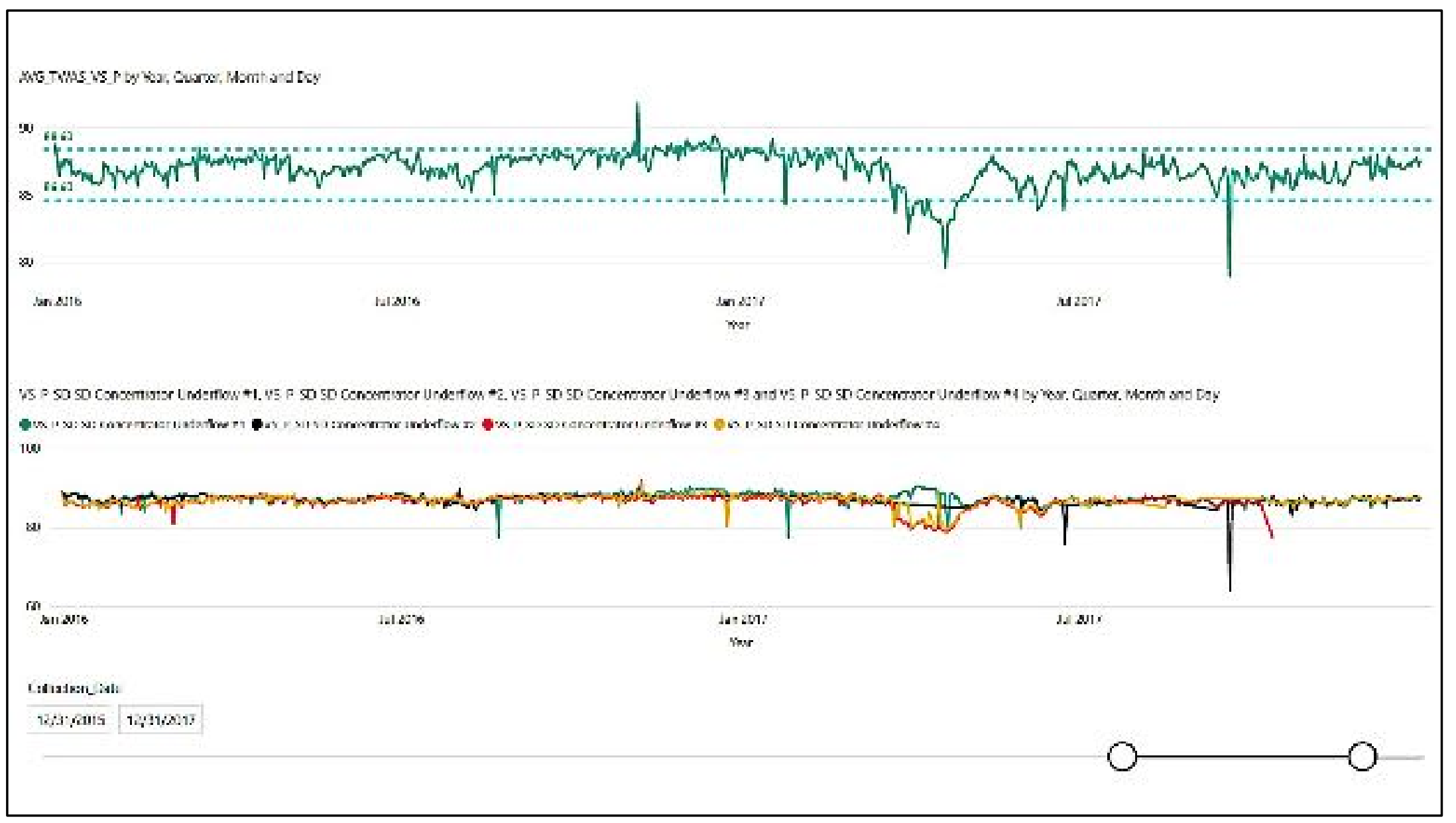




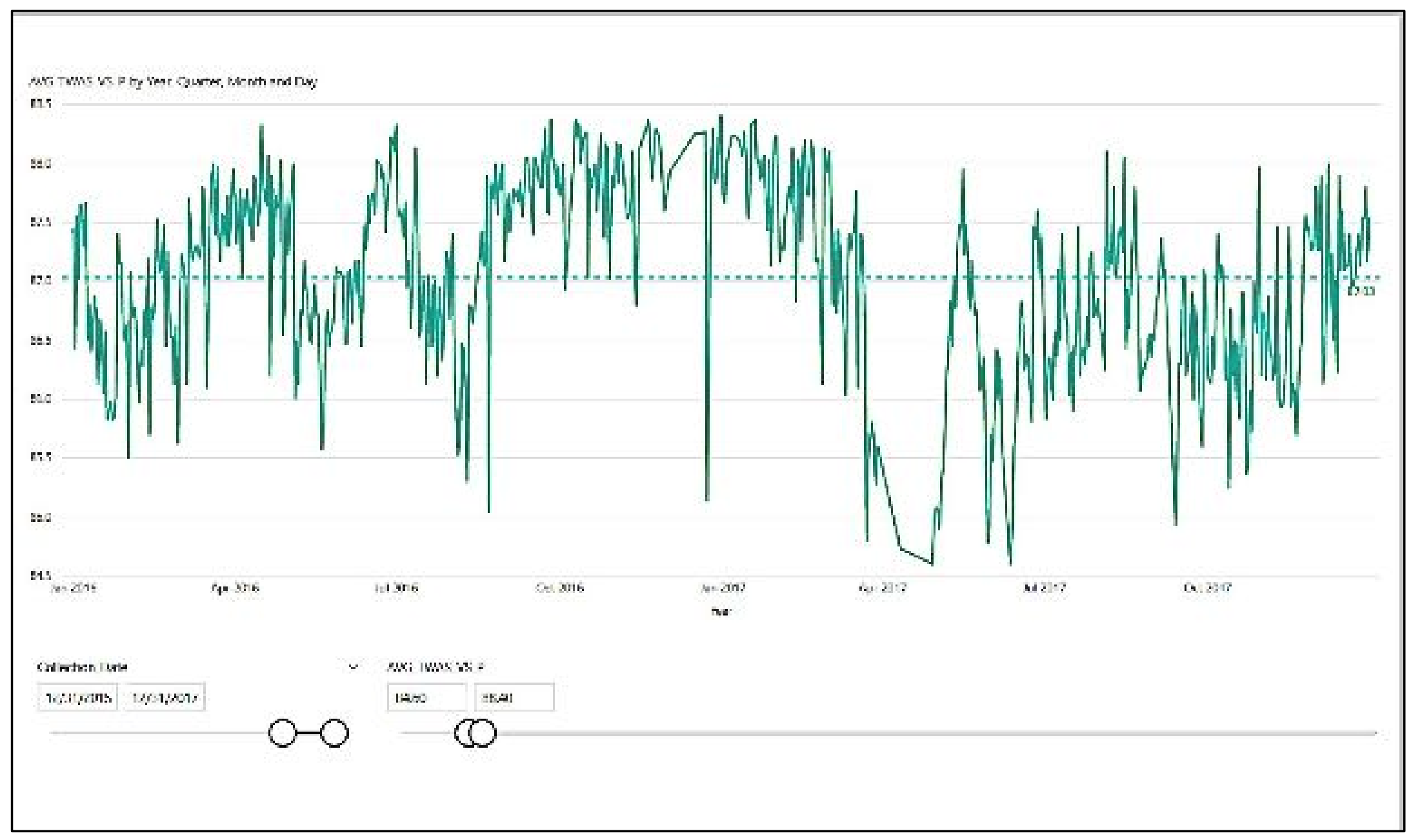

280 


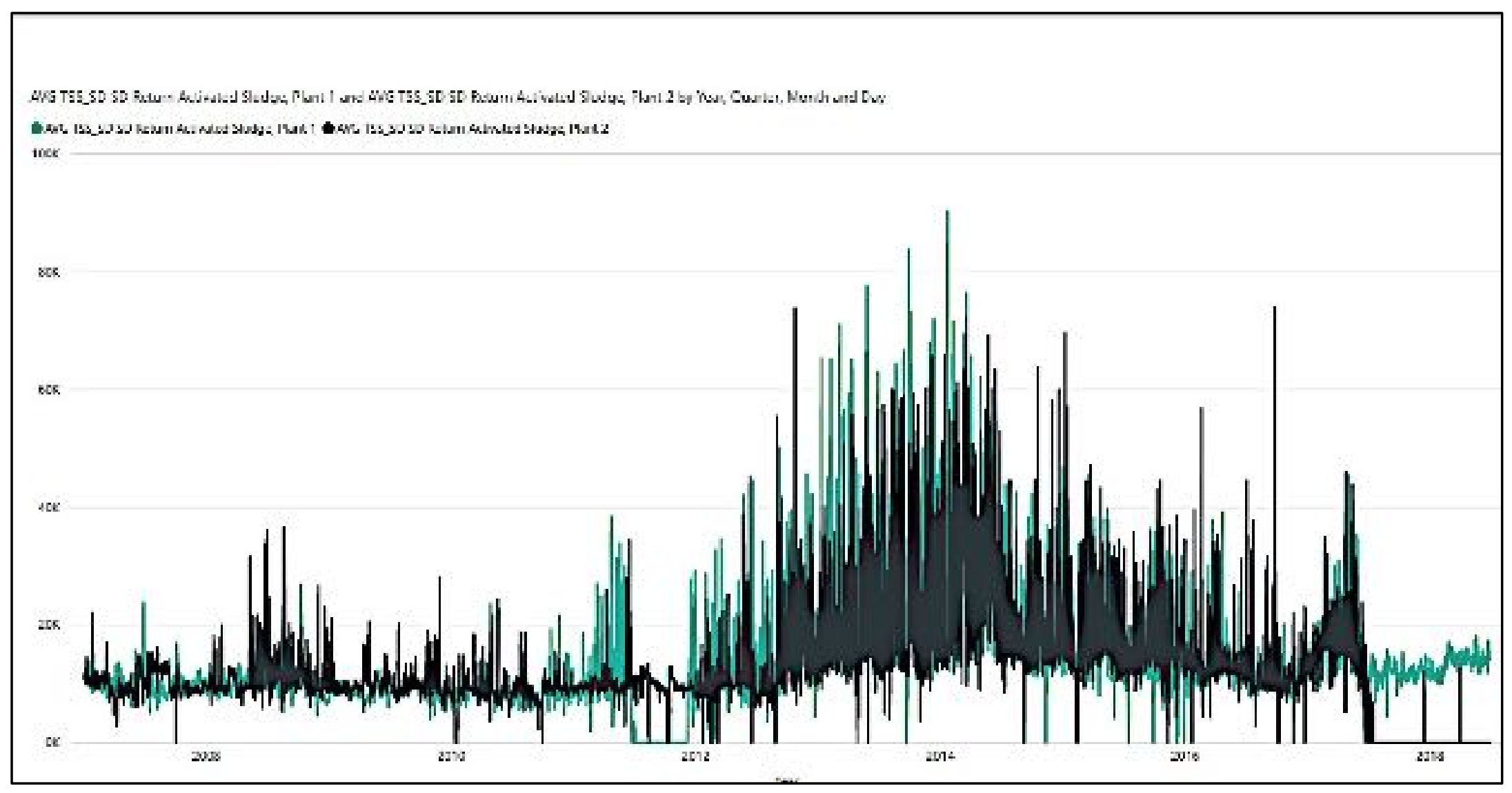




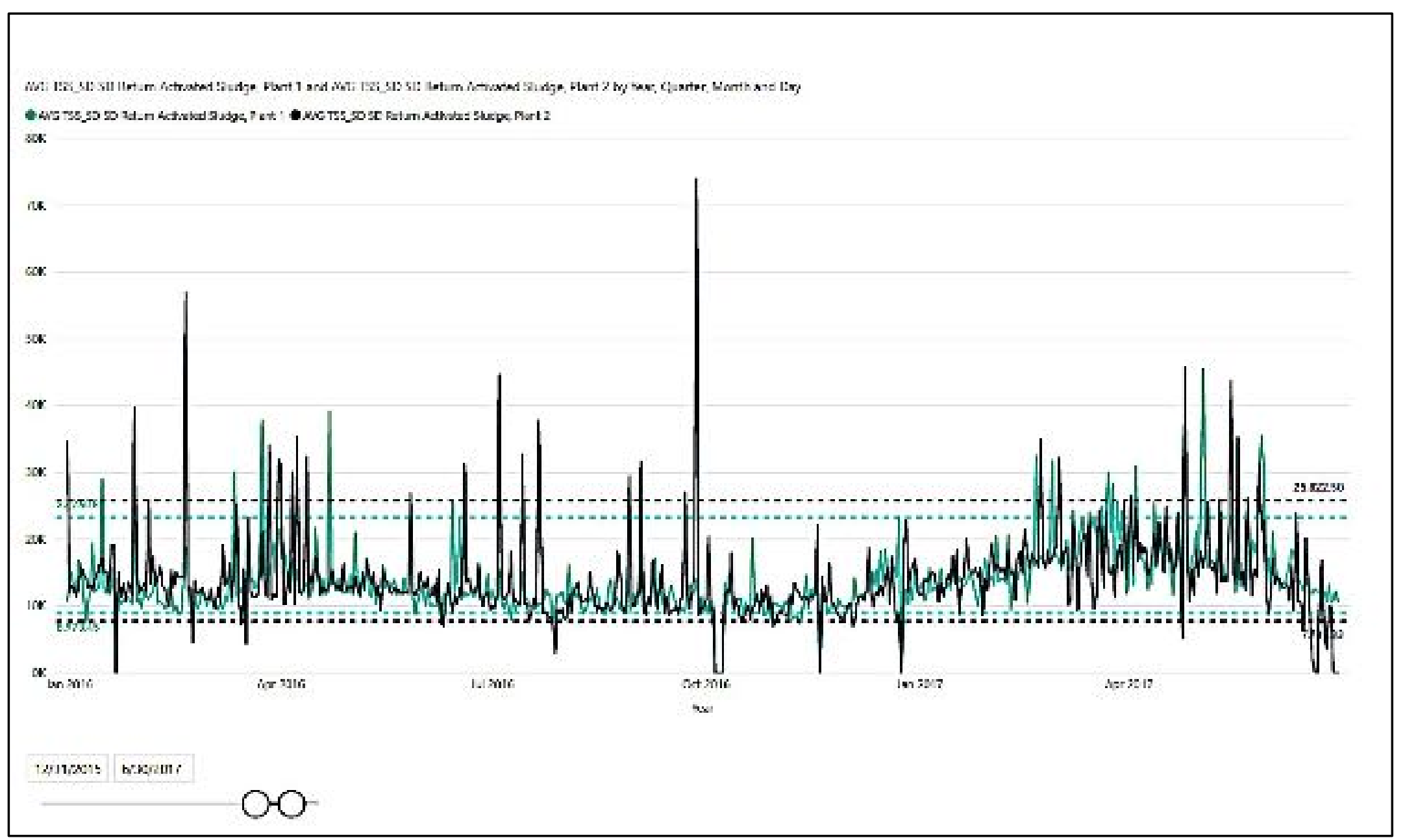




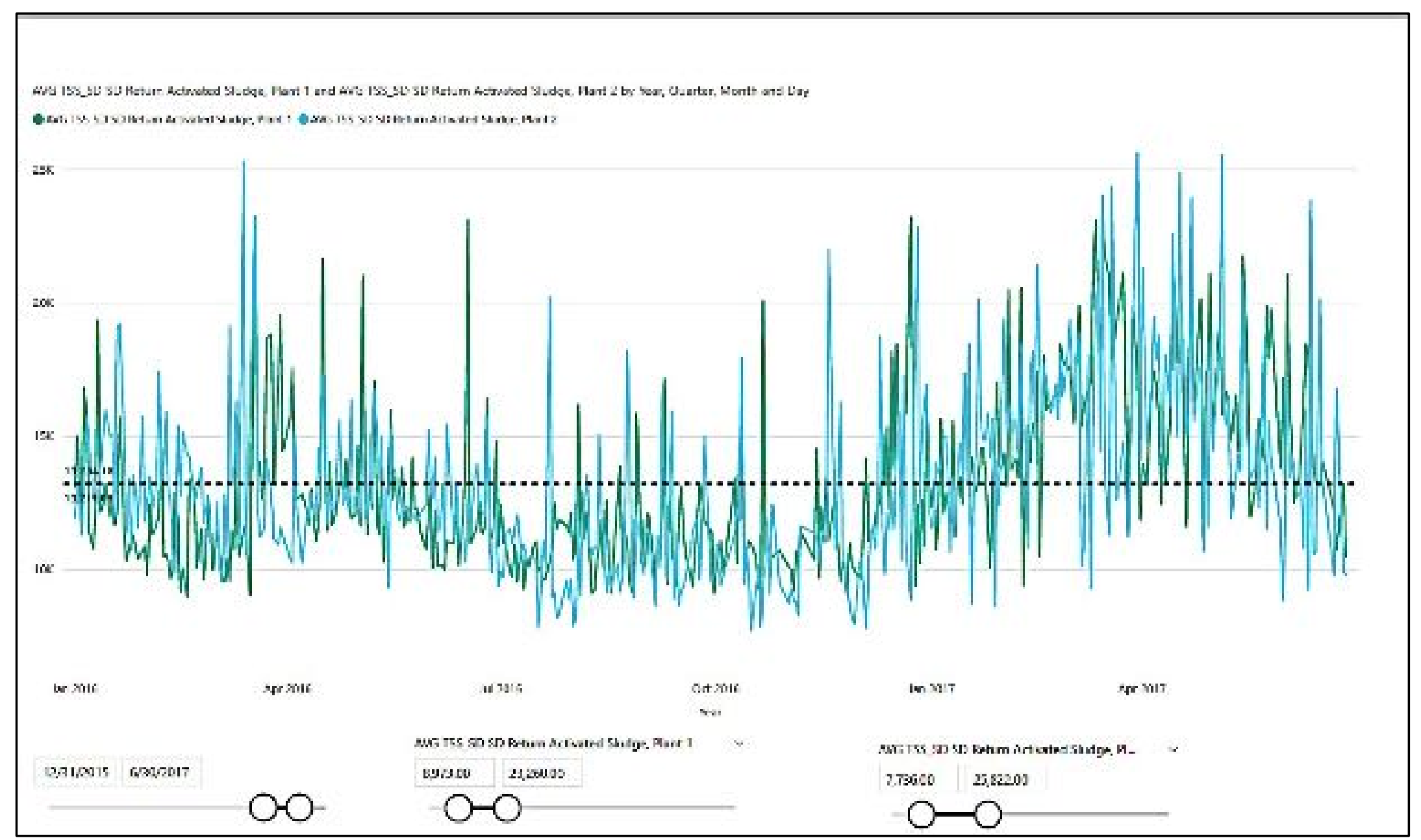




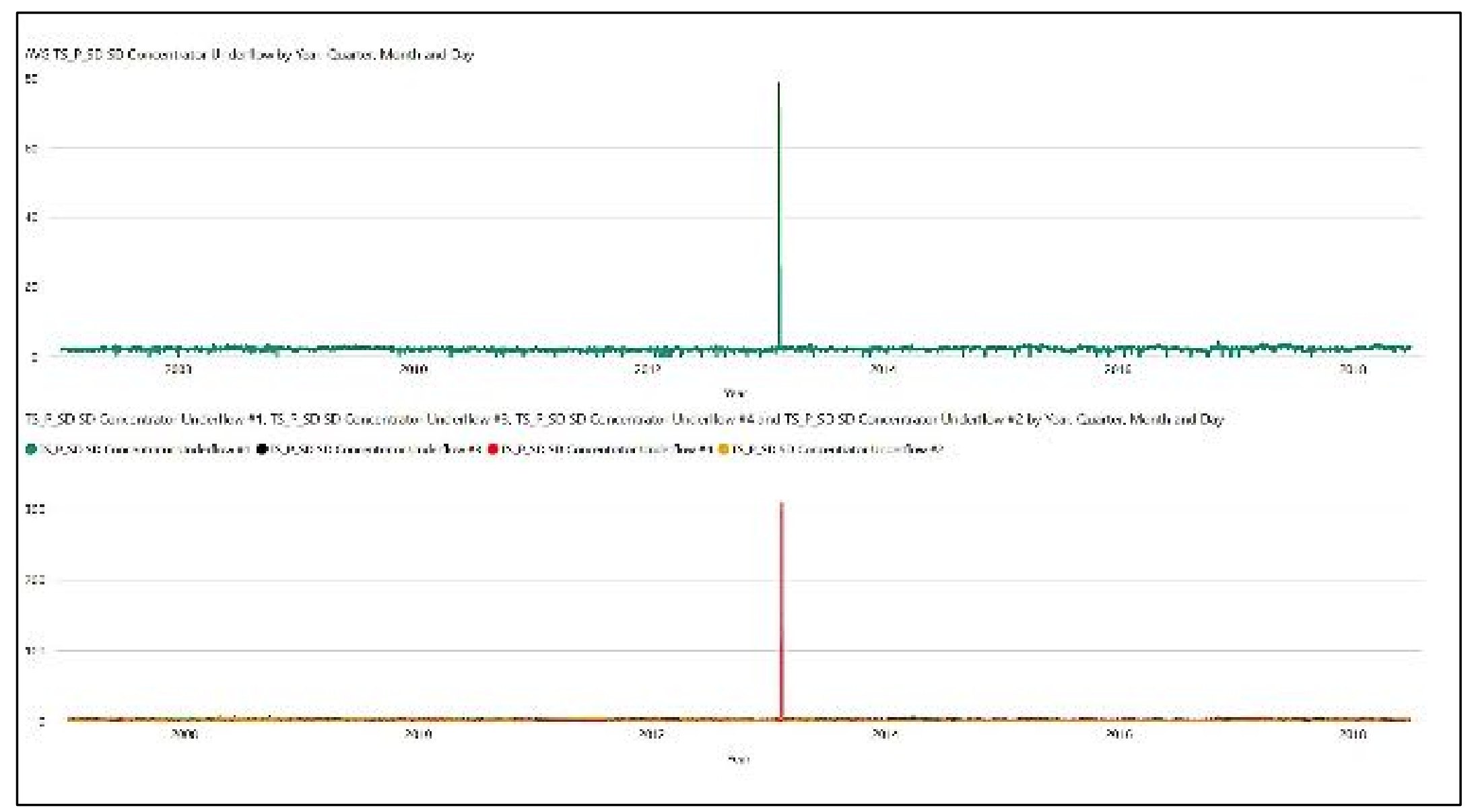




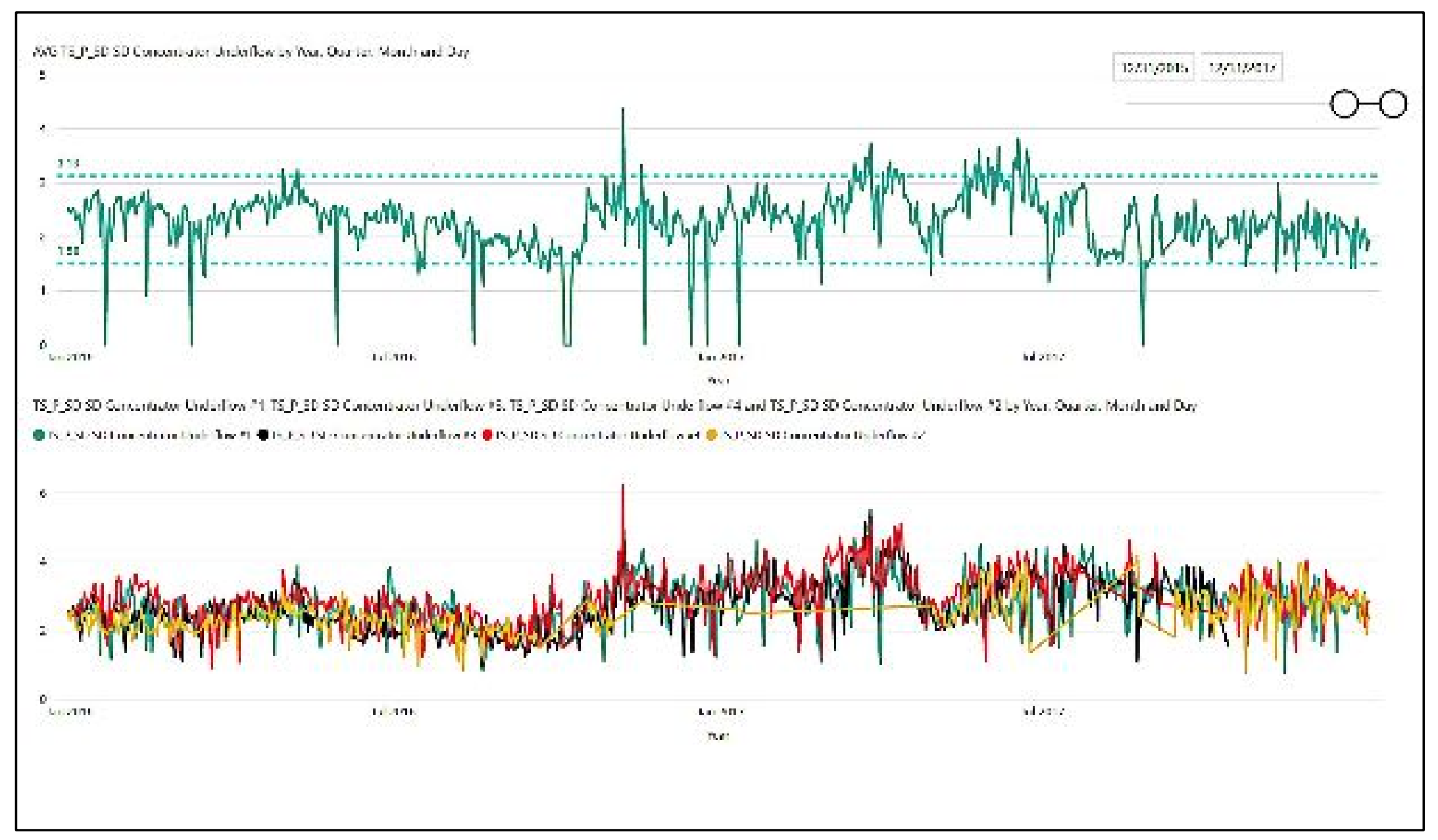




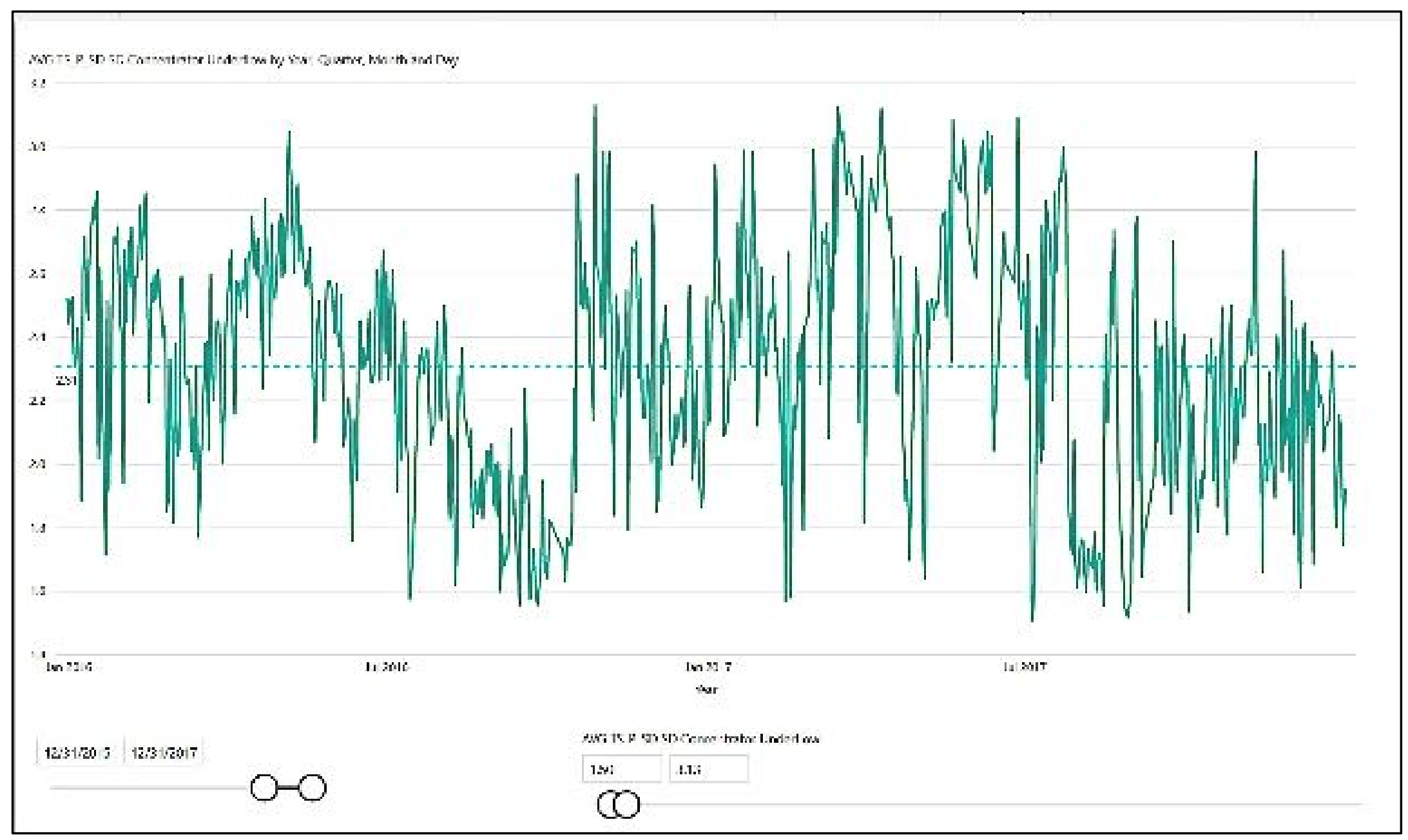

286 


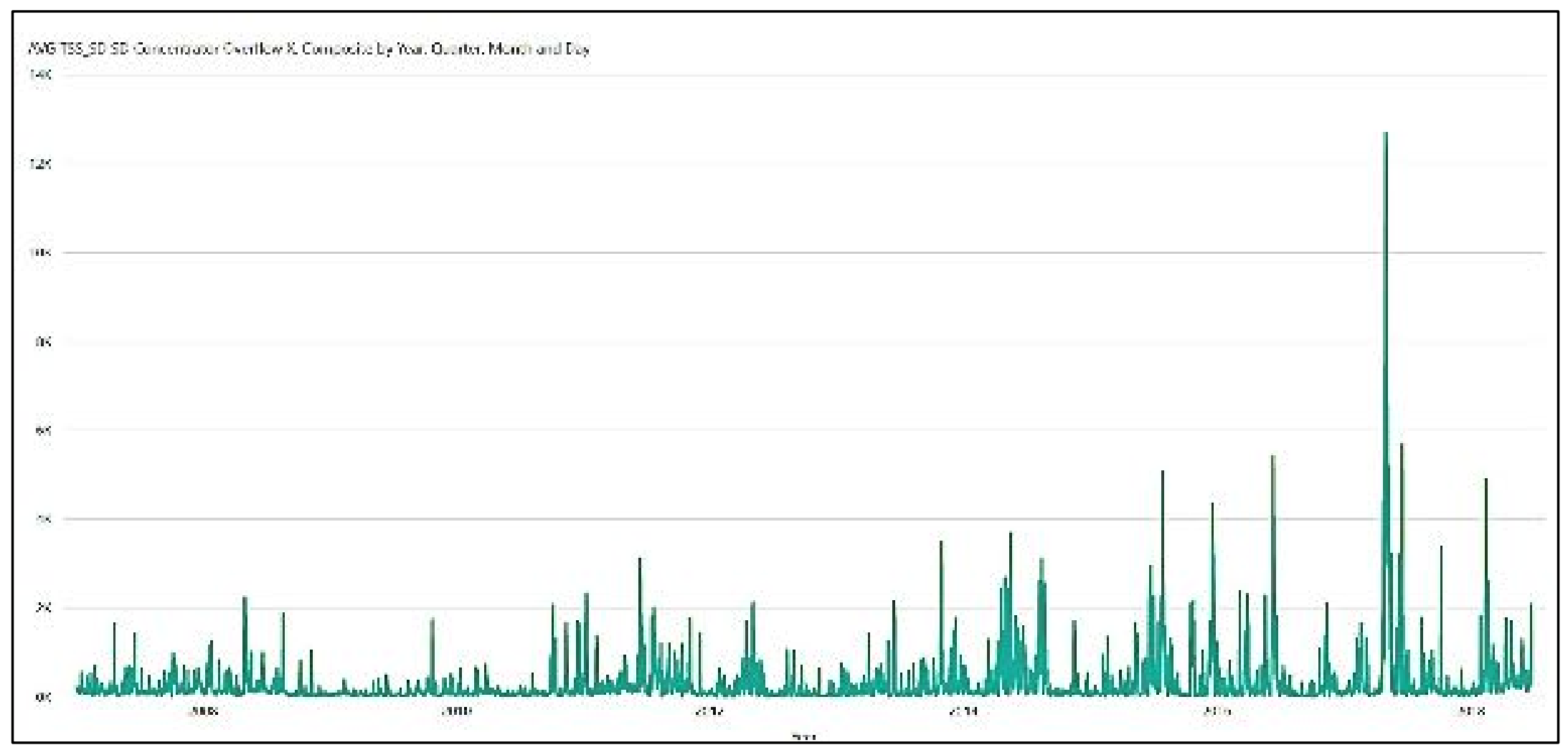




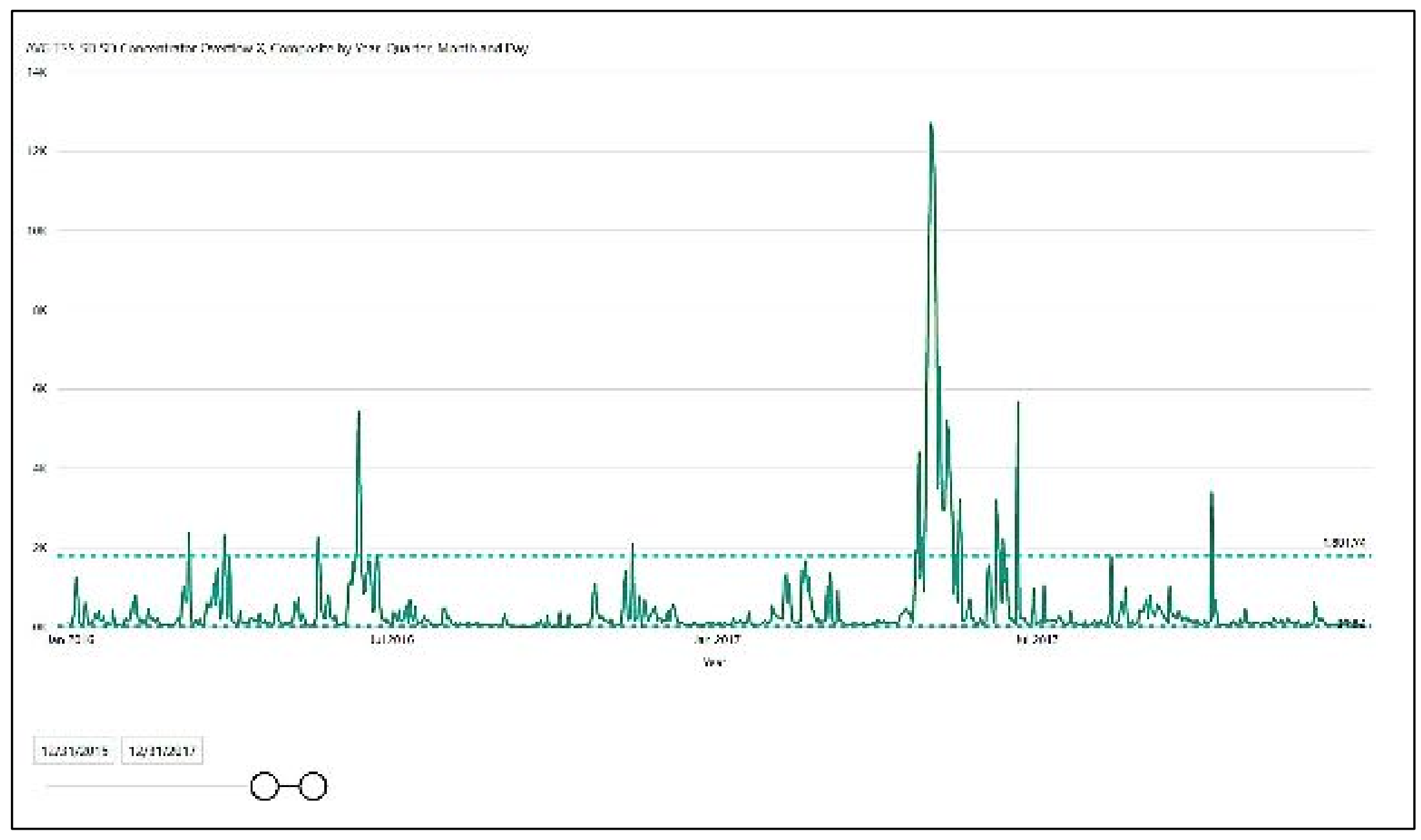




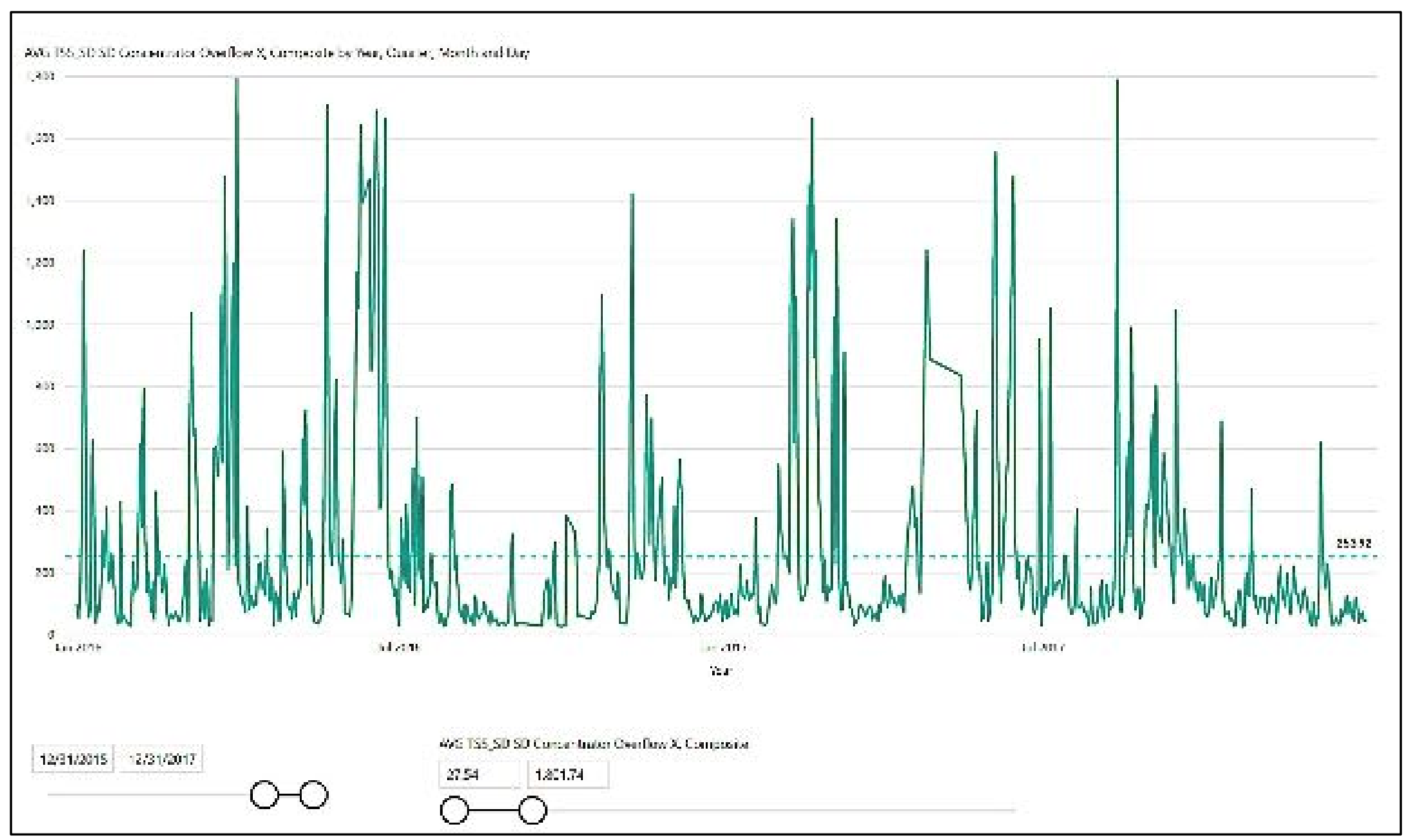

289 







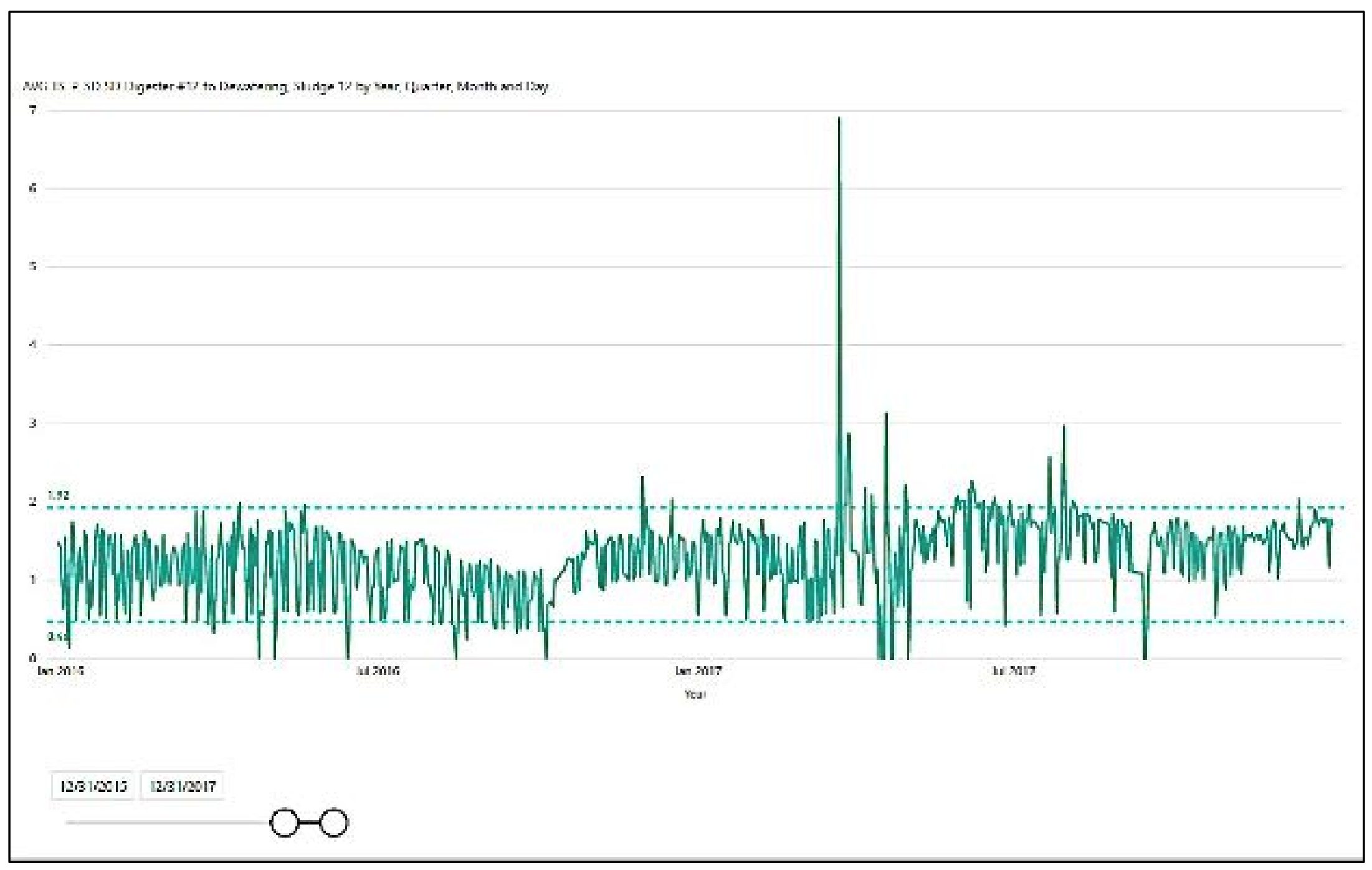




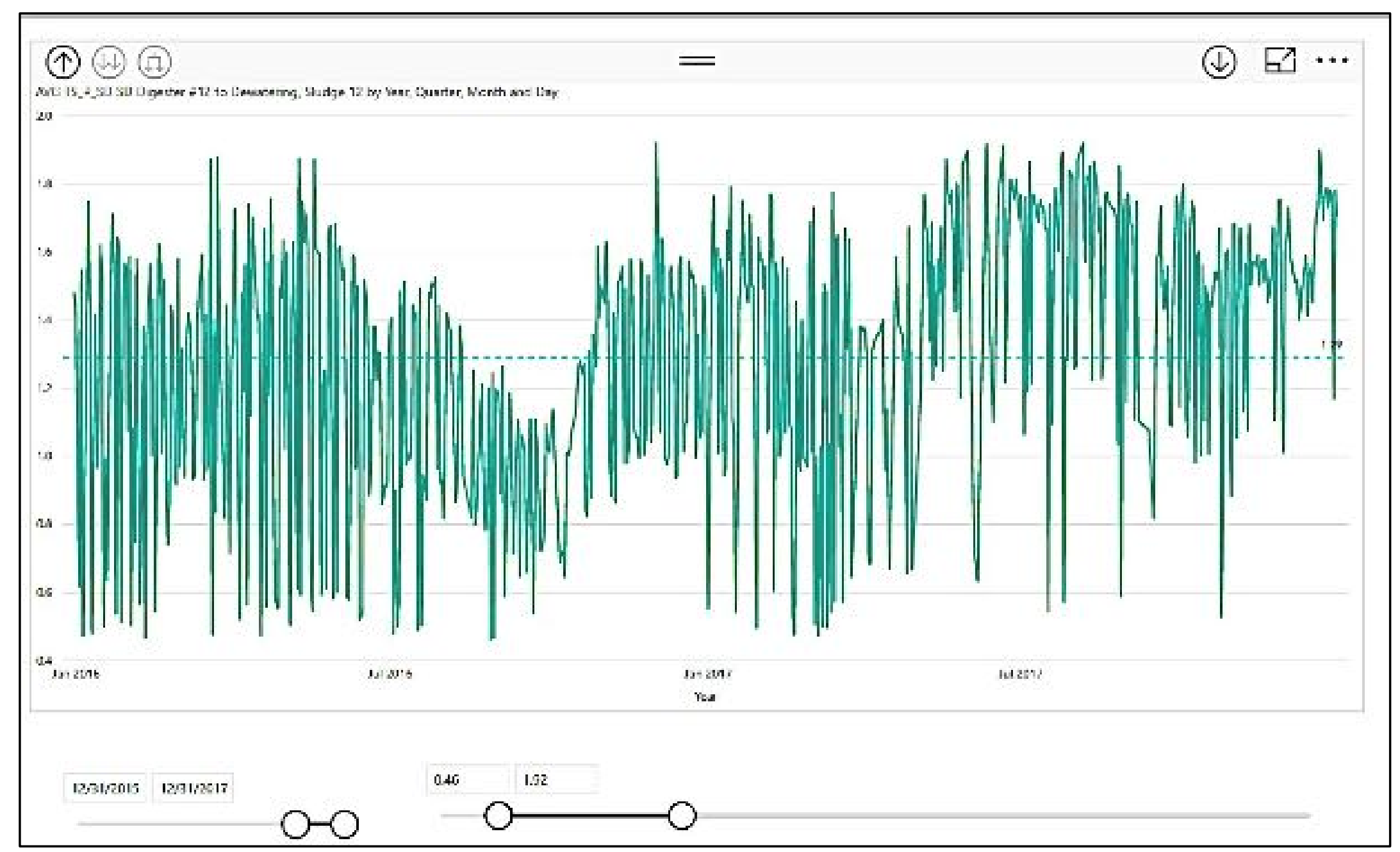




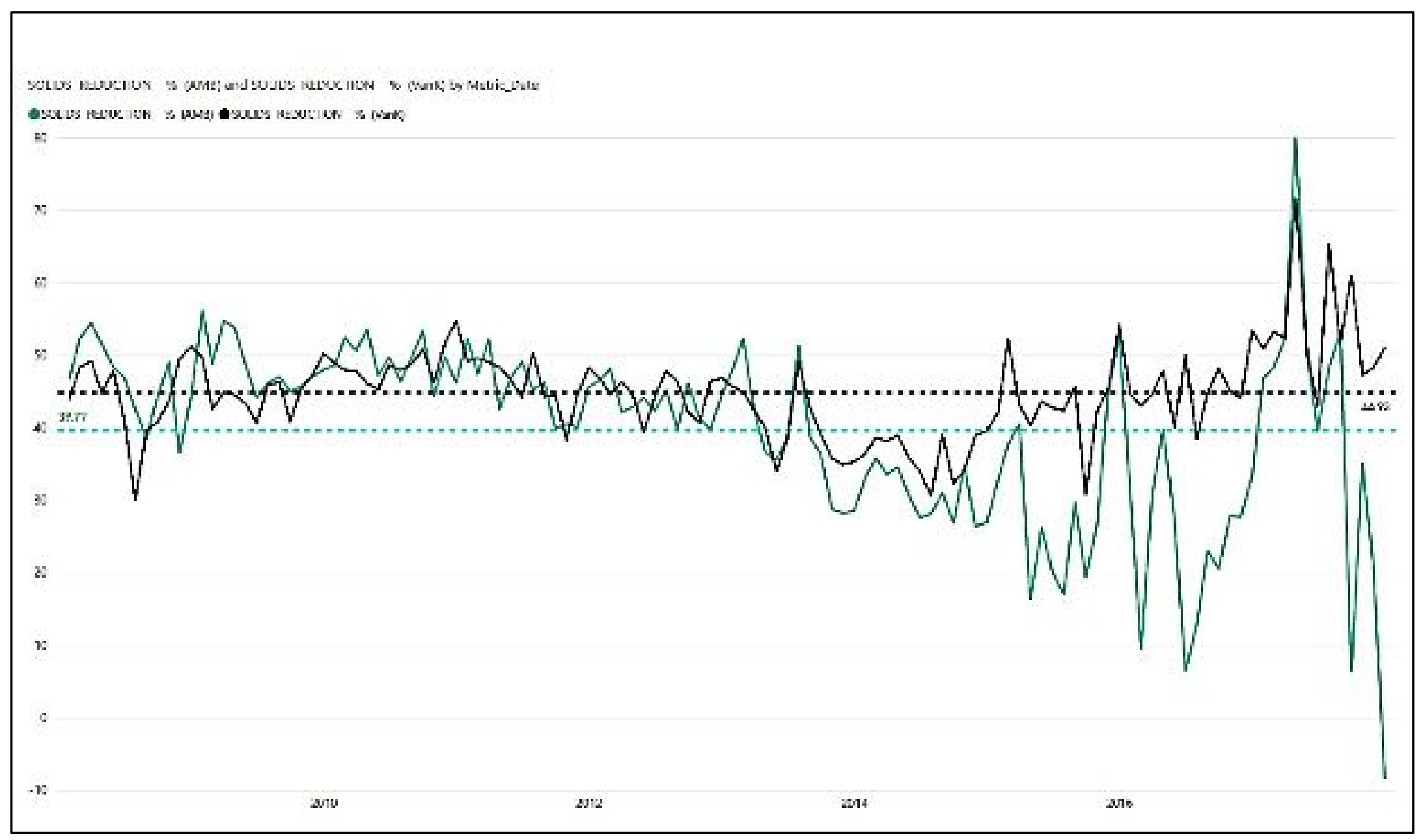




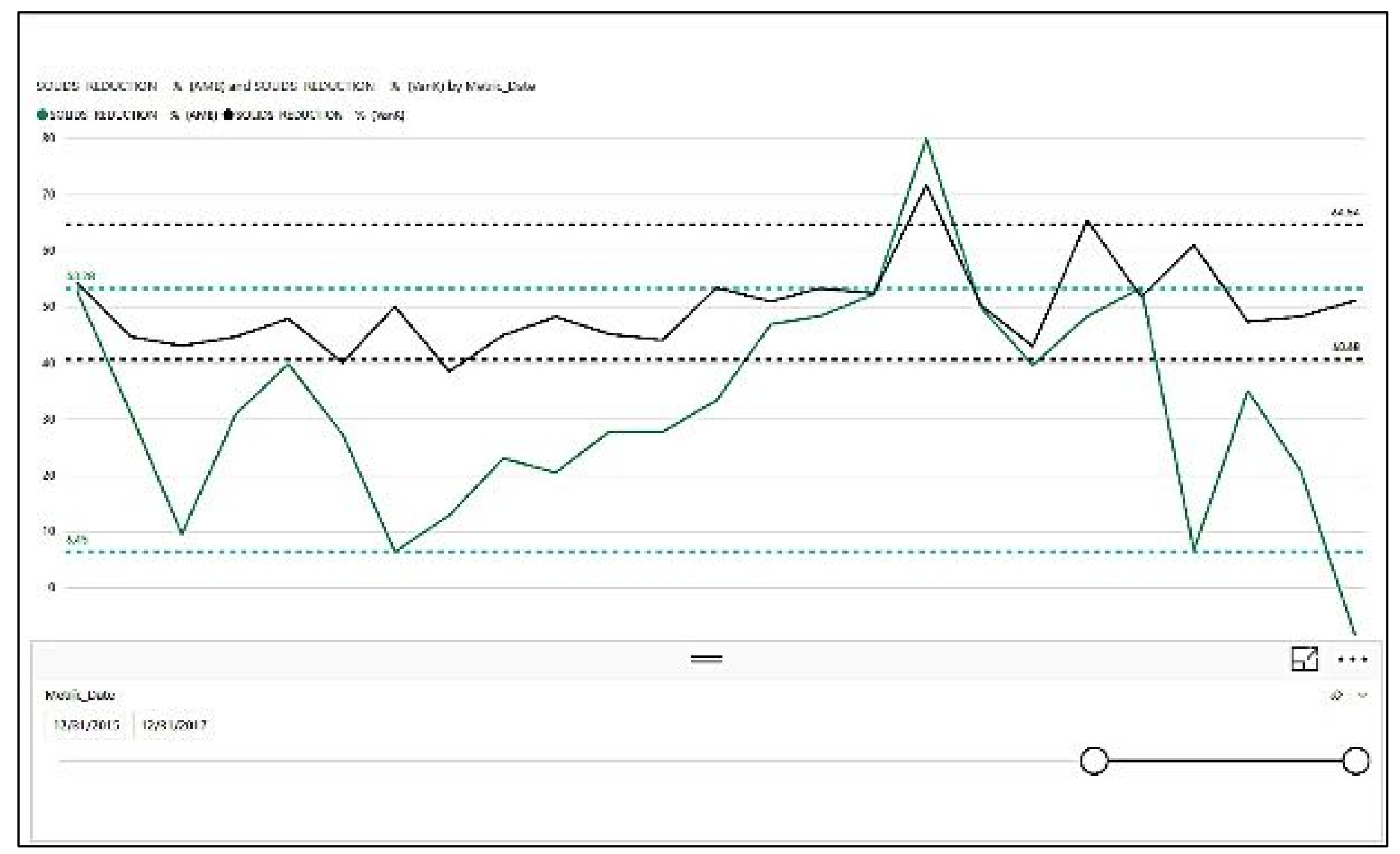




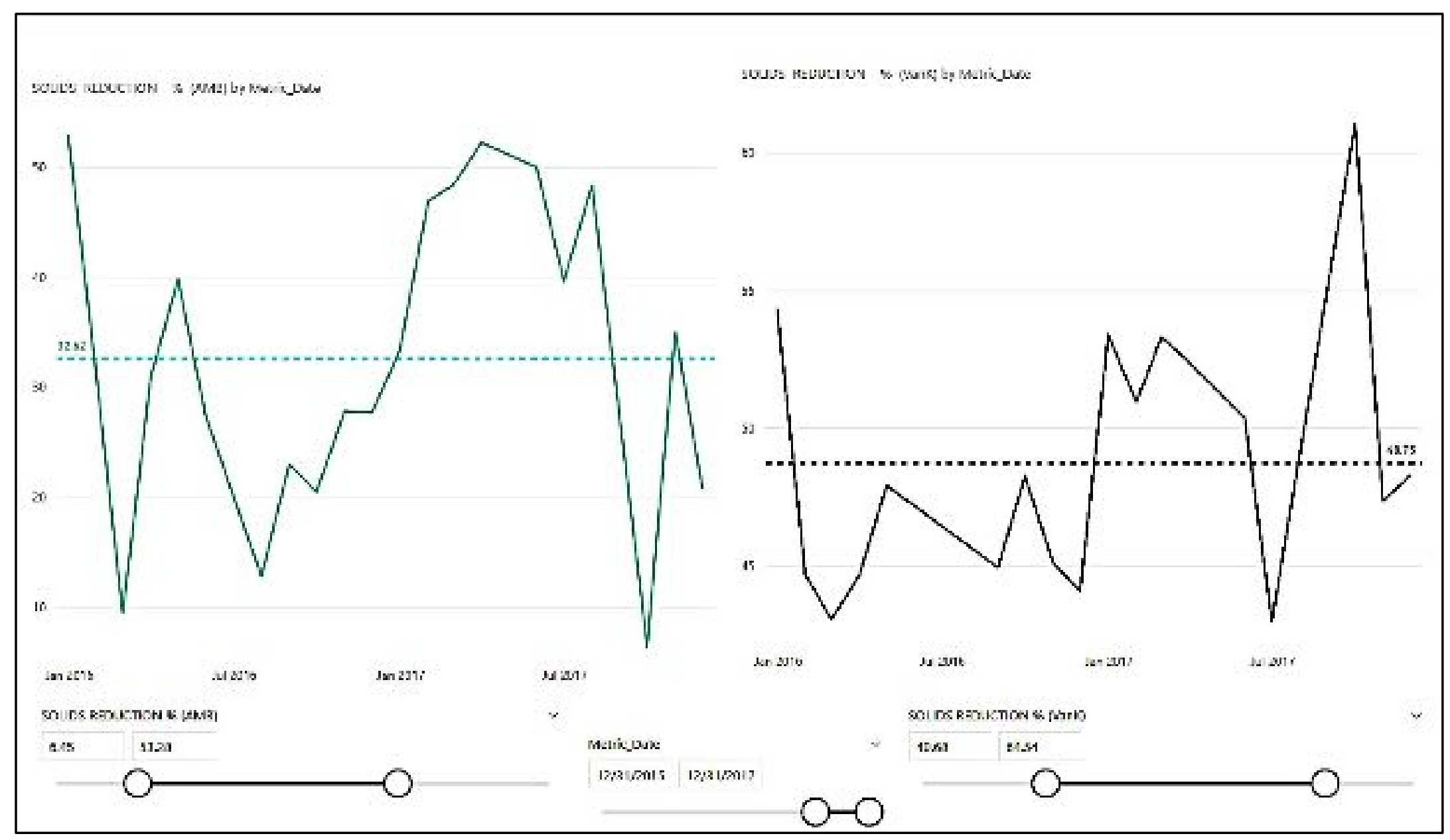




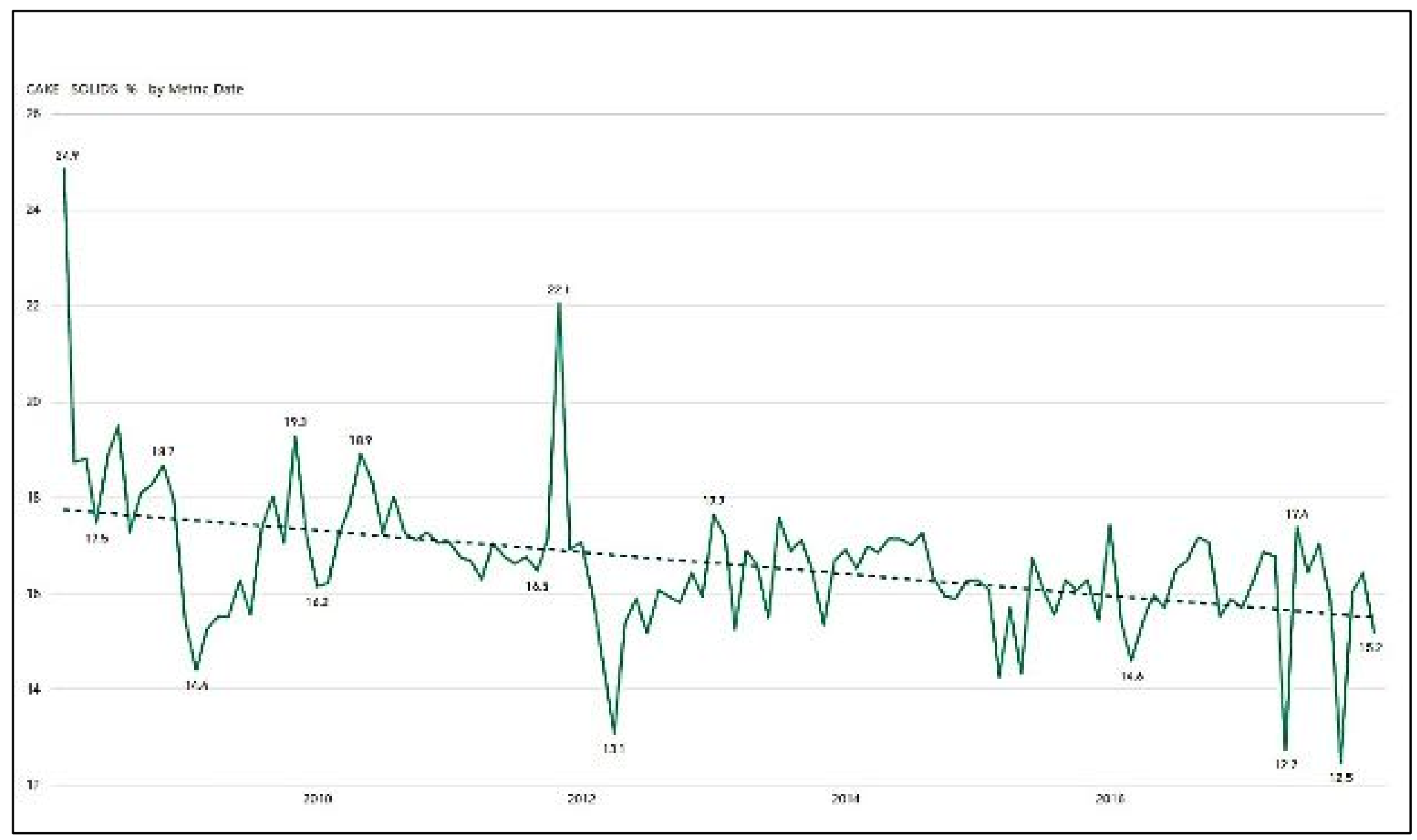

296 


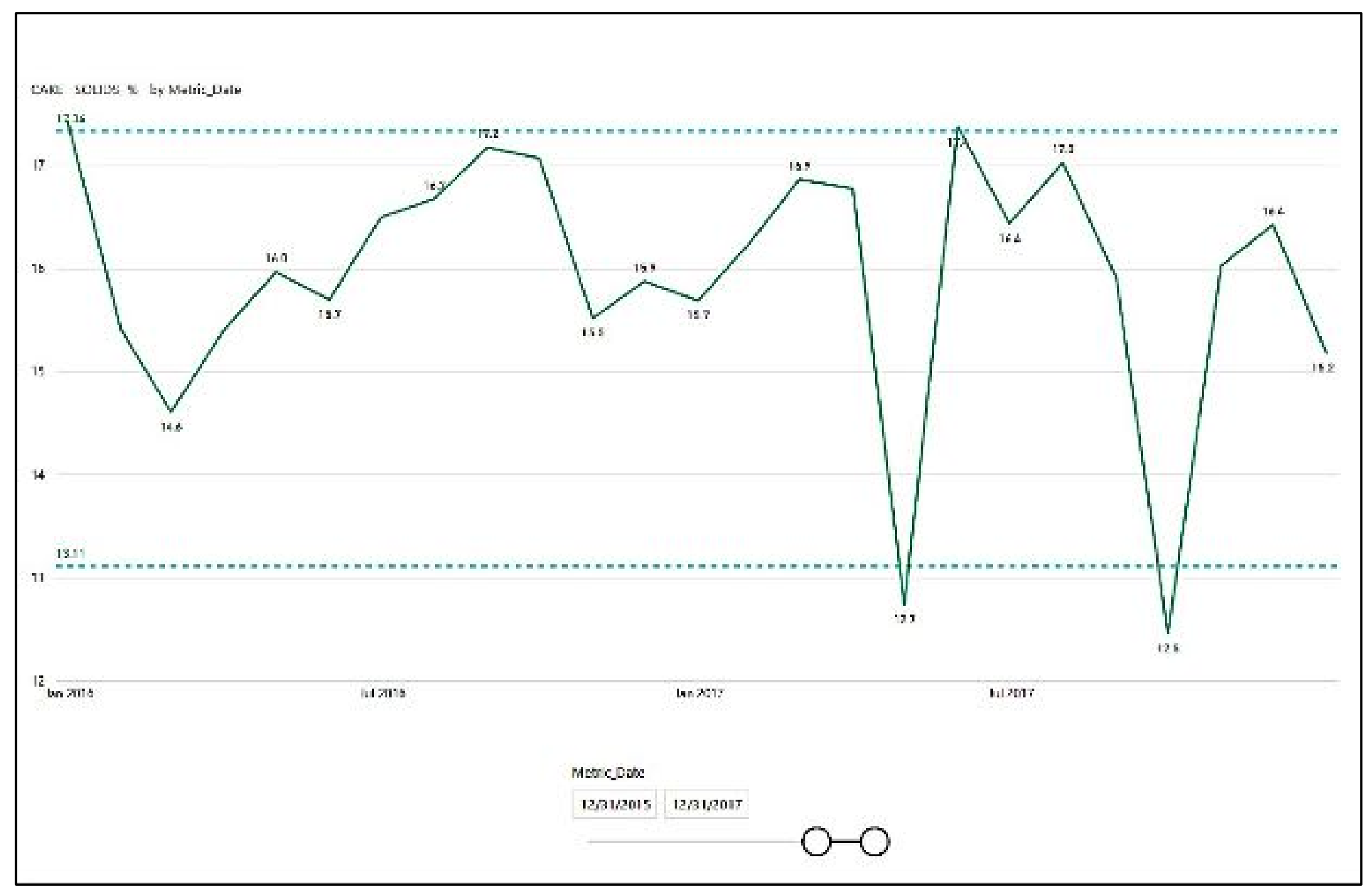




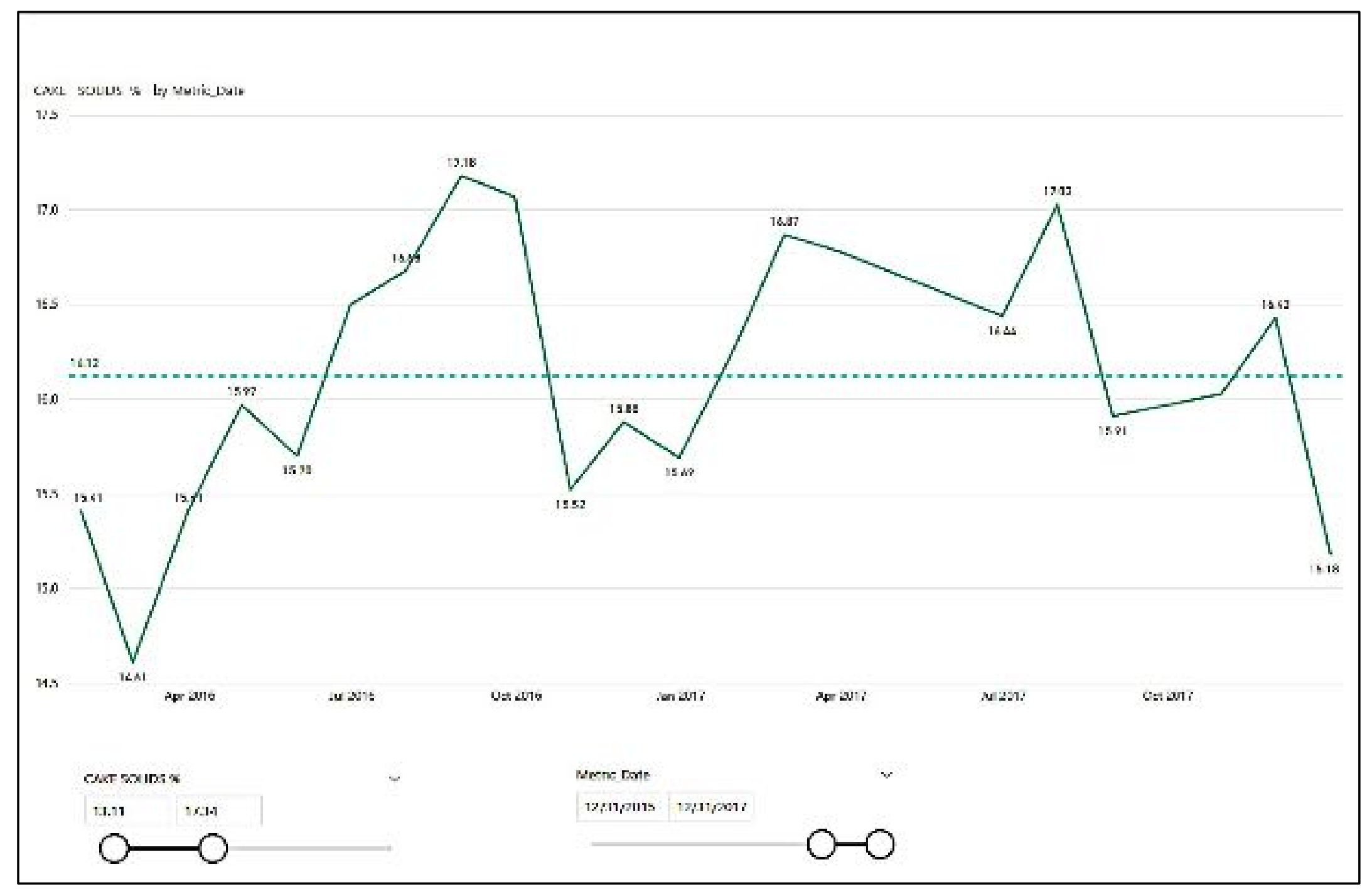




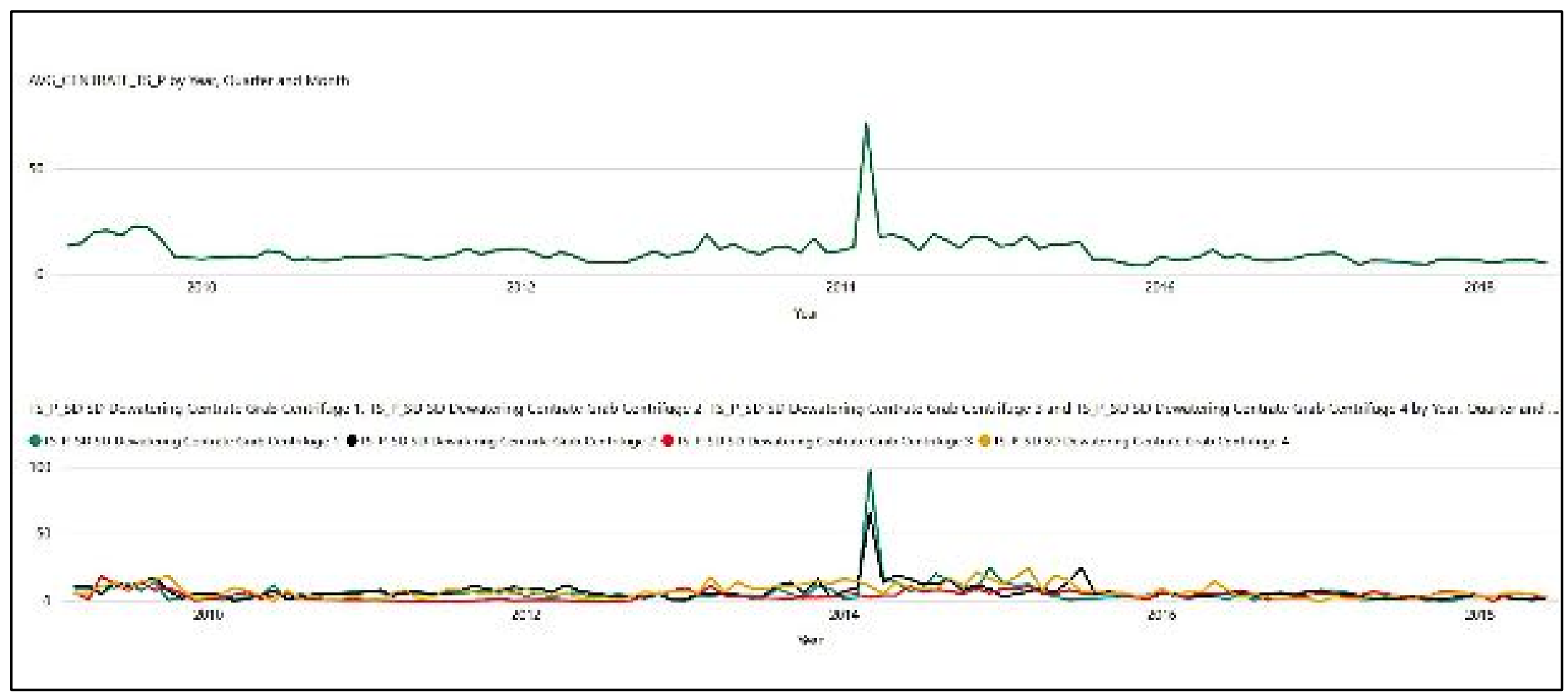

299 


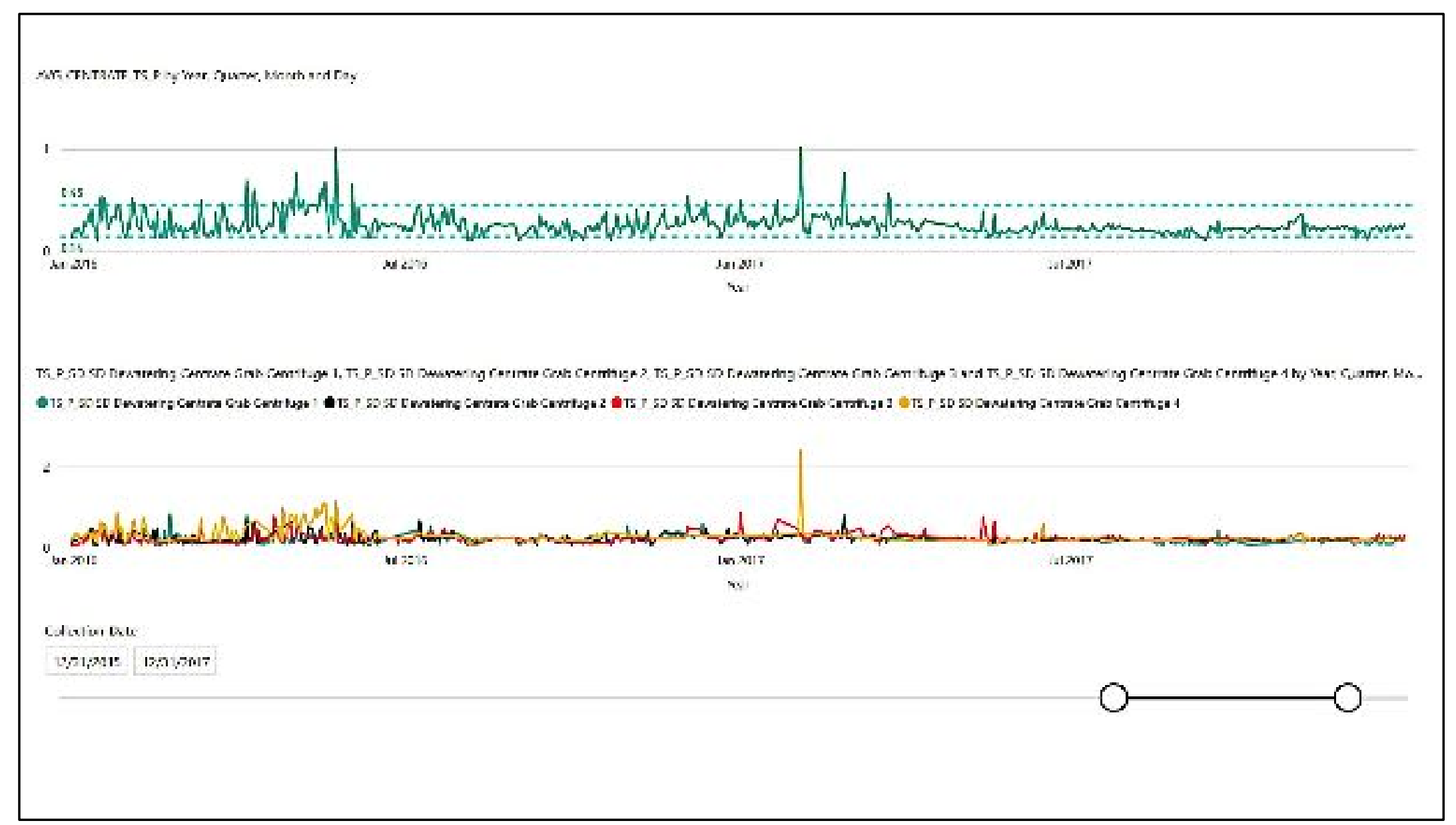




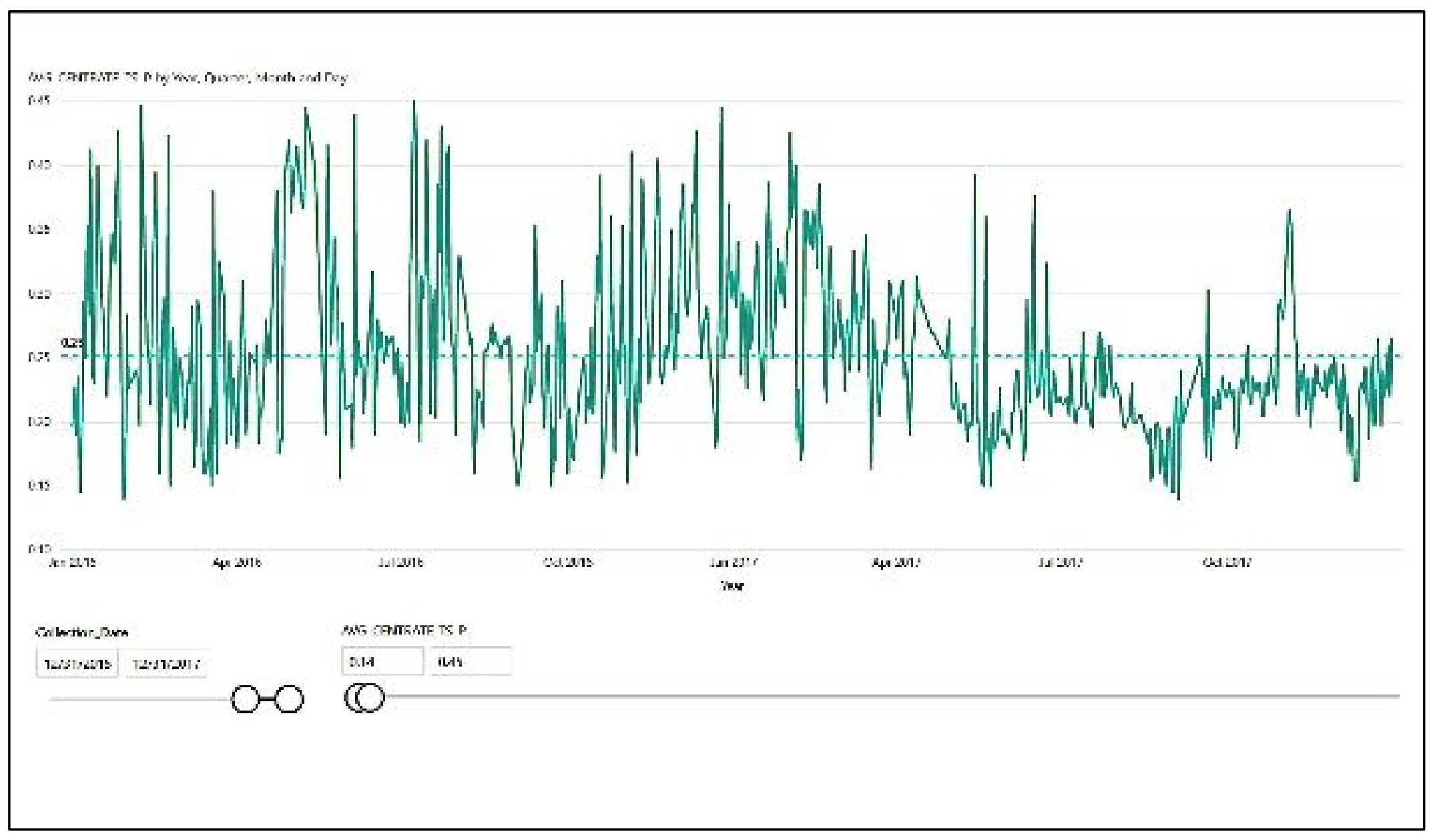


Central District WWTP Historical Data Analysis for MBM inputs

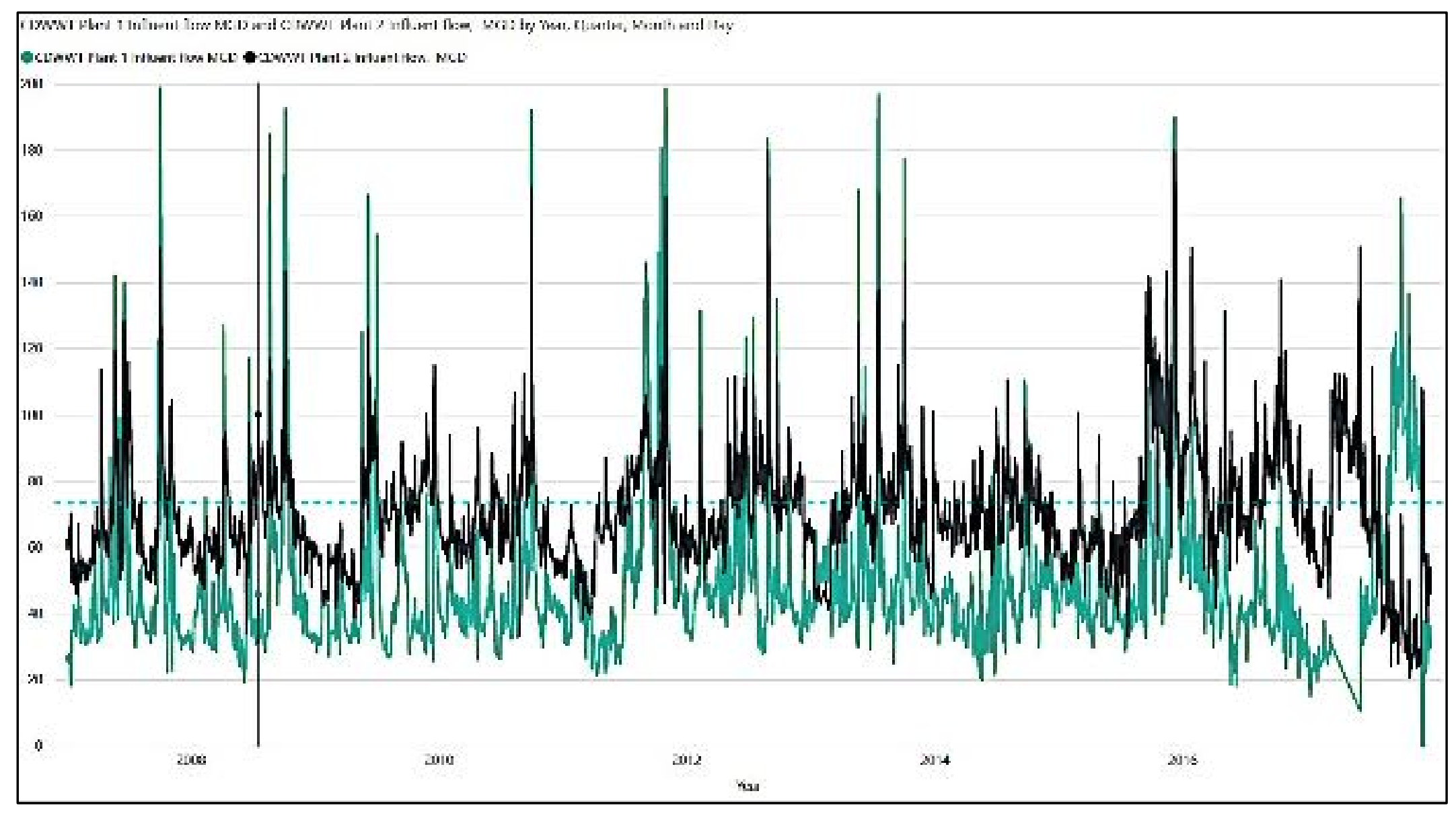




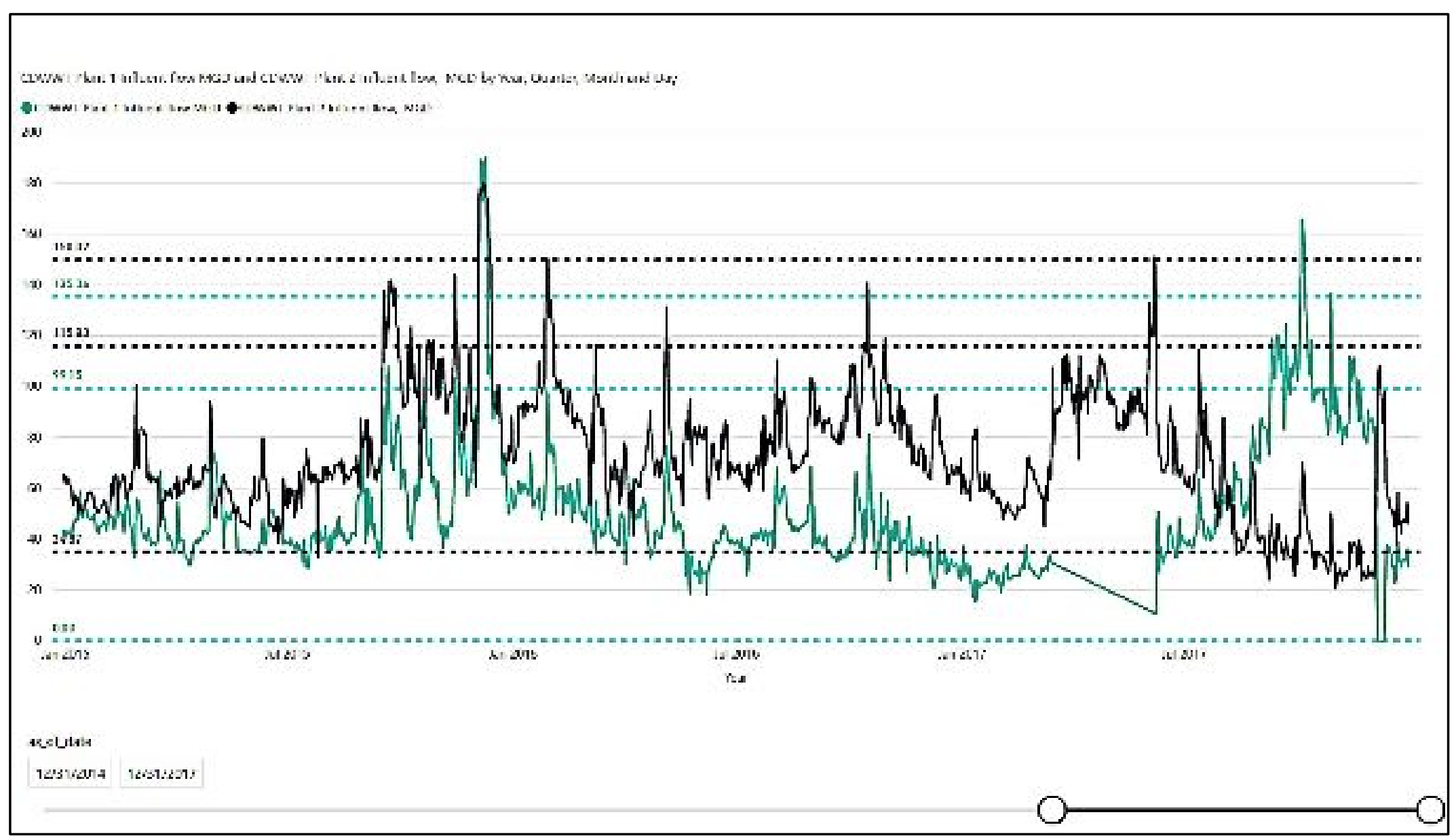




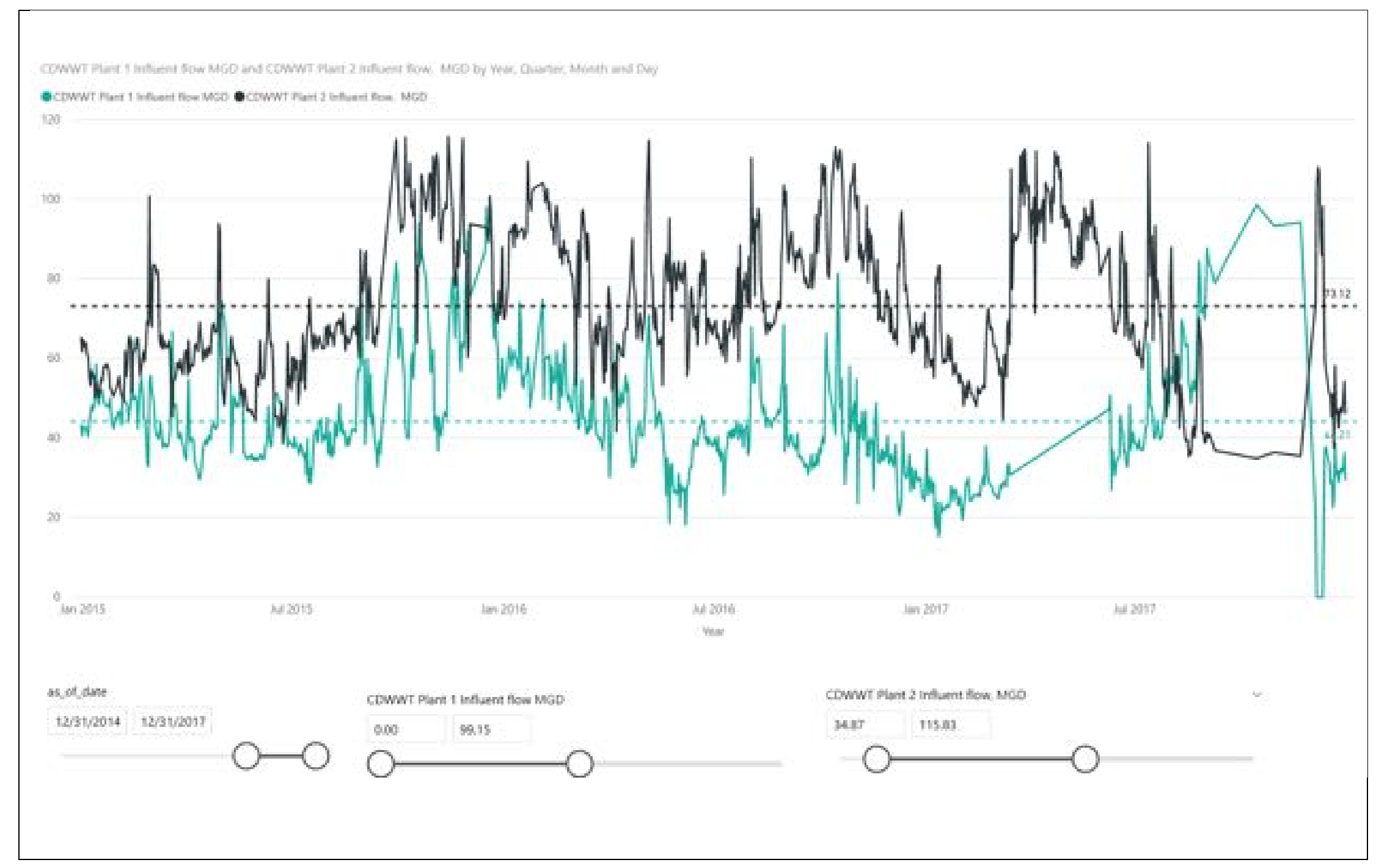




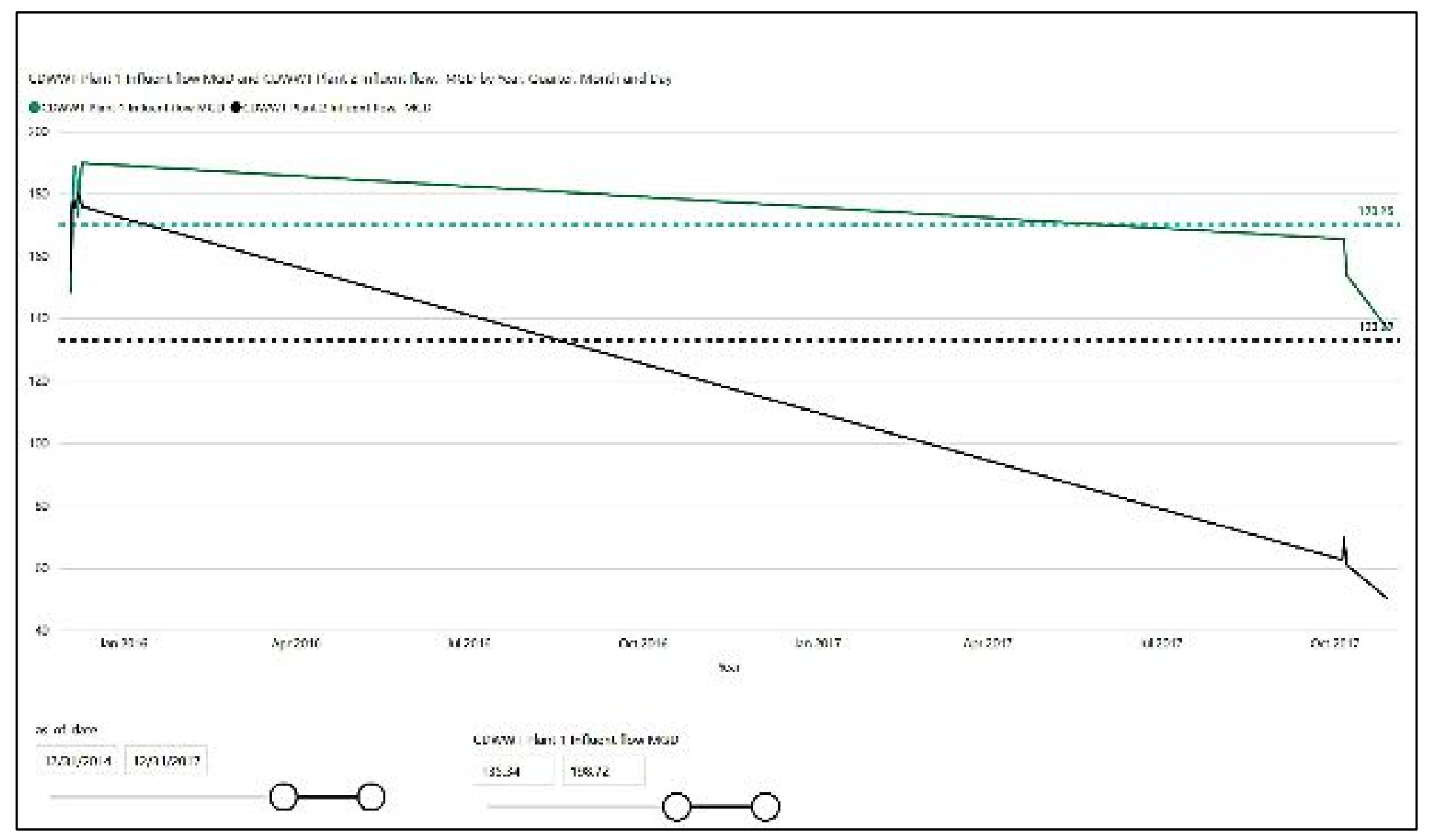




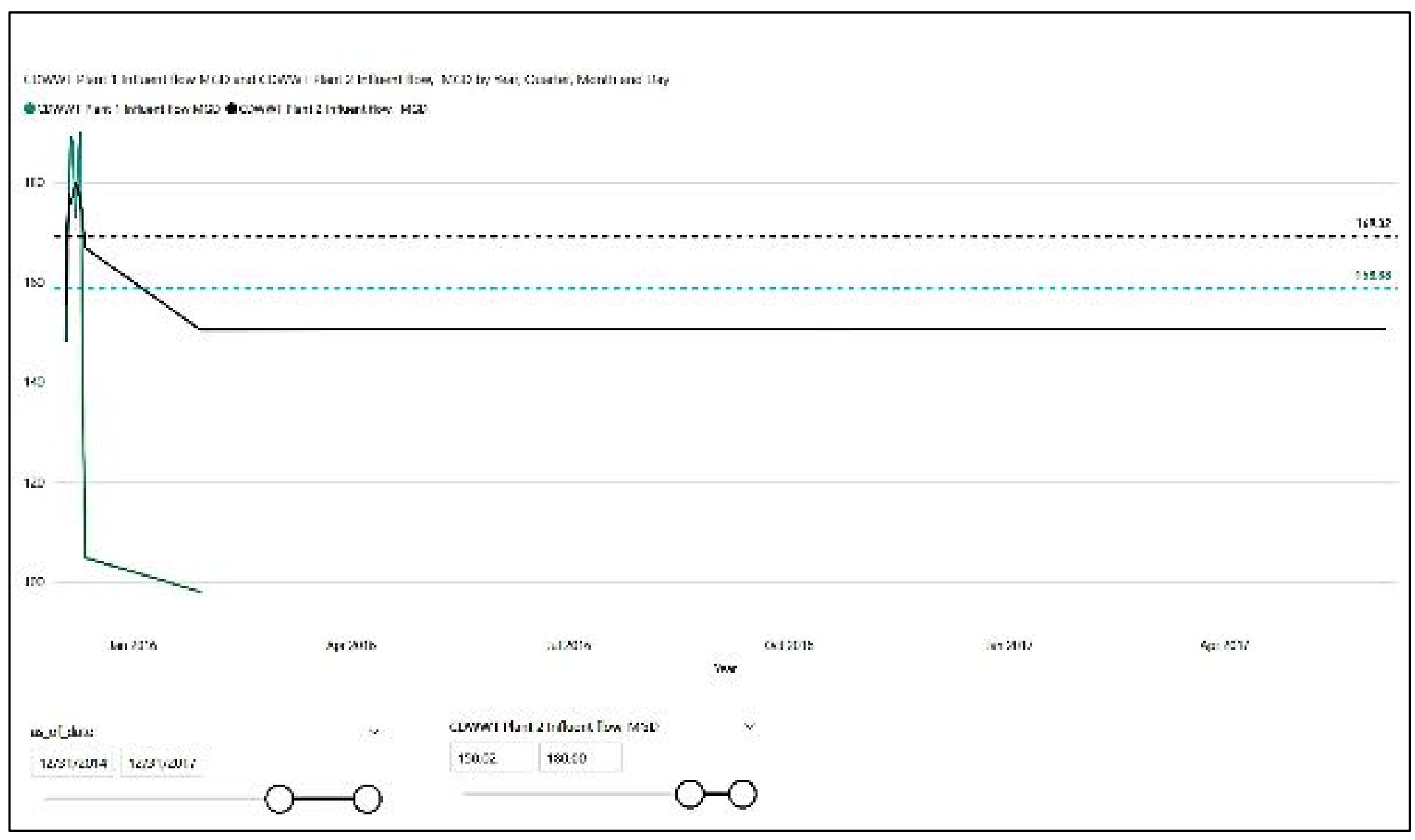




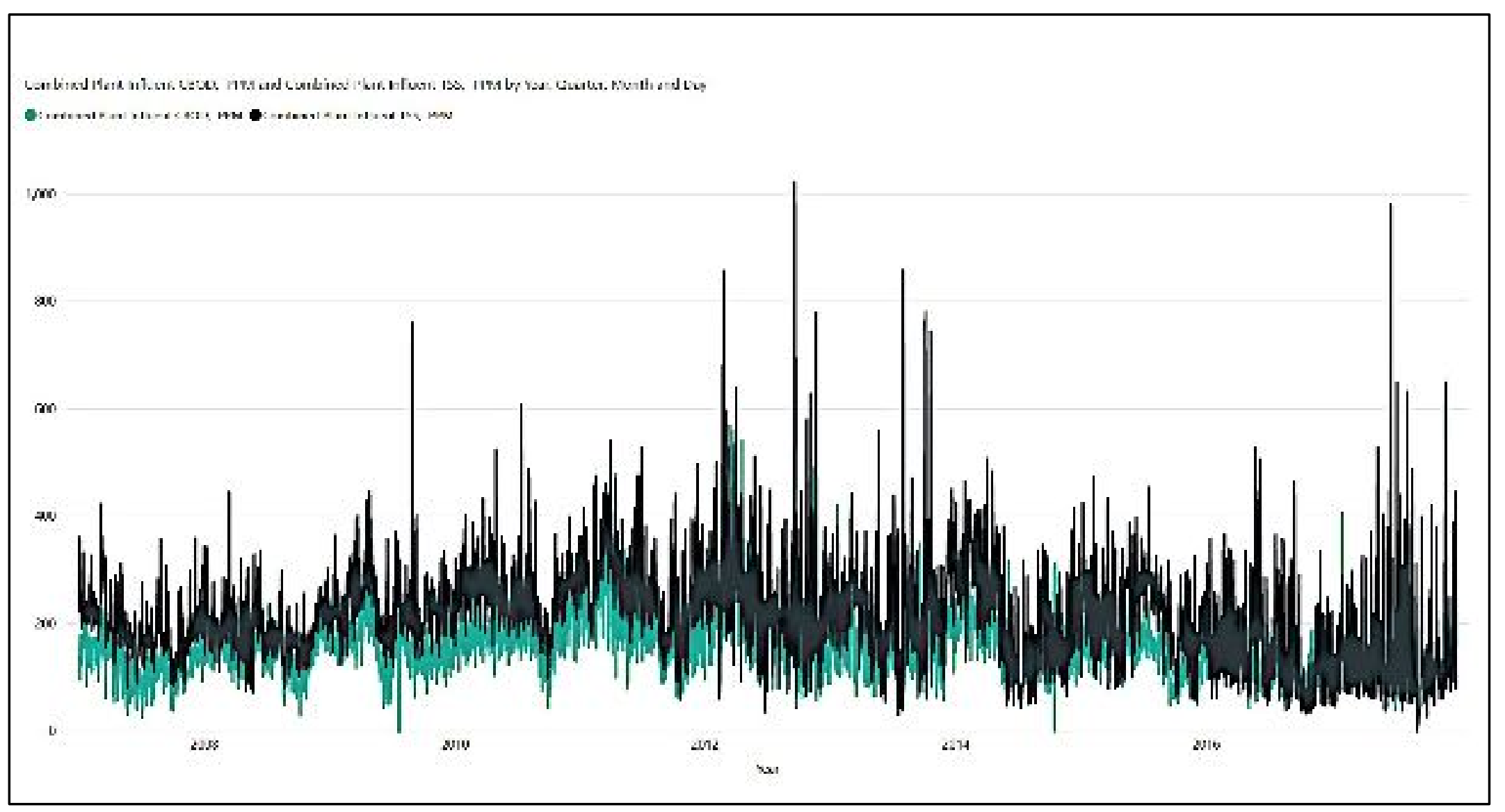




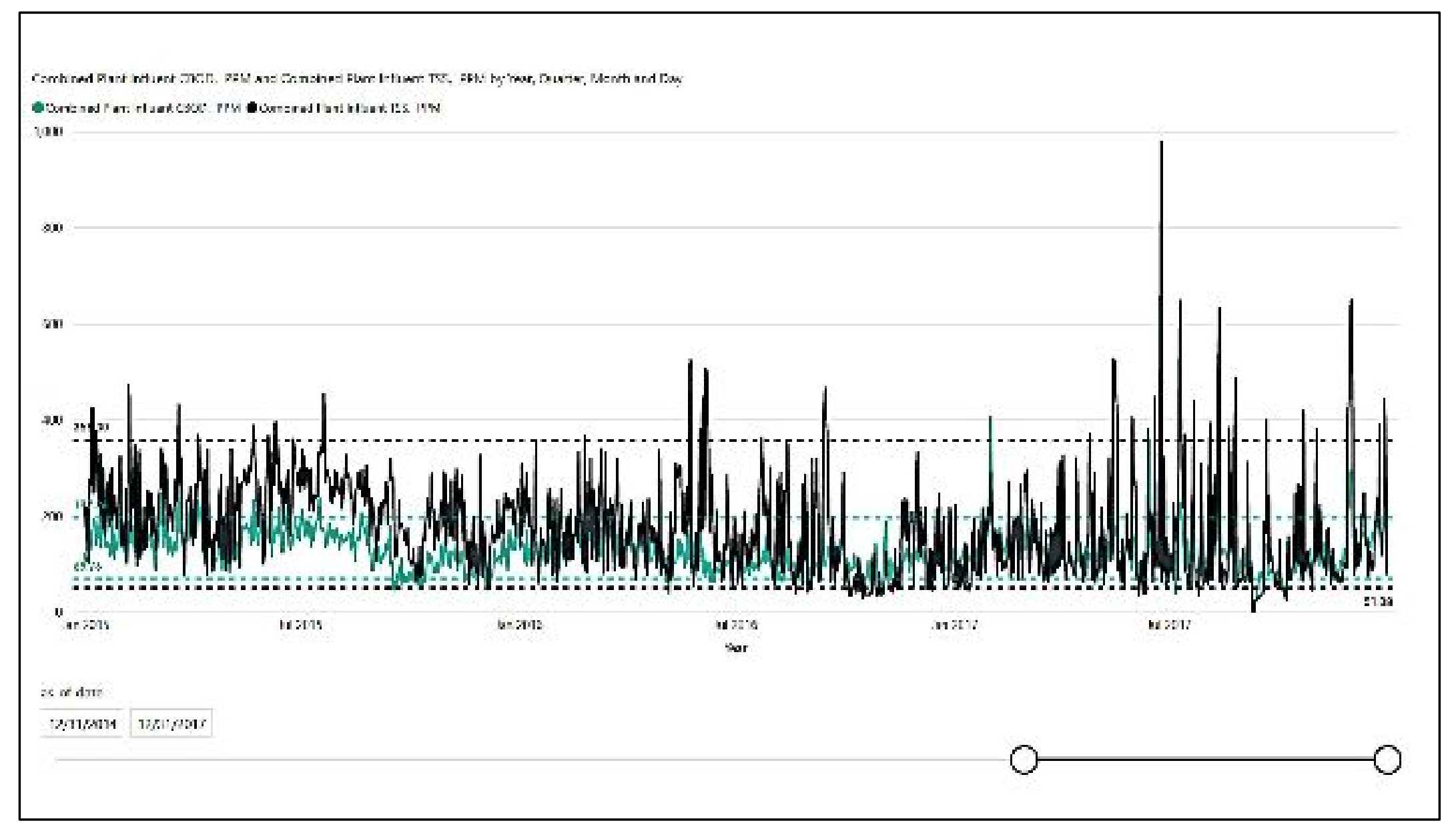




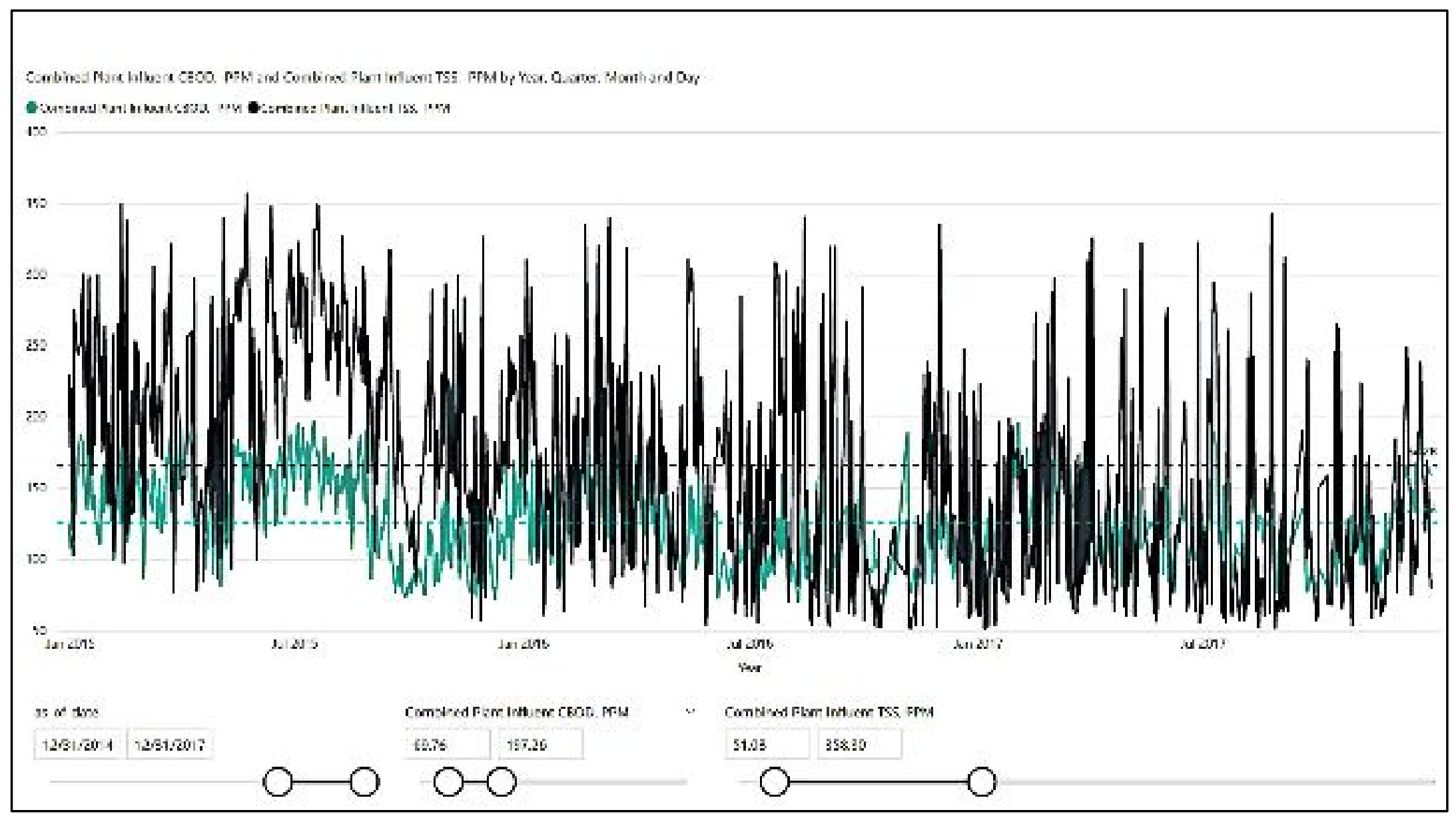




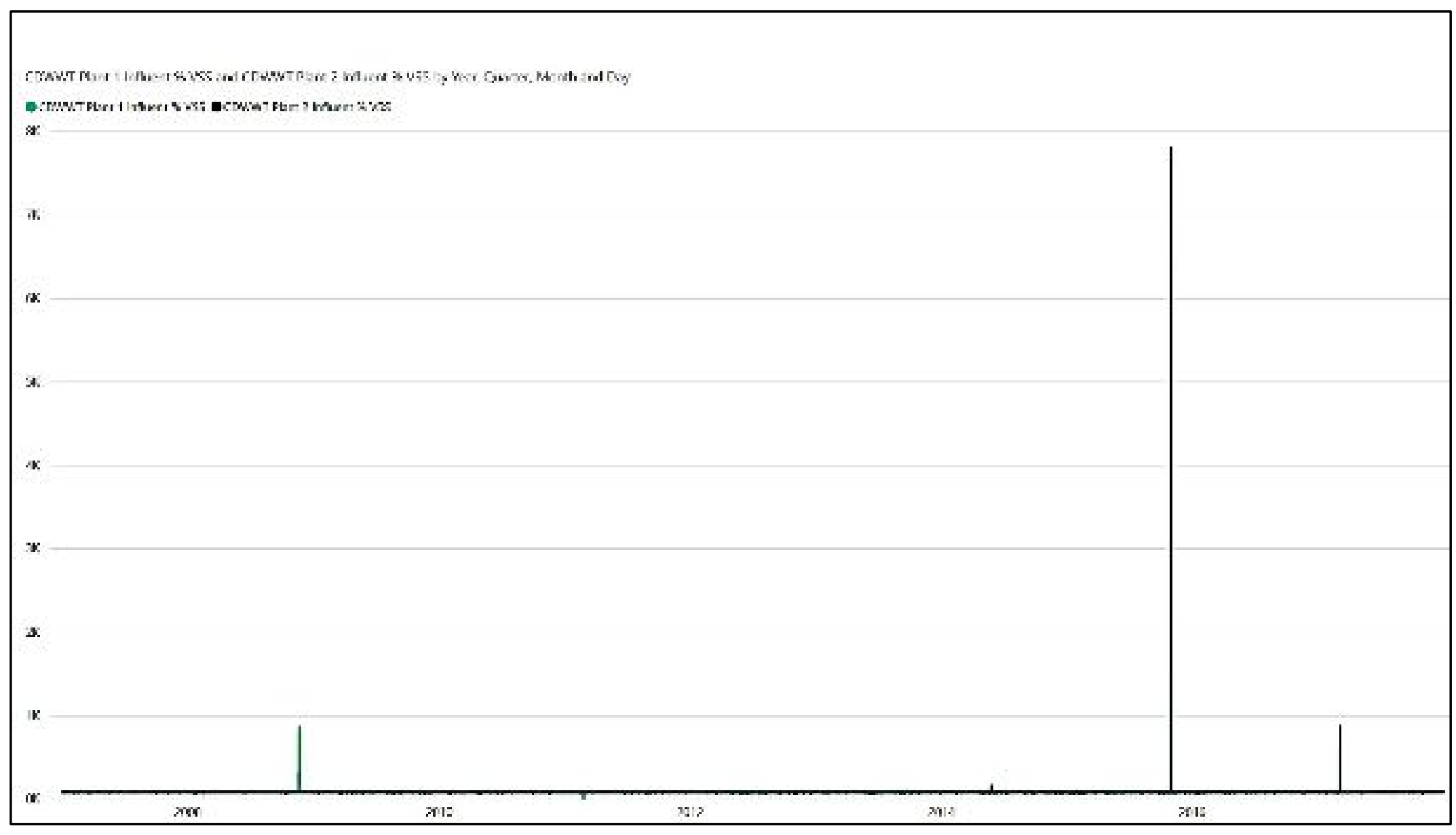




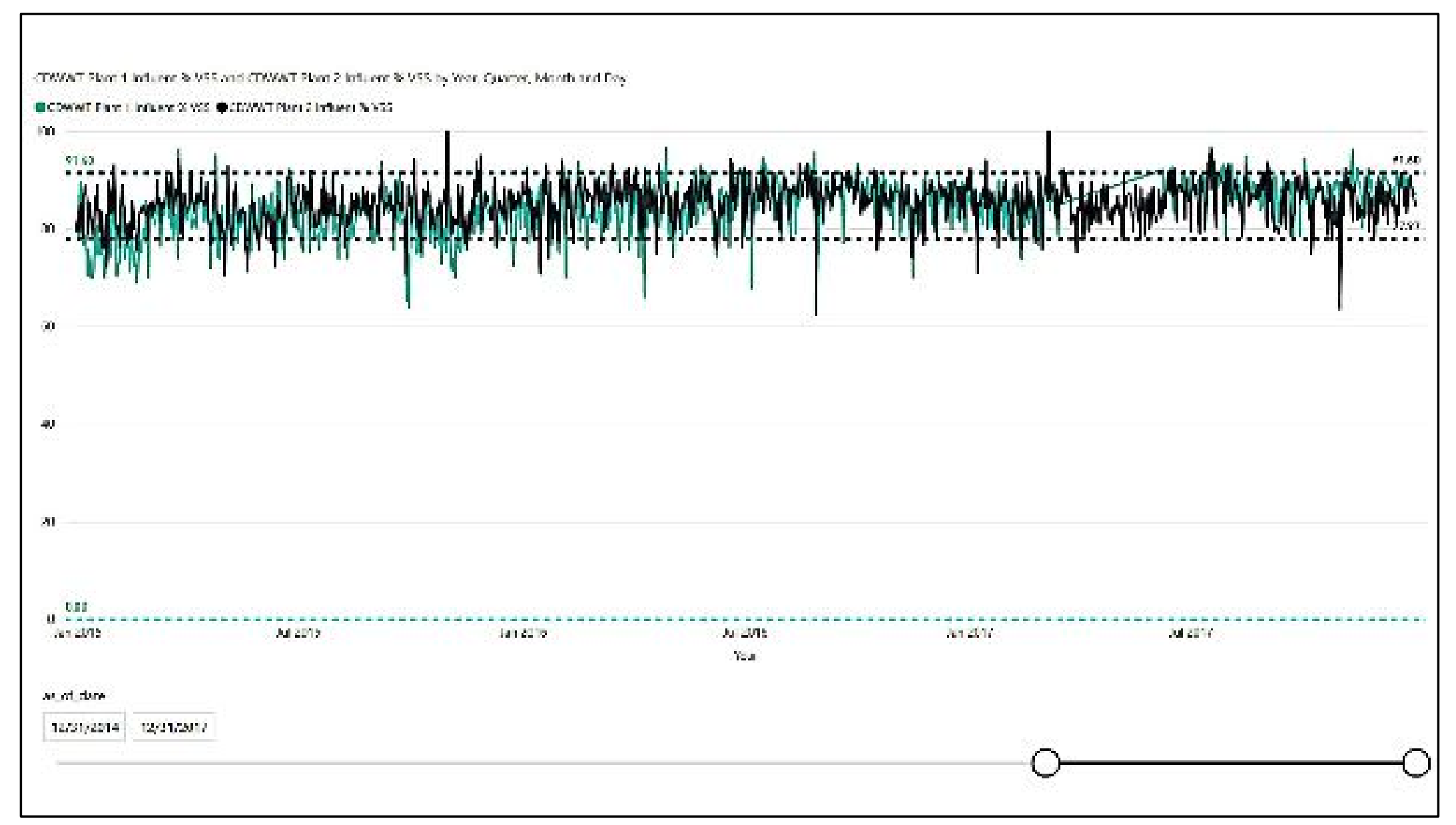




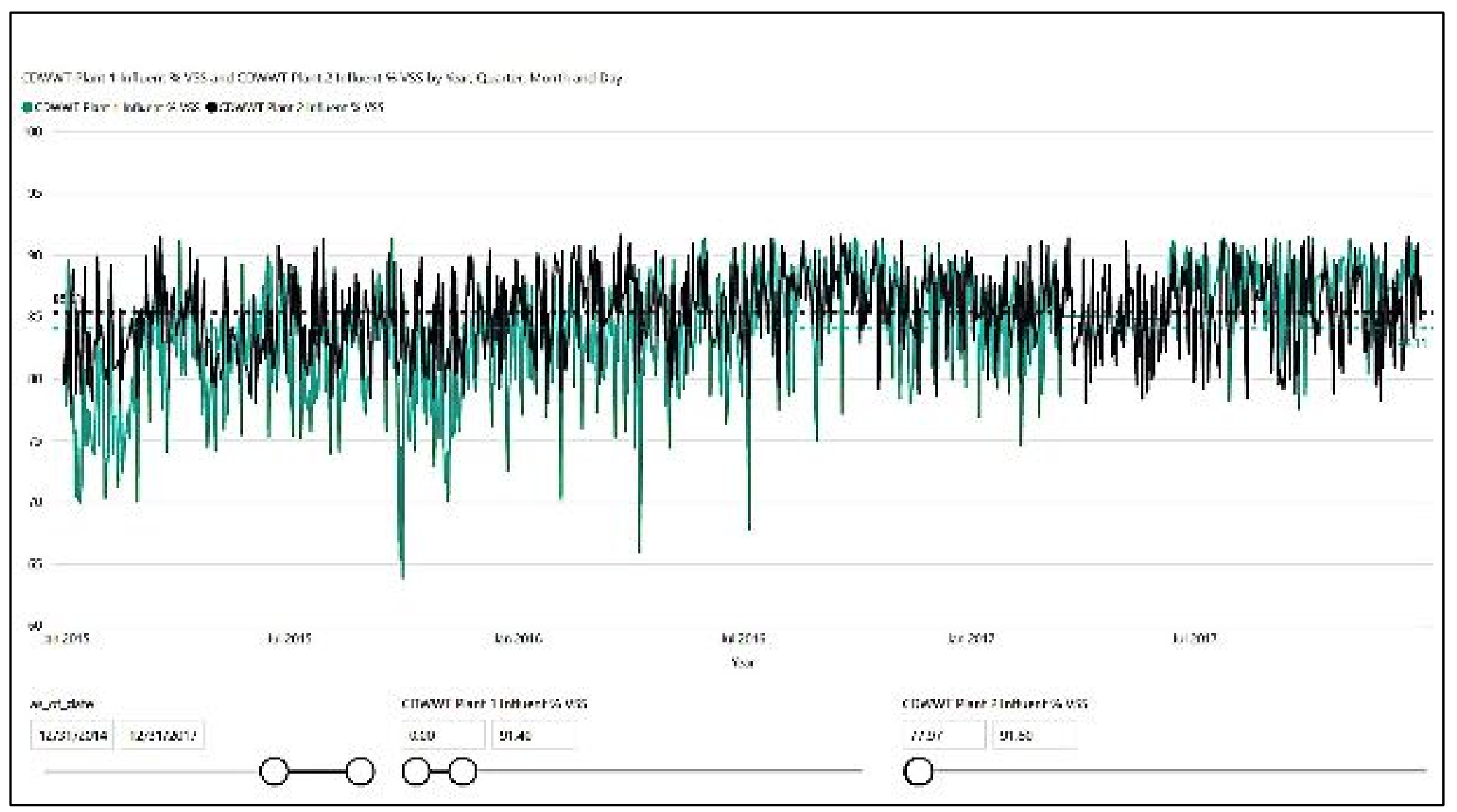




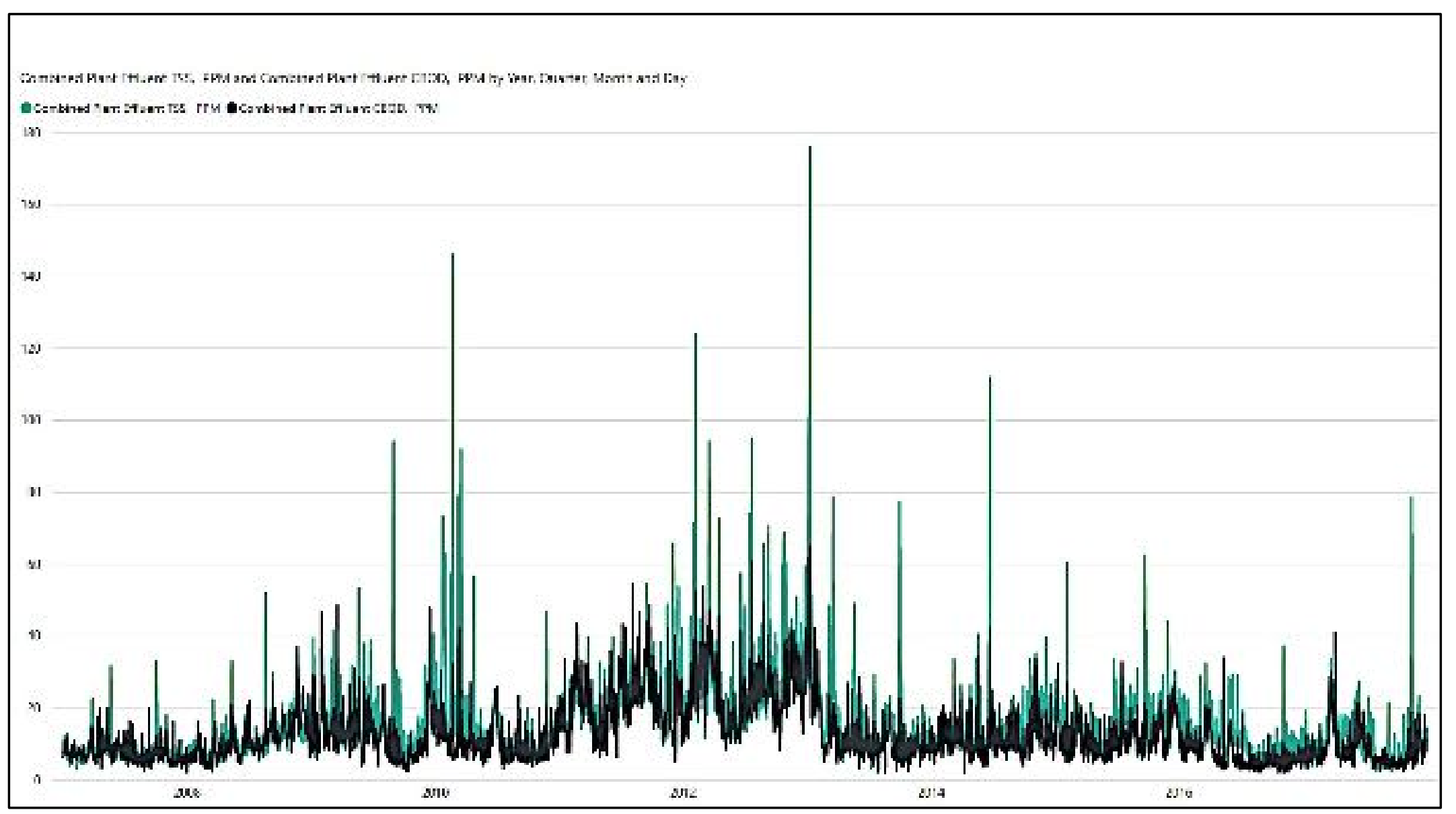




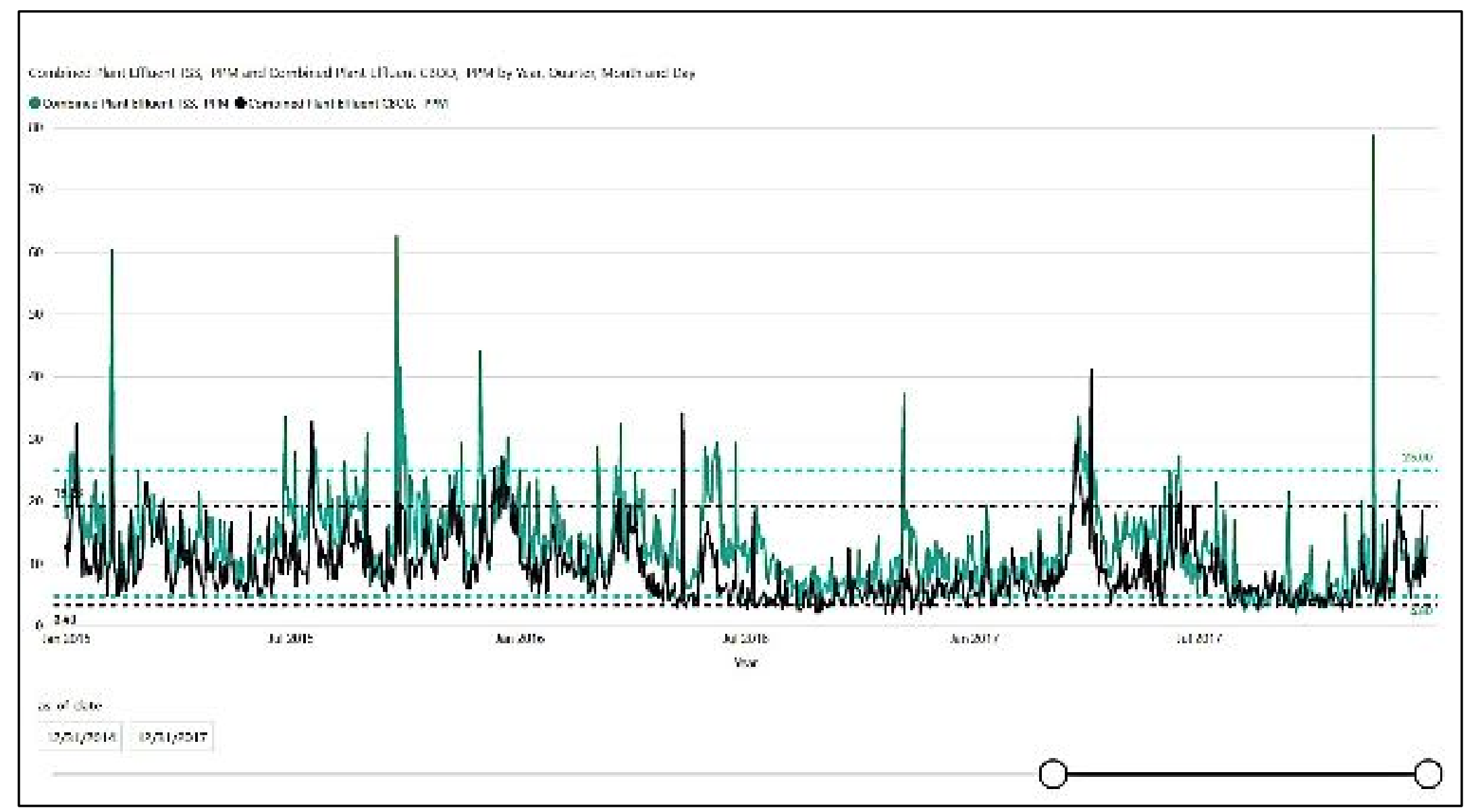




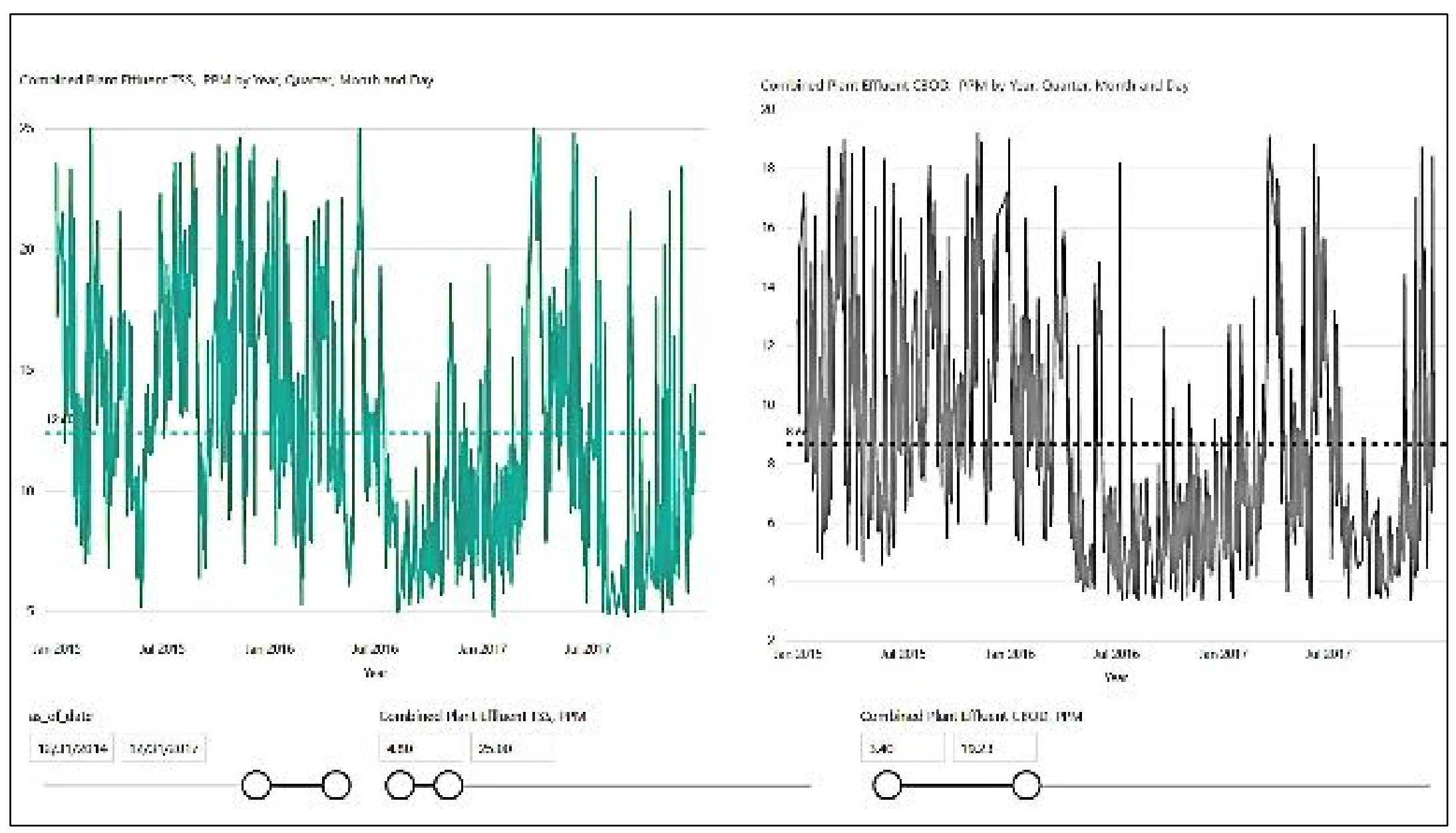




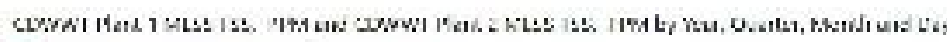

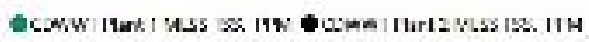

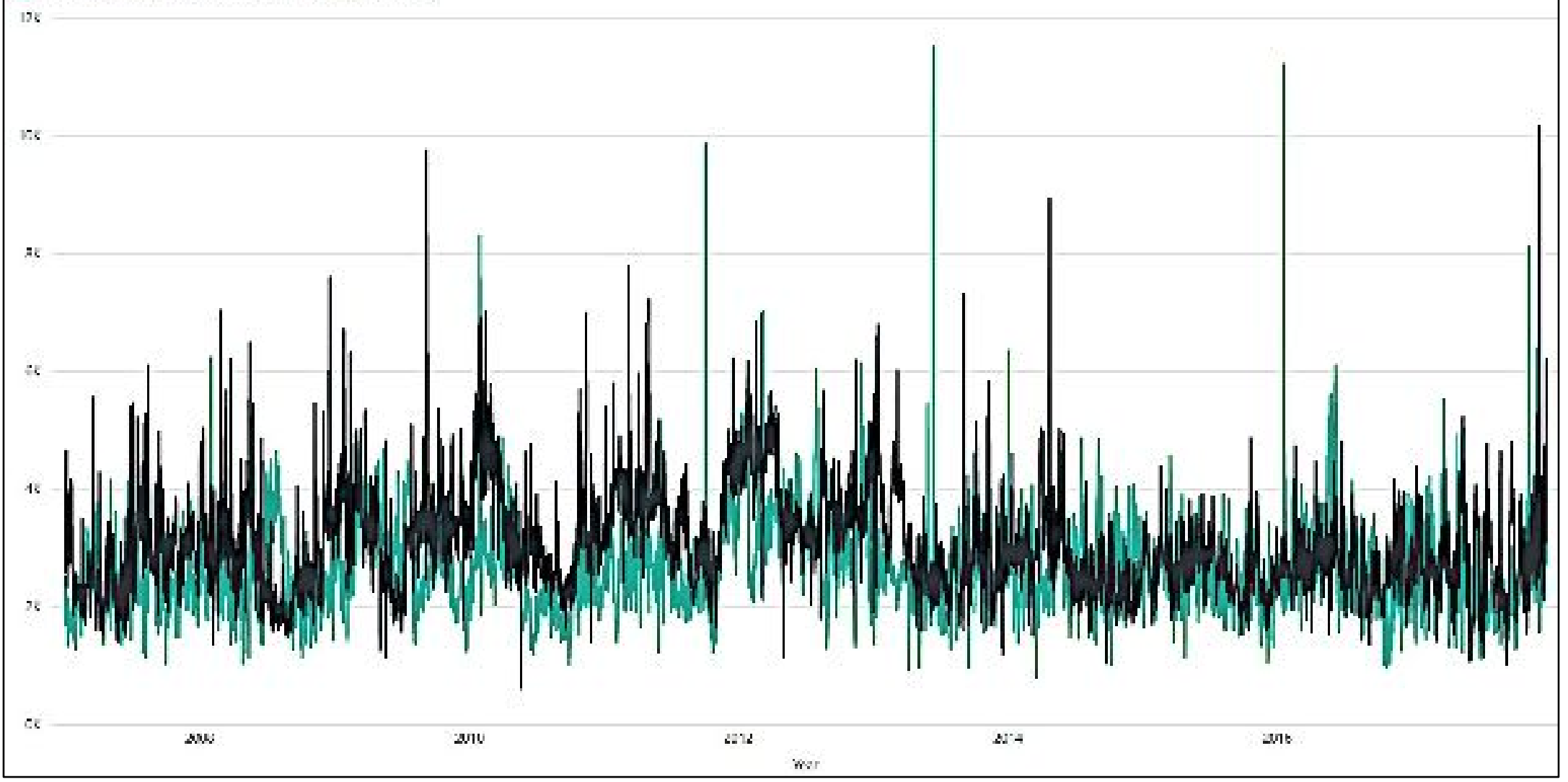




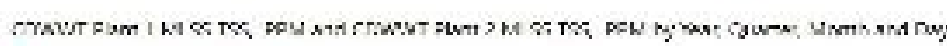

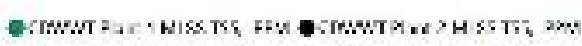

i.

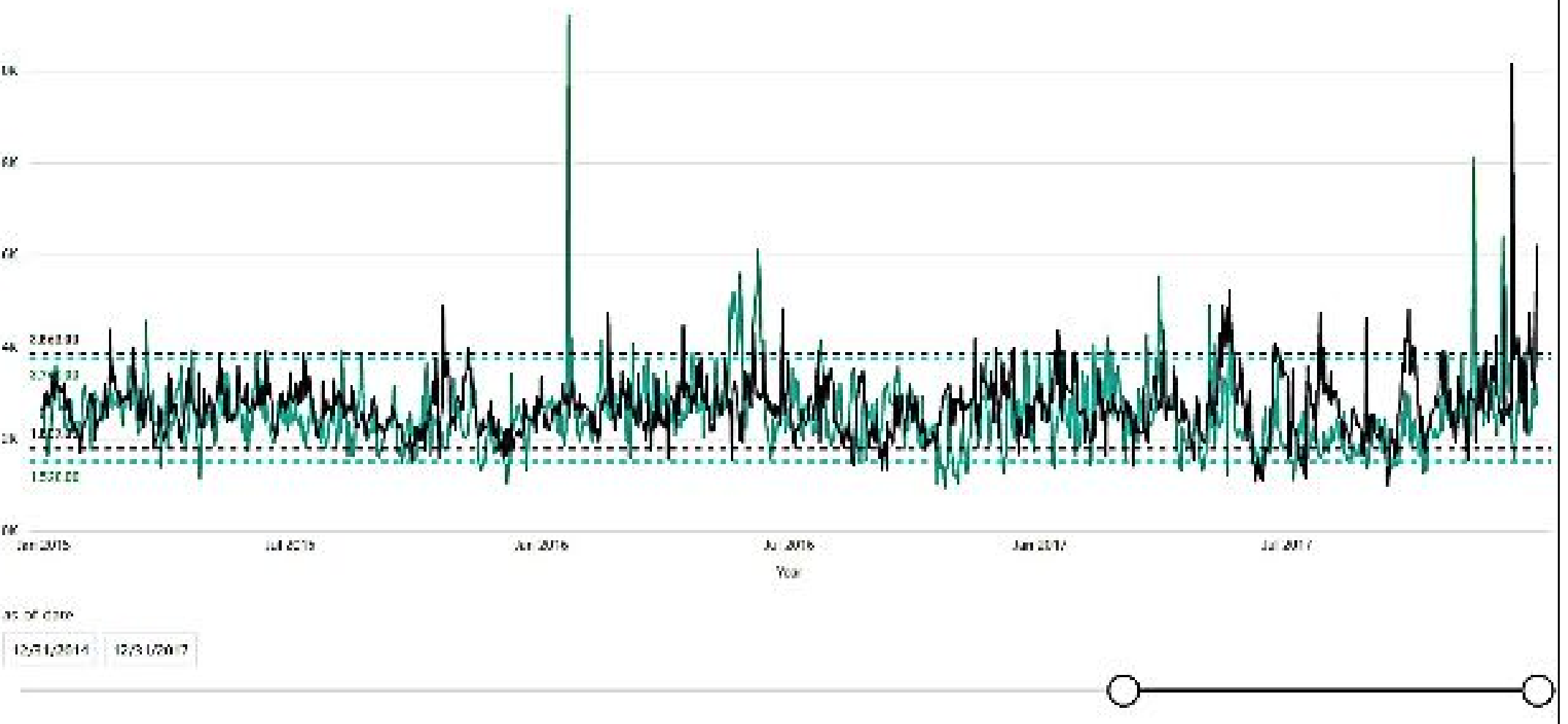




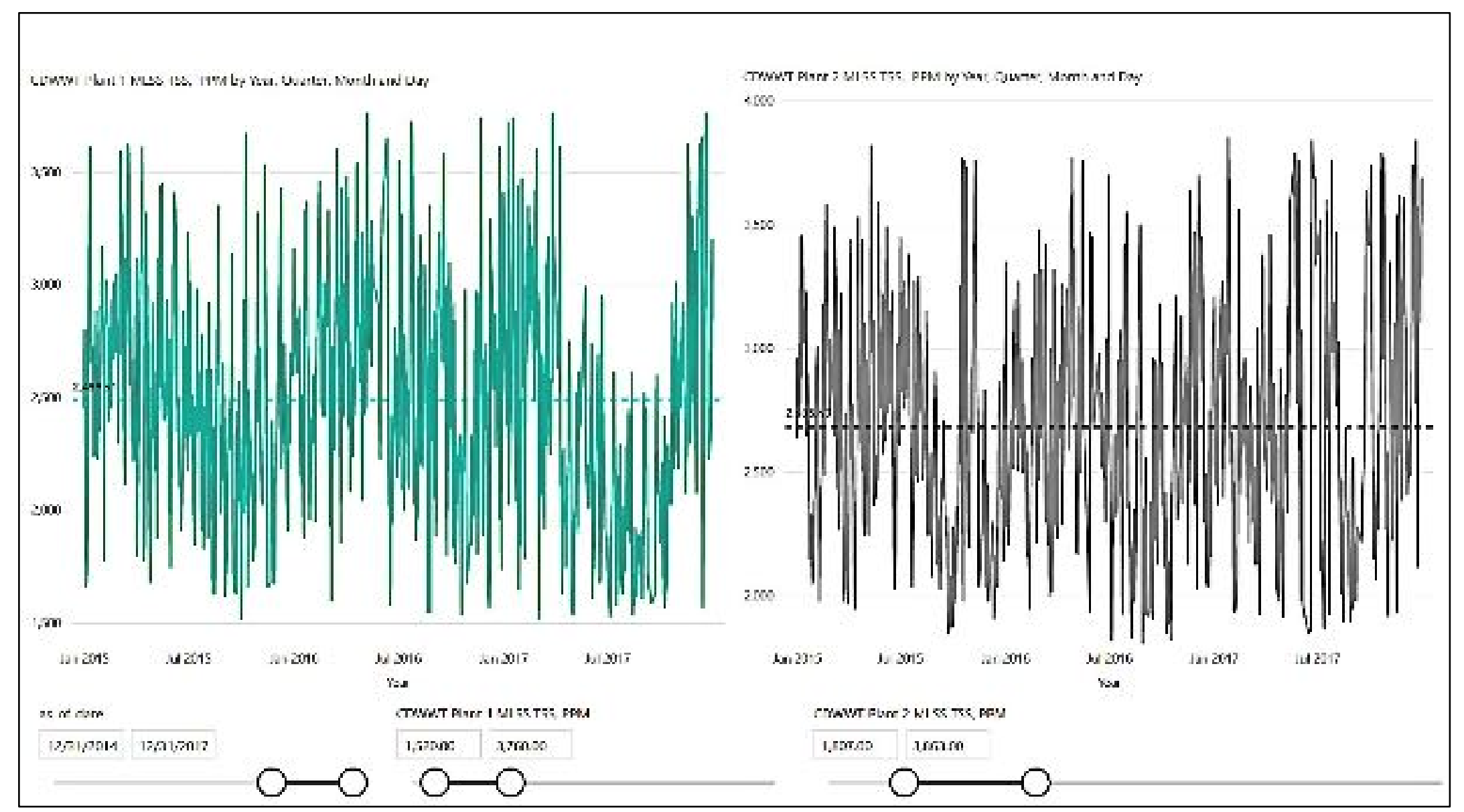




$$
[\|
$$




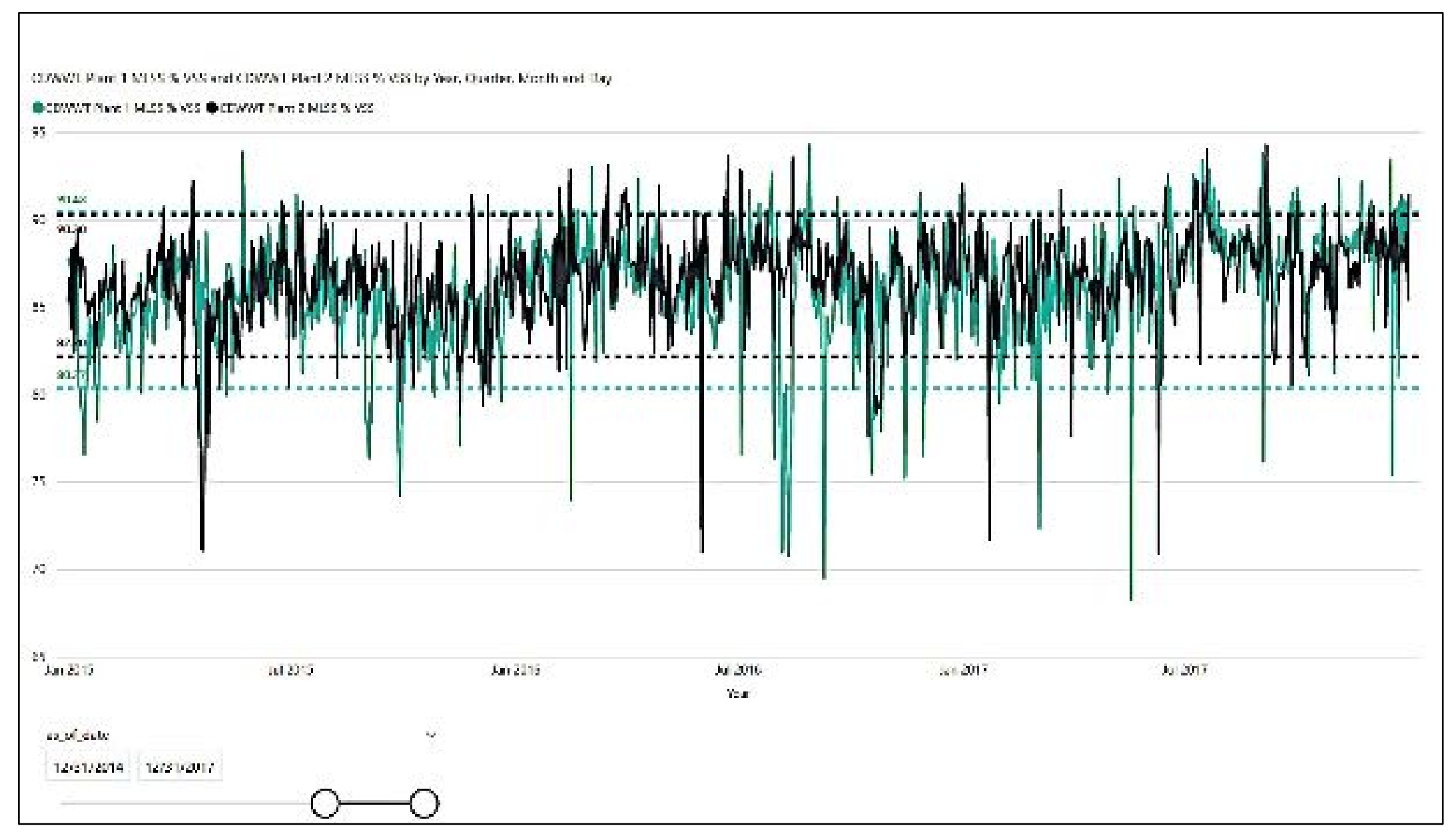




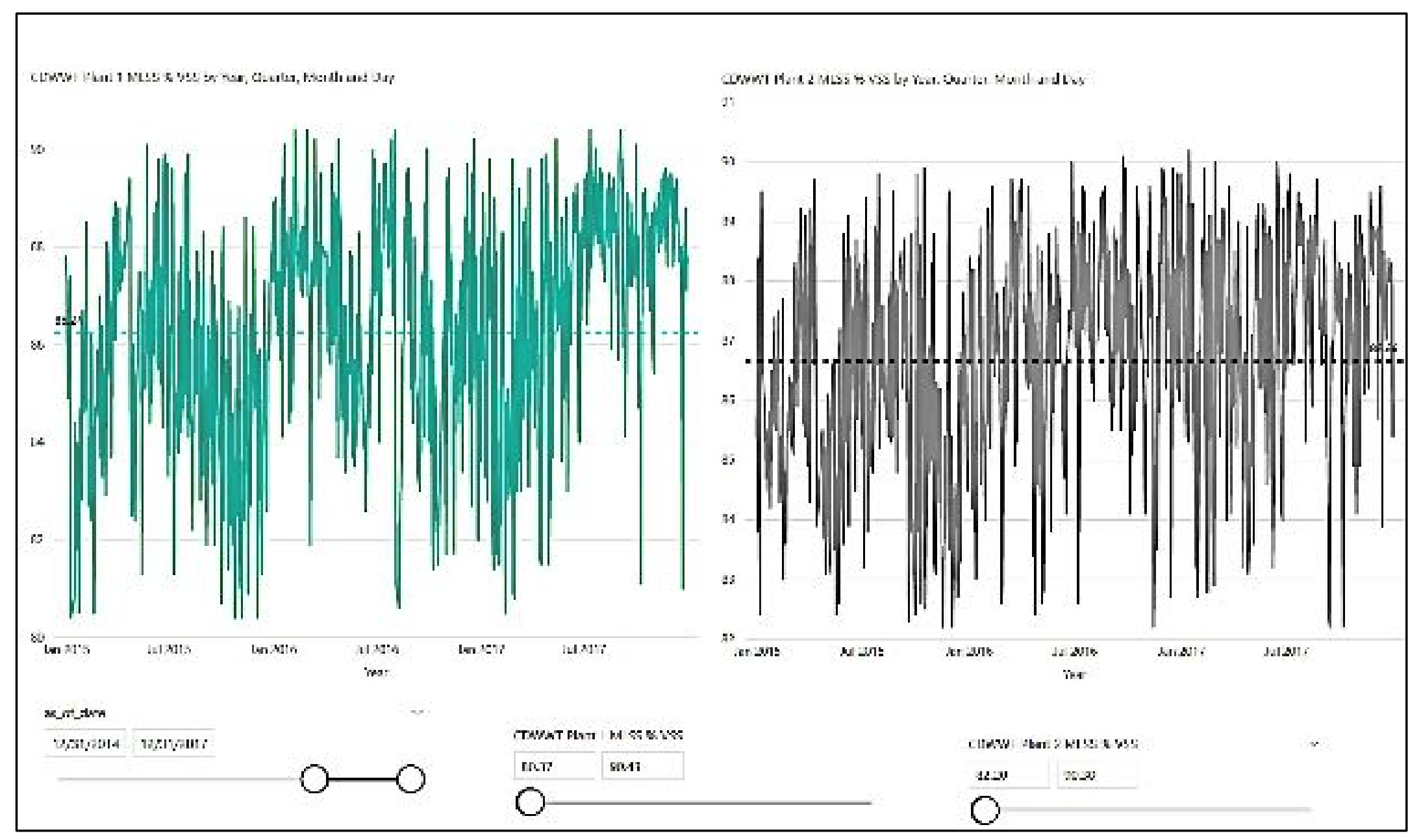




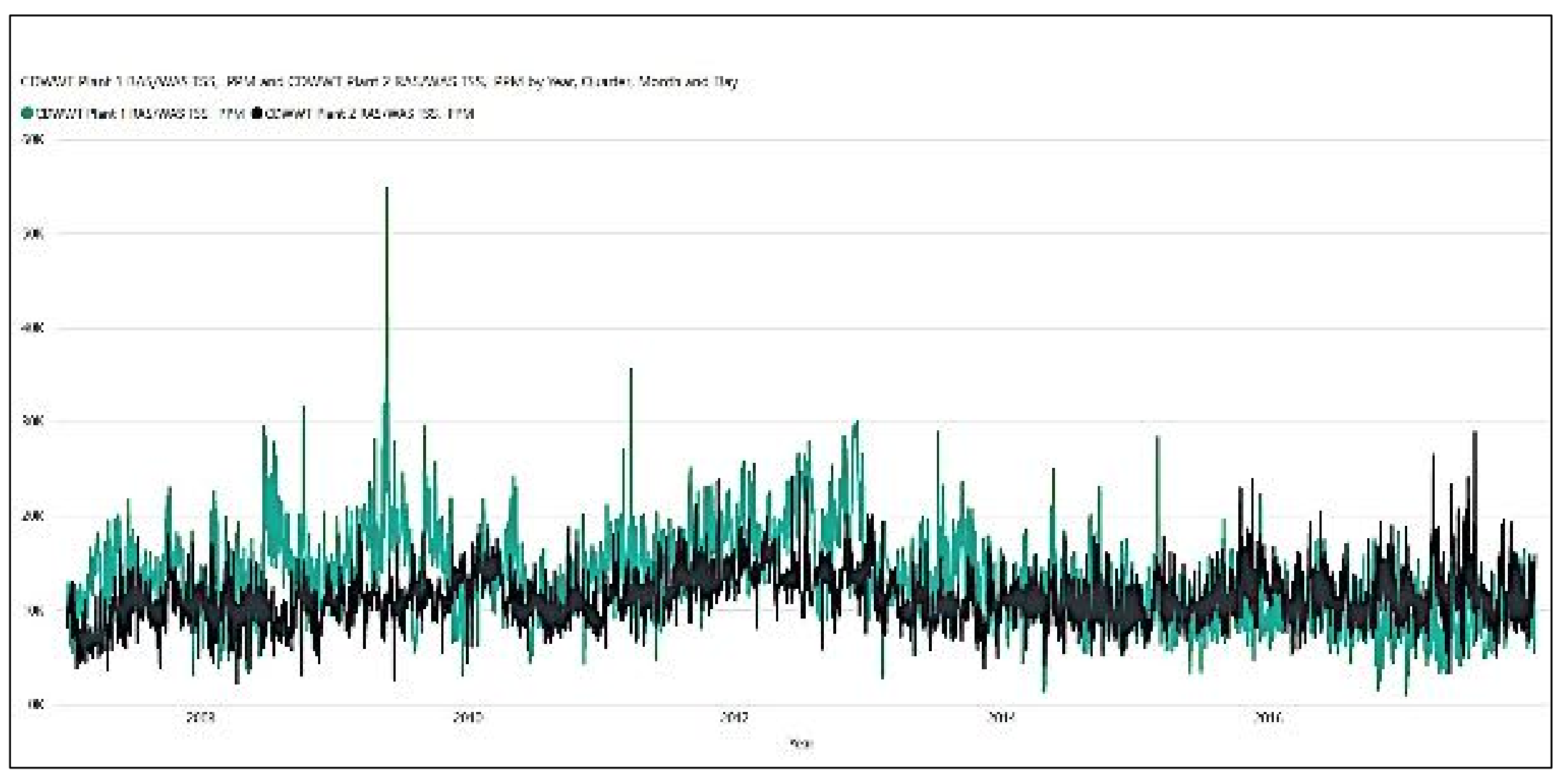




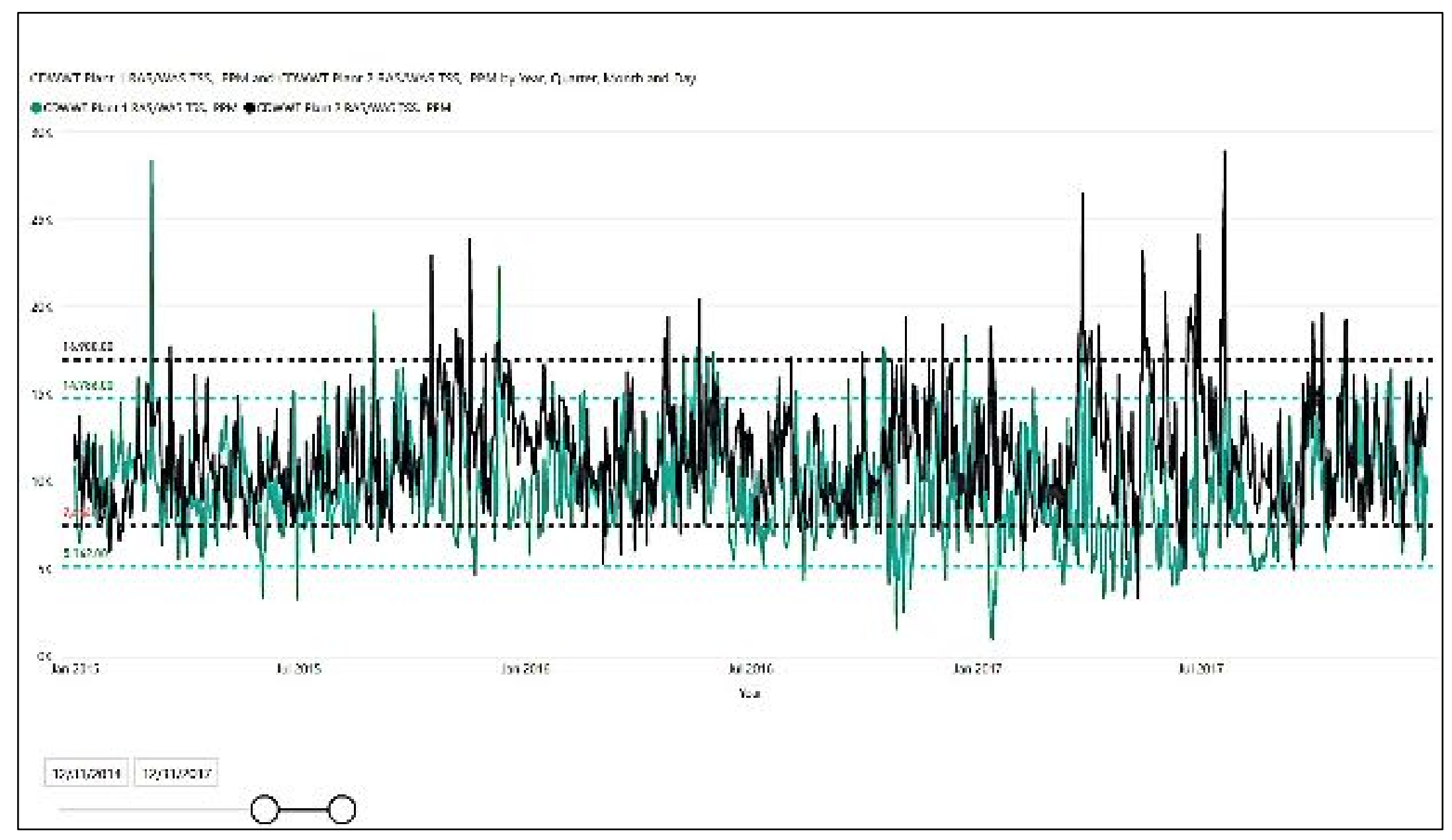




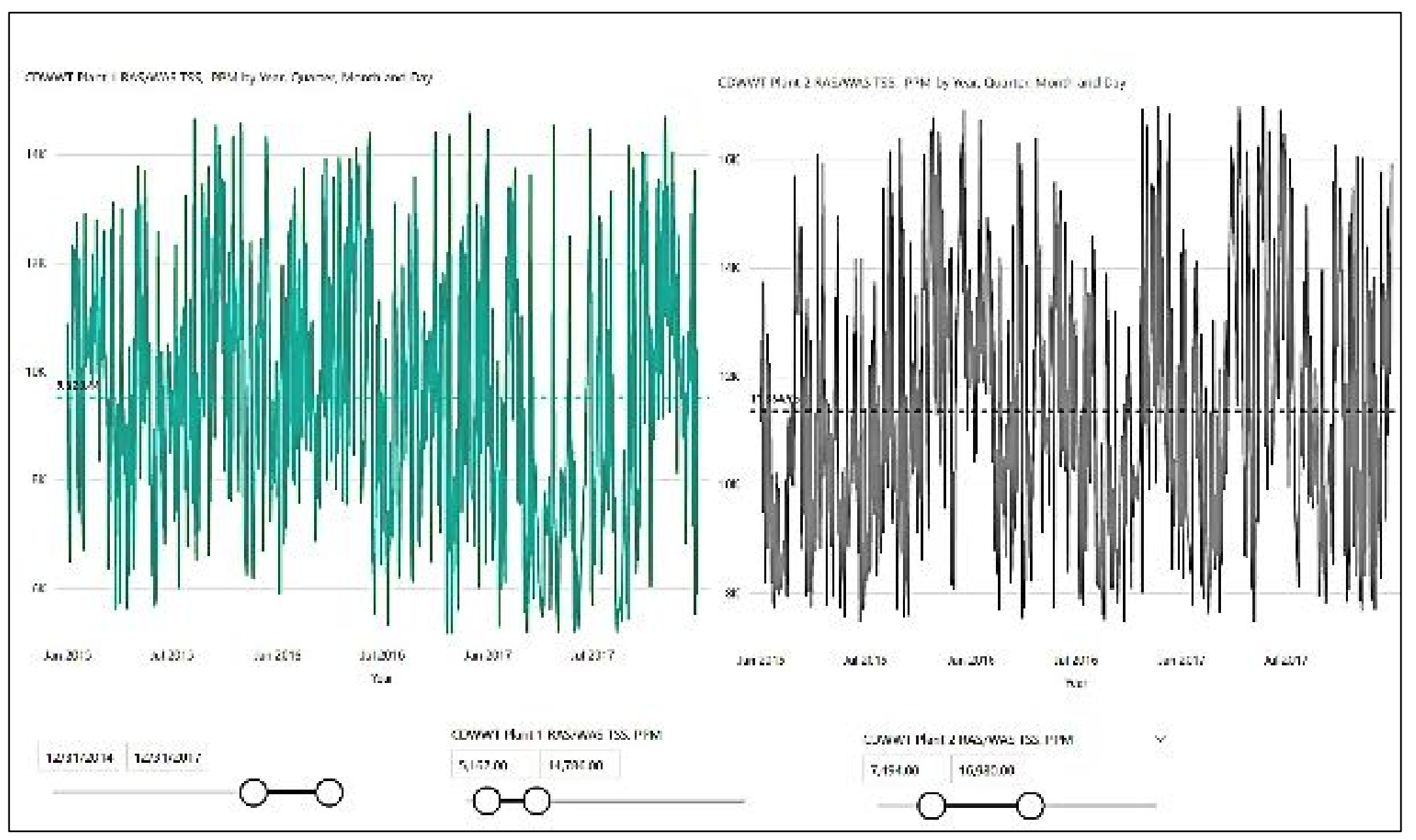




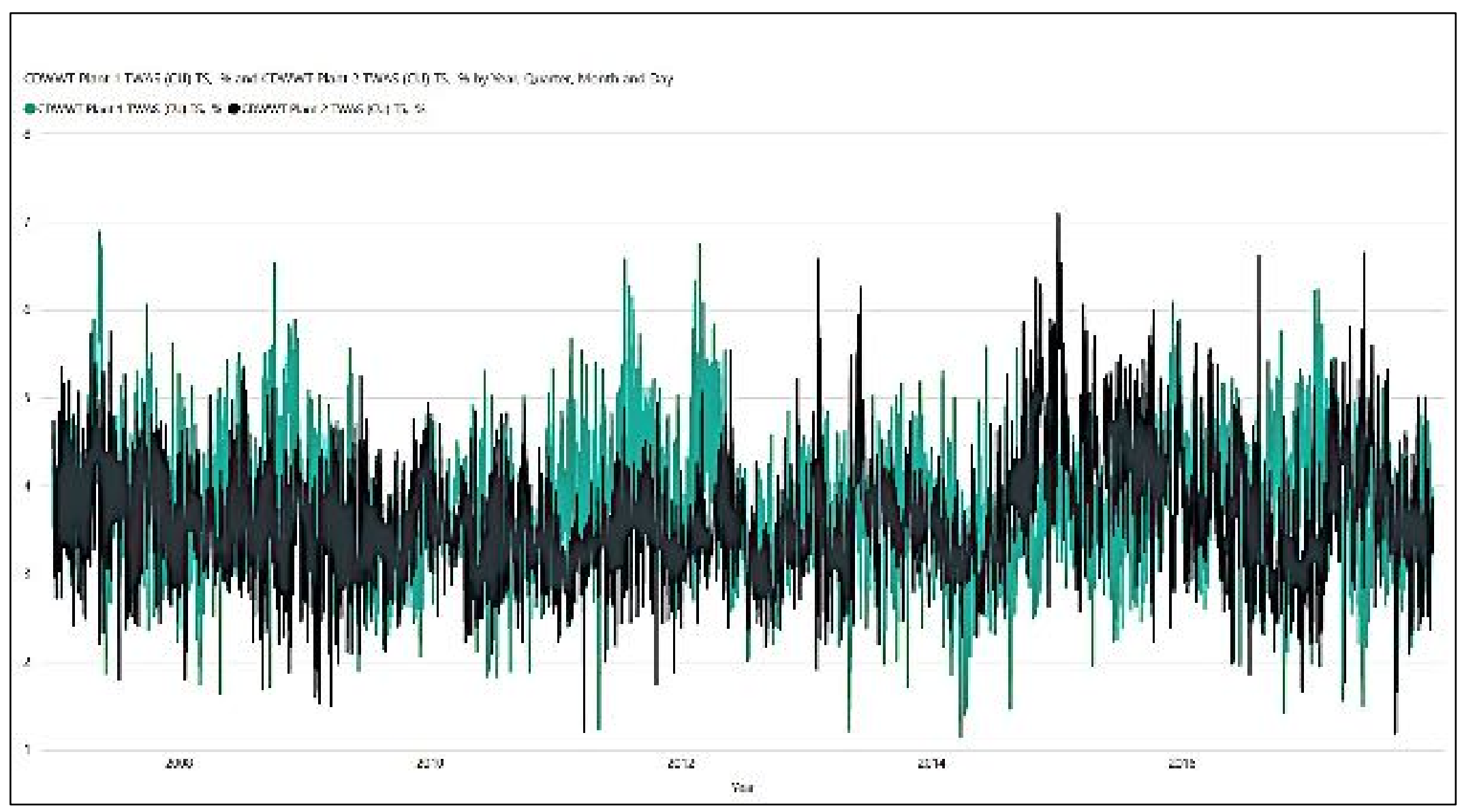




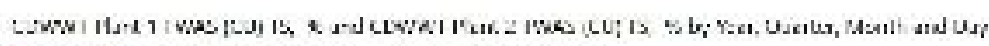

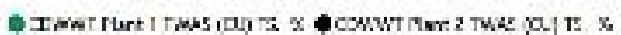

s

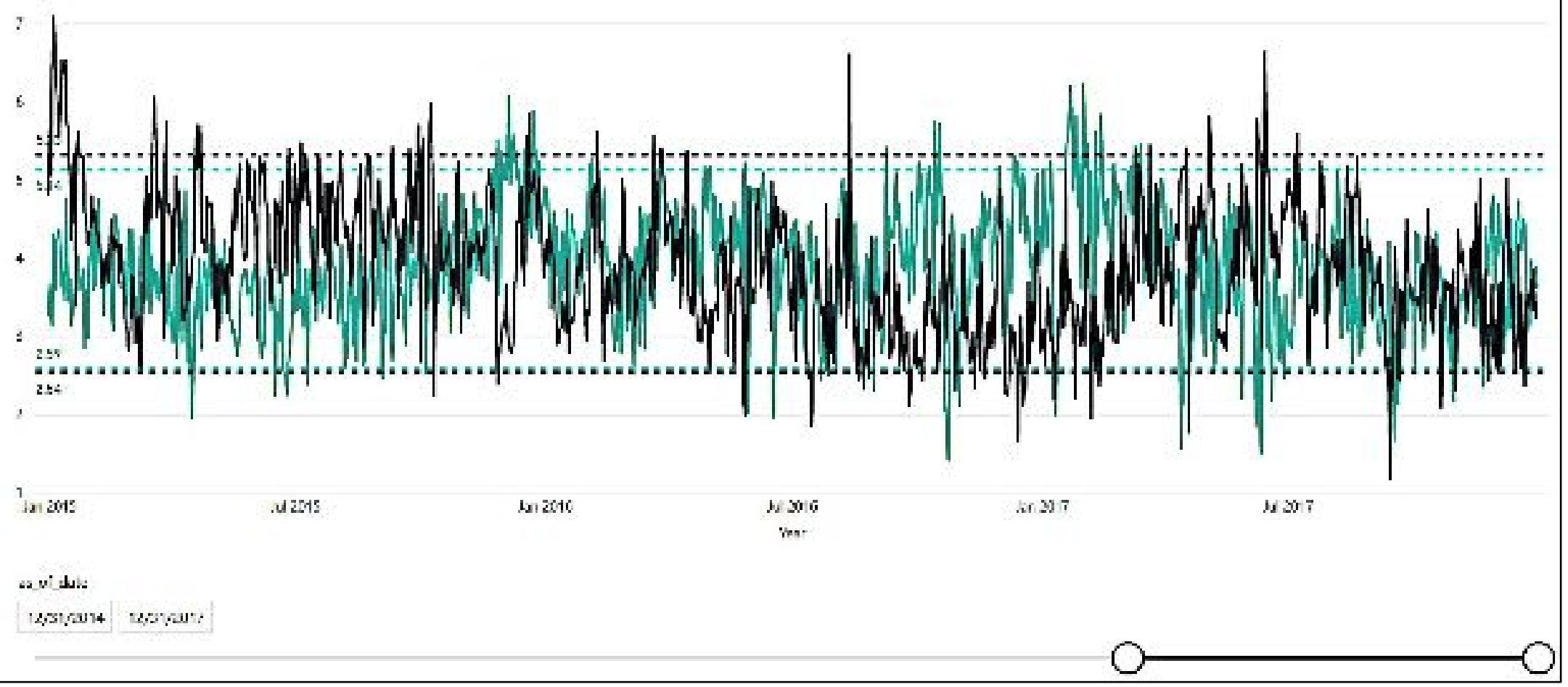




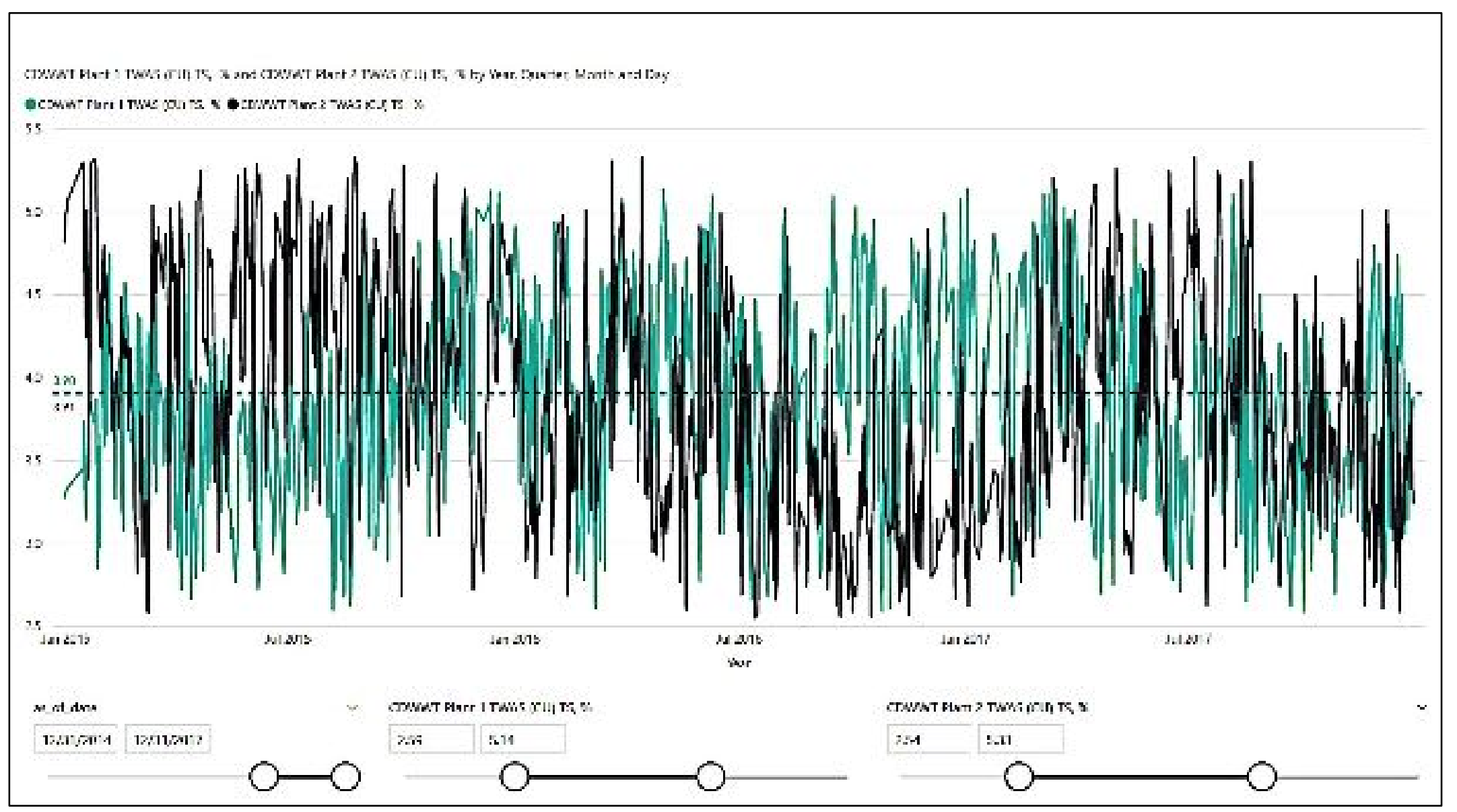




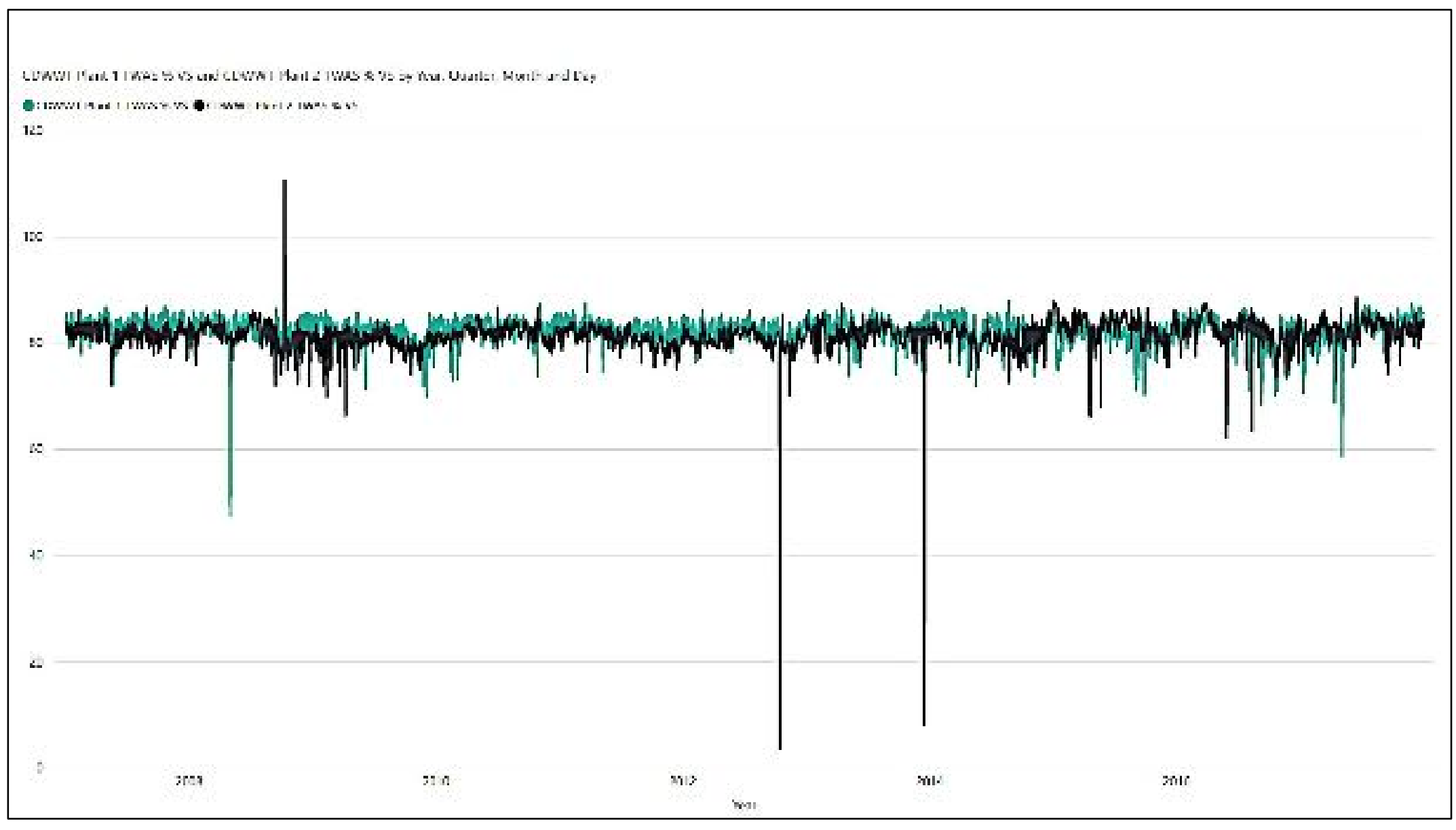




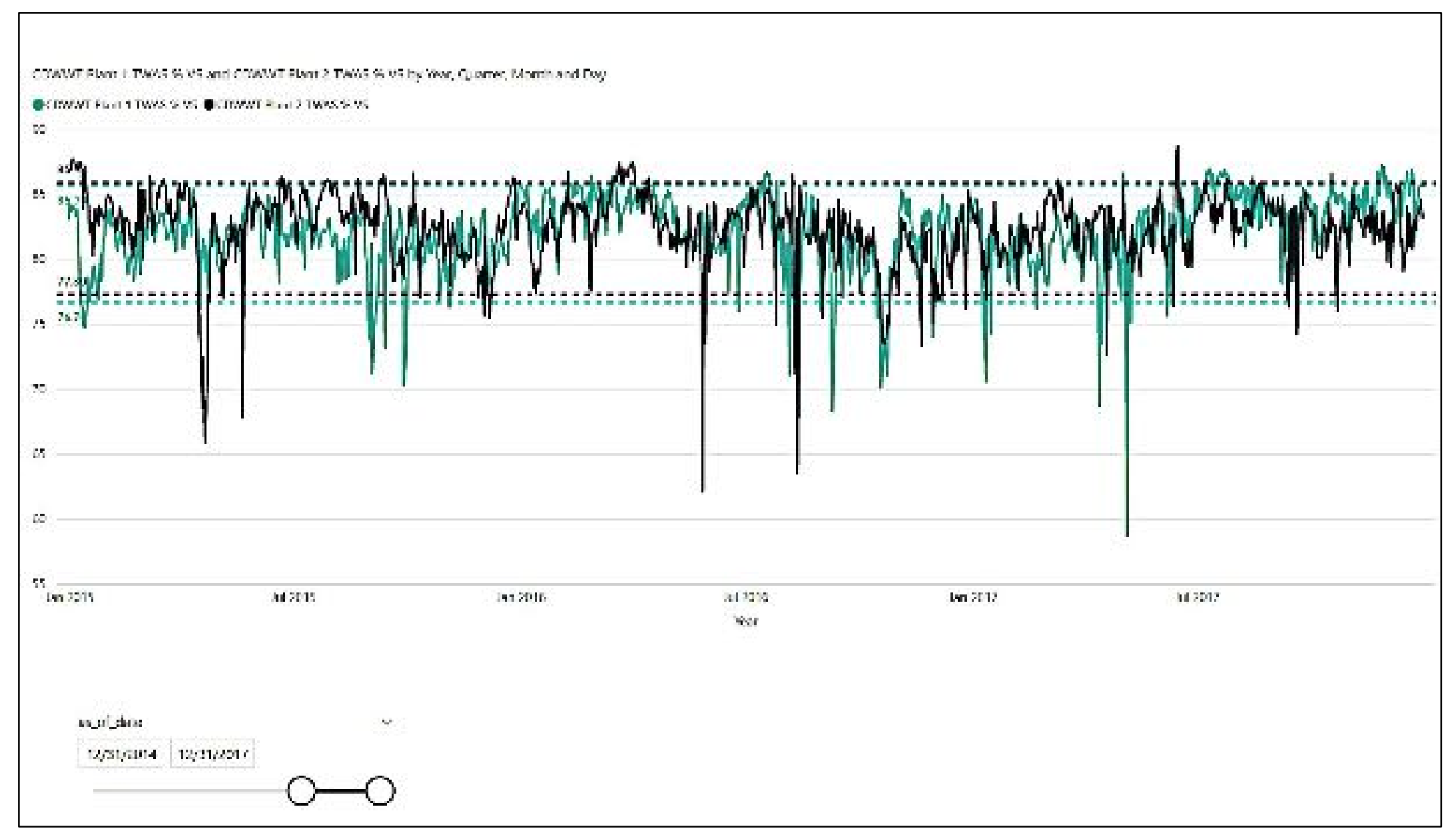




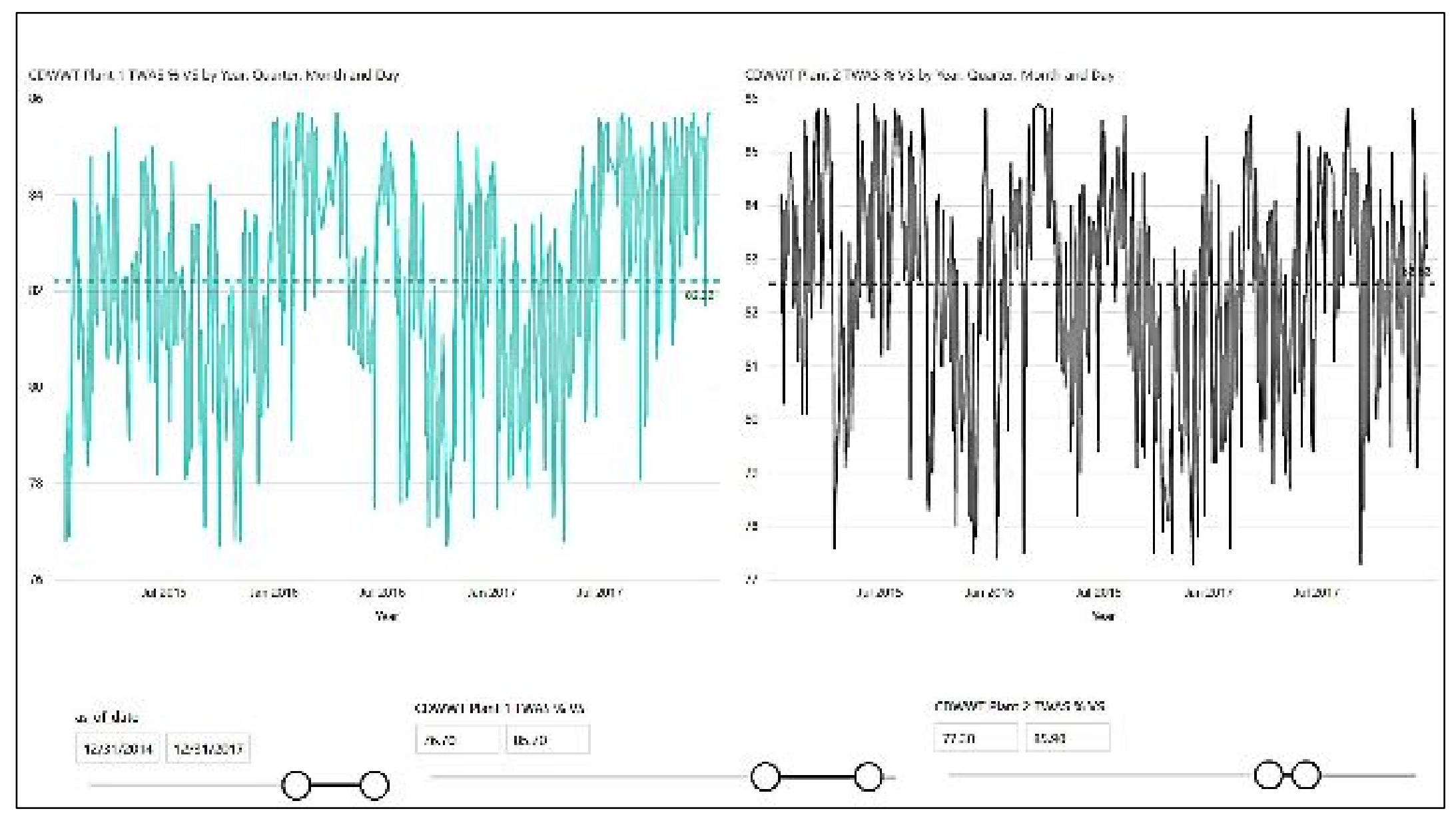




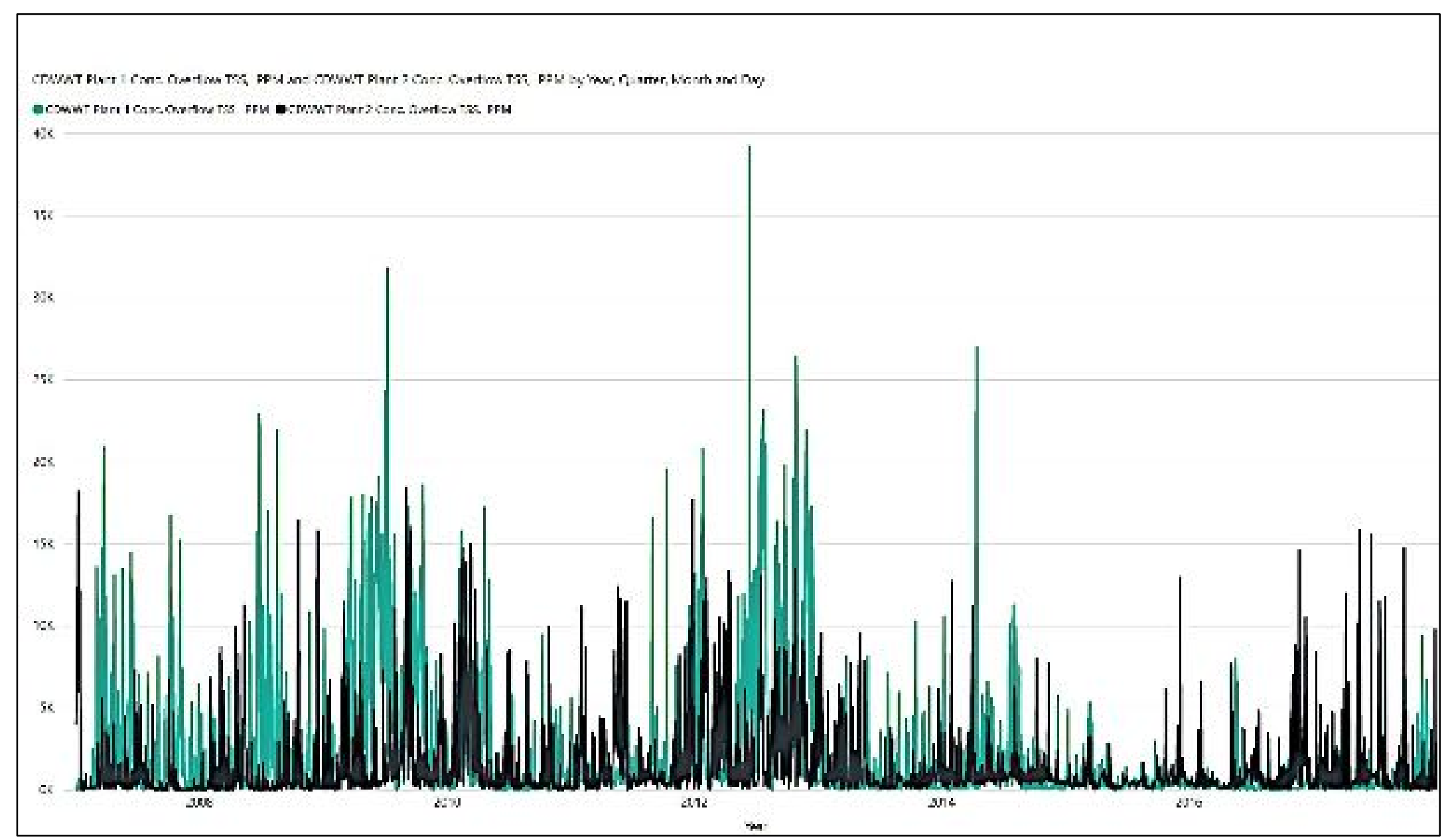




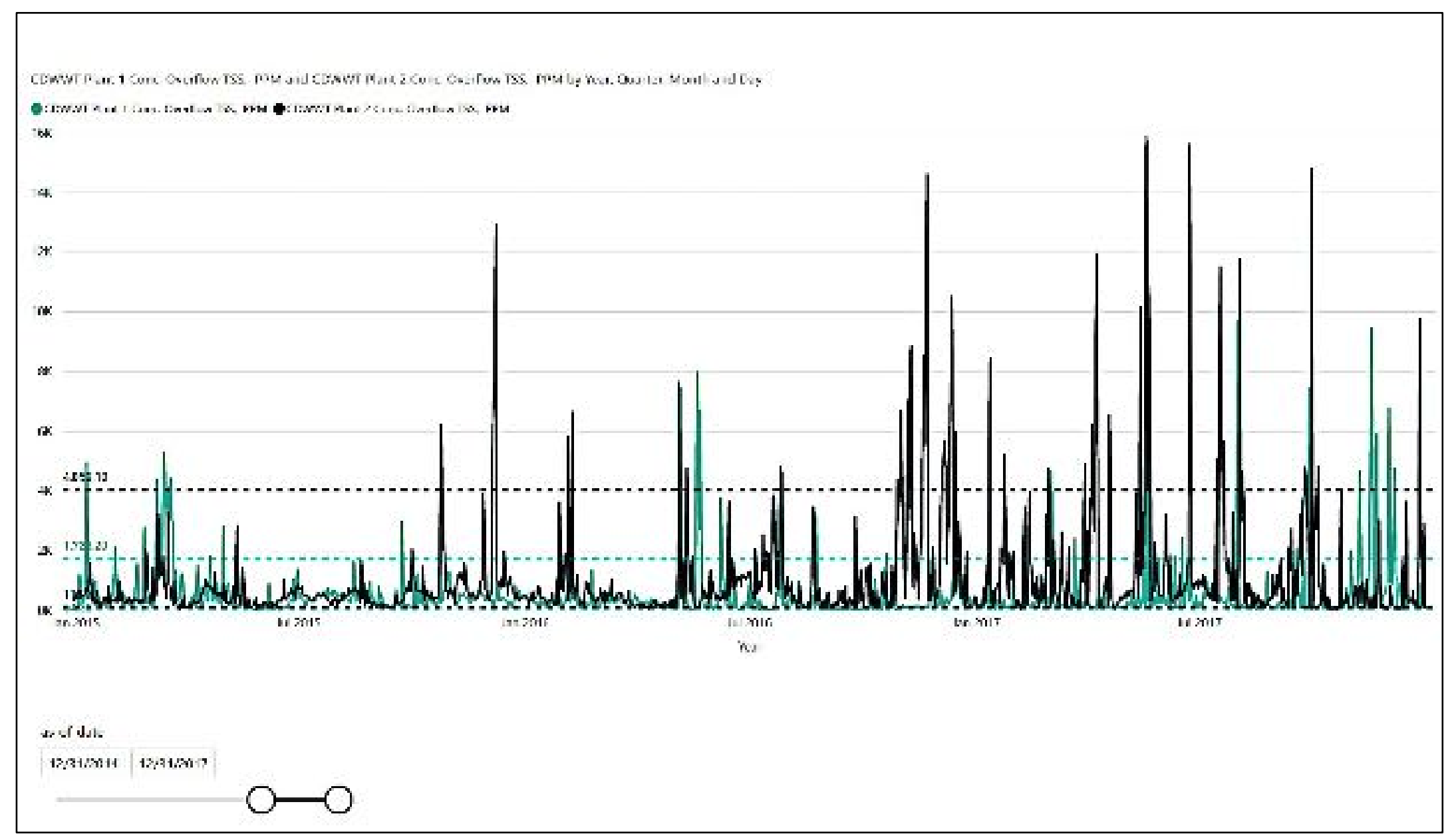




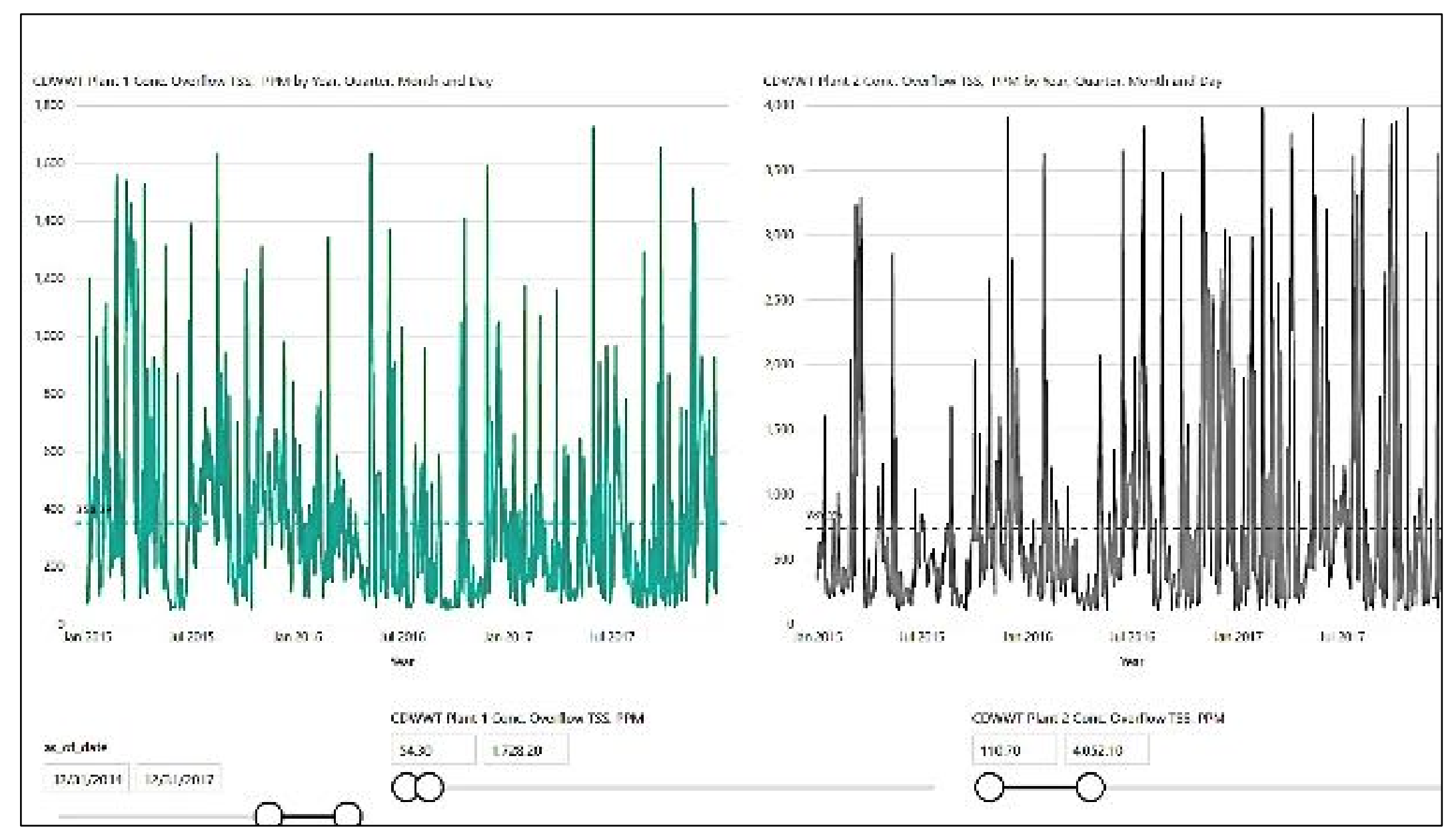





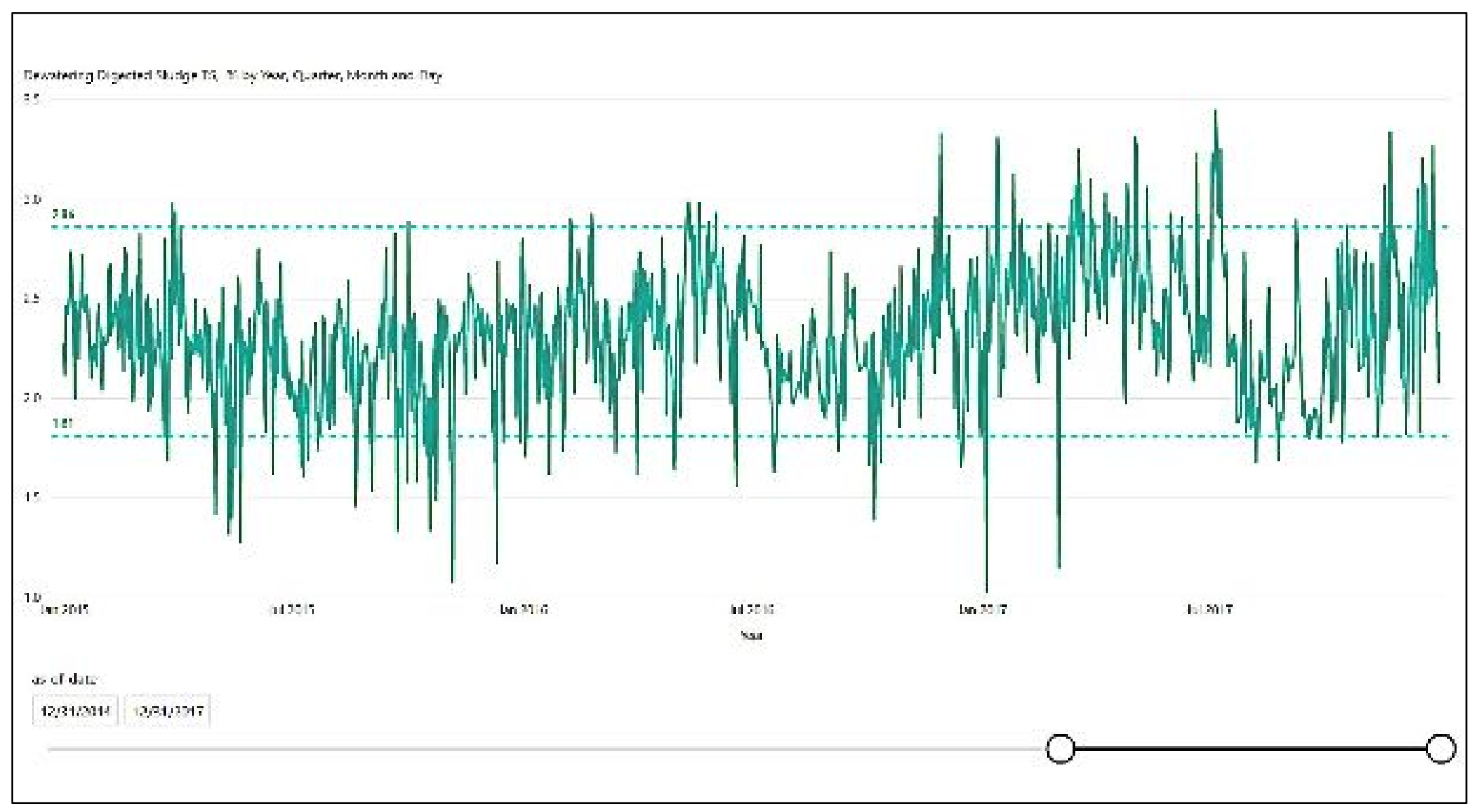

335 


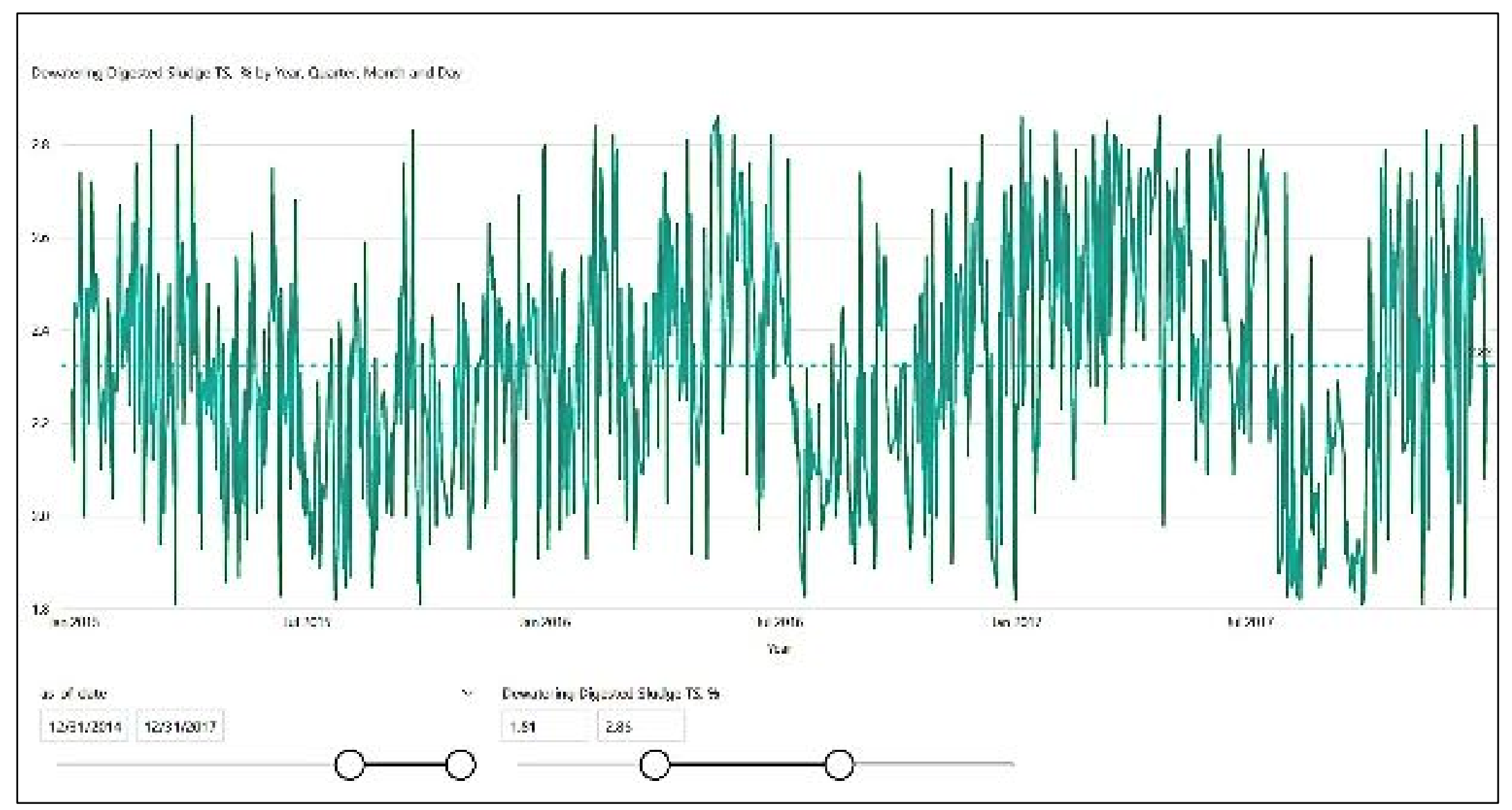




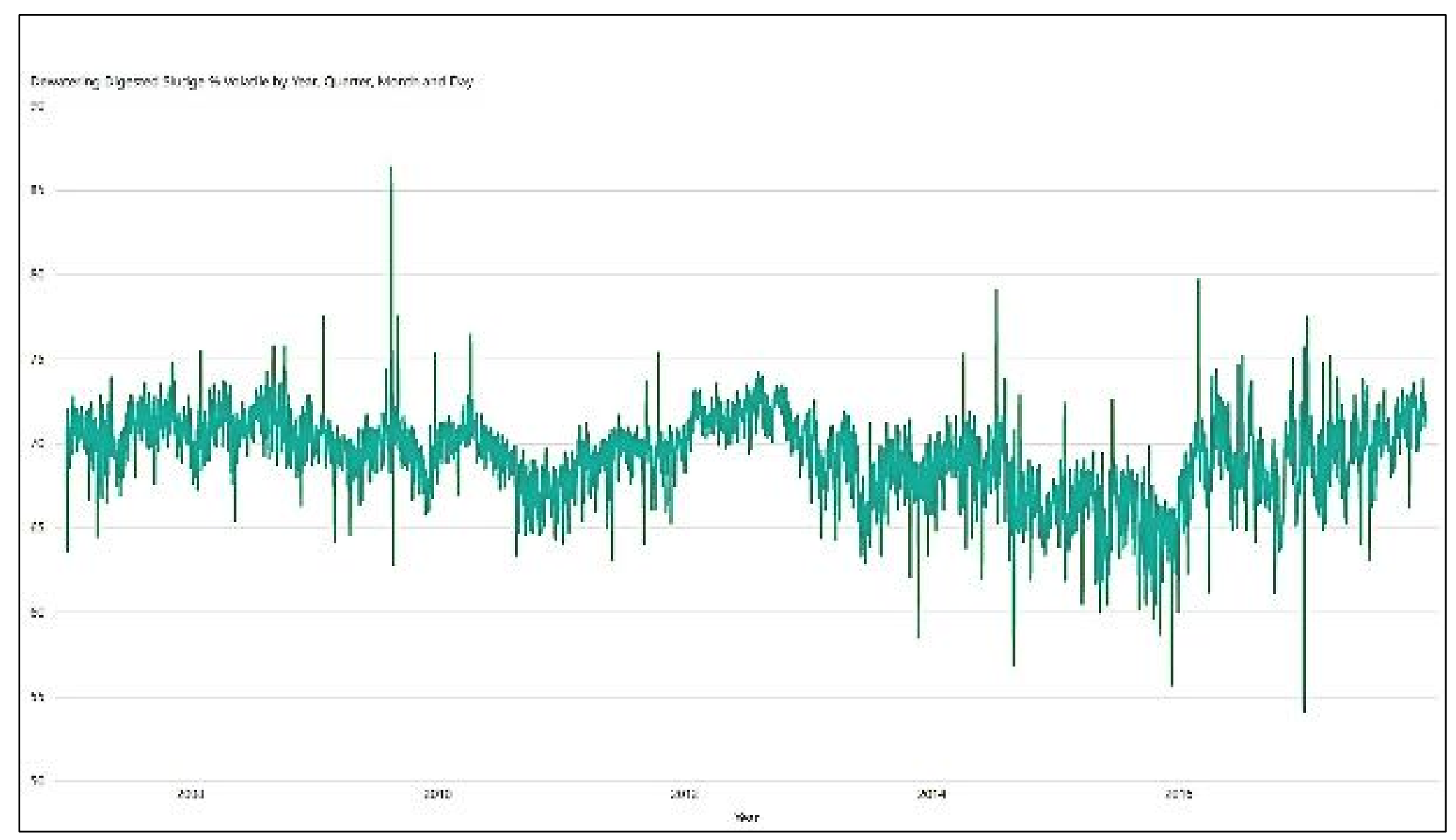

337 


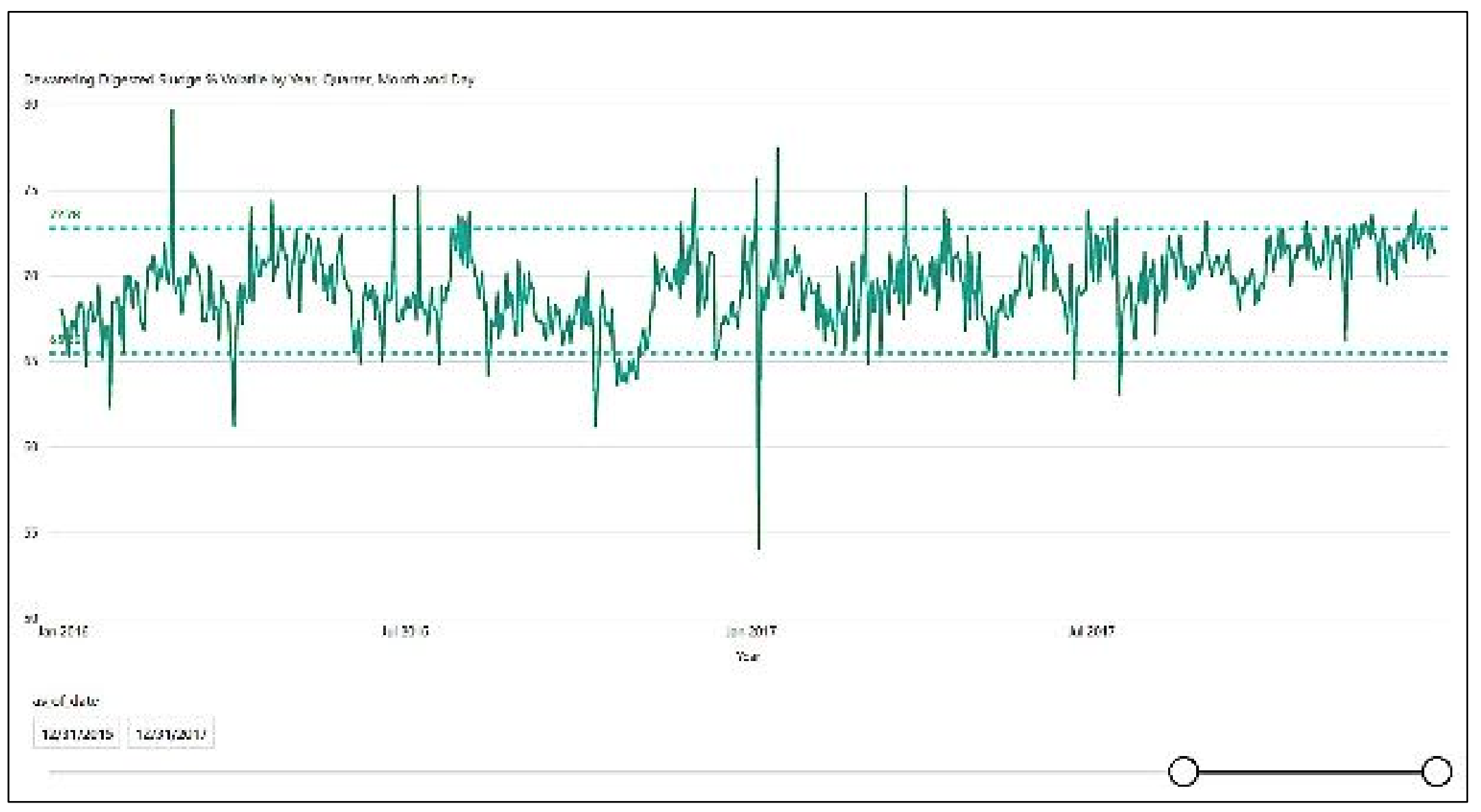




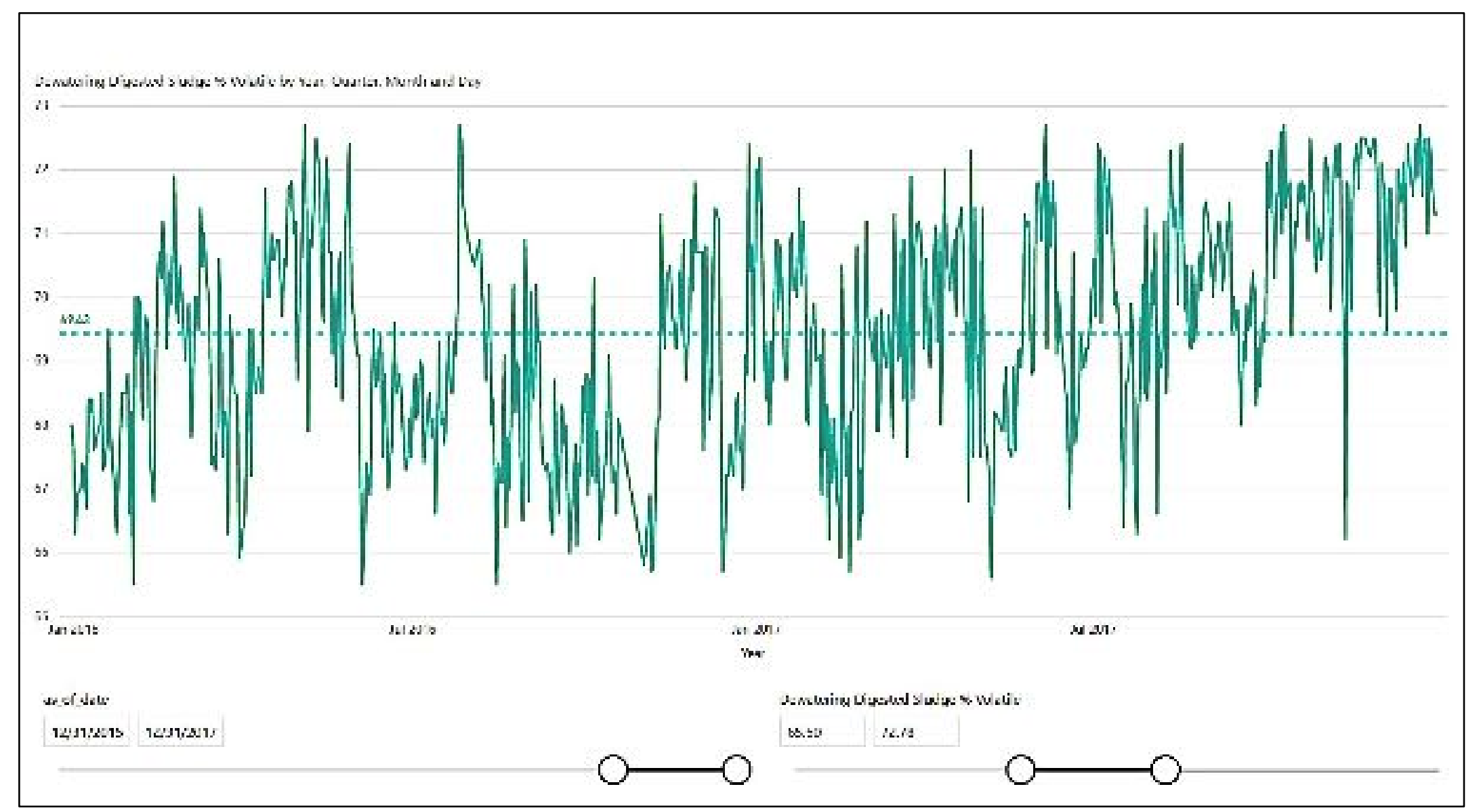




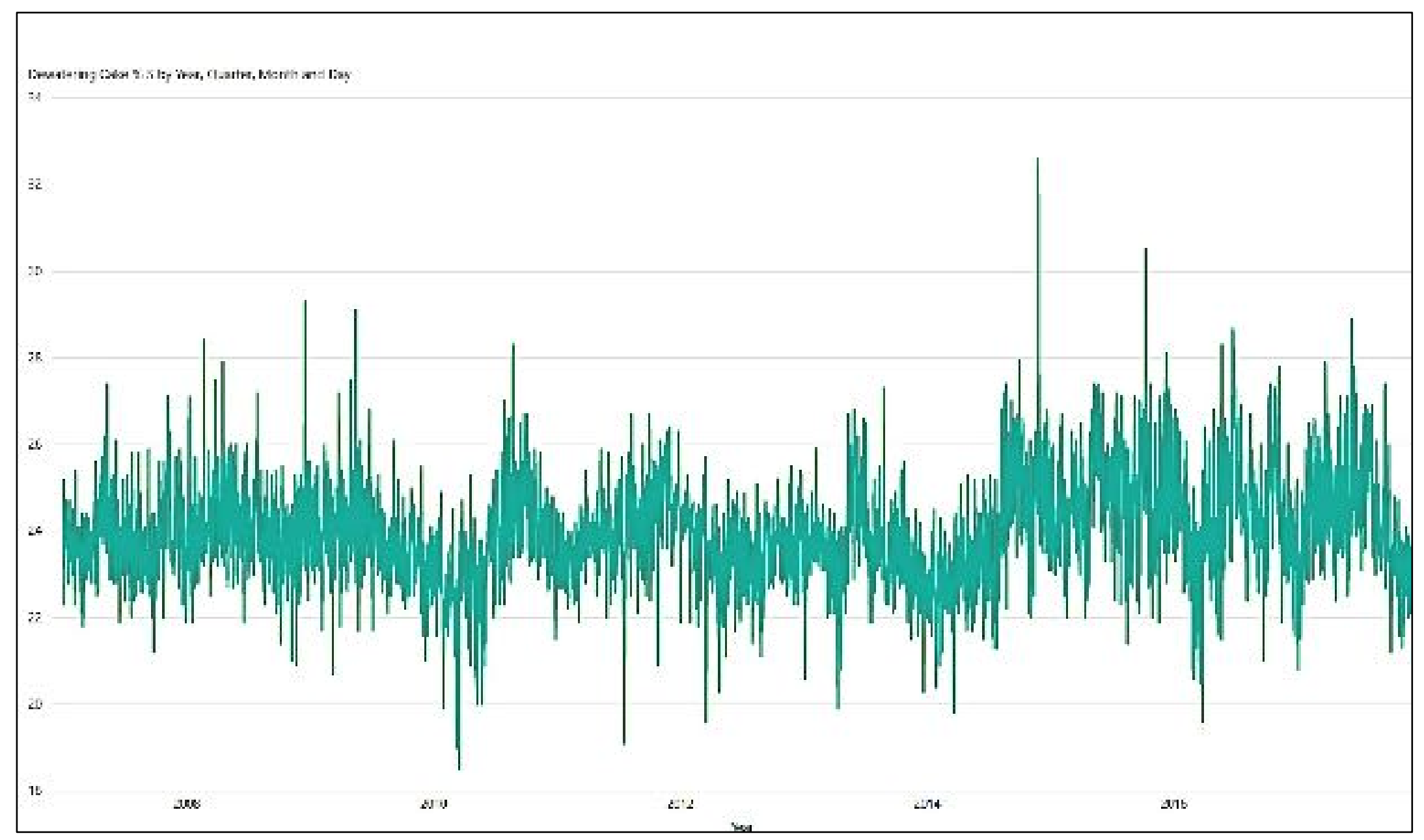




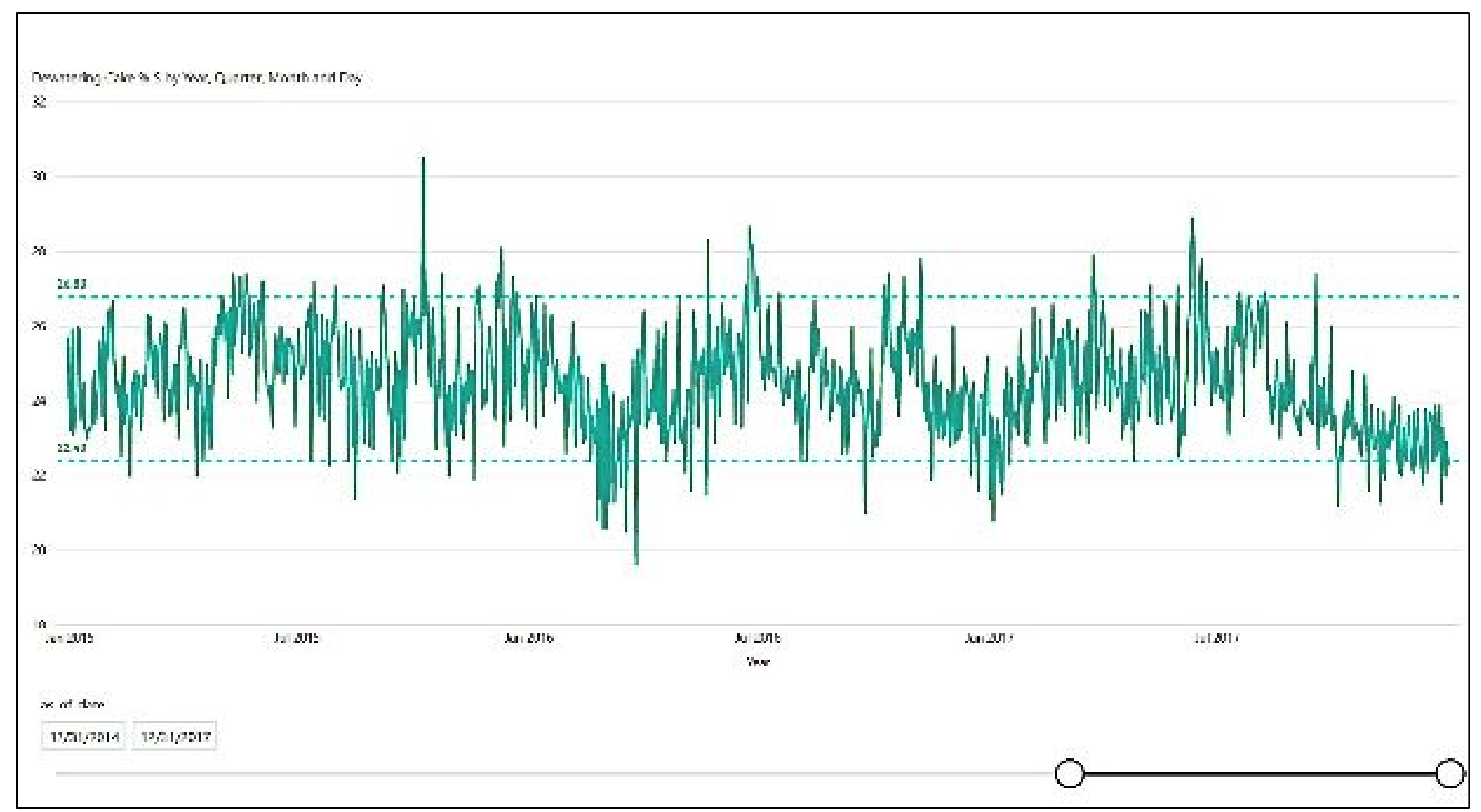




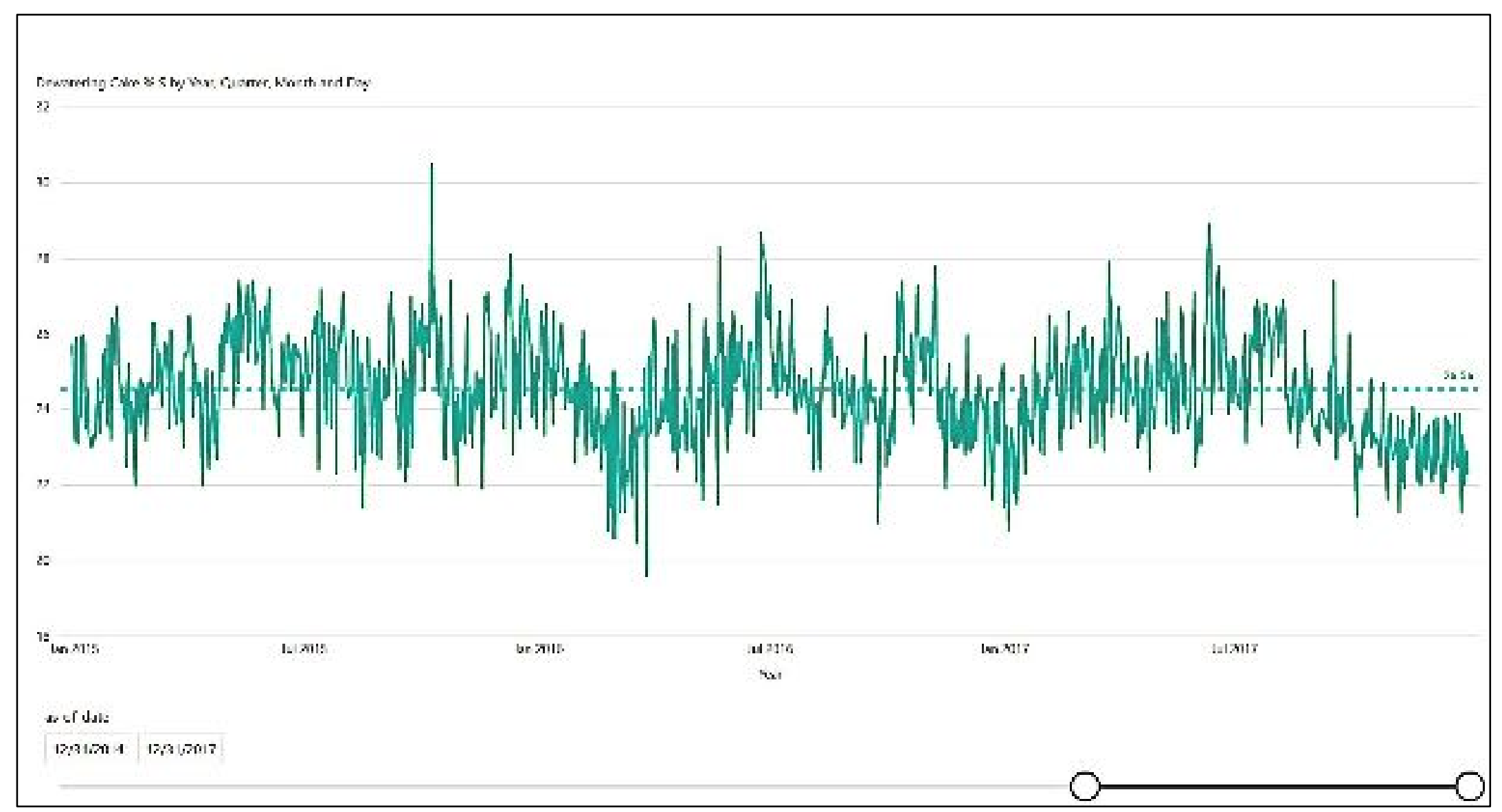




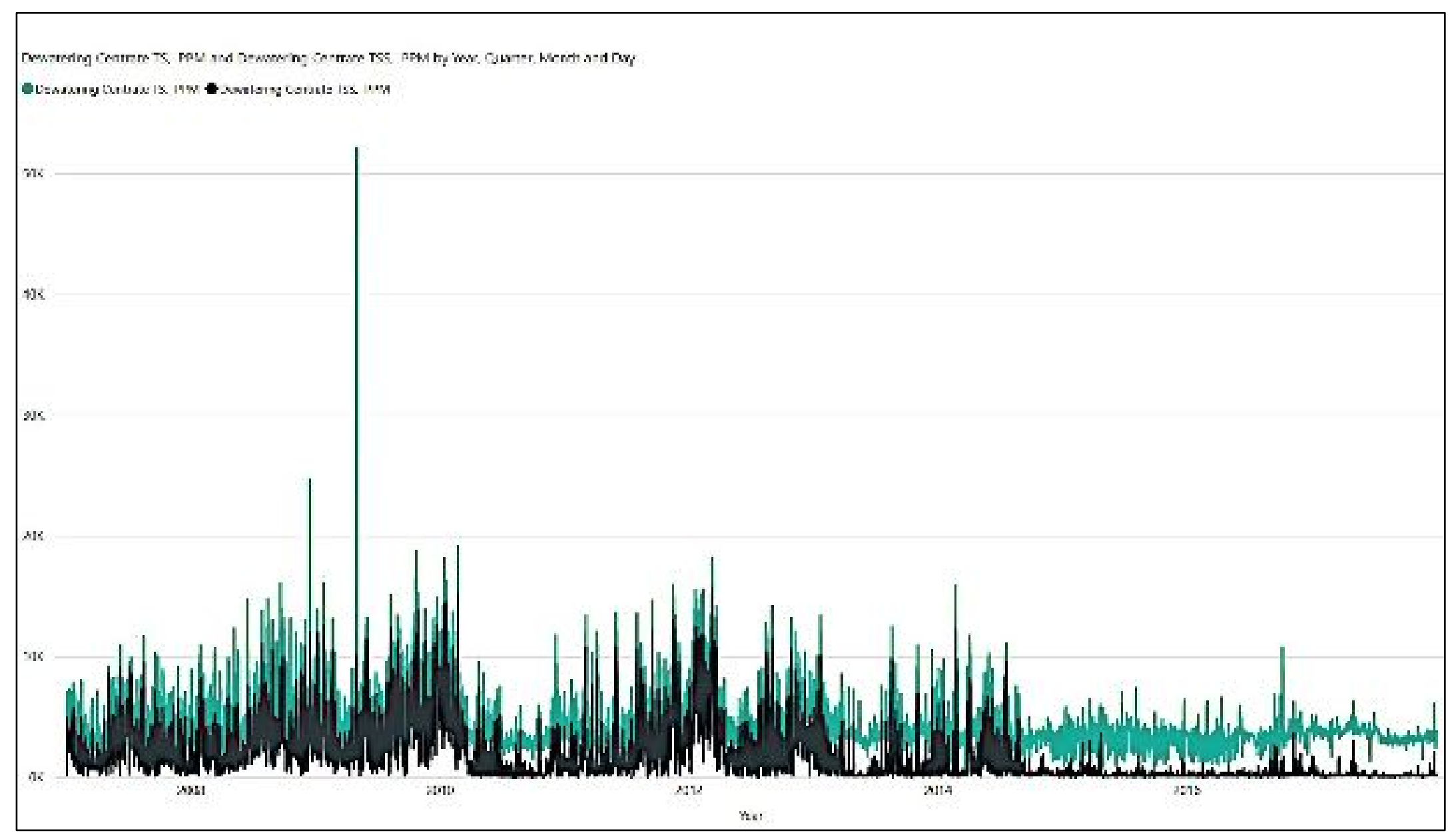




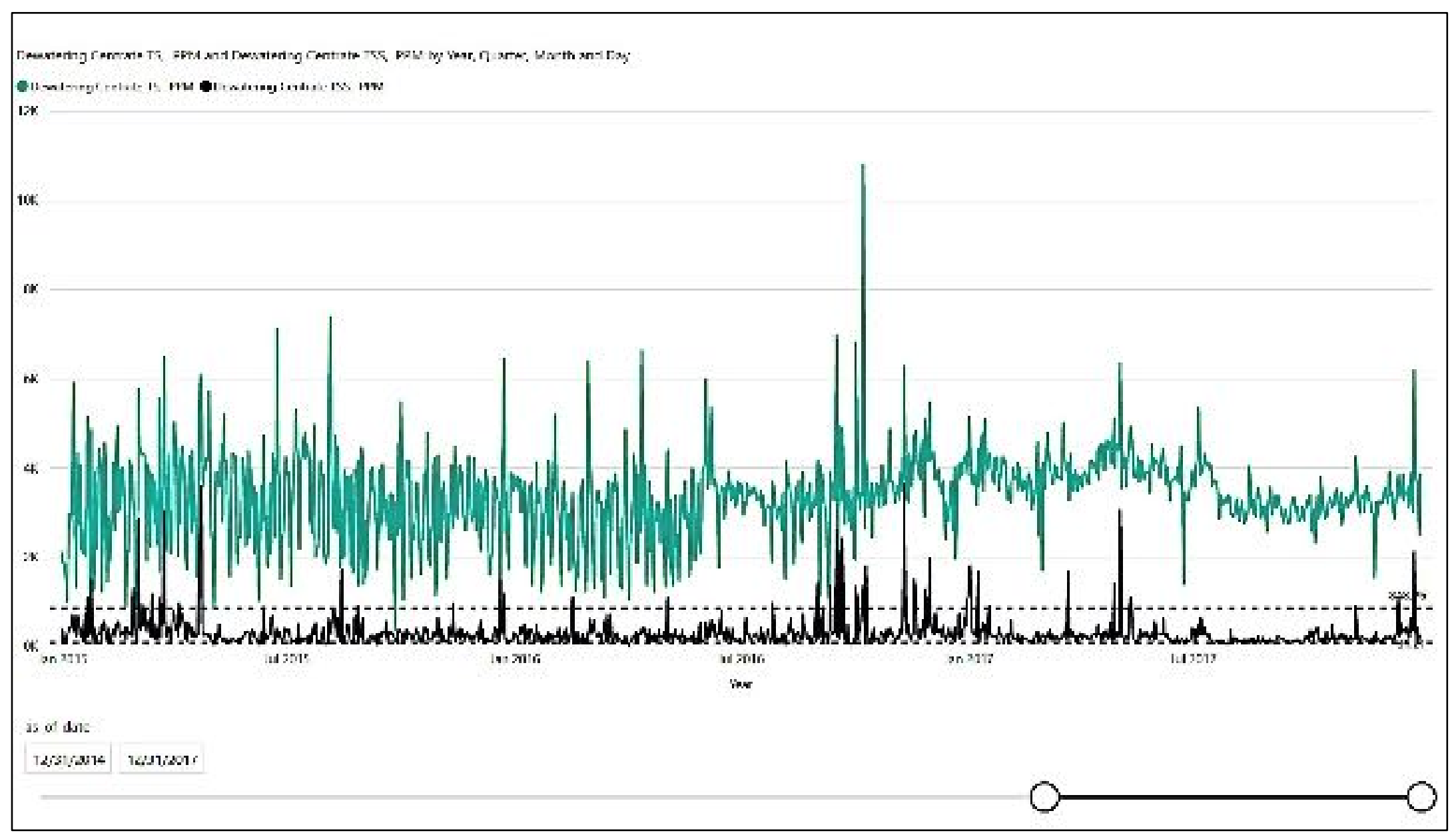




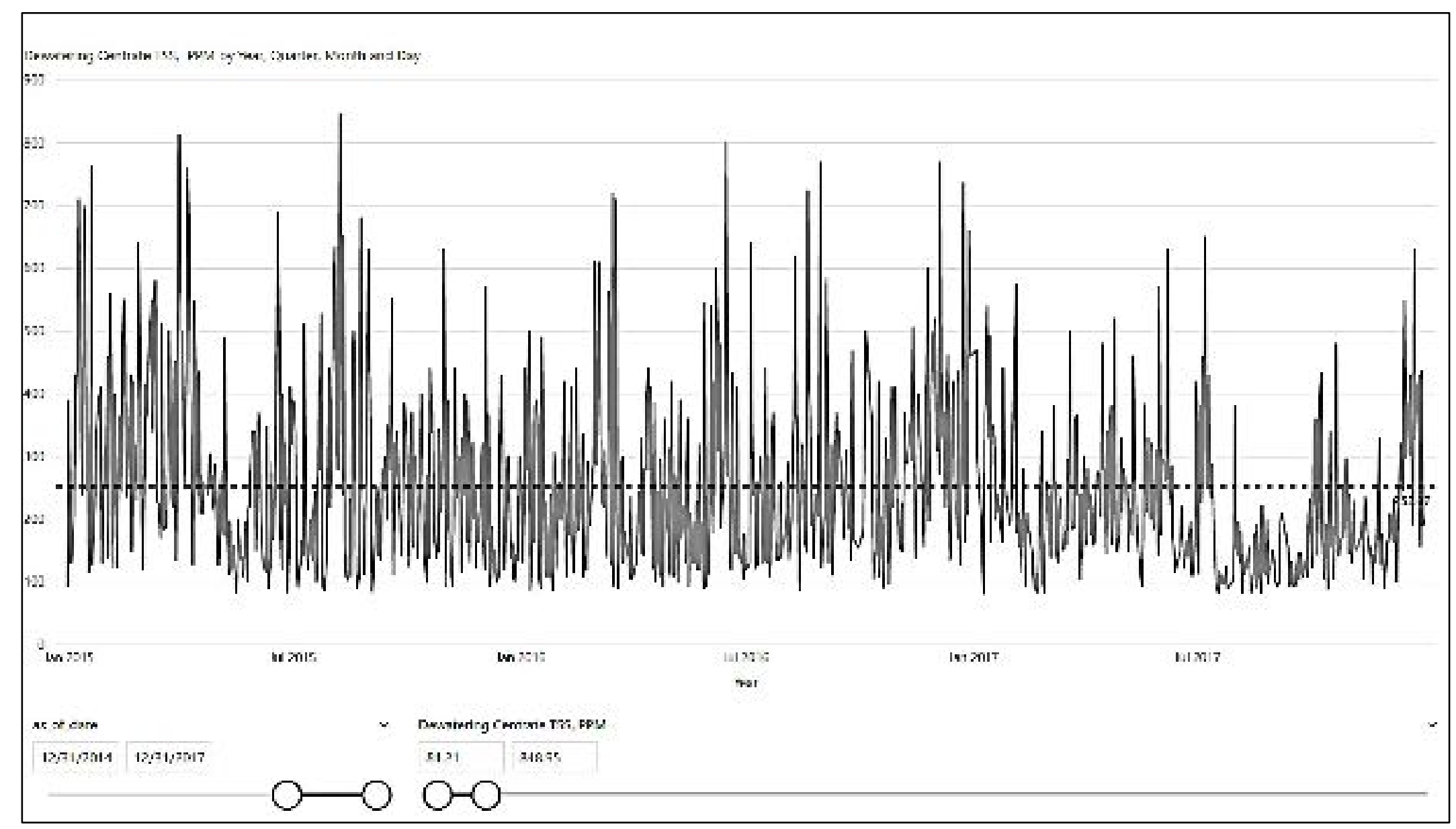


South District WWTP Historical Data Analysis for MBM calibration

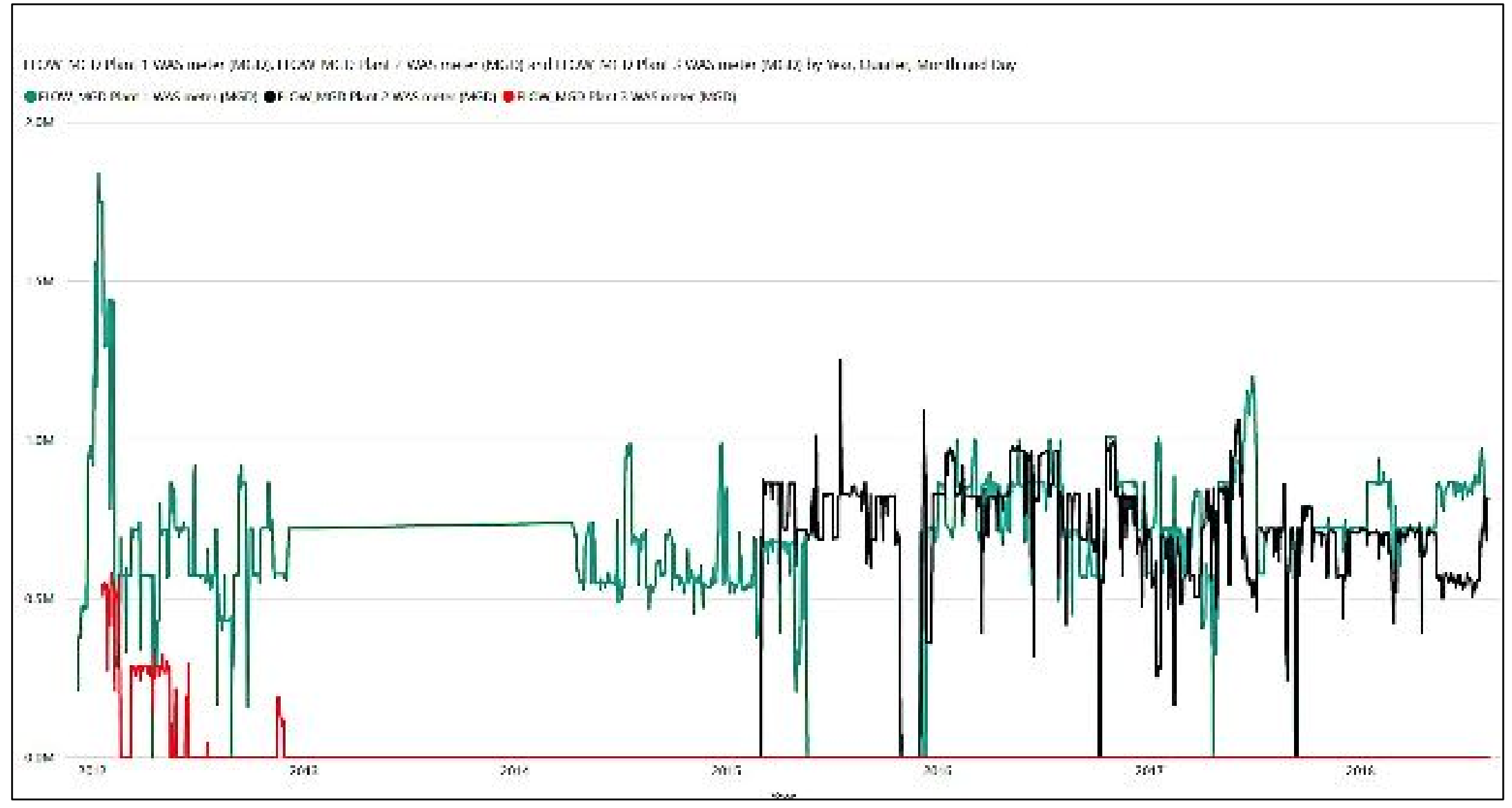




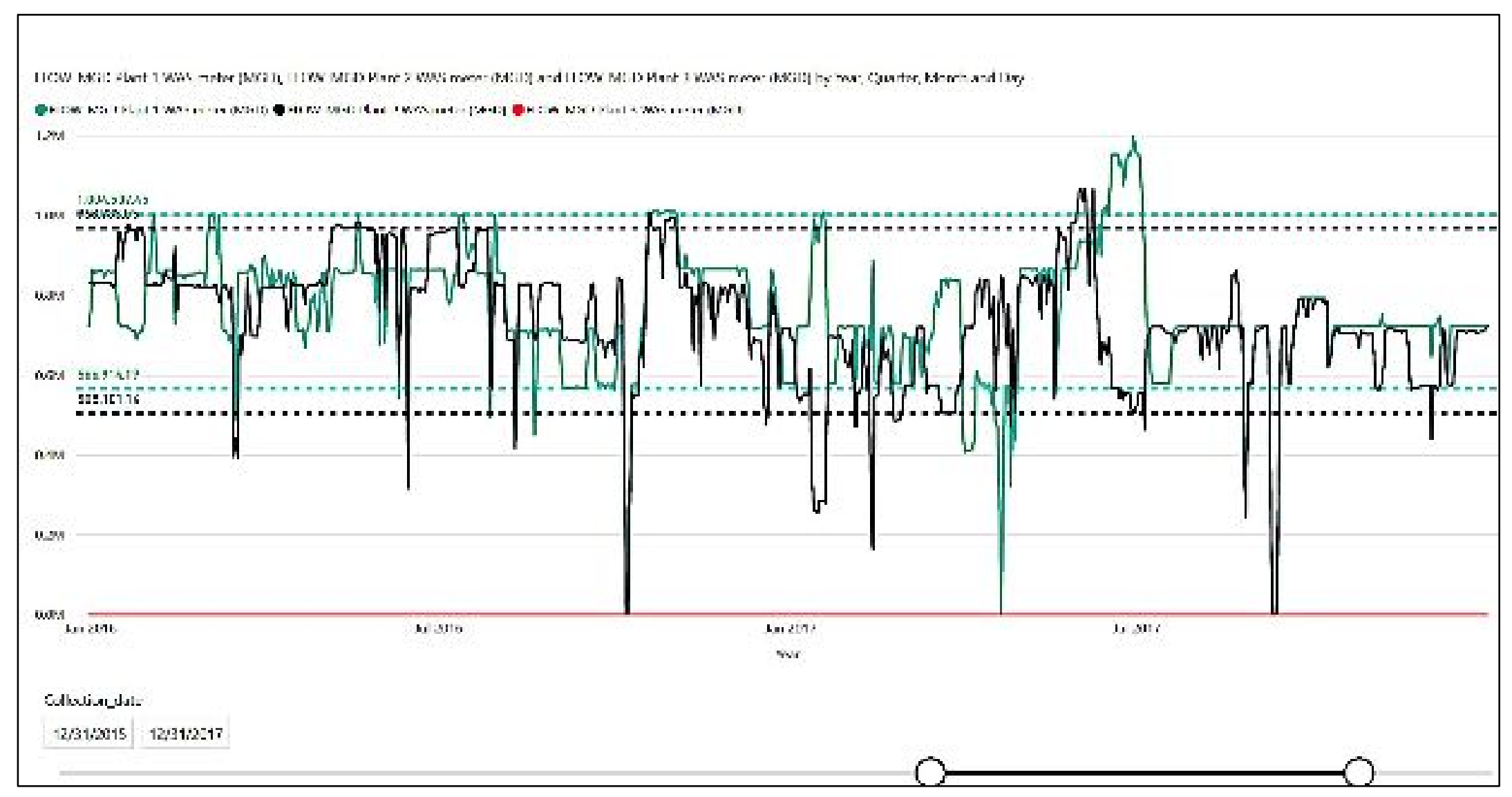









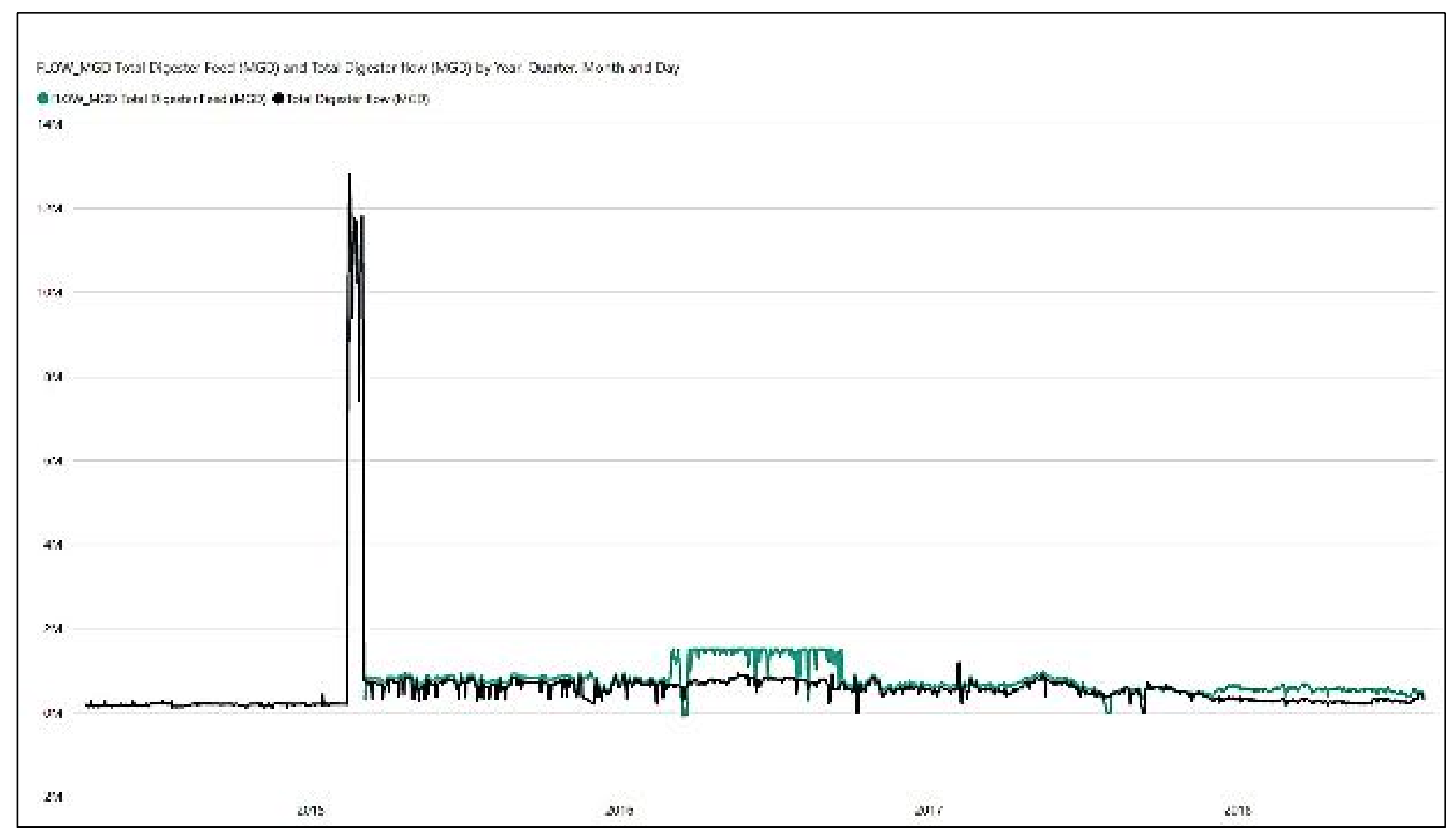




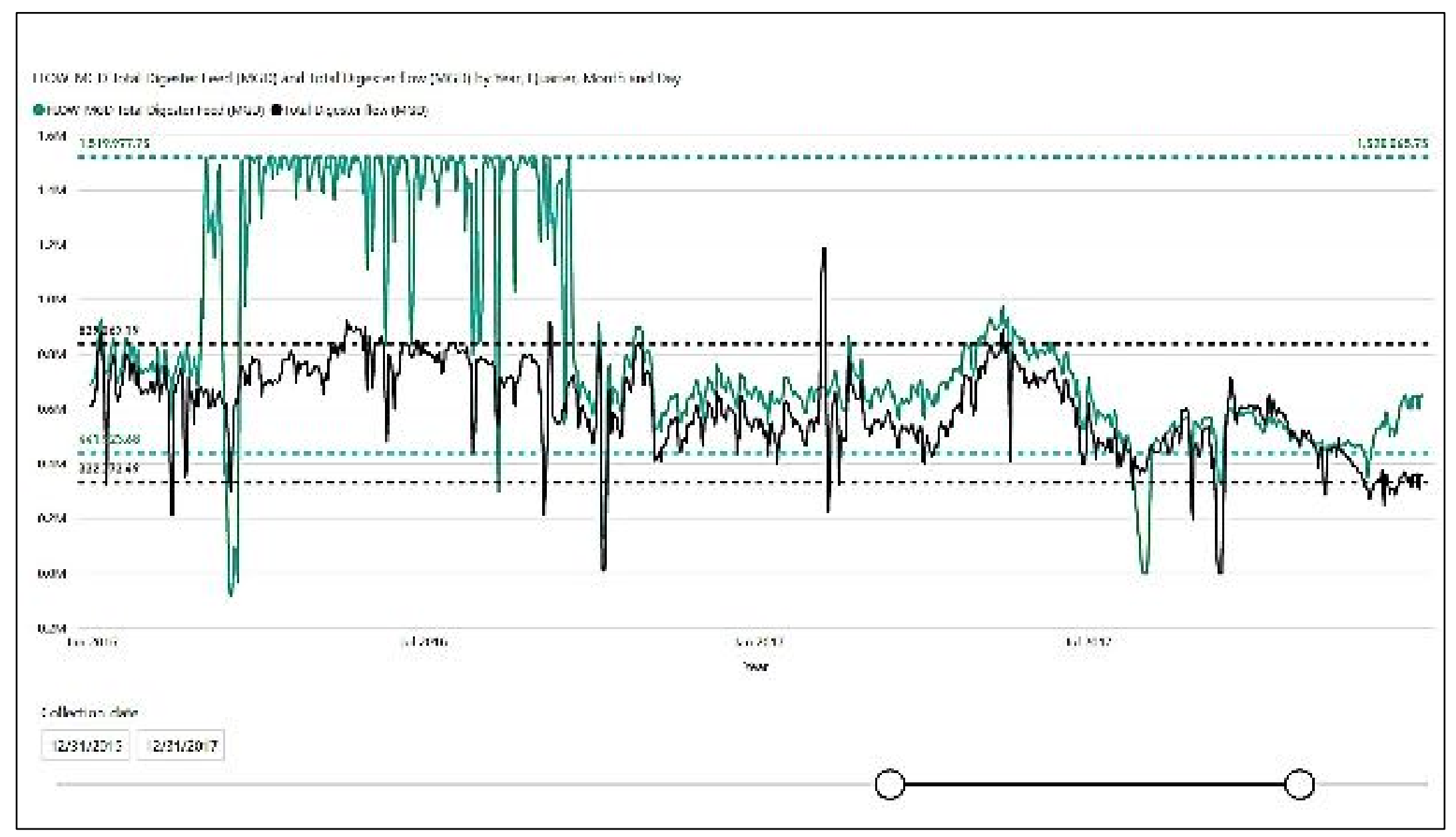




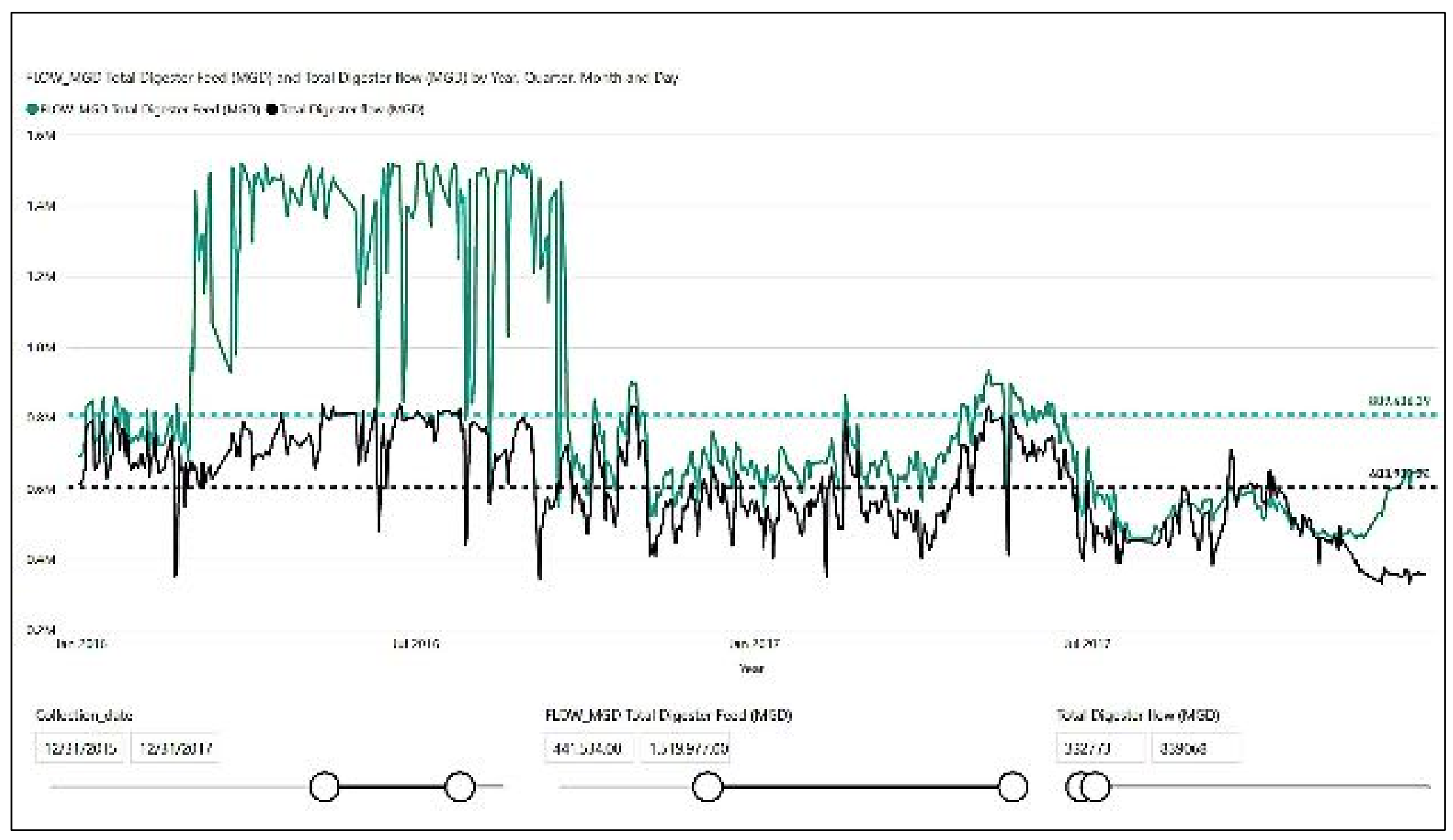




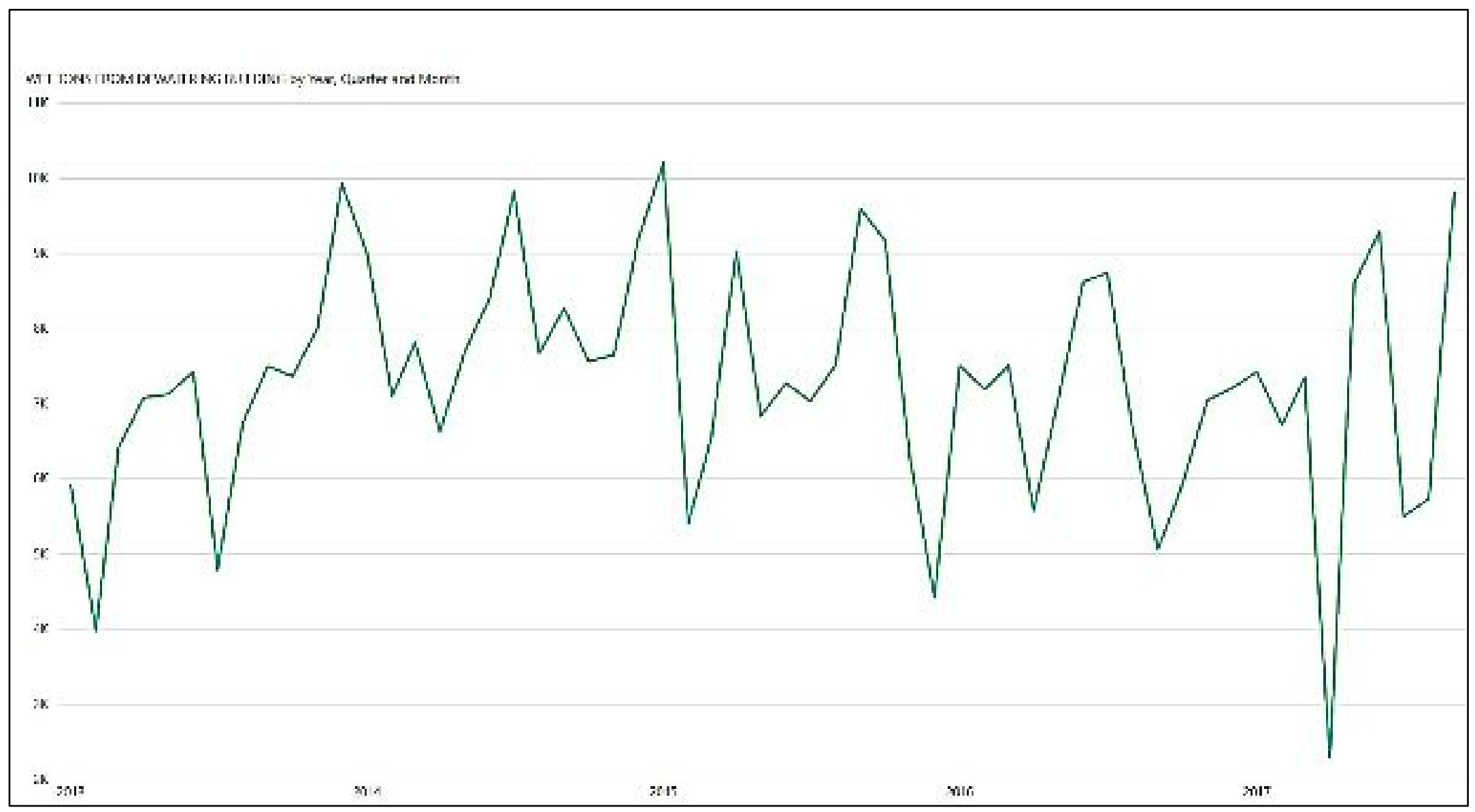

352 


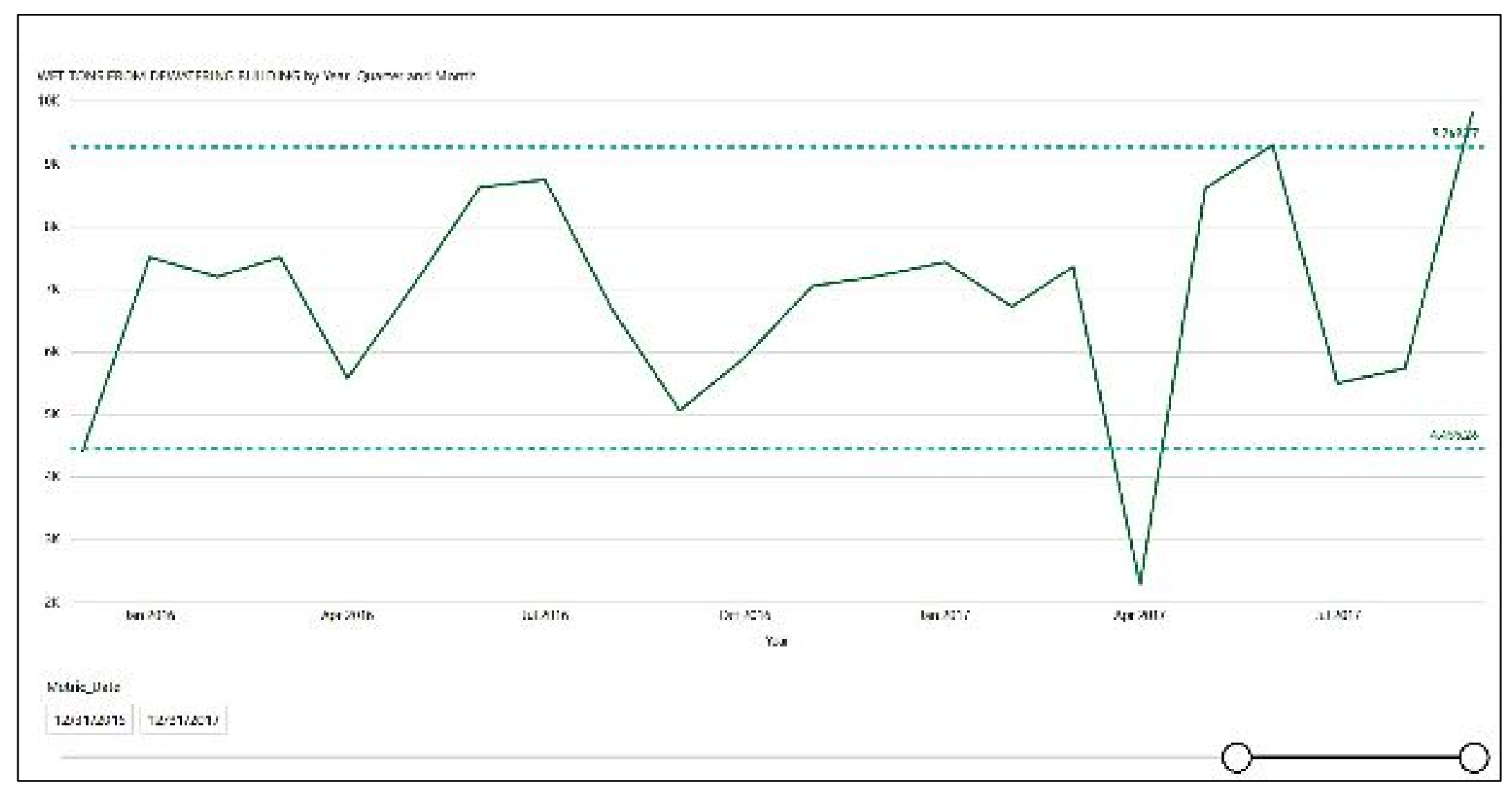




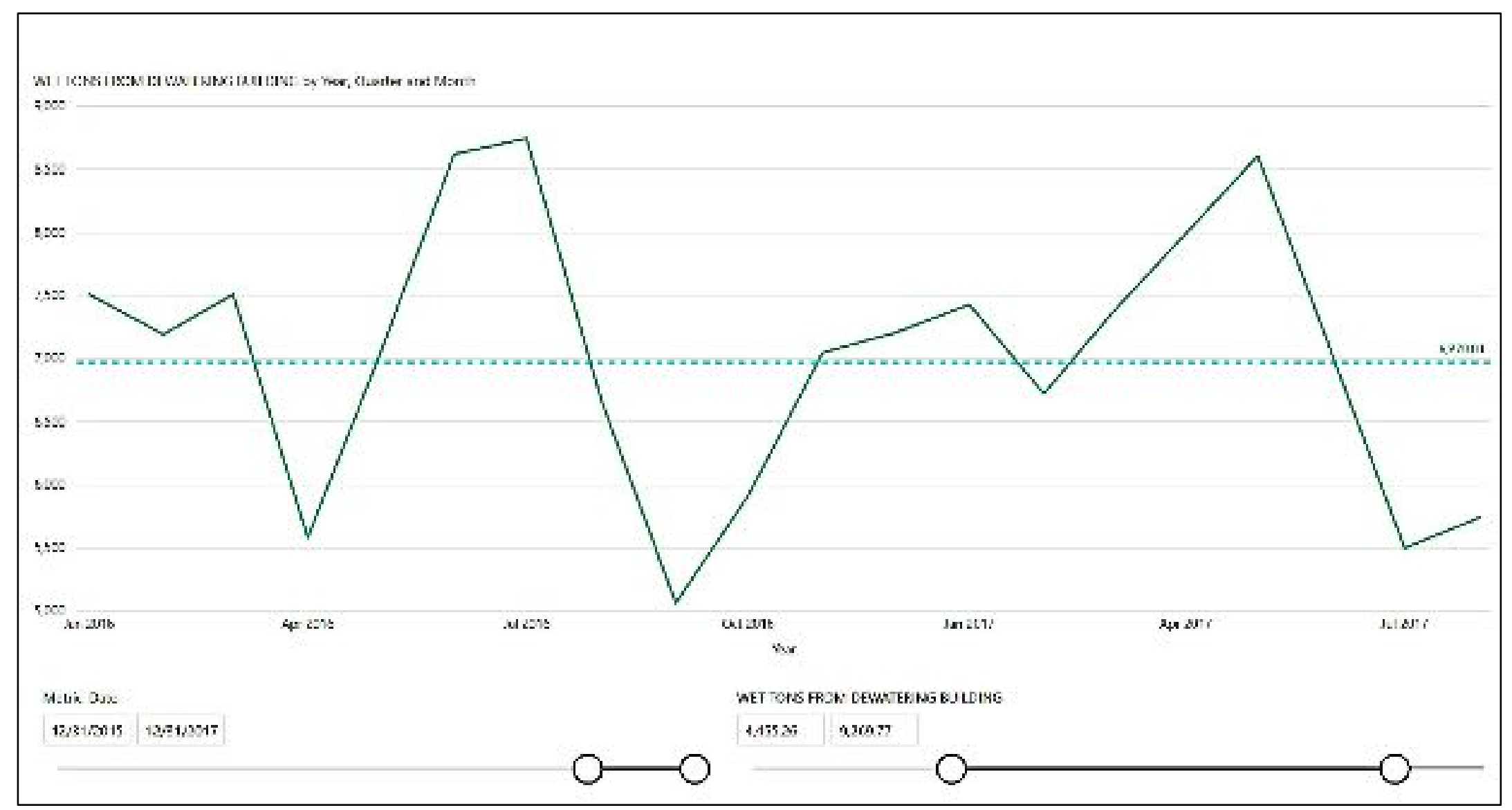


Central District WWTP Historical Data Analysis for MBM calibration

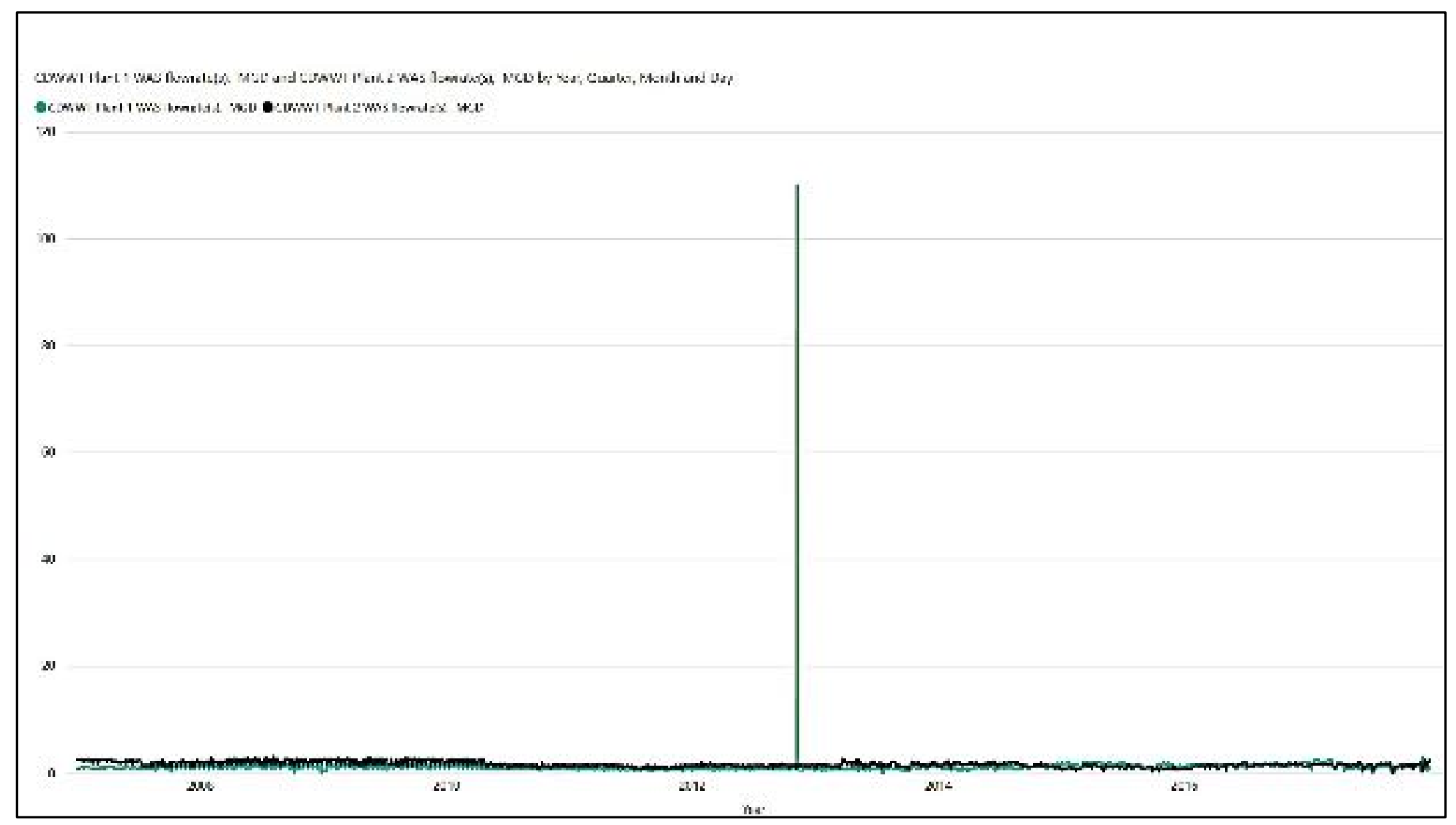




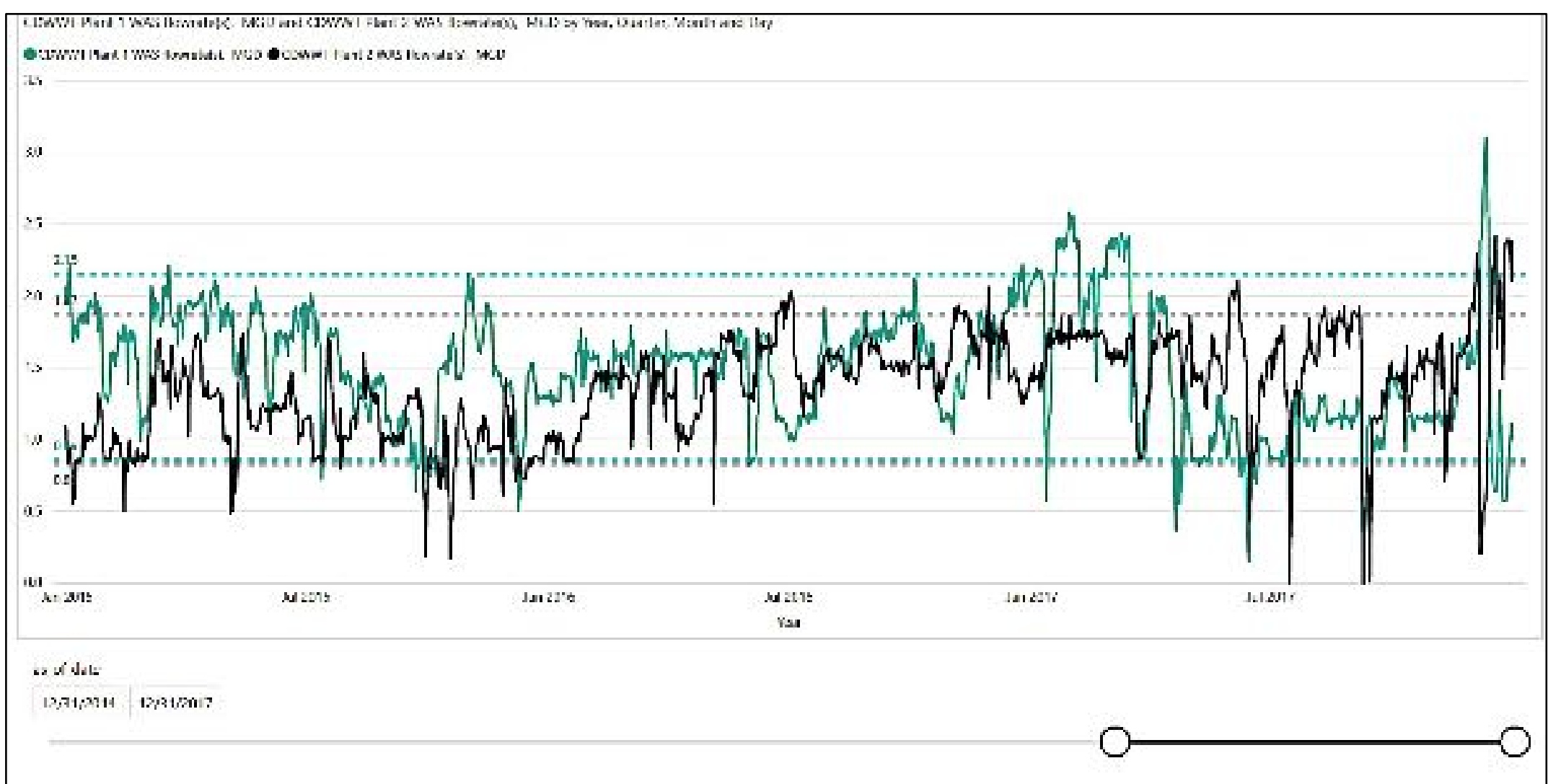




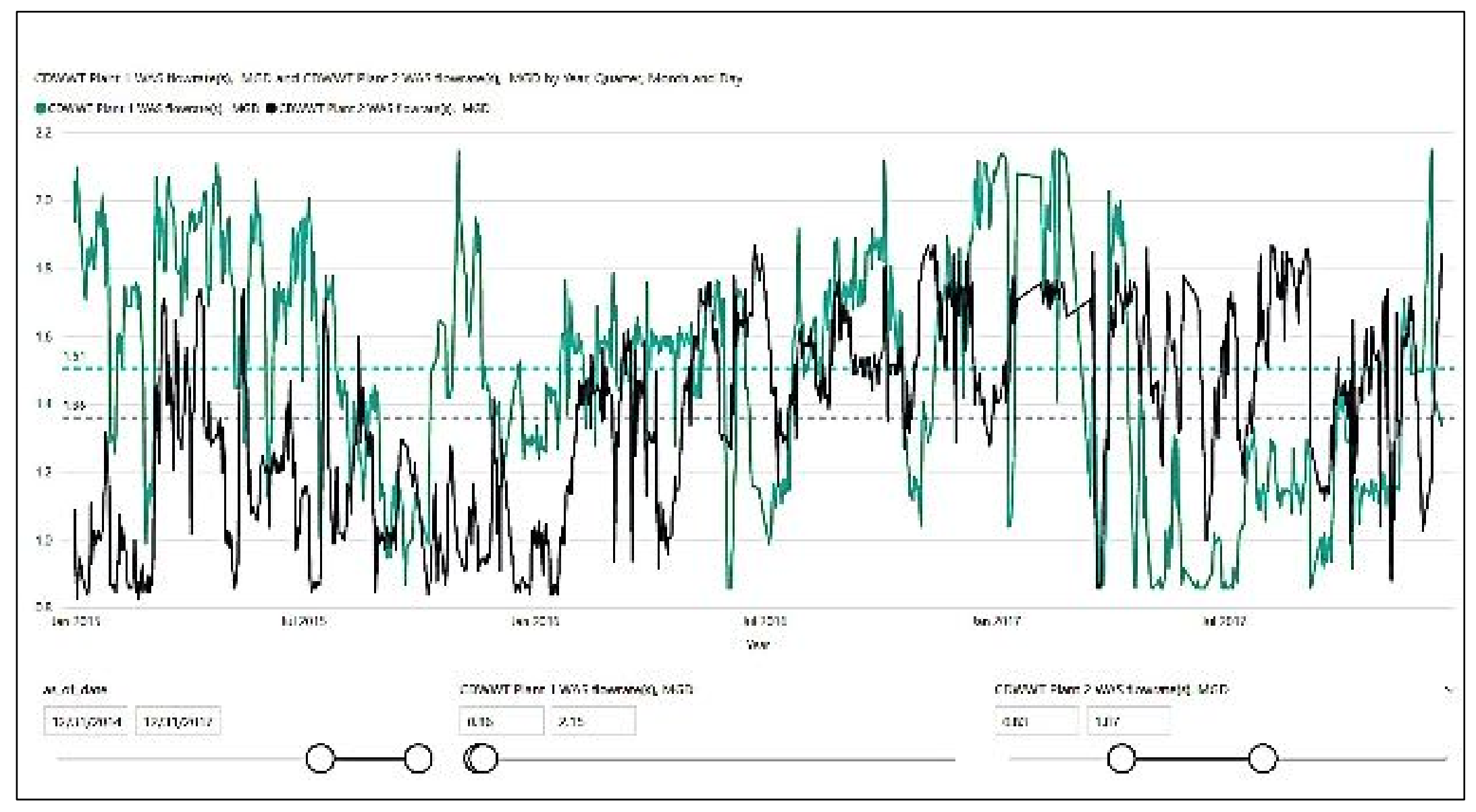




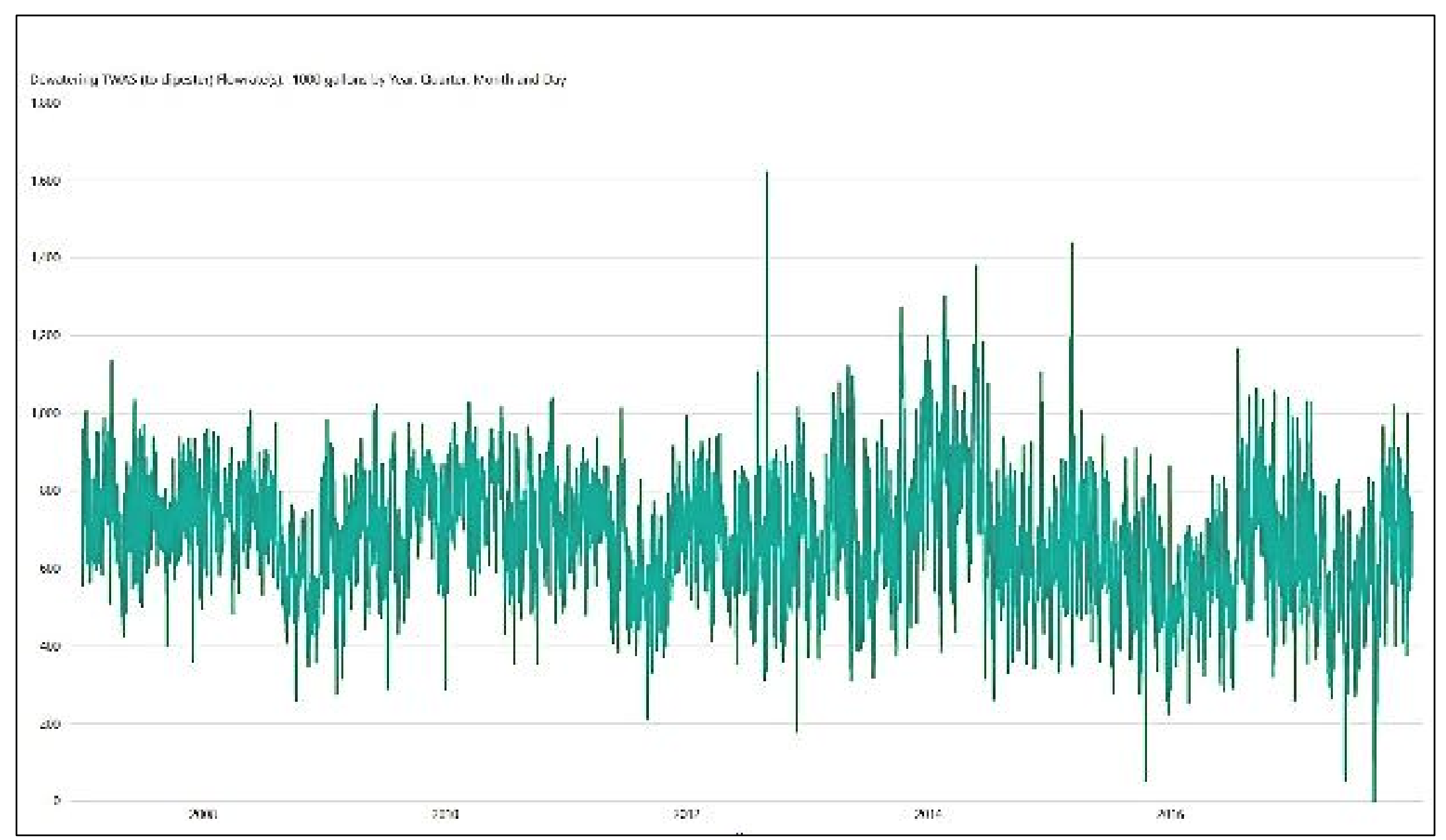




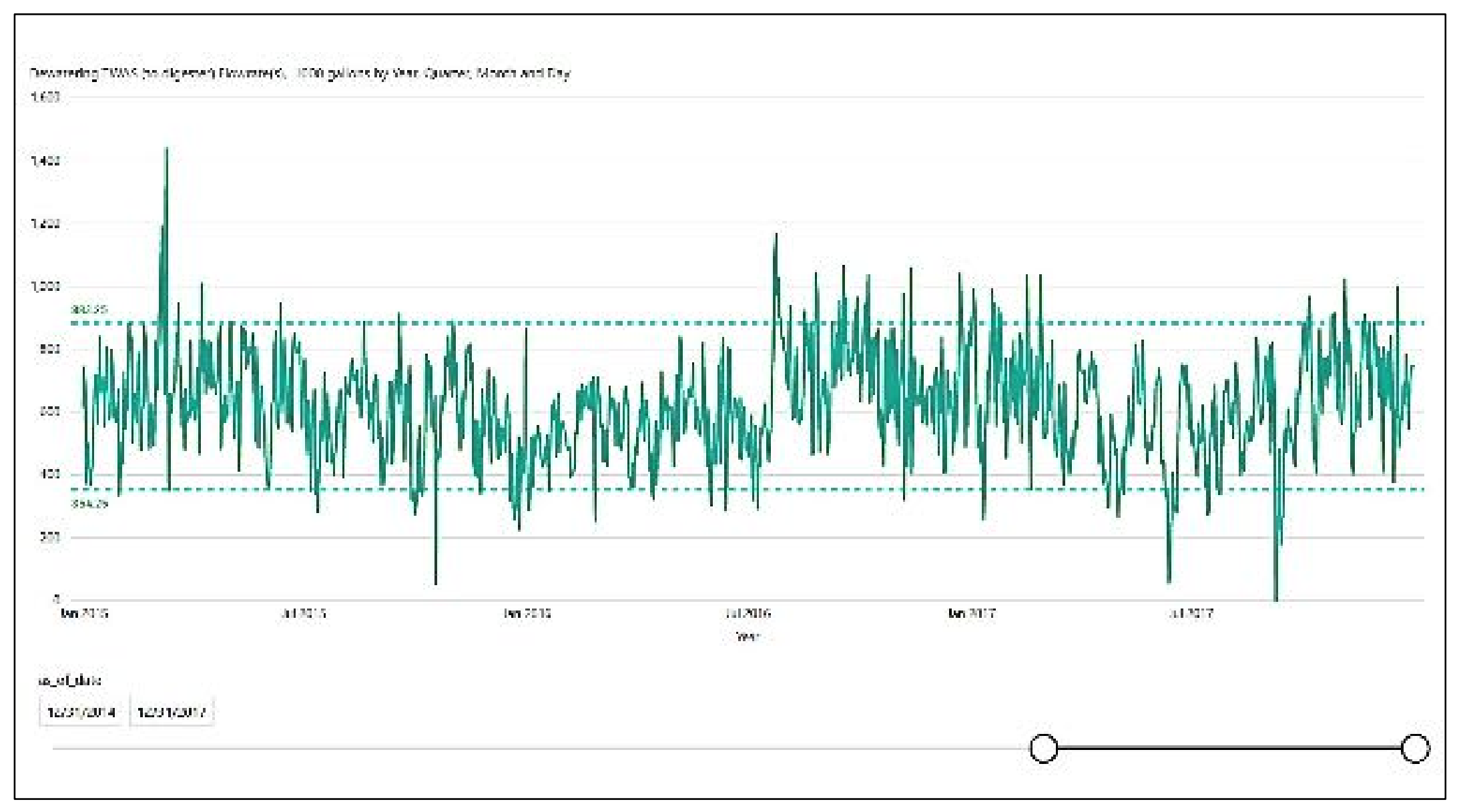

359 


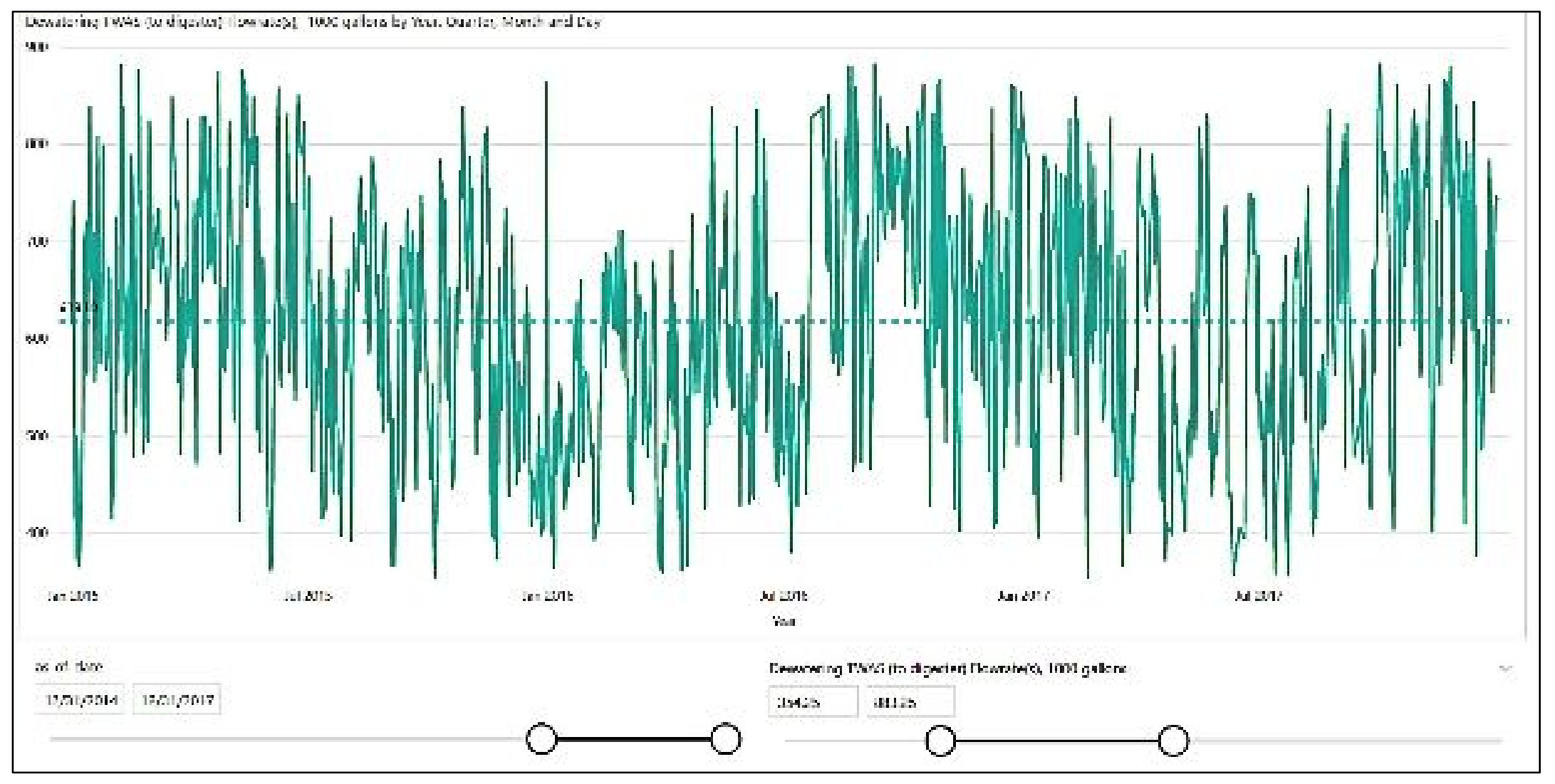

360 


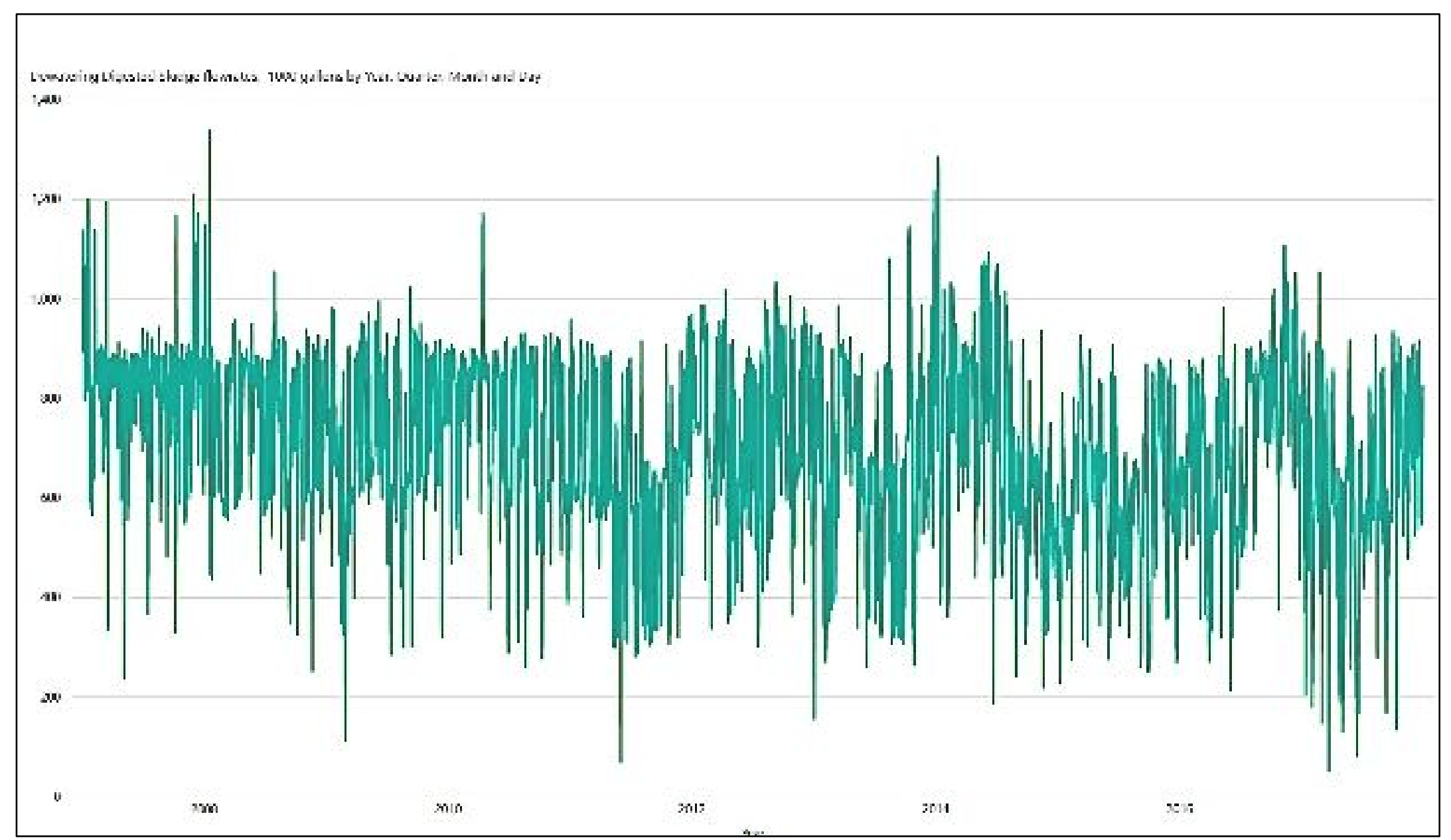




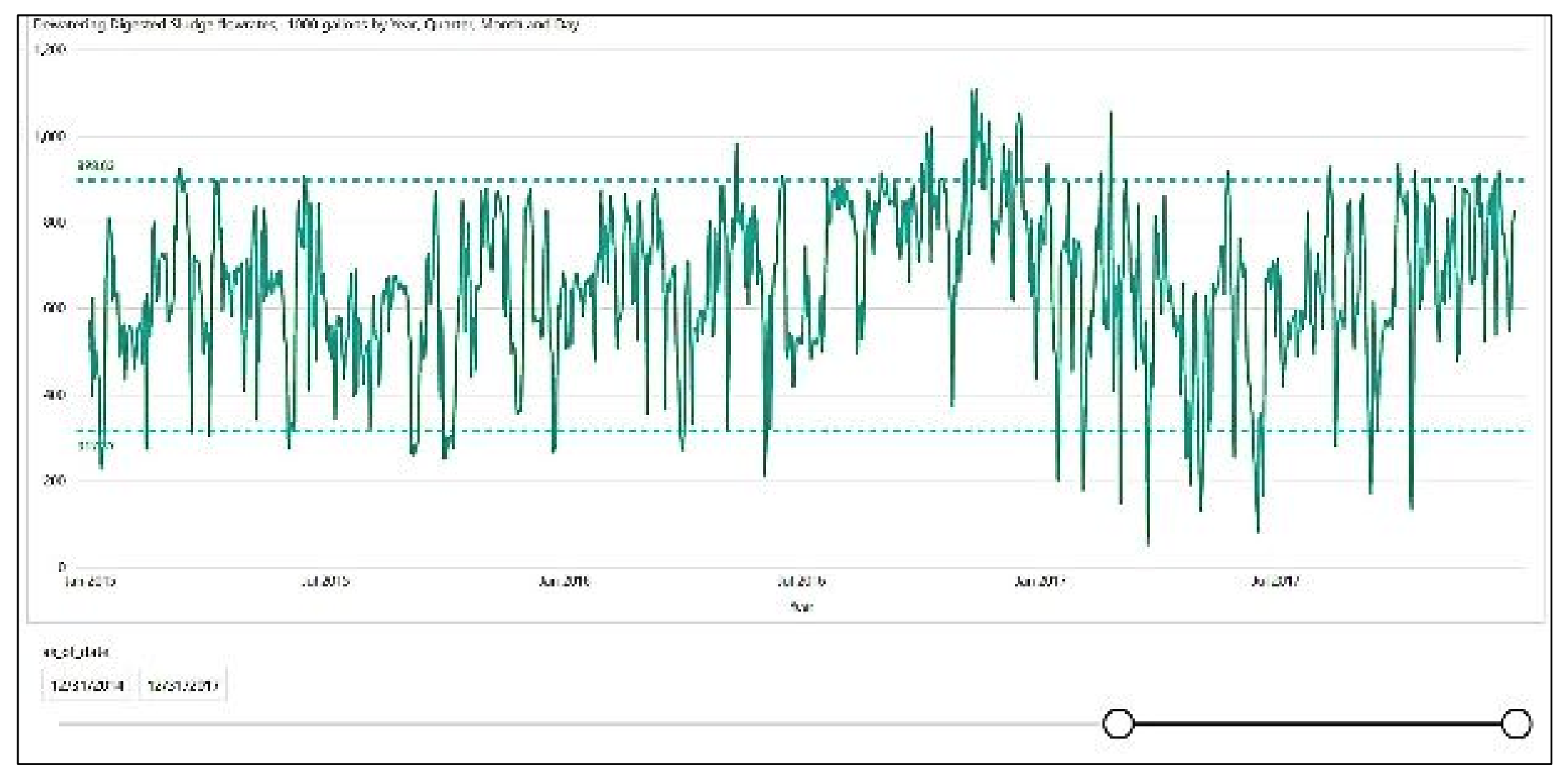




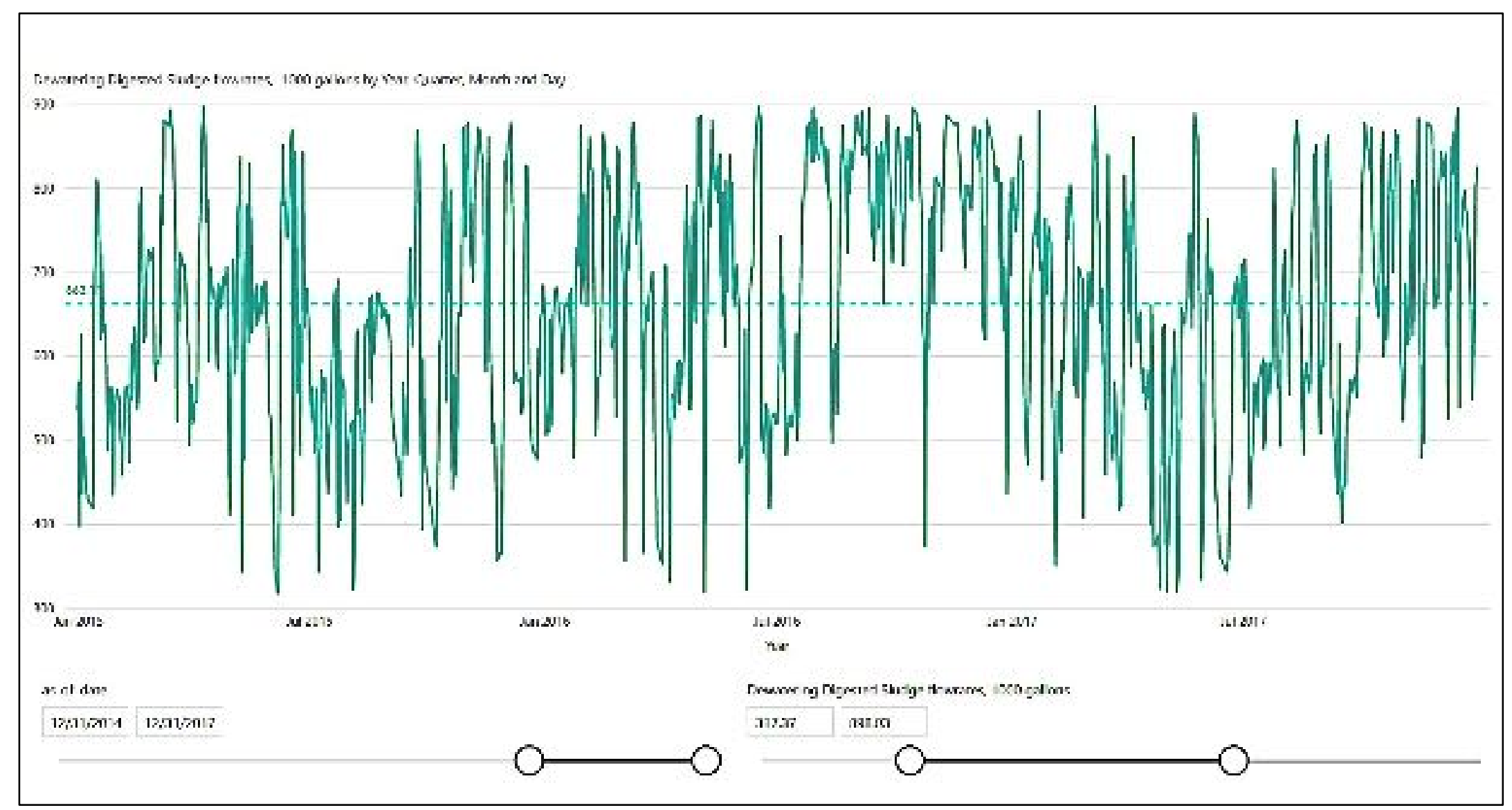




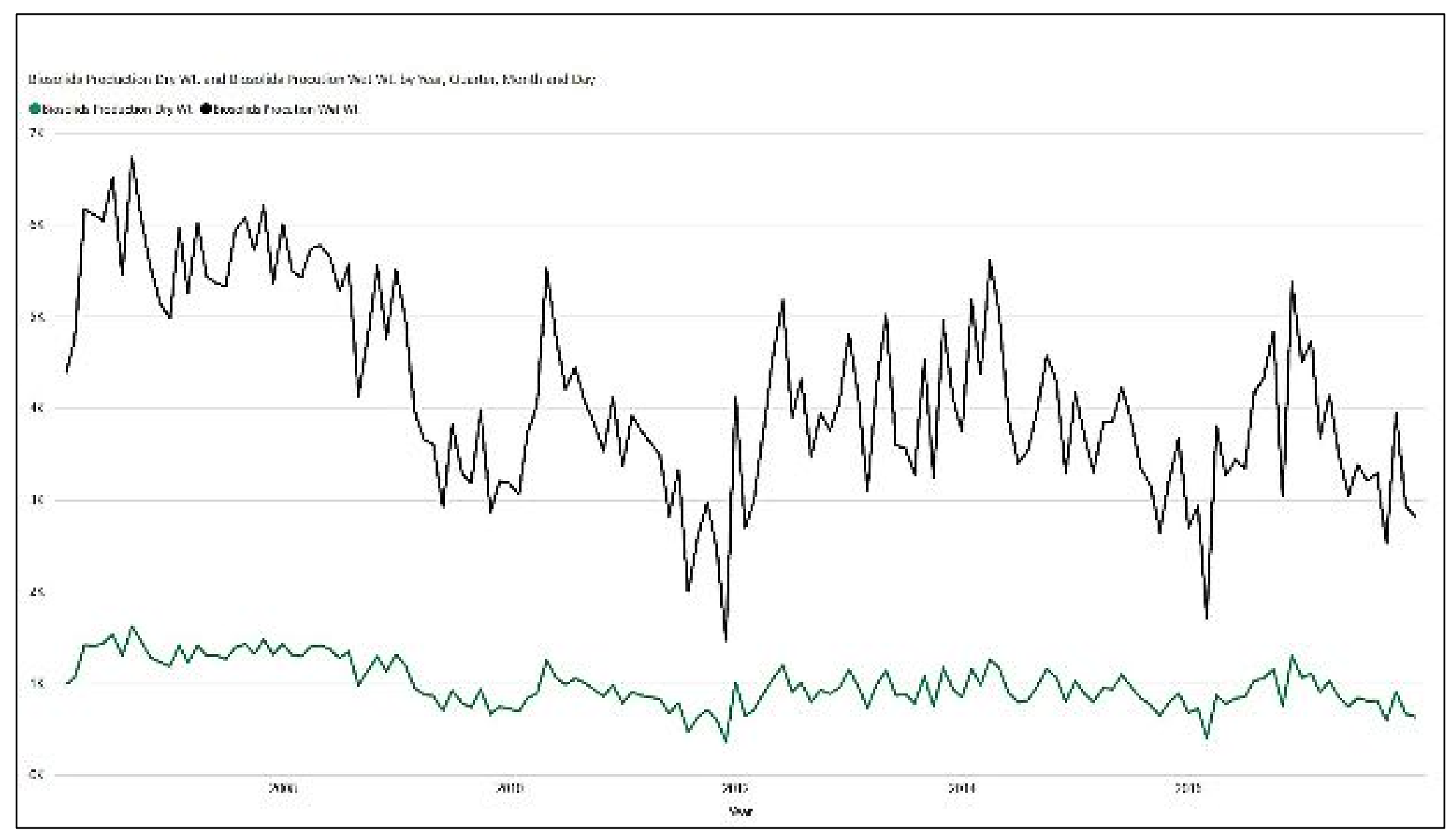




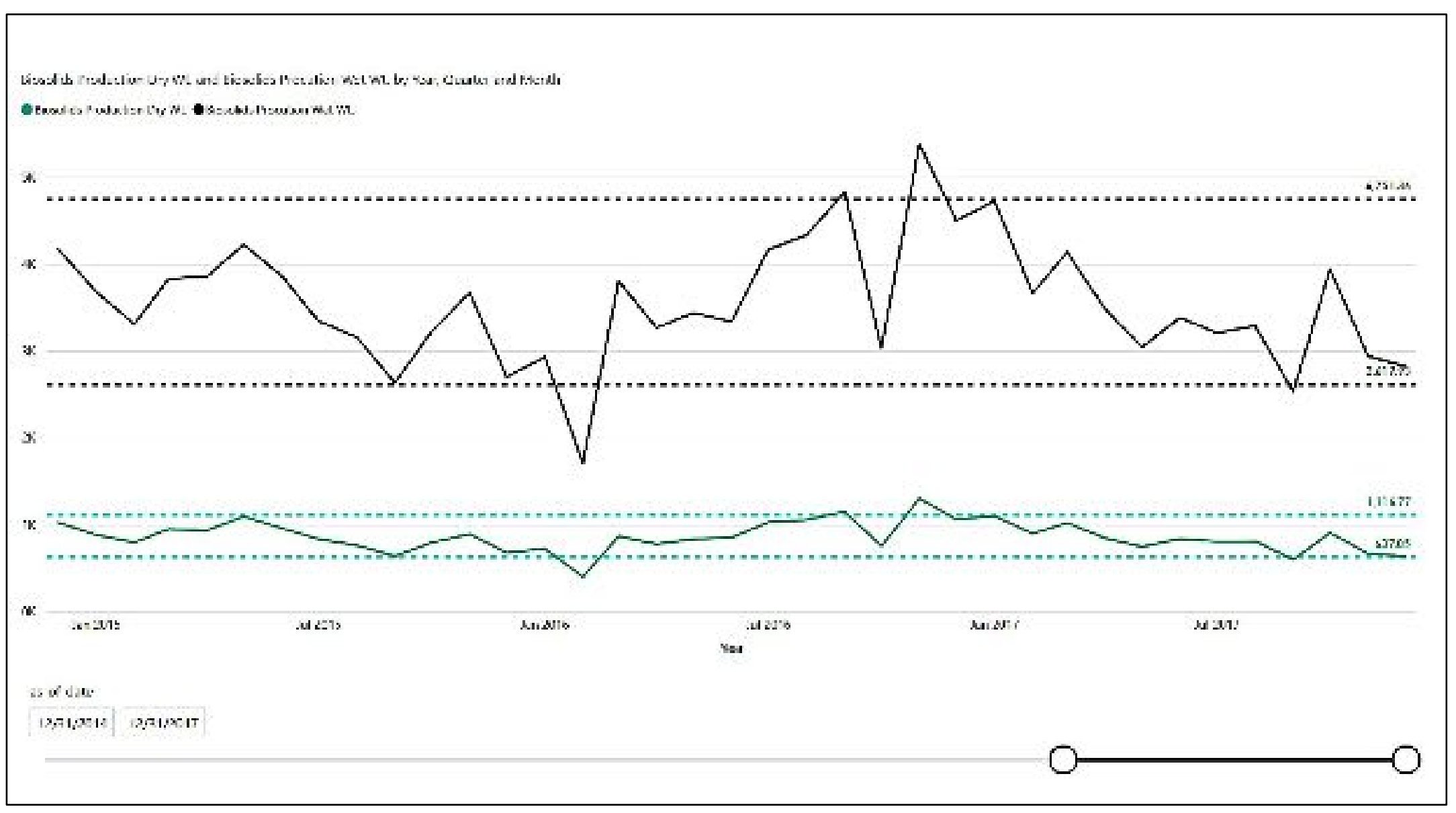




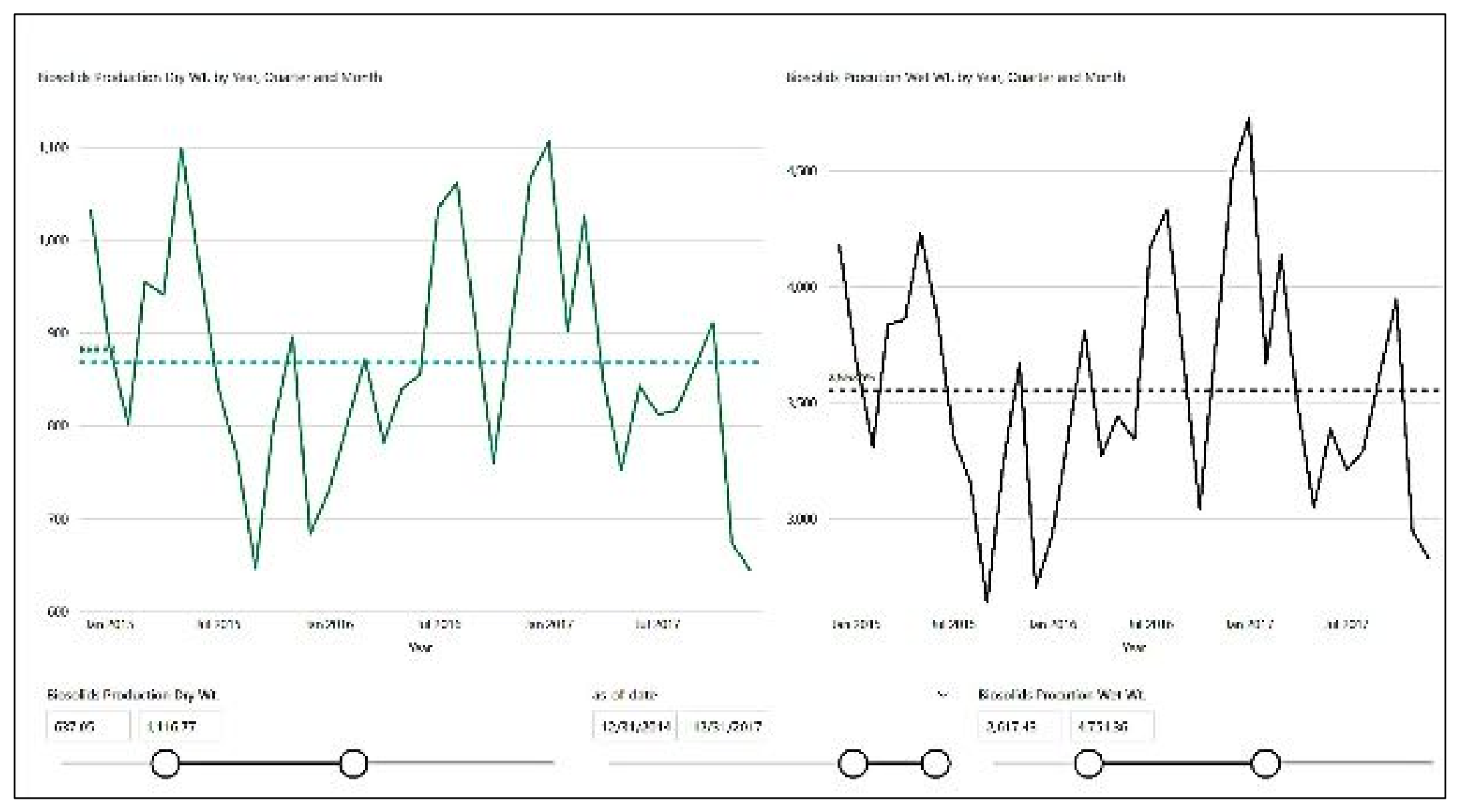

366 
APPENDIX 3: MASS BALANCE MODEL PROCESS FLOW DIAGRAM FOR SDWWTP AND CDWWTP 


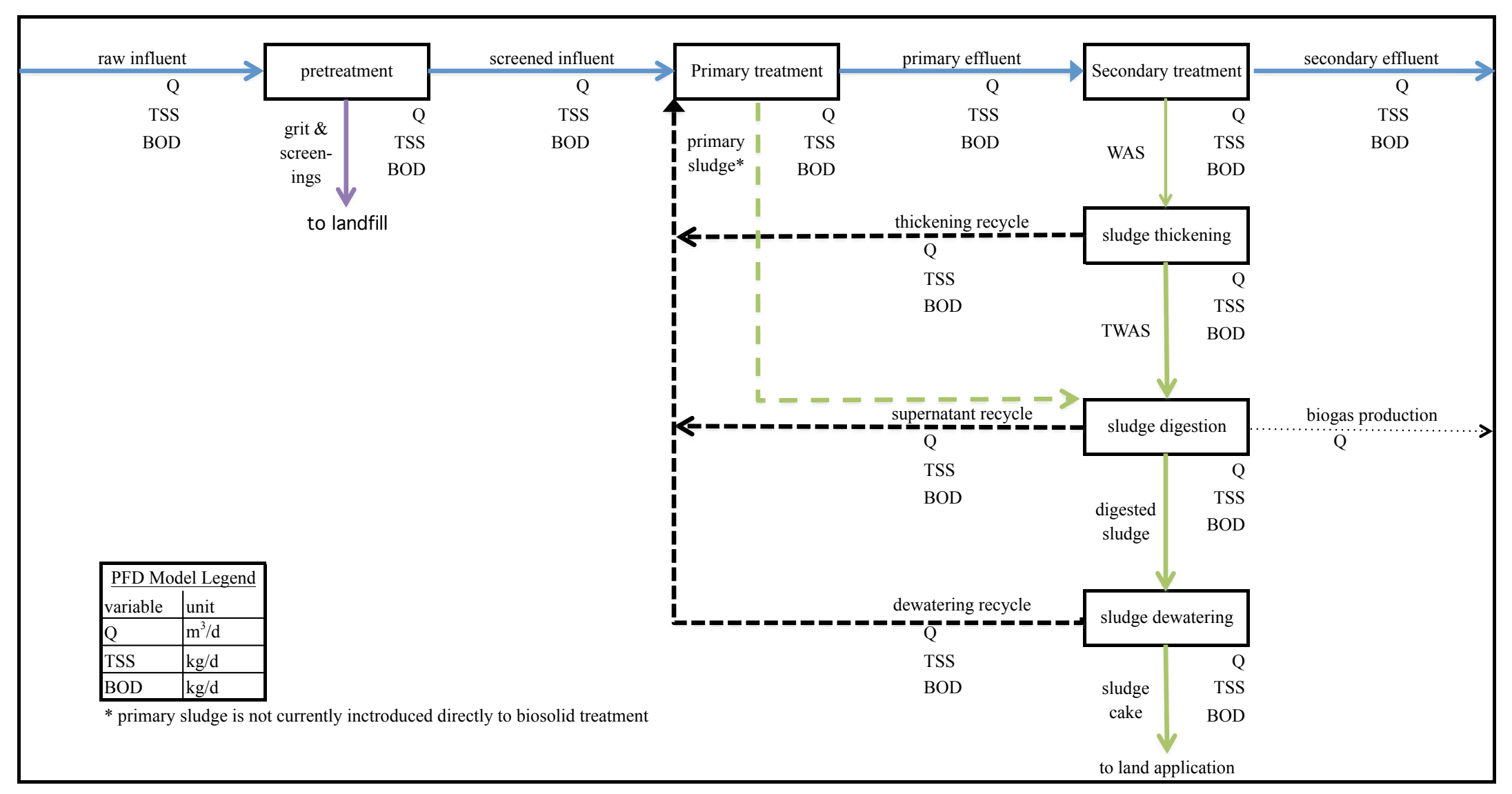


APPENDIX 4: SCENARIO SD-A USER INPUTS AND MASS BALANCE NUMERICAL MODEL 


\begin{tabular}{|c|c|c|c|c|c|c|c|c|}
\hline $\begin{array}{l}\text { Data Input for Mass } \\
\text { Balance Model } \\
\quad \text { defined variable } \\
\text { (analyte/flow stream) }\end{array}$ & $\begin{array}{l}\text { SDWWTP } \\
\text { abbreviation }\end{array}$ & $\begin{array}{cc}\text { standard unit } & \text { standard } \\
\text { value } & \text { unit }\end{array}$ & SI unit value & Data Source & data filter & $\begin{array}{c}\text { data } \\
\text { frequency }\end{array}$ & $\begin{array}{c}\text { data period } \\
\text { start }\end{array}$ & $\begin{array}{l}\text { data period } \\
\text { end }\end{array}$ \\
\hline \multicolumn{9}{|l|}{ Plant Influent } \\
\hline & & & & & average of 90 th & & & \\
\hline Average Daily Flow & $\mathrm{ADF}$ & $98.64 \mathrm{mgd}$ & $373,393 \mathrm{~m}^{3} / \mathrm{d}$ & historical plant data & percentile & daily & $12 / 31 / 15$ & $12 / 31 / 17$ \\
\hline Wet Weather Peak Factor & Pfactor & $2.53[-]$ & $2.53[-]$ & by permit & $\mathrm{n} / \mathrm{a}$ & $\mathrm{n} / \mathrm{a}$ & $\mathrm{n} / \mathrm{a}$ & $\mathrm{n} / \mathrm{a}$ \\
\hline $\begin{array}{l}\text { Wet Weather Peak Flow } \\
\text { Carbonaceous Biological }\end{array}$ & $\mathrm{PF}$ & $249.56 \mathrm{mgd}$ & $944,684 \mathrm{~m}^{3} / \mathrm{d}$ & calculated & $\begin{array}{l}\mathrm{n} / \mathrm{a} \\
\text { average of } 90 \mathrm{th}\end{array}$ & $\mathrm{n} / \mathrm{a}$ & $\mathrm{n} / \mathrm{a}$ & $\mathrm{n} / \mathrm{a}$ \\
\hline Oxygen Demand & CBOD & $214.28 \mathrm{mg} / \mathrm{L}$ & $214.28 \mathrm{~g} / \mathrm{m}^{3}$ & historical plant data & $\begin{array}{l}\text { percentile } \\
\text { average of 90th }\end{array}$ & monthly & $12 / 31 / 15$ & $12 / 31 / 17$ \\
\hline $\begin{array}{l}\text { Total Suspended Solids } \\
\text { Total Suspended Solids }\end{array}$ & TSS & $223.8 \mathrm{mg} / \mathrm{L}$ & $223.8 \mathrm{~g} / \mathrm{m}^{3}$ & $\begin{array}{l}\text { historical plant data } \\
\text { assumed, historical }\end{array}$ & percentile & monthly & $12 / 31 / 15$ & $12 / 31 / 17$ \\
\hline $\begin{array}{l}\text { after grit removal } \\
\text { Volatile fraction of }\end{array}$ & TSS & $200 \mathrm{mg} / \mathrm{L}$ & $200 \mathrm{~g} / \mathrm{m}^{3}$ & $\begin{array}{l}\text { data not available } \\
\text { assumed, historical }\end{array}$ & $\mathrm{n} / \mathrm{a}$ & $\mathrm{n} / \mathrm{a}$ & $\mathrm{n} / \mathrm{a}$ & $\mathrm{n} / \mathrm{a}$ \\
\hline $\begin{array}{l}\text { influent TSS } \\
\text { Volatile fraction of grit }\end{array}$ & VF & $81.5 \%$ & $82 \%$ & $\begin{array}{l}\text { data not available } \\
\text { assumed, historical }\end{array}$ & $\mathrm{n} / \mathrm{a}$ & $\mathrm{n} / \mathrm{a}$ & $\mathrm{n} / \mathrm{a}$ & $\mathrm{n} / \mathrm{a}$ \\
\hline removed & Grit VF & $10 \%$ & $10 \%$ & data not available & $\mathrm{n} / \mathrm{a}$ & $\mathrm{n} / \mathrm{a}$ & $\mathrm{n} / \mathrm{a}$ & $\mathrm{n} / \mathrm{a}$ \\
\hline \multicolumn{9}{|l|}{$\begin{array}{l}\text { Plant Effluent } \\
\text { Conditions }\end{array}$} \\
\hline $\begin{array}{l}\text { Total Suspended Solids } \\
\text { Carbonaceous Biological }\end{array}$ & TSS & $3.59 \mathrm{mg} / \mathrm{L}$ & $3.59 \mathrm{~g} / \mathrm{m}^{3}$ & historical plant data & $\begin{array}{l}\text { average of 90th } \\
\text { percentile } \\
\text { average of } 90 \text { th }\end{array}$ & daily & $12 / 31 / 15$ & $12 / 31 / 17$ \\
\hline Oxygen Demand & CBOD & $5.18 \mathrm{mg} / \mathrm{L}$ & $5.18 \mathrm{~g} / \mathrm{m}^{3}$ & historical plant data & percentile & daily & $12 / 31 / 15$ & $12 / 31 / 17$ \\
\hline UBOD factor & UBOD & $1.42 \mathrm{lb} / \mathrm{lb}$ & $1.42 \mathrm{~g} / \mathrm{g}$ & assumed, literature & $\mathrm{n} / \mathrm{a}$ & $\mathrm{n} / \mathrm{a}$ & $\mathrm{n} / \mathrm{a}$ & $\mathrm{n} / \mathrm{a}$ \\
\hline effluent BOD to TSS & BOD/TSS & $68 \%$ & $68 \%$ & assumed, literature & $\mathrm{n} / \mathrm{a}$ & $\mathrm{n} / \mathrm{a}$ & $\begin{array}{l}\mathrm{n} / \mathrm{a} \\
\mathrm{n} / \mathrm{a}\end{array}$ & $\mathrm{n} / \mathrm{a}$ \\
\hline \multicolumn{9}{|l|}{ Plant Primary } \\
\hline $\begin{array}{l}\text { Treatment Conditions } \\
\text { Concentration of Primary }\end{array}$ & & & & & & & $\mathrm{n} / \mathrm{a}$ & \\
\hline $\begin{array}{l}\text { Solids } \\
\text { primary solids specific }\end{array}$ & PS TSS & $0 \mathrm{mg} / \mathrm{L}$ & $0 \mathrm{~g} / \mathrm{m}^{3}$ & not applicable & $\mathrm{n} / \mathrm{a}$ & $\mathrm{n} / \mathrm{a}$ & $\mathrm{n} / \mathrm{a}$ & $\mathrm{n} / \mathrm{a}$ \\
\hline gravity & PS sg & $1[-]$ & $1[-]$ & not applicable & $\mathrm{n} / \mathrm{a}$ & $\mathrm{n} / \mathrm{a}$ & $\mathrm{n} / \mathrm{a}$ & $\mathrm{n} / \mathrm{a}$ \\
\hline
\end{tabular}




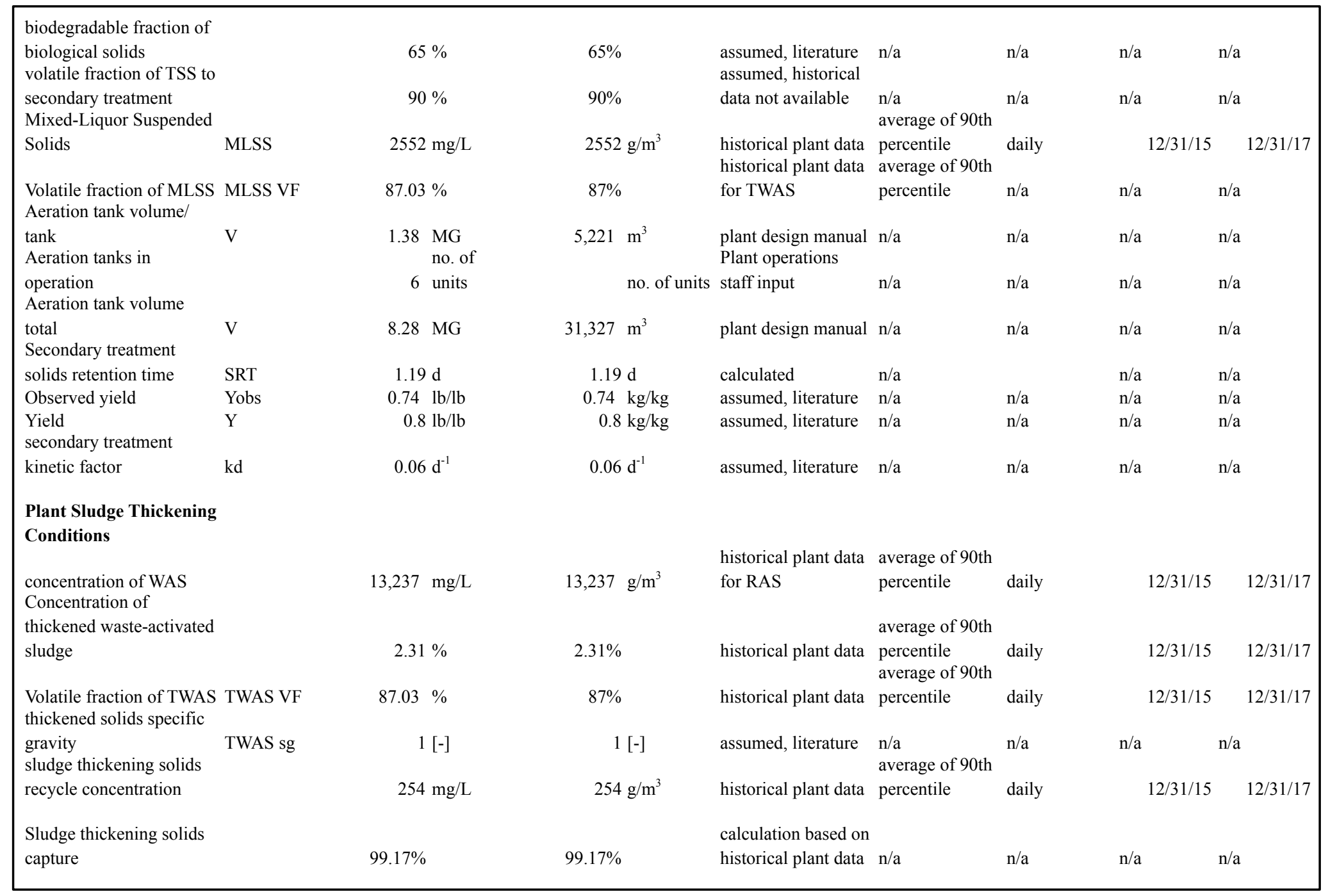




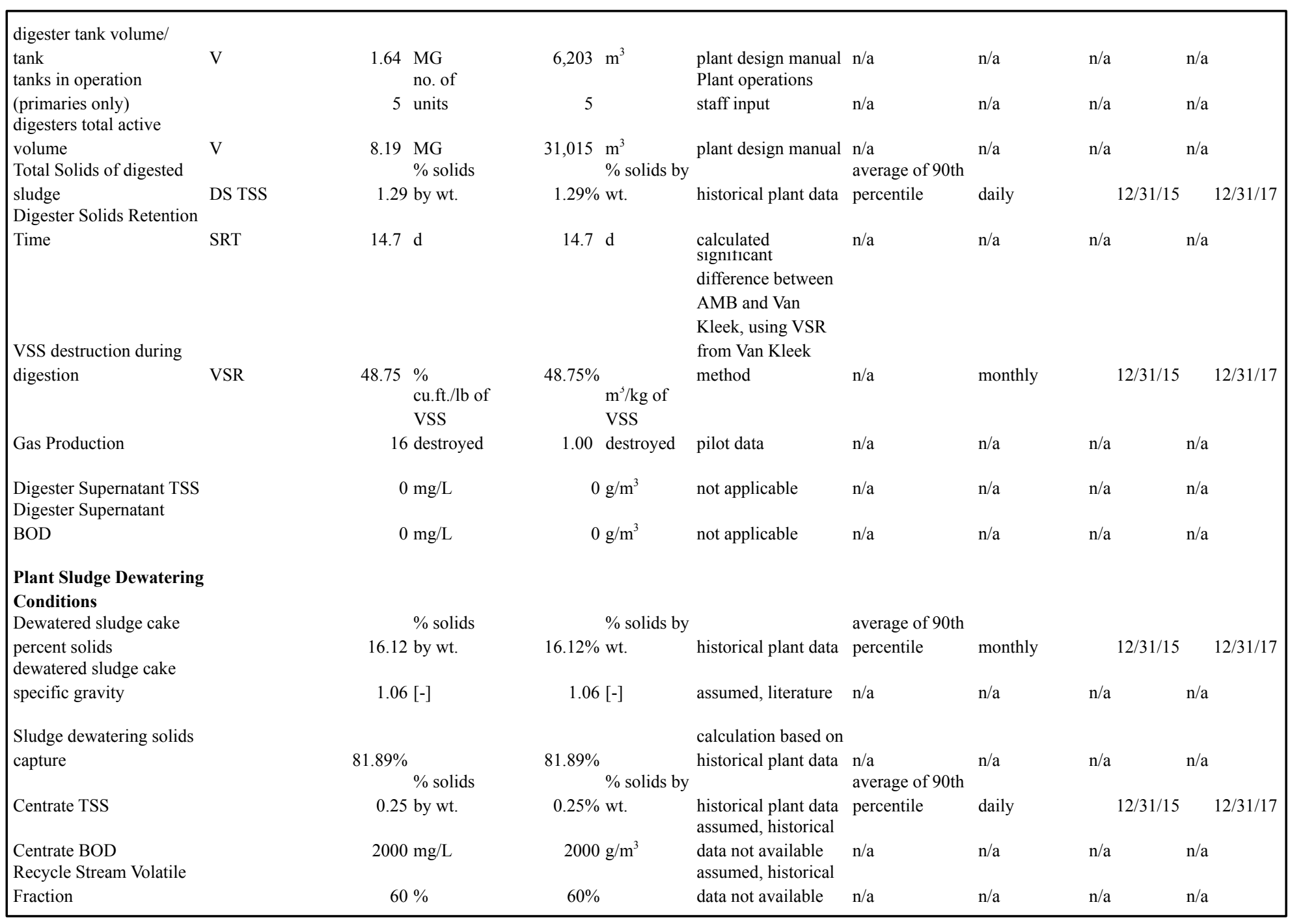




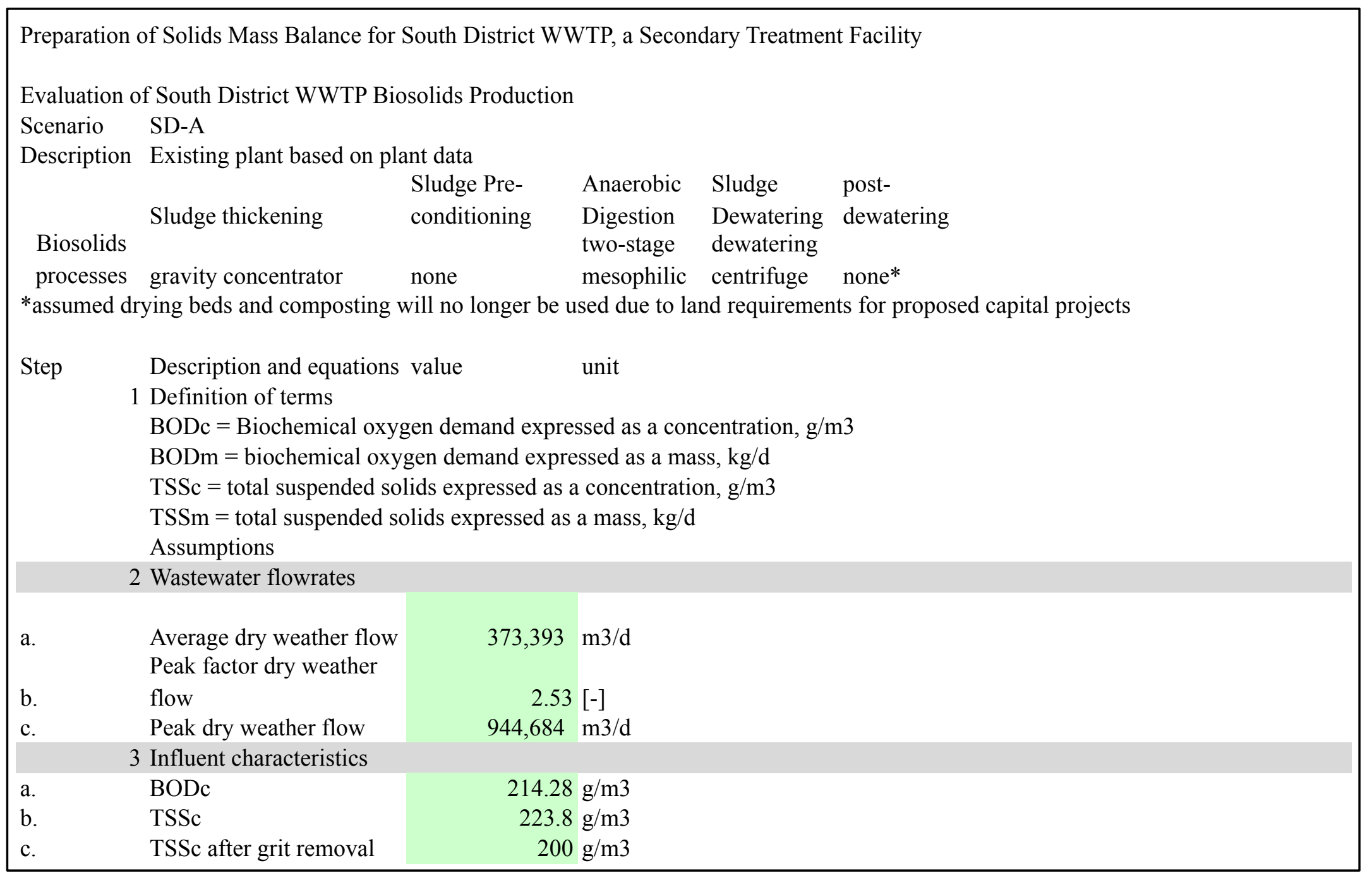




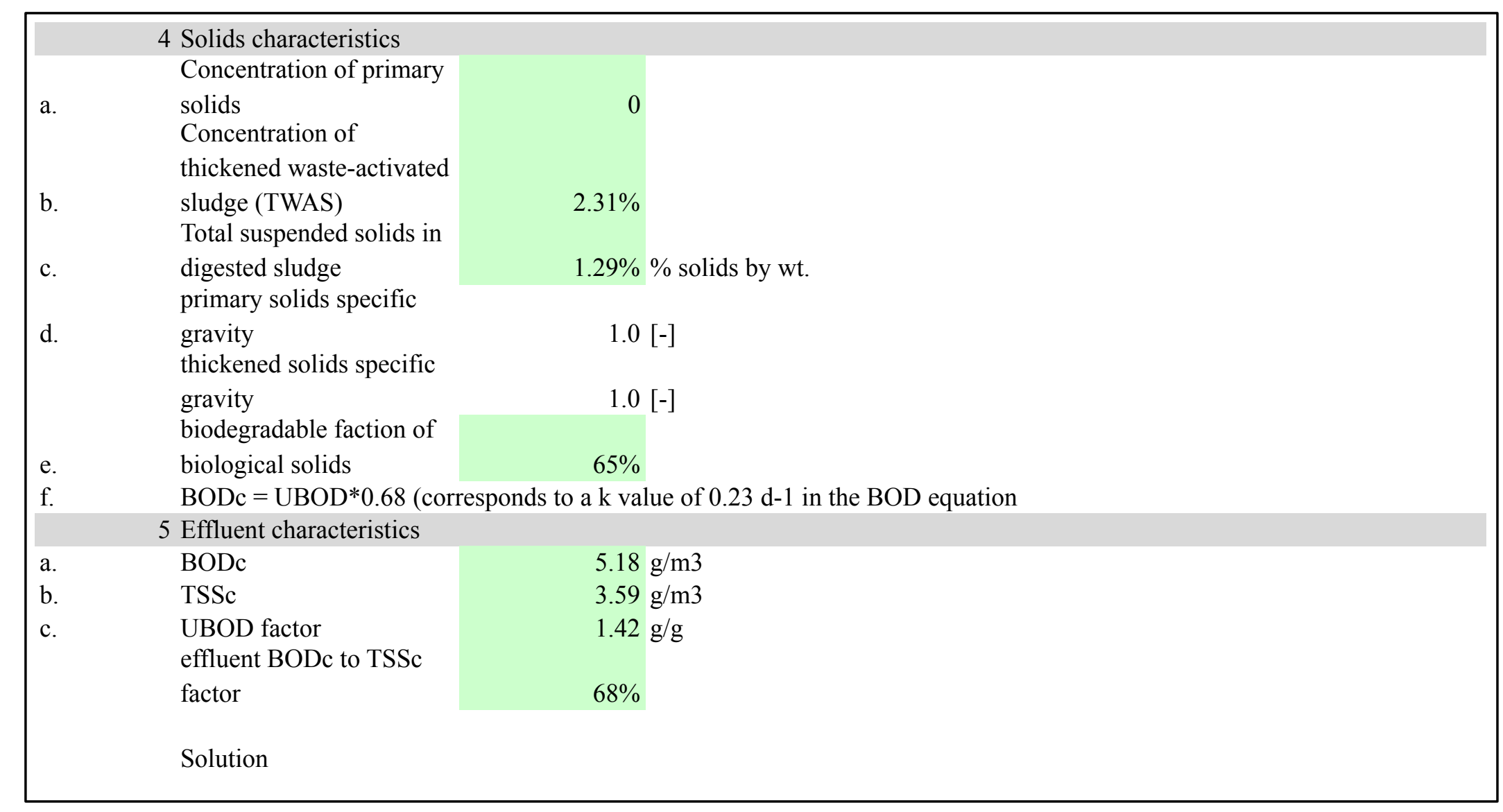




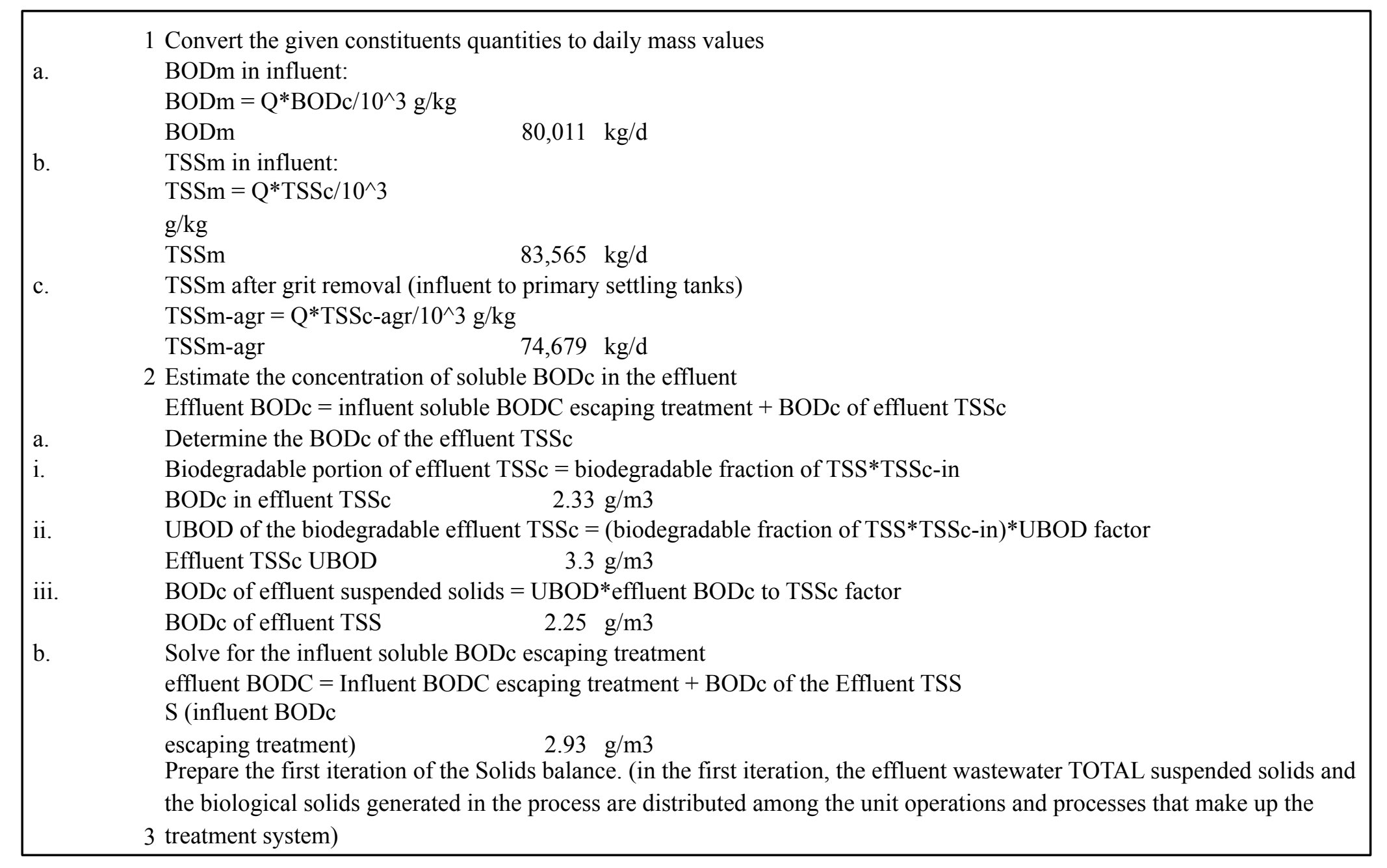




\begin{tabular}{|c|c|}
\hline a. & Primary Settling - South District does not have primary clarifiers, using this section just for grit removal \\
\hline \multirow[t]{3}{*}{ i. } & Operating Parameters: \\
\hline & BODc removed \\
\hline & TSSc removed \\
\hline \multirow[t]{2}{*}{ ii. } & BODm removed $=$ BODc removed $*$ BODm-influent \\
\hline & BODm removed $\quad 0 \mathrm{~kg} / \mathrm{d}$ \\
\hline \multirow[t]{2}{*}{ iii. } & BODm to secondary $=$ BODm in influent - BODm removed \\
\hline & BODm to secondary $\quad 80,011 \mathrm{~kg} / \mathrm{d}$ \\
\hline \multirow[t]{2}{*}{ iv. } & TSSm removed $=$ TSSc removed $*$ TSSm-influent \\
\hline & TSSm removed $\quad 0 \mathrm{~kg} / \mathrm{d}$ \\
\hline \multirow[t]{2}{*}{ v. } & TSSm to secondary $=($ TSSm after grit - TSSm removed $)$ \\
\hline & TSSm to secondary $\quad 74,679 \mathrm{~kg} / \mathrm{d}$ \\
\hline b. & Determine the volatile fraction of primary sludge \\
\hline \multirow[t]{3}{*}{ i. } & $\begin{array}{l}\text { Operating parameters: } \\
\text { Volatile fraction of TSSc }\end{array}$ \\
\hline & in influent \\
\hline & $\begin{array}{l}\text { Volatile fraction in grit } \\
\text { volatile fraction in } \\
\text { incoming TSSc } \\
\text { discharged to the } \\
\text { secondary process }\end{array}$ \\
\hline
\end{tabular}




\begin{tabular}{|c|c|}
\hline ii. & $\begin{array}{l}\text { Volatile suspended solids }(\mathrm{VSSm}) \text { in influent prior to grit removal = volatile fraction of TSSc in influent*TSSm prior to grit } \\
\text { removal } \\
\text { VSSm in influent prior to } \\
\text { grit removal } \\
\qquad 68,106 \mathrm{~kg} / \mathrm{d}\end{array}$ \\
\hline iii. & $\begin{array}{l}\text { VSSm removed in grit chamber }=\text { volatile fraction in grit* }(\mathrm{TSSm} \text { prior to grit removal }-\mathrm{TSSm} \text { after grit removal }) \\
\text { VSSm removed in grit }\end{array}$ \\
\hline iv. & $\begin{array}{l}\text { chamber } \\
\text { VSSm in secondary influent }=\text { volatile fraction in incoming TSSc discharged to the secondary } \\
\text { process*TSSm to secondary }\end{array}$ \\
\hline v. & $\begin{array}{l}\text { VSSm in secondary influer } \quad 67,217.09 \mathrm{~kg} / \mathrm{d} \\
\text { VSSm in primary sludge }=\text { VSSm prior to grit removal - VSS in removed grit - VSSm to } \\
\text { secondary influent }\end{array}$ \\
\hline & VSSm in primary sludge \\
\hline vi. & $\begin{array}{l}\text { Volatile fraction in primary sludge }=\mathrm{VSSm} \text { in primary sludge } / \mathrm{TSSm} \text { removed } \\
\text { Volatile fraction in } \\
\text { primary sludge } \\
\quad 0.0 \%\end{array}$ \\
\hline
\end{tabular}




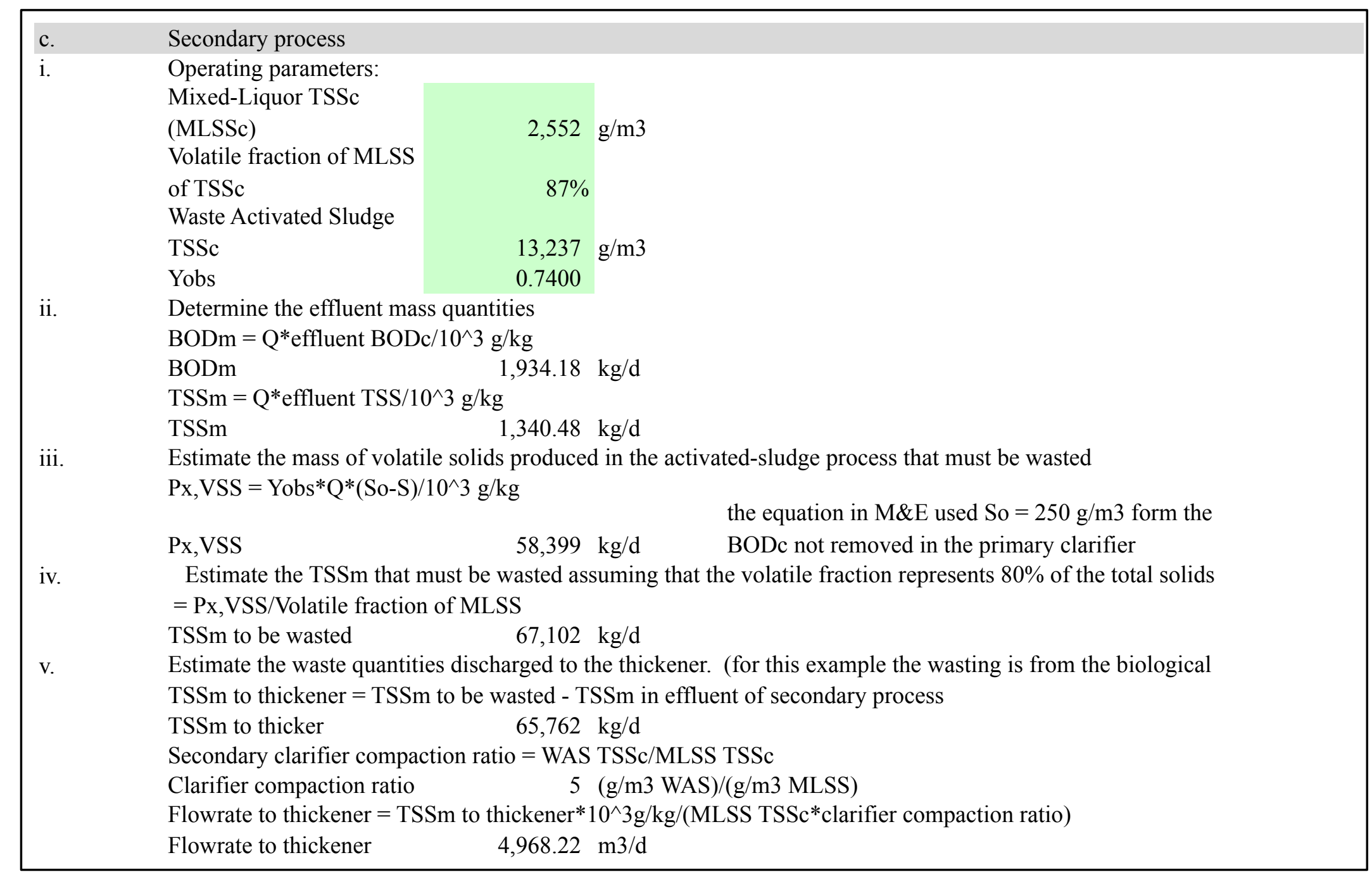




\begin{tabular}{|c|c|c|}
\hline d. & \multicolumn{2}{|c|}{ Gravity Concentrator Sludge Thickeners } \\
\hline i. & $\begin{array}{l}\text { Operating Parameters: } \\
\text { Concentration of } \\
\text { thickened sludge }\end{array}$ & $2.31 \%$ \\
\hline & $\begin{array}{l}\text { Calculated solids recovery } \\
\text { Assumed specific gravity } \\
\text { of feed and thickened } \\
\text { sludge }\end{array}$ & $99.17 \%$ \\
\hline ii. & $\begin{array}{l}\text { Determine the flowrate of } \\
\text { Flowrate of thickened slud } \\
\text { Flowrate of thickened } \\
\text { sludge }\end{array}$ & $\begin{array}{l}\text { m to Thickener* solids recovery } /\left(10^{\wedge} 3 \mathrm{~kg} / \mathrm{m} 3^{*} \text { Concentration of thickened }\right. \\
2,823 \mathrm{~m} 3 / \mathrm{d}\end{array}$ \\
\hline iii. & $\begin{array}{l}\text { Determine the flowrate rec } \\
\text { Recycled flowrate }=\mathrm{Q} \text { to } \mathrm{t} \\
\text { Thickener recycled }\end{array}$ & $\begin{array}{l}\text { he plant influent } \\
\text { Q of thickened sludge }\end{array}$ \\
\hline
\end{tabular}




\begin{tabular}{|c|c|}
\hline \multirow[t]{3}{*}{ iv. } & Determine the TSSm to the digester \\
\hline & TSSm to digester $=$ TSSm to digester* ${ }^{*}$ solids capture \\
\hline & TSSm to digester $\quad 65,217 \mathrm{~kg} / \mathrm{d}$ \\
\hline \multirow[t]{3}{*}{ v. } & Determine the TSSm recycled to the plant influent \\
\hline & TSSm recycled to influent $=\mathrm{TSSm}$ to thickener $-\mathrm{TSSm}$ to digester \\
\hline & TSSm recycled to influent $\quad 544.8 \mathrm{~kg} / \mathrm{d}$ \\
\hline \multirow[t]{7}{*}{ vi. } & Determine the BODc of the TSSc in the recycled flow. \\
\hline & TSSc in recycled flow $=$ TSSm recycled to influent $*\left(10^{\wedge} 3 \mathrm{~g} / \mathrm{kg}\right) /$ Thickener recycle flow rate \\
\hline & TSSc in recycle flow $\quad 254.0 \mathrm{~g} / \mathrm{m} 3$ \\
\hline & $\begin{array}{l}\text { BODc of the TSSc }=\text { TSSc in recycle flow*biodegradable fraction in biological solids*UBOD factor*effluent } \\
\text { BODc to TSSc factor }\end{array}$ \\
\hline & BODc of the TSSc $\quad 159.4 \mathrm{~g} / \mathrm{m} 3$ \\
\hline & $\begin{array}{l}\text { BODm from recycle to influent }=\text { BODc of recycle flow to influent }{ }^{*} \text { recycle flow rate } / 10^{\wedge} 3 \mathrm{~g} / \mathrm{kg} \\
\text { BODm from recycle to }\end{array}$ \\
\hline & $342.0 \mathrm{~kg} / \mathrm{d}$ \\
\hline
\end{tabular}




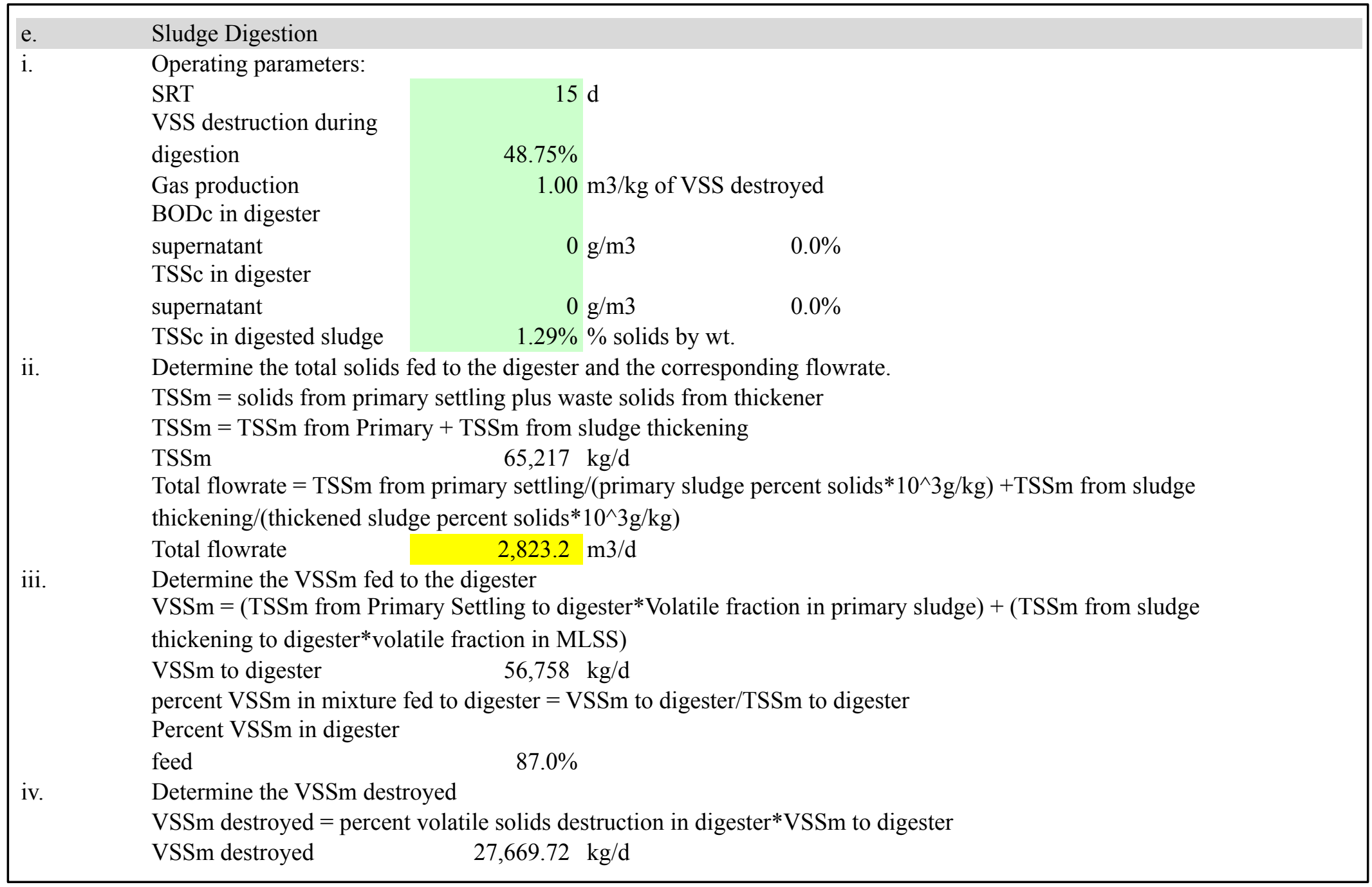




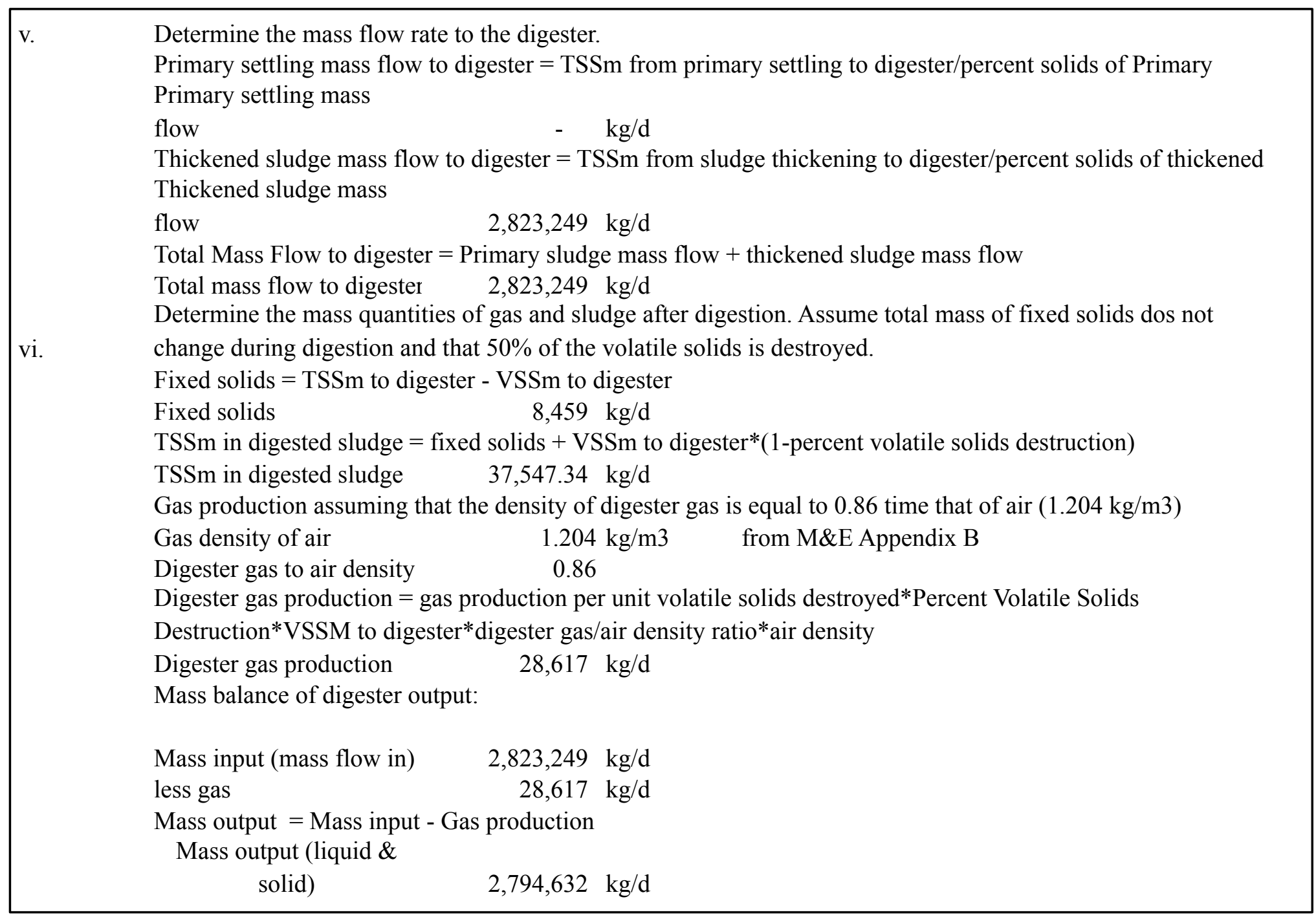




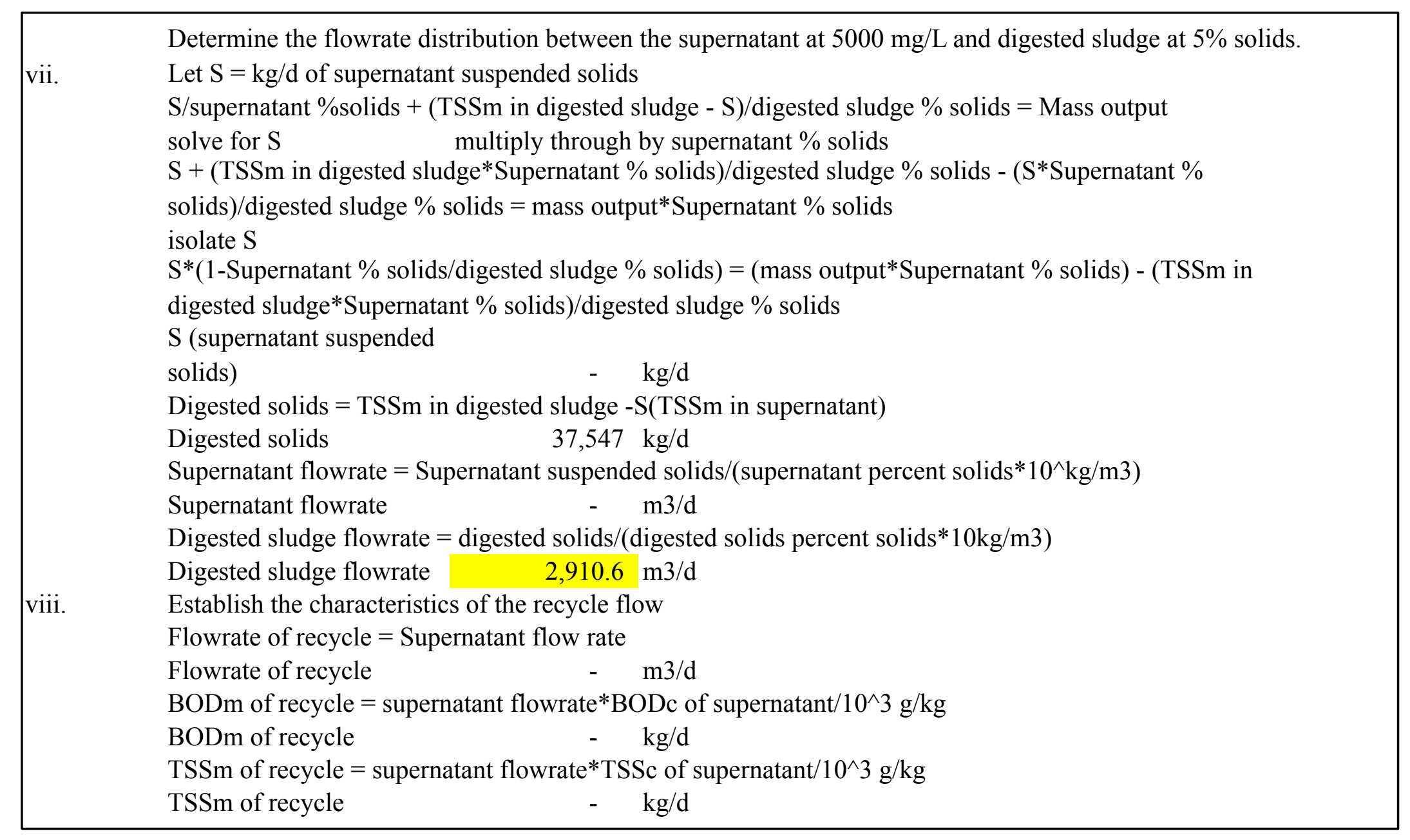




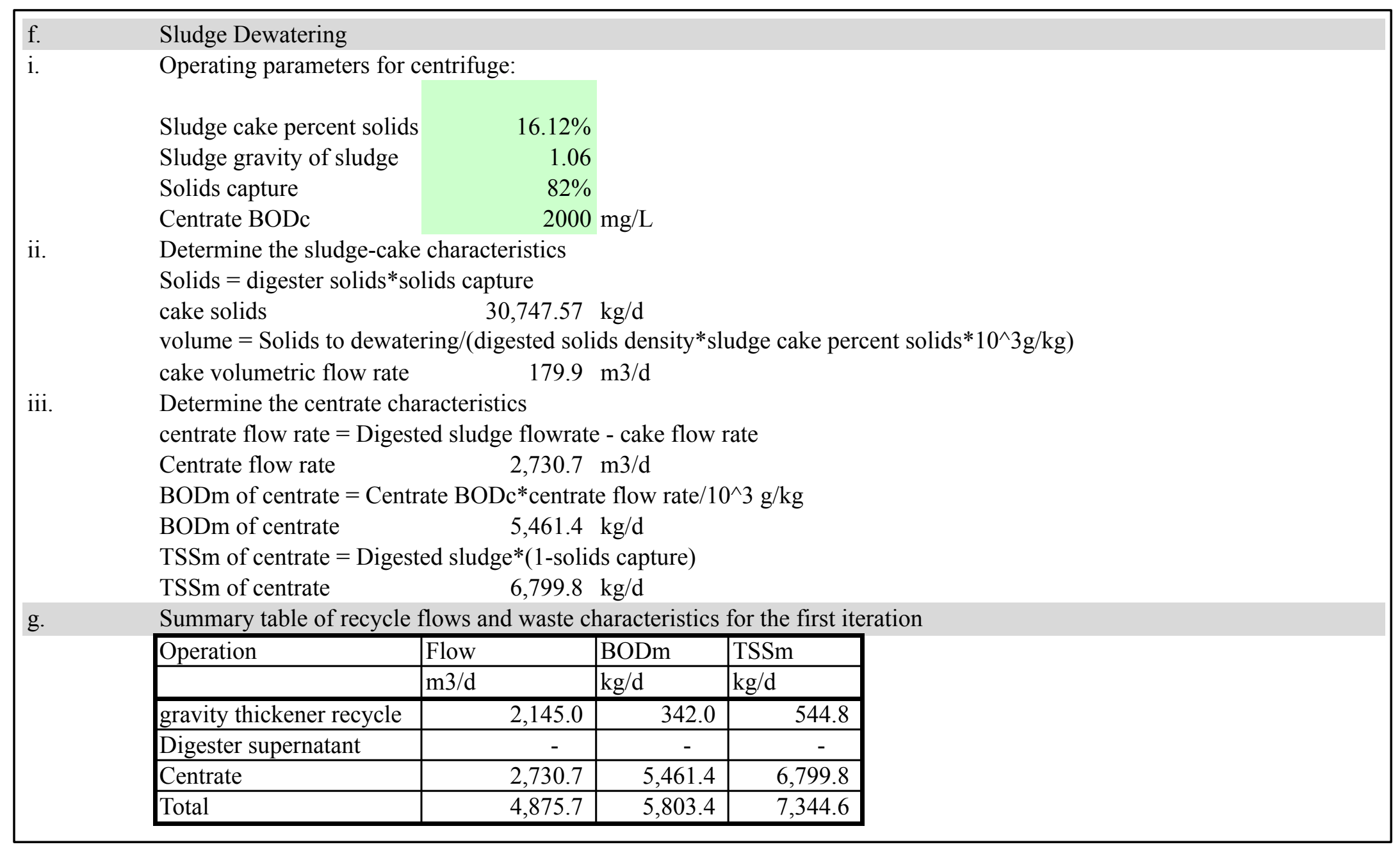




\begin{tabular}{|c|c|}
\hline \multicolumn{2}{|c|}{$\begin{array}{l}4 \text { Prepare the second iteration of the solids balance } \\
\text { a. Primary Settling }\end{array}$} \\
\hline \multirow{3}{*}{ i. } & Operating parameters, same as those for first iteration \\
\hline & BODc removed $\quad 0 \%$ \\
\hline & TSSc removed $\quad 0 \%$ \\
\hline \multirow[t]{5}{*}{ ii. } & TSSm and BODm entering the primary tanks \\
\hline & $\mathrm{TSSm}=$ influent TSSm + Recycled TSSm \\
\hline & TSSm to primary $\quad 82023 \mathrm{~kg} / \mathrm{d}$ \\
\hline & BODm $=$ influent BODm + Recycled BODm \\
\hline & BODm to primary $\quad 85814 \mathrm{~kg} / \mathrm{d}$ \\
\hline \multirow[t]{2}{*}{ iii. } & BODm removed $=$ percent $\mathrm{BODc}$ removed $*$ BODm to primary \\
\hline & BODm removed $\quad-\mathrm{kg} / \mathrm{d}$ \\
\hline \multirow[t]{2}{*}{ iv. } & BODm to secondary $=$ BODm to primary settling - BODm removed \\
\hline & BODm to secondary $\quad 85814 \mathrm{~kg} / \mathrm{d}$ \\
\hline \multirow[t]{2}{*}{ v. } & TSSm removed $=$ percent $\mathrm{TSSm}$ removed $* \mathrm{TSSm}$ to primary \\
\hline & TSSm removed $\quad-\quad \mathrm{kg} / \mathrm{d}$ \\
\hline \multirow[t]{2}{*}{ vi. } & TSSm to secondary $=$ TSSm to primary $-\mathrm{TSSm}$ removed \\
\hline & TSSm to secondary $\quad 82023 \mathrm{~kg} / \mathrm{d}$ \\
\hline b. & Determine the volatile fraction of the primary sludge and the effluent suspended solids \\
\hline \multirow[t]{3}{*}{ i. } & Operating parameters: \\
\hline & $\begin{array}{l}\text { Incoming Wastewater, same as those for first iteration } \\
\text { Volatile fraction of solids } \\
\text { in recycle returned to } \\
\text { headworks } \\
\text { hed }\end{array}$ \\
\hline & $\begin{array}{l}\text { Although the computations are not shown, the computer change in the volatile fraction determined in the first iteration is } \\
\text { slight and, therefore, the values determined previously are used for the second iteration. If the volatile fraction of the return } \\
\text { is less than about } 50 \% \text {, the volatile fractions should be recomputed. }\end{array}$ \\
\hline
\end{tabular}




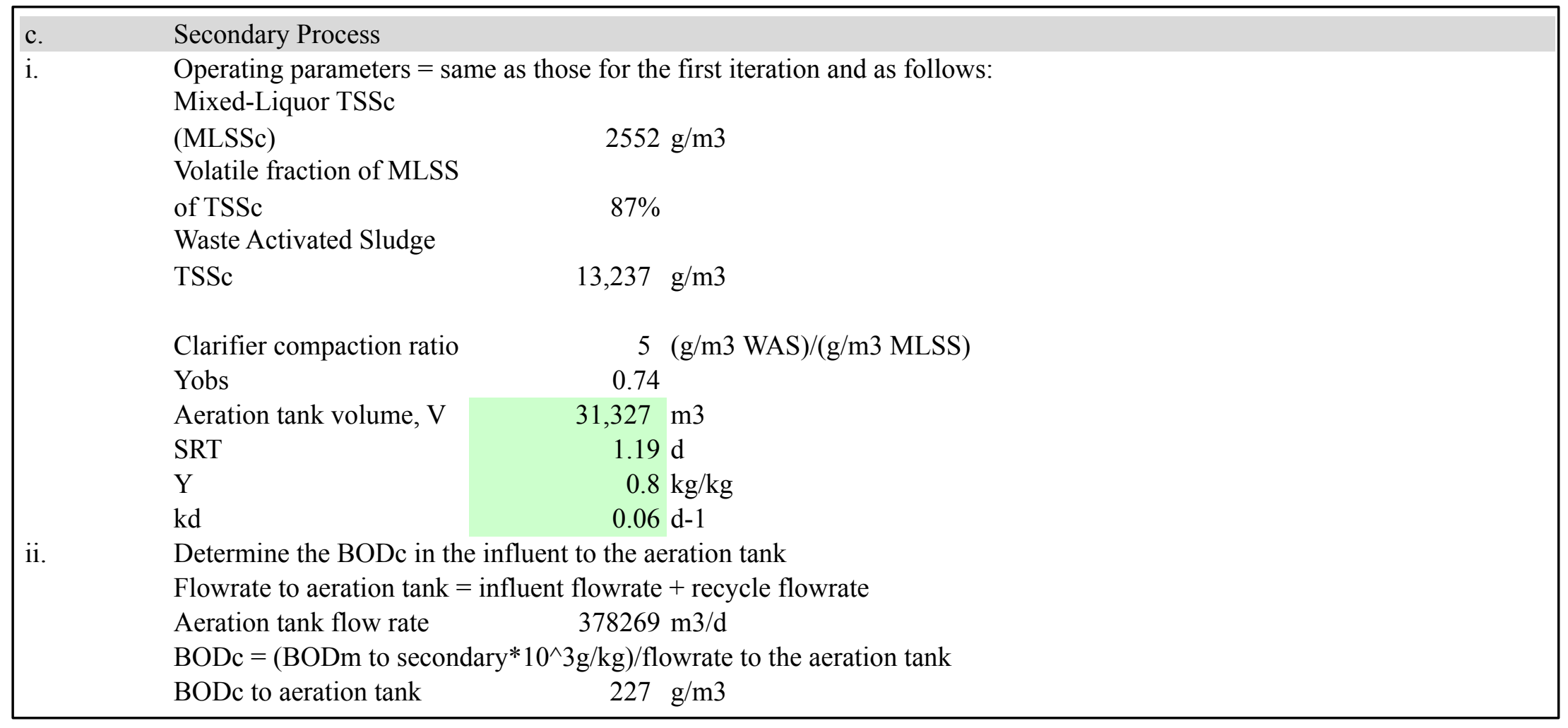




\begin{tabular}{|c|c|}
\hline \multirow[t]{3}{*}{ iii. } & Determine the new concentration of mixed liquor VSS \\
\hline & $\mathrm{X}_{\mathrm{vss}}=[(\mathrm{SRT})(\mathrm{Q})(\mathrm{Y})(\mathrm{So}-\mathrm{S})] /\left\{\mathrm{V}^{*}[1+(\mathrm{kd}) \mathrm{SRT}]\right\}$ \\
\hline & $\mathrm{X}_{\text {vss }} \quad 2403 \mathrm{~g} / \mathrm{m} 3$ \\
\hline \multirow[t]{3}{*}{ iv. } & Determine the mixed liquor suspended solids \\
\hline & $\mathrm{X}_{\mathrm{sS}}=\mathrm{X}_{\mathrm{vs}} /$ volatile fraction of MLSS \\
\hline & $\begin{array}{lll}\text { Xss } & 2,761 \mathrm{~g} / \mathrm{m} 3\end{array}$ \\
\hline \multirow[t]{4}{*}{ v. } & $\begin{array}{l}\text { Determine the cell growth } \\
P x, \mathrm{vss}=\text { Yobs* } \mathrm{Q}^{*}(\text { So-S }) /\left(10^{\wedge} 3 \mathrm{~g} / \mathrm{kg}\right)\end{array}$ \\
\hline & $P x$, vss $62,683 \mathrm{~kg} / \mathrm{d}$ \\
\hline & $P x, \mathrm{sss}=P x, \mathrm{vss} /$ volatile fraction of MLSS \\
\hline & $P x, \mathrm{Tss} \quad 72,025 \mathrm{~kg} / \mathrm{d}$ \\
\hline \multirow[t]{6}{*}{ vi. } & $\begin{array}{l}\text { Determine the waste quantities discharged to the thicker } \\
\text { Effluent TSSm (specified }\end{array}$ \\
\hline & in the first iteration) $\quad 1,340 \mathrm{~kg} / \mathrm{d}$ \\
\hline & $\begin{array}{l}\text { Total TSSm to be wasted to the thicker }=P x \text {,vss }- \text { TSSm in secondary Effluent } \\
\text { Total TSSm to be wasted }\end{array}$ \\
\hline & to the thicker $\quad 70,684 \mathrm{~kg} / \mathrm{d}$ \\
\hline & Flowrate $=\left(\right.$ Total TSSm wasted to thickener* $\left.10^{\wedge} 3 \mathrm{~g} / \mathrm{kg}\right) /\left(\mathrm{X}_{\mathrm{SS}} *\right.$ clarifier compaction ratio $)$ \\
\hline & Flowrate to thickener $\quad 4,936.44 \mathrm{~m} 3 / \mathrm{d}$ \\
\hline
\end{tabular}




\begin{tabular}{|c|c|}
\hline d. & Gravity Thickener \\
\hline i. & $\begin{array}{l}\text { Operating Parameters: } \\
\text { Concentration of } \\
\text { thickened sludge } \\
\text { Assumed solids recovery } \\
\begin{array}{l}\text { Assumed specific gravity } \\
\text { of feed and thickened } \\
\text { sludge }\end{array}\end{array}$ \\
\hline ii. & $\begin{array}{l}\text { Determine the flowrate of the thickened sludge } \\
\text { Flowrate of thickened sludge }=\text { flowrate to thickener*percent solids recovery } /\left(10^{\wedge} 3 \mathrm{~kg} / \mathrm{m} 3 * \text { Percent solids of }\right. \\
\text { thickened sludge }) \\
\text { Flowrate of thickened } \\
\text { sludge } \\
\qquad 3,034.6 \mathrm{~m} 3 / \mathrm{d}\end{array}$ \\
\hline iii. & $\begin{array}{l}\text { Determine the flowrate recycled to the plant influent } \\
\text { Recycle flowrate = flowrate to thicker - flowrate of thicken sludge } \\
\text { Recycle flowrate } \\
1,901.9 \mathrm{~m} 3 / \mathrm{d}\end{array}$ \\
\hline
\end{tabular}




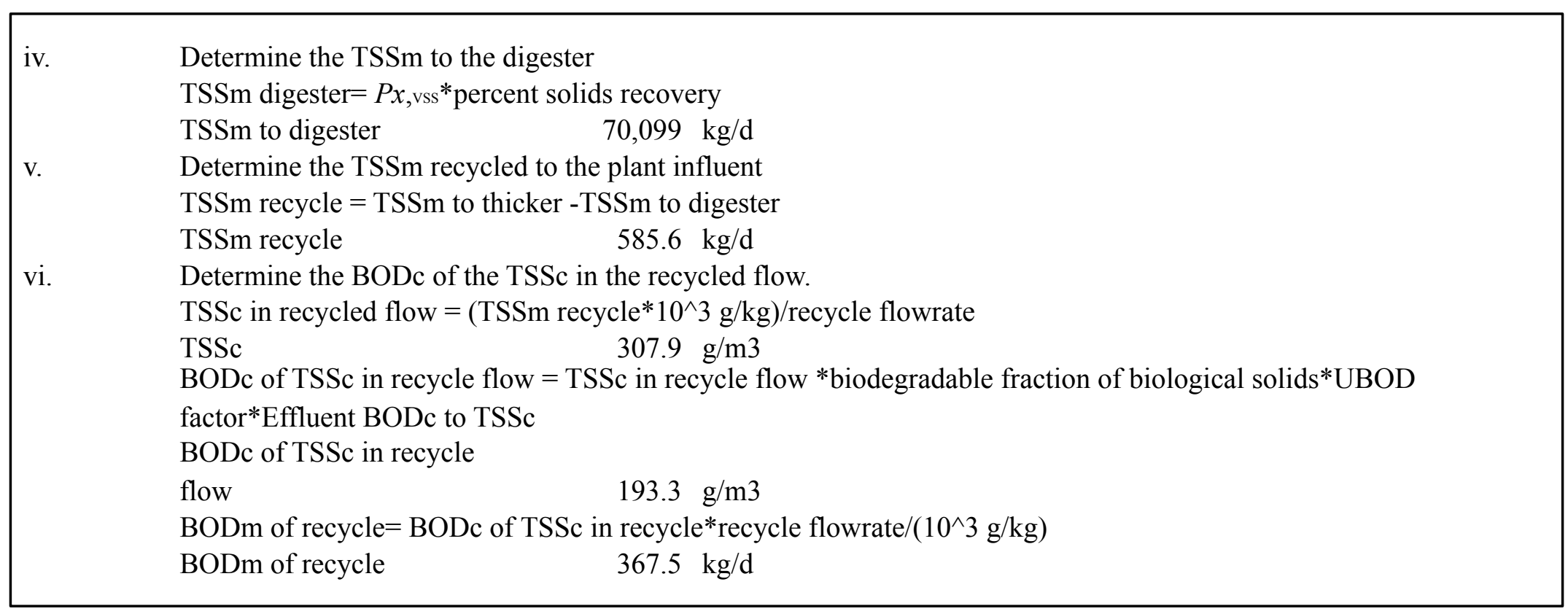




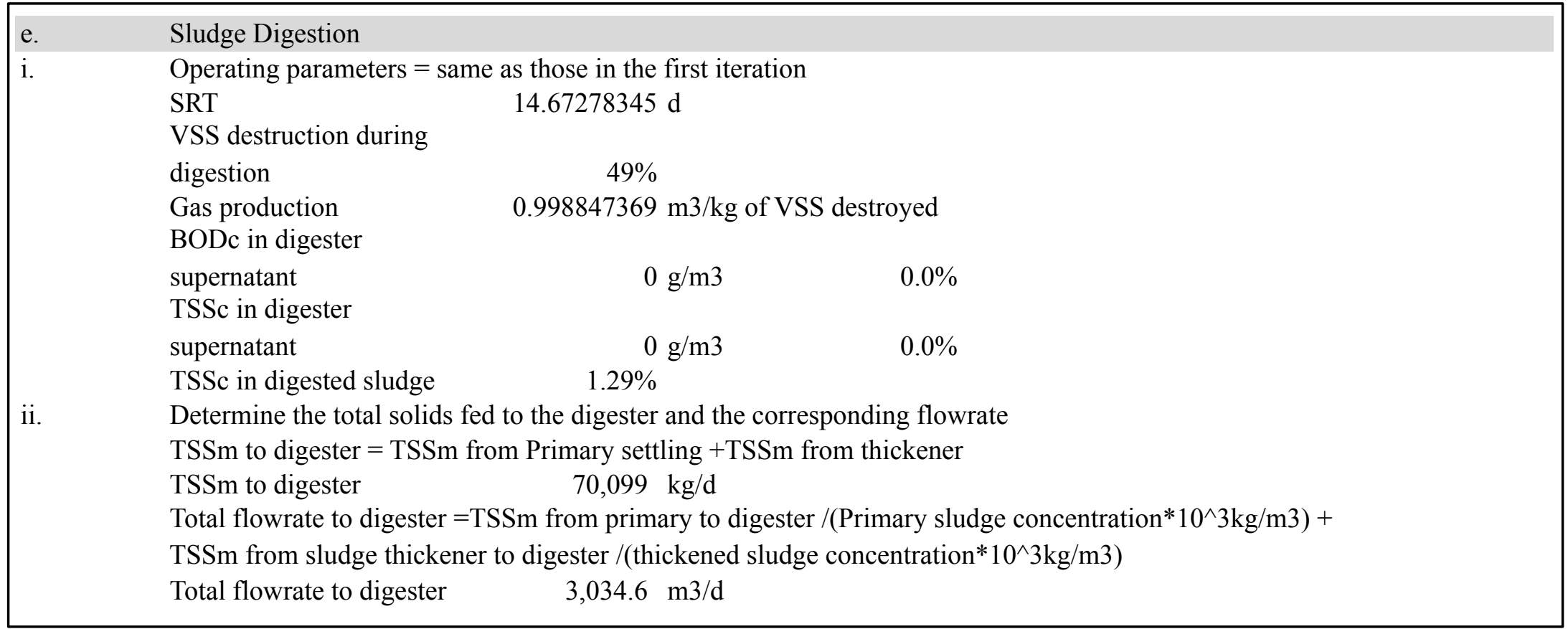




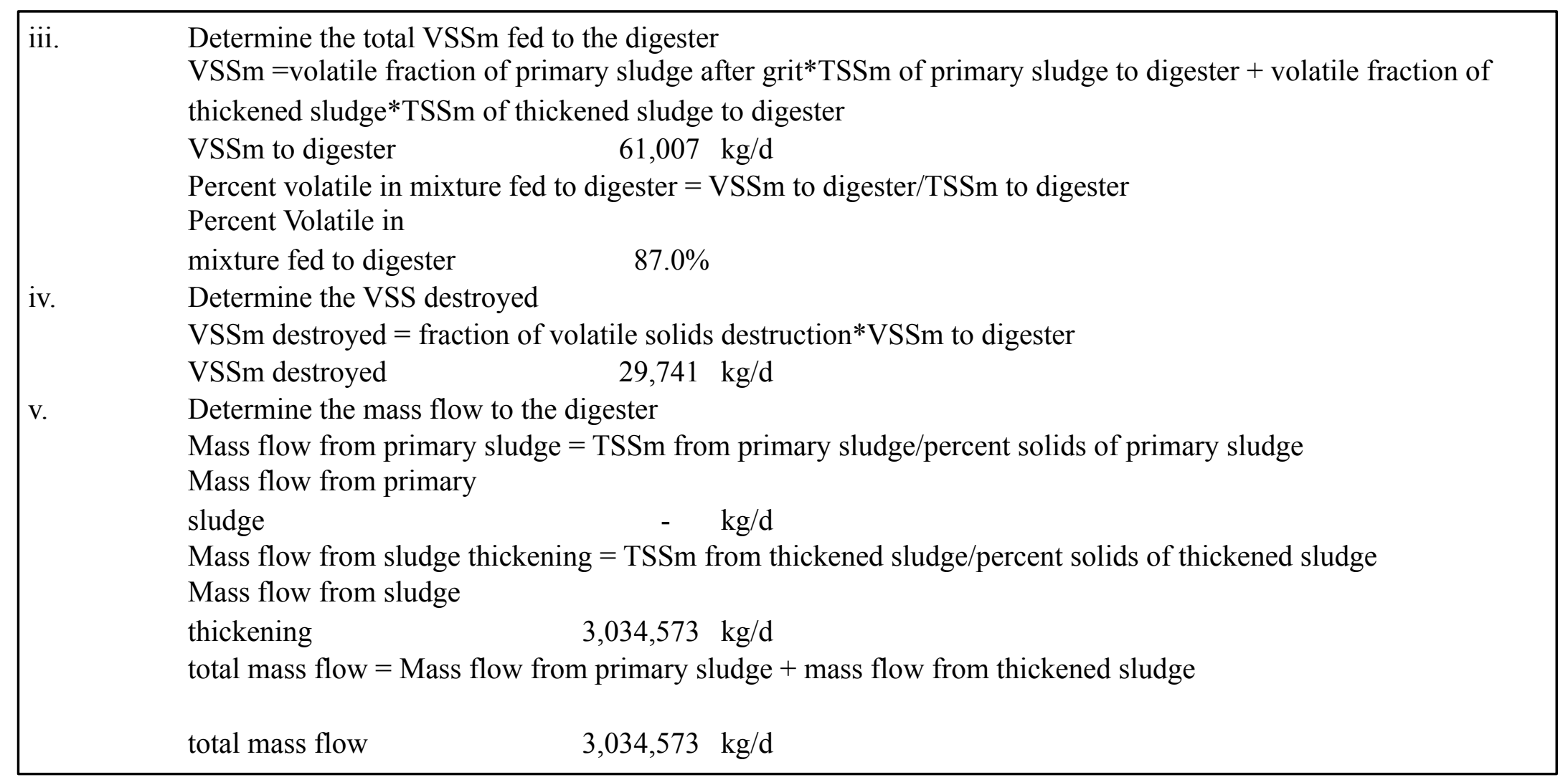




\begin{tabular}{|c|c|}
\hline \multirow[t]{15}{*}{ vi. } & $\begin{array}{l}\text { Determine the mass quantities of gas and sludge after digestion. Assume that the total mass of fixed solids } \\
\text { does not change during digestion and the } 50 \% \text { of the volatile solids is destroyed } \\
\text { Fixed solids = TSSm to digester - VSSm to digester }\end{array}$ \\
\hline & Fixed solids \\
\hline & TSSm in digested sludge $=$ fixed sludge $+(1$-percent volatile solids destroyed $) * V S S m$ to digester \\
\hline & TSSm in digested sludge $\quad 40,358 \mathrm{~kg} / \mathrm{d}$ \\
\hline & Gas production assuming that the density of digester gas is equal to 0.86 time that of air $(1.204 \mathrm{~kg} / \mathrm{m} 3)$ \\
\hline & Gas density of air $\quad 1.204 \mathrm{~kg} / \mathrm{m} 3 \quad$ from M\&E Appendix B \\
\hline & Digester gas to air density \\
\hline & Digester gas production $=$ gas production per unit volatile solids destroyed*Percent Volatile Solids \\
\hline & Destruction*VSSM to digester*digester gas/air density ratio*air density \\
\hline & Digester gas production \\
\hline & $\begin{array}{l}\text { Mass balance of digester output: } \\
\text { Mass input (total mass }\end{array}$ \\
\hline & $3,034,573 \mathrm{~kg} / \mathrm{d}$ \\
\hline & Less gas produced \\
\hline & Mass output $=$ Mass input - gas produced \\
\hline & $3,003,813 \mathrm{~kg} / \mathrm{d}$ \\
\hline
\end{tabular}




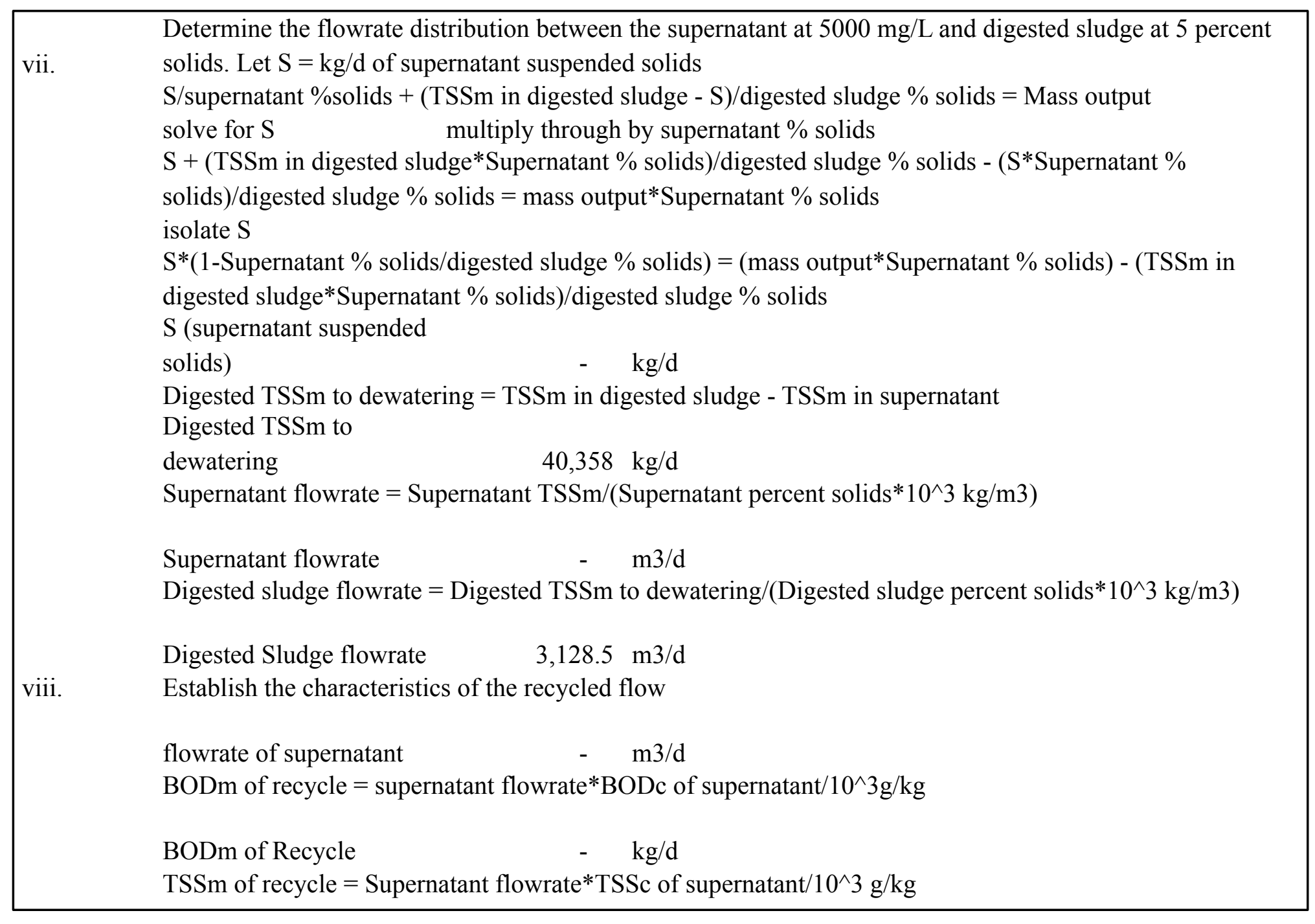




\begin{tabular}{|c|c|}
\hline f. & Sludge Dewatering \\
\hline \multirow[t]{5}{*}{ i. } & Operating parameters for centrifuge + same as those in the first iteration \\
\hline & Sludge cake percent solids \\
\hline & Sludge gravity of sludge \\
\hline & Solids capture \\
\hline & Centrate BODc \\
\hline \multirow[t]{5}{*}{ ii. } & Determine the sludge-cake Characteristics \\
\hline & TSSm of sludge-cake $=$ TSSm of digested sludge to Dewatering*solids capture \\
\hline & TSSm of sludge-cake \\
\hline & Volume of sludge-cake $=$ TSSm of sludge-cake $/\left(\right.$ sludge cake density*sludge-cake percent solids $* 10^{\wedge} 3 \mathrm{~kg} / \mathrm{m} 3$ ) \\
\hline & Volume of sludge-cake \\
\hline \multirow[t]{7}{*}{ iii. } & Determine the centrate characteristics \\
\hline & Flow of centrate $=$ Flowrate of digested sludge to dewatering-volume of sludge-cake \\
\hline & Flow of centrate \\
\hline & BODm of centrate $=$ BODc of centrate* Flowrate of centrate $/ 10^{\wedge} 3 \mathrm{~g} / \mathrm{kg}$ \\
\hline & BODm of centrate \\
\hline & TSSm $=$ TSSm of digested sludge to Dewatering*(1-percent solids capture) \\
\hline & TSSm of centrate \\
\hline
\end{tabular}




\begin{tabular}{|c|c|c|c|c|c|c|c|}
\hline \multirow[t]{15}{*}{ g. } & \multicolumn{7}{|c|}{ Prepare a summary Table of the recycle flows and Waste Characteristics for the second iteration } \\
\hline & \multicolumn{7}{|c|}{$\begin{array}{c}\text { Incremental change from previous } \\
\text { iteration }\end{array}$} \\
\hline & Operation & Flow & BODm & TSSm & 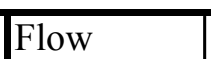 & \begin{tabular}{|l|l|} 
BODm & \\
\end{tabular} & TSSm \\
\hline & & $\mathrm{m} 3 / \mathrm{d}$ & $\mathrm{kg} / \mathrm{d}$ & $\mathrm{kg} / \mathrm{d}$ & $\mathrm{m} 3 / \mathrm{d}$ & $\mathrm{kg} / \mathrm{d}$ & $\mathrm{kg} / \mathrm{d}$ \\
\hline & gravity thickener recycle & $1,902.0$ & 367.5 & 585.6 & -243.0 & 25.6 & 40.8 \\
\hline & Digester supernatant & - & - & - & 0.0 & 0.0 & 0.0 \\
\hline & Centrate & $2,935.1$ & $5,870.2$ & $7,309.0$ & 204.4 & 408.8 & 509.2 \\
\hline & Total & $4,837.1$ & $6,237.7$ & $7,894.6$ & -38.6 & 434.4 & 550.0 \\
\hline & \multicolumn{7}{|c|}{ Percent of incremental change from } \\
\hline & Operation & & $\mathrm{BODm} /$ & $\mathrm{TSSm} /$ & \multirow{6}{*}{\multicolumn{3}{|c|}{$\begin{array}{l}\text { As calculated result ended in more } \\
\text { than a } 5 \% \text { difference a third iteration is } \\
\text { warranted }\end{array}$}} \\
\hline & & Flow/ change & change & change & & & \\
\hline & gravity thickener recycle & $-13 \%$ & $7 \%$ & $7 \%$ & & & \\
\hline & Digester supernatant & $\mathrm{N} / \mathrm{A}$ & $\mathrm{N} / \mathrm{A}$ & $\mathrm{N} / \mathrm{A}$ & & & \\
\hline & Centrate & $7 \%$ & $7 \%$ & $7 \%$ & & & \\
\hline & Total & $-1 \%$ & $7 \%$ & $7 \%$ & & & \\
\hline
\end{tabular}




\begin{tabular}{|c|c|}
\hline \multicolumn{2}{|c|}{$\begin{array}{l}5 \text { Third iteration of the solids balance to be compared to results of second iteration } \\
\text { a. Primary Settling }\end{array}$} \\
\hline \multirow[t]{3}{*}{ i. } & Operating parameters, same as those for first iteration \\
\hline & BODc removed $\quad 0 \%$ \\
\hline & TSSc removed \\
\hline \multirow[t]{5}{*}{ ii. } & TSSm and BODm entering the primary tanks \\
\hline & $\mathrm{TSSm}=$ influent TSSm + Recycled TSSm \\
\hline & TSSm to primary $\quad 82573 \mathrm{~kg} / \mathrm{d}$ \\
\hline & BODm $=$ influent BODm + Recycled BODm \\
\hline & BODm to primary $\quad 86248 \mathrm{~kg} / \mathrm{d}$ \\
\hline \multirow[t]{2}{*}{ iii. } & BODm removed = percent BODc removed*BODm to primary \\
\hline & BODm removed $\quad-\quad \mathrm{kg} / \mathrm{d}$ \\
\hline \multirow[t]{2}{*}{ iv. } & BODm to secondary $=$ BODm to primary settling - BODm removed \\
\hline & BODm to secondary $\quad 86248 \mathrm{~kg} / \mathrm{d}$ \\
\hline \multirow[t]{2}{*}{$\mathrm{v}}$. & TSSm removed $=$ percent $\mathrm{TSSm}$ removed $* \mathrm{TSSm}$ to primary \\
\hline & TSSm removed $\quad-\quad \mathrm{kg} / \mathrm{d}$ \\
\hline \multirow[t]{2}{*}{ vi. } & TSSm to secondary $=$ TSSm to primary $-\mathrm{TSSm}$ removed \\
\hline & TSSm to secondary $\quad 82573 \mathrm{~kg} / \mathrm{d}$ \\
\hline b. & Determine the volatile fraction of the primary sludge and the effluent suspended solids \\
\hline \multirow[t]{3}{*}{ i. } & Operating parameters: \\
\hline & $\begin{array}{l}\text { Incoming Wastewater, same as those for first iteration } \\
\text { Volatile fraction of solids } \\
\text { in recycle returned to } \\
\text { headworks }\end{array}$ \\
\hline & $\begin{array}{l}\text { Although the computations are not shown, the computer change in the volatile fraction determined in the first } \\
\text { iteration is slight and, therefore, the values determined previously are used for the second iteration. If the } \\
\text { volatile fraction of the return is less than about } 50 \% \text {, the volatile fractions should be recomputed. } \\
\text { The volatile fraction of each returned recycle stream should be a measured quantity to know the total VSSm } \\
\text { returned }\end{array}$ \\
\hline
\end{tabular}




\begin{tabular}{|c|c|}
\hline \multirow{7}{*}{$\begin{array}{l}\text { c. } \\
\text { i. }\end{array}$} & Secondary Process \\
\hline & $\begin{array}{l}\text { Operating parameters = same as those for the first iteration and as follows: } \\
\text { Mixed-Liquor TSSc }\end{array}$ \\
\hline & \multirow{2}{*}{$2552 \mathrm{~g} / \mathrm{m} 3$} \\
\hline & \\
\hline & \multirow[t]{2}{*}{$87 \%$} \\
\hline & \\
\hline & $13,237 \mathrm{~g} / \mathrm{m} 3$ \\
\hline & 5 (g/m3 WAS)/(g/m3 MLSS) \\
\hline & Yobs \\
\hline & Aeration tank volume \\
\hline & $1.19 \mathrm{~d}$ \\
\hline & $0.8 \mathrm{~kg} / \mathrm{kg}$ \\
\hline & $0.06 \mathrm{~d}-1$ \\
\hline \multirow[t]{5}{*}{ ii. } & Determine the BODc in the influent to the aeration tank \\
\hline & Flowrate to aeration tank $=$ influent flowrate + recycle flowrate \\
\hline & Aeration tank flow rate $\quad 378,230 \mathrm{~m} 3 / \mathrm{d}$ \\
\hline & $\mathrm{BODc}=\left(\mathrm{BODm}\right.$ to secondary* $\left.10^{\wedge} 3 \mathrm{~g} / \mathrm{kg}\right) /$ flowrate to the aeration tank \\
\hline & BODc to aeration tank $\quad 228.0 \mathrm{~g} / \mathrm{m} 3$ \\
\hline
\end{tabular}




\begin{tabular}{|c|c|}
\hline \multirow[t]{3}{*}{ iii. } & Determine the new concentration of mixed liquor VSS \\
\hline & $\mathrm{X}_{\mathrm{vss}}=[(\mathrm{SRT})(\mathrm{Q})(\mathrm{Y})(\mathrm{So}-\mathrm{S})] /\left\{\mathrm{V}^{*}[1+(\mathrm{kd}) \mathrm{SRT}]\right\}$ \\
\hline & $\begin{array}{lll}X_{\text {vss }} & 2,415 & \mathrm{~g} / \mathrm{m} 3\end{array}$ \\
\hline \multirow[t]{3}{*}{ iv. } & Determine the mixed liquor suspended solids \\
\hline & $\mathrm{X}_{\mathrm{ss}}=\mathrm{X}_{\mathrm{vss}} /$ volatile fraction of MLSS \\
\hline & $\begin{array}{ll}X_{\text {ss }} & 2,775 \mathrm{~g} / \mathrm{m} 3\end{array}$ \\
\hline \multirow[t]{5}{*}{$\mathrm{v}}$. & Determine the cell growth \\
\hline & $P x$, vss $=$ Yobs $* \mathrm{Q}^{*}(\mathrm{So}-\mathrm{S}) /\left(10^{\wedge} 3 \mathrm{~g} / \mathrm{kg}\right)$ \\
\hline & $P x$,vss $\quad 63,005 \mathrm{~kg} / \mathrm{d}$ \\
\hline & $P x, \mathrm{sss}=P x$, vss $/$ volatile fraction of MLSS \\
\hline & $P x$, vss $\quad 72,394 \mathrm{~kg} / \mathrm{d}$ \\
\hline \multirow[t]{6}{*}{ vi. } & $\begin{array}{l}\text { Determine the waste quantities discharged to the thicker } \\
\text { Effluent TSSm (specified }\end{array}$ \\
\hline & in the first iteration) $\quad 1,340 \mathrm{~kg} / \mathrm{d}$ \\
\hline & $\begin{array}{l}\text { Total TSSm to be wasted to the thicker }=P x \text {,vss }- \text { TSSm in secondary Effluent } \\
\text { Total TSSm to be wasted }\end{array}$ \\
\hline & to the thicker $\quad 71,054 \mathrm{~kg} / \mathrm{d}$ \\
\hline & Flowrate $=\left(\right.$ Total TSSm wasted to thickener* $\left.10^{\wedge} 3 \mathrm{~g} / \mathrm{kg}\right) /\left(\mathrm{X}_{\mathrm{SS}}{ }^{*}\right.$ clarifier compaction ratio $)$ \\
\hline & Flowrate to thickener $\quad 4,936.92 \mathrm{~m} 3 / \mathrm{d}$ \\
\hline
\end{tabular}




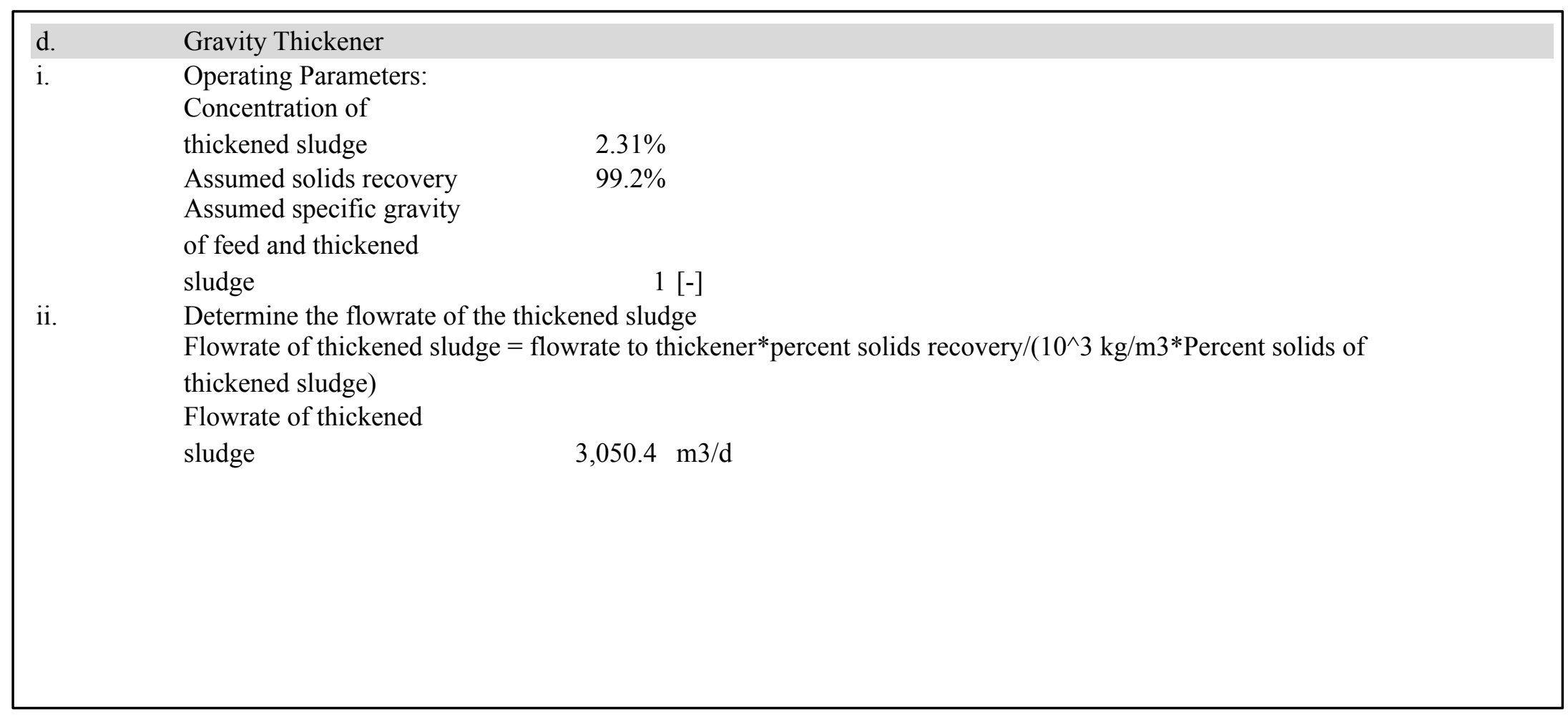




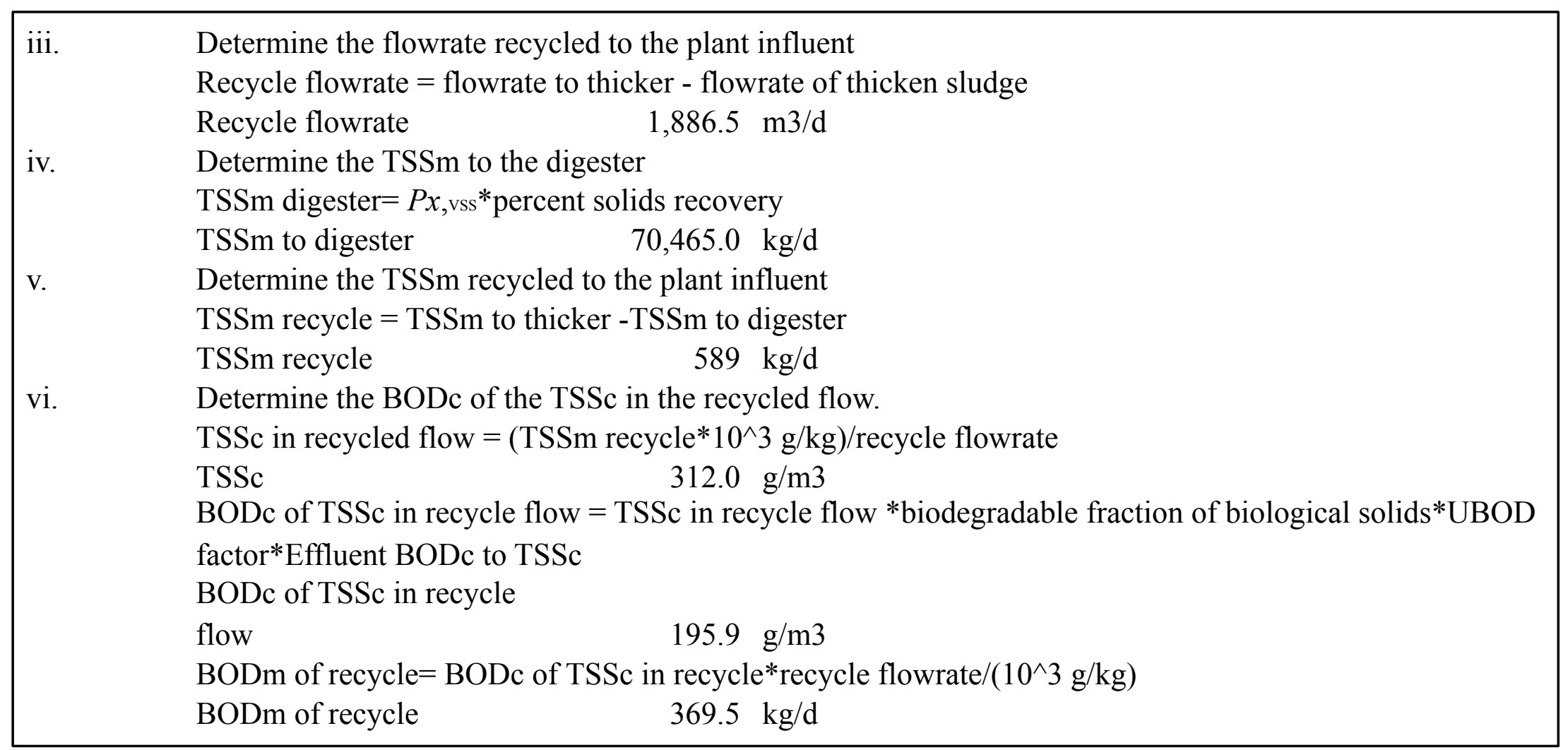




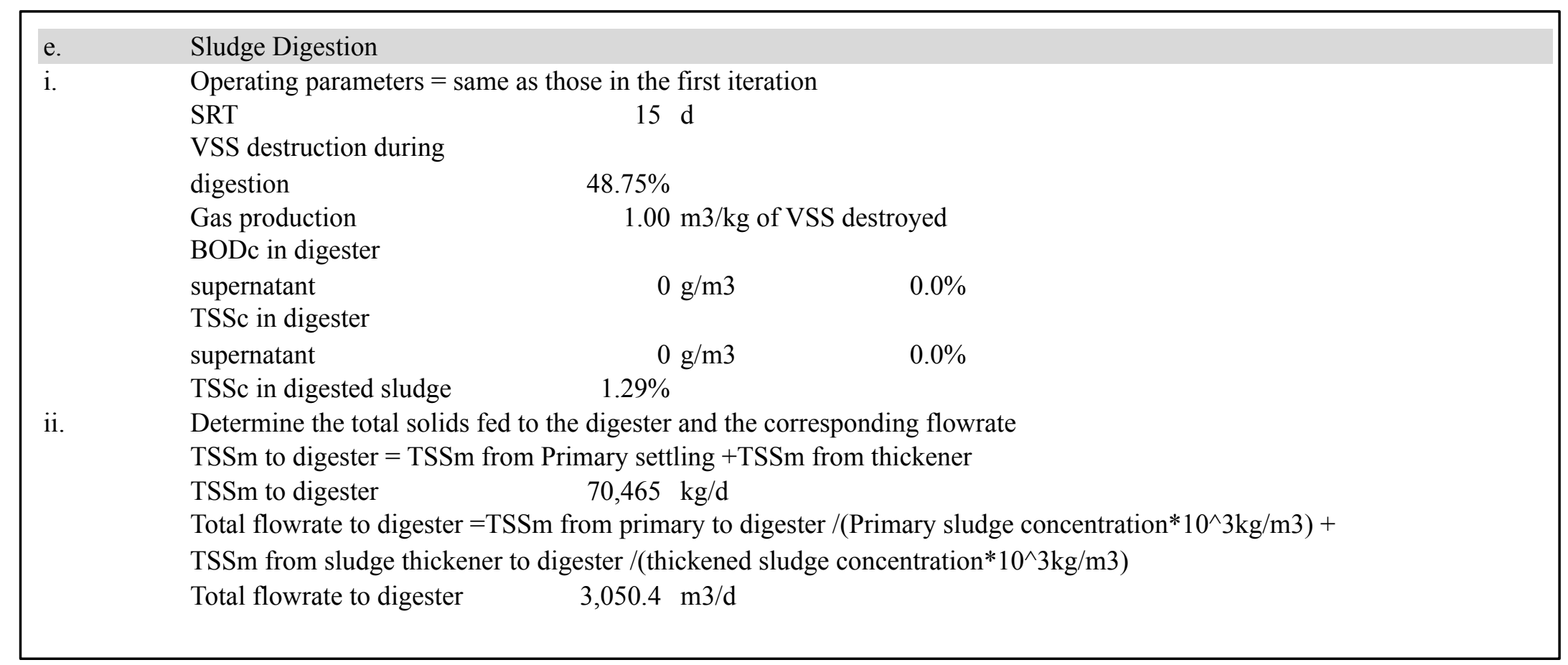




\begin{tabular}{|c|c|}
\hline \multirow[t]{4}{*}{ iii. } & $\begin{array}{l}\text { Determine the total VSSm fed to the digester } \\
\text { VSSm =volatile fraction of primary sludge after grit*TSSm of primary sludge to digester }+ \text { volatile fraction of } \\
\text { thickened sludge*TSSm of thickened sludge to digester }\end{array}$ \\
\hline & VSSm to digester $\quad 61,326 \mathrm{~kg} / \mathrm{d}$ \\
\hline & $\begin{array}{l}\text { Percent volatile in mixture fed to digester }=\text { VSSm to digester/TSSm to digester } \\
\text { Percent Volatile in }\end{array}$ \\
\hline & mixture fed to digester \\
\hline \multirow[t]{3}{*}{ iv. } & Determine the VSS destroyed \\
\hline & VSSm destroyed $=$ fraction of volatile solids destruction*VSSm to digester \\
\hline & VSSm destroyed $\quad 29,896 \mathrm{~kg} / \mathrm{d}$ \\
\hline \multirow[t]{7}{*}{ v. } & Determine the mass flow to the digester \\
\hline & $\begin{array}{l}\text { Mass flow from primary sludge }=\text { TSSm from primary sludge/percent solids of primary sludge } \\
\text { Mass flow from primary }\end{array}$ \\
\hline & sludge $\quad-\mathrm{kg} / \mathrm{d}$ \\
\hline & $\begin{array}{l}\text { Mass flow from sludge thickening }=\text { TSSm from thickened sludge/percent solids of thickened sludge } \\
\text { Mass flow from sludge }\end{array}$ \\
\hline & thickening $\quad 3,050,434 \mathrm{~kg} / \mathrm{d}$ \\
\hline & total mass flow $=$ Mass flow from primary sludge + mass flow from thickened sludge \\
\hline & $3,050,434 \mathrm{~kg} / \mathrm{d}$ \\
\hline
\end{tabular}




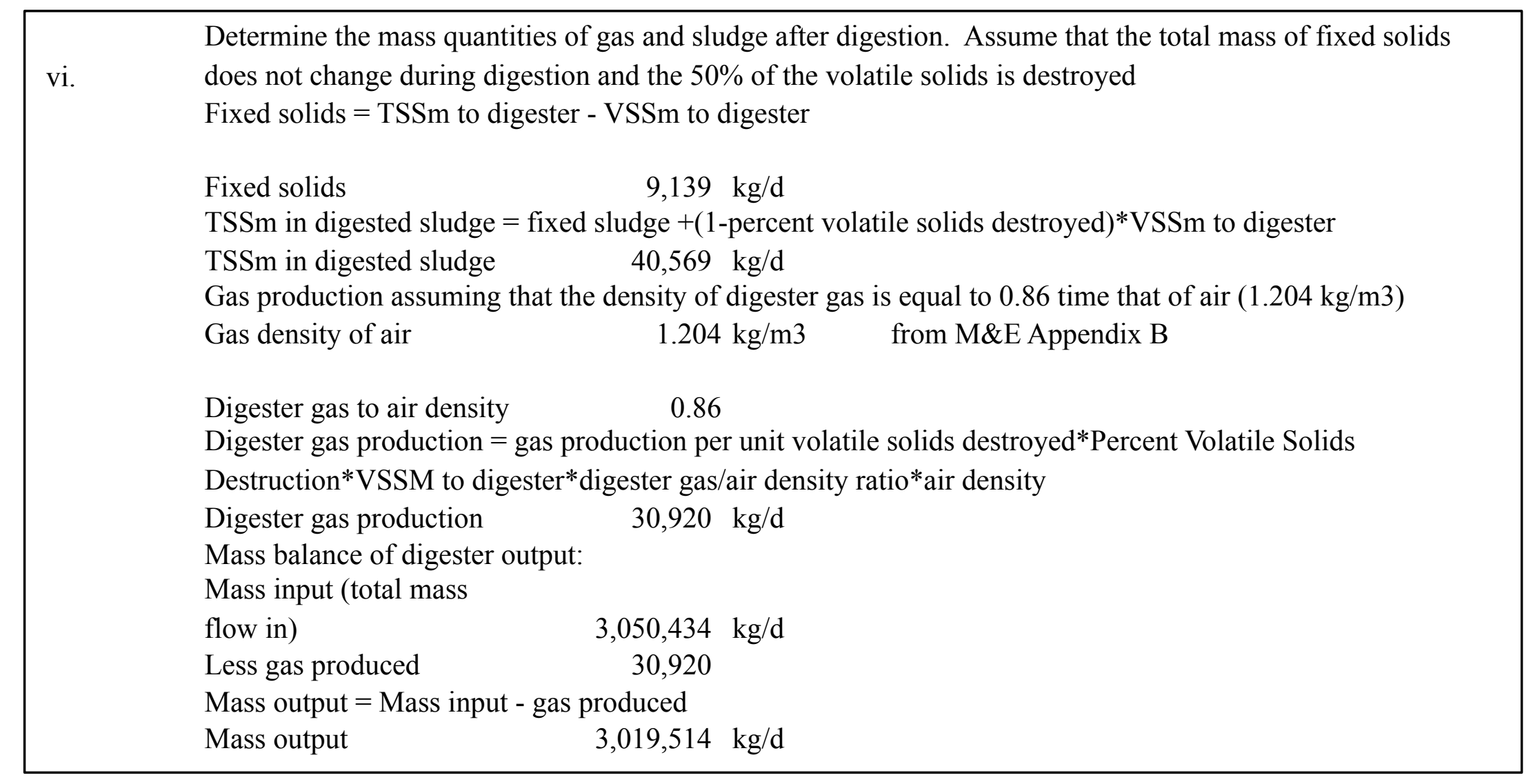




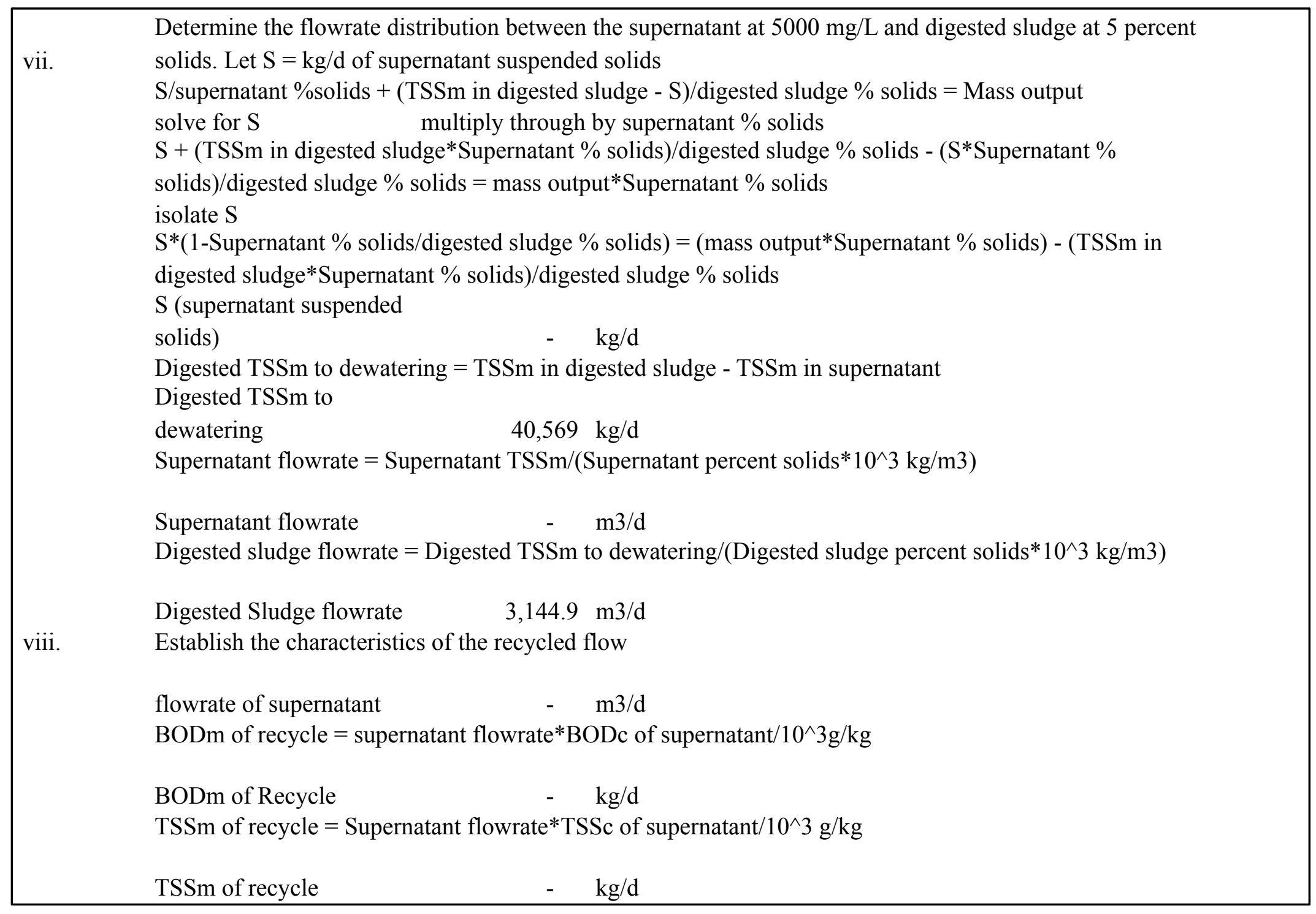




\begin{tabular}{|c|c|}
\hline f. & Sludge Dewatering \\
\hline \multirow[t]{5}{*}{ i. } & Operating parameters for centrifuge + same as those in the first iteration \\
\hline & Sludge cake percent solids \\
\hline & Sludge gravity of sludge \\
\hline & Solids capture \\
\hline & Centrate BODc $\quad 2,000 \mathrm{mg} / \mathrm{L}$ \\
\hline \multirow[t]{5}{*}{ ii. } & Determine the sludge-cake Characteristics \\
\hline & TSSm of sludge-cake $=$ TSSm of digested sludge to Dewatering*solids capture \\
\hline & TSSm of sludge-cake $\quad \mathbf{3 3 , 2 2 2} \mathrm{kg} / \mathrm{d}$ \\
\hline & Volume of sludge-cake $=$ TSSm of sludge-cake $/\left(\right.$ sludge cake density*sludge-cake percent solids $* 10^{\wedge} 3 \mathrm{~kg} / \mathrm{m} 3$ ) \\
\hline & Volume of sludge-cake $\quad 194.4 \mathrm{~m} 3 / \mathrm{d}$ \\
\hline \multirow[t]{7}{*}{ iii. } & Determine the centrate characteristics \\
\hline & Flow of centrate $=$ Flowrate of digested sludge to dewatering-volume of sludge-cake \\
\hline & Flow of centrate $\quad 2,950.4 \mathrm{~m} 3 / \mathrm{d}$ \\
\hline & BODm of centrate $=$ BODc of centrate*Flowrate of centrate $/ 10^{\wedge} 3 \mathrm{~g} / \mathrm{kg}$ \\
\hline & BODm of centrate $\quad 5,900.9 \mathrm{~kg} / \mathrm{d}$ \\
\hline & TSSm $=$ TSSm of digested sludge to Dewatering*(1-percent solids capture) \\
\hline & TSSm of centrate \\
\hline
\end{tabular}




\begin{tabular}{|c|c|c|c|c|c|c|c|}
\hline \multirow[t]{15}{*}{ g. } & \multicolumn{7}{|c|}{ Prepare a summary Table of the recycle flows and Waste Characteristics for the second iteration } \\
\hline & \multirow[b]{2}{*}{ Operation } & \multirow[b]{2}{*}{ Flow } & \multirow[b]{2}{*}{ BODm } & \multirow[b]{2}{*}{ TSSm } & \multicolumn{3}{|c|}{$\begin{array}{c}\text { Incremental change from previous } \\
\text { iteration }\end{array}$} \\
\hline & & & & & Flow & BODm & TSSm \\
\hline & & $\mathrm{m} 3 / \mathrm{d}$ & $\mathrm{kg} / \mathrm{d}$ & $\mathrm{kg} / \mathrm{d}$ & $\mathrm{m} 3 / \mathrm{d}$ & $\mathrm{kg} / \mathrm{d}$ & $\mathrm{kg} / \mathrm{d}$ \\
\hline & gravity thickener recycle & $1,886.0$ & 369.5 & 588.7 & -16.00 & 1.92 & 3.06 \\
\hline & Digester supernatant & - & - & - & 0.00 & 0.00 & 0.00 \\
\hline & Centrate & $2,950.4$ & $5,900.9$ & $7,346.9$ & 15.34 & 30.68 & 37.93 \\
\hline & Total & $4,836.4$ & $6,270.3$ & $7,935.6$ & -0.66 & 32.60 & 40.99 \\
\hline & \multicolumn{7}{|c|}{ Percent of incremental change from } \\
\hline & Operation & \multirow[b]{2}{*}{ Flow/ change } & \multirow{2}{*}{$\begin{array}{c}\begin{array}{c}\text { BODm/ } \\
\text { change }\end{array} \\
\end{array}$} & \multirow{2}{*}{$\begin{array}{c}\begin{array}{c}\text { TSSm/ } \\
\text { change }\end{array} \\
\end{array}$} & \multirow{6}{*}{\multicolumn{3}{|c|}{$\begin{array}{l}\text { As calculated result ended in less than } \\
\text { a } 5 \% \text { difference no further iteration is } \\
\text { necessary }\end{array}$}} \\
\hline & & & & & & & \\
\hline & gravity thickener recycle & $-0.8 \%$ & $0.5 \%$ & $0.5 \%$ & & & \\
\hline & Digester supernatant & $\mathrm{N} / \mathrm{A}$ & $\mathrm{N} / \mathrm{A}$ & $\mathrm{N} / \mathrm{A}$ & & & \\
\hline & Centrate & $0.5 \%$ & $0.5 \%$ & $0.5 \%$ & & & \\
\hline & Total & $0.0 \%$ & $0.5 \%$ & $0.5 \%$ & & & \\
\hline
\end{tabular}




\begin{tabular}{|c|c|c|c|c|c|c|c|}
\hline Model Calibration & units & model result & $\begin{array}{l}\text { historical } \\
\text { data }\end{array}$ & diff. & $\%$ diff. & $\begin{array}{c}\text { flow } \\
\text { correction } \\
\text { factor* }\end{array}$ & $\begin{array}{l}\text { corrected } \\
\text { flow }\end{array}$ \\
\hline WAS flow & $\mathrm{m}^{3} / \mathrm{d}$ & 4,937 & 5,746 & $(809)$ & $-16.4 \%$ & 1.16 & 5,746 \\
\hline $\begin{array}{l}\text { TWAS (Digester feed) } \\
\text { flow }\end{array}$ & $\mathrm{m}^{3} / \mathrm{d}$ & 3,050 & 2,285 & 765 & $25.1 \%$ & 0.75 & 2,285 \\
\hline $\begin{array}{l}\text { Digester sludge } \\
\text { (dewatering feed) flow** }\end{array}$ & $\mathrm{m}^{3} / \mathrm{d}$ & 3,145 & - & 859 & $27.3 \%$ & 0.73 & 2,285 \\
\hline $\begin{array}{l}\text { Dewatered Biosolids (dry } \\
\text { wt.) }\end{array}$ & $\mathrm{MT} / \mathrm{yr}$ & 12,126 & 12,229 & (103) & $-0.8 \%$ & & \\
\hline $\begin{array}{l}\text { Dewatered Biosolids (wet } \\
\text { wt.) }\end{array}$ & MT/yr & 75,223 & 75,862 & (639) & $-0.8 \%$ & & \\
\hline
\end{tabular}

*Correction factor used if there is more than a $5 \%$ difference

** Digested sludge historical data was not available, difference was computed comparing TWAS flow from histrocial data to digested sludge from the model as it can be assumed that QTWAS = QDS for the study plants 
APPENDIX 5: PROCESS FLOW DIGARAMS OF MASS BALANCE MODEL SCENARIOS OUTPUTS 
Scenarios SD-A Process Flow Diagram with Mass Balance Model Output

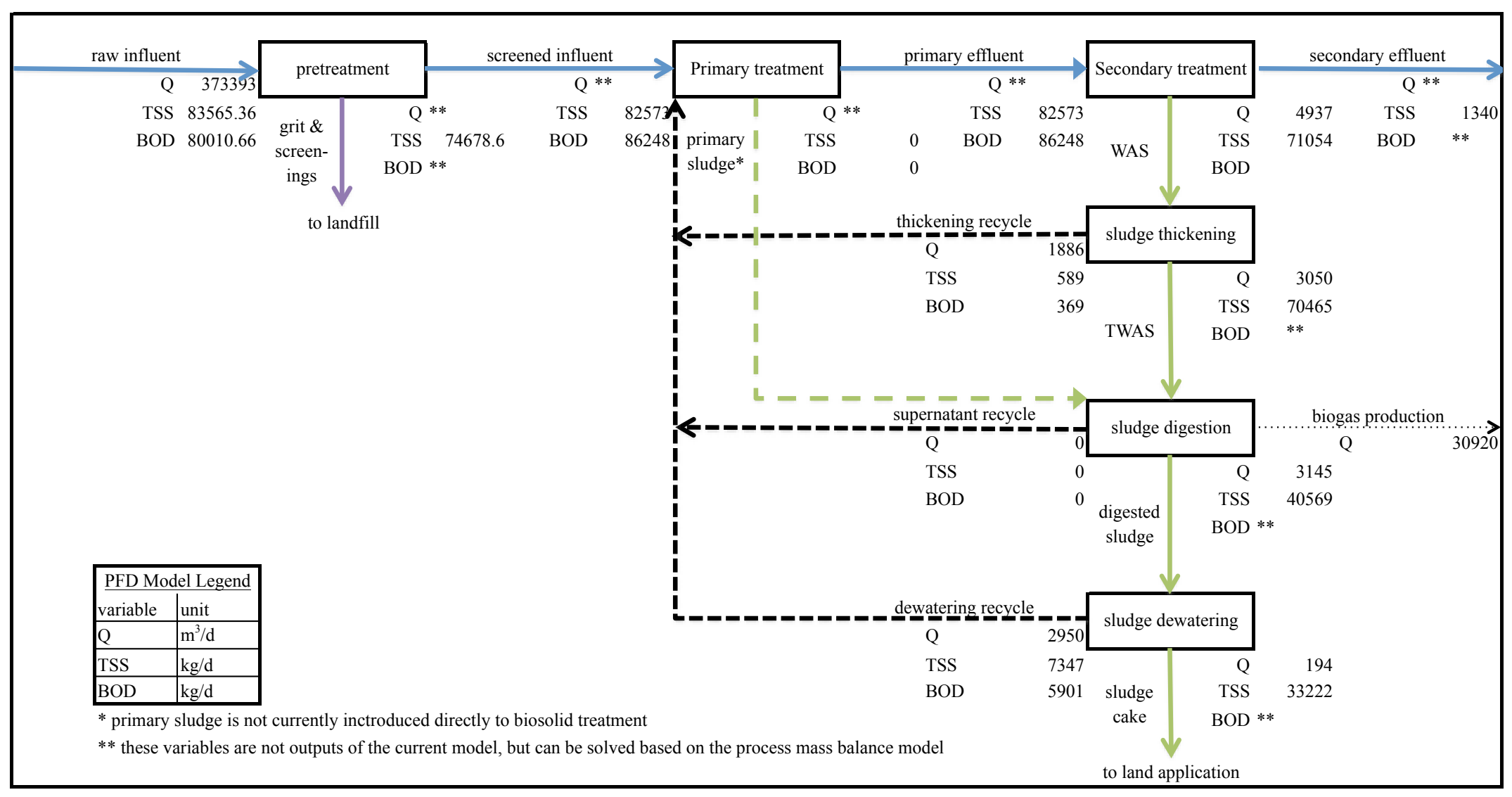


Scenario SD-B Process Flow Diagram with Mass Balance Model Output

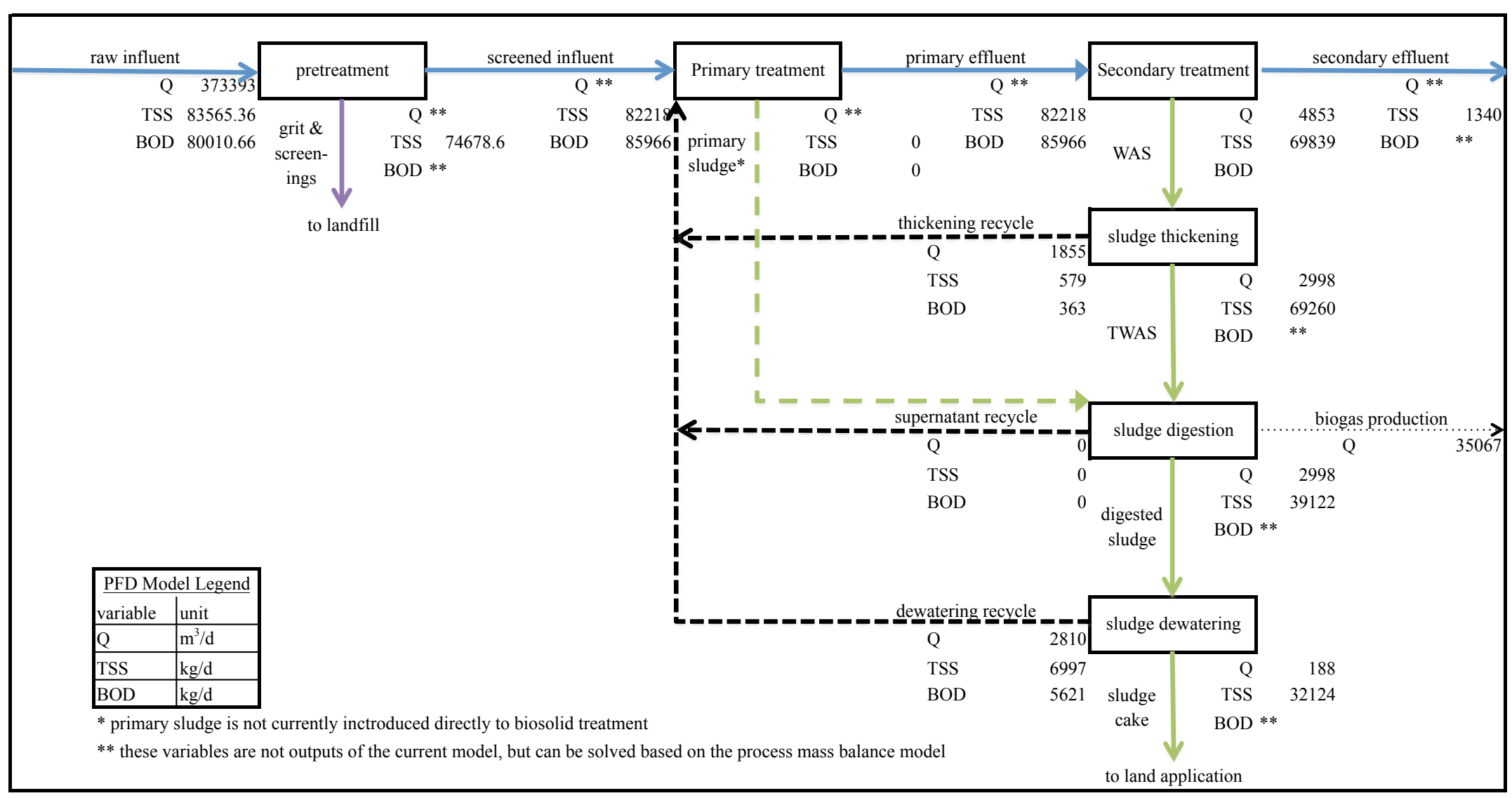


Scenario SD-C Process Flow Diagram with Mass Balance Model Output

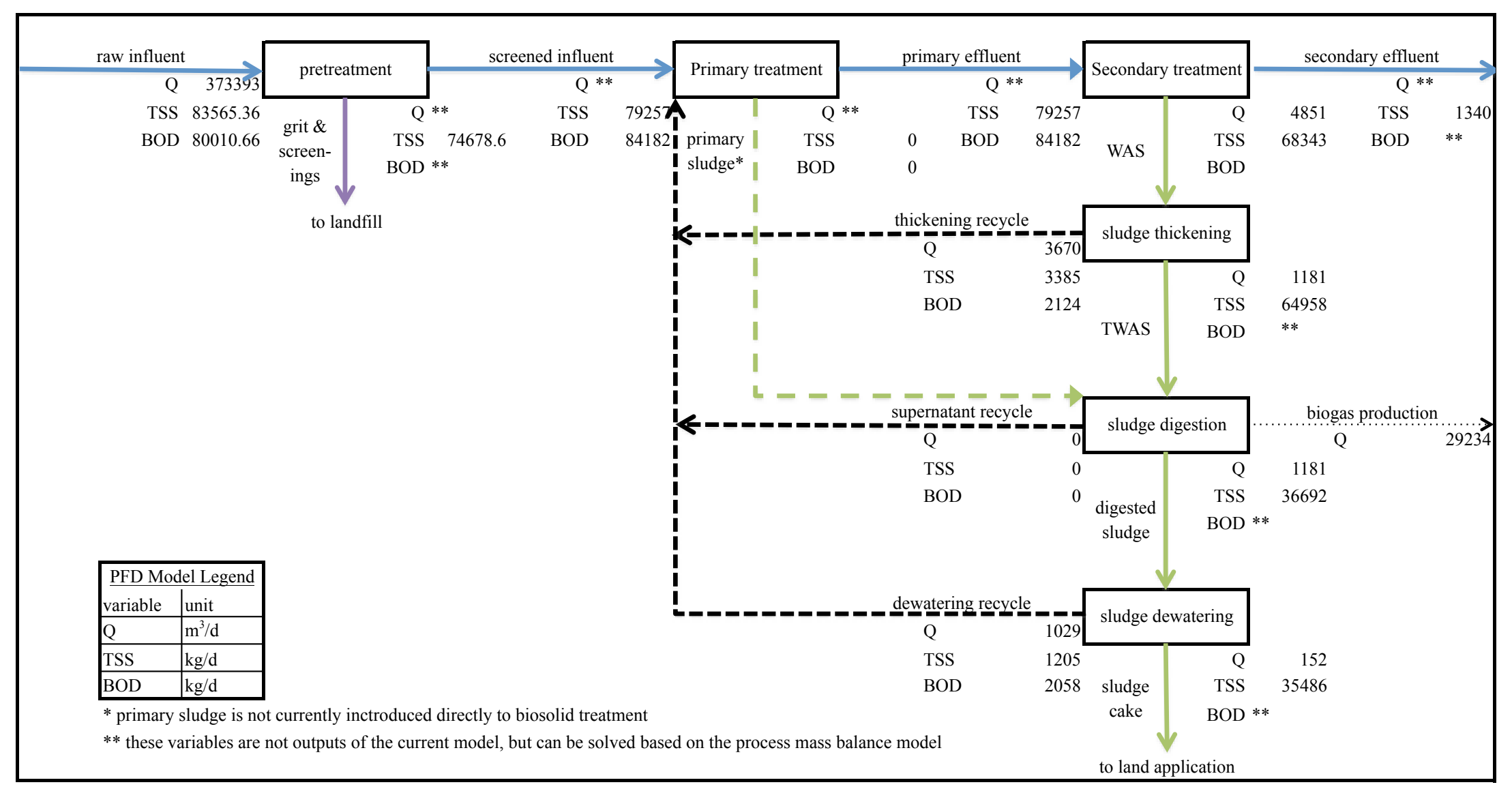


Scenario SD-D Process Flow Diagram with Mass Balance Model Output

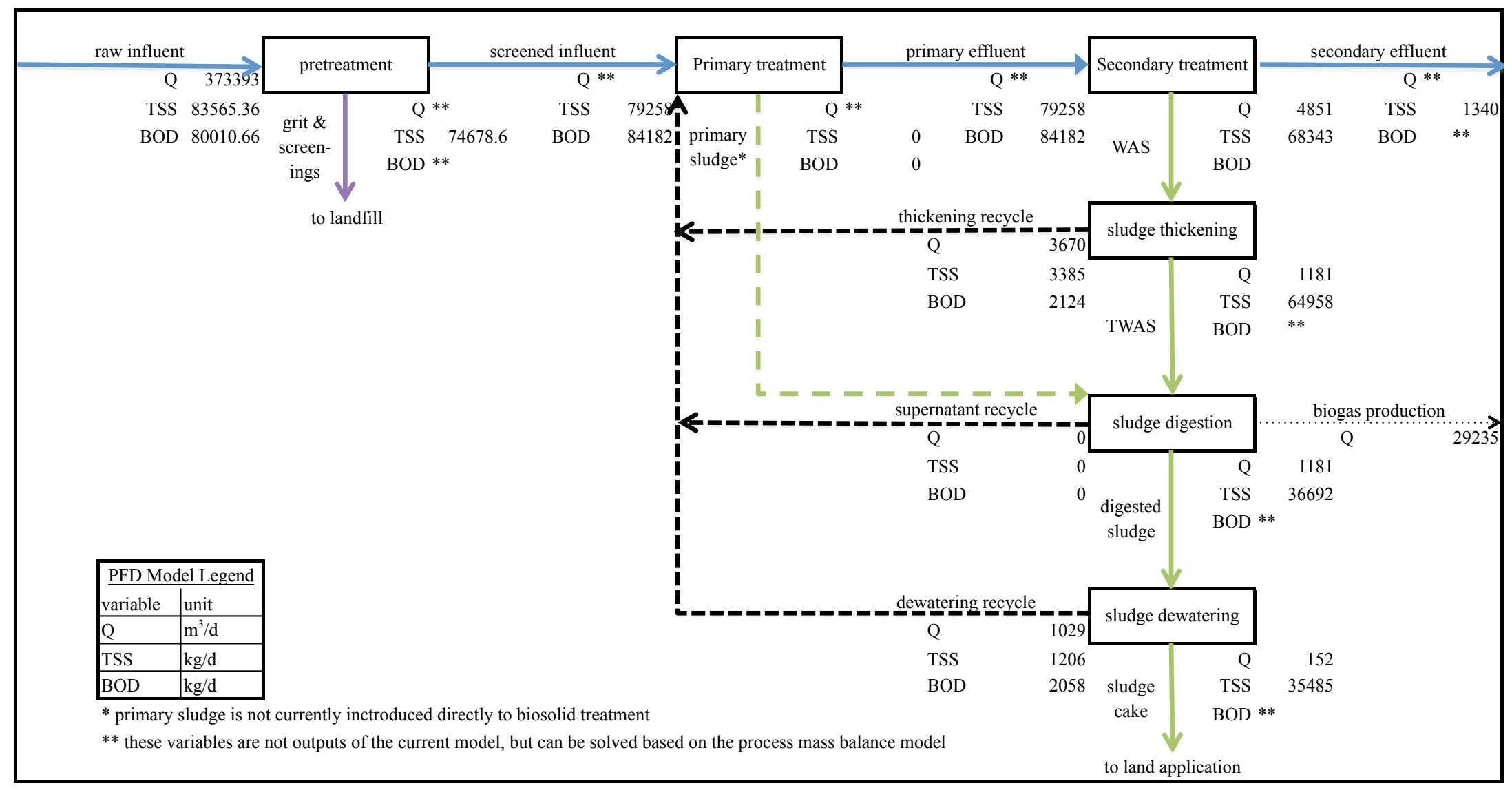


Scenario SD-E Process Flow Diagram with Mass Balance Model Output

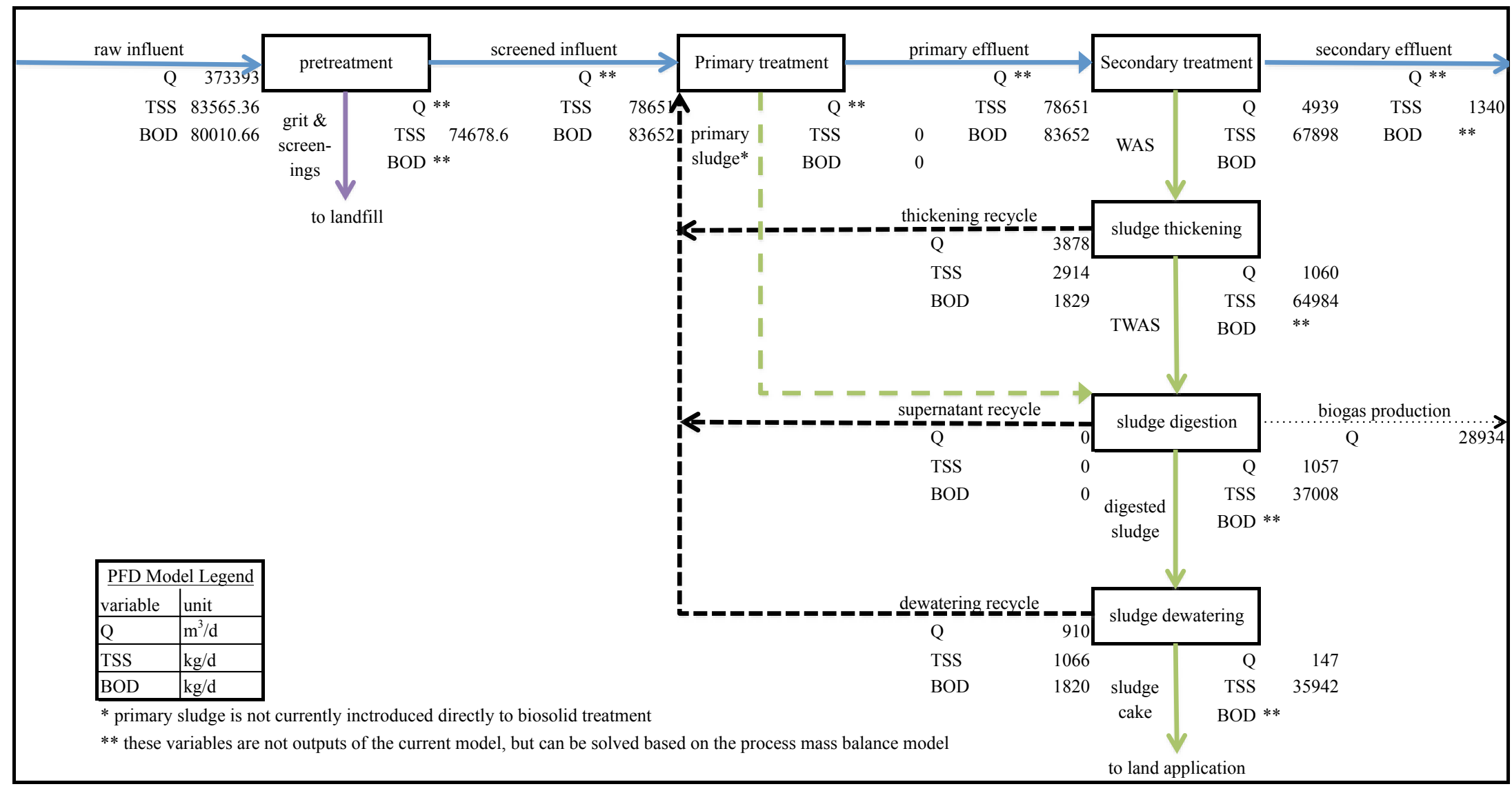


Scenario CD-A Process Flow Diagram with Mass Balance Model Output

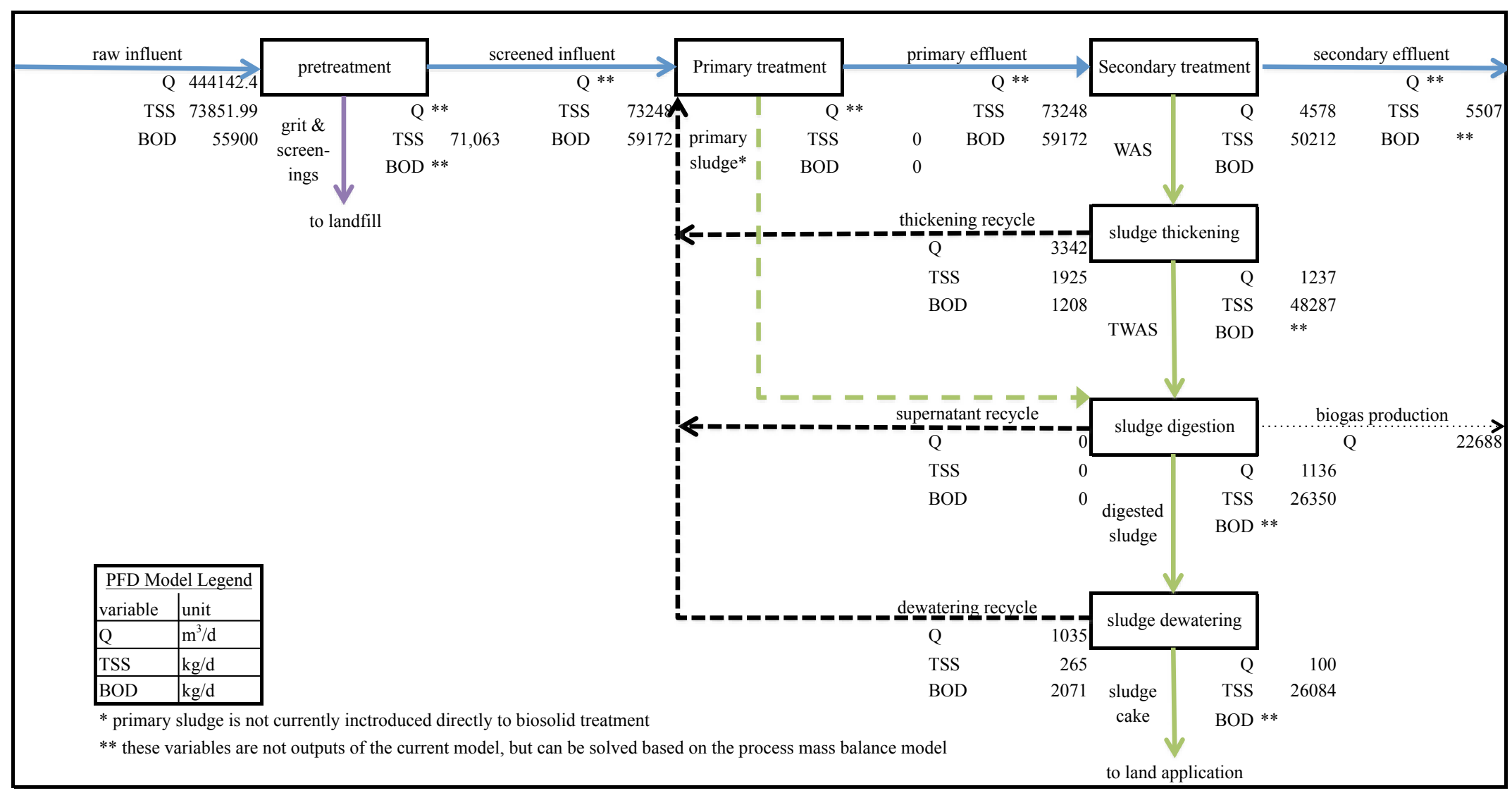


Scenario CD-B Process Flow Diagram with Mass Balance Model Output

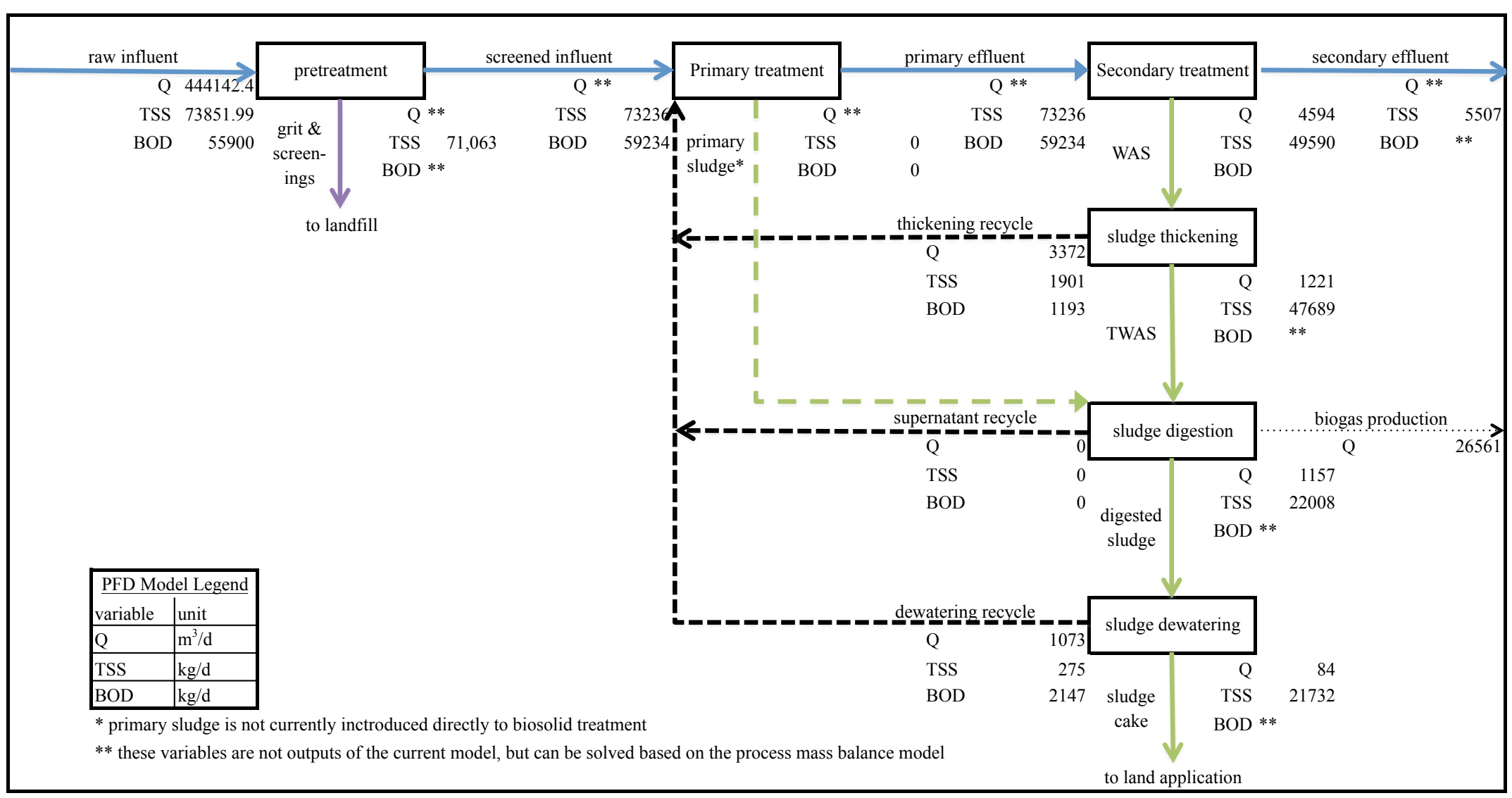


Scenario CD-C Process Flow Diagram with Mass Balance Model Output

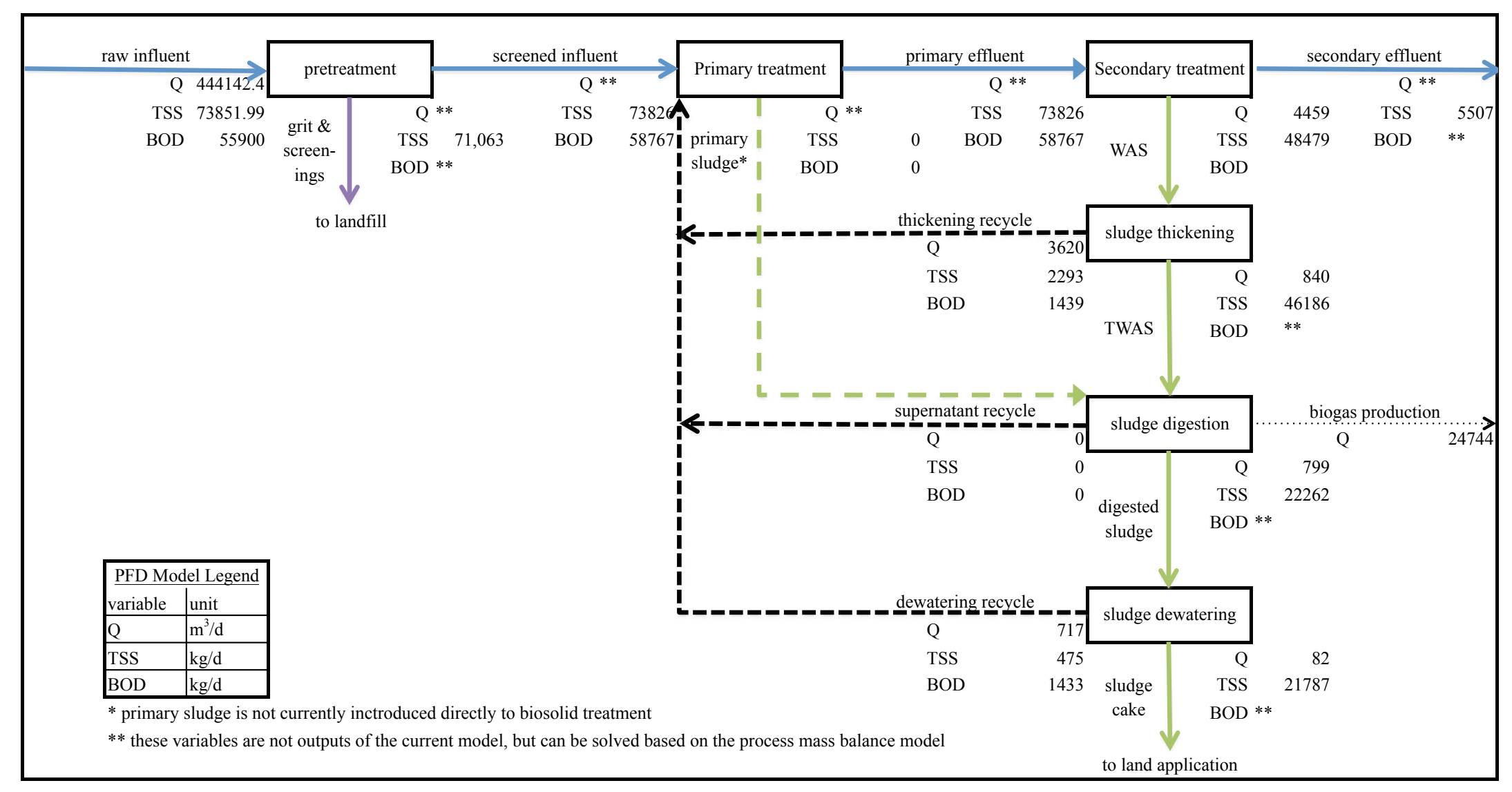


Scenario CD-D Process Flow Diagram with Mass Balance Model Output

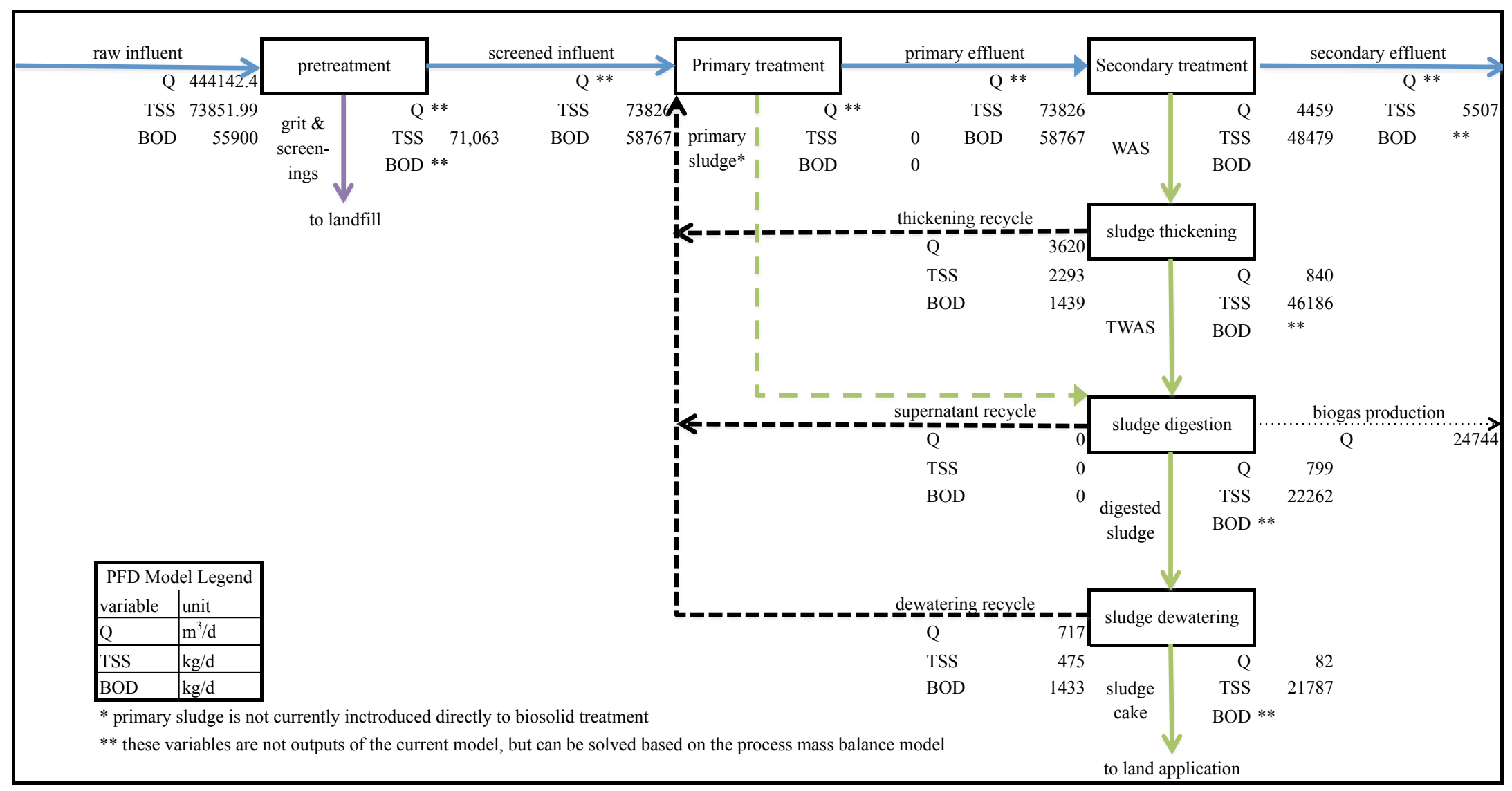


Scenario CD-E Process Flow Diagram with Mass Balance Model Output

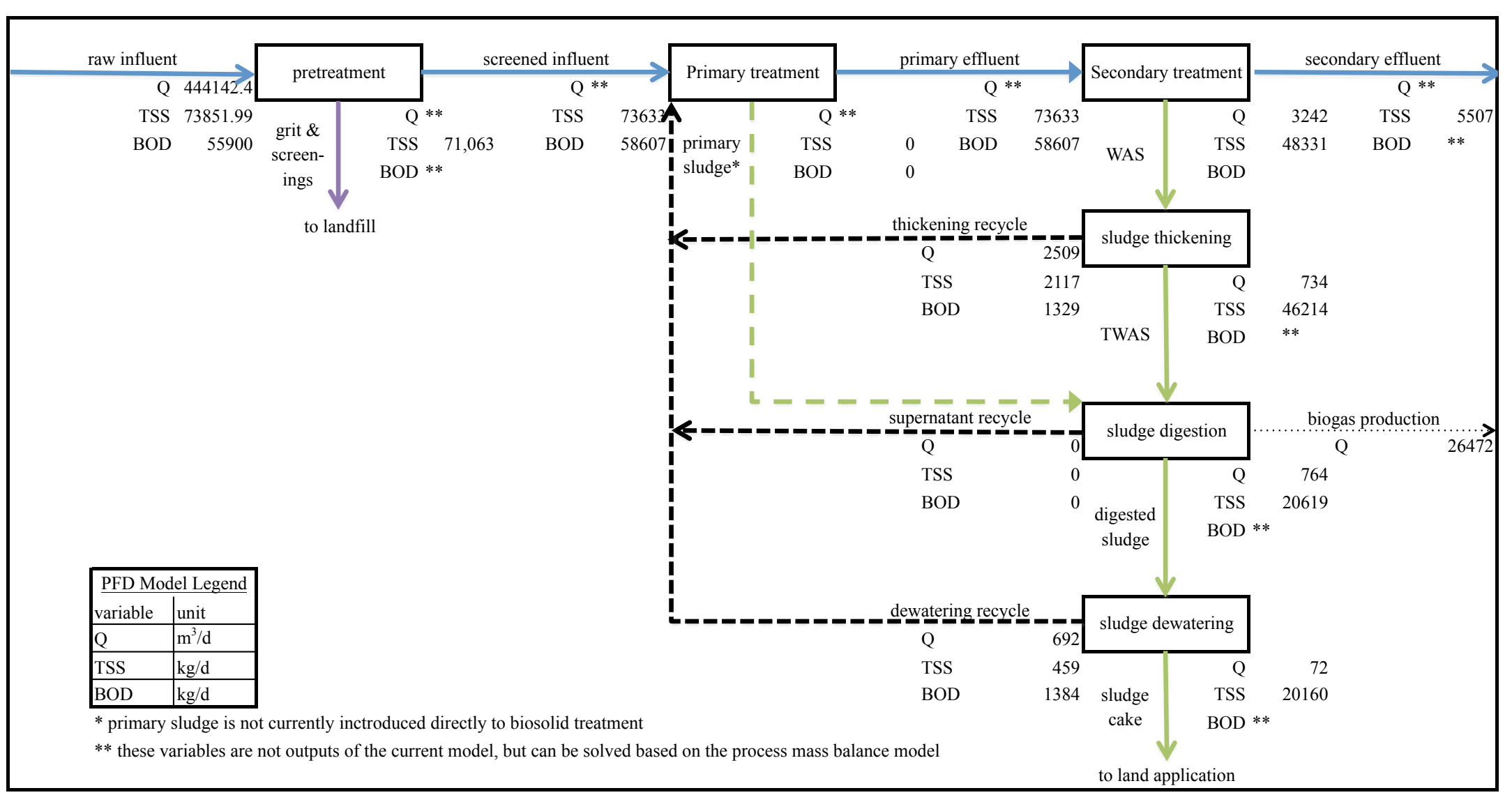


VITA

\section{MANUEL EZEQUIEL MONCHOLÍ}

Born, Miami, Florida

2001

B.E., Chemical Engineering

Stevens Institute of Technology

2004

M.S., Environmental Engineering

Florida International University

2004 - present $\quad$ Process Engineer

Miami-Dade Water and Sewer Department

2009-2018

Doctoral Candidate

Florida International University

\section{PUBLICATIONS}

1. Moos, L. P., Scinto, L. J., Johnson, D., Wein, G., Williams, R., Tilen, E. J., Mancholi [sp], M. E., Iqbal , A. (2005) "Natural Attenuation of Trichloroethylene in Wetland Soil" Waste Management '05 Conference, Tucson, AZ

2. Coro, E., Kundral, S., Mudragada, R., Moncholi, M., Mora, N., Laha, S., Tansel, B. (2010) "Effects of Carbon Dioxide Stripping on Solids Settling in Pure Oxygen WWTP" Proceedings of the World Environmental and Water Resources Congress 2010, American Society of Civil Engineers

3. Vadiveloo, E., Fergen, R., Moncholi, M., Pitt, P., Sharp, R., Wankmuller, D., Latimer, R. (2012) "A Theoretical and Practical Evaluation of Struvite Control and Recovery: Two Case Studies" Proceedings of the Water Environment Federation, Residuals and Biosolids 2012 Water Environment Federation

4. Sharp, R., Vadiveloo, E., Fergen, R., Moncholi, M., Pitt, P., Wankmuller, D., Latimer, R. (2013) "A Theoretical and Practical Evaluation of Struvite Control and Recovery" Water Environment Research, Volume 85, Number 8, August 2013, pp. 675-686(12) Water Environment Federation

5. Behrens, F., Hirani, Z., Moncholi, M., Marrero, L., Glenny, Y., Casado, L., Umble, A., Schmidt, H. (2014) "Assessing the Potential Causes of cBOD and TSS spikes in Influent Wastewater at the Miami-Dade's Central District WWTP” 
Proceedings of the Water Environment Federation, WEFTEC 2014: Session 310 through Session 317, pp. 5935-5953(19) Water Environment Federation

6. Mudragada, R., Kundral, S., Coro, E., Moncholi, M. E., Laha, S., Tansel, B. (2014) "Phosphorous removal during sludge dewatering to prevent struvite formation in sludge digesters by full scale evaluation" Journal of Water Process Engineering Volume 2, June 2014, Pages 37-42 Elsevier Science Direct

7. Kundral, S., Mudragada, R., Coro, E., Moncholi, M., Mora, N., Laha, S., Tansel, B. (2015) "Improving Settling Characteristics of Pure Oxygen Activated Sludge by Stripping of Carbon Dioxide" Water Environment Research, Volume 87, Number 6, June 2015, pp. 498-505(8) Water Environment Federation

8. Casado, L., Glenny, Y., Arrebola, V., Schmidt, H., Moncholi, M., Edwards, D. (2016) "Time and Money - Managing and Implementing Florida's Largest Wastewater Capital Program" Proceedings of the Water Environment Federation, WEFTEC 2016: Session 510 through Session 525, pp. 811-829(19) Water Environment Federation

9. Hull, T., Moncholi, M., Coro, E. (2016) "48 Ways to Fuel Your Cogen: Generator Fuel Flexibility at the Miami-Dade South District WWTP" Proceedings of the Water Environment Federation, WEFTEC 2016: Session 220 through Session 229, pp. 2555-2563(9) Water Environment Federation

10. Boe, R., Moncholi, M., Griborio, A. (2017) "A Case Study in the Holistic Evaluation of Wet Weather Flow Management Options for Large Scale Facilities" Proceedings of the Water Environment Federation, WEFTEC 2017: Session 400 through Session 409, pp. 2650-2663(14) Water Environment Federation

11. Goss, T., Stitt, B., Moncholi, M., Diaz, I. (2017) “Centrifuge Piloting at Miami's Central District WWTP - Overcoming Obstacles with a Difficult to Handle Sludge" Proceedings of the Water Environment Federation, WEFTEC 2017: Session 510 through Session 519, pp. 4491-4508(18) Water Environment Federation

12. Goss, T., Brian, S., Moncholi, M., Abu-Orf, M., Diaz, I. (2017) "Piloting to Establish Performance Criteria at Miami's South District WWTP" Proceedings of the Water Environment Federation, Residuals and Biosolids 2017, pp. 613632(20) Water Environment Federation

13. Brian, S., Goss, T., Moncholi, M., Abu-Orf, M., Diaz, I. (2017) "Enhanced Dewatering with Struvite Recovery: Pilot Testing of AirPrex ${ }^{\circledR}$ Technology at Miami's South District WWTP" Proceedings of the Water Environment Federation, Residuals and Biosolids 2017, pp. 139-154(16) Water Environment Federation 